\title{
ATENGŌ̃O PRIMÁRIA À SAÚDE NO BRASIL
}

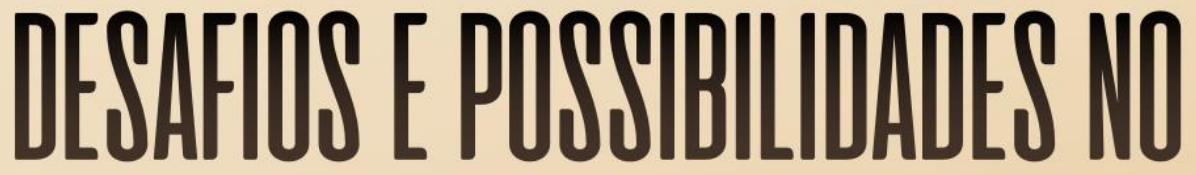 \\ GENÁRIO CONTEMPDRRANED}

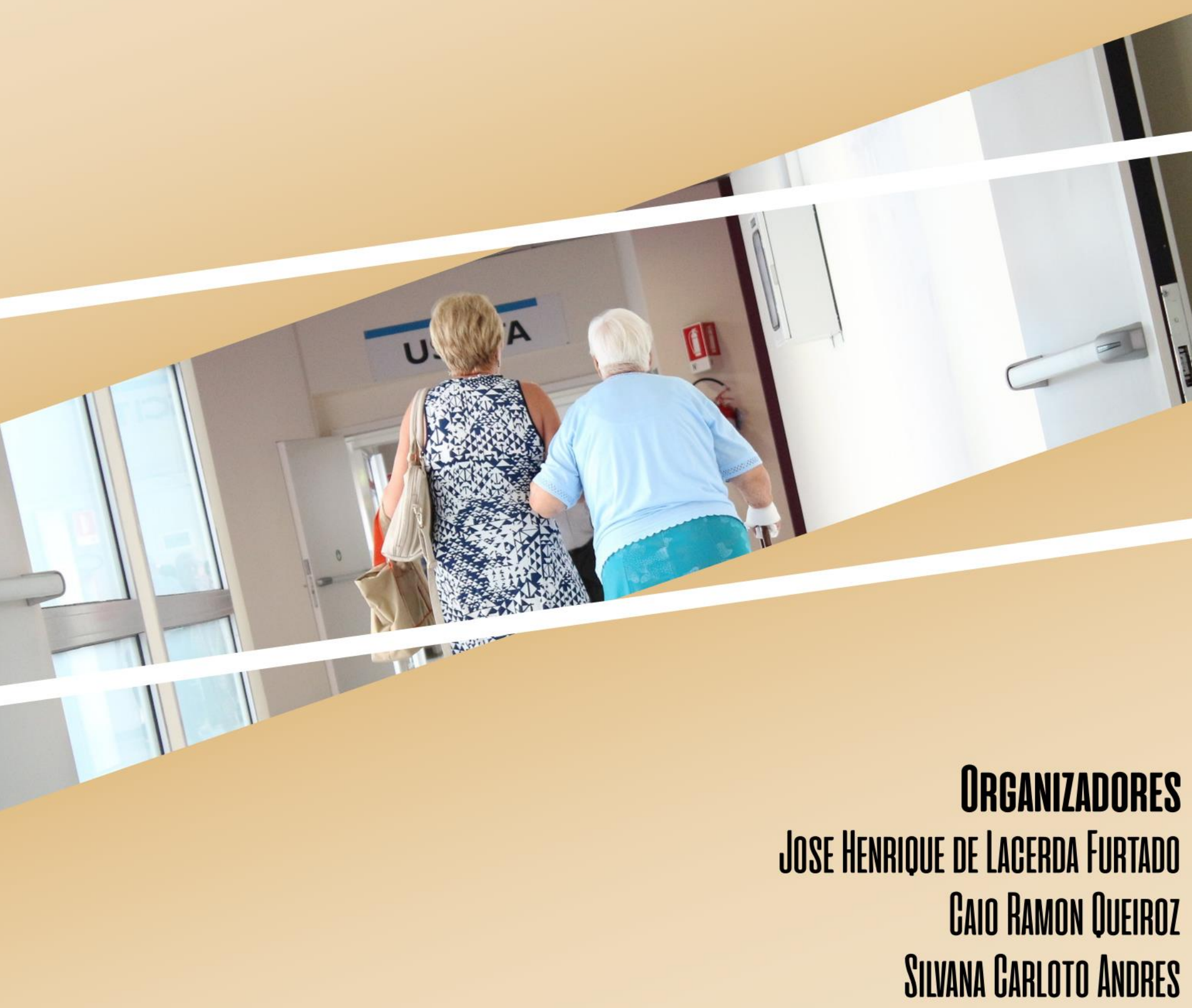




\section{ZAMPLLA}

2021 - Editora Amplla

Copyright (C) Editora Amplla

Editor Chefe: Leonardo Pereira Tavares

Design da Capa: Editora Amplla

Projeto Gráfico e Diagramação: Higor Costa de Brito

Atenção Primária à Saúde no Brasil: desafios e possibilidades no cenário contemporâneo está licenciado sob CC BY 4.0.

(c) (i) Esta licença exige que as reutilizações deem crédito ao criador. Ele permite que os ou formato, mesmo para fins comerciais.

O conteúdo da obra e seus dados em sua forma, correção e confiabilidade são de responsabilidade exclusiva dos autores, não representando a posição oficial da Editora Amplla. É permitido o download da obra e o compartilhamento desde que sejam atribuídos créditos aos autores. Todos os direitos para esta edição foram cedidos à Editora Amplla.

ISBN: 978-65-88332-27-6

DOI: 10.51859/amplla.aps276.1121-0

Editora Amplla

Campina Grande - PB - Brasil contato@ampllaeditora.com.br www.ampllaeditora.com.br 


\section{CONSELHO EDITORIAL}

Andréa Cátia Leal Badaró - Universidade Tecnológica Federal do Paraná Andréia Monique Lermen - Universidade Federal do Rio Grande do Sul Antoniele Silvana de Melo Souza - Universidade Estadual do Ceará Bergson Rodrigo Siqueira de Melo - Universidade Estadual do Ceará Bruna Beatriz da Rocha - Instituto Federal do Sudeste de Minas Gerais Caio César Costa Santos - Universidade Federal de Sergipe Carina Alexandra Rondini - Universidade Estadual Paulista Carla Caroline Alves Carvalho - Universidade Federal de Campina Grande Carlos Augusto Trojaner - Prefeitura de Venâncio Aires Carolina Carbonell Demori - Universidade Federal de Pelotas Cícero Batista do Nascimento Filho - Universidade Federal do Ceará Clécio Danilo Dias da Silva - Universidade Federal do Rio Grande do Norte Daniela de Freitas Lima - Universidade Federal de Campina Grande Denise Barguil Nepomuceno - Universidade Federal de Minas Gerais Dylan Ávila Alves - Instituto Federal Goiano Edson Lourenço da Silva - Instituto Federal de Educação, Ciência e Tecnologia do Piauí Elane da Silva Barbosa - Universidade Estadual do Ceará Érica Rios de Carvalho - Universidade Católica do Salvador Gilberto de Melo Junior - Instituto Federal do Pará Higor Costa de Brito - Universidade Federal de Campina Grande Italan Carneiro Bezerra - Instituto Federal da Paraíba Ivo Batista Conde - Universidade Estadual do Ceará Jaqueline Rocha Borges dos Santos - Universidade Federal Rural do Rio de Janeiro Jessica Wanderley Souza do Nascimento - Instituto de Especialização do Amazonas João Henriques de Sousa Júnior - Universidade Federal de Santa Catarina João Manoel Da Silva - Universidade Federal de Alagoas

João Vitor Andrade - Universidade de São Paulo Joilson Silva de Sousa - Instituto Federal do Rio Grande do Norte José Cândido Rodrigues Neto - Universidade Estadual da Paraíba Jose Henrique de Lacerda Furtado - Instituto Federal do Rio de Janeiro Josenita Luiz da Silva - Faculdade Frassinetti do Recife Josiney Farias de Araújo - Universidade Federal do Pará Karina de Araújo Dias - SME/Prefeitura Municipal de Florianópolis Laíze Lantyer Luz - Universidade Católica do Salvador Lindon Johnson Pontes Portela - Universidade Federal do Oeste do Pará Lucas Capita Quarto - Universidade Federal do Oeste do Pará Lúcia Magnólia Albuquerque Soares de Camargo - Unifacisa Centro Universitário Luciana de Jesus Botelho Sodré dos Santos - Universidade Estadual do Maranhão Luís Paulo Souza e Souza - Universidade Federal do Amazonas Luiza Catarina Sobreira de Souza - Faculdade de Ciências Humanas do Sertão Central Manoel Mariano Neto da Silva - Universidade Federal de Campina Grande Marcelo Alves Pereira Eufrasio - Centro Universitário Unifacisa Marcelo Williams Oliveira de Souza - Universidade Federal do Pará Marcos Pereira dos Santos - Faculdade Rachel de Queiroz Marcus Vinicius Peralva Santos - Universidade Federal da Bahia Marina Magalhães de Morais - Universidade Federal de Campina Grande Nadja Maria Mourão - Universidade do Estado de Minas Gerais Natan Galves Santana - Universidade Paranaense Nathalia Bezerra da Silva Ferreira - Universidade do Estado do Rio Grande do Norte Neide Kazue Sakugawa Shinohara - Universidade Federal Rural de Pernambuco Neudson Johnson Martinho - Faculdade de Medicina da Universidade Federal de Mato Grosso Patrícia Appelt - Universidade Tecnológica Federal do Paraná 
Paulo Henrique Matos de Jesus - Universidade Federal do Maranhão Rafael Rodrigues Gomides - Faculdade de Quatro Marcos

Reângela Cíntia Rodrigues de Oliveira Lima - Universidade Federal do Ceará Rebeca Freitas Ivanicska - Universidade Federal de Lavras

Renan Monteiro do Nascimento - Universidade de Brasília Ricardo Leoni Gonçalves Bastos - Universidade Federal do Ceará Rodrigo da Rosa Pereira - Universidade Federal do Rio Grande Sabrynna Brito Oliveira - Universidade Federal de Minas Gerais Samuel Miranda Mattos - Universidade Estadual do Ceará Shirley Santos Nascimento - Universidade Estadual Do Sudoeste Da Bahia Silvana Carloto Andres - Universidade Federal de Santa Maria Silvio de Almeida Junior - Universidade de Franca Tatiana Paschoalette Rodrigues Bachur - Universidade Estadual do Ceará Telma Regina Stroparo - Universidade Estadual do Centro-Oeste Thayla Amorim Santino - Universidade Federal do Rio Grande do Norte Virgínia Maia de Araújo Oliveira - Instituto Federal da Paraíba Virginia Tomaz Machado - Faculdade Santa Maria de Cajazeiras Walmir Fernandes Pereira - Miami University of Science and Technology Wanessa Dunga de Assis - Universidade Federal de Campina Grande Wellington Alves Silva - Universidade Estadual de Roraima Yáscara Maia Araújo de Brito - Universidade Federal de Campina Grande Yasmin da Silva Santos - Fundação Oswaldo Cruz

Yuciara Barbosa Costa Ferreira - Universidade Federal de Campina Grande 


\section{ZIAMPLLA}

2021 - Editora Amplla

Copyright (c) Editora Amplla

Editor Chefe: Leonardo Pereira Tavares

Design da Capa: Editora Amplla

Projeto Gráfico e Editoração: Higor Costa de Brito

Dados Internacionais de Catalogação na Publicação (CIP)

Sueli Costa CRB-8/5213

Atenção primária à saúde no Brasil [livro eletrônico]: desafios e possibilidades no cenário contemporâneo / organização

Jose Henrique de Lacerda Furtado; Caio Ramon Queiroz; Silvana

Carloto Andres. Campina Grande : Editora Amplla, 2021.

$356 \mathrm{p}$.

Formato: PDF

ISBN : $978-65-88332-27-6$

1. Atenção primária à saúde 2. Saúde pública - Brasil

3. Sistema Único de Saúde I. Furtado, Jose Henrique de Lacerda

II. Queiroz, Caio Ramon III. Andres, Silvana Carloto IV. Título

$\mathrm{CDD}-362.1$

\section{Índices para catálogo sistemático:}

1. Saúde pública : Brasil 362.1

Editora Amplla

Campina Grande - PB - Brasil contato@ampllaeditora.com.br www.ampllaeditora.com.br 


\section{PREFÁCIO}

A conquista do direito à saúde, legitimada na Constituição Federal de 1988, inaugurou no país uma nova forma de organização da oferta dos serviços de saúde à população. Na perspectiva da saúde como um direito universal, o Sistema Único de Saúde (SUS) foi implantado no país, adotando a Atenção Primária à Saúde (APS) como estratégia principal de ampliação do acesso aos serviços ofertados.

No entanto, não podemos deixar de reconhecer os diversos desafios que ela sempre enfrentou e vem enfrentando cronicamente, para se consolidar enquanto modelo assistencial que objetiva não só, ampliar o acesso ao sistema de saúde, mas também, tentar reverter o enfoque curativo, individual e hospitalar, tradicionalmente instituído nos sistemas de saúde nacionais, em um modelo preventivo, coletivo, territorializado e democrático ${ }^{1}$.

Nos últimos anos no Brasil, vivenciamos um cenário acentuado de desmonte da APS e das políticas públicas como um todo, ameaçando diversos direitos sociais legalmente constituídos e dificultando ainda mais, a manutenção de uma APS forte, em uma perspectiva abrangente e integral. Com a pandemia de COVID-19, este cenário só se acentuou, lançando foco aos diversos problemas estruturais que sempre estiveram presentes ao longo desses anos.

Diante disso, eu, em parceria com o pesquisador Caio Ramon Queiroz e a pesquisadora Silvana Carloto Andres, aceitamos o desafio de organizar essa obra intitulada "Atenção Primária à Saúde no Brasil: desafios e possibilidades no cenário contemporâneo", que objetivou englobar estudos que discutissem a temática relacionada aos desafios da APS no cenário atual brasileiro, com foco tanto em estudos teórico-conceituais, quanto em relatos de experiências e pesquisas desenvolvidas nas diversas regiões do país.

Sendo assim, esta coletânea é composta por 28 capítulos, que contribuem significativamente para essa reflexão tão importante e necessária no contexto pandêmico atual, tendo em vista que a APS constitui-se enquanto a principal porta de

1 FAUSTO, M. C. R.; MATTA, G.C. Atenção Primária à Saúde: histórico e perspectivas. In: MOROSINI, M. V. G.C. Modelos de atenção e a saúde da família/Organizado por Márcia Valéria G. C. Morosini e Anamaria D'Andrea Corbo. Rio de Janeiro: EPSJV/FIOCRUZ, 2007. 
entrada do sistema público de saúde brasileiro, com potencial para resolver grande parte das demandas de saúde da população.

Dessa forma, os capítulos foram organizados de modo a proporcionar um encadeamento temático das leituras, a fim de despertar o interesse do leitor a aprofundar as reflexões oportunizadas pelos mesmos, iniciando com os capítulos que abordam diretamente a temática relacionada à APS no enfrentamento à pandemia de COVID-19, prosseguindo para os estudos que versam sobre as estratégias de fortalecimento da APS e por fim, para os estudos que abordam os diversos desafios cotidianamente enfrentados pelas equipes inseridas no sistema público de saúde do país.

Por fim, deixo meus sinceros agradecimentos a todos (as) que aceitaram fazer parte de mais esse desafio coletivo, desde os (as) pesquisadores (as) autores (as) dos capítulos aqui publicados, até a equipe da Editora Amplla, por ter viabilizado as condições para que essa construção compartilhada de conhecimento se tornasse realidade e estive disponível para consulta de forma ampla a todos e todas.

Considerando que este $e$-book constitui-se enquanto um mecanismo de luta e resistência coletiva em defesa do SUS e da garantia da saúde enquanto direito universal, fica aqui o convite à leitura e às reflexões propostas.

Jose Henrique de Lacerda Furtado

Doutorando em Saúde Pública (ENSP/FIOCRUZ) Mestre em Educação Profissional em Saúde (EPSJV/FIOCRUZ) Técnico Administrativo em Educação/Enfermagem do Instituto Federal do Rio de Janeiro (IFRJ- 


\section{SUMÁRIO}

CAPÍTULO I - ATENÇÃO PRIMÁRIA À SAÚDE FRENTE A PANDEMIA DE COVID-19 NO BRASIL: POSSIBILIDADES E DESAFIOS. .11

DII: 10.51859/AMPLLA.APS276.1121-1

CAPÍTULO II - ATENÇÃO BÁSICA FRENTE À PANDEMIA DO NOVO CORONAVÍRUS: UMA REVISÃO INTEGRATIVA .......26

QDI: 10.51859/AMPLLA.APS276.II21-2

CAPÍTULO III - OS IMPACTOS DA COVID-19 NO ATENDIMENTO ODONTOLÓGICO EM ATENÇÃO PRIMÁRIA À SAÚDE .. 43

DII: 10.51859/AMPLLA.APS276.IIZ1-3

CAPÍTULO IV - INTERPROFISSIONALIDADE NA ATENÇÃO PRIMÁRIA À SAÚDE 52

DDI: 10.51859/AMPLLA.APS276.II21-4 CAPÍTULO V - PLANEJAMENTO DA ATENÇÃO PRIMARIA A SAÚDE PARA ATENDIMENTO AO PACIENTES COM SINTOMAS RESPIRATÓRIOS EM TEMPOS DE PANDEMIA DE COVID-19 61

DDI: 10.51859/AMPLLA.APS276.II21-5 CAPÍTULO VI - VISITA DOMICILIAR NO CONTEXTO DA ATENÇÃO PRIMARIA À SAÚdE DESAFIOS DE MÉDICOS E ENFERMEIROS: RELATO DE EXPERIÊNCIA 68

DII: 10.51859/AMPLLA.APS276.IIZ1-6 CAPÍTULO VII - UTILIZAÇÃO DE LIVES COMO EDUCACÇ̃O EM SAÚDE DURANTE A PANDEMIA DO COVID-19 76

DOI: 10.51859/AMPLLA.APS276.|I21-7 CAPÍTULO VIII - INTRODUÇÃO À ATENÇÃO PRIMÁRIA À SAÚDE NO BRASIL: DESAFIOS E POSSIBILIDADES NO CENÁRIO CONTEMPORÂNEO .82

DII: 10.51859/AMPLLA.APS276.|I21-8 CAPÍTULO IX - A RESIDÊNCIA MULTIPROFISSIONAL EM SAÚDE DA FAMÍLIA E COMUNIDADE COMO INSTRUMENTO PARA FORTALECIMENTO E DEFESA DO SISTEMA ÚNICO DE SAÚDE .101

DII: 10.51859/AMPLLA.APS276.|I21-9 CAPÍTULO X - AMPLIANDO E CONHECENDO A SAÚDE DO TERRITÓRIO ATRAVÉS DA VIVÊNCIA DE ESTÁGIO EM NUTRIÇÃO SOCIAL: UM RELATO DE EXPERIÊNCIA .115

DU: 10.51859/AMPLLA.APS276.1121-10 CAPÍTULO XI - A ATENÇÃO PRIMÁRIA ANTE A ANSIEDADE: UMA INQUIRIÇÃO CONCERNENTE A UM MAL DO SÉCULO XXI. .127 
CAPÍTULO XII - ERRADICAÇÃO DA SíFILIS CONGÊNITA: DESAFIOS ENFRENTADOS PELA ATENÇÃO PRIMÁRIA À SAÚDE E A CONTRIBUIÇÃO DA ENFERMAGEM .142

DVI: 10.51859/AMPLLA.APS276.1121-12

CAPÍTULO XIII - O ENFERMEIRO PRESENTE NA REDE SOCIAL DE APOIO DE ADOLESCENTES GRÁVIDAS 150

DDI: 10.51859/AMPLLA.APS276.1121-13 CAPÍTULO XIV - A CONSULTA DE ENFERMAGEM NA ASSISTÊNCIA DO PRÉ-NATAL DE BAIXO RISCO ATENDIDO NA ATENÇÃO PRIMARIA À SAÚDE. .161

DOI: 10.51859/AMPLLA.APS276.1121-14 CAPÍTULO XV - ATUAÇÃO DO ENFERMEIRO NA PREVENÇÃO E COMBATE À DESNUTRIÇÃO INFANTIL NA ESTRATÉGIA SAÚDE DA FAMÍLIA. .173

DOI: 10.51859/AMPLLA.APS276.1121-15 CAPITULO XVI - MULHERES NO CLIMATÉRIO E SUA SEXUALIDADE: UMA PERSPECTIVA BIOPSICOSSOCIAL 187

DDI: 10.51859/AMPLLA.APS276.1121-16 CAPÍTULO XVII - PERFIL SOCIOECONÔMICO E CLÍNICO DE MULHERES CADASTRADAS EM UNIDADE DE SAÚDE COM CITOPATOLOGIA ONCÓTICA ALTERADA 202

DVI: 10.51859/AMPLLA.APS276.1121-17

CAPÍTULO XVIIII - PERCEPÇÃO DE GESTANTES QUANTO AO USO DO SULFATO FERROSO .217

DLI: $10.51859 / A M P L L A . A P S 276.1121-18$ CAPÍTULO XIX - CONCEPÇÕES E DESAFIOS DA ATUAÇÃO FONOAUDIOLÓGICA NO NÚCLEO AMPLIADO DE SAÚDE DA FAMÍLIA E ATENÇÃO PRIMÁRIA 226

DLI: $10.51859 / A M P L L A . A P S 276.1121-19$ CAPÍTULO XX - INOVAÇÃO E EDUCAÇÃO EM SAÚdE: UMA REVISÃO DE LITERATURA SOBRE AVALIAÇÃO DA NECESSIDADE DE CRIAÇÃO DE FACILITADORES PARA AJUDAR IDOSOS NA AUTOGESTÃO MEDICAMENTOSA ......... 236

ODI: 10.51859/AMPLLA.APS276.1121-20 CAPÍTULO XXI - MEDICINA POPULAR NA ATENÇÃO BÁSICA: UTILIZAÇÃO DAS PLANTAS MEDICINAIS PELOS RESIDENTES DA ÁREA FITOGEOGRÁFICA DO CERRADO BRASILEIRO. .251

DOI: 10.51859/AMPLLA.APS276.1121-21 CAPÍTULO XXII - O CONHECIMENTO BÁSICO EM SAÚDE BUCAL COMO FATOR QUANTIOSO PARA O BEM-ESTAR GERAL 267

0DI: 10.51859/AMPLLA.APS276.1121-22 CAPÍTULO XXIII - MANIFESTAÇÕES ORAIS DO DIABETES MELLITUS. 275 
CAPÍTULO XXIV - MANIFESTAÇÕES ORAIS DA DOENÇA CELÍACA

0DI: 10.51859/AMPLLA.APS276.1121-24

CAPÍTULO XXV - INTOXICAÇ̃̃O POR MEDICAMENTOS NO BRASIL: UMA REVISÃO SISTEMÁTICA. 300

DDI: 10.51859/AMPLLA.APS276.1121-25 CAPÍTULO XXVI - RESILIÊNCIA DA EQUIPE DE ENFERMAGEM DIANTE DO PACIENTE ONCOLÓGICO PALIATIVO .......317 DDI: 10.51859/AMPLLA.APS276.1121-26 CAPÍTULO XXVII - SAÚDE EM AMBIENTES PENITENCIÁRIOS NO BRASIL: UM PANORAMA DA ESTRUTURA FÍ́ICA E COMPOSIÇÃO. 328

DOI: $10.51859 / A M P L L A . A P S 276.1121-27$ CAPÍTULO XXVIIII - O PAPEL DO ENFERMEIRO NA PREVENÇÃO DE INFECÇÃO POR CORRENTE SANGUÍNEA. 343 


\title{
CAPÍTULO I
}

\section{ATERÇÃO PRIITÍRIA À SAÚLE FRERTE A PAחDETIIIA DE COUID-19 חO BRASIL: POSSIBILIDADESE DESAFIOS}

\author{
DII: 10.51859/AMPLLA.APS276.|I2I-1
}

\author{
Caroline Tianeze de Castro ${ }^{1}$ \\ Romana Santos Gama ${ }^{2}$ \\ Ana Flávia Souto Figueiredo Nepomuceno ${ }^{3}$ \\ Mariana Souto Figueiredo ${ }^{4}$ \\ Beatriz Tianeze de Castro ${ }^{5}$
}

\begin{abstract}
${ }^{1}$ Farmacêutica. Mestre em Saúde Coletiva. Instituto Multidisciplinar em Saúde, Universidade Federal da Bahia UFBA.

2 Farmacêutica. Mestranda em Medicina e Saúde. Faculdade de Medicina da Bahia, Universidade Federal da Bahia UFBA.

${ }^{3}$ Farmacêutica. Mestranda em Farmácia. Faculdade de Farmácia, Universidade Federal da Bahia - UFBA.

${ }^{4}$ Cirurgiã Dentista. Mestranda em Saúde Coletiva. Instituto Multidisciplinar em Saúde, Universidade Federal da Bahia - UFBA.

${ }^{5}$ Graduanda em Medicina. Faculdade de Saúde Santo Agostinho de Vitória da Conquista - FASA.
\end{abstract}

\section{RESUMO}

O surgimento do vírus SARS-CoV-2 associado à sua rápida transmissão fez com que governantes de todo o mundo adotassem medidas prioritárias a fim de mitigá-lo. Apesar da importância da estruturação adequada do ambiente hospitalar para o combate à pandemia, também é necessário uma abordagem comunitária que promova a vigilância em saúde, atuação específica das equipes de Atenção Primária à Saúde. Sendo assim, pretende-se contextualizar o cenário atual e pontuar os desafios e possibilidades da Atenção Primária à Saúde frente à pandemia da COVID-19. Nos últimos anos, o SUS sofreu com um subfinanciamento crônico que foi agravado com redução e congelamento dos gastos. A Atenção Primária à Saúde no cenário da pandemia do coronavírus tem a potencialidade de se articular intersetorialmente para apoiar sua população em suas diversas vulnerabilidades. Apesar dos desafios enfrentados pela Atenção Primária à Saúde, a pandemia reafirma sua importância para o sistema de saúde e sinaliza a necessidade do seu fortalecimento, readequação e qualificação a fim de garantir a universalidade, integralidade e equidade do cuidado.

Palavras-chave: Atenção Primária à Saúde. Infecções por Coronavírus. Saúde Pública. Sistema Único de Saúde.

\section{IกTRODUÇก̃O}

A COVID-19, doença causada por uma nova cepa de coronavírus (SARS-CoV-2), foi inicialmente identificada na China, e trouxe um alerta a todos os continentes devido 
à sua rápida disseminação e às dificuldades em conter a infecção. A doença se alastrou de forma rápida e agressiva por todo o mundo, levando a uma pandemia após dois meses do primeiro caso reportado (SARTI et al., 2020).

A chegada do vírus SARS-CoV-2, associada à sua rápida transmissão e à falta de tratamento e vacinas fizeram com que governantes de todo o mundo adotassem a quarentena e o isolamento social como medidas prioritárias na mitigação da COVID-19 (AQUINO et al., 2020). No Brasil, a ausência de autoridade sanitária nacional e de coordenação e cooperação entre as esferas Federal e Estaduais para enfrentamento da pandemia têm contribuído para os resultados desastrosos observados no país (GIOVANELLA, 2020), como a elevada mortalidade, que tem sido mantida durante todo o tempo da pandemia, e o advento de uma segunda onda de casos. Além disso, o subfinanciamento crônico do Sistema Único de Saúde (SUS) e o direcionamento de profissionais de saúde e recursos para a assistência hospitalar contribuíram para a fragilização da Atenção Primária à Saúde (APS) durante a pandemia (TEIXEIRA et al., 2020).

Apesar da importância da estruturação adequada do ambiente hospitalar para o atendimento de pacientes graves com COVID-19, deve-se levar em conta que para o controle da epidemia, além da garantia do cuidado individual, é necessária uma abordagem comunitária que promova a vigilância em saúde, atuação específica das equipes de APS, que conhecem seus territórios, sua população e suas vulnerabilidades (GIOVANELLA, 2020). Ademais, a APS é o nível de atenção à saúde mais acessível à comunidade e, em razão do vínculo com o usuário do sistema, tem maior potencialidade em incorporar medidas de educação em saúde, a fim de conscientizar a população quanto a maneira de evitar a doença, a dimensão e a gravidade da epidemia (CABRAL et al., 2020).

Após mais de um ano convivendo com o vírus e atualmente com suas novas variantes, ainda percebemos sobrecarga de um sistema que mesmo sucateado possui potencialidades. O Brasil é o sexto país mais populoso e o quinto com maior território no mundo (IBGE, 2021; UN, 2018), ocupando o segundo lugar em número de mortos no mundo, atrás apenas dos Estados Unidos (WHO, 2021). A má gestão dos recursos de saúde, já escassos, e o não reconhecimento das possibilidades que a APS pode ter no cenário atual dificultam ainda mais a luta contra a COVID-19. Sendo assim, pretende-se 
contextualizar o cenário atual e pontuar os desafios e possibilidades da APS frente à pandemia da COVID-19.

\section{REUISÃO BIBLIOGRÁFICA}

\subsection{COUID-19}

Em dezembro de 2019, a China reportou um surto de pneumonia decorrente do patógeno SARS-CoV-2, que rapidamente se espalhou pelo país. Em 30 de janeiro de 2020, a Organização Mundial de Saúde (OMS) declarou a COVID-19 como uma emergência de saúde pública de importância internacional (WHO, 2020a), e em 11 de março deste mesmo ano, como uma pandemia (WHO, 2020b). O primeiro caso da doença no Brasil foi confirmado em 26 de fevereiro de 2020, no estado de São Paulo, em um homem de 61 anos que esteve na Itália. Menos de um mês após a confirmação do primeiro caso a doença já havia chegado a todos os estados brasileiros (MELO et al., 2020).

A transmissão da COVID-19 ocorre, principalmente, nos três primeiros dias após o início dos sintomas, mas é válido salientar que indivíduos assintomáticos também podem transmitir a infecção. Os sintomas ocasionados pelo novo coronavírus são diversos, mas, de forma geral, tendem a se manifestar através de dispneia, tosse seca e febre. Enquanto que, as principais manifestações clínicas nos quadros graves incluem pneumonia, insuficiência respiratória hipoxêmica e choque séptico. A principal via de infecção é dada por meio de gotículas respiratórias e aerossóis liberados por indivíduos infectados durante a respiração, espirro, tosse e fala, que podem se manter viáveis em superfícies por um longo período, facilitando a disseminação da doença (FREITAS; NAPIMOGA; DONALISIO, 2020; SOUTO et al., 2020; VELAVAN et al., 2020).

Epidemiologicamente, tem sido observado que os quadros mais graves ocorrem em qualquer idade, todavia, indivíduos adultos e com comorbidades pré-existentes tendem a desenvolver a doença em sua maior gravidade. Observa-se, dessa forma, a importância do diagnóstico precoce. Este pode ser realizado através da avaliação dos sintomas e histórico do paciente que, aliada a testes sorológicos e exames de imagem, possibilitam um eventual diagnóstico. O diagnóstico, que deve ser conclusivo, se dá por 
meio da realização de testes moleculares que objetivam avaliar o material genético viral (RNA) em amostras do indivíduo (WHO, 2020c).

Nesse sentido, apesar das informações atualmente existentes sobre a COVID-19, a sua rápida disseminação em todo o mundo impôs desafios sem precedentes para os sistemas de saúde, que precisaram se reorganizar para lidar com o desconhecimento da doença, com a rápida disseminação da infecção, com o número crescente de morbimortalidade, com a ausência de farmacoterapia preventiva, e com as novas demandas em saúde ocasionadas especialmente pela gravidade de uma parcela de casos (DAUMAS et al., 2020).

Diante desse cenário, houve a necessidade da ampliação da rede hospitalar, principalmente dos leitos clínicos e das Unidades de Terapia Intensiva (UTI) para auxiliar no tratamento e manejo de pacientes com a doença. Todavia, mesmo não tendo o seu papel tão evidenciado pelas mídias durante a pandemia, a APS tem desenvolvido um papel fundamental no controle de infecções por COVID-19 no país, principalmente no que tange à ordenação do sistema, coordenação do cuidado e organização das demandas da comunidade, contribuindo para promoção e educação em saúde, detecção e, controle dos casos de infecção por SARS-CoV-2 (CABRAL et al.; 2020).

O Brasil enfrenta ainda imensos desafios com a chegada da COVID-19 que dificultam o controle da epidemia, aumentam o número de pessoas suscetíveis à infecção, reduzem a capacidade de resposta da atenção médica e aumentam os riscos de morte, tais como: a vasta extensão territorial; a alta densidade populacional em algumas cidades; a grande variedade de rotas aéreas, terrestres e marítimas com conexões para todo o mundo; o acesso limitado aos testes diagnósticos do vírus SARSCoV-2; a debilidade do sistema de saúde pública devido ao subfinanciamento crônico; as disparidades sociais, econômicas e regionais; e a falta de articulação entre o governo federal e os estados (GIOVANELLA, 2020; MINAYO et al., 2020; MOREIRA et al., 2020).

Diferentemente de países como Espanha, França e Alemanha, que adotaram medidas de distanciamento físico integral que proporcionaram a redução do número de casos a um nível muito baixo, e que evoluíram com duas fases bem distintas na curva epidêmica, no Brasil a pandemia evoluiu de modo contínuo, com um alto número de casos e óbitos nesses onze meses, sempre acima de 100.000 casos/dia, apresentando um novo aumento no número de casos notificados a partir de novembro de 2020. 
Devido a esse fato, o país é o segundo em número de casos e óbitos, atrás apenas dos Estados Unidos (BRASIL, 2021).

\subsection{Atenção Primária à Saúde no Brasil}

A concepção de APS conhecida atualmente surgiu em 1920, no Reino Unido, com o Relatório Dawson. Este relatório descreveu as funções de cada nível de atenção em saúde e as relações que deveriam existir entre eles, sendo o texto inaugural da regionalização dos sistemas de atenção à saúde organizados com base na saúde da população e que influenciou a organização desses sistemas em vários países do mundo (MENDES, 2015).

A APS foi consagrada a partir da Conferência Internacional sobre Atenção Primária em Saúde, organizada pela Organização Mundial da Saúde (OMS) e o Fundo das Nações Unidas para a Infância (Unicef), realizada em 1978 em Alma-Ata (GIOVANELLA; MENDONÇA, 2012; RODRIGUES et al., 2014). Na ocasião, a APS foi definida como a porta de entrada dos sistemas de saúde e o primeiro elemento de um processo contínuo de atenção (RODRIGUES et al., 2014).

No entanto, não há uniformidade no emprego da expressão atenção primária à saúde nos diversos países, havendo, segundo Giovanella e Mendonça (2012), quatro linhas principais de interpretação: (1) programa focalizado e seletivo, com cesta restrita de serviços; (2) um dos níveis de atenção, que corresponde aos serviços ambulatoriais médicos não especializados de primeiro contato, incluindo ou não amplo espectro de ações de saúde pública e de serviços clínicos direcionados a toda a população; (3) abrangente ou integral, como uma concepção de modelo assistencial e de organização do sistema de saúde conforme proposto em Alma-Ata para enfrentar necessidades individuais e coletivas; (4) filosofia que orienta processos emancipatórios pelo direito universal à saúde.

A criação do SUS se deu com a promulgação da Carta Magna no ano de 1988 e foi fruto de uma série de reivindicações sociais responsáveis por tornar a saúde no Brasil um direito universal, equânime e igualitário (SOUSA; FERNANDES, 2020).

Durante a implantação do SUS notou-se uma série de necessidades em saúde advindas principalmente do crescimento das Doenças Crônicas Não Transmissíveis (DCNT), de quadros de desnutrição, parasitoses e mortalidade infantil. Agravos esses 
que exigiram mudanças na abordagem das doenças mais prevalentes. Esta necessidade culminou com a implantação do Programa de Agentes Comunitários (PACS) no ano de 1990 e posterior implantação do Programa Saúde da Família (PSF), no ano de 1994 (CARVALHO, 2013; MOROSINI; FONSECA; LIMA, 2018). O PSF foi apresentado no primeiro documento ministerial como um programa, passando, em seguida, a ser considerado uma estratégia de reorientação do modelo assistencial, com potencial caráter substitutivo das práticas convencionais, denominado atualmente Estratégia de Saúde da Família (ESF) (GOMES et al., 2011). Esta estratégia permitiu a ampliação da cobertura em saúde, em um movimento inicialmente voltado para os brasileiros com maior vulnerabilidade social (CARVALHO, 2013; MOROSINI; FONSECA; LIMA, 2018).

A ESF incorpora os princípios do SUS e reinventa a atenção à saúde a partir de diretrizes que criam uma nova forma de produzir as ações e serviços de saúde, na perspectiva de mudança e conversão do modelo assistencial mecanicista e biomédico em um modelo de saúde coletivo, multiprofissional e centrado na família e na comunidade (GOMES et al., 2011).

Ademais, a ESF está pautada na atenção ao primeiro contato, longitudinalidade, integralidade e coordenação do cuidado em saúde. A atenção ao primeiro contato considera a APS como a porta de entrada para as questões de saúde e a sua capacidade para lidar com problemas amplos, heterogêneos e influenciados pelo contexto social. A longitudinalidade diz respeito ao aporte regular de cuidados à saúde e seu uso consistente ao longo do tempo. A integralidade exige a prestação de um conjunto de serviços que atendam às necessidades mais comuns da população adscrita, aliada à responsabilização pela oferta de serviços em outros pontos de atenção à saúde, considerando os processos biológicos, psicológicos e sociais causais das doenças. Já a coordenação implica na capacidade de garantir a continuidade da atenção, de um modo integrado e organizado (STARFIELD, 2002). Atualmente a APS é uma importante estratégia de organização, orientação e oferta do cuidado no país (MENDES, 2015; GIOVANELLA, 2009).

A combinação de diversos tipos de densidades tecnológicas, a atuação multidisciplinar, o cuidado integral, longitudinal e territorializado com ênfase nas práticas preventivas, características da APS, contribuíram para melhorias nos indicadores de saúde como: redução da mortalidade materno-infantil, controle das 
doenças crônicas, aumento das consultas de pré-natal, expansão de acesso aos tratamentos, controle de algumas doenças infecciosas, e diminuição das internações por doenças preveníveis evitando casos de maior complexidade na assistência à saúde (MACINKO; MENDONÇA, 2018). Sendo assim, a APS deve ser considerada um importante pilar frente às situações emergenciais vivenciadas no Brasil (DUNLOP et al., 2020), como as epidemias de dengue, zika, chikungunya, febre amarela e COVID-19 (SARTI et al., 2020).

\subsection{Desafios da Atenção Primária à Saúde frente à pandemia}

Com a chegada da pandemia no Brasil, os gestores das diversas esferas governamentais se mobilizaram para responder às demandas da pandemia. Dessa forma, maiores esforços foram direcionados para atender aos casos de insuficiência respiratória aguda, como a ampliação de leitos de unidades de terapia intensiva, abertura de hospitais de campanha e aquisição de equipamentos como respiradores e equipamentos de proteção individual (TEIXEIRA et al., 2020).

Essas ações, apesar de necessárias devido à alta taxa de letalidade da COVID-19 em decorrência do número expressivo de pacientes que necessitam de internação hospitalar, não são suficientes para o enfrentamento do novo coronavírus (SEIXAS et al., 2021). A ênfase inicial na estruturação da assistência hospitalar, dos serviços de urgência e de terapia intensiva dos municípios de médio e grande porte levou a uma desmobilização das unidades de atenção básica, com deslocamento de profissionais das equipes para polos de atendimento a vítimas da COVID-19 e redirecionamento dos recursos da atenção básica para a assistência hospitalar, favorecendo o enfraquecimento da já fragilizada APS (TEIXEIRA et al., 2020).

Deve-se destacar alguns fatores que também contribuíram para o enfraquecimento da APS no controle da pandemia, como a Política Nacional de Atenção Básica (PNAB) de 2017 e a Emenda Constitucional (EC) 95. A PNAB 2017 promoveu a flexibilização da APS, a relativização da cobertura em saúde, a segmentação do cuidado, a redução de agentes comunitários de saúde, a flexibilização de carga horária de profissionais e a descaracterização da ESF como modelo assistencial primordial da APS brasileira (MOROSINI; FONSECA; LIMA, 2018; TEIXEIRA et al., 2020). Outrossim, a PNAB 2017 provocou uma mudança gradual do modelo assistencial, desprivilegiando o 
monitoramento das condições de vida e saúde da população do território em detrimento da assistência individual, focada em agravos (BRASIL, 2017).

A ESF se pauta no cuidado multiprofissional, sendo composta por no mínimo um médico generalista, ou especialista em Saúde da Família, ou médico de Família e Comunidade; um enfermeiro generalista ou especialista em Saúde da Família; um auxiliar ou técnico de enfermagem; e agentes comunitários de saúde. A ESF efetua ações que acolhem os indivíduos da comunidade, com estratégias voltadas ao cuidado em saúde individual e coletivo, desvelando as desigualdades sociais e as iniquidades em saúde (GONDIM; MONKEN, 2008; JAPIASSU; RACHED, 2020). Todavia, a PNAB de 2017 desarmoniza a ESF ao modificar a equipe multiprofissional e priorizar o direcionamento da saúde para a doença, prejudicando a humanização do atendimento em saúde (CABRAL et al., 2020).

Ainda, com o dano ao atendimento integral, há uma fragilidade na educação em saúde, visto o desfalque na ESF. Somado a isto, a pequena quantidade de computadores e a ausência de acesso à internet nas unidades podem impactar no alcance das ações em saúde realizadas na APS, lesando a comunidade nas informações recebidas (CABRAL et al., 2020).

O SUS sofre também com um subfinanciamento crônico que foi agravado pela política neoliberal adotada pelo atual governo e que vem se instaurando no país desde 2016. A EC 95, que congelou gastos sociais por 20 anos, promove o desfinanciamento e sucateamento do SUS (MENEZES; MORETTI; REIS, 2019) e ocasionou a redução de R\$ 20 bilhões dos recursos da saúde no orçamento federal de 2020 (GIOVANELLA, 2020).

De acordo com Medina et al. (2020), essas ameaças recentes foram somadas a problemas cronicamente enfrentados na APS brasileira. A precariedade das relações trabalhistas em grande parte das equipes, a prática de contratação de organizações sociais e de outras formas de privatização da gestão de unidades básicas de saúde que mercantiliza as relações e fragiliza vínculos, problemas organizacionais com baixa integração entre a APS e outros níveis de atenção na rede regionalizada comprometendo a coordenação e continuidade com a fragmentação do cuidado, a insuficiente mediação de ações intersetoriais para incidir na determinação social, promover a saúde e reduzir as desigualdades, são alguns dos obstáculos para a exigida atuação da ESF neste momento (MEDINA et al., 2020). 
Além disso, a doença provocada pelo SARS-CoV-2 é um fenômeno complexo e multidimensional, que apresenta um determinante social, o qual impacta na sua transmissibilidade, capacidade infecciosa e deterioração do sistema imune de cada indivíduo (BREILH, 2020; SEIXAS et al., 2021).

Apesar da COVID-19 ter chegado ao Brasil através das classes mais altas da sociedade, a doença se disseminou e tem maior impacto entre a população que sofre com maior vulnerabilidade social, econômica e de saúde, como negros, quilombolas, indígenas, população da favela e em situação de rua (ALBUQUERQUE; RIBEIRO, 2020; MENDES; OLIVEIRA, 2020; SANTOS et al., 2020). A pandemia vem aprofundando as desigualdades no país, o qual é um dos mais desiguais do mundo, tanto em número de casos e óbitos quanto no aumento da pobreza e das disparidades raciais (ALBUQUERQUE; RIBEIRO, 2020).

Não obstante, a pandemia também tem evidenciado as desigualdades regionais, afligindo mais fortemente as regiões brasileiras mais pobres, como o Norte e o Nordeste, que são responsáveis por um terço dos casos e óbitos por COVID-19 no Brasil. Nessas regiões, a oferta de serviços de saúde está mais concentrada nas capitais e em poucos polos regionais nas áreas metropolitanas e de urbanização consolidada (ALBUQUERQUE; RIBEIRO, 2020; KERR et al., 2020).

Sendo assim, para o enfrentamento da pandemia de COVID-19 há a necessidade de se alinhar o cuidado individual à abordagem comunitária a partir de estratégias de cuidado em saúde integrais e articuladas através da APS.

\subsection{Possibilidades da Atenção Primária à Saúde frente à pandemia}

Apesar dos desafios mencionados que contribuíram para o sucateamento do SUS nos últimos anos e a não cobertura total em diversos municípios brasileiros, a APS possui um enorme potencial para ajudar na pandemia e desafogar os serviços especializados de casos leves da infecção pelo SARS-CoV-2. Sarti et al. (2020) aponta que investir na atenção primária seria uma das formas mais efetivas para o controle da COVID-19 e para um bom enfrentamento da pandemia. Isso porque a APS em sua essência já possui o conhecimento do território e da comunidade onde atua, apresenta o vínculo com o usuário dos serviços, e devido à sua ampla capacidade de capilarização garantiria a 
integralidade da assistência, bem como o monitoramento dos mais vulneráveis e dos casos suspeitos (SOEIRO et al., 2020).

Independentemente de estarmos combatendo a COVID-19, suas consequências, e agora suas novas variantes, há mais de um ano ainda é importante fortalecer a APS como estratégia para promover ações de vigilância em saúde, educação em saúde e proporcionar à população acesso equitativo a atendimento médico, telemedicina, testes diagnósticos e vacinação. Medina et al. (2020) sugerem que a atuação da APS pode ser dividida em quatro áreas: (i) vigilância em saúde nos territórios; (ii) atenção aos usuários com COVID-19; (iii) suporte social a grupos vulneráveis; e (iv) continuidade das ações próprias da APS. Temos como exemplo diversos municípios que usaram a APS como uma das ferramentas para o combate ao vírus em um dessas quatro áreas e/ou todas elas. (OLIVEIRA et al., 2020; VALE et al., 2020; GUIMARÃES et al., 2020)

A atuação da APS na educação em saúde em tempos de alta disseminação de notícias falsas e o não reconhecimento do presidente quanto a gravidade do vírus, poderia e ainda pode trazer benefícios e conhecimento à população. Orientações de prevenção e promoção à saúde, reforço do uso e distribuição de máscaras, esclarecimento acerca do tratamento, continuidade ao acompanhamento e tratamento de pacientes com doenças crônicas e atendimento às demandas agudas são algumas das tantas ações que a APS pode realizar durante o combate ao vírus. Em Recife, o Núcleo de Apoio à Saúde da Família (NASF) foi dispositivo importante para fortalecer o combate ao coronavírus e o trabalho da APS (OLIVEIRA et al., 2020).

Além das possibilidades citadas acima, algumas Unidades Básicas de Saúde da Família podem ser direcionadas para atendimento a pacientes com quadros leves com objetivo de prestar maior assistência à população e aliviar Unidades de Pronto Atendimento e serviços de emergência. Em Canaã dos Carajás, no estado do Pará, houve uma reorganização da Rede de Atenção à Saúde, com expansão da APS para dar suporte aos pacientes com casos leves e manter as atividades de assistência à saúde já fornecidas pela APS (VALE et al., 2020).

Recentemente, com o surgimento de vacinas eficazes contra o SARS-CoV-2, a APS também tem o potencial de implementar a Campanha Nacional de Vacinação contra a COVID-19, alcançando brasileiros de todos os extratos populacionais e regiões geográficas. Isto porque a vacinação é uma ação prioritária, efetiva e estratégica da APS, 
a qual possibilita a inclusão e acesso de toda a população à imunização (SIQUEIRA et al., 2017).

A APS no cenário da pandemia de coronavírus tem a potencialidade de se associar às iniciativas solidárias das organizações comunitárias, articular-se intersetorialmente para apoiar sua população em suas diversas vulnerabilidades e garantir a continuidade das ações de promoção, prevenção e cuidado criando novos processos de trabalho na vigilância em saúde, no apoio social e sanitário aos grupos vulneráveis, na continuidade da atenção rotineira para quem dela precisa (CABRAL et al., 2020).

\section{COISIDERAÇÔES FInRIS}

Diante do elucidado, percebe-se que há muitos desafios para a APS no Brasil. A pandemia além de reafirmar a importância da atenção primária para o sistema de saúde, trouxe um alerta que apesar dos inúmeros desafios que estão sendo enfrentados, a APS deve ser fortalecida e encontrar meios para superá-los a fim de garantir a universalidade e integralidade no cuidado. Deve-se aproveitar as potencialidades já existentes como a distribuição territorial, proximidade e vínculo com os usuários para ofertar um maior suporte e acesso às diversas estratégias possíveis no combate à COVID-19.

Dessa forma, é necessário a readequação e qualificação da APS no contexto da pandemia. Há a necessidade de que os gestores reconheçam o papel imprescindível da APS na orientação da Rede de Atenção à Saúde (RAS), sua capacidade em se adequar aos diferentes contextos sanitários para promover uma atenção integral e equânime, e contestem as ações que têm desmobilizado e desqualificado a APS no Brasil.

\section{REFERÊกCIAS}

ALBUQUERQUE, M. V.; RIBEIRO, L. H. L. Desigualdade, situação geográfica e sentidos da ação na pandemia da COVID-19 no Brasil. Cadernos de Saúde Pública, v.36, n.12, p.e00208720, 2020.

AQUINO, E. M. L. et al. Medidas de distanciamento social no controle da pandemia de COVID-19: potenciais impactos e desafios no Brasil. Ciênc. Saúde Coletiva, Rio de Janeiro, v.25, supl.1, p.2423-2446, 2020. 
BRASIL. MINISTÉRIO DA SAÚDE. Portaria n. 2.436, de 21 de setembro de 2017. Brasília, 2017. https://bvsms.saude.gov.br/bvs/saudelegis/gm/2017/prt2436_22_09_2017.ht ml. Acesso em 08 mar 2021.

BRASIL. MINISTÉRIO DA SAÚDE. Boletim Epidemiológico Especial Doença pelo coronavírus COVID-19 n. 46. Brasília, 2021. Disponível em: https://www.gov.br/saude/ptbr/media/pdf/2021/janeiro/22/boletim_epidemiologico_covid_46-final.pdf. Acesso em 08 mar 2021.

BREILH, J. SARS-CoV2: rompiendo el cerco de la ciencia del poder Escenario de asedio de la vida, los pueblos y la ciencia - Universidad Andina Simón Bolívar. In: ALZUETA, E. R. et al. (org.). Posnormales. Buenos Aires. p. 394. Disponível em: https://www.uasb.edu.ec/web/spondylus/contenido?sars-cov2-rompiendo-elcerco-de-la-ciencia-del-poder-escenario-de-asedio-de-la-vida-los-pueblos-y-laciencia. Acesso em 08 mar 2021.

CABRAL, E. R. M. et al. Contributions and challenges of the Primary Health Care across the pandemic COVID-19. InterAmerican Journal of Medicine and Health, v. 3, p. $1-12,2020$.

CARVALHO, G. A saúde pública no Brasil. Estudos avançados, v. 27, n. 78, p. 7-26, 2013.

DAUMAS, R. P. et al. O papel da atenção primária na rede de atenção à saúde no Brasil: limites e possibilidades no enfrentamento da COVID-19. Cadernos de Saúde Pública, v. 36, p. e00104120, 2020.

DUNLOP, C. et al. The coronavirus outbreak: the central role of primary care in emergency preparedness and response. BJGP open, v. 4, n. 1, 2020.

FREITAS, A. R. R.; NAPIMOGA, M.; DONALISIO, M. R. Análise da gravidade da pandemia de Covid-19. Epidemiologia e Serviços de Saúde, v. 29, p. e2020119, 2020.

GIOVANELLA, L. et al. Saúde da família: limites e possibilidades para uma abordagem integral de atenção primária à saúde no Brasil. Ciência \& Saúde Coletiva, v. 14, p. 783-794, 2009.

GIOVANELLA, L.; MENDONÇA, M. H. M. Atenção Primária à Saúde. In: GIOVANELLA, L. et al. (org.). Políticas e sistemas de saúde no Brasil. 2. ed. rev ed. Rio de Janeiro: Editora Fiocruz, 2012. p. 575-626.

GIOVANELLA, L. O SUS e a Atenção Primária à Saúde na rede de enfrentamento da pandemia. 2020. Disponível em: https://cee.fiocruz.br/?q=node/1162. 
GOMES, K. O. et al. Atenção primária à saúde-a "menina dos olhos" do sus: Sobre as representações sociais dos protagonistas do sistema único de saúde. Ciência e Saúde Coletiva, v. 16, n. SUPPL. 1, p. 881-892, 2011.

GONDIM, G. M. M.; MONKEN, M. Territorialização em Saúde. In: PEREIRA, Isabel B.; LIMA, Júlio C. F. (org.). Dicionário da educação profissional em saúde. 2.ed. rev. ed. Rio de Janeiro: EPSJV, 2008. p. 392-399.

GUIMARÃES, F. et al. A organização da atenção Primária à Saúde de Belo Horizonte no enfrentamento da Pandemia Covid 19: relato de experiência. APS EM REVISTA, v.2, n.2, p.74-82, 2020.

Instituto Brasileiro de Geografia e Estatística (IBGE). Comissão Nacional de Classificação. Disponível em: https://cnae.ibge.gov.br/en/component/content/article/947a12/7a12-vamos-conhecer-o-brasil/nosso-territorio/1461-o-brasil-nomundo.html. Acesso em 10 mar 2021.

JAPIASSU, R. B.; RACHED, C. D. A. Como a estratégia de saúde da família pode ser considerada ferramenta de apoio no combate ao Covid-19? International Journal of Development Research, v. 10, n. 5, p. 36069-36074, 2020.

KERR, L. et al. COVID-19 in northeast Brazil: Achievements and limitations in the responses of the state governments. Ciência e Saúde Coletiva, v. 25, p. 40994120, 2020.

MACINKO, J.; MENDONÇA, C. S. Estratégia Saúde da Família, um forte modelo de Atenção Primária à Saúde que traz resultados. Saúde em Debate, v. 42, p. 18-37, 2018.

MEDINA, M. G. et al. Atenção primária à saúde em tempos de COVID-19: o que fazer? Cadernos de Saúde Pública, v. 36, n. 8, p. e00149720, 2020.

MELO, C. M. L. et al. COVID-19 pandemic outbreak: The Brazilian reality from the first case to the collapse of health services. Anais da Academia Brasileira de Ciências, v. 92 , n. 4, p. 1-14, 2020.

MENDES, E. V. A construção social da atenção primária à saúde. Brasília: Conselho Nacional de Secretários de Saúde, 2015.

MENDES, L. P.; OLIVEIRA, F. H. F. Os vulneráveis em tempos de pandemia - uma análise a partir dos(as) trabalhadores(as) subalternos(as) e dos(as) idosos(as). PEGADA A revista da geografia do Trabalho, v. 21, n. 2, p. 511-531, 2020.

MENEZES, A. P. R.; MORETTI, B.; REIS, A. A. C. O futuro do SUS: impactos das reformas neoliberais na saúde pública - austeridade versus universalidade. Saúde em Debate, v. 43, n. spe5, p. 58-70, 2019. 
MINAYO, M. C. S. et al. Pandemia exacerba desigualdades na Saúde. Ciência \& Saúde Coletiva, v. 25, n. 9, p. 3555-3556, 2020.

MOREIRA, R. M. et al. How prepared is Brazil to tackle the COVID-19 disease? Journal of global health, 2020.

MOROSINI, M. V. G. C.; FONSECA, A. F.; LIMA, L. D. Política Nacional de Atenção Básica 2017: retrocessos e riscos para o Sistema Único de Saúde. Saúde em Debate, v. 42, n. 116, p. 11-24, 2018.

OLIVEIRA, M. A. et al. A prática do núcleo de apoio à saúde da família do Recife no enfrentamento à pandemia COVID-19. APS EM REVISTA, v.2, n.2, p.142-150, 2020.

RODRIGUES, L. B. B. et al. A atenção primária à saúde na coordenação das redes de atenção: uma revisão integrativa. Ciência \& Saúde Coletiva, v. 19, n. 2, p. 343352, 2014.

SANTOS, M. P. A. et al. População negra e Covid-19: Reflexões sobre racismo e saúde. Estudos Avancados, v. 34, n. 99, p. 225-244, 2020.

SARTI, T. D. et al. Qual o papel da Atenção Primária à Saúde diante da pandemia provocada pela COVID-19? Epidemiologia e serviços de saúde: revista do Sistema Único de Saúde do Brasil, v. 29, n. 2, p. e2020166, 2020.

SEIXAS, C. T. et al. A crise como potência: os cuidados de proximidade e a epidemia pela Covid-19. Interface - Comunicação, Saúde, Educação, v. 25, n. suppl 1, 2021.

SIQUEIRA, L. G. et al. Avaliação da organização e funcionamento das salas de vacina na Atenção Primária à Saúde em Montes Claros, Minas Gerais, 2015. Epidemiologia e serviços de saúde: Revista do Sistema Único de Saúde do Brasil, v. 26, n. 3, p. 557-568, 2017.

SOEIRO, R. E. et al. Atenção Primária à Saúde e a pandemia de COVID-19: reflexão para a prática. InterAmerican Journal of Medicine and Health, v. 3, 2020.

SOUSA, C.; FENANDES, V. C. Aspectos históricos da saúde pública no Brasil: uma revisão integrativa. JMPHC| Journal of Management \& Primary Health Care, v. 12, 2020.

SOUTO, X. M. COVID-19. Recital-Revista de Educação, Ciência e Tecnologia de Almenara/MG, v. 2, n. 1, p. 12-36, 2020.

STARFIELD, B. Atenção primária: equilíbrio entre necessidades de saúde, serviços e tecnologia. Brasília: UNESCO, Ministério da Saúde, 2002.

TEIXEIRA, C. P. et al. COVID-19 e Atenção Primária: as experiências nos territórios (Rede PROFSAÚDE). Rio de Janeiro: ANAIS/SESSÕES TEMÁTICAS/PROFSAÚDE, 2020. 
United Nations. Department of Economic and Social Affairs. Population Division. World Urbanization Prospects: The 2018 Revision, custom data acquired via website, 2018. https://esa.un.org/unpd/wpp/. Acesso em 10 mar 2021.

VALE, E. et al. Reorganização da Rede de Atenção à Saúde para o enfrentamento da COVID-19 no município de Canaã dos Carajás, Pará. APS EM REVISTA, v. 2, n. 2, p. 83-90, 2020.

VELAVAN, T. P.; MEYER, C. G. The COVID-19 epidemic. Tropical medicine \& international health, v. 25, n. 3, p. 278, 2020.

WHO. COVID-19 Public Health Emergency of International Concern (PHEIC) Global research and innovation forum. 2020a. Disponível em: https://www.who.int/publications/m/item/covid-19-public-health-emergencyof-international-concern-(pheic)-global-research-and-innovation-forum. Acesso em 08 mar 2021.

WHO. Coronavirus disease 2019 (COVID-19) Situation Report-51. 2020b. Disponível em: https://www.who.int/docs/default-source/coronaviruse/situationreports/20200311-sitrep-51-covid-19.pdf?sfvrsn=1ba62e57_10. Acesso em 08 mar 2021.

WHO. Clinical management of severe acute respiratory infection (SARI) when COVID19 disease is suspected: interim guidance, 13 March 2020. World Health Organization. 2020c. Disponível em: https://apps.who.int/iris/handle/10665/331446. Acesso em 08 mar 2021.

WHO. Coronavirus (COVID-19) Dashboard. 2021. Disponível em: https://covid19.who.int/. Acesso em 10 mar 2021. 


\title{
ATERÇÃO BÁSICA FRENTE À PAחDEETIA DO NOUD CORONAUÍRUS: UTHA REUISÃO IITEGRAT|UA
}

\author{
DDI: 10.51859/AMPLLA.APS276.II21-2
}

\author{
Sarlene Gomes de Souza ${ }^{1}$ \\ Vinicia de Holanda Cabral ${ }^{2}$ \\ Eduardo de Jesus Santana ${ }^{3}$ \\ Luana Mendonça Arrais ${ }^{4}$ \\ Pedro Diógenes Peixoto de Medeiros ${ }^{5}$
}

\begin{abstract}
${ }^{1}$ Mestra em Educação. Programa de Pós-Graduação em Educação - UECE. Docente convidada do Curso de Graduação em Medicina. Universidade Estadual do Ceará - UECE.

2 Enfermeira. Universidade Estadual do Ceará - UECE. Graduanda do curso de Medicina. Universidade Estadual do Ceará - UECE.

${ }^{3}$ Farmacêutico. Universidade Federal do Ceará - UFC. Graduando do curso de Medicina. Universidade Estadual do Ceará - UECE.

${ }^{4}$ Graduanda do curso de Medicina. Universidade Estadual do Ceará - UECE.

${ }^{5}$ Graduando do curso de Medicina. Universidade Estadual do Ceará - UECE.
\end{abstract}

\section{RESUTO}

Este estudo objetiva descrever e analisar as experiências e as reflexões sobre o uso e desenvolvimento de novas ferramentas e estratégias da atenção básica em meio à pandemia de COVID-19 presentes na literatura. Trata-se de uma revisão integrativa da literatura com pesquisa realizada em janeiro de 2021, nas bases de dados da BVS, MEDLINE, BDENF, PUBMED, LILACS e SCIELO de artigos publicados de janeiro de 2020 a janeiro de 2021. Foram analisadas 21 publicações, destas, com predominância de trabalhos de revisão da literatura $(47,6 \%)$ e da área da saúde pública $(42,8 \%)$. As análises foram desenvolvidas à luz de três categorias empíricas, o uso de novas tecnologias, educação para mudança e desafios para o cuidado. Foi evidenciado uma reorganização do nível primário de saúde, com a incorporação do uso das Tecnologias de Informação e Comunicação (TICs) na saúde. As ações de educação em saúde são uma das principais estratégias de intervenção. Em relação aos desafios vividos pela APS estão a falta de sincronia entre as orientações locais, nacionais e internacionais, interferências políticas nos investimentos em saúde, progressivo sucateamento da APS, desinformação propagada através das mídias sociais, fracasso na adoção de medidas preventivas e restritivas, ausência de infraestrutura nas unidades de saúde e falta de treinamento para os profissionais de saúde. Ressalta-se que a Atenção Primária é imprescindível no enfrentamento da COVID-19. Seu fortalecimento é vital para qualquer proposta de intervenção. Contudo, para máxima eficiência, é preciso ter seus impasses atenuados, com maior investimento.

Palavras-chave: Atenção primária à saúde. Saúde Pública. Infecções por Coronavírus. Educação em Saúde. Acesso a Medicamentos Essenciais e Tecnologias em Saúde. 


\section{IกTRODUÇÃO}

A assistência à saúde da população brasileira foi recentemente desafiada com o surgimento do novo coronavírus e com a disseminação do patógeno no país. Nesse contexto, a rede de atenção primária desenvolveu novas estratégias e práticas de atuação a fim de conseguir atender às novas demandas e, ainda, de manter, quando possível, o prosseguimento de ações próprias da atenção básica no contexto pandêmico da COVID-19.

A Atenção Primária à Saúde (APS) trata-se da principal porta de entrada do SUS e, assim, exerce posição primordial em filtrar o fluxo de pacientes frente à descentralização em rede do sistema. Tal responsabilidade confirma-se no desempenho interventivo dos cuidados primários em saúde em processos de diagnóstico precoce e de tratamento de episódios agudos, por exemplo (OLIVEIRA; PEREIRA, 2013).

Esse nível de atenção em saúde mostra-se, logo, essencial no combate à nova doença e atribui-se, ainda, à resolução de cerca de $85 \%$ das necessidades básicas de saúde da população, sendo responsável, entre 2001 e 2016, por uma diminuição em 45\% das hospitalizações (PINTO; GIOVANELLA, 2018). Além disso, a APS integra o objetivo em disciplina previsto pelo Programa Nacional de Imunização (PNI), na prevenção de diversas doenças (BRASIL, 2013).

O desmazelo governamental, entretanto, em oferta de verbas políticas e financeiras à capacitação da APS - no cenário pandêmico - tem ameaçado desestruturar padrões interinos de conduta, acelerando o avanço agravante de quadros clínicos e subsequentes internações hospitalares antes preveníveis, em ritmo favorável ao aumento de casos de COVID-19 e ao colapso do SUS em uma esfera maior (SOUZA et al., 2020).

O Ministério da Saúde reconheceu a Emergência em Saúde Pública de Importância Nacional (BRASIL, 2020a) e disponibilizou protocolos e guias a fim de orientar a atuação dos profissionais no combate à nova doença, entre eles: o Protocolo de Manejo Clínico para COVID-19 na Atenção Primária (BRASIL, 2020b). Foi disponibilizado, ainda, em caráter excepcional e temporário, o atendimento pelo serviço de Telemedicina, que permitia a orientação dos usuários e emissão de atestados com assinatura eletrônica (BRASIL, 2020c). Outro aporte fornecido pelo MS, o Programa 
Telessaúde, permitia aos profissionais e gestores tirarem dúvidas sobre o manejo clínico dos pacientes com COVID-19, com base nas evidências mais atualizadas (BRASIL, 2011).

O uso amplo de estratégias e do serviço remoto, entretanto, era algo novo tanto para os profissionais quanto para os usuários, e seria necessário avaliar sua eficácia e impacto. Além desses, existiam outros desafios para a continuidade nas ações da atenção básica como: a escassez de recursos humanos e a falta de espaço físico nos serviços que fossem adequados para a organização dos pacientes sintomáticos respiratórios (FARIAS et al., 2020). É importante destacar, ainda, a necessidade das ações de educação em saúde, pois um novo modo de se comportar era necessário, alterando o dia-a-dia da população e sua forma de interação social.

Dessa forma, considerando a relevância primordial da atuação da atenção primária e procurando conhecer as diversas estratégias desenvolvidas no amplo território brasileiro para se adaptar à essa nova realidade e atender às diferentes necessidades da população, questiona-se: quais as estratégias e ações desenvolvidas pela atenção primária no contexto da pandemia da COVID-19?

O trabalho objetiva descrever e analisar as experiências e as reflexões sobre o uso e desenvolvimento de novas ferramentas e estratégias da atenção básica em meio à pandemia de COVID-19 presentes na literatura. Esse estudo irá contribuir para os profissionais de saúde da atenção básica, gestores e para a população em geral, a partir do maior esclarecimento sobre o tema e do compartilhamento das experiências de adaptação nesse novo panorama epidemiológico.

\section{METODOLOGIA}

O estudo em questão trata-se de uma revisão integrativa da literatura, com caráter exploratório-descritivo, de abordagem qualitativa, que busca apresentar e discutir acerca das novas estratégias desenvolvidas na atenção básica no contexto da pandemia de COVID-19.

A pesquisa foi realizada em janeiro de 2021, nas bases de dados da Biblioteca Virtual em Saúde (BVS), MEDLINE, Banco de Dados em Enfermagem (BDENF), PUBMED, LILACS e SCIELO. Foram utilizados descritores e linguagem natural de forma combinada com os operadores booleanos a partir dos termos e seus correlatos: ("coronavirus infections" OR COVID-19 OR "new coronavirus disease") AND ("primary health care" OR 
"primary care" OR "community health") AND (access OR benefits OR importance OR relevance $O R$ help $O R$ efficiency $O R$ strategies $O R$ instruments $O R$ tools $O R$ actions $O R$ results OR outcome OR effect) AND Brazil e seus correspondentes em português.

Para essa busca, considerou-se a estratégia PICo que, segundo esclarece Araújo (2020), considera a população, ou o paciente ou o problema abordado (Population/Patient/Problem), o fenômeno de interesse (Interest) e o contexto (Context), se adequando à recuperação de publicações do tipo qualitativas (Quadro 1).

Quadro 1 - Estratégia PICo.

\begin{tabular}{|c|c|c|}
\hline Acrônimo & Definição & Aplicação \\
\hline P & Population/ Patient/ Problem & Novo coronavírus/ COVID-19 \\
\hline I & Interest & Ações/ estratégias \\
\hline Co & Context & Atenção Primária \\
\hline
\end{tabular}

Fonte: Autoria própria com base em Araújo (2020).

Os critérios de inclusão aplicados sobre os resultados foram: (1) texto está disponivel em sua integralidade; (2) todas as categorias de artigo (inclusive alguns PrePrints, aguardando a revisão de pares para publicação); (3) realizados a partir de 2020; (4) escritos nos idiomas português, inglês ou espanhol e por fim, (5) estar diretamente relacionado ao objeto de estudo ora apresentado.

Dessa forma, por meio das nossas buscas foram encontrados 81 artigos, aos quais se seguiu aplicação dos critérios de inclusão, assim, foi possível incluir 21 artigos. Para organizar e tabular os dados, foi utilizado instrumento de coleta de dados, desenvolvido pelos autores. Seguiu-se, então, uma análise crítica das publicações, que foram examinadas, agrupadas por similaridade de conteúdo e comparadas, configurando-se três categorias temáticas, a serem desenvolvidas nos resultados: o uso de novas tecnologias, educação para mudança e desafios para o cuidado.

\section{RESULTADOS E DISCUSSÃO}

Após catalogação dos achados, foi possível categorizá-los a partir de aspectos metodológicos e campo de origem. Constatou-se que das 21 publicações mapeadas, todas estavam postas com características de abordagem predominantemente 
qualitativa. Com relação ao tipo de estudo realizado, dez deles realizaram discussões ou revisões da literatura existente - artigos, documentos públicos, entre outros, (47,6\%); seis são relatos de experiência (28,5\%); dois são estudos transversais (9,5\%), os seguintes, tiveram a frequência de um trabalho por tipo de estudos, do tipo comment, estudo reflexivo e artigo opinião (4,7\% cada) (Gráfico 1). A respeito da área de estudo, nove são do campo da saúde pública ou coletiva (42,8\%); seis do campo da enfermagem (28,5\%); quatro da medicina (19\%) e dois da odontologia $(9,5 \%)$.

Gráfico 1 - Frequência relativa de trabalhos mapeados por tipos de estudos.

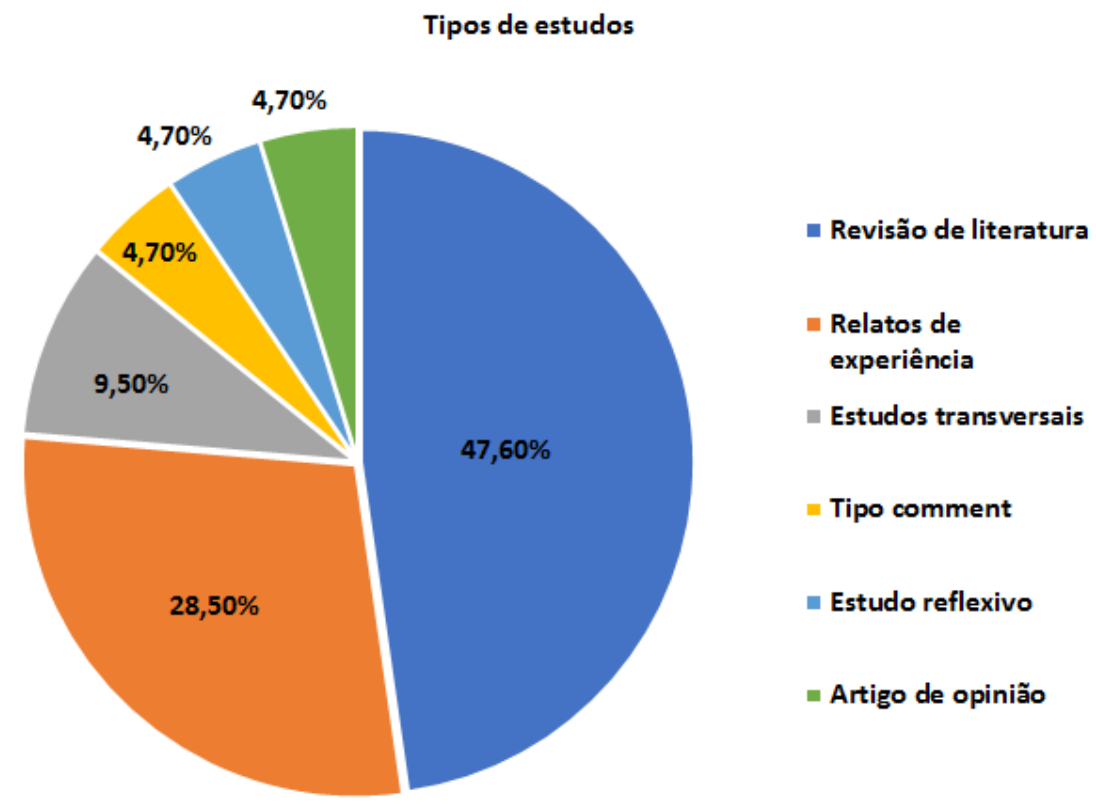

Fonte: Autoria própria.

Notabiliza-se a escassez em estudos empíricos acerca da temática, visto a contemporaneidade da temática do estudo e, provavelmente, a dificuldade de realização de estudos nas condições atuais sob medidas sanitárias restritivas, como o isolamento social, o que atesta os dois estudos transversais referidos anteriormente a emprego de questionários online nos processos metodológicos de pesquisa. No entanto, o somatório de estudos mostra que o objeto de estudo aqui apresentado, conta com um corpo de profissionais pesquisadores empenhados em analisar as implicações do panorama pandêmico na Atenção Básica. 


\subsection{O uso de nouas tecnologias}

No contexto da pandemia do novo coronavírus, os trabalhadores da Atenção Básica foram surpreendidos pelo desafio de manter seus atendimentos junto às limitações exigidas pelo isolamento social. Nesse sentido, estratégias de teleatendimento e de educação em saúde foram desenvolvidas em busca de alternativas de viabilização da assistência à saúde. (DIAS e RIBEIRO, 2020).

Maciel et al. (2020) e Júnior et al. (2020) ressaltam a importância do uso das Tecnologias de Informação e Comunicação (TICS) na saúde, como estratégia de manutenção dos atendimentos e do isolamento social, além de oferecer oportunidade para uma maior eficiência e a efetividade do trabalho dos profissionais da Atenção Básica, pois favorecem a descentralização, a longitudinalidade e a acessibilidade aos cuidados disponibilizados pela APS, com a possibilidade de atendimentos à distância, podendo, ainda, reduzir custos e deslocamentos.

A reorganização dos serviços a partir da incorporação de novas tecnologias que mantivessem o fluxo de atendimento - agora em caráter virtual, é reforçada nos estudos de Leite et al. (2020) e Prado et al. (2020), com o uso da telemedicina em todas suas modalidades de teleatendimento (teleorientação, teleconsulta, telemonitoramento e telerregulação), que inclui, mais especificamente, telemonitoramento de pessoas contaminadas pelo coronavírus, a partir da vigilância do quadro clínico dos pacientes, além do suporte psicológico.

Considerou-se, dessa forma, que as TICs e as demais soluções tecnológicas instituídas na atenção primária durante essa situação pandêmica é um diferencial para expandir os cuidados de saúde à população, abrangendo outros aspectos com a inatividade física (SOUZA FILHO e TRITANY, 2020), o qual é considerado como fator estratégico no combate à COVID-19, uma vez que tal prática fortalece o sistema imunológico e previne a incidência e/ou o agravamento de patologias crônicas, além de melhorar quadros de ansiedade e estresses.

Outro aspecto considerado foi a Teleodontologia, que tem se mostrado bastante eficaz tanto a nível de custo quanto à amplitude de acesso, comportando vantagens de resolutividade por redução dos custos de tratamento e do tempo de espera de pacientes em consultas. Uma análise prática da Teleodontologia em áreas rurais evidenciou tal 
raciocínio, explicitando, inclusive, sua aplicabilidade em triagem de lesões orais em programas escolares e em áreas com acesso limitado aos cuidados prolongados. Em atribuição, o uso das TICs como meio ao atendimento odontológico remoto e ao exercício emergencial de Equipes de Saúde Bucal (ESB) previne a ida desnecessária de usuários às unidades de saúde, evitando contato próximo. (CARRER et al., 2020).

Em soma, quanto à telefonoaudiologia para pacientes em domicílio durante a pandemia do COVID-19, é relevante citar o relato de experiência de Dimer et al. (2020), o qual demonstrou a utilidade do teleatendimento na fonoterapia para pacientes que antes eram recebidos em ambulatórios, uma vez que se adaptou o tratamento sob os regimentos oficiais de vigilância sanitária, a exemplo da medida de isolamento social.

Destaca-se, no entanto, que o acesso a ferramentas tecnológicas se dá de forma heterogênea entre os diversos grupos sociais, o que pode gerar segregação, principalmente, em direção à população de baixa renda. Posto isso, é imperativo reivindicar investimentos estatais não só para a aquisição e a manutenção de aparelhos e aplicativos, mas, sobretudo, também, na promoção de acessibilidade a essas tecnologias (MACIEL et al., 2020).

\subsection{Educação para mudança}

A realização de ações de educação em saúde configura-se como uma das principais estratégias de intervenção em prol de melhor instruir a população, conter a disseminação da doença e, assim, efetivar a adesão comum às orientações de saúde como o isolamento social, o uso de máscara, a higienização e a etiqueta respiratória (OLIVEIRA et al., 2021; DIAS e RIBEIRO, 2020).

Essas ações, pautadas na Atenção Básica, podem ser realizadas a partir de diferentes canais de comunicação como rádios, carros de som, panfletos, cartazes, redes sociais, contatos telefônicos e, presencialmente, nas Unidades de Saúde da Família (DIAS e RIBEIRO, 2020; MACIEL et al., 2020).

A partir das experiências dos muitos países que sofreram com a COVID-19 (Estados Unidos, Reino Unido, China, Cingapura, Japão, Espanha, Itália, dentre outros), principalmente, no que se refere à evolução local do índice de mortalidade pela doença, foi evidenciado que, tanto as medidas de prevenção, quanto a forma como elas foram implementadas e aceitas pela população se relacionam intimamente, e tem 
consequências no enfrentamento e na progressão da doença (OLIVEIRA; LUCAS; IQUIAPAZA, 2020).

A relevância das atividades educativas é exemplificada no estudo de Oliveira et al. (2021), no qual, ao relatar a experiência da Atenção Básica em Salvador, Bahia, mostra como os profissionais puderam orientar os pacientes durante a consulta e nas visitas domiciliares, além do uso de materiais educativos visuais, na entrada dos serviços e em outros locais estratégicos, que traziam orientações sobre a lavagem de mãos, a importância de evitar tocar no rosto, o uso de lenço descartável para higiene nasal, o uso de máscara, a importância da limpeza rotineira de objetos e superfícies e, por fim, a importância do distanciamento social.

No entanto, para alcançar seus objetivos, a educação em saúde requer estratégias diversas como a transposição de barreiras culturais e sociais, pois uma parcela significativa dos usuários possui conhecimento sobre a COVID-19, bastante divulgado pelos serviços de saúde e pela mídia, mas possuem muita resistência e negam essas informações (DIAS e RIBEIRO, 2020). Nesse sentido, Rios (2020) retrata a amplitude e o didatismo alcançados por estratégias interventivas pautadas na Educação em Saúde e na Educação Permanente ao se coordenar uma articulação entre focos de atenção primária e de vigilância sanitária por iniciativa de autonomia de equipes interprofissionais em tempos de COVID-19.

Além disso, é importante destacar que o treinamento da equipe multiprofissional é fundamental para que as ações de educação em saúde sejam realizadas de forma consistente e alinhadas às melhores evidências científicas atualizadas e considerando-se, ainda, que é a partir do acesso à informação correta que a população pode se proteger adequadamente, evitando a aglomeração, a contaminação e a transmissão da COVID-19 (OLIVEIRA et al., 2021).

Destaca-se o trabalho do ACS, nesse momento, que é primordial visto sua atuação ser um elo importante entre o serviço e a comunidade e pela sua capilaridade no território, podendo atingir uma maior parcela da população e obter melhor resultado em suas práticas (MACIEL et al., 2020). A participação da população nas ações comunitárias é fundamental para um bom resultado, sendo a formação de redes solidárias comunitárias, nos moldes de Nunciaroni et al. (2020), um exemplo de nova potência para mudar a realidade das comunidades, tão afetadas nesta pandemia, e que 
evidenciam a força do povo em atuar para a própria saúde, quando esquecidas pelo Estado.

Nesse contexto, aliás, Farias et al. (2020) salienta a iniciativa articulada pelo Grupo de Trabalho de Saúde da População Negra da Sociedade Brasileira de Medicina de Família e Comunidade (SBMFC) e Associação de Medicina de Família e Comunidade do Rio de janeiro (AMFaC-RJ), os quais disponibilizaram um manual de orientações para populações vulneráveis, com destaque para os indivíduos que necessitam trabalhar durante a quarentena. Tal estratégia de intervenção proporcionou, assim, alternativas de auxílio social em circunstâncias de isolamento social, evocando o princípio democrático de acesso à saúde previsto na legislação brasileira.

A reorganização da Atenção Primária deve, segundo Nunciaroni et al. (2020), se caracterizar em três eixos: (1) protagonismo comunitário; (2) protagonismo da abordagem familiar e (3) a continuidade e o aprimoramento das redes solidárias, objetivando a superação da pandemia com redução das iniquidades e ampliação de acesso ao cuidado. Ao retornar para sua vocação na ação comunitária, a APS poderá potencializar as inovações que surgem das massas populares e amenizar os impactos trazidos pela pandemia e pelas medidas restritivas, necessárias para conter a doença (LEITE et al., 2020).

A atuação das equipes de APS é crucial em todas as etapas da pandemia, a qual prossegue com diferentes ritmos e estágios no amplo e diverso território brasileiro. Para continuação do retardo dos casos e retomada de atividades, é imprescindível a ampliação da vigilância em saúde, com a participação das equipes de APS, de forma a prevenir novas ondas de infecção. Um maior enfoque na atenção primária para o enfrentamento da pandemia de COVID-19 foi o ponto-chave do artigo de Dimer et al. (2020), o qual explicitou o quão relevante a APS tem se demonstrado durante a pandemia de COVID-19.

\subsection{Desafios para o cuidado}

O combate à disseminação do novo coronavírus depende da adesão da comunidade, mas essa tarefa requer a ação complexa de transpor barreiras socioculturais que interferem nas escolhas dos indivíduos. Além disso, destaca-se a falta de sincronia entre as orientações locais, nacionais e internacionais, promovendo 
descrédito e desconfiança nas ações dos profissionais das ESF, visto a dificuldade de adesão em massa da população e a subsequente vulnerabilidade à propagação do patógeno viral (DIAS e RIBEIRO, 2020).

Confirmando essas dificuldades, Costa et al. (2021), ao investigar 775 ACS atuantes em 368 municípios dos 26 estados brasileiros, mostrou que apenas $2 \%$ deles acreditavam na influência do seu aconselhamento para os moradores das comunidades, pois fatores como a necessidade de trabalhar, a influência da mídia, o negacionismo e a desinformação nas redes sociais impactavam na baixa adesão ao distanciamento social.

Júnior et al. (2020) relata que o avanço do uso massificado de mídias sociais, como fontes informacionais, tem propulsionado a circulação fácil e rápida de fake News (notícias falsas), tornando o processo de desmascaramento da notícia falsa mais penoso e quase sempre ineficiente.

Em soma, a dificuldade de monitoramento dos casos de COVID-19, pelo seu rápido avanço e disseminação (XIMENES NETO et al., 2020), e o grau de ineficácia na cobertura do isolamento social em países como Brasil, Bolívia, Chile e Colômbia, onde, contudo, constatou-se medidas de apoio alimentar e monetário, permite inferir o desamparo submetido a pequenas empresas e setores informais da economia no período pandêmico, já que, comumente, tais atividades de mercado necessitam de um empenho diário em prol da subsistência operacional (GIOVANELLA et al., 2021).

Outra questão apontada é a necessidade urgente de treinamento continuado dos profissionais da Atenção Básica a partir de protocolos estabelecidos e atualizados, que possibilitem melhor efetividade no processo de trabalho e gere mais segurança aos profissionais de todos os níveis (OLIVEIRA et al., 2021; MACIEL et al., 2020; COSTA et al., 2021). Sobre esse tema, Vieira-Meyer et al. (2020), ao avaliar 4048 dentistas que trabalhavam na rede pública de saúde na atenção primária ou secundária brasileira, verificaram que 99,41\% desses profissionais acreditavam que a COVID -19 podia ser transmitida por procedimentos odontológicos e que $83,55 \%$ não acreditavam que os equipamentos de proteção individual (EPI) de rotina seriam suficientes para protegê-los do contágio. Refletiu-se, no referido estudo, que os cirurgiões-dentistas provavelmente não tiveram acesso a protocolos e orientações consistentes, apontando-se uma falha na velocidade que as informações chegavam a esses profissionais e na incerteza dos materiais divulgados. 
Ademais, uma parcela significativa de ACS relatou não receber equipamento de proteção nos respectivos locais de trabalho, conferindo um fator adicional de risco surtido na alta taxa de contaminação desses trabalhadores (COSTA et al., 2021). As dificuldades financeiras são destacadas por Giovanella et al. (2020) e Pingel et al. (2020) como fatores que dificultam a manutenção e aquisição de recursos, dificultando a manutenção desses cuidados nas unidades básicas de saúde durante a pandemia de COVID-19.

Destaca-se, ainda, que a Atenção Primária se encontra sobrecarregada, visto que as epidemias de arboviroses não deixaram de existir, assim, torna-se fundamental que os trabalhadores continuem com as atividades de promoção e prevenção dessas enfermidades: Dengue, Zika e Chikungunya (MACIEL et al., 2020).

Nesse sentido, ao contabilizar-se a responsabilidade do SUS em $95 \%$ das vacinas aplicadas no país e, ainda, ao antecipar em um mês o período de vacinação contra Influenza por parte do Governo, intensificou-se a crescente demanda de usuários em busca de atendimento pela rede pública de saúde, sobretudo, em reação à evolução do cenário pandêmico no Brasil (SOUZA et al., 2020). As APS acompanham cerca de 100 milhões de brasileiros, todavia, em base da capacidade de oferta de mão-de-obra prevista, esperava-se poder amparar 150 milhões de pessoas. Logo, cerca de 50 milhões de indivíduos não estão sendo contemplados na atenção primária, o que representa um complexo desafio político e social de ameaça ao bem-estar da comunidade, principalmente, no momento da pandemia de COVID-19 (HARZHEIM et al., 2020).

Outros desafios encontrados abordam a questão da proibição às operadoras de planos de saúde odontológicos, por exemplo, da veiculação de publicidades utilizando o termo "Teleodontologia", fazendo com que esse ramo tenha maior impasse em ser identificado no Brasil e, assim, em ser utilizado para, por exemplo, auxiliar no distanciamento social durante a pandemia de COVID-19 (CARRER et al., 2020), além das dificuldades de adaptação à telefonoaudiologia em domicílio, averiguadas no Rio Grande do Sul, que apontam fatores como a inexperiência e a adversidade acerca do meio tecnológico impossibilitando o acesso, sobretudo, ao segmento sexagenário e a dificuldade de concentração de crianças como limitante da produtividade da consulta, acarretando, até mesmo, a redução do tempo estipulado ao serviço, trazendo, assim, o 
questionamento acerca da eficácia do serviço em comparação ao atendimento presencial (DIMER et al., 2020).

\section{CONSIDERAÇÔES FInAIS}

Esta revisão integrativa demonstrou, por meio das análises dos 21 artigos mencionados acima, que a Atenção Primária à Saúde (APS), no contexto do SUS, tem sido imprescindível no enfrentamento do Novo Coronavírus, apesar dos impasses que a envolvem.

Uma APS eficiente, com ações pautadas pela integralidade, longitudinalidade, orientação comunitária e alinhada às necessidades de saúde da população, é a base para qualquer proposta de intervenção. Vale citar que a atuação das equipes de APS tem se mostrado crucial em todos os estágios da pandemia.

Importante relatar que a APS, para conseguir exercer seu papel na totalidade, precisa ter seus impasses atenuados, a exemplo do subfinanciamento, para garantir o atendimento de um maior número de pacientes e, desse modo, contribuir mais com o combate à COVID-19. Assim, urge às autoridades governamentais destinarem maiores esforços e verbas à capacitação e expansão da APS nesse cenário de crise de saúde, de modo que o SUS consiga suprir as demandas dos seus usuários.

É válido citar que o Governo Federal tem auxiliado no investimento da APS, sendo exemplos de investimentos: implantação da Teleconsulta (TeleSUS), Saúde na Hora, Contratação de 7.500 médicos para a APS, 50 milhões de novos cadastros na APS, Monitoramento dos casos - TeleSUS. Além de Outras ações de base importantes, tais como: Repasse de R\$ 200 milhões mensais para APS e Teleconsulta em saúde mental para os profissionais da linha de frente. Apesar desses investimentos federais, é preciso mencionar que o uso das TICs deve ser ampliado continuamente, e não se restrinjam ao momento atual da pandemia, visando, sobretudo, potencializar e otimizar as atividades desenvolvidas por essas tecnologias. Além disso, é preciso garantir condições dignas de trabalho, capacitação e educação permanente do ACS, porquanto não se pode esquecer que o trabalho desenvolvido pelo ACS é primordial para a execução das premissas que orientam a APS brasileira.

Concluindo, pode-se notar que a APS mostra sua efetiva contribuição no combate ao Covid-19 e que, apesar do Governo estar investindo nessa área, esse 
investimento ainda não é suficiente, uma vez que há diversas carências nesse setor, sendo exemplo os equipamentos de proteção individual insuficientes e a falta de salário dignos e oferta de apoio psicológico ao ACS e sua família, os quais devem ocorrer, para que a APS possa fornecer um maior suporte a todos os brasileiros.

\section{REFERÊNCIAS}

ARAÚJO, W. C. O. Recuperação da informação em saúde: construção, modelos e estratégias. Convergências em Ciência da Informação, v. 3, n. 2, p. 100-134, maio/ago. 2020 Disponível em: http://www.repositorio.ufc.br/handle/riufc/52993. Acesso em: 10 jan. 2021.

BRASIL. Ministério da Saúde. Portaria GM/MS № 2.546/2011. Redefine e amplia o Programa Telessaúde Brasil, que passa a ser denominado Programa Nacional Telessaúde Brasil Redes (Telessaúde Brasil Redes). Diário Oficial União: Brasília, DF, 27 out. 2011. Disponível em: https://bvsms.saude.gov.br/bvs/saudelegis/gm/2011/prt2546_27_10_2011.ht ml. Acesso em: 10 jan. 2021.

BRASIL. Ministério da Saúde. Secretaria de Atenção à Saúde. Departamento de Atenção Básica. Política Nacional de Atenção Básica. Brasília: Ministério da Saúde, 2012. Disponível em: http://189.28.128.100/dab/docs/publicacoes/geral/pnab.pdf. Acesso em: 10 jan. 2021.

BRASIL. Ministério da Saúde. Secretaria de Vigilância em Saúde. Departamento de Vigilância Epidemiológica. Programa Nacional de Imunizações (PNI): 40 anos. Brasília: Ministério da Saúde, 2013. Disponível em: https://bvsms.saude.gov.br/bvs/publicacoes/programa_nacional_imunizacoes_ pni40.pdf. Acesso em: 10 jan. 2021.

BRASIL. Lei no 13.979/2020. Dispõe sobre as medidas para enfrentamento da emergência de saúde pública de importância internacional decorrente do coronavírus responsável pelo surto de 2019. Brasília: 6 fev. 2020a. Disponível em: $<$ https://www.in.gov.br/en/web/dou/-/lei-n-13.979-de-6-de-fevereiro-de2020-242078735>. Acesso em: 10 jan. 2021.

BRASIL. Ministério da Saúde. Secretaria de Atenção Primária à Saúde. Protocolo de Manejo Clínico do Coronavírus (COVID-19) na Atenção Primária à Saúde. Brasília (DF): abril 2020b. Disponível em: https://saude.rs.gov.br/upload/arquivos/202004/14140606-4-msprotocolomanejo-aps-ver07abril.pdf. Acesso em: 10 jan. 2021.

BRASIL. Ministério da Saúde. Portaria no 467/2020. Dispõe, em caráter excepcional e temporário, sobre as ações de Telemedicina, com o objetivo de regulamentar e operacionalizar as medidas de enfrentamento da emergência de saúde pública 
de importância internacional previstas no art. 3으 da Lei no 13.979, de 6 de fevereiro de 2020, decorrente da epidemia de COVID-19. Diário Oficial da União: Brasília, DF, 23 mar. 2020c. Disponível em: http://www.in.gov.br/en/web/dou//portaria-n-467-de-20-de-marco-de-2020-249312996. Acesso em: 10 jan. 2021.

CARRER, F. C. A. et al. Teleodontologia e SUS: uma importante ferramenta para a retomada da Atenção Primária à Saúde no contexto da pandemia de COVID-19. Scielo Preprints, 2020. DOI 10.1590/SciELOPreprints.837. Disponível em: https://preprints.scielo.org/index.php/scielo/preprint/view/837/1159. Acesso 15 jan. 2021.

COSTA, N.R. et al. Community health workers' attitudes, practices and perceptions towards the COVID-19 pandemic in Brazilian low-income communities. Work, Amsterdam, v. 68, n. 1, p. 3-11, 2021. Disponível em: https://www.arca.fiocruz.br/handle/icict/46048. Acesso em: 15 jan. 2021.

DIAS, E.G.; RIBEIRO, D.R.S.V. Manejo do cuidado e a educação em saúde na atenção básica na pandemia do Coronavírus. Journal of Nursing and Health, Pelotas, v. 10, n. 4, e20104020, 2020. DOI 10.15210/JONAH.V10I4.19092. Disponível em: https://periodicos.ufpel.edu.br/ojs2/index.php/enfermagem/article/view/1909 2/11689. Acesso em: 15 jan. 2021.

DIMER, N. A. et al. Pandemia do COVID-19 e implementação de telefonoaudiologia para pacientes em domicílio: relato de experiência. CoDAS, São Paulo, v. 32, n. 3, e20200144, 2020. DOI 10.1590/2317-1782/20192020144. Disponível em: http://www.scielo.br/scielo.php?script=sci_arttext\&pid=S2317$17822020000300401 \&$ Ing=en\&nrm=iso. Acesso em: 17 jan. 2021.

FARIAS, L. A. B. G.; PESSOA COLARES, M.; DE ALMEIDA BARRETO, F. K.; PAMPLONA DE GÓES CAVALCANTI, L. O papel da atenção primária no combate ao Covid-19: impacto na saúde pública e perspectivas futuras. Revista Brasileira de Medicina de Família e Comunidade, Rio de Janeiro, v. 15, n. 42, 2455, 2020. DOI: 10.5712/rbmfc15(42)2455.

Disponível

em: https://rbmfc.org.br/rbmfc/article/view/2455. Acesso em: 15 jan. 2021.

GIOVANELLA, Ligia et al. ¿Es la atención primaria de salud integral parte de la respuesta a la pandemia de Covid-19 en Latinoamérica? Trabalho, Educação e Saúde, Rio de Janeiro, v. 19, e00310142, 2021. DOI 10.1590/1981-7746-sol00310. Disponível em: http://www.scielo.br/scielo.php?script=sci_arttext\&pid=S1981$77462021000100402 \&$ Ing=en\&nrm=iso. Acesso em: 17 jan. 2021.

GIOVANELLA, Ligia et al. A contribuição da atenção primária à saúde na rede SUS de enfrentamento à Covid-19. Scielo Preprints, 2020. DOI 10.1590/SciELOPreprints.1286. Disponível em: https://preprints.scielo.org/index.php/scielo/preprint/download/1286/2009/2 115. Acesso em 17 jan. 2021. 
HARZHEIM, Erno et al. Ações federais para apoio e fortalecimento local no combate ao COVID-19: a Atenção Primária à Saúde (APS) no assento do condutor. Ciência e Saúde coletiva, Rio de Janeiro, v. 25, supl. 1, p. 2493-97, 2020. DOI 10.1590/1413-81232020256.1.11492020. Disponível em: http://www.scielo.br/scielo.php?script=sci_arttext\&pid=S1413$81232020006702493 \&$ Ing=en\&nrm=iso. Acesso em: 17 jan. 2021.

JÚNIOR, J. G. et al. Coping strategies and health promotion through teaching-service integration in the context of the COVID-19 pandemic. Revista Brasileira de Medicina de Família e Comunidade, Rio de Janeiro, v. 15, n. 42, 2526, 2020. DOI 10.5712/rbmfc15(42)2526.

file://C:/Users/User/Downloads/2526-Texto\%20do\%20artigo-13767-1-1020200717\%20(1).pdf. Acesso em: 17 jan. 2021.

LEITE, luri da Costa, et al. O papel da atenção primária na rede de atenção à saúde no Brasil: limites e possibilidades no enfrentamento da COVID-19. Cadernos de Saúde Pública, Rio de Janeiro, v. 36, n. 6, e00104120, 2020. DOI 10.1590/0102$311 \times 00104120$. http://cadernos.ensp.fiocruz.br/csp/artigo/1093/o-papel-da-atencao-primariana-rede-de-atencao-a-saude-no-brasil-limites-e-possibilidades-noenfrentamento-da-covid-19. Acesso em: 15 jan. 2021.

MACIEL, F.B.M. et al. Agente comunitário de saúde: reflexões sobre o processo de trabalho em saúde em tempos de pandemia de Covid-19. Ciência e Saúde Coletiva, Rio de Janeiro, v. 25, supl. 2, p. 4185-95, 2020. DOI 10.1590/1413812320202510.2.28102020.

NUNCIARONI, A. T. et al. Novo Coronavírus: (re)pensando o processo de cuidado na Atenção Primária à Saúde e a Enfermagem. Revista Brasileira de Enfermagem, Brasília, v. 73, supl. 2, e20200256, 2020. DOI 10.1590/0034-7167-2020-0256. Disponível em: http://www.scielo.br/scielo.php?script=sci_arttext\&pid=S0034$71672020001400403 \&$ Ing=en\&nrm=iso. Acesso em: 15 jan. 2021.

OLIVEIRA, A. C.; LUCAS, T. C.; IQUIAPAZA, R. A. O que a pandemia da COVID-19 tem nos ensinado sobre adoção de medidas de precaução? Texto e Contexto Enfermagem, Florianópolis, v. 29, e20200106, 2020. DOI 10.1590/1980-265xtce-2020-0106. Disponível em: https://www.scielo.br/scielo.php?pid=S010407072020000100201\&script=sci_arttext\&tlng=pt. Acesso em: 17 jan. 2021.

OLIVEIRA, L. M. S. et al. Estratégia de enfrentamento para covid-19 na atenção primária à saúde: relato de experiência em Salvador-BA. Scielo Preprints, 2021. DOI 10.1590/1983-1447.2021.202001380. Disponível em: https://preprints.scielo.org/index.php/scielo/preprint/view/1564. Acesso em: 15 jan. 2021. 
OLIVEIRA, M. A. C.; PEREIRA, I. C. Atributos essenciais da atenção primária e a estratégia de saúde da família. Revista Brasileira de Enfermagem, Brasília, v. 66, n. SPE, p. 158-164, 2013. DOI 10.1590/S0034-71672013000700020. Disponível em: http://www.scielo.br/scielo.php?script=sci_arttext\&pid=S0034$71672013000700020 \&$ Ing=en\&nrm=iso. Acesso em: 15 jan. 2021.

PINGEL, E. S. et al. Committing to Continuity: Primary Care Practices During COVID-19 in an Urban Brazilian Neighborhood. Health Education e Behavior, v. 48, n. 1, p. 2933, 2020. DOI 10.1177/1090198120979609. Disponível em: https://journals.sagepub.com/doi/10.1177/1090198120979609. Acesso em: 17 jan. 2021.

PINTO, L.F.; GIOVANELLA, L. The Family Health Strategy: expanding access and reducing hospitalizations due to ambulatory care sensitive conditions (ACSC). Ciência e Saúde Coletiva, Rio de Janeiro, v. 23, n. 6, p. 1903-1914, 2018. DOI 10.1590/1413-81232018236.05592018.

Disponível em: http://www.scielo.br/scielo.php?script=sci_arttext\&pid=S1413$81232018000601903 \&$ Ing=en\&nrm=iso. Acesso em: 17 jan. 2021.

RIOS, A. F. M. et al. Atenção Primária à saúde frente à Covid-19 em um centro de saúde. Enfermagem em Foco, Salvador, v. 11, n. 1.ESP, p. 246-51, 2020. DOI 10.21675/2357-707X.2020.v11.n1.ESP.3666. Disponível em: http://revista.cofen.gov.br/index.php/enfermagem/article/view/3666. Acesso em: 15 jan. 2021.

PRADO, N. M. B. L. et al. The international response of primary health care to COVID-19: document analysis in selected countries. Cadernos de Saúde Pública, Rio de Janeiro, v. 36, n. 12, e00183820, 2020. DOI 10.1590/0102-311x00183820. Disponível em: http://www.scielo.br/scielo.php?script=sci_arttext\&pid=S0102311X2020001205001\&lng=en\&nrm=iso. Acesso em: 18 jan. 2021.

SOUZA, C. D. F. et al. The need to strengthen Primary Health Care in Brazil in the context of the COVID-19 pandemic. Brazilian Oral Research, São Paulo, v. 34, e047, 2020. DOI 10.1590/1807-3107bor-2020.vol34.0047. Disponível em: http://www.scielo.br/scielo.php?script=sci_arttext\&pid=S1806$83242020000100801 \&$ Ing=en\&nrm=iso. Acesso em: 18 jan. 2021.

SOUZA FILHO, B. A. B.; TRITANY, E. F. COVID-19: importância das novas tecnologias para a prática de atividades físicas como estratégia de saúde pública. Cadernos de Saúde Pública, Rio de Janeiro, v. 36, n. 5, e00054420, 2020. DOI 10.1590/0102311x00054420.

em: http://www.scielo.br/scielo.php?script=sci_arttext\&pid=S0102311X2020000500505\&lng=en\&nrm=iso. Acesso em: 18 jan. 2021.

VIEIRA-MEYER, A. P. G. F. et al. Brazilian Primary and Secondary Public Oral Health Attention: Are Dentists Ready to Face the COVID-19 Pandemic? Disaster Medicine and Public Health Preparedness (online), p. 1-8, 2020. DOI 
10.1017/dmp.2020.342.

em: https://www.ncbi.nlm.nih.gov/pmc/articles/PMC7684023/. Acesso em:18 jan. 2021.

XIMENES NETO, F. R. G. et al. Coordenação do cuidado, vigilância e monitoramento de casos da COVID-19 na Atenção Primária à Saúde. Enfermagem em Foco, Salvador, v. $11, \quad$ n. 1 , p. $239-245$, 2020. DOI 10.21675/2357707X.2020.v11.n1.ESP.3682.

Disponível

em: http://revista.cofen.gov.br/index.php/enfermagem/article/view/3682. Acesso em: 17 jan. 2021. 


\title{
CAPÍTULO III
}

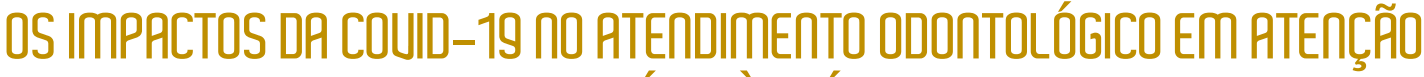 PRIIÍŔRIP ค̀ SAÚLE}

\author{
DDI: 10.51859/AMPLLA.APS276.|III-3
}

\author{
Geovanna de Castro Bizarria ${ }^{1}$ \\ Antonio Weynisson Felix Santana ${ }^{2}$ \\ Vania Mesquita Rodrigues ${ }^{3}$ \\ Filipe Levy Sousa Teixeira ${ }^{4}$ \\ Vivianne Coelho Noronha Diógenes ${ }^{5}$
}

\footnotetext{
${ }^{1}$ Graduanda do curso de Odontologia. Centro Universitário Doutor Leão Sampaio - Unileão

${ }^{2}$ Graduando do curso de Odontologia. Centro Universitário Doutor Leão Sampaio - Unileão

${ }^{3}$ Graduanda do curso de Odontologia. Centro Universitário Doutor Leão Sampaio - Unileão

${ }^{4}$ Graduando do curso de Odontologia. Centro Universitário Doutor Leão Sampaio - Unileão

${ }^{5}$ Mestre em Saúde da Família. Professora do Departamento de Odontologia. Centro Universitário Doutor Leão Sampaio - Unileão
}

\section{RESUMO}

Em dezembro de 2019, uma nova cepa de Coronavírus surgiu e foi responsável por um surto epidêmico de caráter respiratório, altamente contagioso, capaz de promover uma pneumonia acentuada aos infectados, e que em decorrência de sua rápida disseminação evoluiu de forma acelerada para nível pandêmico. Diante dos agravantes associados a pandemia, em território nacional, destaca-se que o atendimento odontológico foi significativamente afetado, sobretudo, na Atenção Primária à Saúde (APS), o qual necessitou de uma eficaz reorganização na coordenação do cuidado à saúde no Brasil. A pesquisa tem por objetivo entender, por meio da análise literária, os impactos ocasionados pela COVID-19 nos atendimentos odontológicos, no âmbito da Atenção Primária. O trabalho se trata de uma Revisão Narrativa da Literatura (RNL), que apresenta um caráter amplo, com o intuito de descrever o desenvolvimento de um determinado assunto através da análise e interpretação dos resultados científicos existentes. A pesquisa foi realizada devido à necessidade de uma maior abordagem sobre a temática. Com ela, constatou-se que, embora a Odontologia se mostre fundamental na Atenção Primária à Saúde (APS), existem muitos aspectos deficientes no atendimento odontológico em APS, os quais sofreram, consideravelmente, maiores impactos no contexto da pandemia da COVID-19. Com isso, para reduzir os índices de contaminação entre o cirurgião dentista e paciente, a APS precisou desenvolver medidas preventivas, sobretudo, novas normas de biossegurança e protocolos de atendimentos odontológicos, restringindo-os à urgência e emergência.

Palavras-chave: Novo Coronavírus. Odontologia. Atenção Básica. 


\section{IกTRODUÇÃO}

O novo Coronavírus é responsável por causar a manifestação da COVID-19, a qual, potencialmente, pode gerar uma infecção do trato respiratório superior, que de forma ampla, desencadeia-se em uma pneumonia infecciosa, em seres humanos. A COVID-19 surgiu em dezembro de 2019 e foi responsável por um surto epidêmico que rapidamente evoluiu para o nível pandêmico. Vale destacar que doença possui agente causal caracterizado geneticamente como um membro da família Coronaviridae de vírus envelopados com um genoma de RNA de fita única de sentido positivo (SILVEIRA et al., 2021).

Existem três possíveis maneiras diferentes para a manifestação do novo coronavírus, na saliva, causar a infecção: primeiramente pela existência do vírus no trato respiratório inferior e superior que pode adentrar na cavidade oral, em conjunto com as gotículas de líquido trocadas por esses órgãos. Já a segunda forma, será quando o vírus presente no sangue acessar a boca, via fluido do sulco gengival (crevicular), um exsudato específico da cavidade oral, e a terceira maneira é por meio da infecção das glândulas salivares maiores e menores, com liberação subsequente de partículas, na saliva, por dutos salivares (SANTOS; BARBOSA, 2020).

Hodiernamente, o sistema de saúde pública vem sendo afetado diretamente pelo agravamento da pandemia do COVID-19. Por consequência da intensa disseminação do vírus, os limites da capacidade do sistema de saúde foram ultrapassados, levando-o ao colapso. Desse modo, vários países elaboraram medidas restritivas para a população no geral, com o intuito de combater a contaminação. Sendo assim, as medidas de restrição foram manifestadas também para os profissionais de saúde bucal, sobretudo, os cirurgiões-dentistas. Vale ressaltar que tais eventos foram atribuídos nos sistemas de saúde pública e privada, principalmente no âmbito da atenção primária (LEON; GIACAMAN, 2020).

Em decorrência da situação agravante da contaminação da COVID-19, que pode se espalhar através das partículas em aerossóis produzidas na clínica odontológica, vários profissionais da odontologia precisaram restringir e até mesmo adiar os atendimentos eletivos de pacientes, tratando apenas urgências e emergências odontológicas, quando necessário. Nesse contexto, medidas como limpeza de 
superfícies e do ambiente odontológico com produtos específicos, formas de contaminação, distanciamento social e biossegurança são fundamentais para reduzir os impactos da pandemia, e consequentemente, sua propagação desenfreada (SANTOS; BARBOSA, 2020).

Diante dos conflitos pertinentes causados por essa pandemia no território nacional, faz-se necessária uma eficaz organização da Atenção Primária à Saúde (APS). O Ministério da Saúde (MS), por intermédio da Secretaria de Atenção Primária à Saúde (SAPS) e em parceria com a Secretaria de Vigilância em Saúde (SVS), desenvolveu uma série de estratégias para atuação das equipes de APS, com apoio dos gestores locais e em articulação com o Conselho Nacional de Secretários Estaduais (CONASS) e Municipais de Saúde (CONASEMS). A APS tem atuação significativa na organização e coordenação do cuidado para o enfrentamento a COVID-19 no Brasil, principalmente para $80,9 \%$ das pessoas que possivelmente apresentarão os sintomas leves da doença e, consequentemente, devem permanecer isoladas em suas residências a fim de evitar a propagação do vírus. Contudo, as ações de vigilância em saúde nos territórios deverão ser executadas de forma integrada e persistente (HARZHEIM et al., 2020).

$\mathrm{O}$ trabalho tem por objetivo entender, por meio da análise literária, os impactos ocasionados pela COVID-19 nos atendimentos odontológicos, no âmbito da Atenção Primária.

\section{METODOLOGIA}

O presente artigo, trata-se de uma Revisão Narrativa da Literatura (RNL), apresentando um caráter amplo e com objetivo de descrever o desenvolvimento de um determinado assunto através da análise e interpretação dos resultados científicos existentes, sob uma perspectiva teórica ou contextual. Para isso, foi formulada a seguinte pergunta norteadora: "Como a Covid-19 afetou o atendimento odontológico no âmbito da Atenção Primária?". A partir disso, foram empregadas as seguintes etapas no desenvolvimento da pesquisa: formulação de pergunta norteadora; seleção da literatura; obtenção dos artigos; análise dos artigos; avaliação dos resultados encontrados e apresentação da revisão.

Para a determinação da amostra, foram realizadas buscas por trabalhos publicados em periódicos indexados nas bases eletrônicas de dados pela Biblioteca 
Virtual em Saúde (BVS) e SciELO. Foram utilizados os Descritores em Ciências da Saúde (DeCS): atenção primária, covid-19, odontologia, biossegurança, pandemia, todos no idioma português, associados por meio do conector booleano "AND". Assim, após a combinação dos descritores foram encontrados 5148 trabalhos científicos relevantes às temáticas, dos quais, ao serem submetidos aos critérios de elegibilidade: textos completos, gratuitos e entre os últimos 5 anos, foram reduzidos a 2436, tendo 932 duplicados, restando 1504. Por fim, após a leitura de títulos, resumos e documentos por completo, selecionou-se 12 artigos para a elaboração do trabalho e ainda 3 manuais disponíveis na íntegra, como no Google Acadêmico, sendo um do Conselho Federal de Odontologia e dois governamentais.

Foram incluídos no estudo, artigos com período de publicação entre os cinco últimos anos (2017-2021), em virtude da necessidade de se traçar um panorama consistente durante os anos e, também, sem distanciamento da situação atual. Entretanto, vale destacar, que os artigos que falam especificamente do novo Coronavírus surgem a partir do ano de 2019, haja vista que de acordo com a literatura, esse é o ano de sua origem. Para a contextualização dos anos anteriores (2017-2018), selecionou-se trabalhos que abordavam o tema da Atenção Primária em Odontologia.

\section{REUISÃO BIBLIOGRÁFICA}

A prática odontológica na Atenção Básica é um atributo necessário para a sociedade e deve ser efetivada no Sistema Único de Saúde (SUS). Diversos programas foram implementados pelo Ministério da Saúde - como o Programa Nacional de Melhoria do Acesso e da Qualidade da Atenção Básica (PMAQ-AB) - e afirmam, por meio da avaliação dos serviços de saúde, que o atendimento odontológico é uma estratégia fixa e deve ser considerada para a realização decisões e ações centrais que resultem na melhoria da qualidade de ações da saúde (NEVES; GIORDANI; HUGO, 2017).

No Brasil, evidências científicas indicam a necessidade de melhorar as condições de trabalho e a infraestrutura para os dentistas do SUS (NEVES; GIORDANI; HUGO, 2017). O atendimento odontológico na Atenção Primária em Saúde (APS) possui algumas fragilidades no contexto cotidiano. Ao abordar sobre os agravantes relacionados a COVID-19, devemos salientar, principalmente, as questões como a 
insuficiência de condições materiais para a integralidade do cuidado. (HARZHEIM et al., 2020).

Dessa maneira, compreende-se que são muitas as responsabilidades dos cirurgiões-dentistas frente às novas medidas a serem tomadas devido à Pandemia da COVID-19. Tais medidas, devem coexistir a partir de uma boa orientação e um correto manejo do paciente, uma exímia limpeza do consultório, uma impecável esterilização do instrumental odontológico, e uso obrigatório de todos os equipamentos de proteção individual (FALCON-GUERRERO; FALCON-PASAPERA, 2020).

Sob esse viés, a agência de saúde recomenda que pacientes que apresentem suspeita da doença e se encontrem com febre, dor de garganta, entre outros sintomas da doença, não procurem atendimento odontológico. Se o paciente não seguir esta recomendação, é relevante que o cirurgião-dentista saiba constatar casos suspeitos de COVID-19. À vista disso, a temperatura corporal é o primeiro indicador avaliado, a partir do uso do termômetro digital na testa, evitando contato físico (TUÑAS et al., 2020).

Ademais, a disseminação do vírus durante os atendimentos odontológicos ocorre veementemente por intermédio das gotas ou aerossóis que, quando presentes nas superfícies, as partículas podem entrar em contato com a mucosa por meio das mãos. O patógeno apresenta ameaça clínica variada, como uma síndrome gripal, que apresenta sintomas mais leves até quadros de Síndrome do Desconforto Respiratório Agudo (SDRA), a qual pode sofrer evolução fatal (RIVERA, 2020).

A princípio, é relevante que se compreenda como os riscos advindos da pandemia da COVID-19 irão prejudicar o atendimento odontológico na APS. Desse modo, tendo como base a literatura científica, é necessário enfatizar, além dos prejuízos, quais condutas a Equipe de Saúde Bucal (ESB) deve aderir com relação à biossegurança, Equipamentos de Proteção Individual (EPI's), técnicas e procedimentos, manuseio de pacientes, entre outras questões que se tornaram necessárias de adaptação durante a Pandemia ocasionada pelo novo Coronavírus (SECRETARIA DE ATENÇÃO PRIMÁRIA À SAÚDE, 2020).

Levando em consideração esses aspectos, o Ministério da Saúde recomenda selecionar ações preventivas para a disseminação do vírus. Com isso, a ESB deve agir em conjunto com os demais membros da equipe de APS, de modo a possibilitarem uma articulação mútua, promovendo a triagem e classificação dos pacientes e, assim, 
contribuírem para organização dos serviços e diminuição da exposição de pacientes não infectados com pacientes infectados. Deve-se ressaltar, ainda, que os atendimentos à urgência odontológica deverão ocorrer individualmente, evitando o compartilhamento de ambientes devido à transmissão do patógeno, sobretudo, quando são utilizados equipamentos que produzam aerossóis (SECRETARIA DE ATENÇÃO PRIMÁRIA À SAÚDE, 2020).

Os profissionais de saúde bucal, sendo esses membros fundamentais da APS, têm como dever, orientar os pacientes no que diz respeito aos comportamentos de prevenção necessários. Dessa forma, a higienização das mãos frequentemente, a etiqueta respiratória e de tosse, o uso constante de máscara, a advertência para que não toquem em superfícies, as quais podem estar contaminadas, e ainda atentá-los para que não toquem os olhos, boca e nariz com as mãos, são medidas fundamentais para que não ocorra contaminação e devem ser instigadas pelos profissionais de saúde (FALCON-GUERRERO; FALCON-PASAPERA, 2020).

Antes de iniciar qualquer atendimento odontológico, a clínica deve ser cuidadosamente limpa, ou seja, materiais, equipamentos do consultório, maçanetas, cadeiras e banheiro devem ser rigorosamente desinfetados. Por esse motivo, recomenda-se o uso de Hipoclorito de Sódio a 0,1\%, Peróxido de Hidrogênio a 0,5\%, álcool a 70\%, e até mesmo outro desinfetante padronizado pelo serviço de saúde para desinfetar todas superfícies que tiveram contato. Outro ponto relevante, é a remoção de todas as revistas das salas de espera para evitar contato direto ao tocar em objetos contaminados e depois tocar no nariz, boca ou olhos, evitando assim a propagação entre pacientes, dentista e equipe auxiliar (FRANCO et al., 2020).

Além disso, a utilização dos sugadores de alta potência é importante para que o trabalho a quatro mãos seja estimulado, de modo que seja controlada a disseminação do vírus, a partir do não uso da seringa tríplice na sua forma de spray, sem acionar os dois botões ao mesmo tempo para regular a saída de água de refrigeração. Por conseguinte, os motores que possuem válvulas de antirretração ou antirrefluxo são recomendados para que possam evitar a contaminação cruzada. Não obstante, mesmo considerada uma das várias e principais medidas de biossegurança nos consultórios odontológicos, faz-se necessário enfatizar a importância de realizar a autoclavagem das peças de mão após todos os atendimentos. Convém enfatizar, também, que é essencial 
uma maior atenção no manuseamento de materiais perfurocortantes, uma vez que as infecções podem ocorrer após um incidente com os mesmos (FRANCO et al., 2020).

Compreende-se, também, que durante 0 atendimento seguro e efetivo, 0 cirurgião-dentista e toda sua equipe auxiliar devem usar os EPI's, sendo eles: luvas de procedimento não cirúrgicos, máscara (N95, FFP2 ou Padrão FFP3), avental impermeável com mangas longas, punho de malha ou elástico e abertura posterior, óculos de proteção e protetor facial (face shield), gorro descartável e calçados fechados com solado antiderrapante (TUÑAS et al, 2020).

Cabe ainda destacar, que Tuñas et al. (2020) leva em consideração a necessidade do paciente fazer o processo de bochecho com Peróxido de Hidrogênio a $1 \%$ ou Lodopovidona a $0,2 \%$, uma vez que a solução mais usada na odontologia, Clorexidina a $0,12 \%$, não possui eficácia suficiente na prevenção da propagação da COVID-19. No entanto, é válido ressaltar que as máscaras N95 ou equivalentes, que contêm válvula expiratória, não podem ser usadas nos ambientes hospitalares, pois permitem a saída de ar expirado. Nesse caso, devem ser usadas máscaras cirúrgicas de tripla camada convencionais (CONSELHO FEDERAL DE ODONTOLOGIA, 2020).

Ademais, esses EPI'S citados são de caráter obrigatório para o atendimento odontológico, mormente, na Atenção Básica em que apresenta um maior fluxo de indivíduos (BOUSQUAT et al., 2017). Posteriormente, após cada procedimento deve ser feita a desinfecção dos EPIS descartáveis, ressaltando que as máscaras devem ser retiradas pelos elásticos, não podendo ser tocadas pelo profissional e, logo em seguida, desinfecção das mãos e do ambiente com álcool em gel a 70\% e outros produtos químicos citados anteriormente (CONSELHO FEDERAL DE ODONTOLOGIA, 2020).

Urge, portanto, que os EPI's são imprescindíveis para os profissionais de saúde, sobretudo, para os que atuam na APS (COORDENADORIA DE VIGILÂNCIA EM SAÚDE, 2020). Por conta disso, a Odontologia apresenta diversas normas de biossegurança que são essenciais para a proteção dos dentistas, além de atualizações frequentes que devem ser respeitadas e seguidas com rigor. Vale salientar que a escassez dos EPI's põe em risco os pacientes, os profissionais de saúde e até mesmo aos familiares desses trabalhadores, contribuindo, assim, para a disseminação do vírus (FARIAS et al., 2020). 


\section{COISIDERAÇÔES FInPIS}

A realidade no cotidiano do atendimento odontológico em APS se mostra bastante fragilizada e com diversas dificuldades para o seu correto funcionamento. Dito isso, o agravante da pandemia do novo Coronavírus intensificou os problemas já existentes na APS, sobretudo, relacionados à odontologia.

A forma de transmissão do vírus está intrinsecamente associada à região anatômica de atuação dos cirurgiões-dentistas, os protocolos de biossegurança tiveram que ser reestruturados e se tornaram mais rigorosos, os atendimentos foram restringidos a urgências e emergências odontológicas, assim, os tratamentos preventivos e terapêuticos de manutenção da saúde bucal foram imediatamente suspensos. Todas essas medidas tiveram como objetivo diminuir a velocidade de contágio pelo COVID-19 e, por consequência, prevenir a saúde dos profissionais e pacientes.

A pesquisa mostra a carência de artigos que abordem especificamente a temática do trabalho. Desse modo, ressalta-se a importância da publicação de novos estudos a respeito do tema, visto que diversas medidas foram implementadas no atendimento odontológico em APS por conta da pandemia do novo Coronavírus, impactando diretamente a classe odontológica.

\section{REFERÊCCIAS}

BOUSQUAT, A. et al. Atenção primária à saúde e coordenação do cuidado nas regiões de saúde: perspectiva de gestores e usuários. Ciênc. saúde coletiva. vol.22, n.4, pp.1141-1154, 2017.

CONSELHO FEDERAL DE ODONTOLOGIA (CFO), Recomendações AMIB/CFO para atendimento odontológico COVID- 19: Comitê de Odontologia AMIB/CFO de enfrentamento ao COVID-19 Departamento de Odontologia AMIB. ed. $3^{\circ}$, Brasil, de 01 de julho de 2020. Disponível em: http://website.cfo.org.br/amib-cfoapresentam-versao-atualizada-de-recomendacoes-para-fortalecer-a-lutacontra-a-covid-19-na-odontologia/

COORDENADORIA DE VIGILÂNCIA EM SAÚDE (COVISA). Nota Técnica 04/DVE/2020: Biossegurança no atendimento de pacientes com suspeita de infecção por novo Coronavírus (SARS-CoV2) nos estabelecimentos assistenciais de saúde. Brasil, 2020. Disponível em: https://pesquisa.bvsalud.org/portal/resource/pt/biblio1096484 
FALCON-GUERRERO, B. E.; FALCON-PASAPERA, G. S. Medidas Preventivas de COVID-19 no Consultório Odontológico. Int. J. Odontostomat. , Temuco, v. 14, n. 4, p. 468473, dec. 2020.

FARIAS, L. A. B. G.; COLARES, M. P.; BARRETO, F. K. A.; CAVALCANTI, L. P. O papel da atenção primária no combate ao Covid-19: impacto na saúde pública e perspectivas futuras. Revista Brasileira de Medicina de Família e Comunidade, Rio de Janeiro, v. 15, n. 42, p. 2455, 2020.

FRANCO, A. B. G. et al. Atendimento odontológico em UTI's na presença de COVID-19. InterAmerican Journal of Medicine and Health, v. 3, n. 2, p. 411-413, 2020.

FRANCO, A. G.; AMORIM, J. C. F.; CARVALHO, G. A. P.; DIAS, S. C.; FRANCO, A. B. G. Importância da conduta do cirurgião-dentista frente à contenção e prevenção do Covid-19. InterAmerican Journal of Medicine and Health. v. 3, n. 2, p. 387-389, 2020.

HARZHEIM, E. et al. Ações federais para apoio e fortalecimento local no combate ao COVID-19: a Atenção Primária à Saúde (APS) no assento do condutor. Ciênc. Saúde Coletiva, Rio de Janeiro , v. 25, n.1, p.2493-2497, 2020.

LEON, S.; GIACAMAN, R. A. Desigualdades em Saúde Bucal de Idosos em Tempos de COVID-19. Teleodontologia e Odontologia de Intervenção Mínima como Caminhos de Solução. Int. J interdiscip. dente. , Santiago, v. 13, n. 3, p. 147-150, 2020.

NEVES, M.; GIORDANI, J. M. A.; HUGO, F. N. Atenção primária à saúde bucal no Brasil: processo de trabalho das equipes de saúde bucal. Ciênc. Saúde Coletiva, Rio de Janeiro, v. 24, n. 5, p. 1809-1820, 2017.

RIVERA, C. Sprays dentais para o propósito da pandemia de COVID-19. Int. J. Odontostomat. , Temuco, v. 14, n. 4, p. 519-522, 2020.

SANTOS, K. F. dos.; BARBOSA, M. COVID-19 e a Odontologia na prática atual. Revista Eletrônica Acervo Saúde, v. 12, n. 11, p. e5113, 2020.

SECRETARIA DE ATENÇÃO PRIMÁRIA À SAÚDE (SAPS). Atendimento Odontológico no SUS, Brasília, março de 2020. Disponível em: http://website.cfo.org.br/wpcontent/uploads/2020/03/COVID-19_ATENDIMENTO-ODONTOLOGICO-NOSUS.pdf

SILVEIRA, M. G. de S. et al . Changes in dental practice in times of COVID-19: review and recommendations for dental health care. RGO, Rev. Gaúch. Odontol., Campinas , v. 69, n.1, p. 132-135, 2021.

TUÑAS, I. T. C.; SILVA, E. T.; SANTIAGO, S. B. S.; MAIA, K. D.; JÚNIOR, G. O. S. Doença pelo Coronavírus 2019 (COVID-19): Uma abordagem preventiva para Odontologia. Revista Brasileira de Odontologia. v.77, n.1, p. 1-6, 2020. 


\title{
CAPITULO IV
}

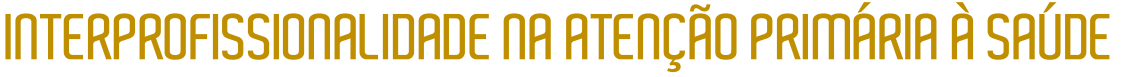

\section{D미: 10.51859/AMPLLA.APS276.|III-4}

\author{
Jaqueline Rocha Borges dos Santos ${ }^{1}$ \\ Luciana Macedo Brito ${ }^{1}$
}

\begin{abstract}
${ }^{1}$ Professora Adjunta do Departamento de Ciências Farmacêuticas. Universidade Federal Rural do Rio de Janeiro UFRRJ.
\end{abstract}

\section{RESUMO}

A Atenção Primária à Saúde (APS) ou Atenção Básica ( $A B$ ) ocupa um lugar de destaque no desenvolvimento de ações com caráter preventivo e de promoção da saúde. Neste contexto, a compreensão do processo de trabalho e como a APS se articula inserida na Rede de Atenção à Saúde (RAS) são fundamentais para a discussão de uma modelo de prática de trabalho em saúde. A partir disto, as reflexões acerca de estratégia de trabalho na APS inserem a interprofissionalidade em saúde no cerne para a implantação das práticas colaborativas. Com isto, o arcabouço conceitual se soma às percepções de experiências que dialogam com as Tecnologias da Informação e Comunicação (TIC) para garantia das atividades vinculadas à APS, especialmente em cenário de pandemia. Neste sentido, este capítulo reforça o modelo da Educação Interprofissional (EIP) em saúde como necessário aos processos de trabalho na APS para garantia do cuidado centrado ao paciente/usuário, família e comunidade.

Palavras-chave: Educação Interprofissional. Equipe de Saúde. Tecnologia da Informação e Comunicação. Aprendizado Colaborativo.

\section{IกTRODUÇก̃O}

A Atenção primária à Saúde (APS) constitui um espaço estratégico para o desenvolvimento e a prática da Educação Interprofissional (EIP) em Saúde. A primeira definição foi apontada na Conferência de Alma-Ata (1979), conforme segue:

"Cuidados essenciais baseados em métodos de trabalho e tecnologias de natureza prática, cientificamente críveis e socialmente aceitáveis, universalmente acessíveis na comunidade aos indivíduos e às famílias, com a sua total participação e a um custo suportável para as comunidades e para os países, à medida que se desenvolvem num espírito de autonomia e autodeterminação". Dessa definição emergiram, 
naquele momento, elementos essenciais da APS: a educação em saúde; o saneamento básico; o programa materno-infantil, incluindo imunização e planejamento familiar; a prevenção de endemias; o tratamento apropriado das doenças e danos mais comuns; a provisão de medicamentos essenciais; a promoção de alimentação saudável e de micronutrientes; e a valorização das práticas complementares. Principalmente, aponta para a saúde como expressão de direito humano. (ORGANIZAÇÃO MUNDIAL DA SAÚDE/UNICEF, 1979, p. 14)

Concebida como a base, o alicerce para a prevenção e a promoção da saúde, a APS ocupa um lugar de destaque na relação com o território, com a comunidade. A APS representa a porta de entrada, bem como recebe atribuição que a coloca como coordenadora e ordenadora da Rede de Atenção à Saúde (RAS). Para tanto, vale recordar a definição para RAS:

"A Rede de Atenção à Saúde (RAS) é definida como arranjos organizativos de ações e serviços de saúde, de diferentes densidades tecnológicas, que integradas por meio de sistemas de apoio técnico, logístico e de gestão, buscam garantir a integralidade do cuidado." Portaria número 4279 (BRASIL, 2010)

A Figura 1 demonstra a relação de construção existente na RAS, em que a Atenção Básica ( $A B$ ) ou APS atua como estratégia essencial à existência da rede. 
Figura 1 - Apresenta a Rede de Atenção à Saúde em desenho que considera a Atenção

Básica ou Atenção Primária à Saúde na essência da coordenação e ordenamento, apontando a inter-relação entre os pontos de atenção em rede ao paciente/usuário do Sistema Único de Saúde.

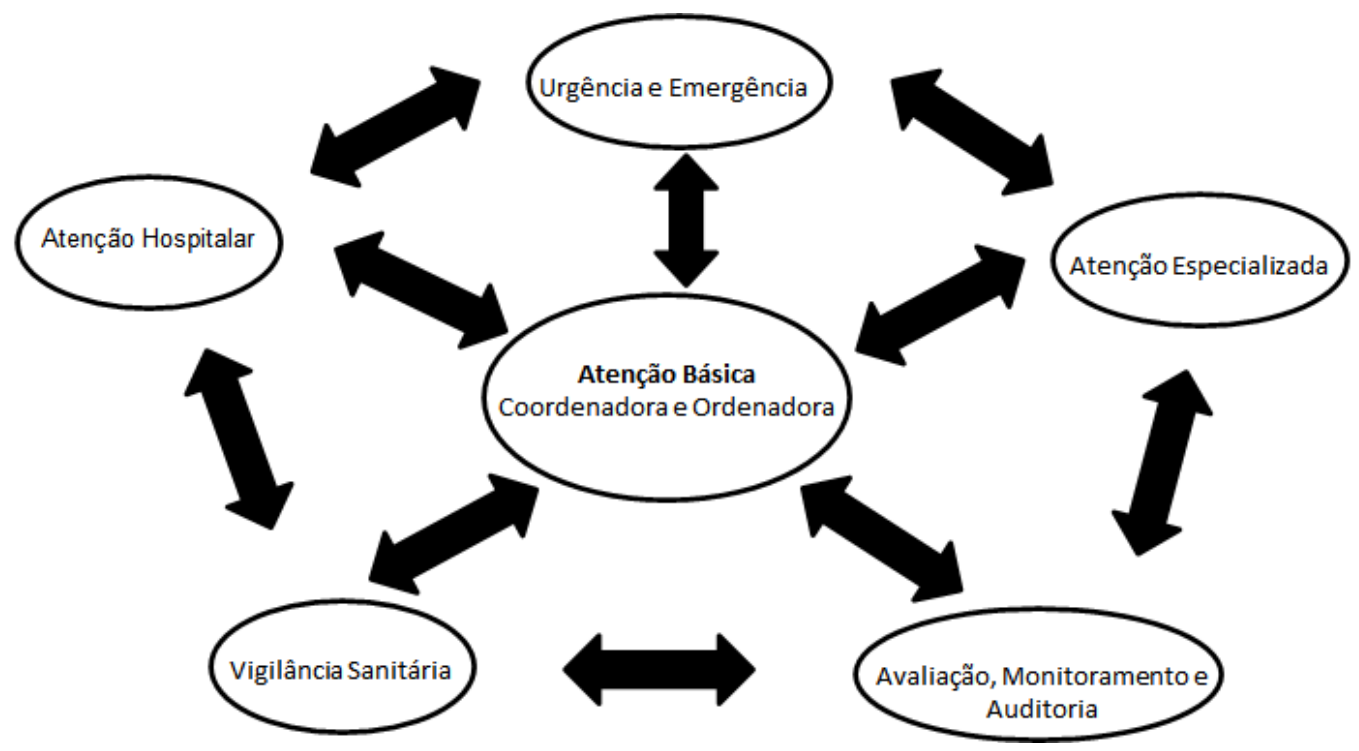

Fonte: Adaptado de Mendes (2011, p.84).

A partir do momento que iniciamos a reflexão sobre o papel da APS e da RAS como modelos de Políticas de Saúde no Brasil, logo pensamos como são geridas e construídas as relações de comunicação que justificam o elo de interdependência estabelecida na RAS, com a APS ao centro e no início das ações. Naturalmente passamos a inserir a relação com os profissionais de saúde e a necessidade de trabalho em equipe. O contexto do trabalho em equipe nos traz a noção de integração como um conceito estratégico. É considerado estratégico por atuar como um promotor de mudanças na abordagem sobre as teorias do adoecimento. Logo, as alterações em processos de trabalho, de modo a inserir o trabalho em equipe, são necessárias para a promoção de resultados em saúde mais resolutivos, com desfechos e eficazes. Neste contexto, o resgate das teorias acerca dos processos de adoecimento e como estes são dinâmicos, complexos e multifatoriais, conduzem ao entendimento de que um único profissional da saúde agrega menos à compreensão destes processos. Por esta razão, a articulação de uma série de saberes ordenados colabora à maior compreensão dos processos de adoecimento. O contexto do trabalho em equipe não é originário somente do caráter de racionalização da assistência médica, mas sim da necessidade de integração das 
disciplinas e das profissões, fundamental para aplicabilidade a partir da concepção biopsicossocial do processo saúde-doença. Por isto, parte-se da premissa de que a organização do trabalho em saúde tem início na APS, no sentido de romper com o modelo tradicional biomédico, em que o médico é considerado o profissional central, somado à fragmentação e à despersonalização do cuidado. De acordo com Fortuna et al. (2005, p.264) é possível identificar processos grupais em uma rede de relações entre pessoas, rede de relações de poderes, saberes, afetos, desejos e interesses. Assim, temse o início da concepção e compreensão de um trabalho em equipe.

\section{ESTRATÉGIA DE TRABALHO NA ATERÇÃO PRIITÁRIA À SAÚDE}

O trabalho em equipe na APS merece ser tratado como estratégico ao andamento qualitativo das ações, projetadas ao usuário/paciente, família e sociedade. Neste contexto, vale a distinção entre interprofissionalidade e interdisciplinaridade, uma vez que estes se referem à integração, respectivamente, de práticas profissionais e disciplinas ou campos de conhecimento (PEDUZZI et al., 2013). Em ambos os conceitos e práticas adotadas, entende-se que a comunicação entre os profissionais da saúde compõe uma competência a ser inserida na APS.

Weller et al. (2014) colocam que a extensa literatura sobre equipes identificou modelos mentais compartilhados, respeito mútuo, confiança e comunicação em circuito fechado como as condições básicas necessárias para equipes eficazes. Todavia, apontam que há uma série de desafios nos serviços de saúde. Estes autores direcionam os desafios para o desenvolvimento de equipes de saúde eficazes, às estruturas educacionais, psicológicos e organizacionais. Neste sentido, as intervenções educacionais podem promover uma melhor compreensão dos princípios do trabalho em equipe, ajudar a equipe a compreender os papéis e perspectivas mutuamente e ajudar a desenvolver estratégias específicas de comunicação, porém, podem não ser suficientes por si só. Já as barreiras psicológicas, como silos e hierarquias profissionais, e barreiras organizacionais, como equipes geograficamente distribuídas, podem aumentar a chance de falhas de comunicação com potencial para danos ao paciente.

Assim, emerge a necessidade de formação em EIP para sustentar o trabalho em equipe com os preceitos e as competências às práticas colaborativas. Vale, portanto, 
compreender as definições de EIP e prática colaborativa interprofissional, conforme seguem:

\begin{abstract}
"Educação interprofissional ocorre quando duas ou mais profissões aprendem umas com as outras para melhorar os resultados de saúde", e "a prática colaborativa interprofissional ocorre quando um certo número de trabalhadores da saúde de diferentes formações trabalha junto com os pacientes, suas famílias, cuidadores e comunidades para fornecer um serviço abrangente e oferecer a mais alta qualidade praticável de atendimento". (WHO, 2010)
\end{abstract}

Intrinsecamente temos as competências requeridas às práticas colaborativas, a saber: (1) comunicação interprofissional; (2) cuidado centrado no paciente/usuário, família e comunidade; (3) clareza de papéis; (4) funcionamento da equipe; (5) liderança colaborativa; (6) resolução de conflitos (BARR, 2005; BARR; LOW, 2013; BARR et al., 2016). Com o olhar voltado à formação de equipes por práticas colaborativas no cotidiano de trabalho, entende-se que a interprofissionalidade deve ser a mola propulsora à proposta de equipe de trabalho que esteja voltada, de fato, ao cuidado do usuário/paciente, família e comunidade. Ao mesmo tempo, este cuidado compõe as competências colaborativas que entrelaçadas almejam a centralidade do cuidado e a resolutividade ao processo de cuidado. Por esta razão, mudanças na formação que começam com a graduação são requeridas, para a inclusão de componentes curriculares que perpassem fortemente a interprofissionalidade, tanto em arcabouço conceitual como em práticas projetadas ao serviço e à comunidade.

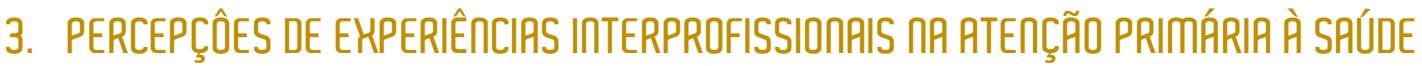

No cenário de pandemia associado à COVID-19, mudanças foram requeridas com uma ressignificação do processo de trabalho relacionado à APS a partir de construção interprofissional em saúde. Neste momento emerge o vínculo com construções no contexto das Tecnologias da Informação e Comunicação (TIC). Neste tópico falaremos de mídias sociais e a educação interprofissional, como estratégias de continuidade às ações educativas adaptadas ao modelo remoto. 


\subsection{Mídias sociais e a educação interprofissional}

Umas das principais ferramentas no combate à COVID-19 tem sido a educação em saúde com o compartilhamento de informações sobre as medidas de prevenção e tratamento dessa doença, considerando a fragilidade no que tange às alternativas medicamentosas eficazes para combatê-la. A educação em saúde envolve ações para orientar a população acerca de práticas saudáveis e responsabilidade em saúde, com a participação de diferentes categorias da saúde, além de propiciar atuação interprofissional.

A Organização Pan-Americana da Saúde (Opas) e a Organização Mundial da Saúde (OMS) reconhecem as TIC como importantes apoios virtuais no processo de saúde-doença-cuidado. Essas tecnologias, também são dispositivos de promoção, controle social e empoderamento da população no cuidado à saúde, possibilitando maior interação e troca de experiência entre os sujeitos envolvidos (OPAS, 2018, COSTA et al., 2018). Desta forma, as TIC se mostram importantes ferramentas em processos educativos, sejam elas formais ou não.

França et al. (2019) apontam que as mídias e as plataformas virtuais integram a vida e constituem importantes canais de comunicação que participam ativamente das ações humanas diárias. Em termos de educação em saúde em um cenário de pandemia, onde o contato físico precisa ser limitado ao máximo, encontramos nesses meios de comunicação a possibilidade de transmitir conhecimentos e informações sobre práticas de autocuidado que alcancem o maior número possível de pessoas (FRANÇA et al., 2019). Ao se optar pelo uso das mídias sociais como estratégia para promover a educação em saúde, contemplando conteúdos pertinentes e confiáveis, leva-se em consideração que elas induzem a busca de autonomia por parte dos sujeitos diante do cuidado consigo e com o outro no processo saúde-doença. Deve-se considerar que são variados os conteúdos contemplados na experiência da educação em saúde mediada por tecnologias digitais, correlacionados com uma perspectiva de saúde que vai além da pandemia de COVID-19 e estimula o encontro de diferentes saberes e a participação de diversas categorias profissionais. Práticas integradas ensejam a experiência interprofissional (SILVA et al., 2020). 
A iniciativa da criação de um perfil social do Programa de Educação pelo Trabalho (PET) para a Saúde com a proposta de EIP da Universidade Federal Rural do Rio de Janeiro (UFRRJ) mostrou-se como uma estratégia interprofissional de educação em saúde fundamental durante o período pandêmico, uma vez que a produção e divulgação de materiais educativos ampliam o raio de atuação, sensibilizando a população quanto às medidas necessárias ao autocuidado e ao tratamento.

Como um todo, o PET Saúde com a EIP tem viabilizado a integração do trabalho colaborativo entre tutores, preceptores, discentes e equipes de saúde. Este é considerado um ponto relevante do projeto que associa à EIP ao trabalho colaborativo. Assim, proporciona aos envolvidos, teoria, prática e vivência do trabalho interprofissional (ALVES et al., 2020).

\section{CONSIDERAÇÔES FInAIS}

A abordagem sobre a APS com a interprofissionalidade em saúde na condição de estratégia ao trabalho em equipe, reforça a necessidade de reorientação ao efetivo funcionamento dos serviços de saúde. Para tanto, o alinhamento conceitual e a formação em EIP são requeridos, seja no contexto acadêmico (com o processo de formação garantido na graduação) ou no contexto dos serviços de saúde (com o processo de educação continuada e permanente). As competências para as práticas colaborativas uma vez garantidas com a formação, estabelecem um novo perfil formativo ou modificam o olhar dos trabalhadores já inseridos nos serviços. Sob esta égide, os desafios se concentram nos processos de trabalho no cotidiano da APS, em que as equipes de saúde dialogam de maneira assertiva e resolutiva às necessidades apontadas pelo território. No cenário de pandemia novos recursos se somam à continuidade das ações na APS, em que as TIC ganham espaço e mitigam a necessidade de garantia de educação em saúde no contexto da APS, com o propósito preventivo. Assim, os esforços em políticas públicas devem ser crescentes para fortalecer o elo ensino-serviço-comunidade, contando com a participação ativa de Instituições de Ensino Superior (IES) à consolidação da EIP nos espaços de saber que colocam a saúde como campo majoritário às ações na APS. 


\section{REFERÊCCIAS}

ALVES, F. A. P.; Medeiros, K. da S.; SANTOS, E. G. dos S.; ARAÚJO, G. K. N. de A.; SANTOS, L. M. de S. S.; SOUTO, R. Q.; LÚCIO, F. P. da S.; BORBA, A. K. de O. T.; JARDIM, V. C. F. da S. A interdisciplinaridade como estratégia de ensino e aprendizagem. Revista de Enfermagem UFPE on line, p. 13:e240192, 2019. Disponível em: https://doi.org/10.5205/1981-8963.2019.240192. Acesso em: 5 mar. 2021.

BARR, H. Interprofessional education today, yesterday and tomorrow: a review. London, UK: Higher education academy, health sciences and practice network, 2005. 47p. Disponível em: CAIPE (2002) Interprofessional Education- Today, Yesterday and Tomorrow (Barr, H.) Higher Education Academy, Learning \& Teaching Support Network for Health Sciences \& Practice, Occasional Paper 1 CAIPE. Acesso em: 1 mar. 2021.

BARR, H.; LOW, W. Introducing interprofessional education. United Kington: Center for the advancement of interprofessional education (CAIPE), England, 2013. 36p. Disponível em: CAIPE (2013) Introducing Interprofessional Education, (Barr, H. \& Low, H.). - CAIPE. Acesso em: 2 mar. 2021.

BARR, H.; GRAY, R.; HELME, M.; LOW, H.; REEVES, S. Interprofessional education: guidelines 2016. Centre for the advancement of interprofessional education (CAIPE), England, 2016. 26p. Disponível em: CAIPE (2016) Interprofessional Education Guidelines, (Barr, H., Gray, R., Helme, M,. Low, H. \& Reeves, S.). CAIPE. Acesso em: 2 mar. 2021.

BRASIL. Ministério da Saúde. Portaria número 4279, de 30 de dezembro de 2010. Estabelece diretrizes para a organização da rede de atenção à saúde no âmbito do Sistema Único de Saúde. Brasília, Diário Oficial da União, 2010, seção 1, p.88. Disponível em: 07_jan_portaria4279_301210.pdf (saude.gov.br). Acesso em: 1 mar. 2021.

COSTA, C.I.A.; PACHECO, S.T.A.; SOEIRA, G.; ADAME, D.G.; PERES, P.L.P.; ARAÚJO, B.B.M. Construção e validação de materiais educativos para criança com doença crônica: uma revisão integrativa. Revista de Enfermagem UERJ, v.26, p. 34208, 2018. Disponível em: https://doi.org/10.12957/reuerj.2018.34208. Acesso em: 10 mar. 2021.

FORTUNA, C.M.; MISHIMA, S.M.; MATUMOTO, S.; PEREIRA, M.J.B. O trabalho de equipe no programa de saúde da família: reflexões a partir de conceitos do processo grupal e de grupos operativos. Rev. Latino-Americana de Enfermagem [online], v. 13, n. 2, p. 262-268, 2005. Disponível em: Team work in a family health care program: the team process concept and operational teams (scielo.br). Acesso em: 8 mar. 2021.

FRANÇA, T.; RABEL, E.T.; MAGNAGO, C. As mídias e as plataformas digitais no campo da educação permanente em saúde: debates e propostas. Saúde em Debate, v. 43, 
n. 1, p. 106-15, 2019. Disponível em: As mídias e as plataformas digitais no campo da Educação Permanente em Saúde: debates e propostas (scielo.br). Acesso em: 11 mar. 2021.

MENDES, E.V. As redes de atenção à saúde. Brasília, Organização Pan-Americana da Saúde, 2011. 549 p. Disponível em: index.php (paho.org). Acesso em: 9 mar. 2021.

ORGANIZAÇÃO MUNDIAL DA SAÚDE/UNICEF. Cuidados primários de saúde. Relatório da Conferência Internacional sobre Cuidados Primários de Saúde, Alma-Ata, Rússia. Brasília: Unicef, 1979. Disponível em: https://bvsms.saude.gov.br/bvs/publicacoes/declaracao_alma_ata.pdf. Acesso em: 8 mar. 2021.

ORGANIZAÇÃO PAN-AMERICANA DA SAÚDE. Relatório da Reunião OPAS/OMS Brasil: Diálogo Estratégico para a Preparação do Documento de Referência para a Renovação da Promoção da Saúde no Contexto dos Objetivos de Desenvolvimento Sustentável. Brasília: OPAS, 2018. Disponível em: https://iris.paho.org/handle/10665.2/50462. Acesso em: 11 mar. 2021.

PEDUZZI, M.; NORMAN, I.J.; GERMANI, A.C.C.G.; SILVA, J.A.M.; SOUZA, G.C. Interprofessional education: training for healthcare professionals for teamwork focusing on users. Revista da Escola de Enfermagem USP, v. 47, n. 4, p. 977-83, 2013. DOI: 10.1590/S0080-623420130000400029. Disponível em: Educação interprofissional: formação de profissionais de saúde para o trabalho em equipe com foco nos usuários (scielo.br). Acesso em: 9 mar. 2021.

SILVA, M. M. S.; CARVALHO, K. G.; CAVALCANTE, L. K. da S.; SARAIVA, M. J. G.; LOMEO, R. C.; VASCONCELOS, P. R. Interseção de saberes em mídias sociais para educação em saúde na pandemia de covid-19. SANARE (Sobral, Online), v. 19, n. 2, p. 8491, 2020. ISSNe: 2317-7748.

WELLER, J.; BOYD, M.; CUMIN, D. Teams, tribes and patient safety: overcoming barriers to effective teamwork in healthcare. Postgraduate Medical Journal, v. 90, n. 1061, p. 149-54, 2014. Disponível em: http://dx.doi.org/10.1136/postgradmedj2012-131168. Acesso em: 9 mar. 2021.

WORLD HEALTH ORGANIZATION (WHO). Framework for Action on Interprofessional Education \& Collaborative Practice. Health Professions Networks Nursing \& Midwifery Human Resources for Health, Geneva: World Health Organization, 2010. p.64. Disponível em: Framework for Action on Interprofessional Education \& Collaborative Practice (who.int). Acesso em: 10 mar. 2021. 


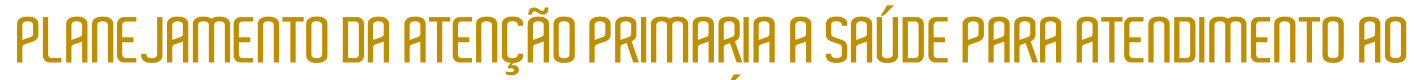

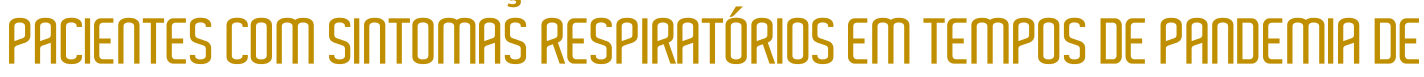 COUID-19
}

\author{
DDI: 10.51859/AMPLLA.APS276.1121-5
}

\author{
Rafaella França Torres ${ }^{1}$ \\ Silvana Carloto Andres ${ }^{2}$ \\ Liane Bahú Machado ${ }^{3}$ \\ Andressa Leão ${ }^{4}$ \\ Melissa Medeiros Braz ${ }^{5}$ \\ Fábio Piazer Franco ${ }^{6}$
}

\footnotetext{
${ }^{1}$ Enfermeira.

${ }^{2}$ Enfermeira. Mestranda da Universidade Federal de Santa Maria - UFSM.

${ }^{3}$ Enfermeira. Mestranda da Universidade Federal de Santa Maria - UFSM.

${ }^{4}$ Enfermeira.

${ }^{5}$ Fisioterapeuta. Professora e doutora da Universidade Federal de Santa Maria - UFSM.

${ }^{6}$ Enfermeiro. Coordenador Técnico do Hospital de Caridade de Jaguari/RS
}

\section{RESUTO}

A pandemia de COVID-19 é um desafio sem antecedentes para a ciência e para a sociedade, cobrando respostas rápidas e diversas dos sistemas públicos de saúde que precisam ser reorganizados, em todos os seus componentes, para o seu enfrentamento. Desse modo, a atenção primária a saúde é considerada um importante setor frente a situações emergenciais. A atenção primária a saúde, obtém o conhecimento do território, o vínculo entre o paciente e a equipe de saúde, e o acompanhamento e atendimento precoce dos casos suspeitos e leve, testagem de pacientes sintomáticos, contribui como estratégia fundamental tanto para a contenção da pandemia, quanto para o não agravamento das pessoas com a Covid-19.

Palavras-chave: Atenção Primária à Saúde. COVID-19. Pandmia.

\section{IกTRODUÇÃO}

Preparar um sistema de Unidades Básicas de Saúde (UBS) para responder com qualidade a situações de emergência pública não é usual e nada fácil. No Brasil encontrase um dos maiores sistemas de saúde universal do mundo o Sistema Único de Saúde (SUS), aportado em rede de Atenção Primaria a Saúde (APS), mas que apresenta problemas recorrentes de financiamento, gestão, profissionais e estruturação física dos 
serviços. Mesmo com estas barreiras e limitações, a APS tem alcançado resultados positivos, há inúmeras evidências que demonstram influência significativa na redução de mortalidade e desigualdades em saúde, que se estabelecem nos níveis de promoção e prevenção de saúde o que tende a ser potencializado pelo acordo de políticas públicas (AQUINO, 2020).

A pandemia de COVID-19 é um desafio sem antecedentes para a ciência e para a sociedade, cobrando respostas rápidas e diversas dos sistemas públicos de saúde que precisam ser reorganizados, em todos os seus componentes, para o seu enfrentamento. Desse modo, a APS é considerada um importante setor frente a situações emergenciais, tais quais as epidemias de dengue, Zika, febre amarela, Chikungunya e, agora, a Covid19 (GUIMARÃES, 2020).

A APS, obtém o conhecimento do território, o vínculo entre o paciente e a equipe de saúde, e o acompanhamento e atendimento precoce dos casos suspeitos e leve, testagem de pacientes sintomáticos, contribui como estratégia fundamental tanto para a contenção da pandemia, quanto para o não agravamento das pessoas com a Covid19.

À APS ainda caberá também abordar problemas oriundos do isolamento social prolongado e da precarização da vida social e econômica, como transtornos mentais, violência doméstica, alcoolismo e agudização ou desenvolvimento de agravos crônicos, cujas consequências são de difícil previsão, exigindo cuidados integrados longitudinais. Tudo isso soma-se ao conjunto de problemas já vivenciados pelas pessoas e que se apresentam no cotidiano dos serviços. (MARIA GUADALUPE, 2020).

$\mathrm{Na}$ ausência de vacinas para todos os grupos prioritários de forma rápida, e de medicamentos específicos para o tratamento da COVID-19, e à alta transmissibilidade da infecção, as únicas intervenções eficazes para o controle da pandemia são medidas de saúde pública como isolamento, distanciamento social e vigilância dos casos, com o propósito de reduzir o contágio, evitando sofrimento e morte, ao frear a velocidade da pandemia. Ao mesmo tempo é necessário dotar o sistema de recursos para oferecer a atenção adequada e oportuna (ENGSTROM, 2020)

No Brasil, e em diversos países do mundo, a resposta sanitária tem sido centrada nos serviços hospitalares, com ações para a ampliação do número de leitos, especialmente, de unidades de tratamento intensivo e respiradores pulmonares. Sem 
retirar a importância da adequada estruturação da atenção especializada voltada aos casos mais graves da COVID-19, é preciso alertar que, no âmbito da atenção primária à saúde (APS), muito pode e precisa ser feito (MARIA GUADALUPE, 2020).

Neste sentido esse relato tem o objetivo de narrar as dificuldades enfrentadas pela equipe de saúde na APS para o atendimento de pacientes com sintomas gripais.

\section{METODOLOGIA}

Trata-se de um relato de experiência vivenciado pela equipe de saúde que compõem o unidade básica de saúde, pertencente a rede da APS, a UBS fica localizada em uma cidade do interior do Rio Grande do Sul.

A organização da UBS se deu no início de março, havendo mudanças na estrutura física, reestruturando salas anteriormente utilizadas pela equipe administrativa/ gestão, para atendimentos de consulta clinicas, e as salas anteriormente utilizadas para atendimentos clínicos passam a ser usadas exclusivamente para atendimentos de pacientes com sintomas respiratório leves e testagem e coleta de material para detecção de COVID-19.

Todos os pacientes que apresentam sintomas respiratórios, ou assintomáticos, porém tiveram contato com pessoas positivas, são triadas pela equipe de enfermagem e médica, recebendo tratamento adequado para a sintomatologia apresentada.

A UBS disponibiliza três tipos de teste: RT-PCR: É o exame capaz de identificar o vírus ativo no corpo humano. Esse teste leva, no mínimo, seis horas para ficar pronto. 0 material utilizado para a análise é retirado das vias aéreas do paciente, por meio de um tipo de cotonete, e é encaminhado ao laboratório determinado pelo estado do Rio Grande do Sul. $\underline{R T-P C R}$ rápido: É o mesmo tipo de teste do RT-PCR comum, no entanto seu processamento é muito mais rápido, levando cerca 20minutos. Sorológico: É um exame feito a partir de uma pequena amostra de sangue do paciente. Ele indica se houve ou não criação de anticorpos contra o coronavírus, o que pode indicar que a pessoa já foi ou não infectada pelo vírus. A sorologia é recomendada a partir do oitavo dia do aparecimento dos sintomas.

Nesse decorrer da pandemia a equipe precisou se readequar diversas vezes dependo das normativas, protocolos e legislação em vigor determinadas via governo federal e/ou estadual. É importante salientar que alguns colaboradores da equipe foram 
afastados por serem portadores de alguma doença crônica e novos colaboradores foram contratados para suprimir a demanda.

\section{RESULTARDOS E DISCUSSÔES}

A ideia inicial ao enfrentamento da covid, foram instruídos os pacientes crônicos a ficarem em casa e apenas procurar o serviço se fosse realmente necessário, com isso, pode-se notar uma diminuição da procura dos mesmos ao serviço, porém, agora tornouse preocupante as complicações pertinentes ao descontrole das doenças crônicas (GUIMARÃES, 2020).

Para que haja a manutenção do acesso ao cuidado relacionado a outros agravos, a APS tem papel fundamental durante a pandemia, priorizando as atividades preventivas, como a vacinação, o atendimento as gestantes e recém-nascidos, já que a cancelamento dessas atividades por muito tempo pode ter consequência em um aumento da morbimortalidade por outros motivos, acrescendo os efeitos da pandemia (DAUMAS, 2020).

A APS é dita como componente mais abrangente pensando que atua na centralidade ao cuidado da população, porém, em vista o cenário pandêmico que estamos vivendo, pode-se perceber que a ação brasileira frente a este momento está sendo centrado na área hospitalar, criando novos leitos e adquirindo respiradores, esquecendo de dar ênfase a APS, e tendo em vista essa desvalorização, frente ao combate da pandemia, foi a ideia de reestruturação da atenção à população (FERNANDEZ, 2020). Para melhor planejamento, foi necessário suspender algumas atividades de rotina e aumentar as demandas espontâneas, suspendendo grupos e consultas eletivas, mantendo apenas as consultas de pré-natal e puerpério e os fluxos de atendimentos ficaram voltados com a identificação de pacientes sintomáticos ainda na recepção (FERNANDEZ, 2020).

A velocidade de disseminação do vírus é inquietante para os serviços da APS, assim faz-se necessário algumas estratégias para melhor combater e amparar a comunidade, e uma dessas táticas é a educação em saúde, que sempre foi uma forte ferramenta para APS, mas, agora tornando-se essencial, tendo em vista que, a cada dia aparecem diversas notícias nas mídias a respeito do contagio e tratamento para o vírus, 
sendo muitas delas falsas (fake News), nesse sentido é mais que necessário a divulgação de informações corretas dentro da mídia (CABRAL, 2020).

Diversos países estão com altas taxas de profissionais da saúde infectados pela covid-19, o que acaba os afastando das atividades diárias, colaborando para que haja um colapso do sistema. A partir disso, surgem questões importantes, como por exemplo, proteger os profissionais em atividade e como sanar a falta destes profissionais afastados. A sobrecarga dos sistemas que são experimentados em outros países pode ser um grande modelo para o Brasil, e para fortalecimento do Sistema Único de Saúde, com priorização dos alicerces e preparação para uma grande demanda de casos graves que pode estar por vir (FARIAS, 2020).

Por fim, a APS realmente precisou-se reinventar para o novo cenário que foi imposto, adequar uma porta de entrada para o paciente sintomático respiratório foi um deles, já que a maioria das unidades são pequenas e sem muitas portas de entrada, porém acabou adequando-se na medida do possível. Seguido vem a proteção dos profissionais atuantes, disponibilizando todos os materiais de proteção individual, uma questão que está sendo deixada de lado é a saúde mental dos mesmos, pois o trabalho está exaustivo, vivendo todo dia o aumento das aglomerações e dos casos positivos, um profissional para atender os profissionais é essencial nesse momento (MENDONÇA, 2020).

A garantia dos cuidados aos pacientes não sintomáticos durante a pandemia foi outro enfrentamento para as equipes da APS, visto que no inicio esses atendimentos foram cancelados, porém com o passar dos meses e com a persistência do vírus, foi preciso adequar de uma maneira a não deixar esses pacientes desassistidos, tentando ajustar o fluxo mantendo a redução na circulação de pessoas. Já que a ideia é não deixar ninguém para trás, fez-se necessário a criação de novas estratégias e muita criatividade para que o serviço funcionasse de maneira efetiva, como o exemplo da vacinação em drive thru. Então sem a implementação de metodologias eficientes e seguros para a APS, é dificílimo proteger a saúde da população e diminuir a morbimortalidade na pandemia (MENDONÇA, 2020). 


\section{CONSIDERAÇÔES FInRIS}

O novo planejamento do processo de trabalho tem fortalecido as ações de combate ao vírus, sem deixar de lado o essencial que é o cuidado da atenção primária em saúde, e, os profissionais da saúde estão acolhendo bem os novos métodos impostos pelo cenário atual, seguindo o mesmo propósito, a resposta dos usuários está sendo positivo, com maior valorização da equipe e fortalecendo vínculo.

No entanto, vale ressaltar as medidas de prevenção e quanto ao isolamento social, por meio da educação em saúde que está diretamente ligado a responsabilidade dos profissionais da saúde. Portanto, diante do cenário que está sendo vivenciado no atual momento, as chances aumentam de uma crise humanitária e econômica para os próximos anos.

\section{REFERÊCCIAS}

Aquino E., Silveira I.H, Pescarini J., Aquino R., Souza-Filho J.A. Medidas de distanciamento social no controle da pandemia de COVID-19: potenciais impactos e desafios no Brasil. Ciênc Saúde Colet 2020; 25 Suppl 1:2423-46.

Cabral, E. R. DE M.; Bonfada, D.; Melo, M. C. DE; Cesar, I. D.; Oliveira, R. E. M. DE; Bastos, T. F.; Bonfada, D.; Machado, L. O.; Rolim, A. C. A.; Zago, A. C. W. Contributions and challenges of the Primary Health Care across the pandemic COVID19. InterAmerican Journal of Medicine and Health, v. 3, p. 1 - 12, 11 Apr. 2020.

Daumas R.P et al., O papel da atenção primária na rede de atenção à saúde no Brasil: limites e possibilidades no enfrentamento da COVID-19. Cad. Saúde Pública 2020; 36(6):e00104120. Doi: 10.1590/0102-311X00104120

Engstrom E., Giovanella L., Melo E., Mendes A., Grabois V., Mendonça M.H.M. Recomendações para a organização da atenção primária à saúde no SUS no enfrentamento da COVID-19. Observatório Covid 19: série linha de cuidado covid-19 na Rede de Atenção à Saúde. Fiocruz 2020.

Farias L.A.B.G., Colares M.P., Barretoti F.K.A., Cavalcanti L.P.G. O papel da atenção primária no combate ao Covid-19: impacto na saúde pública e perspectivas futuras. Rev Bras Med Fam Comunidade. Rio de Janeiro, 2020 Jan-Dez; 15(42):2455. DOI 10.5712/rbmfc15(42)2455

Fernandez M. V., Castro D. M., Fernandes L. M. M., Alves I. C. Reorganizar para avançar: a experiência da Atenção Primária à Saúde de Nova Lima/MG no enfrentamento da pandemia da COVID-19. APS em Revista. Vol. 2, n.2, p.74-82. Junho, 2020 ISSN 2596-3317. DOI 10.14295/aps.v2i2.128 
Guimarães F.G, Carvalho T.M.L, Bernardes R.M, Pinto J.M. A organização da atenção primária à saúde de Belo Horizonte no enfrentamento da pandemia COVID-19: relato de experiência. APS em Revista 2020; 2:74-82

Maria Guadalupe Medina Lígia Giovanella Aylene Bousquat, Maria Helena Magalhães de Mendonça. Atenção primária à saúde em tempos de COVID-19: o que fazer?. ESPAÇO TEMÁTICO: COVID-19 - CONTRIBUIÇÕES DA SAÚDE COLETIVA • Cad. Saúde Pública 36 (8) 17 Ago 20202020 • https://doi.org/10.1590/0102$311 \times 00149720$

Mendonça, C., Rosset, I., Gonçalves, M., Molina Bastos, C., de Medeiros, A., Dias, A., Nascimento, F., Masiero, F., Pelegrini, G., Ragnini, J. M., Leite, L., Arruda, N., de Freitas, P., Firmino, R., Reolom, R. P., Tolio, R., \& Aliatti Mantese, G. H. (2020). Resposta assistencial de um serviço docente assistencial de APS à pandemia da COVID-19. APS EM REVISTA, 2(1), 33-37. https://doi.org/10.14295/aps.v2i1.63 


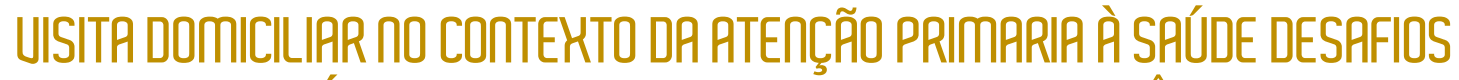 DE mÉDICOS E ERFERMEIROS: RELATO DE EYPERIÊCCIA
}

\section{DUI: 10.51859/AMPLLA.APS276.IIII-6}

\author{
Silvana Carloto Andres ${ }^{1}$ \\ Fernanda Birk ${ }^{2}$ \\ Andressa Leão ${ }^{3}$ \\ Liane Bahú Machado ${ }^{4}$ \\ Melissa Medeiros Braz ${ }^{5}$
}

\footnotetext{
${ }^{1}$ Enfermeira. Mestre.

${ }^{2}$ Médica.

${ }^{3}$ Enfermeira.

${ }^{4}$ Enfermeira. Mestranda da Universidade Federal de Santa Maria - UFSM.

${ }^{5}$ Fisioterapeuta. Professora e doutora da Universidade Federal de Santa Maria - UFSM.
}

\section{RESUINO}

A Visita Domiciliar (VD) é uma ferramenta muito utilizada pela equipe que atua na Atenção Primaria à Saúde (APS), possui importância na saúde pública, pois é através dela que pode avaliar as condições ambientais e físicas que o indivíduo e sua família vivem. O objetivo do estudo foi avaliar a importância que a equipe multiprofissional atribui à Visita Domiciliar no contexto da APS, e discutindo os desafios para que a VD possa vir a contribuir para a reorientação do trabalho em equipe e para a produção do cuidado em saúde. Trata-se de um relato de experiência da equipe de enfermagem e médica de uma Unidade Básica de Saúde, situada no interior do Rio Grande do Sul. A experiência se baseou nas VDs no decorrer do ano de 2020, e teve como desafio a pandemia do COVID-19, que limitou algumas VDs. A visita domiciliar é parte fundamental da atenção primária e existe desde os primórdios do atendimento em saúde pública. Atualmente, um dos maiores desafios é garantir ênfase em promoção à saúde e prevenção de doenças dentro do modelo curativo que ainda vivemos. Além disso, a pandemia de COVID 19 demonstrou que, apesar do desafio em adaptar a equipe, bem como orientar familiares e pacientes sobre os cuidados a fim de evitar disseminação da doença, fica evidenciada a necessidade em manter as visitas domiciliares a fim de reduzir descompensação de doentes crônicos, bem como evitar sobrecarga às unidades de saúde, devido à falta de acompanhamento.

Palavras-chave: Atenção Primaria à Saúde. Visita Domiciliar. Covid-19.

\section{IกTRODUÇก̃O}

A Visita Domiciliar (VD) é uma ferramenta muito utilizada pela equipe que atua na Atenção Primaria à Saúde (APS), possui importância na saúde pública, pois é através 
dela que pode avaliar as condições ambientais e físicas que o indivíduo e sua família vivem. Facilitando assim à assistência, tratamento, orientações e o levantamento de dados sobre as condições de habitação e saneamento, e aplicar medidas de intervenções que propiciem uma melhora na qualidade de vida do mesmo, além do foco no cuidado e acompanhamento clinico da comunidade (BRANDÃO, XIMENES e BARROS, 2018).

Para a realização da VD é importante que a equipe multidisciplinar tenha preparo profissional, empenho e disponibilidade de tempo para desempenhar suas atividades durante a VD, sem comprometimento da qualidade da mesma (CONCEIÇÃO et al., 2019). Na Política Nacional de Atenção Básica foi aprovada pela Portaria no 2.488, de 21 de outubro de 2011, estabelecendo a revisão de diretrizes e normas para a organização da atenção básica VDs dos profissionais de nível superior - médicos e enfermeiros - eram marcadas de acordo com as agendas de trabalho das equipes (BRASIL, 2012).

Sendo assim além das potencialidades, a atividade de VD enfrenta muitos desafios: a consulta do médico nas residências não é uma prática tão regular, geralmente é realizada em casos em que o enfermeiro não consegue dar encaminhamento, ou precisasse de uma opinião médica, e quando o paciente não tem meios de se locomover até a unidade, e outras dificuldades inerentes à própria prática da VD como a mudança de famílias, endereços errados e recusas, entre outras situações adversas (ROCHA et al., 2017).

Os problemas com que os profissionais se deparam nas VDs envolvem não apenas o enfrentamento da doença em si, mas, também, situações relacionadas ao contexto social e cultural em que vive a família, para os quais a medicina tecnológica, em geral, tem pouco para ofertar, sendo necessário reconhecer os limites dos profissionais e admitir que as alternativas e encaminhamentos para os problemas passam, necessariamente, pela participação do usuário e sua família, bem como, por ações intersetoriais e de articulações com a sociedade civil (BRANDÃO, XIMENES e BARROS, 2018).

Com isso o trabalho multidisciplinar surge como estratégia de trabalho, visando promover serviços com maior qualidade e planejamentos de ações mais adequados ao usuário. Este planejamento entre as equipes resulta em um melhor aproveitamento de 
tempo, possibilitando redução de custos, evitando duplicidade de atendimentos e intervenções desnecessárias (HILGERT, COSTA e PISSAIA 2017).

As VDs permitem conhecer as condições de vida e habitação das famílias, as relações que estabelecem no ambiente doméstico, as condições de adoecimento daquela família, e, consequentemente, podem facilitar o planejamento e o direcionamento das ações visando a promoção da saúde e o fortalecimento do autocuidado.

Este relato se justifica preencher uma lacuna existente sobre a assistência multiprofissional em domicílio. Neste sentido, este relato possui o objetivo de avaliar a importância que a equipe multiprofissional atribui à Visita Domiciliar no contexto da APS, e discutindo os desafios para que a VD possa vir a contribuir para a reorientação do trabalho em equipe e para a produção do cuidado em saúde.

\section{MATERIAL E MÉTODOS}

Trata-se de um relato de experiência da equipe de enfermagem e médica de uma Unidade Básica de Saúde, situada no interior do Rio Grande do Sul. As visitas domiciliares aconteceram mediante demanda advinda dos Agentes Comunitários de Saúde (ACS) e/ou solicitação dos familiares via contato telefônico. A experiência se baseou nas VDs no decorrer do ano de 2020, e teve como desafio a pandemia do COVID-19, que limitou algumas VDs, devido aumento da demanda de atendimento na unidade de saúde e restrições impostas por normativa estabelecida via pandemia. Priorizou-se então VD a pacientes acamados, com morbidades crônicas, idosos e pessoas com algum tipo de deficiência mental ou física.

As VDs foram realizadas em média uma vez na semana e independe de serem realizadas pela médica ou enfermeira, eram acompanhadas de mais um membro da equipe, agente comunitário de saúde ou técnico de enfermagem.

Nesta Unidade de Saúde, por ter seus pacientes predominantemente moradores na Zona rural, as VDs aconteciam durante um dia, divididas em dois turnos, uma VD no turno da manhã e outra no turno da tarde, devido ao difícil acesso a casa do paciente e distância geográfica entre a casa do paciente e Unidade de Saúde.

Considerando o fato de que o presente estudo se trata de um relato de experiência a partir das vivências profissionais, não foi necessário aprovação do Comitê 
de Ética em Pesquisa ou Termo de Consentimento Livre e Esclarecido. Assegura-se que foram respeitados os princípios éticos, bem como manteve-se sigilo sobre toda e qualquer informações referentes aos pacientes, durante a pesquisa e após esse período (MACHADO e ANDRES, 2021).

\section{REUISÃO BIBLIOGRÁFICA}

Elencou-se como itens para discussões os seguintes tópicos: A Atuação Da equipe medica e de enfermagem nas Visitas Domiciliares na APS; Dificuldades enfrentadas pela equipe nas Visitas Domiciliares; e; Visita Domiciliar como instrumento de prevenção e promoção de saúde.

\subsection{A Atuação da equipe médica e de enfermagem nas Uisitas Domiciliares na APS}

A visita domiciliar é um instrumento de trabalho que pertence ao mundo dos cuidados de saúde desde o início do desenvolvimento da medicina e enfermagem e dos cuidados em saúde. Numa grande parte da história da humanidade, até o início do último século, ela era o principal instrumento de contato entre o médico, os outros profissionais de saúde e o paciente; porém, a fragmentação e a verticalização dos serviços de saúde, ocorrendo em paralelo com a tecnologização, colocaram a visita domiciliar em segundo plano, colaborando para um esquecimento e um certo desprestígio dessa prática. No Brasil, algumas experiências e situações ocorrendo tanto no âmbito da saúde pública quanto no da saúde suplementar estão contribuindo para oferecer novamente suas letras de nobreza a esse instrumento de trabalho, revalorizando-o e reconhecendo sua complexidade (BRASIL, 2012).

Neste sentido a atuação da equipe na APS tem como objetivo a efetivação das suas atividades a partir do conhecimento das ações a serem desenvolvidas, devendo tais profissionais possuir um olhar particular para cada usuário assistido. Dessa forma, identifica-se que é indispensável a utilização de ferramentas que auxiliem o processo assistencial no ambiente domiciliar, como a construção do vínculo por meio da boa dinâmica, buscando sempre utilizar a escuta e um bom acolhimento, realizando um atendimento no qual identifiquem os pacientes com um todo e não apenas a patologia como foco (KAWATA et al., 2013). 


\subsubsection{Dificuldades enfrentadas pela equipe nas Uisitas Domiciliares}

A manutenção dos cuidados de saúde das VDs encontrou como principal desafio a pandemia da COVID 19, pois muitos dos pacientes que necessitam deste acompanhamento domiciliar se configuram nos chamados grupos de risco da doença. $\mathrm{A}$ prática de cuidados domiciliares por equipes de APS pode se apresentar como uma alternativa viável para fonte de cuidado a pessoas vivendo com problemas de saúde crônicos, bem como para cuidados crônicos a pessoas que não podem se deslocar à UBS (SAVASSI et al., 2020).

Para diminuir o risco da equipe ser vetor de contaminação deve-se estar atento às medidas de prevenção de transmissão da COVID-19 também nas visitas aos domicílios. A equipe deve avaliar a necessidade real da VD neste momento, além do acompanhamento clínico habitual, também investigar a possibilidade de sintomas respiratórios no paciente e/ou nos demais moradores e frequentadores do domicílio.

Durante a visita das equipes de saúde, as famílias receberam orientações de como evitar a transmissão e contaminação por COVID-19, diminuindo o número de frequentadores do domicílio, restringindo apenas aos familiares que ali residem, uso de máscaras, janelas e portas abertas para melhorar o fluxo de ar e a ventilação dos ambientes, orientações sobre limpeza e desinfecção das superfícies de uso comum na casa, bem como a importância da lavagem adequada das mãos.

O aumento na demanda de atendimentos na Unidade de Saúde também é exposta como dificuldade encontrada para a realização das VDs impedindo que os profissionais estivessem disponíveis para a demanda do atendimento domiciliar, visto que a maioria dos pacientes reside na zona rural, o que necessita de tempo para o deslocamento até o domicilio, podendo ser realizada somente uma VD por turno de atendimento.

\subsubsection{Visita Domiciliar como instrumento de prevenção e promação de saúde}

As visitas domiciliares são instrumentos fundamentais para entender o paciente de forma completa, e não apenas a doença que ele apresenta. Neste contexto, é possível conhecer as relações sociais que o paciente vivencia, avaliando suporte, bem como possíveis conflitos familiares. Instrumentos como Ecomapa e Genograma, dentro outros, são estratégias importantes nesta etapa. Conhecendo o ambiente do paciente, também é de extrema importância identificar dificuldades e potenciais riscos para 
realizar um tratamento proposto ou ações preventivas de saúde, como condições sanitárias insalubres, má iluminação, tapetes e degraus que facilitem quedas (SAVASSI, 2016).

Há medidas preventivas e de promoção à saúde que podem ser realizadas durante a visita domiciliar, mais facilmente, através do conhecimento do espaço e rotina do paciente. Dentre elas, a alimentação, como o preparo de alimentos, horários das refeições, se há rotina estabelecida, e o uso de medicamentos com a finalidade de averiguar horários corretos de uso, forma de administração, possíveis interferências alimentares ou interações medicamentosas (MENDES, 2007).

Nas zonas rurais, o nível primário tem papel ainda mais fundamental. Devido à distância e difícil acesso a centros de saúde, em muitas localidades, o posto de saúde é o único ponto de acesso à saúde dessa população. Assim, as visitas domiciliares tornamse uma forma de reduzir a fragmentação da atenção e o foco em episódios de doenças graves, através de organização e planejamento. Durante a pandemia da COVID 19, evidenciou-se a importância da prevenção, na saúde, tendo em vista o aumento do risco de agravamento da doença, se associada a outras patologias como hipertensão arterial e diabetes mellitus (ESTRELA et al., 2020).

\section{CONSIDERAÇÔES FInRIS}

A lógica da doença nos atendimentos da atenção primária, ainda é um obstáculo aos profissionais que são treinados, ao longo da formação, à visão fragmentária e curativa. Assim, torna-se essencial, a força coletiva do trabalho em equipe nas visitas domiciliares, possibilitando a integralidade nos cuidados de saúde.

A visita domiciliar é parte fundamental da atenção primária e existe desde os primórdios do atendimento em saúde pública. No entanto, os desafios desta prática foram mudando e, atualmente, um dos maiores desafios é garantir ênfase em promoção à saúde e prevenção de doenças dentro do modelo curativo que ainda vivemos. Ademais, compreender e adaptar o atendimento na atenção básica às individualidades de cada região, especialmente, de zonas rurais.

Além disso, a pandemia de COVID 19 demonstrou que, apesar do desafio em adaptar a equipe, bem como orientar familiares e pacientes sobre os cuidados a fim de evitar disseminação da doença, fica evidenciada a necessidade em manter as visitas

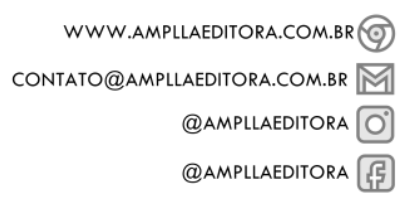


domiciliares a fim de reduzir descompensação de doentes crônicos, bem como evitar sobrecarga às unidades de saúde, devido à falta de acompanhamento.

Neste sentido, a situação mundial com as infecções causadas por Sars-cov 2, também traz um novo questionamento sobre como é preciso ainda mais atualizações e adaptações para manter acompanhamento domiciliar, inclusive, para pacientes curados de infecção respiratória (COVID 19) devido às sequelas e agravamento de doenças de base (SAVASSI, 2020).

\section{REFERÊNCIAS}

BRANDÃO, M. G. A.; XIMENES, M. A. M., BRARROS, L. Moreira. COMPETÊNCIAS DO PROFISSIONAL ENFERMEIRO NO CONTEXTO DA ATENÇÃO BÁSICA. Rev. Saúde.Com. v. 14, n. 3, p.1217-1226, 2018.

CONCEIÇÃO, A. S et. al. Ações da enfermeira na visita domiciliar da atenção básica. Revista Eletrônica Acervo Saúde / Electronic Journal Collection Health I ISSN 2178-2091. REAS/EJCH | Vol.Sup.20.

ESTRELA, F. M. et al. Covid-19 e doenças crônicas: impactos e desdobramentos frente à pandemia. Rev baiana enfermagem. v. 34, 2020.

HILGERT, M. A.; COSTA, A. E. K.; PISSAIA, L. F. Qualificação da assistência ao idoso na atenção básica: realização da visita domiciliar pela equipe multiprofissional. REVISTA ESPAÇO CIÊNCIA \& SAÚDE, v. 5, n. 2, 2017.

KAWATA, L. S. et al. Os desempenhos da enfermeira na saúde da família. Construindo competência para o cuidado. Texto Contexto Enf, Florianópolis, v. 22, n. 4, p. 961-70, 2013.

MACHADO, L. B.; ANDRES, S. C. A consulta de enfermagem no contexto da Atenção Primaria em Saúde: Relato de experiência. Research, Society and Development, v. 10, n.1, 2021.

MENDES, A. O.; OLIVEIRA, F. A. Visitas domiciliares pela equipe de Saúde da Família: reflexões para um olhar ampliado do profissional. REVISTA BRASILEIRA DE MEDICINA DE FAMílIA E COMUNIDADE, v. 2, n. 8, p.253-60, 2007.

ROCHA, K. B. et. al. A visita domiciliar no contexto da saúde: uma revisão de literatura. PSICOLOGIA, SAÚDE \& DOENÇAS, v. 18, n. 1, p.170-185, 2017.

SAVASSI, L. C. M. et. al. Recomendações para a atenção domiciliar em período de pandemia por covid-19: recomendações conjuntas do gt atenção domiciliar sbmfc e da abrasad. Rev Bras Med Fam Comunidade. Rio de Janeiro, v. 15, n. 42, 2020. 
SAVASSI, L. C. M. Os atuais desafios da Atenção Domiciliar na Atenção Primária à Saúde: uma análise na perspectiva do Sistema Único de Saúde. REVISTA BRASILEIRA DE MEDICINA DE FAMÍLIA E COMUNIDADE, v. 11, n. 38, 2016. 


\title{
UTILIZAÇÃO DE LIUESCOMO EDUCAÇÃO ET SAÚDE DURAกTE A PARDETIIA DO COUID-19
}

\author{
DDI: 10.51859/AMPLLA.APS276.1121-7
}

\author{
João Eduardo Gomes de Oliveira ${ }^{1}$ \\ Bárbara Gomes de Oliveira ${ }^{2}$
}

\footnotetext{
${ }^{1}$ Graduando do curso de Nutrição. Faculdade Regional da Bahia - UNIRB

${ }^{2}$ Graduanda do curso de Fisioterapia. Faculdade Regional da Bahia - UNIRB
}

\section{RESUTO}

Este capítulo tem como objetivo relatar as lives realizadas diante a pandemia do covid19, como forma de educação em saúde, com enfoque alimentação saudável, como aumento da prevenção e melhorias na sociedade. Na educação em saúde em particular, a tecnologia é uma grande aliada na transmissão do conhecimento devido ao contexto do covid-19. Desta forma, trata- se de um relato de experiência, denominado Nutri live, afim de disseminação cientifica, com uma educação assegurada. Observou-se uma quebra de paradigma da tecnologia, criando humanização com a população. A base foi esclarecer e expor a importância da alimentação saudável em diversos contextos, incluídos os tabus enraizados. Além disso, dentro desse contexto, todos tiveram que se adaptar as plataformas digitais, uma consolidação de formas e possibilidades na educação em saúde na atualidade, devido ao novo vírus.

Palavras-chave: COVID-19. Atenção primária. Alimentação saudável. Educação em saúde.

\section{IกTRODUÇก̃O}

Em 11 de março de 2020 a Organização Mundial de Saúde (OMS) decretou estado de pandemia pelo novo coronavírus (COVID-19) e após quatro meses do primeiro registro na China, o COVID-19 interrompeu mais de 10 mil vidas no Brasil (WHO, 2020). Com isso, o uso das Tecnologias de Informação e Comunicação (TIC) vem surgindo com inúmeros benefícios, inclusive para a educação e a saúde, criando novas formas e possibilidades. Deste modo, o surgimento da Internet foi fundamental neste processo, pois possibilita a facilidade do acesso a conteúdo, sem barreiras de tempo nem de espaço (TORNERO, 2007). 
O Instagram, apresentou um crescimento de $70 \%$ no que se refere a realização de lives, tanto para transmissão como para consumo. O Facebook fez implementações na sua configuração para realização de tais atividades e, plataformas de streaming como a Netflix e Amazon, já chegaram a registrar um crescimento de $20 \%$ só no mês de março de 2020, segundo dados da Business Insider (LESKIN, 2020).

A prática da educação em saúde é caminho integrador do cuidado, constituindo um espaço de reflexão-ação, fundado em saberes técnico-científicos e populares, culturalmente significativos para o exercício democrático, capaz de provocar mudanças individuais e prontidão para atuar na família e na comunidade, interferindo no controle e na implementação de políticas públicas, contribuindo para a transformação social (CATRIB, 2003). Diante do contexto da pandemia do Covid-19, a tecnologia se tornouse um motor da educação, para enfrentar as demandas emergenciais.

Sendo assim, o objetivo deste estudo é relatar as lives realizadas diante a pandemia do covid-19, como forma de educação em saúde, com enfoque alimentação saudável.

\section{FERRAMEETTAS TECกOLÓGICAS MA PROTOÇÃO DE EDUCAÇÃO ET SAÚDE}

A internet tem se apresentado como poderosa ferramenta de comunicação, sendo utilizada como um meio de troca de idéias e promoção, e assim vem expandindo as formas e ferramentas comunicacionais da sociedade contemporânea (YOUNG, 2012). Essas tecnologias assumem um papel de destaque quando instituídas para a produção e a difusão de informações, além de contribuírem para o desenvolvimento de novas formas de aprender e adquirir conhecimento e habilidades no ensino e nas práticas de saúde (LOPES et al., 2018). A educação e a saúde são áreas de produção e aplicação de saberes destinado ao desenvolvimento humano (PEREIRA, 2003). Sem saúde não há educação, assim como sem educação não há saúde (COSTA, 2012).

A ideia da utilização de ferramentas tecnológicas que facilitem a compreensão de conteúdos surge como uma alternativa contínua de educação centrada na aprendizagem significativa, destacando conteúdo on-line juntamente à utilização de recursos visuais possibilita uma melhor assimilação das informações (BRASIL, 2014). 0 uso desses recursos possibilita uma aprendizagem mais realista, preparando para possíveis situações-problemas identificadas na sociedade (FIGUEIREDO, 2014). 
Todas as ferramentas tecnológicas se fazem necessárias nos processos de produção, nessa perspectiva, segundo Gomes \& Merhy (2011),

[...] Não cabe hierarquização de valor entre elas; a depender da situação, cada uma terá sua importância, embora todas as situações exigem o uso das tecnologias (GOMES \& MERHY, 2011).

Os cenários educacionais, como promoção de educação e saúde "implica uma mudança social e cultural que valoriza um novo tipo de saber e exige o conhecimento e domínio de novas habilidades intelectuais e práticas/experienciais" (RIEDNER; PISCHETOLA, 2016, p. 38). Dessa maneira, conforme Meyer (2000):

O profissional de saúde, entendido também como educador, deve superar o academicismo de formação eminentemente técnica para um processo pedagógico que permita ao usuário questionar sobre temas correlatos à sua saúde, principalmente em tempos de comoção e crise humanitária imposta pela pandemia (MEYER, 2000).

Assim, a educação em saúde adota uma postura dialógica em que se desenvolvem rupturas, conflitos e aberturas para novas configurações subjetivas na vida dos sujeitos, como é o caso do isolamento social (GONZÁLES-REY, 2003). A doença pode ser abordada pelo usuário a partir de suas reflexões, baseado em suas vivências do cotidiano. Dessa forma, o profissional de saúde poderá compreender como o sujeito percebe a realidade, quais aspectos do aprendizado são significativos em sua sociedade.

\section{3. mÉTODO}

Trata- se de um relato de experiência elaborado pelos discentes do curso de nutrição e fisioterapia, de uma instituição de ensino superior no Agreste Alagoano. As lives ocorreram no Instagram do I Simpósio de Nutrição do Agreste Alagoano (https://www.instagram.com/sinuaanutricao/), na qual foram realizadas uma sequência de 3 dias alternados de educação em saúde, onde ficou denominada como: Nutri live. 
Figura 1: Temas abordados.

\begin{tabular}{|c|c|}
\hline Sequência & Temática \\
\hline 1 Nutri live & Imunidade e coronavírus \\
\hline 2 Nutri live & Compulsão alimentar \\
\hline 3 Nutri live & Alimentação na infância \\
\hline
\end{tabular}

Fonte: Autoria própria.

As lives foram ministradas por discentes do curso de nutrição (modeladores) e nutricionistas (palestrantes).

A divulgação e disseminação das lives foram disponibilizados em forma link de divulgação em mídias sociais como: WhatsApp, assim disseminado em todo território brasileiro. As lives tiveram duração máxima de 60 minutos, momento em que também foram tiradas dúvidas referente a atualidade por meio de comentários.

\section{RESULTADO E DISCUSSÃO}

A partir das lives, foi possível experimentar uma realidade incomum, porém necessário no período de Pandemia da Covid-19. A princípio, surgiram muitas dúvidas entre os discentes sobre como seriam a educação em saúde, de maneira que a aprendizagem da população fosse assegurada, chegando ao público-alvo.

Estas lives, como forma de educação em saúde teve como base esclarecer e expor a importância da alimentação saudável em diversos contextos, e alguma maneira, contribuir para a prevenção e recuperação da sociedade, diante o contexto atual, ressaltando que nenhum alimento isolado ou especifico tem o poder de melhorar o sistema imunológico, e sim o contexto de hábitos saudáveis. Acerca da viralização dos transtornos alimentares em tempos de coronavírus, tornando episódios recorrentes em muitas pessoas, por meio das mudanças bruscas na rotina e o estresse.

Também emancipou o cuidadocom as práticas alimentares adequadas na infância, onde são essenciais, pois elas tendem a se manter como bons hábitos ao longo da vida, cabendo decisões de saúde para cuidar de si e da coletividade.

Sendo assim, tentando quebrar o paradigma de uma construção de conhecimento verticalizado em que nós seriamos os emissores e eles apenas os receptores, contrariando assim o nosso intuito, o que nessa perspectiva é de suma 
relevância ressaltar a importância da educação problematizadora, uma vez que ela serve à libertação, se funda na criatividade e estimula a reflexão e a ação verdadeira dos homens sobre a realidade (FREIRE, 2005). Além disso, observou-se que havia uma necessidade de aprofundamento das temáticas, em virtude do engessamento de determinados tabus da sociedade, assim criando uma humanização com a população.

Notou ainda, que existe uma grande quantidade e diversidade de recursos tecnológicos para o campo educacional, na qual podem ser utilizados em momentos oportunos. Porém ainda existe uma grande resistência em relação as plataformas digitais, pois podem ser tornar cansativo e desmotivador.

\section{COISIDERAÇÔES FInRIS}

Esta experiência oportunizou aos discentes uma experiência no âmbito da educação em saúde de forma online, devido ao cenário ocasionado pela COVID-19. Pode-se dizer que o objetivo foi alcançado, difundindo conhecimento científico sobre alimentação saudável.

Contribuiu para a educação em saúde da população, enquanto ferramenta que possui crescimento de utilização a cada dia. Lives como essas colabora para o aumento da prevenção e melhorias na sociedade. Espera-se que, depois dessa pandemia a educação volte melhor e mais forte.

\section{REFERÊกCIAS}

Almeida BO, Alves LR. Lives, educação e covid-19: estratégias de interação na pandemia. Interfaces científicas ;2020.

BRASIL. Panorama Setorial da Internet. TIC no setor de Saúde: disponibilidade e uso das tecnologias de informação e comunicação em estabelecimentos de saúde brasileiros. Centro de Estudos das Tecnologias da Informação e da Comunicação no Brasil (CETIC), v. 6, n. 1, p. 1-10, 2014.

Catrib AMF, Pordeus AMJ, Ataíde MBC, Albuquerque VLM, Vieira NFC. Promoção da Saúde: saber fazer em construção. In: Barroso GT, Vieira NFC, Varela ZMV, organizadores. Educação em Saúde: no contexto da promoção humana. Fortaleza: Demócrito Rocha; 2003.

COSTA, V. V. Educação e Saúde. Unisa Digital, p. 7-9, 2012.

FIGUEIREDO, A. E. Laboratório de Enfermagem: estratégias criativas de simulações como procedimento pedagógico. Rev Enferm UFSM, v. 4, p. 844-849, 2014. 
FREIRE, Paulo. Pedagogia do oprimido. 42a ed. Rio de Janeiro (RJ): Paz e Terra; 2005.

GOMES, L. B.; MERHY, E. E. Compreendendo a Educação Popular Em Saúde: Um Estudo Na Literatura Brasileira. Cadernos de Saúde Pública, v. 27, n. 1, p. 7-18, Jan. 2011.

GONZÁLES-REY, F. L. Sujeito e Subjetividade: uma aproximação histórico cultural. São Paulo: Thomson Learning, 2003.

LESKIN, Paige. Instagram Live usage jumped 70\% last month. A psychologist says it's because 'people are not designed to be isolated.' 16 de abril de 2020. Disponível na URL: http://twixar.me/y31m. Acesso em: 1 de fevereiro 2021.

LOPES, A. M. et al. Congresso Internacional de Educação e Tecnologias: Encontro de Pesquisadores em Educação a Distância, v. 7, n. 1, p. 285-290, 2012, 2018.

MEYER, D. Educação, saúde e prescrição de 'formas de ser e habitar': uma relação a ser ressignificada na contemporaneidade. In: FONSECA, T. (Ed.). Formas de ser e de habitar a contemporaneidade. Porto Alegre: Editora UFRGS, 2000. p. 71-80.

PEREIRA, A. L. F. As tendências pedagógicas e a prática educativa nas ciências da saúde. Cad. Saúde Pública, v. 19, n. 5, p. 1527-1534, 2003.

RIEDNER, D. D. T.; PISCHETOLA, M. Tecnologias Digitais no Ensino Superior: uma possibilidade de inovação e comunicação? Educação, Formação \& Tecnologias, v. 9. n. 2, p. 37-55, 2016.

Santos KSS, Moura SST, Souza VKS, Sanches LMP,. Projeto "contêiner saúde": o uso do podcast como ferramenta educacional e populações vulneráveis. UM RELATO DE EXPERIÊNCIA. II ENEXC; 2016.

TORNERO, J. M. P. 2007. O Desenvolvimento da Sociedade da informação: do paradigma da cultura de massas ao paradigma da cultura multimídia. In José Manuel Pérez Tornero (cord.) Comunicação e Educação na Sociedade da Informação: novas linguagens e consciência crítica.

WHO, World Health Organization. Disponível em https://www.who.int/ Acesso em: 1 de fevereiro 2021.

YOUNG, R. R. Genetic toxicology: Web resources. Toxicology, Rockville, p. 103-121. 2012. 


\title{
CAPÍTULO VIII
}

\section{IחTRODUÇÃO À ATERÇÃO PRIITÁRIA À SAÚDE กO BRASIL: DESAFIOSE POSSIBILIDADES NO CENÁRIO CONTETRPORÂกEO}

\section{DDI: 10.51859/AMPLLA.APS276.1121-8}

\author{
Renata Falchete do Prado ${ }^{1}$ \\ Juliana Falchete Martins Prado ${ }^{2}$ \\ 1 PhD, Cirurgiã-Dentista, Programa de Pós-Graduação em Ciências Aplicadas à Saúde Bucal - UNESP - SP \\ ${ }^{2}$ Mestre, Psicóloga - Serviço Público Municipal de Mogi das Cruzes - SP
}

\section{RESUMO}

Este texto busca elencar os principais tópicos sobre os desafios da Atenção Primária à Saúde no cenário contemporâneo, apontar possibilidades e formas de superá-los, baseadas na Política Nacional de Atenção Básica vigente.

Palavras-chave: PNAB. Instituto Brasileiro de Geografia e Estatística (IBGE). Formação profissional. Minorias. Gestão.

\section{IกTRODUÇก̃O}

Desde o início do programa de agentes comunitários de saúde em 1991, uma lógica voltada à promoção da saúde e prevenção de doenças ganha cada vez mais solidez, mostrando-se mais eficaz e economicamente viável que o tratamento da doença e reabilitação dos danos.

O conceito de saúde proposto pela Organização Mundial de Saúde (OMS) em 1946, compreendendo um estado de completo bem-estar físico, mental e social, e não apenas como a ausência de doença ou enfermidade embasou o movimento social que se reuniu em 1978 durante a Conferência Internacional sobre Cuidados Primários de Saúde, realizada em Alma-Ata, na República do Cazaquistão. A conferência explicitou a necessidade de ação urgente de todos os governos, de todos os que trabalham nos campos da saúde e do desenvolvimento e da comunidade mundial para promover a saúde de todos os povos do mundo. A promoção e proteção da saúde dos povos são essenciais para o contínuo desenvolvimento econômico e social e contribui para a 
qualidade de vida e para a paz mundial (DECLARAÇÃO DE ALMA ATA SOBRE CUIDADOS PRIMÁRIOS, [s.d.]).

A melhora na qualidade da saúde, incluindo a do trabalhador, tem direta relação com o desejado aumento da renda per capita do país, o que significaria ter um crescimento sustentável da economia dentro de um projeto de desenvolvimento com equidade e inclusão social, inclusive que não privilegie somente o consumo individual, mas fortaleça o setor público (KREIN, 2013).

A Política Nacional de Atenção Básica à Saúde (PNAB) buscou organizar a atenção básica no âmbito do Sistema Único de Saúde (SUS). A primeira edição da PNAB oficial foi promulgada em 2006 (Ministério da Saúde. [s.d.]), e a segunda edição foi realizada em 2011 (Ministério da Saúde. [s.d.]).

Levantando muita discórdia, com curta duração de consulta pública para transparência (27/07 a 6/08/2017), sua revisão é aprovada em 21 de setembro de 2017 por Ricardo Barros e, uma semana após, sua consolidação aponta os caminhos que devem ser traçados para que o Estado de fato execute seu dever em relação à saúde para com cada cidadão brasileiro (Ministério da Saúde. [s.d.]).

Robustos dados comprovam a eficácia da Estratégia da Saúde da Família (ESF) nos indicadores de saúde e na vida de milhões de brasileiros (DESCONSIDERANDO EVIDÊNCIAS CIENTÍFICAS E CONSULTA PÚBLICA, MINISTÉRIO DA SAÚDE APROVA REBAIXAMENTO DA PNAB - ABRASCO, [s.d.]). No entanto, segundo o COREN do Rio Grande do Sul a proposta do Ministério da Saúde revogou a prioridade do modelo assistencial da Estratégia Saúde da Família (ESF) no âmbito do SUS, já que rompeu com a centralidade da Saúde da Família na organização do SUS ao instituir financiamento específico para quaisquer outros modelos na Atenção Básica que não contemplam a composição de equipes multiprofissionais com a presença de agentes comunitários de saúde (COREN-RS | REVISÃO DA PNAB ESTÁ EM CONSULTA PÚBLICA. ENFERMAGEM, PARTICIPE!, [s.d.]). 


\section{REUISÃO BIBLIOGRÁFICA}

\subsection{Cenário Contemporâneo Brasileiro}

Segundo o IBGE, em 2020, a população nacional estimada era de 212.767.407. A expectativa de vida foi de 76 anos. A taxa bruta de natalidade em 2020 (número de nascidos vivos a cada 1000 habitantes) foi de 14 crianças. A taxa bruta de mortalidade em 2020 foi de 6,56 pessoas. A taxa de mortalidade infantil foi de 11,56.

$14,1 \%$ da população é composta por desempregados (IBGE). 6,5\% estão em extrema pobreza(RELATÓRIO DO DESENVOLVIMENTO HUMANO 2018 | PNUD BRASIL, [s.d.]). 31,7\% desta população não dispõem de domicílio com esgotamento sanitário (rede geral ou fossa séptica ligada à rede). $20,9 \%$ da população não tem acesso à internet. Somente $37,9 \%$ das pessoas de 15 anos ou mais praticam atividade física. 0 PIB em 2020 fechou em queda de 3,4\%. Taxa de analfabetismo de 6,6\%. IDH que mede a prosperidade em função das condições de vida da população, assim como o acesso à educação e saúde foi de 0,71, em octagésimo quarto lugar entre 189 países analisados em termos de Desenvolvimento Humano. Comparando-se com demais países latinoamericanos, o IDH brasileiro é menor do que os do Chile, da Argentina, do Uruguai, do Peru e da Colômbia.

A cada 100.000 habitantes, atribui-se às condições domiciliares e à poluição ambiental $29,9 \%$ da taxa de mortalidade segundo Human development indices and indicators: 2018 Statistical Update (RELATÓRIO DO DESENVOLVIMENTO HUMANO 2018 | PNUD BRASIL, [s.d.]).

O índice de desenvolvimento humano ajustado às pressões do planeta, IDHP reúne informações sobre as emissões de dióxido de carbono e a pegada material dos países (medida de extração de matéria-prima no mundo para atender à demanda nacional). Nesse ranking, o Brasil se apresentou dez posições acima, já nações como a China recuaram.

A política ambiental é ponto de tensão entre o governo brasileiro e os países desenvolvidos que aderiram ao Acordo de Paris, que tem entre os seus objetivos orientar a migração para uma economia verde, a preservação da natureza e a redução drástica da emissão de gases de efeito estufa. O propósito é evitar que a elevação da 
temperatura comprometa a vida humana e de todas as espécies do planeta (A IMPORTÂNCIA DO MEIO AMBIENTE, [s.d.]).

A nação acumula recordes diários de elevação do número de novos casos diagnosticados com COVID19, bem como do número de óbitos em $24 \mathrm{hs}$. A pandemia assola a economia brasileira, a população empobrece a cada dia e a campanha de vacinação ainda não surtiu efeitos significativos em seu controle.

\subsection{Desafios}

Considerando-se as grandes Políticas Nacionais (saúde da criança e do adolescente; mulher/gestante; homem, idoso; minorias: população em situação de rua, LGBTQ+, indígenas e quilombolas, população rural, imigrantes, pessoa com deficiência; saúde mental entre outros) o maior desafio é fazer as Políticas saírem do papel, porque elas já contemplam as demandas específicas da população e elencam ações e tecnologias de cuidados que visam a prevenção e promoção de saúde, colocá-las em prática é o mais difícil.

\subsubsection{Formação dos profissionais}

A reestruturação da atenção primária fundamentada na ESF mostra o atrelamento da PNAB com a Política Nacional de Promoção da Saúde. Manter a saúde ao invés de recuperá-la é o foco! É necessário toda uma nova visão, por parte dos profissionais da saúde, para que estejam preparados para um jeito novo de trabalhar na saúde. Portanto, a Educação Continuada, prevista na PNAB tem papel crucial na concretização da promoção da saúde. Esta temática é encontrada no artigo 5 da PNAB (DO PROCESSO DE TRABALHO NA ATENÇÃO BÁSICA), em seu inciso XIX, no qual fica explícito que a aprendizagem deve transformar as práticas dos trabalhadores da saúde.

Tomando-se a evolução das práticas pedagógicas nas instituições formadoras de profissionais de saúde, durante a última metade do século $X X$, pode-se observar ações que vêm ao encontro do aperfeiçoamento desta formação mais centrada na atenção primária. A Organização Pan-Americana da Saúde, em 1972, propôs a construção de um modelo alternativo para explicar o processo saúde-doença. Assim os modelos explicativos na prática pedagógica passam a considerar as inter-relações entre 0 conceito de saúde, os modos de produção e as formações socioeconômicas; as interrelações entre a organização das ações de saúde, os modos de produção e as formações

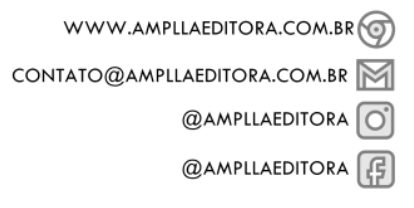


socioeconômicas e os conceitos de saúde, ocorrendo investigações históricas sobre a formação, o desenvolvimento e a consolidação das organizações práticas e da educação médica no continente latino-americano (BRASIL - OPAS/OMS | ORGANIZAÇÃO PANAMERICANA DA SAÚDE, [s.d.]). A preocupação teórico-metodológica se evidencia tanto na busca do entendimento do processo saúde-doença como no estudo da organização social das práticas de saúde.

Tomando como exemplo a odontologia, a adição das disciplinas de ciências sociais (sociologia, antropologia e psicologia) na Lei de Diretrizes e Base 5692/71, bem como do estudo de problemas brasileiros e a adição da disciplina de metodologia científica ao currículo mínimo, além de atividades extramuros, significou um avanço na aproximação da universidade com a realidade social brasileira e a pesquisa, mas permaneceu a tendência ao ensino acadêmico, voltado para a formação técnicoprofissional, sem alterar-se a estrutura curricular, o que ocorreu com a Lei de Diretrizes e Bases da Educação Nacional (LDB) 9.394, de 20 de dezembro de 1996 (MALTAGLIATI; GOLDENBERG, 2007).

Apesar do maior enfoque em atenção primária e prática médica generalista, o Sistema Único de Saúde (SUS) ainda carrega muito de seu passado hospitalocêntrico e dependente de especialistas. O Ministério da Educação e o Ministério da Saúde procuraram alterar a prevalência dessa característica, com a criação das Diretrizes Curriculares Nacionais (DCN) do curso de graduação em medicina, emitidas pelo Conselho Nacional de Educação. As DCN visaram a capacitação do médico nos diferentes níveis de atenção, especialmente primário e secundário, fomentando a aptidão desses profissionais para promover, recuperar e reabilitar a saúde, a fim de prevenir agravos.

O mínimo de $30 \%$ da carga horária prevista para o internato médico da Graduação em Medicina será desenvolvido na Atenção Básica (MINISTÉRIO DA EDUCAÇÃO CONSELHO NACIONAL DE EDUCAÇÃO CÂMARA DE EDUCAÇÃO SUPERIOR, [s.d.]). Portanto, a reforma determinada pelas DCN do curso de graduação em medicina estabeleceu como eixo do modelo didático-assistencial a atenção primária à saúde (CHEHUEN NETO et al., 2019).

Foi observado o expressivo aumento de profissionais dedicados à Atenção Primária à Saúde (APS) ao longo dos anos, sendo esse um importante facilitador do acesso e da utilização dos serviços de saúde. A APS no Brasil reduziu a mortalidade 
infantil e a adulta para algumas condições de saúde sensíveis à atenção primária, melhorou a equidade do acesso e reduziu hospitalizações desnecessárias (GOMES; GUTIÉRREZ; SORANZ, 2020).

Infelizmente observou-se que $82,5 \%$ dos alunos de medicina do estudo de Chehuen Neto estão contra a obrigatoriedade de atuar dois anos em medicina da família antes da residência médica, sendo este um desafio a ser superado. Alguns países mostram bons resultados por meio de incentivos na atuação em atenção primária, como por exemplo, bonificações. O alcance de metas em promoção de saúde como: número de pacientes que param de fumar, hipertensos controlados, controle glicêmico e do peso corpóreo resultam em bonificações financeiras aos médicos. Outra reforma atrativa poderia ser alterações no plano de carreira. Tais estratégias não são exclusividade da profissão médica, sendo que poderiam causar bons resultados se aplicadas nas demais profissões de saúde.

\subsubsection{Abrangência e cobertura}

De acordo com o site E-gestor, que contém os dados de Informação e gestão da Atenção Básica, a cobertura populacional por equipes da ESF em dezembro de 2020 foi estimada em 63,62\%, e por equipes da Atenção Básica a cobertura é de 76,08\%. Tais dados são oriundos do Sistema do Cadastro Nacional de Estabelecimentos de Saúde (SCNES) e do IBGE. A cobertura, como indicador, foi selecionado considerando-se a centralidade da Atenção Básica no SUS, com a proposta de constituir-se como ordenadora do cuidado nos sistemas locorregionais de Saúde e eixo estruturante de programas e projetos; além de favorecer a capacidade resolutiva e os processos de territorialização e regionalização em saúde (E-GESTOR AB, [s.d.]). A cobertura universal é preponderante para a reorganização de sistemas locais de saúde e para a reversão atual do modelo hegemônico de assistência.

Há que se distinguir cobertura estimada da atenção primária - muitas vezes interpretada como equivalente a acesso - das múltiplas dimensões contidas no termo acesso. Neste indicador, a cobertura é entendida como a possibilidade quantificada de obter o cuidado, podendo não ser efetivada por razões diversas, como é o caso das barreiras encontradas pelos indivíduos na busca do cuidado. Municípios com menor porte populacional apresentam maiores coberturas, o que não se traduz, 
necessariamente, em maior acessibilidade geográfica ou organizacional (GARNELO et al., 2018).

Gomes et al. 2020 consideram que a inclusão da ESF para a população ribeirinha e fluvial, a equipe de Consultório na Rua, o Núcleo de Apoio a Saúde da Família (Nasf), o Programa Saúde na Escola (PSE) e a Academia da Saúde foram inclusões importantes da revisão da PNAB 2017 para a ampliação do acesso e o fomento à resolutividade da atenção em saúde (GOMES; GUTIÉRREZ; SORANZ, 2020).

\subsubsection{Pandemia COUID19}

Quando a Organização Mundial da Saúde (OMS) declarou a pandemia de COVID19 como emergência de Saúde Pública de importância Internacional , a Secretaria de Atenção Primária à Saúde voltou suas ações para o enfrentamento do novo coronavírus junto com o Centro de Operações de Emergência em Saúde Pública (COECOVID-19), principalmente para nortear a atuação do Ministério da Saúde (MS) quanto à emergência de Saúde Pública no âmbito da Atenção Primária (PORTAL DA SECRETARIA DE ATENÇÃO PRIMÁRIA À SAÚDE, [s.d.]).

Mesmo reconhecendo as diversas fragilidades de atuação das equipes, ressaltase que a ESF é o modelo mais adequado por seus atributos de responsabilidade territorial e orientação comunitária, para apoiar as populações em situação de isolamento social pois, mais do que nunca, é preciso manter o contato e o vínculo das pessoas com os profissionais responsáveis pelo cuidado à saúde. Cabe à APS a vigilância no território, a atenção com os doentes por COVID, o suporte social à grupos vulneráveis e por último, mas não menos importante, a continuidade das ações próprias da APS (MEDINA; MAGALHÃES DE MENDONÇA; AQUINO, [s.d.]).

\subsubsection{Minorias}

O que constitui uma minoria não é sua quantidade numérica, por si só, mas sim um conjunto de elementos como: não dominância; cidadania e; solidariedade entre seus membros para que sejam preservadas as suas culturas, tradições, religião ou idiomas (TREVIZAN e AMARAL, 2010). Séguin, 2002, relaciona as minorias aos grupos denominados vulneráveis, pois são grupos que sofrem discriminações e são vítimas de intolerância. Paula et al., associa minoria à situação de inferioridade ou subordinação em relação ao outro grupo, chamado majoritário ou dominante (2017). 
Pessoas de grupos minoritários demandam tratamento diferenciado para se enquadrarem à sociedade e terem garantidos seus direitos fundamentais. O papel do Estado é fundamental neste sentido, elaborando e implantando Políticas Públicas que ofereçam ações afirmativas, diminuindo as barreiras das desigualdades. No SUS, um dos princípios norteadores que visa eliminar as barreiras das desigualdades é a equidade. Equidade é reconhecer que há condições e necessidades diferentes de vida e saúde entre as pessoas e que, o direito à saúde perpassa por essas diferenças e deve atender a diversidade (FIOCRUZ, PenseSUS).

Um estudo que relaciona minorias, vulnerabilidade, risco e adesão na saúde coletiva, aponta que um desafio importante à saúde pública é construir e oferecer tecnologias, dispositivos e instrumentos de cuidado que respondam às diversas necessidades dos grupos sociais (BERTOLOZZI et al., 2009).

Dentre as Políticas Públicas de Saúde específicas de grupos minoritários, destacase três que se mostram desafiadoras para a atenção primária: população em situação de rua (PSR), indígenas e população LGBT.

Situação de rua é um fenômeno que ocorre como resultado de diversos fatores como: fatores estruturais (falta de moradia, trabalho e renda); fatores biográficos individuais (doenças mentais e uso/abuso/dependência de álcool e outras drogas, quebra de vínculos familiares) e; desastres naturais (terremotos, desmoronamentos, inundações, etc) (LOPES, 2006).

A População em Situação de Rua (PSR) é um grande desafio ao SUS no que toca os princípios de universalidade, equidade e integralidade, pois esse grupo minoritário encontra-se à margem da rede de atenção à saúde (PAIVA et al., 2015). Apesar de ser um problema antigo, as ações que visam sanar as demandas da PSR são recentes e, em diversas regiões do país, encontram-se inexistentes ou insuficientes.

Alguns marcos são importantes de serem destacados: o I e o II Encontros Nacionais da População em Situação de Rua; a Política Nacional de Assistência Social - PNAS (2005) que incluiu a PSR no âmbito da proteção social especial; a Política Nacional para a População em Situação de Rua - PNPSR (2009) que se constituiu na primeira iniciativa nacional de reconhecimento dos direitos dessa população e, por fim, o Consultório na Rua (PAIVA et al., 2015). 
O Ministério da Saúde (2014) divulgou resultados da Pesquisa Nacional sobre a População em Situação de Rua, destacando QUE:

- $\quad 29,7 \%$ dos entrevistados afirmaram ter algum problema de saúde.

- Os problemas mais prevalentes foram: hipertensão $(10,1 \%)$, problemas psiquiátricos/mental (6,1\%), HIV/ aids (5,1\%), e problemas de visão/cegueira $(4,6 \%)$.

- $18,7 \%$ dos entrevistados afirmaram que fazem uso de algum medicamento, os Postos/Centros de Saúde são os principais meios de acesso a eles.

- $43,8 \%$ dos entrevistados afirmaram que procuram primeiramente 0 hospital/emergência quando estão doentes, e $27,4 \%$ procuram o posto de saúde.

- Os locais mais usados pelas Pessoas em Situação de Rua para tomar banho são a rua $(32,6 \%)$, os albergues/abrigos $(31,4 \%)$, os banheiros públicos $(14,2 \%)$ e a casa de parentes ou amigos $(5,2 \%)$.

- Os locais mais usados pelas pessoas em situação de rua para fazer suas necessidades fisiológicas são a rua (32,5\%), os albergues/abrigos $(25,2 \%)$, os banheiros públicos $(21,3 \%)$, os estabelecimentos comerciais $(9,4 \%)$ e a casa de parentes ou amigos (2,7\%).

A PSR apresenta condições sociais e de saúde peculiares e precárias, inclusive no que se refere ao acesso aos direitos sociais básicos e constitucionais. Abreu e Oliveira apontam que a falta de acesso ao mercado formal de trabalho, à educação de qualidade, aos serviços de saúde entre outros, materializam os pontos de atenção que devem ser sanados nas políticas públicas voltadas para essa minoria (2016).

Como forma de ultrapassar os obstáculos, o Consultório na Rua se apresenta como uma potente estratégia de trabalho em saúde à PSR. Cabe, em seu trabalho cotidiano, abrir brechas nas endurecidas estruturas da saúde e de outras políticas sociais brasileiras, para que todos, sem exceção, sejam acolhidos e possam usufruir daquilo que é de todos, o bem público (ABREU e OLIVEIRA, 2016).

Os povos indígenas brasileiros, ou povos originários, são compostos por 305 etnias, falam 274 línguas e totalizam aproximadamente 897 mil indivíduos, segundo o IBGE (2010). Presentes em todas as Unidades Federativas do Brasil, cada povo possui uma cultura própria, há povos que convivem em centros urbanos, meios rurais e 
também, outros que não mantém contato algum com o "homem branco", os chamados povos isolados.

Os povos indígenas enfrentam várias ameaças à integridade de seus territórios, saberes, organização social e econômica, muitos deles estão seguindo para o desaparecimento. Por exemplo, no estado de Rondônia, onde há intensa exploração madeireira, garimpeira e agropecuária, tem-se observado altíssima mortalidade (BRASIL, 2002).

Com tamanha diversidade, a saúde dos povos indígenas se constitui um grande desafio para o SUS, para tanto foi criada uma secretaria específica, em 2010, dentro do Ministério da Saúde para elaborar e implantar políticas públicas para essa minoria, a Secretaria Especial de Saúde Indígena (SESAI) (FUNAI, s.d.).

A Política Nacional de Atenção à Saúde dos Povos Indígenas tem por objetivo central:

Garantir aos povos indígenas o acesso à atenção integral à saúde, de acordo com os princípios e diretrizes do Sistema Único de Saúde, contemplando a diversidade social, cultural, geográfica, histórica e política de modo a favorecer a superação dos fatores que tornam essa população mais vulnerável aos agravos à saúde de maior magnitude e transcendência entre os brasileiros, reconhecendo a eficácia de sua medicina e o direito desses povos à sua cultura (BRASIL, 2002, p. 13).

Foram criados 34 Distritos Sanitários Especiais Indígenas (DSEI), com função central de assegurar a assistência médica e odontológica à população indígena. As DSEls foram instituídas de acordo com áreas territoriais indígenas, seguindo os princípios de descentralização e hierarquização do SUS. Contemplando unidades de saúde nas comunidades indígenas, polos-base em territórios indígenas que deveriam comportar as Casas de Saúde Indígena (CASAIs), criadas em áreas estratégicas juntas à localização dos DSEls ou em outros centros urbanos de referência para receber pacientes indígenas encaminhados para exames e tratamentos de casos de média e alta complexidades (CARDOSO, 2014).

Em 2009 foi publicado o relatório Diagnóstico Situacional do Subsistema de Saúde Indígena, que apontou alguns problemas enfrentados, destaca-se:

- Modelo assistencial ainda centrado na concepção médico-curativa e não na prevenção e promoção de saúde; 
- Indicadores apontam que o modelo adotado não tem conseguido sanar os principais problemas de saúde, pois as DSEls estão divididas a partir da lógica geográfica apenas, não considerando as especificidades das necessidades e problemas de saúde;

- Alto índice de encaminhamentos para consultas especializadas e internações hospitalares, indicando diminuta resolutividade nas ações prestadas no nível da APS. Além de ênfase na medicalização das populações indígenas (Institute of Development Studies, 2009).

A população LGBT (lésbicas, gays, bissexuais, travestis e transexuais) é vulnerável por diversos fatores culturais, religiosos, ideológicos, entre outros, o que afeta o acesso aos serviços públicos de saúde e também os atendimentos em direitos humanos. A homofobia, ódio explícito, persistente e generalizado, manifesta-se numa escala de violências que abrange desde agressões verbais incluídas nos tipos penais contra a honra até extremos episódios de violência física, que podem culminar na morte da vítima (CARDOSO e FERRO, 2012).

O Brasil registrou, de janeiro a maio de 2019, 141 mortes de pessoas LGBT, foram 126 homicídios e 15 suicídios, o que representa a média de uma morte a cada 23 horas (SOUSA e ARCOVERDE, 2019).

Há dificuldade de se obter dados reais sobre a violência contra a população LGBT, pois esses crimes nem sempre são monitorados e sistematizados. Um dos motivos para a subnotificação destes crimes encontra-se ligado ao preconceito enraizado e disseminado pelas instituições públicas refletindo na falta de registros e nas investigações pouco rígidas por parte da polícia. Estima-se, portanto, que o número de vítimas da homofobia seja muito maior do que os dados revelados pelos indicadores divulgados pelo Governo e pela mídia (MOTT e CERQUEIRA, 2000).

O Disque Defesa Homossexual (DDH), iniciativa pioneira para sanar o problema da subnotificação dos crimes de homofobia, foi criado no Rio de Janeiro. A implantação do DDH proporcionou visibilidade à temática da homofobia, explicitando as violências que ocorrem nas diversas instituições e redes sociais como a família, comunidade, a escola, o trabalho, serviços públicos, etc. (CARDOSO e FERRO, 2012).

A Política Nacional de Saúde Integral LGBT, reconhece a ligação entre os efeitos da discriminação e da exclusão e o processo de saúde-doença dessa população. 
Propondo em suas diretrizes e objetivos as mudanças na determinação social da saúde, com vistas à redução das desigualdades relacionadas à saúde destes grupos sociais (BRASIL, 2013).

Para tanto esta Política propõe ações voltadas para a "promoção, prevenção, recuperação e reabilitação da saúde, além do incentivo à produção de conhecimentos e o fortalecimento da representação do segmento nas instâncias de participação popular" (BRASIL, 2013, p.8).

Cardoso e Ferro (2012) apontam que, dentro das diversidades encontradas na população LGBT, há alguns desafios para a saúde pública, dentre eles:

a) Lésbicas e Gays:

Diminuta procura aos serviços de saúde que agravam doenças como câncer de mama e de colo de útero;

Motivos que levam à baixa procura dos serviços de saúde: discriminação e despreparo profissional para receber e lidar com as especificidades desse público, associação do público homossexual com o HIV/AIDS;

Uso abusivo/dependência de álcool, tabaco e outras drogas;

Doenças sexualmente transmissíveis;

Sofrimentos psíquicos graves, incluindo as ideações/tentativas de suicídio.

b) Travesti e Transexuais:

Além dos problemas acima citados, que também afetam essa população, somase a patologização da transexualidade, na Classificação Internacional das Doenças (CID10) o Transtorno de Identidade Sexual, que persiste mesmo após a retirada desse transtorno na versão CID11 em 2018, passando a ser chamado de incongruência de gênero (OMS, [s.d.]);

Dificuldade de acesso aos tratamentos de readequação de gênero, compostos desde tratamentos hormonais até procedimentos cirúrgicos, levando esse público a realizar procedimentos clandestinos arriscados (exemplo da injeção de silicone industrial no corpo) e automedicação (exemplo ingestão de hormônios sem orientação médica) podendo ocasionar agravos à saúde, incluindo o risco de morte;

Falta de acesso à escolarização e profissionalização, mantendo esse público ligado fortemente a trabalhos sexuais. 


\subsection{Possibilidades}

\subsubsection{Gestão}

Em pesquisa científica conduzida em Manaus, avaliando a implantação do Programa Saúde da Família (PSF) entre os anos 2001 e 2006, foi observado que o cenário político da gestão do PSF foi marcado pela disputa de hegemonia entre os governos estaduais e municipais pelo controle da AB (SILVA; GARNELO; GIOVANELLA, 2010). Também não foram encontradas programação de estratégias que favorecessem a descentralização do planejamento e gestão local na rede de USF no município.

Pode-se elencar uma série de falhas da gestão a seguir. Uso incipiente dos instrumentos de planejamento, baixa qualidade técnica na programação instituída, infraestrutura inadequada, qualificação precária e tomada de decisão pouco sustentada por procedimentos racionais de planejamento.

A peça chave em gestão parece ser o planejamento e ações idôneas. O planejamento deve ser baseado no perfil epidemiológico da população atendida, bem como suas demandas e necessidades prioritárias. A APS deve primar pela busca de atividades inovadoras e intersetoriais.

\subsubsection{Participação social}

A despeito da Lei 8142 determinar sobre a obrigatoriedade da participação da comunidade na gestão do Sistema Único de Saúde (SUS) (L8142, [s.d.]), a participação social da comunidade ainda deixa muito a desejar. $\mathrm{O}$ fato da comunidade participar no sistema de saúde é visto como condição fundamental para o exercício pleno da saúde, capaz de promover equidade e de transformar a atenção à saúde (SOUSA COELHO; JOSÉ HEMETÉRIO ANDRADE, [s.d.]). No entanto, o que se observa é que a participação e o controle social não estão efetivados em plenitude. Contribui para isso a falta de informação e a existência de interesses múltiplos para que a população não saiba que possui direitos e que pode exigi-los (ROLIM et al., 2013).

A sociedade (ampla) e a comunidade (local) devem contestar o Estado participando de Movimentos Sociais. Estes movimentos representam legalmente a voz de determinados grupos sociais que buscam, de forma solidária e democrática, defender seus interesses e direitos, a exemplo dos movimentos de portadores de necessidades 
especiais, dos indígenas, dos homossexuais, de saúde mental, dentre outros (PARTICIPAÇÃO COMUNITÁRIA E CONTROLE SOCIAL, [s.d.]).

Compreende-se que a participação social no SUS, com a participação popular presente em todas as esferas de gestão do SUS, legitima os interesses da população no exercício do controle social. Ao transferir poderes a seus representantes, o cidadão define uma carga de participação da sociedade nas decisões sobre as políticas públicas, ressaltando que estes responderão não apenas aos interesses pessoais e sim do coletivo. Assim, ao falar de controle social não se pretende apenas que se consigam implantar mecanismos que reduzam, eliminem ou previnam os desperdícios, os desvios e as iniquidades na aplicação dos recursos públicos, mas também assegurar que os gestores públicos se comprometam com a excelência na concepção e implementação dos programas, projetos, ações e serviços de saúde (ROLIM et al., 2013). Cabe nesta visão pró-ativa do cidadão politizado a modificação do termo arraigado entre os profissionais de saúde, o paciente, substituindo-o pelo termo usuário do serviço.

Outro ponto levantado na pesquisa de Rolim et al. diz respeito quanto à efetividade do controle social sobre as políticas públicas incorrer também em nível macroeconômico e político, já que as definições em torno dos orçamentos públicos são resultados das negociações com os organismos financeiros internacionais (refinanciamento da dívida externa e da contratação de novos empréstimos).

Reconhece-se que para o alcance do efetivo controle social no SUS, os desafios e as dificuldades a serem superados são diversos, mas deve-se seguir o exemplo dos variados movimentos sociais históricos que mudaram o curso da atenção em saúde no nosso País.

\section{CONSIDERAÇÔES FInRIS}

Em tempos de Pandemia, crise econômica e outros problemas sociais no Brasil, inúmeros são os desafios enfrentados pelo SUS, especialmente no que toca a Atenção Primária à Saúde. Ao longo deste capítulo alguns deles foram destacados. Os avanços na Saúde desde a Constituição de 88 e a implantação do SUS são inegáveis e devem servir de norte para que a luta por uma saúde de qualidade a todos os brasileiros continue. Apontou-se anteriormente que as Políticas já existentes são a principal potência e, também, o principal desafio a ser enfrentado. Tirá-las do papel e torná-las 
prática já representaria um forte avanço, finaliza-se este capítulo aqui, com este convite/provocação: a saúde, representada aqui pelo SUS, é direito de todos e dever do Estado, cabendo a todos os brasileiros a função de defendê-lo.

\section{REFERÊCCIAS}

A importância do meio ambiente. [s.d.]. Disponível em: https://www.correiobraziliense.com.br/opiniao/2020/11/4890515-aimportancia-do-meio-ambiente.html. Acesso em: 5 mar. 2021.

ABREU, Deivid; OLIVEIRA, Walter Ferreira de. Atenção à saúde da população em situação de rua: um desafio para o Consultório na Rua e para o Sistema Único de Saúde. Cadernos de Saúde Pública. 2016. Disponível em: https://www.scielosp.org/article/csp/2017.v33n2/e00196916/ . Acesso: 06 Mar. 2021.

BERTOLOZZI, Maria Rita;NICHIATA, Lucia Yasuko Izumi; TAKAHASHI, Renata Ferreira; CIOSAK, Suely Itsuko; HINO, Paula; VAL, Luciane Ferreira do; GUANILLO, Mónica Cecília de La Torre Uguarte; PEREIRA, Érica Gomes. Os conceitos de vulnerabilidade e adesão na Saúde Coletiva. Rev. esc. enferm. USP, São Paulo , v. 43, n. spe2, p. 1326-1330, 2009 . Disponível em: http://www.scielo.br/scielo.php?script=sci_arttext\&pid=S008062342009000600031\&lng=en\&nrm=iso>. Acesso: 06 mar. 2021.

BRASIL. Fundação Nacional de Saúde. Política Nacional de Atenção à Saúde dos Povos Indígenas. - 2a edição - Brasília: Ministério da Saúde. Fundação Nacional de Saúde, $2002 . \quad 40 \quad$ p. $\quad$ Disponível em: https://bvsms.saude.gov.br/bvs/publicacoes/politica_saude_indigena.pdf Acesso: 07 Mar. 2021.

BRASIL. Ministério da Saúde. Secretaria de Gestão Estratégica e Participativa. Departamento de Apoio à Gestão Participativa. (2013). Política Nacional de Saúde Integral de Lésbicas, Gays, Bissexuais, Travestis e Transexuais / Ministério da Saúde, Secretaria de Gestão Estratégica e Participativa, Departamento de Apoio à Gestão Participativa. Brasília : 1. ed., 1. reimp.

BRASIL. Ministério da Saúde. Secretaria de Gestão Estratégica e Participativa, Departamento de Apoio à Gestão Participativa. Saúde da população em situação de rua : um direito humano / Ministério da Saúde, Secretaria de Gestão Estratégica e Participativa, Departamento de Apoio à Gestão Participativa. Brasília: Ministério da Saúde, 2014.

Brasil - OPAS/OMS I Organização Pan-Americana da Saúde. [s.d.]. Disponível em: https://www.paho.org/pt/brasil. Acesso em: 5 mar. 2021.

CARDOSO, Marina Denise. Saúde e povos indígenas no Brasil: notas sobre alguns temas equívocos na política atual. Cad. Saúde Pública, Rio de Janeiro, v. 30, n. 4, p. 
860-866, Apr. 2014 Disponível em: http://www.scielo.br/scielo.php?script=sci_arttext\&pid=S0102311X2014000400860\&lng=en\&nrm=iso. Acesso: 07 Mar. 2021.

CARDOSO, Michelle Rodrigues; FERRO, Luís Felipe. Saúde e população LGBT: demandas e especificidades em questão. Psicol. cienc. prof., Brasília , v. 32, n. 3, p. 552563, 2012 . Disponível em: http://www.scielo.br/scielo.php?script=sci_arttext\&pid=S141498932012000300003\&lng=en\&nrm=iso . Acesso: 07 Mar. 2021.

CHEHUEN NETO, José Antonio; FERREIRA, Renato Erothildes; ANDRADE, Andressa Carvalho Quinet De; OLIVEIRA, Jonas Munck De; BRESSER, Matheus; APOLINÁRIO, Matheus Magalhães; BARROS, Pedro Murari De. Reforma curricular e intenção profissional de especialização médica. Revista Bioética, [S. I.], v. 27, n. 4, p. 630-642, 2019. DOI: 10.1590/1983-80422019274347. Disponível em: http://dx.doi.org/10.1590/1983-80422019274347. Acesso em: 5 mar. 2021.

Coren-RS | Revisão da PNAB está em consulta pública. Enfermagem, PARTICIPE! [s.d.]. Disponível em: https://www.portalcorenrs.gov.br/site_antigo/index.php?categoria=servicos\&pagina=noticiasler\&id=5998. Acesso em: 5 mar. 2021.

Declaração de Alma Ata sobre Cuidados Primários. . [s.l: s.n.].

Desconsiderando evidências científicas e consulta pública, Ministério da Saúde aprova rebaixamento da PNAB - ABRASCO. [s.d.]. Disponível em: https://www.abrasco.org.br/site/noticias/movimentos-

sociais/desconsiderando-evidencias-cientificas-e-consulta-publica-ministerioda-saude-aprova-rebaixamento-da-pnab/30456/. Acesso em: 5 mar. 2021.

e-Gestor

AB.

[s.d.].

Disponível

em: https://egestorab.saude.gov.br/paginas/acessoPublico/relatorios/relHistoricoC oberturaAB.xhtml. Acesso em: 5 mar. 2021.

FIOCRUZ. [s.d]. Portal Pense SUS. Disponível em: https://pensesus.fiocruz.br/equidade. Acesso: 05 mar. 2021.

FUNAI. [s.d]. http://www.funai.gov.br/index.php/saude . Acesso em: 05 Mar. 2021.

GARNELO, Luiza; LIMA, Juliana Gagno; ROCHA, Esron Soares Carvalho; HERKRATH, Fernando José. Acesso e cobertura da Atenção Primária à Saúde para populações rurais e urbanas na região norte do Brasil. Saúde em Debate, [S. I.], v. 42, n. spe1, p. 81-99, 2018. DOI: 10.1590/0103-11042018s106. Disponível em: http://www.scielo.br/scielo.php?script=sci_arttext\&pid=S0103$11042018000500081 \&$ Ing=pt\&tlng=pt. Acesso em: 5 mar. 2021.

GOMES, Clarice Brito e Souza; GUTIÉRREZ, Adriana Coser; SORANZ, Daniel. Política Nacional de Atenção Básica de 2017: análise da composição das equipes e cobertura nacional da Saúde da Família. Ciência \& Saúde Coletiva, [S. I.], v. 25, 
n. 4, p. 1327-1338, 2020. DOI: 10.1590/1413-81232020254.31512019. Disponível em: http://www.scielo.br/scielo.php?script=sci_arttext\&pid=S141381232020000401327\&tlng=pt. Acesso em: 5 mar. 2021.

Institute of Development Studies; Saúde Sem Limites; Centro Brasileiro de Análise e Planejamento. Diagnóstico situacional do Subsistema de Saúde Indígena relatório inicial (revisado). Brasília: Consórcio Institute of Development Studies/Saúde Sem Limites/Centro Brasileiro de Análise e Planejamento; 2009.

KREIN, José Dari. O capitalismo contemporâneo e a saúde do trabalhador Contemporary capitalism and worker's healthRev. bras. Saúde ocup. [s.l: s.n.].

L8142. [s.d.]. Disponível em: http://www.planalto.gov.br/ccivil_03/leis//8142.htm. Acesso em: 5 mar. 2021.

LOPES, Maria Lucia. (2006). Mudanças recentes no mundo do trabalho e o fenômeno População em Situação de Rua no Brasil - 1995 a 2005. Brasília.

MALTAGLIATI, Luciana Ávila; GOLDENBERG, Paulete. Curriculum reform and research in dentistry at the undergraduate level: History under construction. In: HISTORIA, CIENCIAS, SAUDE - MANGUINHOS 2007, Anais [...]. : Fundação Oswaldo Cruz, 2007. p. 1329-1340. DOI: 10.1590/s0104-59702007000400012. Disponível em: http://naeg.prg.usp.br/infousp/usp/. Acesso em: 5 mar. 2021.

MEDINA, Maria Guadalupe; MAGALHÃES DE MENDONÇA, Maria Helena; AQUINO, Rosana. Atenção primária à saúde em tempos de COVID-19: o que fazer? ¿qué debemos hacer? Lígia Giovanella 2 Aylene Bousquat 3 Comitê Gestor da Rede de Pesquisa em Atenção Primária à Saúde da Abrasco 4 ESPAÇO TEMÁTICO: COVID19-CONTRIBUIÇÕES DA SAÚDE COLETIVA. [S. I.], [s.d.]. DOI: 10.1590/0102$311 \times 00149720$.

\section{MINISTÉRIO DA EDUCAÇÃo CONSELHO NACIONAL DE EDUCAÇÃO CÂMARA DE} EDUCAÇÃO SUPERIOR. . [s.l: s.n.].

Ministério

da Saúde.

[s.d.].

Disponível

em: http://bvsms.saude.gov.br/bvs/saudelegis/gm/2006/prt0648_28_03_2006_co mp.html. Acesso em: 5 mar. 2021a.

Ministério

da Saúde.

[s.d.].

Disponível

em: http://bvsms.saude.gov.br/bvs/saudelegis/gm/2011/prt2488_21_10_2011.htm I. Acesso em: 5 mar. 2021b.

Ministério

$$
\text { da Saúde. }
$$

[s.d.].

Disponível

em: http://bvsms.saude.gov.br/bvs/saudelegis/gm/2017/prc0002_03_10_2017.htm I. Acesso em: 5 mar. 2021c.

MOTT, Luiz Roberto de; CERQUEIRA, Marcelo. (2000). Causa mortis: homofobia. Violação de direitos humanos e assassinato de homossexuais no Brasil. Salvador, BA: Editora Grupo Gay da Bahia. 
OMS. 19 de junho de 2018. OMS anuncia retirada dos transtornos de identidade de gênero de lista de saúde mental. Disponível em: https://unaids.org.br/2018/06/oms-anuncia-retirada-dos-transtornos-deidentidade-de-genero-de-lista-de-saude-mental/ . Acesso: 07 Mar. 2021.

PAIVA, Irismar Karla Sarmento; LIRA, Cindy Damaris Gomes; JUSTINO, Jéssica Micaele Rebouças; MIRANDA, Moêmia Gomes de Oliveira; SARAIVA, Ana Karinne de Moura. Direito à saúde da população em situação de rua: reflexões sobre a problemática. Ciênc. saúde coletiva, Rio de Janeiro , v. 21, n. 8, p. 2595-2606, Ago. 2016 . Disponível em: http://www.scielo.br/scielo.php?script=sci_arttext\&pid=S141381232016000802595\&Ing=en\&nrm=iso. Acesso: 06 Mar. 2021.

PARTICIPAÇÃO COMUNITÁRIA E CONTROLE SOCIAL. . [s.I: s.n.].

PAULA, Carlos Eduardo Artiaga et al. Vulnerabilidade legislativa de grupos minoritários. Ciênc. saúde coletiva, Rio de Janeiro, v. 22, n. 12, p. 3841-3848, Dez. 2017. Disponível em: http://www.scielo.br/scielo.php?script=sci_arttext\&pid=S141381232017021203841\&Ing=en\&nrm=iso. Acesso: 06 Mar. 2021.

Portal da Secretaria de Atenção Primária a Saúde. [s.d.]. Disponível em: https://aps.saude.gov.br/politicas/pnan/diretrizes. Acesso em: 8 set. 2020.

Relatório do Desenvolvimento Humano 2018 | PNUD Brasil. [s.d.]. Disponível em: https://www.br.undp.org/content/brazil/pt/home/library/idh/relatorios-dedesenvolvimento-humano/relatorio-do-desenvolvimento-humano-2018.html. Acesso em: 5 mar. 2021.

ROLIM, Leonardo Barbosa; DE SÁ, Rachel; LUNA, Barreto; CRUZ, Callou; JIMENA, Karla; DE, Araújo; SAMPAIO, Jesus. Participação popular e o controle social como diretriz do SUS: uma revisão narrativa Social control and popular participation as a guideline of SUS: a narrative reviewSaúde em Debate. [s.I.] : Centro Brasileiro de Estudos de Saúde, 2013.

SÉGUIN, Elida. Minorias e grupos vulneráveis: uma abordagem jurídica. Rio de Janeiro: Forense, 2002.

SILVA, Nair Chase Da; GARNELO, Luiza; GIOVANELLA, Ligia. Extensão de Cobertura ou Reorganização da Atenção Básica? A trajetória do Programa de Saúde da Família de Manaus-AMSaúde e Sociedade. [s.l.] : Faculdade de Saúde Pública, Universidade de São Paulo. Associação Paulista de Saúde Pública., 2010.

SOUSA, Viviane; ARCOVERDE, Léo. Brasil registra uma morte por homofobia a cada 23 horas, aponta entidade LGBT. G1. São Paulo, 15 de Maio de 2019. Disponível em: https://g1.globo.com/sp/sao-paulo/noticia/2019/05/17/brasil-registra-umamorte-por-homofobia-a-cada-23-horas-aponta-entidade-lgbt.ghtml . Acesso: 07 Mar. 2021. 
SOUSA COELHO, Juliana; JOSÉ HEMETÉRIO ANDRADE, Rua. Construindo a Participação Social no SUS: um constante repensar em busca de equidade e transformação 1 Building Social Participation on the Brazilian Health System: a constant rethinking that seeks fairness and transformation Resumo. [s.l: s.n.].

TREVIZAN, Ana Flávia; AMARAL, Sérgio Tibiriçá. (2010). Diferenciação entre minorias e grupos vulneráveis. Disponível em http://intertemas.toledoprudente.edu.br/index.php/ETIC/article/download/23 19/1814 . Acesso: 06 mar. 2021. 


\title{
CAPÍTULO IX
}

\section{A RESIDÊRCIA MUULTIPROFISSIONAL EET SAÚDE DA FAMIÍLIAE COMUUIIDADE COMO IISTRUMTENTO PARA FORTALECIMEETTO E DEFESA DO SISTEMRA ÚIICO DE SAÚDE}

\author{
DDI: 10.51859/AMPLLA.APS276.II21-9
}

\author{
Fernanda Thayná de Souza Pinheiro ${ }^{1}$ \\ João Paulo Xavier Silva ${ }^{2}$
}

\begin{abstract}
${ }^{1}$ Enfermeira. Residente em Saúde da Família e Comunidade pela Escola de Saúde do Ceará - ESP /CE.
${ }^{2}$ Enfermeiro. Doutorando em Cuidados Clínicos em Enfermagem e Saúde pela Universidade Estadual do Ceará - UECE.
\end{abstract}

\section{RESUITO}

Desde a criação do Sistema Único de Saúde (SUS) por intermédio da Constituição Federativa do Brasil no ano de 1988, diversas medidas contrárias à sua efetivação têm, ao longo dos anos, sido implementadas. Por tanto, torna-se inevitável e essencial elucidar caminhos para seu fortalecimento. Nesta ótica, objetiva-se com este estudo discutir aspectos históricos da construção da saúde, compreender o desmonte deste direito social e tecer discussões quanto a residência multiprofissional como instrumento formativo para manutenção do SUS. Os ideais sanitaristas de cunho popular necessitam ser afirmados para que independentemente dos entraves políticos e dos diferentes cenários sociais do país direitos essenciais, como o da saúde, não possam ser negados.

Palavras-chave: Sistema Único de Saúde. Atenção Primária à saúde. Residência Multiprofissional.

\section{IกTRODUÇก̃O}

O Sistema Único de saúde (SUS) foi criado há 30 anos pela Constituição Federativa do Brasil com um objetivo nunca antes visto, proporcionar o acesso a saúde de modo integral e equânime para todos os brasileiros e para os estrangeiros que estivessem no território. O desafio mais grandioso é firmar este direito social de modo gratuito (PAIM, 2018).

Este projeto já implementado não foi adquirido de modo espontâneo e tão pouco advindo de governantes, mas conquistado com lutas que mobilizaram diferentes classes sociais, indo de encontro ao capitalismo exercido por centenas de anos no processo saúde - doença, marcando a história com esta nova forma de fazer e pensar a 
saúde, sendo conhecido e reconhecido como o célebre movimento da Reforma Sanitária (BASTOS, 2020).

Por esse motivo, o SUS sofre ataques desde sua criação que descredibilizam, subfinanciam e gradualmente desmontam seus pilares. Sejam atuais ou não, tais ataques ao SUS e seus princípios promovem o comprometimento da efetividade de suas ações observado por uma conjuntura de medidas legislativas associado a discursos doutrinários e ideológicos que ferem o direito inalienável à saúde (SOUZA, 2020).

Neste sentido, tais lutas populares e consciência social que culminaram no que hoje é o maior sistema público do mundo são mais do que nunca essenciais para sua manutenção. A pandemia mundial do SARS-CoV-2 reacende esta discussão pois mesmo diante do desserviço do governo e do apoio de parte da população, em um cenário de insegurança e incerteza, o SUS é a melhor estratégia de enfrentamento (ARAUJO, 2020).

Parte integrante e atuante do SUS é a residência multiprofissional na modalidade lato sensu com ênfase em saúde da família, pois integram um ambiente que propicia o ato prático de vivência profissional com a formação para atenção primaria a saúde. Vale salientar a Atenção Básica ( $A B$ ) e seu importante papel com 48 mil Equipes de Saúde da Família (ESF), 31 mil Equipes de Saúde Bucal (ESB) e quase 290 mil Agentes Comunitários de Saúde (ACS) no ano de 2019 e, em 2020, formaram a linha de frente da crise realizando a triagem dos casos suspeitos, orientações para medidas de isolamento domiciliar, coletando exames e gerenciando a rede (ARAUJO, 2020).

Considerando a formação em saúde como um instrumento para além do preparo técnico, mas um ato político e de construção social, a formação no SUS e para o SUS, nos leva a questionarmos a relação entre a própria formação em saúde da família e os ganhos para o sistema, sejam em ações próximas ao cliente ou de manutenção política e de direito social deste bem público, sobretudo por se tratar de um coletivo de profissionais, em sua maioria, recém entregues pela universidade, sejam estas públicas ou privadas (PINHEIRO, 2020).

Acrescenta-se a esse contexto a perspectiva de formação integral em saúde, na relação teórico prática proposta nesse modelo formativo, que se articula às necessidades sociais em suas múltiplas dimensões (DA SILVA, 2020). Desse modo, o contexto do tema em questão elucida a necessidade de investigar a práxis laboral e 
formativa dos resistentes em saúde da família e comunidade e sua intersecção aos aspectos que se conformam sob a égide institucional do SUS e das políticas públicas.

No âmbito da residência, elucidam-se diversos elementos que podem convergir para uma formação integral que tenha o SUS como seu cenário de desenvolvimento. Considerando que os atores sociais, profissionais de diversos cursos da saúde, compõem as turmas de residentes, torna-se salutar um processo investigativo que problematize a formação na perspectiva de sua defesa e fortalecimento.

Compreendendo uma eminente necessidade de revisitar os ideais da reforma sanitária, que se configuram na gênese do SUS, acredita-se que esses atores ao imergir nas vivências teórico práticas desse modelo formativo tenham percepções e sentimentos a compartilhar acerca desse tema. É neste cenário que estudos que discutem caminhos para seu fortalecimento e defesa diante deste ideário tão necessários e urgentes. Inicialmente a importância de pesquisas com esta temática se dá para a manutenção deste direito social e para os trabalhadores da saúde.

É necessário ampliar as discussões para a formação profissional e que esta, ocorrendo de forma regionalizada, possa ampliar tais discussões. Por tanto, a problemática do estudo consiste em: Quais os aspectos históricos da saúde no Brasil até a criação do SUS? Por quê tratar acerca do fortalecimento e defesa do SUS? Qual o papel da formação em saúde sob a perspectiva da residência Multiprofissional em Saúde? Objetivando discutir aspectos históricos e compreender o papel da residência multiprofissional em saúde da família no fortalecimento e defesa do sistema único de saúde.

\section{REUISÃO BIBLIOGRÁFICA}

\subsection{HISTÓRIA E SAÍDE: REFLEKÔES ACERCA DA REALIDADE MACIONAL}

A assistência saúde no Brasil perpassou as mais diferentes épocas e está alinhada ao contexto histórico e sociocultural de cada período. A partir desta perspectiva, contextualizar o tema, essencialmente em ordem cronológica, nos fornece base para a compreensão de como se produz saúde na atualidade. 


\subsubsection{Contertualização histórica acerca da construção da saúde}

Desde a invasão de Portugal ocorrida no século VII até a democracia instaurada na atualidade, o conceito de saúde e as formas de produzi-la tem se modificado. No decorrer destes 500 anos, o cuidar foi exclusivo aos nobres, ricos ou que porventura pudessem pagar, aos escravos, apenas quando o dono das terras custeava atendimento domiciliar com médicos da época, elucidando nas mais diferentes épocas as desigualdades sociais (VIOTTI, 2012).

A produção de saúde do período colonial (1500-1822) ficava a cargo das autoridades espirituais como Pajés das tribos, religiosos franciscanos e jesuítas, barbeiros, curandeiros e parteiras que utilizavam magia ou caridade associando o cuidado do corpo aos rituais empíricos como as sangrias, a biótica e a contribuição dos irmãos. Seguindo o utilizado em Portugal, surge no Brasil as Santas Casas de misericórdia destinado a população mais pobre sendo a primeira 1543, na capitania de São Vicente na Vila de Santos e criada pelo fidalgo de Portugal Bráz Cubas (FERREIRA, 2018).

É importante destacar a visão da época em que a educação era algo negativo que poderia interferir no domínio do povo gerando revolta na então colônia, portanto, os progressos na saúde dependeram de importantes acontecimentos, como a vinda da família real portuguesa no ano de 1808, que havia fugido de Napoleão Bonaparte para a então capital brasileira, a Bahia. Uma das medidas, foi a criação da primeira escola de medica e cirurgia em Salvador, se tornando posteriormente importante para saúde social com ações de saneamento em hospitais, portos e cemitérios (CUNHA et al, 2009).

Após o império no período da primeira república, já no final do século XIX e século $X X$, a economia nacional estava pautada na exportação de café correspondendo $72,5 \%$ da receita, nesta mesma época, havia a percepção de os portos brasileiros eram pestilentos devido à alta taxa de adoecimento e mortalidade, principalmente dos estrangeiros que vieram substituir os escravos "libertos" em 88, o que afastava compradores colocava em risco o lucro. Por esse motivo, iniciou-se medidas sanitárias nos portos e ambiente urbano, vigilância de endemias como febre amarela, varíola, peste bubônica, dentre outras, notificando os casos e isolando enfermos. Ademais, as medidas que prioritariamente eram de higiene não eram esclarecidas à população, mas apenas impostas pelo governo (CUNHA et al, 2009). 
Por esse motivo, os movimentos populares eram gerados por motins que iam de encontro as imposições governamentais. Uma das mais conhecidas foi a Revolta da vacina em 1904 ocorrida no Rio de Janeiro, propriamente causada pela Lei da Vacina Obrigatória contra varíola idealidade e escrita por Oswaldo Cruz, que gerava inclusive a perda das casas por seus moradores executada pelas Brigadas Mata-mosquitos que com poder arbitrário invadia habitações para se fazer cumprir a lei (FINKELMAN, 2012).

Diferentemente deste modo de ação, Carlos Chagas em 1920 investe em educação e propaganda popular sanitária e remodela o Departamento Nacional de Saúde para combater a lepra, as doenças venéreas, incentivando cuidado com higiene infantil e do trabalho, fiscalizando gêneros alimentícios e combatendo a tuberculose (ANDRADE, 2021). É neste período em que os cafeicultores se tornam uma importante classe social, que para manter a distribuição do café e manter seus monopólios passaram a defender os direitos trabalhistas dos ferroviários que costumeiramente realizavam greves por melhores condições de trabalho (DE CARVALHO RODRIGUES, 2019).

É neste momento, que surge o deputado paulista e cafeicultor Eloy Chaves, que para proteger sua posição de fazendeiro cria para os ferroviários as CAPS (Caixas de Aposentadorias e Pensões) em 1923 objetivando tratar questões de doença e morte. Com o desenvolvimento da indústria têxtil e de alimentação, após a segunda guerra mundial em 1945, outras classes trabalhadoras como os operários iniciaram reinvindicações acerca das precárias condições de vida e trabalho acentuadas desde a crise econômica de 1929 e das fraudes da política "café com leite" exercida por São Paulo e Minas Gerais (CERQUEIRA, 2021).

Tais acontecimentos culminaram na revolta não somente de populares como de militares, gerando a conhecida revolução de 30 , com a deposição do então presidente Washington Luiz para ascensão de Getúlio Vargas, permanecendo no poder no período do Estado Novo em 1945 e trazia as propostas de saúde como discurso de modernização do país (NEDRINE e GUTFREIND, 2020).

Getúlio, trazia como diferencial as divisões do país como regiões de saúde e atuava por meio de dois ministérios, o Ministério da Educação e Saúde Pública (MESP) e o Ministério do Trabalho, Indústria e Comércio (MTIC), posteriormente daria origem posteriormente ao Ministério da Educação e Saúde (MES) e ao Departamento Nacional 
de Saúde (DNS) combatendo malária, lepra, febre amarela e tuberculose e fiscalizado por meio das Delegacias Federais de Saúde. O período Getulista ocorrido de 1930 a 1945 iniciou também as Conferências Nacionais de Saúde (CNS) (D'ARAÚJO, 2017).

\subsubsection{Militarismo e saúde}

Do ano de 1945 até o golpe militar de 1964 ocorreu um movimento conhecido como populismo, onde pautas movidas por uma onda de modernização trazia o povo como prioridade por meio e falas que exaltavam a nação e pautas de inclusão social. Neste período pós segunda guerra mundial, a redemocratização segue a todo vapor e traz consigo uma nova Constituição, eleições diretas, valorização e liberdade a imprensa, formação de sindicatos e criação de novos partidos políticos, criação do Ministério da Saúde em 1953 e da Lei Orgânica da Previdência Social (LOPS) em 1960 (SOUSA e FERNANDES, 2020).

À exemplo deste período, líderes como Jânio Quadros (1961) e Juscelino Kubitschek (1956 - 1961) ganharam destaque. Jânio, por seu discurso anticorrupção usando até mesmo uma vassoura em palanques para promover suas falas de "varrer" a corrupção, enquanto Juscelino, apostava em um projeto ousado de desenvolvimento o conhecido "50 anos em 5". 0 fim deste período é marcado pela ascensão dos militares ao poder colocando fim ao governo de contradições de João Goulart (1961 - 1964) (SOUSA e FERNANDES, 2020; SEGURA, 2017).

O regime militar dá início a uns dos períodos delicados de estagnação, tanto no contexto político como social da história, nos anos iniciais ocorrem o conhecido "milagre econômico" e a saúde era custada pelos recursos previdenciários, pois ocorre a unificação dos Institutos de Aposentadorias e Pensões (IAPs) e formando o Instituto Nacional de Previdência Social (INPS) (SEGURA, 2017).

Os militares regiam de modo autoritários campanhas sanitárias de baixa eficácia por se utilizares de ações conservadores e ineficientes e por vezes mudaram a organização previdenciária como em 1977, com o Sistema Nacional de Assistência e Previdência Social (SINPAS) e, dentro dele, o Instituto Nacional de Assistência Médica da Previdência Social (INAMPS). Norteavam - se pela ótica medico centrada e seguiam modelos aplicados nos Estados Unidos que não se adequavam a realidade nacional, à exemplo a medicina preventiva que busca corrigir as injurias nacionais pela ação isolada de profissionais médicos (SEGURA, 2017). 
Por tanto, o cuidado em saúde era inexistente e a assistência ocorria apenas pelo atendimento médico individual e privado para os beneficiados da previdência. Ademais a privatização era até mesmo financiada pelo governo como observada na Lei $n^{\circ} 6168$ de 1974, que criara o Fundo de Apoio ao Desenvolvimento Social (FAS) que terceirizava serviços públicos objetivando gerar lucros a empresas privadas (DIAS,2018).

Iniciado pelo Movimento Democrático Brasileiro (MDB), que era no primeiro momento apoiado por militares, a oposição à ditadura de modo lento começa a se tornar realidade, movida essencialmente pelas perdas econômicas e recessão e que iam de encontro à justificativa dos militares para estar no poder. E assim, por meio das diretas já a ditadura finda com da Lei da Anistia, reorganização da imprensa e força popular e um respiro para a democracia elegendo indiretamente Tancredo Neves, que não viria a chegar ao poder falecendo em 1985 (DIAS,2018)

\subsubsection{O períado democrático brasileiro e a fundamentação de direitos}

O entendimento que o direito a saúde é um bem social construiu-se de modo gradativo e foi fomentado essencialmente no ano de 1986 com a realização da VIII Conferencia Nacional de Saúde, momento este que contou com a participação social e trouxe como pauta a saúde como direito, a necessidade de um novo sistema de saúde nacional e formas para o financiamento deste. Como restado deste marco histórico, criou-se inicialmente o Sistema Unificado e Descentralizado de Saúde (SUDS) (HOCHMAN, 2020).

Esta nova percepção da saúde tornou-se popular, envolveu trabalhadores, estudantes e civis e várias instituições importantes surgiram como em 1976 o Centro Brasileiro de Estudos de Saúde (CEBES) e em setembro de 1979, a Associação Brasileira de Saúde Coletiva (ABRASCO). Tal período, conhecido como movimento da Reforma Sanitária, gerava de comoção nacional e envolvia as mais diferentes classes sociais em busca do único direito, o direito à vida e que esta fosse de qualidade (HOCHMAN, 2020).

O que, até então, era regido por ideias passa em 1988 a ser tornar realidade, e assim o SUDS se torna o Sistema Único de Saúde (SUS) no art. 196 a 200, da Constituição da República Federativa do Brasil e o acesso a saúde um dever do estado e por conseguinte, um direito do povo, sem distinção, hierarquizado, descentralizado, com financiamento, organização e operacionalização pelos estados, municípios e governo 
federal. Todos os aspectos específicos do SUS foram regidos pelas leis orgânicas 8.080 e 8.142 do ano de 1990 (HOCHMAN, 2020; SOUSA,2020).

O SUS passa a ser norteado por princípios e diretrizes, dentre as quais a integralidade, universalidade e equidade. Foram necessárias ainda a criação das Normas Operacionais Básicas (NOB) número 93, 96 e Norma Operacional da Assistência à Saúde (NOAS), que viabilizassem a realização de um sistema de proporções inovadoras, grandiosas e que forneça assistência terapêutica integral; assistência farmacêutica; controle e fiscalização de alimentos, água e bebidas para o consumo humano; formação de Recursos Humanos para área da saúde; dentre outros que buscam atuar a partir da realidade e necessidade em saúde do território nos mais diferentes níveis do cuidado (BARBOSA,2020).

\subsection{A PRIUATIZAÇÃO E O DESTMOกTE DO SUS}

A partir da observação de que o SUS é operante e está presente em todo território nacional, e que legislações discutem o tema a todo momento, questionamentos podem surgir como por qual motivo falar sobre o fortalecimento ou defesa de um sistema que é operante? defende-lo de que e poque? Há diversas vertentes de pensamentos que permeiam o SUS e, neste sentido, se torna essencial discutir e elucidar os fatos e acontecimentos que tornam a temática grave e urgente.

Diferentemente dos ideais que construíam o SUS, ações de cunho internacional da macroeconomia ou mesmo o atual movimento neoliberalista que domina os campos políticos do país, buscam incessantemente refutar tais direitos conquistados por tantas lutas. Tais ações estão presentes desde a década passada quando o SUS ainda galgava seus primeiros passos. A exemplo, a criação do terceiro setor por meio das Organizações Sociais da Saúde (OSS), criada em 1998 pela Lei federal n. 9.637 integrando sistema público e privado qualificando entidades privadas como organização social, em um processo de terceirização (MORAIS, 2018).

Pode-se sitar ainda as Organizações da Sociedade Civil de Interesse Público (OSCIPs), as Fundações Estatais ou a Empresa Brasileira de Serviços Hospitalares (EBSERH). Tais modelos de produzir saúde apesar de não possuírem fins lucrativos contratam em maior proporção serviços privados, não utilizam de licitações e geram 
maiores custos aos cofres públicos pela necessidade da administração indireta, fatos estes que fortalecem o serviço privado (MORAIS, 2018).

O estado tem sido um dos maiores colaboradores para o desmonte, sobretudo por meio do mal financiamento e ineficaz gestão de serviços como observado na Emenda Constitucional 95 de 2016, que reduz o teto de gastos para saúde em um regime fiscal para um sistema já subfinanciado com o pressuposto da diminuição da dívida pública isentando legalmente a responsabilidade do estado, o que implica na redução de ações que contemplem as necessidades da população (MARIANO, 2017).

Pode-se destacar ainda o sucateamento do SUS advindo do descaso com os profissionais, que por vezes trabalham em ambientes insalubres e não contam com o mínimo de aparato de equipamentos ou materiais, fato este que desumaniza e fragiliza os espaços de produção de saúde afetando o atendimento individual e coletivo. Ademais, o número excessivo de clientes nestes espaços traz sobrecarga ao profissional, afeta relações e reduz a qualidade das ações no serviço (SOUZA, 2021).

Como agravante, o atual presidente neoliberal eleito em 2018, não mede esforços para valorizar serviços privados, exercendo um papel de contrarreforma a partir do desfinanciamento e falta de incentivo ao SUS. Tais condutas, trouxe sérios prejuízos a população pobre sobretudo no atual cenário de crise pandêmica pela COVID - 19, que elucidou as desigualdades sociais, não pelo contagio, mas pelos casos de recuperação e morte associados diretamente à assistência em saúde (SOUZA, 2020).

Os interesses capitalistas que desmontam o estado e agridem direitos sociais, ficam evidente ao longo dos anos ao passo que o SUS se torna dependente dos serviços privados, observado principalmente quanto aos leitos de exames ou Serviços de Apoio Diagnóstico e Terapêutico (SADT), que pertencem a entes privados com $72,4 \%$ e $90 \%$ respectivamente. Há incontáveis aspectos que envolvem este processo de desmonte e, para tanto, é necessária a compreensão dos aspectos políticos e de seus impactos sociais nas periferias do país. Tratar sobre saúde é sobre interferir na vida e na morte e esta não pode ou deve ser fonte de lucro (MARIANO,2018; PAIM, 2018). 


\subsection{CAMTIIHOS PARA MARUUTERÇÃO E FORTALECIMERTO DO SUS}

Discutiremos neste tópico a estratégia para fortalecimento e defesa do SUS diante dos ataques sofridos desde a sua criação. O foco deste estudo é elucidar a importância da formação profissional em saúde, a responsabilidade da formação como parte das atribuições do sistema e como a ótica acerca da residência pode contribuir neste processo.

\subsubsection{Formação em saúde no SUS}

A partir do entendimento que a formação em saúde é responsabilidade do estado pela Lei orgânica do SUS 8080/90, que trata em seu artigo IV, a formação de recursos humanos e sua qualificação nos diferentes níveis de ensino, compreendemos também a relação do cumprimento desta alínea com a manutenção de um sistema resolutivo, integral e humanizado. Desde a formação inicial deste profissional à sua educação permanente ao longo de sua carreira, a formação em saúde deve buscar preparar para a atuação diante da realidade nacional nos mais diferentes contextos socio regionais (BRASIL, 1990). O estado criou ao longo dos anos estratégias e programas, afim de contemplar o campo da formação em saúde como observado no quadro abaixo.

QUADRO I - PRINCIPAIS ESTRATEGIAS DE FORMAÇÃO EM SAÚDE PARA O SUS

\begin{tabular}{|l|l|l|}
\hline PROGRAMA/ESTRATÉGIA & ANO & OBJETIVO \\
\hline $\begin{array}{l}\text { I Conferência Nacional de } \\
\text { Recursos Humanos em Saúde }\end{array}$ & 1986 & $\begin{array}{l}\text { Debater a formação e qualificação } \\
\text { profissional, desencadeando a criação } \\
\text { de diversos programas e projetos }\end{array}$ \\
\hline Convocação aos estados & 1996 & $\begin{array}{l}\text { Solicitar que os estados apresentem } \\
\text { projetos de desenvolvimento de } \\
\text { recursos humanos. }\end{array}$ \\
\hline Polos de Formação & 1997 & $\begin{array}{l}\text { Capacitar pela Educação Permanente } \\
\text { as equipes de Saúde da Fam ília }\end{array}$ \\
\hline $\begin{array}{l}\text { Diretrizes Curriculares } \\
\text { Nacionais (DCN's) }\end{array}$ & 2001 & $\begin{array}{l}\text { Reorientar a formação de nível } \\
\text { superior dos cursos da área da saúde }\end{array}$ \\
\hline $\begin{array}{l}\text { Programa de Incentivo às } \\
\text { Mudanças Curriculares das } \\
\text { Escolas Médicas (Promed) }\end{array}$ & 2002 & $\begin{array}{l}\text { Realizar mudanças curriculares do } \\
\text { curso de medicina visando adequar } \\
\text { com a realidade de saúde do país }\end{array}$ \\
\hline $\begin{array}{l}\text { Política de Educação } \\
\text { Permanente }\end{array}$ & 2003 & $\begin{array}{l}\text { Formar e desenvolver trabalhadores, } \\
\text { melhorando a qualidade da atenção à } \\
\text { saúde }\end{array}$ \\
\hline
\end{tabular}




\begin{tabular}{|c|c|c|}
\hline $\begin{array}{l}\text { Vivências e Estágios na } \\
\text { Realidade do SUS - VERSUS }\end{array}$ & 2004 & $\begin{array}{l}\text { Proporcionar aos estudantes a } \\
\text { vivência e a experimentação da } \\
\text { realidade do SUS }\end{array}$ \\
\hline $\begin{array}{l}\text { Programa Nacional de } \\
\text { Reorientação da Formação de } \\
\text { Profissionais em Saúde (Pró- } \\
\text { Saúde) }\end{array}$ & 2005 & $\begin{array}{l}\text { Adequar a formação à realidade de } \\
\text { saúde visando o fortalecimento do } \\
\text { SUS }\end{array}$ \\
\hline $\begin{array}{l}\text { Programa de Educação pelo } \\
\text { Trabalho para a Saúde (PET- } \\
\text { Saúde) }\end{array}$ & 2005 & $\begin{array}{l}\text { Efetivar a aprendizagem adquirida no } \\
\text { próprio trabalho em saúde atuando } \\
\text { como ponte de ligação entre } \\
\text { estudantes, docentes } \\
\text { trabalhadores. }\end{array}$ \\
\hline Residência Multiprofissional & 2005 & $\begin{array}{l}\text { Formar pelo trabalho como } \\
\text { especialização profissional. }\end{array}$ \\
\hline Pacto pela Saúde & 2006 & $\begin{array}{l}\text { Produzir o Pacto pela Vida, em Defesa } \\
\text { do SUS e Pacto de Gestão, } \\
\text { reafirmando dentre outros pontos a } \\
\text { educação na saúde. }\end{array}$ \\
\hline $\begin{array}{l}\text { Programa de Educação pelo } \\
\text { Trabalho na Saúde (PET- } \\
\text { Saúde) }\end{array}$ & 2010 & $\begin{array}{l}\text { Realizar a Integração entre ensino- } \\
\text { serviço-comunidade para } \\
\text { desenvolvimento do SUS }\end{array}$ \\
\hline
\end{tabular}

Fonte: Autoria própria

\subsubsection{Residência multiprofissional com ênfase em saúde da família $e$}

\section{comunidade}

A Residência multiprofissional é uma estratégia especialização lato senso que busca formar por meio do trabalho em saúde e possui uma carga horaria de 5.760 (cinco mil setecentos e sessenta) horas, em $80 \%$, com atividades práticas e $20 \%$ teóricas. Dentro desta formação, há diversas modalidades para as mais diferentes categorias profissionais, dentre estas a de Saúde da Família e Comunidade que atua na Atenção Primaria em Saúde (APS) por meio da Estratégia Saúde da Família (ESF) que se configura como o principal acesso ao SUS e fornece diversos serviços básicos para as mais diferentes faixas estarias do território (DA SILVA,2020).

É sabido que a APS foi resultado dos movimentos sociais da reforma sanitária, que trouxeram a integralidade e a equidade como pauta e o resultado foi a criação deste serviço descentralizado e regionalizado que organiza o cuidado, previne doenças e agravos e atua nas doenças agudas e na continuidade do cuidado às doenças crônicas (MACINKO, 2018). 
Fortalecer a ESF é também fortalecer o SUS e seus princípios. Neste sentido, a residência multiprofissional em saúde da família e comunidade se configura como um importante instrumento para a qualificação profissional e do serviço, permitindo uma maior disponibilidade de profissionais a população e a formação integral e humanística de um futuro servidor que compreende a importância das ações e serviços desenvolvidos em cada comunidade em que a residência está inserida (DA SILVA, 2020).

\section{CONSIDERAÇÔES FInAIS}

Frente ao exposto, os desafios para a manutenção do SUS são inúmeros e historicamente, o povo não consistia na prioridade daqueles que detinham o poder. Por tanto, meios para a manutenção desse direito popular devem ser valorizados, fortalecidos e estarem de acordo com os ideais da reforma sanitária.

É neste sentido que as modalidades de residência, e sobretudo as multiprofissionais voltadas ao cuidado da atenção básica pelo programa Saúde da Família e Comunidade, devem direcionar a reflexão de seus profissionais não somente no contexto da saúde como instrumento de trabalho, mas na saúde política, que é indissociável da realidade apresentada nos postos de trabalho.

Encarar a formação em saúde para além do individual, mas sobretudo em âmbito coletivo e social permite reavivar o senso de coletividade, a valorização de direitos e por conseguinte a permanência do SUS independentemente do contexto histórico vivido. Por tanto, torna-se essencial tais discussões nos mais diferentes níveis de formação e a realização de mais estudos e pesquisas que aprofundem esta ótica.

\section{REFERÊRCIAS}

ANDRADE, Clarissa Dias Rodrigues; LOPES, Guilherme Augusto Hilário. BRASIL REPÚBLICA: UMA HISTÓRIA DE SURTOS, PANDEMIAS E EPIDEMIAS. Boletim de Conjuntura (BOCA), v. 5, n. 14, p. 70-92, 2021.

ARAÚJO, Janieiry Lima de; OLIVEIRA, Kalyane Kelly Duarte de; FREITAS, Rodrigo Jácob Moreira de. Em defesa do Sistema Único de Saúde no contexto da pandemia por SARS-CoV-2. Revista Brasileira de Enfermagem, v. 73, 2020.

BARBOZA, Nilton Anderson Santos et al. A história do SUS no Brasil e a política de saúde. Brazilian Journal of Development, v. 6, n. 11, p. 84966-84985, 2020. 
BASTOS, Luzia Beatriz Rodrigues et al. Práticas e desafios da regulação do Sistema Único de Saúde. Revista de Saúde Pública, v. 54, p. 25, 2020.

BRASIL. Lei $N^{\circ}$ 8080/90, de 19 de setembro de 1990. Brasília: DF. 1990. Disponível em: https://conselho.saude.gov.br/legislacao/lei8080_190990.htm Acesso em: 08 de março de 2020.

\section{CERQUEIRA, Anderson Costa. Análise Da Viabilidade Dos Regimes Próprios De} Previdência Social Municipal. Clube de Autores (managed), 2021.

CUNHA, Cristiane Silveira et al. A Importância da chegada da Família Real Portuguesa para o ensino médico e a medicina brasileira. Revista Práxis, v. 1, n. 1, 2009.

DA SILVA, Gilson Fernandes et al. ATUAÇÃO DO RESIDENTE DE ENFERMAGEM NO ENFRENTAMENTO À COVID-19 NO MUNICÍPIO DE CASCAVEL/PR: RELATO DE EXPERIÊNCIA. Varia Scientia-Ciências da Saúde, v. 6, n. 2, p. 129-136, 2020.

DA SILVA, Gilson Fernandes et al. ATUAÇÃO DO RESIDENTE DE ENFERMAGEM NO ENFRENTAMENTO À COVID-19 NO MUNICÍPIO DE CASCAVEL/PR: RELATO DE EXPERIÊNCIA. Varia Scientia-Ciências da Saúde, v. 6, n. 2, p. 129-136, 2020.

D'ARAÚJO, Maria Celina Soares (Ed.). Getúlio Vargas. Edições Câmara, 2017.

DE CARVALHO RODRIGUES, Hellbia Samara Moreira. Marcos históricos que permeiam a saúde pública brasileira: perspectiva de 1950 até 2019.

DIAS, André Bonsanto. A verdade dita é dura:"histórias da verdade" do/no jornalismo e a ditadura militar no Brasil. 2018.

FERREIRA, Marina Lopes et al. Santa Casa de Misericórdia de Uberlândia: Trajetória institucional e mecanismos de legitimação social (1943-1962). 2018.

FINKELMAN, Jacobo. Caminhos da saúde pública no Brasil. Editora Fiocruz, 2002.

HOCHMAN, Gilberto. História, ciência e saúde coletiva. Ciência \& Saúde Coletiva, v. 25, p. 4715-4721, 2020.

MACINKO, James; MENDONÇA, Claunara Schilling. Estratégia Saúde da Família, um forte modelo de Atenção Primária à Saúde que traz resultados. Saúde em Debate, v. 42, p. 18-37, 2018.

MARIANO, Cynara Monteiro. Emenda constitucional 95/2016 e o teto dos gastos públicos: Brasil de volta ao estado de exceção econômico e ao capitalismo do desastre. Revista de investigações constitucionais, v. 4, n. 1, p. 259-281, 2017.

MORAIS, Heloisa Maria Mendonça de et al. Organizações Sociais da Saúde: uma expressão fenomênica da privatização da saúde no Brasil. Cadernos de Saúde Pública, v. 34, p. e00194916, 2018. 
NEGRINI, Márcio Zanetti; GUTFREIND, Cristiane Freitas. Rememorações do autoritarismo brasileiro no filme Revolução de 30 . Contracampo, v. 39, n. 3, 2020.

PAIM, Jairnilson Silva. Sistema Único de Saúde (SUS) aos 30 anos. Ciência \& Saúde Coletiva, v. 23, n. 6, p. 1723-1728, 2018.

PINHEIRO, Fernanda Thayná de Souza et al. Participação universitária em defesa do Sistema Único de Saúde. Saúde em Debate, v. 44, p. 504-515, 2020.

SOUSA, Camila; FENANDES, Violeta Campolina. Aspectos históricos da saúde pública no Brasil: uma revisão integrativa. JMPHC| Journal of Management \& Primary Health Care| ISSN 2179-6750, v. 12, 2020.

SOUZA, Diego de Oliveira. As dimensões da precarização do trabalho em face da pandemia de Covid-19. Trabalho, Educação e Saúde, v. 19, 2021.

SOUZA, Diego de Oliveira. O subfinanciamento do Sistema Único de Saúde e seus rebatimentos no enfrentamento da Covid-19. Physis: Revista de Saúde Coletiva, v. 30, p. e300313, 2020.

SOUZA, Diego de Oliveira. O subfinanciamento do Sistema Único de Saúde e seus rebatimentos no enfrentamento da Covid-19. Physis: Revista de Saúde Coletiva, v. 30, p. e300313, 2020.

VIOTTI, Ana Carolina de Carvalho. As práticas e os saberes médicos no Brasil colonial (1677-1808). 2012. 


\title{
AMTPLIARDO E CONHECERDO A SAÚDE DO TERRITÓRIO ATRALUES DA LUUUERCIA DE

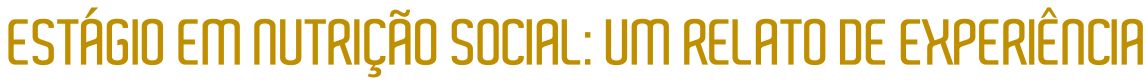

\author{
DDI: 10.51859/AMPLLA.APS276.|121-10
}

\author{
Isabelle Dantas Medeiros ${ }^{1}$ \\ Joice Estevam da Silva ${ }^{2}$ \\ Igor Gondin da Silva ${ }^{3}$
}

1 Discente do curso de Nutrição. Universidade Potiguar - UnP

2 Discente do curso de Nutrição. Universidade Potiguar - UnP

${ }^{3}$ Graduado em Nutrição pelo Centro Universitário Estácio do Ceará. Nutricionista Residente no Programa de Residência em Atenção Básica da Escola Multicampi de Ciências Médicas/ Universidade Federal do Rio Grande do norte - EMCM/UFRN

\section{RESUITO}

A transição nutricional ocorrida no país e no mundo, que trata da mudança dos índices de desnutrição para os de obesidade populacional, resultando na crescente taxa de comorbidades e doenças crônicas não-transmissíveis (DCNTs), traz a necessidade de reformulações urgentes para atender a essa nova demanda em Saúde Pública. Portanto, observar e identificar as reais necessidades em saúde apresentadas em um território, pode favorecer a mudança no comportamento de vida por parte dos indivíduos e coletividades. Este trabalho tem por objetivo relatar a experiência vivenciada em um estágio curricular da disciplina de Nutrição Social, apresentando aspectos característicos que contemplam os determinantes e condicionantes em saúde do local de inserção. A vivência e prática do estágio possibilitaram a observação e exploração da realidade do território. Com isso, conhecer, construir e desenvolver diversas habilidades e competências relacionadas à prevenção e promoção da saúde resultam em uma melhor assistência prestada ao usuário-família-comunidade.

Palavras-chave: Nutrição em Saúde Pública. Atenção Primária em Saúde. Consumo Alimentar. Epidemiologia. Estratégia Saúde da Família.

\section{IกTRODUÇก̃O}

A transição nutricional ocorrida no país e no mundo, que trata da mudança dos índices de desnutrição para os de obesidade populacional, resultando na crescente taxa de comorbidades e doenças crônicas não-transmissíveis (DCNTs), traz a necessidade de reformulações urgentes para atender a essa nova demanda em Saúde Pública. A complexidade dos problemas nutricionais deve ser enfrentada com propostas 
inovadoras de promoção da saúde no campo da alimentação e nutrição (HAACK et al., 2018).

Portanto, conhecer como portadores de DCNTs utilizam os serviços de saúde é fundamental para reduzir barreiras de acesso e orientar políticas de saúde, promovendo equidade no acesso aos recursos, além de orientar o desenho de políticas de redução de vulnerabilidades (MALTA et al., 2017).

A criação de um conjunto de estratégias focadas na melhoria da qualidade de vida dos indivíduos e coletividades, e que pode se materializar por meio de políticas, ações e intervenções no meio com objetivo de atuar sobre os condicionantes e determinantes sociais de saúde, de forma intersetorial e com participação popular, favorecem a mudança no comportamento de vida por parte dos indivíduos e coletividades no território onde residem, estudam, trabalham, entre outros (BRASIL, 2021).

Uma das estratégias aplicadas no cotidiano para a promoção da saúde dentro de um território é o desenvolvimento da promoção da alimentação adequada e saudável (PAAS) que constitui uma estratégia de saúde pública eficaz, com uma abordagem integral, capaz de prevenir carências nutricionais, promover a saúde de forma universal e, ao mesmo tempo, reduzir o excesso de peso e as doenças crônicas não transmissíveis (DCNTs) (HAACK et al., 2018).

Diante disso, este trabalho tem por objetivo relatar a experiência vivenciada em um estágio curricular da disciplina de Nutrição Social, apresentando aspectos característicos que contemplam os determinantes e condicionantes em saúde do local de inserção.

\section{METODOLOGIA}

Trata-se de um relato de experiência da disciplina de estágio supervisionado obrigatório em Nutrição Social do curso de nutrição da Universidade Potiguar (UnP), realizado em dezembro de 2020 na Unidade Básica de Saúde (UBS) Wady Rocha, localizada na zona oeste do município de Caicó/RN. 


\section{RESULTADOS E DISCUSSÔES}

Durante o período de estágio foi possível observar e identificar o perfil epidemiológico da população adscrita por meio de dados registrados na própria UBS, bem como o consumo alimentar realizado através da aplicação do questionário estruturado do Sistema de Vigilância Alimentar e Nutricional (SISVAN) e o rol de ações e/ou programas executados na unidade supracitada.

\subsection{Perfil da população atendida no local de estágio}

O perfil epidemiológico da população adscrita em geral são indivíduos portadores de DCNTs, como dislipidemias, hipertensos, diabéticos, pessoas que apresentam algum grau de sobrepeso e obesidade, e transtornos psíquicos. Em relação aos gêneros que mais procuram o serviço de saúde, as mulheres e idosos de ambos os sexos são os que mais frequentam a unidade. No quadro a seguir é possível observar o quantitativo de pessoas assistidas de acordo com o grupo populacional:

Quadro 1: Usuários assistidos por grupo na UBS Wady Rocha em 2020, Caicó, RN.

\begin{tabular}{|l|l|}
\hline № de crianças menores de 2 anos & 73 \\
\hline № de crianças com diarréia & 03 \\
\hline № de crianças de 2 a <10 anos & 394 \\
\hline № de gestantes & 15 \\
\hline № de mulheres entre 25 e 64 anos & 1361 \\
\hline № de pessoas com Hipertensão & 612 \\
\hline № de pessoas com Diabetes Mellitus & 184 \\
\hline № de pessoas com tuberculose & 01 \\
\hline № de pessoas com Hanseníase & 00 \\
\hline № de pessoas com IST & 00 \\
\hline № de pessoas com transtorno mental & 89 \\
\hline № de pessoas com deficiência física & 30 \\
\hline № de alcoólatras & 52 \\
\hline № de tabagistas & 214 \\
\hline № de pessoas acima de 60 anos & 582 \\
\hline № de pessoas em hemodiálise & 02 \\
\hline
\end{tabular}




\begin{tabular}{|l|l|} 
№ de pessoas com Câncer & 11 \\
\hline № de pessoas acamadas/domiciliadas & 22 \\
\hline № de pessoas com obesidade & 110 \\
\hline № de pessoas com sequelas de AVC & 15 \\
\hline
\end{tabular}

Fonte: UBS Wady Rocha.

Devido ao atual cenário da pandemia da COVID-19, as ações de âmbito coletivo (hiperdia itinerante, grupo de idosos, grupo de crescimento e desenvolvimento, entre outras) estão suspensas. Os principais serviços realizados na UBS são os atendimentos de pré-natal, preventivo e curativos realizados pela equipe de enfermagem, assistência médica (visita domiciliar, atualização de receitas, consultas de rotina), assistência odontológica, campanhas de vacinação, atendimento nutricional, bem como assistência farmacêutica na farmácia distrital. Cabe ressaltar que a referida unidade atuava, também, na assistência em saúde de pessoas assintomáticas e sintomáticas causadas pelo vírus SARS-CoV-2.

\subsection{Coleta e análise de Dados do SISUAR dos usuários}

O SISVAN tem por objetivo realizar a gestão das informações de Vigilância Alimentar e Nutricional (VAN). Trata-se de uma ferramenta para o monitoramento da situação alimentar e nutricional e de apoio aos profissionais de saúde para o diagnóstico local das condições e agravos alimentares e nutricionais, identificando fatores de risco ou proteção para as condições de saúde da população atendida nos serviços de Atenção Básica no Brasil (BRASIL, 2017).

Com o intuito de obter informações acerca do consumo alimentar atual de usuários pertencentes ao território adscrito foram aplicados 34 questionários do SISVAN, enquanto os mesmos aguardavam na sala de espera da UBS. Não foi possível obter uma amostra maior devido ao aumento de casos do COVID-19 no município e na zona geográfica em que a UBS está inserida, havendo uma limitação do estudo.

Com base nos questionários respondidos foi possível observar um certo nível de informação das pessoas em relação à alimentação. As perguntas realizadas estão presentes no formulário de marcadores de consumo alimentar do SISVAN, como mostram os gráficos a seguir: 
Gráfico 1: Você tem costume de realizar refeições assistindo TV, mexendo no computador e/ou celular?

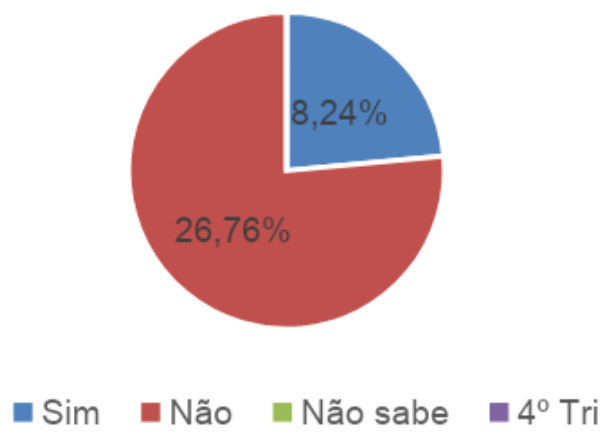

Fonte: Autoria própria.

O gráfico acima demonstra o quantitativo de pessoas que costumam ou não realizar as refeições em frente à TV, computador ou celular. É possível observar que 76\% ( $n=26)$ não possuíam o hábito de realizar as refeições em frente a meios eletrônicos, enquanto, $24 \%$ ( $n=8)$ se distraem com algum meio eletrônico durante as refeições.

Gráfico 2: Quantas refeições você realiza ao longo do dia?

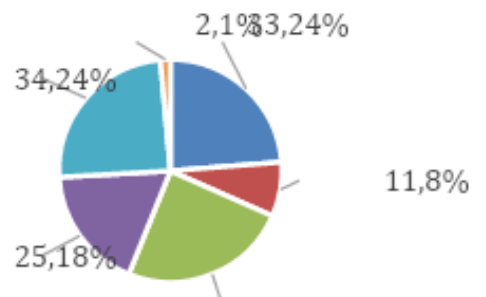

$34,24 \%$

- Café da manhã

- Lanche da manhã

Almoço

- Lanche da tarde

- Jantar

- Ceia

Fonte: Autoria própria.

O gráfico 2 mostra a quantidade de refeições que os entrevistados realizaram ao longo do dia. As mais frequentes são: café da manhã, almoço e jantar, em contrapartida, os lanches (manhã e tarde), bem como a ceia eram pouco realizadas. 
Gráfico 3: Consumo alimentar da população no dia anterior

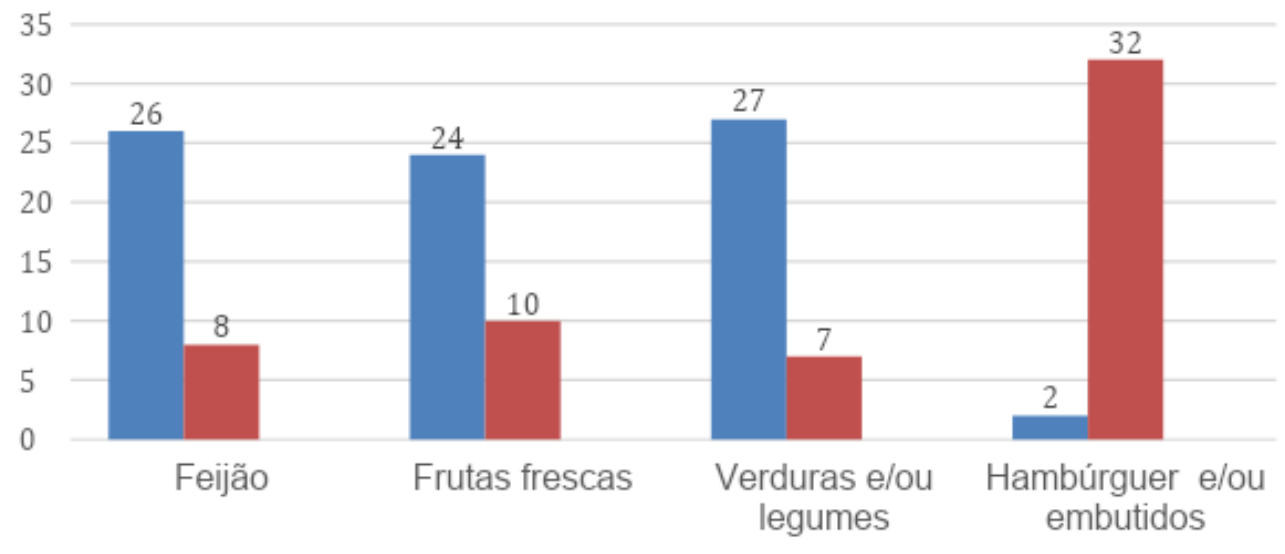

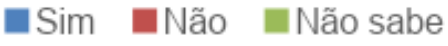

Fonte: Autoria própria.

No gráfico 3, é possível observar um maior consumo alimentar de feijão, frutas frescas, verduras ou legumes em relação ao menor consumo de hambúrguer e/ou embutidos. Com isso, é notório que boa parte dos usuários que frequentam a UBS e participaram da pesquisa possuem um conhecimento mínimo sobre alimentação saudável no dia a dia e seus benefícios à saúde.

Segundo o levantamento de dados realizado pela Vigitel em 2018 sobre o consumo alimentar de frutas e hortaliças é possível observar que a frequência de adultos que consomem regularmente esse tipo de alimento variou entre $23 \%$ em Belém e 44,7\% em Florianópolis.

As maiores frequências, entre homens, foram encontradas em Florianópolis $(38,7 \%)$, Belo Horizonte (36,9\%) e João Pessoa (35,5\%) e, entre mulheres, em Palmas $(51,4 \%)$, Curitiba $(50,8 \%)$ e Belo Horizonte e Florianópolis $(50,1 \%)$. Já as menores frequências do consumo regular de frutas e hortaliças no sexo masculino ocorreram em Belém (16,7\%), Macapá $(20,5 \%)$ e Salvador $(21,8 \%)$ e, no sexo feminino, em Belém (28,3\%), Manaus (28,8\%) e Rio Branco (29,1\%) (BRASIL, 2019). 
Gráfico 4: Consumo alimentar da população no dia anterior

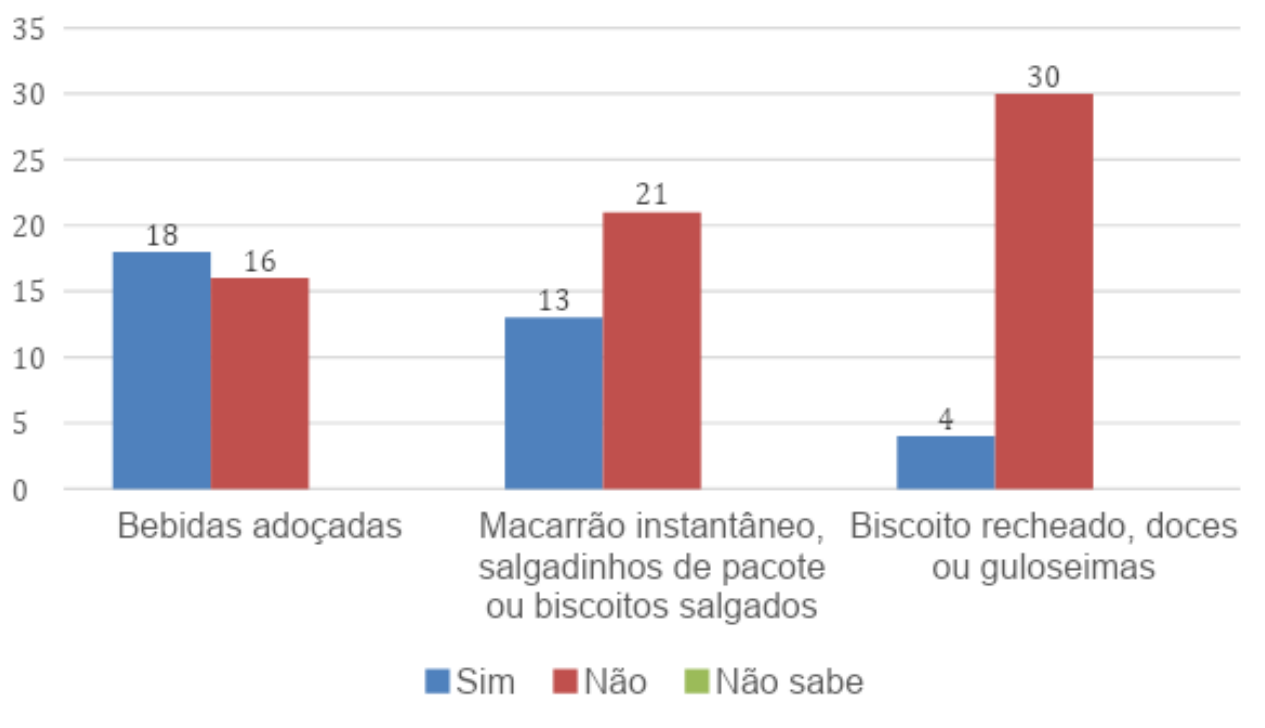

Fonte: Autoria própria.

No gráfico 4, é notório que os entrevistados consumiram mais bebidas adoçadas do que os outros alimentos em questão, o que corrobora com os dados apresentados por uma pesquisa da Vigitel realizada em 2018, onde a frequência de adultos que referiram o consumo de refrigerantes em cinco ou mais dias da semana variou entre $6 \%$ em João Pessoa e Salvador e 23\% em Porto Alegre.

As maiores frequências dessa condição, entre homens, foram encontradas em Porto Alegre (29\%), Rio de Janeiro (23,7\%) e Goiânia (22,1\%) e, entre mulheres, em Porto Alegre (18,1\%), São Paulo (16\%) e Cuiabá (15,3\%). As menores frequências, no sexo masculino, ocorreram em Salvador (5,4\%), João Pessoa $(7,8 \%)$ e Natal $(9,1 \%)$ e, no sexo feminino, em Fortaleza (4,2\%), João Pessoa (4,6\%) e Maceió (4,7\%) (BRASIL, 2019).

Durante a aplicação dos questionários de consumo alimentar, muitos usuários relataram que não consumiam certos tipos de alimentos por não considerarem saudáveis ou por não fazerem bem à saúde. Quando indagados onde obtiam tais informações sobre alimentação e nutrição, muitos citaram os meios de comunicação, como programas de TV, reportagens, leituras em sites e blogs, e nas salas de espera realizadas pelo o nutricionista residente da UBS.

Portanto, nota-se que há uma maior consciência sobre a importância do consumo de alimentação saudável no dia a dia, bem como para a saúde. É importante frisar que o relato do consumo alimentar de apenas um dia não justifica todos os hábitos 
alimentares de um indivíduo, tendo em vista que nenhum alimento é proibido, desde que consumido com moderação, em frequência e quantidades limitadas.

A Vigilância Alimentar e Nutricional é um valioso instrumento de apoio às ações de promoção da saúde que o Ministério da Saúde recomenda que seja adotado pelos profissionais da área e pelos gestores do Sistema Único de Saúde (SUS), visando o aumento da qualidade da assistência à população (BRASIL, 2011).

\subsection{Programas de Promoção e Assistência à Saúde desenuoluidas na UBS}

Nas UBSs há diversos programas que são contemplados no âmbito do SUS, e são executados mesmo com todas as limitações técnico-administrativas e de logística. Dentre esses programas, existem por exemplo: Programa Bolsa Família, Programa Nacional de Suplementação do Ferro, acompanhamento de Crescimento e Desenvolvimento (CeD), Pré-Natal, HiperDia, entre outros.

\subsubsection{Proprama acompanhamento de crescimento e desenvolvimento (CeD)}

O programa de crescimento e desenvolvimento, constitui-se em uma estratégia que somada a capacidade das equipes e dos gestores de organizar seu processo de trabalho e dos processos em educação permanente, contribua para a contínua melhoria do acesso e da qualidade no cuidado às crianças no âmbito da atenção básica em rede, com isso, o programa objetiva acompanhar o crescimento da criança desde os seus primeiros meses de vida (BRASIL, 2012).

Sua operacionalização na unidade está paralisada, devido a pandemia do COVID19, impossibilitando de ser realizado para a segurança das mães e seus bebês, porém, quando era realizado, geralmente acontecia semanalmente, todas as quartas-feiras, juntamente com a enfermeira e demais profissionais da equipe, quando se fizesse necessário.

\subsubsection{Programa pré-natal}

Segundo BRASIL (2012), a UBS deve ser a porta de entrada preferencial da gestante no sistema de saúde. É o ponto de atenção estratégico para melhor acolher suas necessidades, inclusive proporcionando um acompanhamento longitudinal e continuado, principalmente durante a gravidez.

Mesmo antes que a gestante acesse a UBS, a equipe deve iniciar a oferta de ações em saúde referentes à linha de cuidado materno-infantil, assim, o programa pré- 
natal tem por objetivo acompanhar a gestante desde suas primeiras semanas de gestação até o momento do parto, oferecendo toda a assistência que for necessária.

Durante o período de estágio, a operacionalização do programa aconteceu a partir de consultas com médico e enfermeira da equipe, em dias alternados e programados, tendo participação compartilhada com a equipe de residentes em saúde atuantes no território (nutricionista, fisioterapeuta, farmacêutica e médico veterinário). Segundo os mesmos, atualmente os números de gestantes encontram-se em menor proporção, tendo uma menor demanda do programa.

\subsubsection{Programa nacional de suplementação de ferro}

O Programa nacional de suplementação de ferro (PNSF), consiste na suplementação profilática de ferro para todas as crianças de seis a 24 meses de idade, gestantes ao iniciarem o pré-natal, independentemente da idade gestacional até o terceiro mês pós-parto, e na suplementação de gestantes com ácido fólico. A suplementação de ferro e ácido fólico durante a gestação é recomendada como parte do cuidado no pré-natal para reduzir o risco de baixo peso ao nascer da criança, anemia e deficiência de ferro na gestante (WHO, 2012).

Sua operacionalização acontece na consulta pré-natal com a enfermeira da equipe, onde é suplementado sulfato ferroso na quantidade necessária para cada caso apresentado.

\subsubsection{Programa saúde na escola}

O Programa Saúde na Escola (PSE), instituído por Decreto Presidencial no 6.286, de 5 de dezembro de 2007, resulta do trabalho integrado entre o Ministério da Saúde e o Ministério da Educação, na perspectiva de ampliar as ações específicas de saúde aos alunos da rede pública de ensino: Ensino Fundamental, Ensino Médio, Rede Federal de Educação Profissional e Tecnológica, Educação de Jovens e Adultos (BRASIL, 2009).

Sua operacionalização encontra-se paralisada, devido ao não funcionamento das aulas presenciais para os alunos matriculados na rede pública do município. Outra questão levantada segundo relatos da equipe de Agente Comunitário de Saúde (ACS), foi a não realização de nenhuma ação/intervenção em escolas do território durante os últimos 04 anos. 


\subsubsection{Programa bolsa família}

Segundo BRASIL (2020), o Programa Bolsa Família (PBF) é um programa federal de transferência direta de renda à famílias em situação de pobreza (renda entre $R \$ 89$ a $\mathrm{R} \$ 178$ por pessoa) ou de extrema pobreza (renda de até $\mathrm{R} \$ 89$ por pessoa), com a finalidade de promover seu acesso aos direitos sociais básicos e romper com o ciclo intergeracional da pobreza. O PBF é realizado por meio de auxílio financeiro vinculado ao cumprimento de compromissos na Saúde, Educação e Assistência Social.

Sua operacionalização acontece de forma anual, periodicamente duas vezes ao ano, sendo uma em março, e outra em setembro, onde, ACSs aferem alguns dados antropométricos, como peso e altura dos cadastrados, fazendo a atualização no banco de dados.

Alguns programas como Programa Nacional de Suplementação de Vitamina A; Estratégia Amamenta e Alimenta Brasil; Programa Saúde na Escola; Hiperdia itinerante não estão sendo executados na UBS em questão, ou por falta de logística interna e/ou municipal, ou devido ao cenário atual do COVID-19.

Outros estão sendo realizados de forma simples, com limitações, favorecendo a segurança dos profissionais de saúde e da própria população. Porém, é algo bastante desafiador para todos os profissionais envolvidos, principalmente no cenário atual que estamos vivendo.

\section{COISIDERAÇÔES FInRIS}

A vivência e prática do estágio possibilitou a observação e exploração da realidade do território adscrito, como o perfil dos usuários e populações assistidas, condições sociodemográficas, perpassando sobre alimentação e nutrição até os programas de políticas públicas exercidas na assistência em saúde do referido local.

Com isso, conhecer, construir e desenvolver diversas habilidades e competências relacionadas à prevenção e promoção da saúde para indivíduos e coletividades, resultam em uma melhor assistência prestada ao usuário-família-comunidade, bem como na ampliação da visão no quesito profissional de saúde, quanto na formação como futuro Nutricionista e seu possível campo de atuação. 


\section{REFERÊCCIAS}

BRASIL. Ministério da saúde. Secretaria de atenção à saúde. Departamento de atenção básica. Promoção da saúde e da alimentação adequada e saudável. 2021. Disponível

em:https://aps.saude.gov.br/ape/promocaosaude\#: :text=A\%20Promo\%C3\%A 7\%C3\%A30\%20da\%20Alimenta\%C3\%A7\%C3\%A30\%20Adequada,qualidade\%20 de\%20vida\%20e\%20cidadania

BRASIL. Ministério da saúde. Secretaria de Atenção Primária à Saúde. Programa bolsa família. 2020. Disponível em: https://aps.saude.gov.br/ape/bfa

BRASIL. Ministério da Saúde. Secretaria de Vigilância em Saúde. Departamento de Análise em Saúde e Vigilância de Doenças não Transmissíveis. Vigitel Brasil 2018: vigilância de fatores de risco e proteção para doenças crônicas por inquérito telefônico: estimativas sobre frequência e distribuição sociodemográfica de fatores de risco e proteção para doenças crônicas nas capitais dos 26 estados brasileiros e no Distrito Federal em 2018. Brasília: Ministério da $\quad$ Saúde, $2019 . \quad$ Disponível em:http://portalarquivos2.saude.gov.br/images/pdf/2019/julho/25/vigitelbrasi 12018.pdf

BRASIL. Ministério da Saúde. Secretaria de Atenção à Saúde. Departamento de Atenção Básica. Manual operacional para uso do sistema de vigilância alimentar e nutricional sisvan - versão 3.0. 2017. Disponível em: http://sisaps.saude.gov.br/sisvan/public/file/ManualDoSisvan.pdf

BRASIL. Ministério da Saúde. Secretaria de Atenção à Saúde. Departamento de Atenção Básica. Saúde da criança: crescimento e desenvolvimento. Brasília: Ministério da Saúde, 2012. Disponível em: http://bvsms.saude.gov.br/bvs/publicacoes/saude_crianca_crescimento_desen volvim ento.pdf

BRASIL. Ministério da Saúde. Secretaria de Atenção à Saúde. Departamento de Atenção Básica. Atenção ao pré-natal de baixo risco. Brasília: Editora do Ministério da Saúde, 2012. Disponível em: http://bvsms.saude.gov.br/bvs/publicacoes/cadernos_atencao_basica_32_pre natal.pdf

BRASIL. Ministério da Saúde. Secretaria de Atenção à Saúde. Departamento de Atenção Básica. Orientações para a coleta e análise de dados antropométricos em serviços de saúde: Norma Técnica do Sistema de Vigilância Alimentar e Nutricional - SISVAN. Brasília: Ministério da Saúde, 2011. Disponível em: https://bvsms.saude.gov.br/bvs/publicacoes/orientacoes_coleta_analise_dado s_antropometricos.pdf 
BRASIL. Ministério da Saúde. Secretaria de Atenção à Saúde. Departamento de Atenção Básica. Saúde na escola. Brasília: Ministério da Saúde, 2009. Disponível em:http://bvsms.saude.gov.br/bvs/saudelegis/gm/2002/prt0371_04_03_2002 _rep.html

HAACK. A; FORTES. R; ALI. B. A. Políticas e programas de nutrição no Brasil da década de 30 até 2018: uma revisão de literatura. 2018. Disponível em:http://bvsms.saude.gov.br/bvs/periodicos/ccs_artigos/politicas_programas -nutricao.pdf

MALTA et al. Doenças crônicas não transmissíveis e a utilização de serviços de saúde: análise da pesquisa Nacional de saúde no Brasil. 2017. Disponível em: https://www.scielo.br/pdf/rsp/v51s1/pt_0034-8910-rsp-S151887872017051000090.pdf

WORLD HEALTH ORGANIZATION (WHO). Obesity: preventing and managing the global epidemic. WHO Technical Report Series, Geneva, n. 894, 1998 (Technical Report Series, n. 894). 


\title{
CAPITULO XI
}

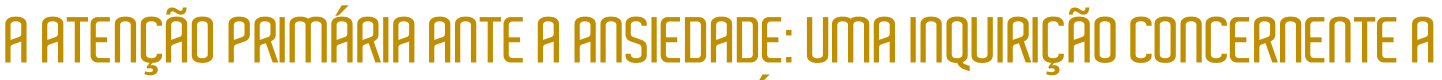 UMTMPL DO SÉCULO KKI}

\author{
DDI: 10.51859/AMPLLA.APS276.|III-11
}

Lara dos Santos Silva ${ }^{1}$ João Vitor Andrade ${ }^{2}$

\begin{abstract}
${ }^{11}$ Graduada em Enfermagem. Universidade Federal de Viçosa - UFV. Especialista em Saúde da Família. Universidade de Ipatinga - ÚNICA. Mestranda no programa de Pós Graduação em Ciências da Saúde. Universidade Federal de Viçosa - UFV

${ }^{2}$ Graduado em Enfermagem. Universidade Federal de Viçosa - UFV. Residente em Enfermagem em Saúde Mental e Psiquiátrica. Universidade de São Paulo - USP
\end{abstract}

\section{RESUMO}

A ansiedade é uma patologia que acomete o estado mental do paciente e se tornou um problema de saúde pública. A Estratégia Saúde da Família (ESF), órgão público que possui o intuito de prevenção, promoção, recuperação e reabilitação em saúde por comunidades no Brasil e dessa forma ações estratégicas necessitam ser impostas para que a ansiedade possa ser abordada. Nesse intuito, objetiva-se realizar uma inquirição concernente às ações da ESF no tocante à atenção integral dos indivíduos acometidos por ansiedade. Realizou-se uma revisão integrativa somada à análise quantitativa de dados secundários do DATASUS e AEPS InfoLogo relacionados aos afastamentos e mortes decorrentes da doença no país dentre os anos 2012-2018. É perceptível altas taxas de concessões para afastamentos e consequentemente maiores gastos federais devido a ansiedade. Mulheres são do sexo mais evidente e disposto à patologia. Se tem altas taxas de transtornos mentais, mas pouca taxa de mortalidade devido a forma que se alimenta o sistema de informação. Ações como educação em saúde são mais colocadas pelas ESF para atender a demanda de ansiedade, mas protocolos também podem e devem ser realizados. Conclui-se que o sistema brasileiro de saúde demanda muitos gastos com o afastamento dos usuários das unidades de saúde com a enfermidade em questão, mesmo que em óbitos não possua um quantitativo expressivo. Necessita-se de maiores estudos com o tema ansiedade e ESF e maiores resolubilidades estratégicas para a ansiedade.

Palavras-chave: Ansiedade. Estratégia Saúde da Família. Transtornos Mentais. Mortalidade. Prevenção de Doenças.

\section{IกTRODUÇก̃O}

A Organização Mundial da Saúde define saúde como "estado de completo bemestar físico, mental e social e não apenas a ausência de doença ou enfermidade" (OMS, 
2006). Nesta perspectiva, quando se tem algum quadro de instabilidade ou alteração em relação a algum dos aspectos concernentes à saúde, tem-se a necessidade do cuidado holístico, devendo este ser o cerne das ações da área da saúde, com intuito atender a todas as dimensões e necessidades do ser humano (HORTA, 1979).

No tocante aos aspectos mentais, destaca-se que a saúde mental é relacionada à autonomia e a gestão da própria vida, sempre tangenciando aspectos emocionais, caracterizando-se como estado de equilíbrio entre a condição externa e interna de cada indivíduo (BRASIL, 2001). Destaca-se que a saúde mental é sobremodo influenciada pelos determinantes sociais da saúde, sendo estes, fatores econômicos, étnico-raciais, sociais, culturais, psicológicos e comportamentais (BUSS, PELLEGRINI FILHO, 2007).

Um dos transtornos que mais se relaciona com os determinantes sociais da saúde é o de ansiedade, sendo que o que difere a ansiedade fisiológica da patológica são a intensidade e duração que ela possui (AMERICAN PSYCHIATRIC ASSOCIATION, 2014). Dados mundiais explicitam que em 2015 a taxa de indivíduos com transtornos de ansiedade era de 3,6\% (264 milhões de pessoas), sendo pontuado um significativo aumento de 14,9\% em relação ao ano de 2005 (OMS, 2017). Nessa lógica de adoecimento, destaca-se que o Brasil figura como o país com a maior taxa de pessoas com transtornos de ansiedade, sendo 9,3\% dos brasileiros (OMS, 2017). Nesta perspectiva, demarca-se que a ansiedade se caracteriza como um crescente problema de saúde pública.

Essa patologia inata ao ser humano, se intensa, prejudica a motivação diária do trabalho, tornando-se um fator negativo. A ansiedade pode ser definida como um sentimento desagradável somado a sensações físicas (KAPLAN E SADOCK, 1990). Classifica-se pelo estado de ansiedade e o traço de ansiedade, sendo um momento transitório de tensão ou apreensão em uma situação e a percepção do medo de acordo com a personalidade do indivíduo, respectivamente (SPIELBERGER; GORSUCH; LUSHENE 1970).

Na Enfermagem, essa doença também é um dado muito averiguado, sendo definida pela NANDA-I ${ }^{\circledR}$ como:

"Sentimento vago e incômodo de desconforto ou temor, acompanhado por resposta autonômica (a fonte é frequentemente não específica ou desconhecida para o 
indivíduo); sentimento de apreensão causado pela antecipação de perigo. É um sinal de alerta que chama a atenção para um perigo iminente e permite ao indivíduo tomar medidas para lidar com a ameaça" (HERDMAN; KAMITSURU, 2018, p. 614).

Ante ao supra referido, destaca-se a importância da Estratégia Saúde da Família (ESF), que visa à promoção, proteção, prevenção, recuperação e reabilitação em saúde, intervindo em fatores que colocam a saúde da população em risco (BRASIL, 2012). Ratifica-se que a ESF juntamente com os demais serviços relacionados à atenção primária no Brasil, visam resolver até $80 \%$ dos problemas de saúde da população (BRASIL, 2012). A ESF constitui-se na porta de entrada do Sistema Único de Saúde (SUS), sendo imprescindível destacar que a proximidade alcançada pela equipe de saúde da ESF com o usuário permite que se conheça a pessoa, a família e a vizinhança (BRASIL, 2012). Essa proximidade garante uma maior adesão do usuário aos tratamentos e às intervenções propostas pela equipe de saúde (BRASIL, 2012).

Frente à articulação que a ESF possui com a comunidade em seu território, a mesma constitui-se em um importante instrumento para o combate à ansiedade, e concomitantemente para fortalecimento da rede de atenção à saúde mental, o que converge para a proposta de assistência pautada nos princípios da Reforma Psiquiátrica e do SUS (BRASIL, 2012). Neste ínterim, o presente trabalho visa realizar uma inquirição concernente às ações da ESF no tocante à atenção integral dos indivíduos acometidos por ansiedade.

Procurar-se-á explanar sobre a Ansiedade no século XXI, demarcando-a como um problema de saúde pública, demonstrando as taxas de afastamentos de trabalho, mortalidade e prejuízos econômicos relacionados à mesma. Ainda, explanar sobre ações da ESF no combate à ansiedade. Descrevendo estratégias/atividades exitosas adotadas pela ESF na manutenção integral da saúde de pessoas com ansiedade.

\section{METODOLOGIA}

A primeira etapa do presente estudo, constitui-se em uma análise quantitativadescritiva, conduzida com dados secundários referentes aos afastamentos e mortes decorrentes da ansiedade no Brasil entre os anos de 2012 a 2018. Os dados referentes aos afastamentos foram obtidos por meio do site do Ministério da Fazenda, 
especificamente no "Base de dados - Estatísticas de Previdência Social” (BRASIL, 2020), e os relacionados a mortalidade estavam alocados no Sistema de Informação sobre Mortalidade - SIM, do Ministério da Saúde e disponíveis na Internet por meio do Departamento de informática do Sistema Único de Saúde - DATASUS (BRASIL, 2019),

O intervalo temporal foi delimitado com o objetivo de se estabelecer uma série histórica que permitisse comparação das frequências anuais de afastamentos e óbitos, além de realizar uma comparação com o quadriênio de pensões e auxílios. As variáveis coletadas em relação aos afastamentos do trabalho foram: ano de afastamento, e em relação a mortalidade, coletou-se as seguintes variáveis: sexo, ano do óbito, sexo, escolaridade, estado civil. Para ambas as coletas, teve-se como base o código "F41 Outros transtornos ansiosos" do Capítulo V da Classificação Internacional de Doenças e Problemas Relacionados à Saúde - 10a revisão (BRASIL, 2019).

A análise dos dados foi realizada por meio da estatística descritiva, a qual possibilita a síntese de valores de uma mesma natureza, proporcionando uma visão global da variação desses valores, organiza e descreve os dados de três maneiras: por meio de tabelas, de gráficos e de medidas descritivas. Utilizou-se o Programa Microsoft Excel $^{\circledR}$, versão 2016 para realização dos cálculos e construção de tabelas.

O estudou respeitou os aspectos éticos em pesquisa, visto que pesquisas baseadas em dados secundários, de domínio público, não necessitam ser submetidas à apreciação do Comitê de Ética em Pesquisa de acordo com a Resolução do Conselho Nacional de Saúde n510, de 7 de abril de 2016 (BRASIL, 2016).

Ademais, para subsidiar a temática e garantir robustez ao presente estudo, conduziu-se uma revisão da literatura no formato integrativa, a qual se configura como uma análise de pesquisas relevantes de maneira sistematizada, servindo como apoio para a tomada de decisões, possibilitando assim a síntese de conhecimento de um determinado assunto (MENDES; SILVEIRA; GALVÃO, 2019).

A revisão integrativa de acordo com Mendes; Silveira e Galvão (2019), dividisse em seis etapas, sendo o estabelecimento da hipótese ou questões de pesquisa, a realização da busca na literatura, a categorização dos estudos, avaliação dos estudos incluídos na revisão, interpretação dos resultados e por último a apresentação da revisão, a qual se dá pelos resultados e conclusão do presente estudo. 
O levantamento bibliográfico foi realizado através das bases de dados Literatura Latino-Americana e do Caribe em Ciências da Saúde (LILACS), U.S. National Library of Medicine National Institute of Health (PubMed), Scientific Electronic Library Online (SciELO) e Base de Dados de Enfermagem (BDENF) no período de agosto a outubro de 2020. A pergunta utilizada para motivar o aprofundamento na temática da revisão foi: Quais estratégias são exercidas pela ESF para indivíduos com ansiedade. Utilizou-se a estratégia PICOT para delimitar a revisão integrativa (MENDES; SILVEIRA; GALVÃO, 2019). Sendo a mesma um acrônimo, representando no presente estudo: P) População (pacientes com ansiedade atendidos na ESF); I) Intervenção (quais as estratégias exercidas pela ESF?); C) Comparação (trazem benefício para as pessoas?); O) Desfecho ou resultados (existe consenso ou protocolos?) e T) Tempo (estudos publicados nos últimos cinco anos 2015/2020). A busca foi realizada de maneira interdependente por dois pesquisadores.

Utilizou-se os descritores controlados disponíveis nos Descritores em Ciência da Saúde (DeCS) : "Anxiety" e "Family Health Strategy", utilizou-se para o cruzamento dos descritores o operador booleano "AND".

Os estudos foram selecionados pela leitura criteriosa dos títulos, resumos e posteriormente dos artigos na íntegra. Os critérios de inclusão definidos foram artigos científicos similares com a temática deste estudo, produções disponíveis na íntegra, nos idiomas português, inglês e espanhol e que detalhasse e versassem o assunto: estratégias/atividades adotadas pela ESF na manutenção integral da saúde de pessoas com ansiedade, independentemente do método de pesquisa utilizado, publicado entre os anos de 2015 a 2020. Artigos que se encontravam repetidos nas bases de dados e não abarcavam a temática principal não foram incluídos na análise. De forma sistematizada foi construído a figura de das bases de dados que adentraram no trabalho (Figura 1).

Para a caracterização dos estudos selecionados utilizou-se um instrumento de fichamento de dados adaptado [incluindo-se os itens autor, ano, título do artigo, idioma, base de dados e país de publicação, nível de evidência, objetivo do estudo e síntese da conclusão], visando a sistematização e organização. A análise dos dados foi realizada por meio da leitura dos artigos, sendo as informações dos mesmos extraídas e inseridas em um quadro elaborado no Microsoft Word ${ }^{\circledR} 2016$ (Figura 2). Tendo como finalidade determinar a confiança dos resultados e fortalecer as conclusões que irão gerar 
conhecimento acerca do tema investigado (GALVÃO, 2006), foram classificados os estudos quanto ao nível de evidencia.

Figura 1: Sistematização da busca nas bases de dados LILACS, PubMed, SciELO e BDENF.

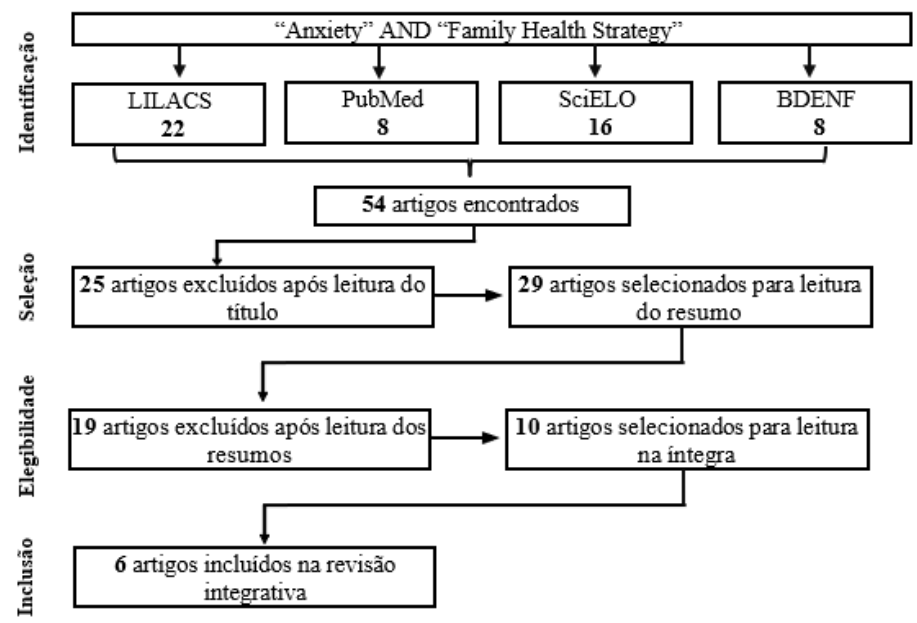

Fonte: Autoria própria.

\section{RESULTADOS}

O total de afastamentos em decorrência dos transtornos mentais foi de 1.525.892, contabilizando $2.088 .263 .325,76$ de reais gastos com as licenças e auxílios por estes afastamentos. O quantitativo de afastamentos do trabalho em decorrência do transtorno de ansiedade no Brasil no período de 2012-2018 foi de 225.900. (AEPS InfoLogo, 2017)

Sendo que destes, 39,66\% (89.613) foram de indivíduos do sexo masculino e 60,34\% (139.287) em indivíduos do sexo feminino (Tabela 1).

Tabela 1 - Número e valor de benefícios concedidos por sexo em decorrência da ansiedade, 2014 a 2018.

\begin{tabular}{ccccccc}
\hline Ano & $\begin{array}{c}\text { Benefícios } \\
\text { a homens }\end{array}$ & $\begin{array}{c}\text { Benefícios } \\
\text { a mulheres }\end{array}$ & $\begin{array}{c}\text { Benefícios } \\
\text { concedidos }\end{array}$ & $\begin{array}{c}\text { Valores } \\
\text { concedidos a } \\
\text { homens }\end{array}$ & $\begin{array}{c}\text { Valores } \\
\text { concedidos a } \\
\text { mulheres }\end{array}$ & $\begin{array}{c}\text { Valores } \\
\text { concedidos }\end{array}$ \\
\hline $\mathbf{2 0 1 2}$ & 1.039 & 17.387 & 28.426 & $15.466 .384,74$ & $18.646 .715,12$ & $34.113 .099,86$ \\
$\mathbf{2 0 1 3}$ & 1.936 & 20.273 & 32.209 & $18.037 .618,28$ & $23.540 .362,42$ & $41.577 .980,70$ \\
$\mathbf{2 0 1 4}$ & 11.890 & 20.637 & 32.527 & $18.798 .014,15$ & $25.825 .212,86$ & $44.623 .227,01$ \\
$\mathbf{2 0 1 5}$ & 9.320 & 16.480 & 25.800 & $16.351 .400,92$ & $22.679 .614,47$ & $39.031 .015,39$ \\
$\mathbf{2 0 1 6}$ & 11.541 & 21.280 & 32.821 & $22.336 .018,13$ & $32.671 .280,53$ & $55.007 .298,66$ \\
$\mathbf{2 0 1 7}$ & 11.400 & 21.188 & 32.588 & $23.158 .941,37$ & $33.874 .024,81$ & $57.032 .966,18$ \\
$\mathbf{2 0 1 8}$ & 14.150 & 27.379 & 41.529 & $29.360 .873,66$ & $44.852 .262,01$ & $74.213 .135,67$ \\
Total & & & $\mathbf{2 2 5 . 9 0 0}$ & & & $\mathbf{3 4 5 . 5 9 8 . 7 2 3}$ \\
\hline
\end{tabular}

Fonte: Elaboração dos autores a partir dos dados de AEPS InfoLogo, 2017. 
Em relação a mortalidade, destaca-se que o quantitativo de óbitos notificados nos anos de 2012 a 2018 foi de 223, sendo 40,8\% no sexo masculino e 51,2\% no sexo feminino. Com maior quantitativo em indivíduos com mais de 50 anos (Tabela 2).

Tabela 2 - Mortalidade por ansiedade em relação ao sexo e faixa etária no período de 2014 a 2018.

\begin{tabular}{cccc}
\hline Faixa Etária & Masculino & Feminino & Total \\
\hline 15 a 19 anos & 1 & - & $\mathbf{1}$ \\
20 a 29 anos & 6 & 5 & $\mathbf{1 1}$ \\
30 a 39 anos & 4 & 13 & $\mathbf{1 7}$ \\
40 a 49 anos & 8 & 13 & $\mathbf{2 1}$ \\
50 a 59 anos & 17 & 17 & $\mathbf{3 4}$ \\
60 a 69 anos & 19 & 18 & $\mathbf{3 7}$ \\
70 a 79 anos & 17 & 14 & $\mathbf{3 1}$ \\
$\geq 80$ anos & 19 & 52 & $\mathbf{7 1}$ \\
Total & $\mathbf{9 1}$ & $\mathbf{1 3 2}$ & $\mathbf{2 2 3}$ \\
\hline
\end{tabular}

Fonte: Elaboração dos autores a partir dos dados de DATASUS, 2021.

No tocante a cor/raça, percebe-se maior mortalidade em indivíduos de cor/raça branca. E no que diz respeito ao grau de escolaridade, demarca-se maior mortalidade em indivíduos com até sete anos de escolaridade (Tabela 3).

Tabela 3 - Mortalidade por ansiedade em relação a escolaridade e a cor/raça no período de 2014 a 2018.

\begin{tabular}{|c|c|c|c|c|c|}
\hline Escolaridade & Branca & Preta & Parda & Ignorado & Total \\
\hline Nenhuma & 22 & 2 & 19 & 1 & 44 \\
\hline 1 a 3 anos & 28 & 4 & 13 & - & 45 \\
\hline 4 a 7 anos & 38 & 2 & 10 & 1 & 51 \\
\hline 8 a 11 anos & 26 & - & 6 & - & 32 \\
\hline$\geq 12$ anos & 11 & - & 3 & - & 14 \\
\hline Ignorado & 25 & 2 & 6 & 4 & 37 \\
\hline Total & 150 & 10 & 57 & 6 & 223 \\
\hline
\end{tabular}

Fonte: Elaboração dos autores a partir dos dados de DATASUS, 2021.

Em relação ao estado civil, chama-se atenção à mortalidade dos indivíduos casados, porém ao dicotomizar essa variável percebe-se que a mortalidade dos não casados é superior em quase todos os anos (Tabela 4). 
Tabela 4 - Mortalidade por ansiedade em relação ao ano de óbito e ao estado civil no período de 2014 a

\begin{tabular}{lcccccccc}
\hline Estado civil & $\mathbf{2 0 1 2}$ & $\mathbf{2 0 1 3}$ & $\mathbf{2 0 1 4}$ & $\mathbf{2 0 1 5}$ & $\mathbf{2 0 1 6}$ & $\mathbf{2 0 1 7}$ & $\mathbf{2 0 1 8}$ & Total \\
\hline Solteiro & 6 & 9 & 7 & 6 & 8 & 8 & 14 & $\mathbf{5 8}$ \\
Casado & 10 & 6 & 9 & 7 & 9 & 16 & 17 & $\mathbf{7 4}$ \\
Viúvo & 6 & 2 & 7 & 8 & 8 & 4 & 13 & $\mathbf{4 8}$ \\
Separado judicialmente & 3 & 2 & - & 2 & 3 & 2 & 4 & $\mathbf{1 6}$ \\
Outro & 1 & - & 1 & 1 & - & 1 & 3 & $\mathbf{7}$ \\
Ignorado & - & 3 & 4 & 3 & 6 & - & 4 & $\mathbf{2 0}$ \\
Total & $\mathbf{2 6}$ & $\mathbf{2 2}$ & $\mathbf{2 8}$ & $\mathbf{2 7}$ & $\mathbf{3 4}$ & $\mathbf{3 1}$ & $\mathbf{5 5}$ & $\mathbf{2 2 3}$ \\
\hline
\end{tabular}

Fonte: Elaboração dos autores a partir dos dados de DATASUS, 2021.

$\mathrm{Na}$ revisão integrativa, demarca-se que a busca resultou em seis artigos científicos para a análise final. Destes, quatro artigos $(66,66 \%)$ na base de dados LILACS, dois $(33,33 \%)$ na SciELO e nenhum nas bases BDENF e PubMed. Em relação aos anos de publicação, dois artigos (33,33\%) foram publicados em cada ano (2018 e 2017), e um artigo (16,66\%) nos anos de 2019 e 2020.

Quanto aos tipos de estudos, foram incluídos quatro $(66,66 \%)$ transversais, um estudo (16,66\%) clinico randomizado e um estudo (16,66\%) intervencionista, exploratório. No que tange ao nível de evidencia observou-se que cinco artigos (83,32\%) são nível VI e um artigo (16,66\%) é nível II.

Com intuito de concentrar, integralizar/sistematizar os achados desta revisão, foi construído um quadro síntese (Figura 2).

Figura 2: Síntese dos artigos selecionados para a análise, 2021.

\begin{tabular}{|c|c|c|c|c|}
\hline $\begin{array}{c}\text { Autores } \\
\text { [Ano] }\end{array}$ & Título & $\begin{array}{l}\text { Tipo de estudo } \\
\text { [Nível de } \\
\text { evidência] }\end{array}$ & $\begin{array}{l}\text { Objetivo } \\
\text { [Amostra] }\end{array}$ & Síntese das conclusões \\
\hline $\begin{array}{l}\text { Menta et } \\
\text { al. [2020] }\end{array}$ & $\begin{array}{l}\text { Prevalência e } \\
\text { correlatos do } \\
\text { transtorno de } \\
\text { ansiedade } \\
\text { generalizada em } \\
\text { idosos } \\
\text { atendidos em } \\
\text { atenção } \\
\text { primária }\end{array}$ & $\begin{array}{c}\text { Transversal } \\
\text { [Nível VI] }\end{array}$ & $\begin{array}{c}\text { Examinar a } \\
\text { prevalência do } \\
\text { transtorno de } \\
\text { ansiedade } \\
\text { generalizada (TAG) em } \\
\text { idosos e suas } \\
\text { associações com } \\
\text { fatores } \\
\text { sociodemográficos e } \\
\text { de saúde. }\end{array}$ & $\begin{array}{l}\text { Estimou-se uma alta prevalência } \\
\text { de TAG nessa população de idosos. } \\
\text { Foram encontradas associações de } \\
\text { TAG com autopercepção de saúde } \\
\text { regular, coabitação com quatro ou } \\
\text { mais pessoas, mais de uma } \\
\text { hospitalização no último ano e } \\
\text { história de quedas. }\end{array}$ \\
\hline $\begin{array}{l}\text { Silva et al. } \\
\text { [2019] }\end{array}$ & $\begin{array}{l}\text { Prevenção da } \\
\text { depressão e } \\
\text { ansiedade em } \\
\text { idosos } \\
\text { residentes na } \\
\text { comunidade: o } \\
\text { papel da } \\
\text { atividade física }\end{array}$ & $\begin{array}{l}\text { Ensaio clínico } \\
\text { randomizado } \\
\text { [Nível II] }\end{array}$ & $\begin{array}{l}\text { Avaliar a eficácia da } \\
\text { atividade física com } \\
\text { uma estratégia de } \\
\text { cuidado escalonado } \\
\text { colaborativo; e } \\
\text { comparar a eficácia da } \\
\text { atividade física na } \\
\text { prevenção da } \\
\text { depressão }\end{array}$ & $\begin{array}{l}\text { Novas políticas de saúde poderiam } \\
\text { ser implementadas, visando } \\
\text { reduzir o número de idosos com } \\
\text { depressão e ansiedade na atenção } \\
\text { primária. Além disso, o } \\
\text { treinamento pode ser } \\
\text { implementado para que as } \\
\text { ferramentas de triagem possam } \\
\text { ser utilizadas para fazer uma }\end{array}$ \\
\hline
\end{tabular}




\begin{tabular}{|c|c|c|c|c|}
\hline & & & $\begin{array}{l}\text { subsindrômica e da } \\
\text { ansiedade. }\end{array}$ & $\begin{array}{l}\text { identificação precoce de } \\
\text { transtornos mentais. }\end{array}$ \\
\hline $\begin{array}{l}\text { Araújo et } \\
\text { al. [2018] }\end{array}$ & $\begin{array}{l}\text { Dor lombar e } \\
\text { transtornos } \\
\text { mentais comuns } \\
\text { na Estratégia } \\
\text { Saúde da } \\
\text { Família: uma } \\
\text { associação } \\
\text { pouco } \\
\text { reconhecida }\end{array}$ & $\begin{array}{l}\text { Transversal } \\
\text { [Nível VI] }\end{array}$ & $\begin{array}{l}\text { Descrever o perfil } \\
\text { sociodemográfico dos } \\
\text { pacientes atendidos } \\
\text { na Estratégia Saúde da } \\
\text { Família de quatro } \\
\text { capitais brasileiras } \\
\text { com dor lombar e } \\
\text { investigar a associação } \\
\text { entre dor lombar e } \\
\text { depressão, ansiedade } \\
\text { e somatização. } \\
\end{array}$ & $\begin{array}{l}\text { Considerando a dor lombar como } \\
\text { uma das queixas de maior } \\
\text { prevalência na Atenção Primária e } \\
\text { sua associação significativa com } \\
\text { ansiedade e somatização, } \\
\text { recomenda-se a abordagem da } \\
\text { ansiedade e somatização em } \\
\text { pacientes com queixa de dor } \\
\text { lombar. }\end{array}$ \\
\hline $\begin{array}{l}\text { López et } \\
\text { al. [2018] }\end{array}$ & $\begin{array}{l}\text { Medicina } \\
\text { Familiar e } \\
\text { Comunitária } \\
\text { como fonte de } \\
\text { cuidados em } \\
\text { Saúde Mental }\end{array}$ & $\begin{array}{l}\text { Transversal } \\
\text { [Nível VI] }\end{array}$ & $\begin{array}{l}\text { Analisar o papel do } \\
\text { médico de família na } \\
\text { atuação em Saúde } \\
\text { Mental na América } \\
\text { lbérica para apoiar a } \\
\text { saúde integral das } \\
\text { pessoas que sofrem } \\
\text { de transtornos em } \\
\text { decorrência de } \\
\text { situações de conflitos } \\
\text { (armados ou não), } \\
\text { emergências e } \\
\text { desastres naturais, } \\
\text { bem como aqueles } \\
\text { presentes no dia a dia. }\end{array}$ & $\begin{array}{l}\text { O corpo docente das residências } \\
\text { do MF deve se encarregar de } \\
\text { ações que promovam o } \\
\text { autocuidado dos alunos, visando } \\
\text { facilitar o processo de } \\
\text { aprendizagem e o preparo para a } \\
\text { prática da profissão em um } \\
\text { ambiente tão complexo como os } \\
\text { centros de Atenção Primária à } \\
\text { Saúde (APS) ou em qualquer } \\
\text { contexto em que se trabalhe com } \\
\text { a estratégia APS. }\end{array}$ \\
\hline $\begin{array}{l}\text { Queiroga } \\
\text { et al. } \\
{[2017]}\end{array}$ & $\begin{array}{l}\text { Estratégias } \\
\text { educativas para } \\
\text { redução da } \\
\text { ansiedade dos } \\
\text { cuidadores de } \\
\text { crianças com } \\
\text { cardiopatia } \\
\text { congênita }\end{array}$ & $\begin{array}{l}\text { Intervencionista, } \\
\text { exploratório, } \\
\text { descritivo } \\
\text { [Nível VI] }\end{array}$ & $\begin{array}{l}\text { Avaliar a realização de } \\
\text { intervenções } \\
\text { educativas para os } \\
\text { cuidadores de crianças } \\
\text { com cardiopatia } \\
\text { congênita como } \\
\text { estratégia para } \\
\text { redução do nível de } \\
\text { ansiedade. }\end{array}$ & $\begin{array}{l}\text { As estratégias de intervenção } \\
\text { educativa produzem efeitos } \\
\text { positivos na melhoria do grau de } \\
\text { ansiedade em cuidadores de } \\
\text { crianças com cardiopatia } \\
\text { congênita. }\end{array}$ \\
\hline $\begin{array}{l}\text { Barreto; } \\
\text { Fermoseli } \\
{[2017]}\end{array}$ & $\begin{array}{l}\text { Prevalência de } \\
\text { ansiedade e } \\
\text { depressão em } \\
\text { idosos de baixa } \\
\text { escolaridade em } \\
\text { Maceió/Al }\end{array}$ & $\begin{array}{l}\text { Transversal } \\
\text { [Nível VI] }\end{array}$ & $\begin{array}{c}\text { Analisar a prevalência } \\
\text { de Ansiedade e } \\
\text { Depressão em idosos } \\
\text { de baixa escolaridade } \\
\text { da comunidade Santo } \\
\text { Onofre em Maceió - } \\
\text { AL. }\end{array}$ & $\begin{array}{l}\text { Os longevos do sexo feminino } \\
\text { apresentam estatisticamente } \\
\text { maior GDS-15 e GAl que os } \\
\text { longevos do sexo masculino. O } \\
\text { teste } \chi 2 \text { apresentou relação } \\
\text { estatisticamente significativa entre } \\
\text { o sexo dos indivíduos e a } \\
\text { ocorrência da Ansiedade ( } \chi 2 \text { = } \\
4,85 ; \mathrm{gl}=1, \mathrm{p}<0,05) \text {. }\end{array}$ \\
\hline
\end{tabular}

Fonte: Autoria própria.

\section{DISCUSSค̃O}

\subsection{Dados sobre Ansiedade}

O grande número de pessoas com ansiedade que precisam deixar de trabalhar, devido à doença, tem subido significativamente, podendo ser facilmente observado no biênio 2017/2018, visto que diferença de afastamentos concedidos chegou a aproximadamente 9 mil a mais no último ano. Os achados de Andrade e colaboradores 
(2019, p.38), vão de encontro com o supra referido, argumentando que "a ansiedade está diretamente relacionada a uma alta utilização de cuidados de saúde, gerando um enorme fardo econômico para a sociedade".

Além do mais, a demasiada capitalização de saída na saúde para portadores de ansiedade que necessitam se afastar do emprego no Brasil é fortemente perceptível. A movimentação maximizada desse recurso financeiro para transtornos mentais e comportamentais chega a ser maior do que a investida para pacientes oncológicos ou cardíacos, por exemplo, como apresenta o total de dados dentre os anos pesquisados no AEPS InfoLogo (2017). Almeida et al (2015) congruiu desta opinião, onde explana que a ansiedade é um problema de saúde pública frequente nos idosos, a ponto de se igualar a diabetes mellitus e a hipertensão arterial.

Não diferente deste estudo, a recorrência de concessão de benefícios ao sexo feminino prevalece ao apresentar quadros ansiogênicos. (MENTA et al, 2020; LÓPEZ et al, 2018). Maximiano-Barreto e Fermoseli (2017) concordaram ao inferir relação entre o sexo e a ocorrência de ansiedade significativamente pelo teste $X^{2}(\chi 2=4,85 ; g l=1, p<$ $0,05)$, sendo o público de mulheres com pouco mais de $78 \%$ contra $21,96 \%$ do sexo masculino. Outros dados sociodemográficos estão prevalentes e convergem entre estudos são de indivíduos de etnia branca e de maior escolaridade. (MENTA et al, 2020; ALEXANDRINO-SILVA et al, 2019; MAXIMIANO-BARRETO e FERMOSELI, 2017).

Quanto à mortalidade, poucas pessoas falecem diretamente pela patologia em estudo. Compreende-se esse fato ao relembrar que nos atestados de óbitos têm-se a causa principal, secundária e terciária, estando esta mais evidente nas causas não principais. Logo, a percepção dos dados adquiridos para este estudo, aborda o quantitativo de óbitos como causa principal, pois são eles os inseridos nos sistemas de notificação e consequentemente alimentam o Sistema de Informação de Mortalidade. Dessa forma é possível explicar o total da baixa da taxa de mortalidade encontrada.

Pensando como diagnósticos secundários ou terciários de uma certidão de óbito, a ansiedade se torna uma patologia de alta mortalidade, por ser uma enfermidade relacionada com a depressão, o uso e abuso de álcool e outras drogas e, além disso, tem associação direta com o suicídio. (ALEXANDRINO-SILVA et al, 2019)

No estudo de Serpytis et al (2018), a ansiedade é considerada uma possível causa de mortalidade se associada com cardiopatias, estando aumentado os distúrbios no 
sexo feminino. Similarmente, a pesquisa de Smeijers et al (2017) associa ansiedade com pré alterações cardíacas em indivíduos acima de 65 anos, implicando no aumento da taxa de mortalidade.

Fernandes et al (2018), apresenta em seu estudo técnicos de enfermagem da atenção básica com ansiedade. Encontra-se como fator desencadeante do adoecimento, a sobrecarga de trabalho, estrutura física comprometida, a desvalorização profissional e a baixa remuneração. Mesmo com tais condições, a maioria dos profissionais foram classificados com baixa ansiedade, refutando a ideia do ter ansiedade se tornar um vínculo de patologia grave. Todavia, os que foram categorizados com alto nível do distúrbio foram facilmente percebidos ao olhar clínico, pela presença dos efeitos que os agravos à saúde mental destes profissionais acarretam na vida pessoal, na atividade cotidiana, no âmbito de trabalho, no relacionamento pessoal e interpessoal e, também, na assistência prestada a comunidade. Esse compilado nos remete a repercussão negativa da doença, mesmo sem ocasionar o óbito.

\subsection{Ações da ESF na manutenção integral da saúde de pessoas com ansiedade}

Os artigos evidenciados neste estudo com assistência da APS perante a ansiedade demonstraram a necessidade da educação em saúde com os usuários do sistema em suas diferentes necessidades.

As intervenções foram chamadas de educativas para produzirem efeitos positivos na melhora ou amenização do quadro de ansiedade, como relataram Queiroga et al (2017) para os cuidadores de crianças cardiopatas e Araújo et al (2018) para os usuários do sistema ESF com queixa de algia lombar. De outra forma, López (2018), procurou abordar a necessidade de promoção do autocuidado da amostra ansiogênica de seu trabalho, os alunos de medicina, como forma de facilitar no processo de aprendizagem destes futuros profissionais.

Não completamente divergente, Silvia et al (2019) coloca a necessidade de novas políticas a serem implementadas na APS para reduzir o número de idosos acometidos. Conjuntamente, demonstra a necessidade da prática física obrigatória a esses pacientes, usuários da unidade de saúde, como forma de triagem precoce para identificação de transtornos mentais. 
Vale a pena ressaltar que a ESF é um sistema complexo dentro da rede municipal, mas cada uma possui equipe única e multidisciplinar, facilitando a inserção de novos protocolos e, destes, estratégias de educação em saúde ou implantação de políticas mais efetivas e organizadas.

O perfil de usuários demonstrados por essas ações já citadas seria dissemelhante, desde cuidadores, idosos, estudantes de medicina ou simplesmente usuários do sistema que se queixam de uma dor lombar. Mostra-se aqui a equidade de possibilidades a distintos indivíduos com introdução de estratégias ou atividades exitosas que possam ser adotadas pela ESF na manutenção integral da saúde de pessoas com ansiedade.

Acentua-se que nem todos os artigos desta revisão apresentaram recursos de prevenção ou promoção da doença em si e, por conseguinte, consegue-se verificar a pequena disponibilidade de artigos sobre o assunto. Outrossim, a qualificação do nível de evidência deste estudo apresentou-se somente em um estudo nível II (ensaio clínico) e os demais de nível VI (transversal), sendo compreendidos como de baixa evidência científica e, por isto, demonstrando a escassez de recursos literários de maior cientificidade para abordar ações perante a ansiedade em uma APS. Assim, deve-se propor a inclusão de protocolos e estruturação das unidades.

\section{CONSIDERAÇÔES FInRIS}

A ansiedade se tornou um mal do século XXI, representada com altas taxas no sistema de saúde, em informes de saúde e ademais, associada a diversas patologias já anteriormente consideradas como graves.

A apresentação de gastos maiores para doenças mentais do que outras patologias, infere a existência de mais transtornos mentais do que outras enfermidades. Óbitos possuem taxas diretamente baixas, mas o percentual de afastamentos e benefícios concedidos a funcionários ansiogênicos é alto e ocasiona ônus ao sistema financeiro do país.

A ESF na população visa minimizar os danos causados pelos impactos da ansiedade e ações de promoção da saúde se tornam fundamentais. A educação em saúde e benfeitorias de protocolos seriam meios viáveis de garantir uma assistência integral ao usuário. 
Uma das limitações do presente estudo foram as baixas disponibilidades e qualidades dos artigos científicos, reforçando-se a importância de investimentos que viabilizem novos estudos sobre a temática.

\section{REFERÊCCIAS}

ALMEIDA, M. A. S. O., Lemes, A. G., Nascimento, F. V., Fonseca, M. N. P. I., Rocha, E. M. D., Volpato, R. J., ... \& CARDOSO, T. P. (2015). Fatores de risco associados à depressão em idosos no interior de Mato Grosso. Revista Baiana de Saúde Pública, 39(3), 627.

AMERICAN PSYCHIATRIC ASSOCIATION. DSM-5: manual diagnóstico e estatístico de transtornos mentais. 5. ed. Porto Alegre: Artmed, 2014.

ANDRADE, J. V. et al. Ansiedade: um dos problemas do século XXI. Revista de Saúde ReAGES, v. 2, n. 4, p. 34-39, 2019.

ANUÁRIO ESTATÍSTICO DA PREVIDÊNCIA SOCIAL InfoLogo - DATAPREV (AEPS InfoLogo). Secretaria Especial de Previdência e Trabalho. Ministério da Economia. 2017. Disponível em: http://www3.dataprev.gov.br/infologo/ Acesso em janeiro 2021.

ARAÚJO, J. A. et al. Dor lombar e transtornos mentais comuns na Estratégia Saúde da Família: uma associação pouco conhecida. Rev Bras Med Fam Comunidade. n. 13, v. 40, p. 1-14, 2018. Doi: http://dx.doi.org/10.5712/rbmfc13(40)1740

BRASIL. Base de dados - Estatísticas de Previdência Social, 2020. Disponível em: http://www3.dataprev.gov.br/infologo/ Acesso em janeiro 2021.

BRASIL. Lei n.10.216 de 06 de abril de 2001. Dispõe sobre a proteção e os direitos das pessoas portadoras de transtorno mental e redireciona o modelo assistencial em saúde mental. Brasília, DF, 9, abr. 2001. Disponível em: http://www.planalto.gov.br/ccivil_03/LEIS/LEIS_2001/L10216.htm Acesso em dezembro 2020.

BRASIL. Ministério da Saúde. Política Nacional de Atenção Básica. Brasília: Ministério da Saúde, 2012

BUSS, P. M.; PELLEGRINI FILHO, A. A saúde e seus determinantes sociais. Physis: revista de saúde coletiva, v. 17, p. 77-93, 2007. Disponível em: https://www.scielosp.org/article/physis/2007.v17n1/77-93/

FERNANDES, B. M. A. et al. Ansiedad en técnicos de enfermería de atención primaria. Enferm. glob., Murcia, v. 17, n. 51, p. 90-122, $2018 . \quad$ Doi: http://dx.doi.org/10.6018/eglobal.17.3.289541. 
GALVAO, C. M. Níveis de evidência. Acta paul. enferm., v. 19, n. 2, p. 5, 2006. Doi: https://doi.org/10.1590/S0103-21002006000200001

HERDMAN, T. H.; KAMITSURU, S. Nanda International nursing diagnoses: definitions \& classification 2018 - 2020. 11aㅡ edi. Porto Alegre (RS): Artmed; 2018.

HORTA, W. A. Processo de enfermagem. São Paulo: EPU, 1979.

LÓPEZ, M.M. et al. La Medicina Familiar y Comunitaria como fuente de cuidados de Salud Mental. Rev Bras Med Fam Comunidade. n. 13 (Suppl 1), p. 54-68, 2018. Doi:http://dx.doi.org/10.5712/rbmfc13(40)1856

MAXIMIANO-BARRETO, Madson Alan; FERMOSELI, André Fernando de Oliveira. Prevalência de ansiedade e depressão em idosos de baixa escolaridade em Maceió/Al. Psic., Saúde \& Doenças, Lisboa, v. 18, n. 3, p. 801-813, dez. 2017. Doi:http://dx.doi.org/10.15309/17psd180314.

MENDES, K. D. S.; SILVEIRA, R. C. C. P.; GALVÃO, C. M. Uso de gerenciador de referências bibliográficas na seleção dos estudos primários em revisão integrativa. Texto \& Contexto-Enfermagem, v. 28, 2019.

MENTA, Caroline et al . Prevalence and correlates of generalized anxiety disorder among elderly people in primary health care. J. bras. psiquiatr., Rio de Janeiro, v. 69, n. 2, p. 126-130, June 2020. Doi:https://doi.org/10.1590/0047-2085000000267.

OMS - Organização Mundial da Saúde. Constituição da Organização Mundial da Saúde. Documentos básicos, suplemento da 45a edição. 2006. Disponível em: https://www.who.int/governance/eb/who_constitution_sp.pdf.

OMS - Organização Mundial da Saúde. Depression and Other Common Mental Disorders: Global Health Estimates. Geneva; 2017

PEREIRA, Naiara Pinto Alves; LANZA, Fernanda Moura; VIEGAS, Selma Maria da Fonseca. Living under treatment for Systemic Hypertension and Diabetes Mellitus: Feelings and behaviors. Rev. Bras. Enferm. v. 72, n. 1, p. 102-110, fev. 2019. Doi:http://dx.doi.org/10.1590/0034-7167-2016-0500.

QUEIROGA, Andrey Vieira et al. Educational strategies for the anxiety reduction of caregivers of children with congenital heart disease Estratégias educativas para redução da ansiedade dos cuidadores de crianças com cardiopatia congênita. Revista de Pesquisa: Cuidado é Fundamental Online, [S.I.], v. 9, n. 4, p. 1061-1067, oct. 2017. ISSN 2175-5361. doi:http://dx.doi.org/10.9789/21755361.2017.v9i4.1061-1067. 
ROTHER, E. T. Revisão sistemática $X$ revisão narrativa. Acta paul. enferm., São Paulo, v. 20, n. 2, p. v-vi June 2007. Disponível em: https://doi.org/10.1590/S010321002007000200001

SERPYTIS, Pranas et al. Diferenças por Sexo na Ansiedade e Depressão após Infarto Agudo do Miocárdio. Arq. Bras. Cardiol., São Paulo, v. 111, n. 5, p. 676-683, Nov. 2018. doi:https://doi.org/10.5935/abc.20180161.

SILVA, C. A. et al. Prevenção da depressão e ansiedade em idosos residents na comunidade: o papel da atividade física. Arco Clin. Psiquiatria (São Paulo). v. 46, n. 1, p.14-20, 2019. Doi: http://dx.doi.org/10.1590/0101-60830000000185

SMEIJERS, Loes et al. Ansiedade e raiva imediatamente antes do infarto do miocárdio e mortalidade em longo prazo: características de pacientes de alto risco. Journal of Psychosomatic Research, v. 93, p. 19-27, 2017. Doi: https://doi.org/10.1016/j.jpsychores.2016.12.001

SPIELBERGER, C. D.; GORSUCH, R. L.; LUSHENE, R. E. Manual for the state-trait anxiety inventory. Palo Alto: Consulting Psychologist Press; 1970. 


\title{
CAPITULO XII
}

\section{ERRADICAÇ̃̃O DA SÍFLLIS COחGÊกITT: DESAFIOS ENFRENTADOS PELA ATERÇÃO PRIITÁRIA À SAÍUEE E ACORTRIBUIÇC̃O DA ERFERTIAGEM}

\author{
DDI: 10.51859/AMPLLA.APS276.1121-12
}

\author{
Beatriz de Brito Pinto ${ }^{1}$ \\ Sandy Siqueira de Alencar Almeida ${ }^{2}$ \\ Márcia Keuly Barbosa Josias ${ }^{3}$ \\ Juliana Bezerra de Oliveira ${ }^{4}$ \\ Jamile Domingos do Nascimento ${ }^{5}$ \\ Liene Ribeiro de Lima ${ }^{6}$
}

\begin{abstract}
${ }^{1}$ Graduanda do curso de Enfermagem. Centro Universitário Católica de Quixadá - UNICATÓLICA
${ }^{2}$ Graduanda do curso de Enfermagem. Centro Universitário Católica de Quixadá - UNICATÓLICA

${ }^{3}$ Graduanda do curso de Enfermagem. Centro Universitário Católica de Quixadá - UNICATÓLICA

${ }^{4}$ Graduanda do curso de Enfermagem. Centro Universitário Católica de Quixadá - UNICATÓLICA

${ }^{5}$ Graduanda do curso de Enfermagem. Centro Universitário Católica de Quixadá - UNICATÓLICA

${ }^{6}$ Docente do curso de Enfermagem. Centro Universitário Católica de Quixadá - UNICATÓLICA
\end{abstract}

\section{RESUTIO}

As Infecções Sexualmente Transmissíveis (IST) apresentam uma alta incidência, onde mais de um milhão de pessoas adquirem uma IST diariamente. Dentre essas infecções, destaca-se a Sífilis Congênita, a qual é responsável por complicações de grande relevância clínica que pode levar ao óbito fetal. Observa-se que, no Brasil, nos anos de 2016 a 2020, foram notificados 106.768 casos de sífilis congênita. Diante disso, a pesquisa teve como objetivo evidenciar os desafios enfrentados pela Atenção Primária a Saúde no combate às altas taxas de sífilis congênita e a contribuição da enfermagem. O estudo trata-se de uma revisão bibliográfica que foi levando em consideração as produções efetuadas nos últimos cinco anos. Constatou-se que dentre os principais desafia enfrentados pelos serviços da Atenção Primária à Saúde são a falta de pré-natal de qualidade, escassez de insumos necessários para o tratamento, falha de comunicação efetiva entre profissional e gestante, deficiência no tratamento em ambos os parceiros e falha nas estratégias de notificação e dificuldade na eficácia em educação em saúde e fatores situação socioeconômica. Diante desse cenário, evidenciou-se a importância da assistência de Enfermagem perante essa gravidade, onde através da sua consulta no âmbito do pré-natal, tem papel relevante na prevenção de agravos e diagnósticos, com ênfase na promoção do cuidado e oferta de assistência integral à saúde da mulher e da criança. Assim, elencar os desafios enfrentados na Atenção Primária contribui para desenvolver e aprimorar ações eficazes no combate à doença e diminuição de impactos para saúde pública brasileira.

Palavras-chave: Desafios. Sífilis Congênita. Atenção Primária a Saúde. Enfermagem. 


\section{IกTRODUÇÃO}

As Infecções Sexualmente Transmissíveis (IST) são infecções transmitidas por meio da relação sexual que tem como agente causador microrganismos, que possam ser vírus, bactérias e protozoários (Ministério da Saúde, 2020).

De acordo com estimativas da Organização Mundial da Saúde (OMS) é visto que mais de um milhão de pessoas adquirem uma IST diariamente. Observa-se que cada ano possui uma estimativa de $\mathbf{5 0 0}$ milhões de pessoas que adquiriram uma das IST curáveis (gonorreia, clamídia, sífilis e tricomoníase) (BRASIL, 2015).

Dentre essas IST, salienta-se que a Sífilis apresenta complicações de grande relevância clínica, pois se trata de uma infecção causada pela bactéria Treponema Pallidum que pode ser transmitida de duas formas: por meio da relação sexual desprotegida ou transmissão vertical durante a gravidez da mãe infectada para o feto (HOLANDA et al., 2020).

A transmissão vertical ocorre por via transplacentária ou durante a passagem do feto pelo canal do parto nos casos em que há lesões ativas (DIAS, et al., 2019). Segundo Freitas et al., (2019), aproximadamente um milhão de mulheres grávidas são infectadas por sífilis em todo o mundo. De acordo com o Departamento de Doenças de Condições Crônicas e Infecções Sexualmente Transmissíveis do Ministério da Saúde, nos anos de 2016 a 2020 foram notificados 106.768 casos de sífilis congênita entre crianças com menos de 7 dias de nascimento e 12 anos de idade. Portanto, a sífilis materna e congênita caracteriza-se como problemas de saúde pública, por sua grande incidência e graves desfechos tanto gestacionais quanto ao feto, sendo responsável por abortamentos, perdas fetais tardias e óbitos neonatais (ARAÚJO et al., 2019).

A transmissão vertical de Sífilis Congênita é abordada por meio de políticas públicas de saúde desde 1990; no entanto, as dificuldades no enfrentamento dessa problemática se configuram com a permanência de números ainda significativos de casos e, decorrente disso, com comorbidades e óbitos neonatais. Dentre as políticas públicas atuais existentes, a Rede Cegonha enfatiza que na assistência prestada pela Atenção Primária à Saúde haja o diagnóstico precoce e tratamento adequado das ISTs, para que assim as mulheres possam ser investigadas por meio da implementação de testes rápidos e triagem para Sífilis. Referida estratégia é determinante para a redução 
vertical da sífilis, pois com a detecção da Sífilis na gestante é possível realizar a prevenção e tratamento a fim de reduzir bruscamente os índices da transmissão vertical dessa IST (SILVA, 2018; FREITAS et al., 2019; SANTOS, GOMES, 2019).

A Sífilis congênita torna-se, assim, importante marcador da qualidade da assistência materno - fetal, uma vez que, os serviços de assistência ao pré-natal ofertados na Atenção Primária são a porta de entrada para a eliminação da transmissão vertical (SANTOS, GOMES, 2019; FREITAS et al., 2019).

Embora os programas de rastreamento da Sífilis no pré-natal tenham obtido boa expansão no território brasileiro, ainda existem inúmeros empecilhos ao rastreio e tratamento de referida patologia (FREITAS et al, 2019). Nota-se que a existência tanto de recursos para diagnóstico e tratamento de forma acessível e simples defronta-se com a disparidade no controle da sífilis (DIAS et al., 2019).

Dentro da Atenção Primária, há a participação do profissional Enfermeiro, onde desempenha diversas atividades com ênfase na promoção do cuidado e oferta de assistência à saúde da mulher e da criança, atuando também na prevenção e tratamento da Sífilis (ARAÚJO et al., 2019).

Diante do contexto da epidemia das IST no aspecto congênito, bem como a atuação dos profissionais de saúde visando minimizar esse cenário epidemiológico, o presente estudo tem como objetivo de descrever os desafios enfrentados no combate à sífilis congênita na Atenção Primária e o papel da enfermagem.

\section{REUISÃO BIBLIOGRÁFICA}

Diante das publicações presentes na literatura científica acerca da sífilis congênita, elencaram-se as problemáticas enfrentadas pela saúde pública brasileira no âmbito da atenção básica e a contribuição da enfermagem apresentados nos tópicos a seguir.

\subsection{Desafios relacionados à redução da Sífilis Congênita}

De acordo com um estudo realizado na América Latina e Caribe (ALC), destacase que os principais desafios relacionados à redução da sífilis congênita são o atendimento qualificado do pré-natal com a cobertura de teste de sífilis, treinamento de profissionais da saúde para o diagnóstico da patologia, tratamento e 
acompanhamento das mães e recém-nascidos infectados, o acesso a partos institucionais, disponibilidade de testes rápidos e de penicilina benzatina e qualidade laboratorial (SILVEIRA et al, 2019).

No cenário brasileiro, mediante pesquisa realizada pela Organização Mundial da Saúde (OMS), em 2016, observou-se disponibilidade escassa de penicilina benzatina para o tratamento após o diagnóstico da sífilis congênita (SILVEIRA et al, 2019). Segundo Dias et al., (2019) a penicilina apresenta eficácia no tratamento da Sífilis na gestante, pois possibilita a cura da infecção e consequentemente previne a transmissão vertical. Assim, é imprescindível sua disponibilização nas Unidades Básicas de Saúde.

Outro aspecto salientado por Miranda et al., (2019) é a dificuldade comunicativa dos profissionais de saúde com as gestantes durante o pré-natal, que resulta na não compreensão da doença e na adesão por parte destas mulheres e de seus companheiros quanto o tratamento. Nesse ínterim, a adoção de medidas de educação em saúde com ênfase na Sífilis congênita, orientações sobre o uso dos preservativos e prevenção de IST são temáticas importantes para serem abordadas por meio de campanhas midiáticas a fim de informar a população (DIAS et al., 2019).

A falta de estratégias para notificar o parceiro com diagnóstico de sífilis compreende um importante fator para o aumento de casos de sífilis congênita, uma vez que quando não há um acompanhamento desse paciente, aumenta as chances de situações de reinfecção e disseminação, além de possíveis complicações da doença. Nota-se que a estratégia de notificação de IST'S possibilita o rastreamento, tratamento de qualidade, apoio emocional e a proteção à saúde. Dessa forma, é necessário que haja o registro e notificação completa dessa IST e, consequentemente, o encaminhamento e acompanhamento rigoroso do casal, fornecimento da medicação e explicação sobre a importância da adesão terapêutica.

Além da dificuldade em notificar os casos de sífilis em parceiros das gestantes, Machado et al (2018) apresenta ainda problemas quanto à adesão ao tratamento e falta de comprometimento da própria mulher e de suas parcerias sexuais em seguir com o tratamento. Com o intuito de conscientizar esse púbico sobre a importância do tratamento, a prática da educação em saúde é, então, o principal mecanismo para alcançar a participação masculina e o tratamento efetivo da Sífilis. 
Sob outro ângulo, os desafios apresentados por gestantes para o aumento da incidência da sífilis congênita, referem-se aos aspectos socioeconômicos, que se reproduzem na dificuldade de se deslocar aos serviços de saúde, falta de comprometimento em realizar as orientações dadas nas consultas de pré-natal sobre os cuidados preventivos para IST, se ausentar do ambiente de trabalho formal e das atividades de casa. Referidas situações são explanadas também por profissionais de Enfermagem na Atenção Primária (MIRANDA et al., 2019).

\subsection{Preualência da Sífilis de transmissão uertical}

A Sífilis é uma doença prevenível e passível de tratamento que, no entanto, observa-se um crescimento ascendente nos últimos 10 anos no país (MIRANDA et al, 2019). Diante disso, a qualidade da assistência ao pré-natal e atuação da atenção básica frente ao combate aos altos índices de sífilis no Brasil possui muitos desafios, pois a representatividade desta doença no cenário epidemiológico do país ainda é preocupante, colocando-se em questão a qualidade do controle da sífilis durante as ações do pré-natal no âmbito da atenção primária (MANTALVÃO, 2017).

Salienta-se que a assistência de pré-natal funciona como uma porta de entrada para observação e a identificação precoce da sífilis em gestantes, sendo utilizada como estratégia importante a fim de evitar a transmissão vertical, refletindo, portanto, na diminuição dos índices de sífilis congênita (FREITAS, 2019).

Segundo Miranda (2019) há falhas na atuação dos profissionais que compõem a Estratégia de Saúde da Família (ESF) quanto às ações de promoção, prevenção e tratamento, que contribuem para o aumento de novos casos da doença. Consequentemente, há necessidade de desenvolver ações de educação permanente e de transformar o processo de trabalho em continuidade programada, bem como, atualizar esses profissionais a título de aprendizagem, de acordo com a conduta da prática atual (LAZARINI, BARBOSA, 2017).

\subsection{Papel da Enfermagem no combate a Sífilis Congênita}

O enfermeiro é o profissional responsável pela consulta enfermagem na assistência pré-natal dentro da atenção básica, assumindo, então papel de extrema relevância na prevenção de agravos e diagnósticos, pois realiza o primeiro contato com as gestantes, desenvolvem ações preventivas individuais e coletivas, além de práticas 
educativas com palestras sobre a sífilis através da ESF em escolas, reuniões em comissões locais nos bairros e nas visitas domiciliares (MIRANDA, 2019).

Diante do diagnóstico de IST, a Enfermagem desempenha papel significativo ao direcionar o cuidado diante a nova realidade das mulheres, pois essa situação pode gerar incompreensão sobre a patologia, conflitos familiares, impactos sociais, tendo repercussões negativas na vida da paciente atendida. Nota-se que há fatores que colaboram para a falta de busca ativa, que são justificados por possíveis julgamentos, preconceitos, abuso físico e psicológico que podem ocorrer (DIAS et.al, 2020).

Em alguns casos, as mulheres não se sentem amparadas por profissionais e serviços de saúde, o que contribui para a visão equivocada sobre a patologia adquirida, que predispõe a alusão à anormalidade e as expõe até ao desenvolvimento de quadros depressivos. Assim, o profissional deve conduzir o cuidado de forma comprometida, sensibilizado com adoção de medidas de cunho educativo e social favorecendo assim o estabelecimento da assistência integral (SILVA et al., 2018).

Auxiliar no processo terapêutico, na promoção da qualidade de vida, desenvolver atividades de educação em saúde e realizar o acolhimento são papéis desempenhados pelo enfermeiro que contribui para a participação ativa da cliente atendida e estímulo do seu autocuidado (SILVA et al., 2018).

Portanto, o protagonismo da mulher/gestante relacionada à valorização da sua responsabilidade atuante no processo de promoção à saúde é primordial para o enfrentamento e continuidade da rede de combate à contaminação pela sífilis. A atuação da Estratégia Saúde da Família (ESF) destaca-se ao revolucionar a realidade da Atenção Primária por propiciar a criação de vínculo entre as clientes e profissionais de saúde (SANTOS et al., 2020).

\section{CONSIDERAÇÔES FInPIS}

A identificação dos principais desafios relacionados à transmissão vertical da Sífilis na Atenção Primária é fundamental para atuação eficiente no combate à doença e seus impactos na saúde pública brasileira.

Com a revisão de literatura constatou-se a necessidade de intensificar e aprimorar as ações de enfermagem durante o pré-natal, por meio da comunicação efetiva entre gestante e profissional, como também a realização de uma educação em 
saúde de qualidade e efetiva com a realidade das mulheres e seus parceiros, a utilização de testes para Sífilis, estratégias de rastreamento e tratamento de parceiros.

Os aspectos socioeconômicos apresentados pelas gestantes também evidenciam a importância do olhar holístico considerando os demais determinantes sociais de saúde que circundam a sua realidade de vida. Ainda outra questão relevante é a necessidade de ofertar e ter a disponibilidade de medicamentos para tratamento da sífilis para as gestantes e seus parceiros. Referidos posicionamentos, coloca em destaque ações de gestão em saúde que devem ser reintegradas a fim de minimizar os índices de morbimortalidade materno-infantis associados à Sífilis Congênita.

\section{REFERÊRCIAS}

ARAÚJO, Michelle Andiara de Medeiros et al. Linha de cuidados para gestantes com sífilis baseada na visão de enfermeiros. 2019.

BRASIL. Ministério da Saúde. Gabinete do Ministro. Infecções Sexualmente Transmissíveis. Brasília, 2020. Disponível em: <http://www.aids.gov.br/ptbr/publico-geral/o-que-sao-ist> Acesso em: 05 de mar de 2021.

DA SILVA, Jéssika Natany et al. IMPACTOS DO DIAGNÓSTICO DA INFECÇÃO SEXUALMENTE TRANSMISSÍVEL NA VIDA DA MULHER. Enfermagem em Foco, [S.I.], v. 9, n. 2, out. 2018. ISSN 2357-707X. Disponível em: <http://revista.cofen.gov.br/index.php/enfermagem/article/view/1058/440>. Acesso em: 06 mar. 2021. doi:https://doi.org/10.21675/2357707X.2018.v9.n2.1058

DIAS, Mariana de Sales et al. Síntese de evidências para políticas públicas de saúde: enfrentamento da sífilis congênita no âmbito da atenção primária à saúde. BIS, Bol. Inst. Saúde (Impr.), p. 89-95, 2019.

Dias MS, Goiotto EM, Cunha MR, Nichiata LIY. Síntese de evidências para políticas de saúde: enfretamento a sífilis congênita no âmbito de atenção primária á saúde.Brasil, 2020.

Freitas CHSM, Forte FDS, Roncalli AG, Galvão MHR, Coelho AA, Dias SMF. Fatores associados ao pré-natal e testagem para HIV e sífilis durante a gravidez na atenção primária à saúde. Rev Saude Publica. 2019; 53: 76.

HOLANDA, Elison Costa et al. Avaliação epidemiológica da sífilis congênita na região Nordeste do Brasil. Research, Society and Development, v. 9, n. 8, p. e914986541-e914986541, 2020.

Lazarini FM, Barbosa DA. Educational intervention in Primary Care for the prevention of congenital syphilis. Rev. Latino-Am. Enfermagem. 2017;25:e2845. 
MIRANDA, Avanilde Paes; NASCIMENTO, Heloiza Helena Gomes do; ROCHA, Maria Imaculada Salustiano. O enfermeiro frente ao acompanhamento de mulheres com sífilis na estratégia saúde da família. Nursing. Säo Paulo, p. 2615-2620, 2019.

MACHADO, Isadora et al. Diagnóstico e tratamento de sífilis durante a gestação: desafio para enfermeiras?. Saúde e Pesquisa, v. 11, n. 2, p. 249-255, 2018.

MANTALVÃO AS. Desafios para Redução da Sífilis Congênita: avaliação da implantação das Ações do Pré-Natal no âmbito da Rede Cegonha na Atenção Básica em Palmas Tocantins. Salvador - BA 2017

SILVA, Jéssika Natany da et al. Impactos do diagnóstico da infecção sexualmente transmissível na vida da mulher. Enferm. foco. Brasília, p. 23-27, 2018.

SANTOS, Priscilla Araújo dos; GOMES, Andréa da Anunciação. Ações na estratégia saúde da família para combate à sífilis congênita. Rev. baiana saúde pública, p. 85-93, 2019.

SILVEIRA, Mariangela F et al. Evolução para a eliminação da sífilis congênita em América Latina e Caribe: uma análise multipaíses. Rev Panam Salud Publica. 2019; 43: e31. 


\title{
OERFERTIEIRO PRESENTE RA REDE SOCIAL DE APOIO DE ADOLESCENTES GRÁUIDAS
}

\author{
DDI: 10.51859/AMPLLA.APS276.1121-13
}

\author{
Carolina Carbonell Demori ${ }^{1}$ \\ Laís Antunes Wilhelm ${ }^{2}$
}

\begin{abstract}
${ }^{1}$ Enfermeira. Doutora em Ciências da Saúde. Universidade Federal de Pelotas-UFPEL
${ }^{2}$ Enfermeira. Doutora em Enfermagem. Professora Adjunta Universidade Federal de Santa Catarina-UFSC
\end{abstract}

\section{RESUTO}

O estudo teve como objetivo conhecer os atores que apoiam adolescentes grávidas durante sua gestação e que forma de apoio oferecem. Trata-se de uma pesquisa qualitativa, desenvolvida de janeiro a julho de 2016, por meio de mapa mínimo das relações e entrevista semiestruturada com vinte e cinco adolescentes grávidas que realizavam o pré-natal nas Unidades Básicas de saúde com estratégia saúde da família em município no interior do Rio Grande do Sul. Os dados foram submetidos à análise de conteúdo. Como resultados tem-se que a rede social de apoio que abrangeu a equipe de saúde teve predominância dos enfermeiros, por meio de atitudes, condutas e práticas de apoio informacional. Conclui-se que o pertencimento a uma rede de apoio social parece estimular as adolescentes grávidas no processo de construção de sua história de vida e vivência da gestação. Identificou-se a necessidade de trabalho integrado da equipe que assiste à adolescente grávida.

Palavras-chave: Gravidez na adolescência. Apoio social. Estratégia saúde da família.

\section{IกTRODUÇÃO}

A rede social é entendida como um conjunto complexo de relações entre membros de uma família ou de um sistema social como a escola, instituições de saúde e de assistência social, dentre outras. É uma ferramenta importante para o desenvolvimento e a proteção da saúde do adolescente e da população em geral (COSTA et al., 2015).

A noção de redes sociais nasceu na Antropologia social e na Sociologia. $\mathrm{Na}$ década de 50, destacam-se os trabalhos de John Barnes que tratou das relações informais de parentesco, amizade e vizinhança em uma comunidade norueguesa de pescadores e camponeses. Barnes introduziu a ideia de rede social como um recurso de 
análise. Para ele, as redes seriam o conjunto de vínculos interpessoais entrecruzados, conectados às ações das pessoas e às instituições da sociedade. Barnes adotou ainda a imagem de rede social como um conjunto de pontos conectados por linhas, em que os pontos representam os indivíduos ou grupos e as linhas indicam a interação entre as pessoas (BARNES, 1987).

Para Silva (2010), as redes sociais podem ser classificadas em formais e informais. A primeira abrange tanto as organizações sociais como hospitais, programas governamentais, serviços de saúde e os profissionais, médicos, assistentes sociais, psicólogos e enfermeiros, que estão organizados para prestar assistência; e a segunda inclui os indivíduos da família, amigos, vizinhos, padres e grupos sociais, como clubes e igreja.

Devido ao termo rede social ser utilizado por diversas áreas do conhecimento e receber destaque nas ciências sociais, há uma polissemia em sua definição conceitual. Assim, adotar-se-á, neste estudo, a conceituação de Sluzki (2010) por considerar-se mais apropriada ao foco deste trabalho.

Para Sluzki (2010, p. 41), "a rede social pessoal pode ser definida como a soma de todas as relações que um indivíduo percebe como significativas ou define como diferenciadas da massa anônima da sociedade". Essa rede é representada por Sluzki através de um Mapa Mínimo das Relações (MMR), que leva em consideração todos os indivíduos que interagem com o sujeito. Sua operacionalização está explicitada na metodologia deste estudo.

As redes sociais são importantes ferramentas de comunicação e auxílio social entre os seus membros. De acordo com Meira et al. (2013), as funções das redes sociais se dividem em apoio emocional - que inclui disponibilidade de alguém com quem se possa falar e que fomenta sentimentos de afeto; apoio material e instrumental - que se caracteriza por ações ou materiais proporcionados por outras pessoas para facilitar ou diminuir tarefas cotidianas; e o apoio de informação - que se refere às informações e orientações recebidas, que ajudam na compreensão do mundo.

No que concerne ao meio social econômico de mães adolescentes, estudo revela que a prevalência de gravidez na adolescência é exponencialmente maior em classes mais desfavorecidas economicamente do que em classes sociais médias ou altas (HEILBORN et al., 2006). Como possível explicação para essa diferença, os estudos 
afirmam que em ambientes fortemente marcados pela desigualdade de gênero e classe social, a maternidade não representa um problema na vida da jovem, mas um reconhecimento social entre elas, que desprovidas de projetos educacionais e laborais, seguem as expectativas tradicionais em relação ao papel de gênero (HEILBORN et al., 2006).

A rede estabelecida com os membros da família é importante para a compreensão do suporte social porque representa a estrutura na qual tal suporte poderá ou não ser encontrado. É importante salientar a possibilidade de redes que não proporcionem suporte adequado, ou seja, não proporcionem o suporte esperado. Não existe, no entanto, suporte sem rede, uma vez que o suporte é a manifestação de apoio de um indivíduo a outro indivíduo (SILVA, 2010).

Em relação aos profissionais de saúde, Meira et al. (2013) apontam em seu estudo que o profissional de saúde ainda não é visto pelas gestantes como parte integrante da rede de apoio. Nesse contexto, para Martins (2009), o atendimento às necessidades da gestante e de seus familiares pode ser prestado na assistência prénatal. Em algumas circunstâncias, é necessário incorporar recursos complementares, como os grupos de educação e promoção à saúde, para que haja correspondência a todas as demandas por cuidados, sejam estas de informação, material ou emocional.

Nesta perspectiva autores da área de enfermagem aludem que na formação acadêmica dos profissionais da saúde, raramente os educadores incluem temas relativos a sexualidade do adolescente. Ressalvadas as exceções, os conteúdos são discutidos de forma eventual, associados ao ensino de procedimentos técnicos, o que acaba reforçando o ocultamento da temática no cuidado (SEHNEM et al., 2013).

Para tanto, há necessidade de adequação da linguagem e da forma de atuação dos profissionais de saúde no nível de compreensão dos vários segmentos que constituem essa população, pois as necessidades de saúde desta parcela da população não podem ser encaradas de forma isolada, visto que estão intrinsecamente relacionadas com o contexto no qual está inserido e podem ser ativadores da rede social de apoio aos adolescentes, aqui incluídas as gestantes adolescentes. 


\section{METODOLOGIA}

Trata-se de um estudo qualitativo, de caráter descritivo realizado em um município no interior do Rio Grande do Sul, Brasil. Optou-se por realizar o estudo em Unidades Básicas de Saúde (UBSs) com Estratégia de Saúde da Família (ESF) da zona urbana deste município, totalizando sete unidades de saúde. As participantes do estudo foram 25 adolescentes grávidas no terceiro trimestre de gestação, pois pressupõe-se que, neste período gestacional, as adolescentes percebem melhor sua rede social de apoio. As adolescentes foram convidadas a participar do estudo na consulta de prénatal, sendo que a amostra foi intencional.

O tamanho da amostra foi determinado pelo critério de saturação de dados em pesquisa qualitativa. Assim, seguiu-se a orientação de que o número ideal de participantes é o que reflete, em quantidade e intensidade, as múltiplas dimensões de determinado fenômeno e busca a qualidade das ações e das interações em todo o decorrer do processo (MINAYO, 2017).

A pesquisa seguiu os preceitos da Resolução no. 466/12 do Conselho Nacional de Saúde do Ministério da Saúde, tendo aprovação do Comitê de Ética, sob o protocolo no 744.013. Para garantir o anonimato, as adolescentes foram identificadas com as letras AG seguidas do número ordinal, conforme a sequência das entrevistas.

Ao início do período de coleta de dados, a pesquisadora entrou em contato, por telefone, com as enfermeiras das UBSs selecionadas para o estudo, solicitando informações sobre dia e hora das consultas de pré-natal e se naquelas datas haveriam gestantes adolescentes agendadas. Conforme resposta positiva, a pesquisadora ia até as unidades para realizar o convite de participação na pesquisa às adolescentes grávidas.

A coleta de dados foi desenvolvida de janeiro a julho de 2016, por meio da construção do Mapa Mínimo das Relações (MMR) e subsequente entrevista semiestruturada. Algumas entrevistas foram realizadas em domicílio e outras nas UBSs conforme disponibilidade de cada participante.

A utilização do $M M R$, antes da entrevista semiestruturada, possibilitou aproximação entre pesquisadora e participante, uma vez que a construção do MMR pode assinalar um caráter lúdico à entrevista permitindo fazer uma leitura da realidade a partir de suas múltiplas dimensões. O MMR está dividido em quatro quadrantes: a 
família; as amizades; as relações de trabalho ou estudo; e, as relações comunitárias, de serviço ou credo (SLUZKI, 2010).

Na dimensão desses quadrantes, apresentam-se três áreas classificadas por um círculo interno, que corresponde às relações íntimas - dentre estas, os familiares com contato cotidiano e os amigos próximos; um círculo intermediário que são as relações pessoais com menor grau de compromisso, tais como familiares intermediários, relações sociais ou profissionais com contato pessoal, porém sem intimidade; e por último, um círculo externo de conhecimentos e relações ocasionais, por exemplo, conhecidos do trabalho ou escola, bons vizinhos, familiares distantes (SLUZKI, 2010).

\section{RESULTADOS E DISCUSSÃO}

Os resultados e a discussão do estudo estão organizados em duas categorias: “A Enfermeira como membro da rede social de apoio" e "As formas de apoio recebidas".

\subsection{A enfermeira como membro da rede social de apoio}

Nos MMRs (Figuras 1 e 2), entre as pessoas citadas pelas participantes que thes prestavam apoio está a enfermeira da ESF onde realizam o pré-natal. Esse dado é relevante, visto que a consulta de pré-natal é desenvolvida pela enfermeira, o que, indiretamente, avalia o serviço de pré-natal que este profissional está prestando no município. Doze das vinte e cinco participantes citaram a enfermeira na construção de seu MMR como alguém com quem podem contar a qualquer momento, que transmite segurança e conhecimento.

Quem não pode faltar aqui nessa rodinha é a enfermeira [citou o nome], ela é muito querida, tenho o celular dela. Imagina se um médico vai me dar o celular (AG2). 
Figura 1. Mapa mínimo das relações da participante AG2. Fonte: Dados da investigação

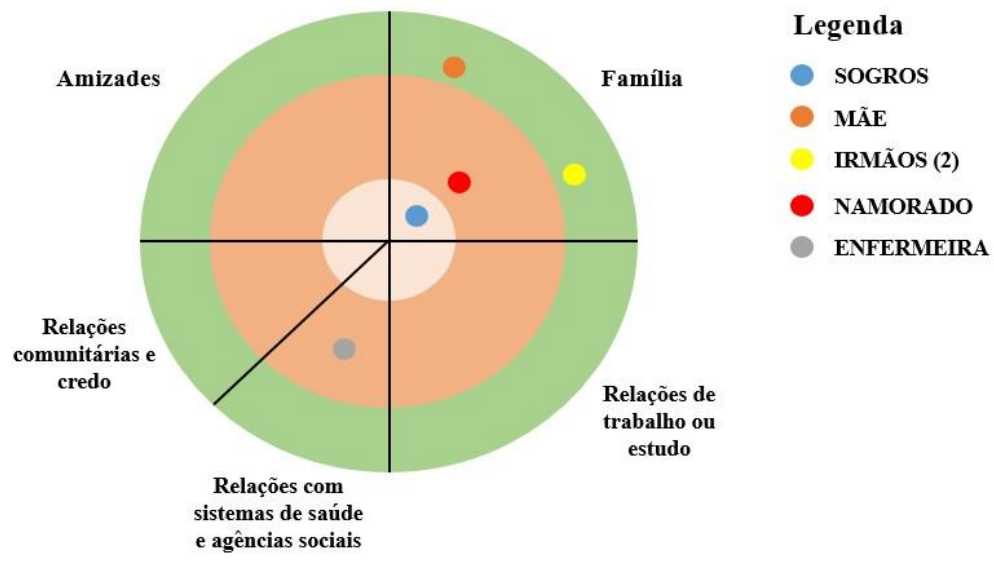

A enfermeira me apoia muito, às vezes mais que minha família. Sempre quando vou no posto ela me atende tira minhas dúvidas. Se todas as vezes que eu mandasse whats para ela [enfermeira] eu ganhasse dinheiro, eu estava rica, nos grupos também, ela não me deixa esquecer das reuniões (AG9).

Figura 2. Mapa mínimo das relações da participante AG9. Fonte: Dados da investigação

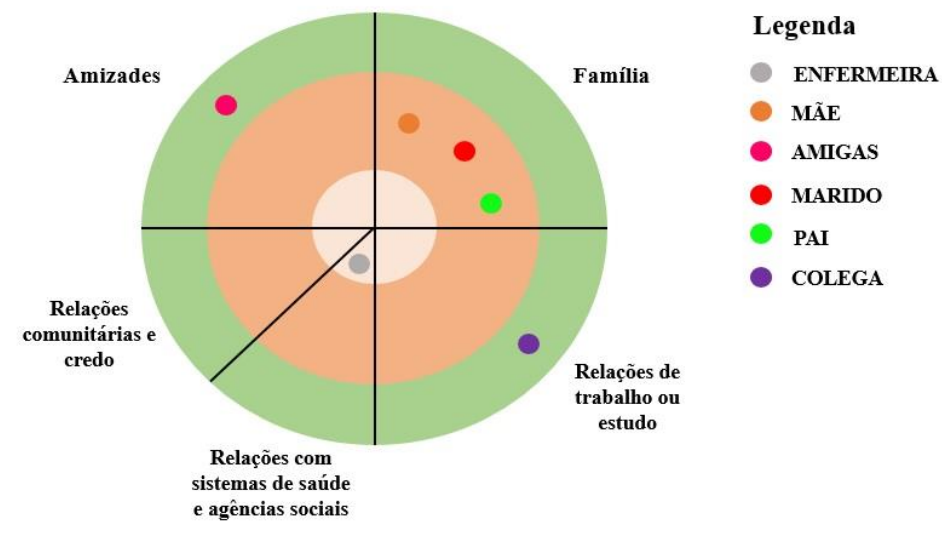

Os depoimentos e os MMRs de AG2 e AG9 revelam a confiança e o apoio percebido pelas participantes sobre as figuras das enfermeiras que assistem seu prénatal. Assim, acredita-se que, quando as referências das adolescentes são compreendidas e consideradas pelos profissionais de saúde, a lógica profissional deixa de ocupar espaço exclusivo. Com isso, é possível apreender as fontes e o modo como as adolescentes constroem referências para as próprias ações. Portanto, salienta-se a importância de uma assistência pré-natal humanizada, capaz de responder às necessidades de saúde de cada adolescente grávida (ARAÚJO e MANDU, 2016). 
Os relatos das participantes direcionam ao entendimento de que o modelo humanista constitui o eixo norteador das práticas das enfermeiras. Nota-se que a representação da gestante adolescente diante do apoio recebido pela enfermeira é de valorização do atendimento de suas necessidades subjetivas.

É possível identificar que as adolescentes percebem que as enfermeiras se empenham para se adequar às suas necessidades individuais. As falas revelam atenção clínica para o desenvolvimento saudável da gestação, considerando as suas individualidades.

Eu mando mensagem. Ela [enfermeira] é minha amiga no Facebook. Se sinto dor, ela me explica o que pode ser. Sempre acho que é trabalho de parto, mas ela me explica que quando for, vou ter certeza que é (AG6).

Ela [enfermeira] é muito atenciosa nas consultas, lê tudinho que diz nos meus exames, explica cada coisa, ela é show (AG7).

Assim, pondera-se que as relações entre as adolescentes e o apoio recebido pelas enfermeiras é fruto da forma de atuação destas.

Se não fosse ela [enfermeira], eu não saberia o que fazer. Até brindes eu ganhei nos grupos (AG11).

Graças a gravidez, ela [enfermeira] entrou na minha vida. Não tem comparação a atenção que ela me dá com a que recebi de algum médico até hoje (AG16).

Ela [enfermeira] é uma amiga. Me dá atenção, conversa, é bem diferente do médico que me atende às vezes. Ela é amiga, sabe? Falo com ela pelo whats, isso nunca ia acontecer entre eu e o médico (AG18).

Observa-se que a enfermeira é referida como uma amiga, alguém que podem contar nas horas incertas. Percebe-se que a adolescente grávida, ao ancorar sua compreensão de que o enfermeiro é mais atencioso e presta um atendimento de mais qualidade em relação a outro profissional, demonstra que a valorização da atenção é mais edificada do que propriamente o conhecimento científico em si. A justificativa para esta interpretação pode acontecer devido ao entendimento que se tem de que a maternidade coloca a adolescente em uma posição mais vulnerável, de fragilidade e que, em vista disso, o apoio afetivo é considerado mais importante em detrimento do conhecimento científico do profissional. A consulta de enfermagem no pré-natal é 
importante ferramenta para o cuidado clínico de enfermagem à gestante, haja vista que a singularidade desse momento na vida da mulher.

\subsection{As formas de apoio recebidas}

Entende-se que o apoio social oferecido à adolescente grávida é um fator fundamental no processo gestacional. Nesse contexto, o apoio corresponde ao suporte emocional e à divisão de responsabilidades.

Me informa tudo, não me deixa com dúvidas, a enfermeira me apoia muito nisso, ela sabe que sou preocupada. Quando vai ter reunião das gestantes ela manda bilhete. Até esqueci de dizer, nessas reuniões ela ensina bastante coisa. Por isso também gosto muito dela (AG3).

Se dependesse de mim eu esquecia até da consulta, mas elas não me deixam esquecer. E é bem legal, elas ensinam muita coisa, sobre o bebê, sobre o parto (AG4).

O apoio social, na perspectiva funcional de informação, configurou-se como importante na gestação, especialmente quando provido por membros da equipe de saúde, uma vez que nessa perspectiva estão as orientações sobre essa vivência. Os profissionais envolvidos no processo gestacional têm o desafio de lidar com as mudanças e as descobertas pelas quais está passando a adolescente grávida que, muitas vezes, tem dificuldades para expressar suas dúvidas e compreender o significado da maternagem e as mudanças ocorridas nessa fase.

Para proporcionar atenção qualificada às adolescentes, é necessário desenvolver técnicas de abordagem que estimulem o interesse destas na discussão da temática sexualidade, por exemplo. Por outro lado, evidências demonstram que, por vezes, o profissional de saúde não é visto pelas gestantes como parte integrante da rede social de apoio (MEIRA et al.,2013). Neste caso, é importante incorporar recursos complementares, como os grupos de educação e promoção à saúde. Também se indica a especificidade da atenção ao adolescente como um aspecto de relevância na criação de um programa eficaz, apresentando-se como desafio aos profissionais de saúde para o acionamento de recursos que atendam tal necessidade (SENNA e DESSEN, 2015).

Em relação ao enfermeiro, em especial, por representar um dos profissionais mais destacados pelas adolescentes grávidas, considera-se que este transparece seus conhecimentos às gestantes na atenção pré-natal. Contudo, na perspectiva do cuidado 
qualificado, ainda há necessidade de adequação da linguagem e da forma de atuação dos membros da equipe de saúde no nível de compreensão das adolescentes, pois as necessidades de saúde desta parcela da população não podem ser encaradas de forma isolada. Tais necessidades estão intrinsecamente relacionadas com o contexto no qual a adolescente está inserida e podem ser ativadores da rede social de apoio aos adolescentes e seus familiares.

\section{COISIDERAÇÔES FInAIS}

Evidenciou-se, neste estudo, que a enfermeira no desenvolvimento de seu papel nos serviços de saúde pode ser protagonista e multiplicador das transformações das práticas de saúde, por meio da educação em saúde. Em conjunto com outros profissionais da área da saúde, o enfermeiro também pode ser fonte de apoio para as adolescentes grávidas.

É necessária a construção de uma rede de apoio social que considere a gravidez na adolescência em todos os seus aspectos, sem apartar os elementos biológicos dos sociais, dos culturais e dos históricos. No entanto, é preciso ter a compreensão das possibilidades e limites de cada adolescente para lograr o êxito em apoiá-las e orientálas na superação das dificuldades.

A construção de uma rede que considere a gravidez na adolescência em todos os seus aspectos, sem apartar os elementos biológicos dos sociais, dos culturais e dos históricos, é necessária. No entanto é preciso ter a compreensão das possibilidades e limites de cada adolescente para lograr o êxito em apoiá-la e orientá-la na superação das dificuldades. A perspectiva de pertencer a uma rede parece estimular as adolescentes grávidas no processo de construção de sua história de vida e experiência da gestação, possibilitando a ela construir sua identidade materna e enfrentar as adversidades deste período.

A perspectiva de pertencer a uma rede de apoio social parece estimular as adolescentes grávidas no processo de construção de sua história de vida e vivência da gestação, possibilitando a construção da identidade materna e o enfrentamento das adversidades deste período. Ao mesmo tempo, os resultados desta pesquisa demonstram a importância de a gravidez na adolescência ser compreendida e 
trabalhada por toda a equipe de saúde. Com isso, ressalta-se a necessidade de atuação inter e multiprofissional nas UBSs.

\section{REFERÊกCIAS}

ARAUJO N.B, MANDÚ E.N. Produção de sentidos entre adolescentes sobre o cuidado de si na gravidez. Interface (Botucatu) 2016;20(57):363-375

BARNES, J. Redes sociais e processo político. In: FELDMAN BIANCO, B. (Org.). Antropologia das sociedades contemporâneas: métodos. São Paulo: Global, 1987. p.159-193.

BOWLING, A. Measuring social networks and social support. Measuring health: a review of quality of life measurements scales. 2a ed. Buckingham: Philadelphia, 1997. p.90-108

COSTA, Rachel Franklin da et al . Redes de apoio ao adolescente no contexto do cuidado à saúde: interface entre saúde, família e educação. Rev. esc. enferm. USP, São Paulo, v. 49, n. 5, p. 741-747, Oct. 2015.

HEILBORN, M.L. et al. (Org) 0 aprendizado da sexualidade, reprodução e trajetórias sociais de jovens brasileiro. Rio de Janeiro: Garamond e Fiocruz, 2006.

MARTINS, G.D.F. Influência do apoio social sobre crenças e práticas maternas em capitais e pequenas cidades brasileiras [dissertação]. Florianópolis: Programa de Pós-Graduação em Psicologia, Universidade Federal de Santa Catarina; 2009.

MEIRA, R.B et al. Rede de apoio social durante a fase gestacional de mulheres. Rev enferm UFPE on line. Recife, V. 7(esp), P.7024-33, dez, 2013

MINAYO, M.C.S. O desafio do conhecimento: pesquisa qualitativa em saúde. 15a ed. São Paulo: Editora Hucitec; 2017.

SEHNEM, G. D. et al. A sexualidade na formação acadêmica do enfermeiro. Esc.Anna Nery. Rev. de Enf. Rio de Janeiro, v. 17, n. 1, p. 90-96, jan./mar. 2013.

SENNA, Sylvia Regina Carmo Magalhães; DESSEN, Maria Auxiliadora. Reflexões sobre a saúde do adolescente brasileiro. Psic., Saúde \& Doenças, Lisboa, v. 16, n. 2, p. 217-229, set. $2015 . \quad$ Disponível <http://www.scielo.mec.pt/scielo.php?script=sci_arttext\&pid=S1645$00862015000200008 \& \operatorname{lng}=p t \& n r m=i s o>$

SILVA, A.F.S Análise de redes sociais informais e o compartilhamento do conhecimento organizacional. Dissertação de Mestrado (Ciências Sociais)-Universidade Federal de Santa Maria, 2010. 
SLUZKI, C.E. Personal social networks and health: conceptual and clinical implications of their reciprocal impact. Families, Systems, \& Health. v.28, n.1, p.1-18. 2010. 


\title{
CAPITULO XIV
}

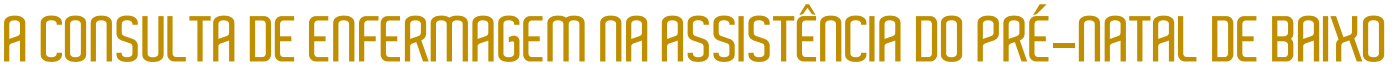 RISCO ATERDIDO NR ATERÇÃO PRIMTRRIA À SAÚDE}

\author{
DII: 10.51859/AMPLLA.APS276.|121-14
}

\author{
Liane Bahu Machado ${ }^{1}$ \\ Silvana Carloto Andres ${ }^{2}$ \\ Andressa Leão ${ }^{3}$ \\ Rafaella França Torres ${ }^{4}$ \\ Melissa Medeiros Braz ${ }^{5}$
}

1 Enfermeira. Mestranda da Universidade Federal de Santa Maria - UFSM.
${ }^{2}$ Enfermeira. Mestre.
${ }^{3}$ Enfermeira.
${ }^{4}$ Enfermeira.
${ }^{5}$ Fisioterapeuta. Professora e doutora da Universidade Federal de Santa Maria - UFSM.

\section{RESUTIO}

A Consulta de Enfermagem está presente na atenção primaria à saúde como ferramenta promotora do cuidado da gestante na atenção ao pré-natal, promovendo ações de prevenção e promoção ao cuidado da saúde. O estudo constitui-se em uma revisão integrativa da literatura, através da busca nas bases de dados: Literatura LatinoAmericana e do Caribe em Ciências da Saúde (LILACS), Scientific Eletronic Library Online (SciELO) e Base de Dados em Enfermagem (BDENF), a busca aconteceu em janeiro de 2021 e abrangeu artigos brasileiros publicados nos anos de 2016 a 2021. Após a análise inicial, foram incluídos no estudo 33 artigos que contemplavam a temática proposta. A atenção Primária a Saúde é uma das portas de entrada do sistema único de saúde no Brasil. Ficou evidente relevância da atuação do profissional enfermeiro no que diz respeito a assistência prestada para as mulheres no período gestacional, através da realização das consultas de enfermagem no pré-natal, pois esta é uma atuação que acontece de maneira a prevenir agravos e promover saúde para contribuir em uma adequada qualidade de vida durante esse momento singular na vida da mulher.

Palavras-chave: Atenção Primária à Saúde. Consulta de Enfermagem. Pré-Natal.

\section{IกTRODUÇก̃O}

A Consulta de Enfermagem (CE) retrata a cientificidade do trabalho dessa profissão, além de respaldar a tomada de decisões, identificar e avaliar as consequências da aplicação da CE pelo enfermeiro no processo saúde-doença do usuário, de sua família e da população. Em 2009, pela importância da função do profissional enfermeiro dentro 
da saúde coletiva, o COFEN publicou a Resolução no 358/2009, que na qual determina sobre a Sistematização da Assistência de Enfermagem (SAE) em serviços públicos ou privados, nos quais realiza-se o cuidado profissional de enfermagem e dá outras providências (COFEN, 2009).

A enfermagem faz uso de diversos tipos de tecnologias para exercer o cuidado e, na sua prática, o enfermeiro da Atenção Primária a Saúde (APS) realiza a Consulta de Enfermagem (CE) que, engloba dentro dessa tecnologia de cuidado uma relação entre os conhecimentos humanos, científicos e empíricos, que sistematiza o nosso exercer, e objetiva a prestação de uma assistência de maior qualidade e que possui efetividade no tocante do cuidado ao usuário/familiares/população, e para além disso a CE está assegurada por questões éticas e pelo modo reflexivo (MEIER, et al 2008).

Uma das formas mais eficazes para conquistar a confiança da população atendida na APS, é fazer cada vez mais uso da CE como estratégia de trabalho, prevendoa nos programas de saúde e valorizando-a como um instrumento qualificado para suceder um atendimento cada vez mais eficiente, responsável e humanizado à população (MACHADO; ANDRES, 2021). Dessa maneira, realizar a CE como estratégia voltada para saúde da materno/infantil, durante o pré-natal, torna-se uma ferramenta na proteção e promoção da saúde dessa população, a fim de identificar e intervir de maneira precoce diante de qualquer sinal alteração de quadro clínico.

É importante que a equipe da APS, preste cuidado de maneira integral e individualizado para cada gestante, buscando atender de maneira singular cada uma de suas demandas e aflições. Também é necessário que haja um cuidado compartilhado entre equipe, para que cada profissional preste a assistência conforme suas atribuições, fazendo os encaminhamentos sempre que necessário, para assim, contemplar a proteção, promoção prevenção de agravos e escuta qualificada das demandas que irão ocorre durante a gestação, proporcionando a criação do vínculo e atendimento humanizado (BRASIL, 2013).

No que diz respeito ao cuidado materno infantil, este vem estruturando-se e fortalecendo-se significativamente, no Brasil, através da criação e do desenvolvimento de diversas políticas públicas e consolidação da Rede Cegonha, com objetivo de minimizar as taxas de mortalidade desta população (BRASIL, 2012). 
Para assegurar que as estratégias, ações e cuidados voltados para as gestantes sejam eficazes e significativos, a atenção pré-natal precisa ser considerada e valorizada como um momento que proporciona um acolhimento adequado, a criação de vínculo de segurança, uma construção individual e que sofre influência diretamente do contexto social, familiar e dos profissionais que trabalham junto à mulher (BARRETO et al., 2015).

Com propósito de garantir um pré-natal de qualidade e eficaz, recomenda-se que as gestantes façam, pelo menos, seis consultas de acompanhamento do pré-natal, e que no mínimo, metade dessas sejam executadas pelos profissionais enfermeiros. Dessa maneira, busca-se estender a cobertura de cuidado e desenvolvimento de estratégias em tempo oportuno, bem como qualificar a assistência prestada para que a mesma seja realizada com responsabilidade, cientificidade e humanização (PEREIRA et al., 2018).

Com isso, sistematizar o cuidado no pré-natal torna-se um caminho importante, necessário e essencial a ser percorrido, valorizando a relevância do mesmo, com intuito de alcançar cada vez mais, maior efetividade e eficácia, para que assim seja obtido um avanço significativo no âmbito da saúde materno-infantil (SILVA et al., 2017).

Assim, este estudo teve como objetivo compreender a importância das ações dos enfermeiros na consulta de enfermagem no pré-natal de baixo risco atendidos na Atenção Primária à Saúde.

\section{MATERIAL E MÉTODOS}

Trata-se de uma pesquisa qualitativa, na forma de uma revisão de literatura narrativa, em razão de que a mesma possibilita efetuar busca e análise com a finalidade de encontrar os resultados sobre o tema estudado. Foram utilizadas as bases de dados eletrônicas: SciELO (Scientific Electronic Library Online) Base de Dados em Enfermagem (BDENF) e Literatura Latino-Americana e do Caribe em Ciências da Saúde (LILACS), manuais e portarias e protocolos desenvolvidos pelo Ministério da Saúde, destacandose estudos descritivos, exploratórios e experimentais. Utilizou-se os seguintes descritores: Atenção Primária à Saúde, cuidados de enfermagem e Gestantes, combinados através do operador booleano "AND", com o objetivo de refinar a pesquisa.

Dentre os critérios de inclusão foram selecionados estudos disponíveis na íntegra, nos idioma português, que continham pelo um dos descritores. Foram incluídos estudos publicados entre os anos de 2016 a 2021, para poder abranger a temática da 
Atenção Primária à saúde, optou-se em artigos brasileiros. Foram excluídas editorias, teses e dissertações. Após a seleção dos artigos a serem utilizados, por meio da análise de várias pesquisas pelos autores, foram excluídos estudos incompletos, que não abordavam o tema, e aqueles não se enquadravam dentro dos idiomas e período de tempo delimitado pelo estudo.

Para análise de dados foi realizado leitura dos artigos escolhidos a partir do ano de publicação, objetivo principal do estudo, modo de utilização, visando assim, uma melhor compreensão do estudo. Uma análise de conteúdo não deixa de ser uma análise de significados, ao contrário, ocupa-se de uma descrição objetiva, sistemática e quantitativa do conteúdo extraído das comunicações e sua respectiva interpretação, a análise de conteúdo é um conjunto de instrumentos de cunho metodológico em constate aperfeiçoamento, que se aplicam a discursos (conteúdos e continentes) extremamente diversificados BARDI (2011).

\section{REUISÃO BIBLIOGRÁFICA}

Após a leitura minuciosa e com aplicação dos critérios de inclusão e exclusão, a busca resultou em 16 artigos os quais elencaram os seguintes eixos para discussão: $A$ Consulta de enfermagem como estratégia fundamental na qualidade do pré-natal; e: $\mathrm{A}$ Atenção Primaria à Saúde na promoção do cuidado da saúde da Gestante.

\subsection{A Consulta de enfermagem como estratégia fundamental na qualidade do pré-natal}

A gestação é retratada como acontecimento complexo e singular, que englobam inúmeras mudanças, biológicas, psicológicas, sociais e culturais, comprovando que os cuidados pré-natais precisam ir ultrapassar a dimensão biológica.

Comprovou-se que a CE durante o período do pré-natal é de extrema importância, principalmente em virtude de como são estabelecidas as relações de comunicação entre o profissional enfermeiro e a gestante e seus familiares, em que são favorecidos um bom acolhimento e a escuta qualificada, tornando um momento para além de somente uma prática profissional que tem como objetivo central o modelo biológico, o que implica em uma troca de conhecimentos e valorização da mulher. A CE auxilia para que a gestante vivencie esse momento da vida com mais tranquilidade e 
segurança, pois Ihe proporciona entender e expressar os inúmeros sentimentos vivenciados (OLIVEIRA et al., 2017).

O enfermeiro é um dos profissionais essenciais para efetuar essa assistência de pré-natal, por ser qualificado para atuar com estratégias de promoção à saúde, prevenção de doenças e utilizar a humanização no cuidado prestado através da consulta de enfermagem. Elaborando um plano de assistência de enfermagem na consulta de pré-natal até o puerpério, conforme necessidades identificadas e priorizadas, estabelecendo as intervenções e orientações, também promovendo a interdisciplinaridade das ações com a odontologia, medicina, nutrição e a psicologia (BORTOLI et al., 2017).

A CE apresenta-se como uma ferramenta relevante, pois têm como objetivo assegurar a ampliação do maior alcance e melhoria da qualidade de assistência no prénatal, especialmente através da introdução das intervenções de maneira preventiva e promocionais as gestantes. É necessário, do profissional além da competência técnica, sensibilidade para entender o ser humano e a oscilação deste, e o sua maneira de viver e habilidade de comunicação, fundamentada na escuta e na ação dialógica (MATOS et al., 2013).

É a CE, que se proporciona um cuidado que compreende para além que somente um momento tecnicista e biológico, mas uma estratégia que busca realizar um acolhimento qualificado e que tem como consequência positiva o fortalecimento do vínculo entre o profissional e o usuário. A realização da CE é fundamentada nos princípios de universalidade, equidade, resolutividade e integralidade. (MACHADO; ANDRES, 2021).

A assistência ao pré-natal constitui-se no exame físico da gestação, investigação dos antecedentes gineco-obstétricos, história de comorbidades, dados socioeconômicos junto das orientações repassadas, pois é por meio das orientações que os profissionais trabalham a parte educativa auxiliando essas mulheres para o esclarecimento de suas dúvidas e inseguranças e romper mitos. Dessa maneira, a gestante passa a sentir-se mais segura e confiante e como consequência disto, passar a preparar-se melhor durante a gestação (ROCHA; ANDRADE, 2017).

A assistência ao pré-natal é essencial para a preparação da maternidade e não pode ser vista como uma simples assistência médica, mas sim, como uma atividade de 
prevenção de alterações clínico-obstétricas e assistência emocional. É necessário que a saúde da mulher seja ponderada em sua totalidade, transpassando a condição biológica de reprodutora e oportunizando para ela, o direito de participar acentuadamente nas tomadas de decisões que compreendam sua saúde (OLIVEIRA et al., 2017).

Todavia, é necessário reforçar que é de responsabilidade dos profissionais da área da saúde uma considerável parcela dos aspectos necessários para assegurar a qualidade da assistência ao pré-natal. Para organizar métodos de assistência de enfermagem, criam-se protocolos de saúde. Estas são ferramentas elaboradas para que os profissionais de saúde desempenhem sua profissão conforme a regulamentação do exercício profissional. Por meio destes, os profissionais irão estar normatizados e respaldados ao exercerem suas atribuições, priorizando pela qualidade dos serviços ofertados (RAMOS et al., 2018).

É fundamental que o acompanhamento pré-natal tenha início o mais precocemente possível e que sejam feitos os exames preconizados, detectadas e tratadas de forma precoce qualquer alteração identificada, para que seja possível evitar qualquer risco ao binômio. Também é essencial que a gestante receba todas as informações, orientações e apoio em relação as modificações provocadas pela gestação, sobre alimentação apropriada, prática de atividades físicas, uso de substâncias perigosas, sinais e sintomas de risco, alívio de desconfortos, aleitamento materno, sobre seus direitos, orientações sobre o local do parto e os tipos de parto, em especial, o fisiológico (ROCHA; ANDRADE, 2017).

Em relação ao tempo das consultas e da maneira de comunicação entre profissional-gestante a partir dos aspectos comprovados, neste estudo e decorrentes das falas das mulheres demonstram o atual modelo de atenção obstétrica ainda predominante no Brasil, isto é, o modelo tecnocrático, que também tem repercussão na atenção pré-natal e faz com que o gestante, ao contrário de serem empoderadas para serem protagonistas no momento de gestação, parto e nascimento, se tornam submissas aos profissionais de saúde e com pouca autonomia (LIVRAMENTO et. al., 2019).

A maneira na qual os profissionais se reportam às gestantes, possuem influência direta na garantia da adesão à assistência pré-natal. Com isso, destaca-se a relevância do envolvimento de todos os profissionais com objetivo de assegurar o acolhimento e 
resolutividade nas ações voltadas para à saúde materna-infantil, assim é necessário que os profissionais estejam mais engajados, proporcionando a atenção ética e integral à mulher na fase reprodutiva de maneira singular. As estratégias que objetivam esse fim fomentam a aproximação da usuária, auxiliando para uma a assistência pré-natal com qualidade (JARDIM et al., 2019).

A partir disso, é indispensável a atuação do enfermeiro neste momento tão único da vida da mulher, no sentido e acolher com atenção, escutar, orientar com embasamento teórico e prático, explanar todas suas dúvidas e inseguranças e principalmente emponderar as gestantes para que as mesmas sintam-se valorizadas e tenham segurança e precisão para a tomada de decisões, que vão de encontro com suas vontades (OLIVEIRA et al., 2017).

\subsection{A Atenção Primaria à Saúde na promoção do cuidado da saúde da Gestante}

O pré-natal revela-se como um período adequado para desenvolver ações educativas e de prevenção, utilizando como ferramentas o vínculo do diálogo e a escuta. Essa estratégia permite aproximação entre enfermeiros, gestante e seu acompanhante, fortalecendo o conhecimento e o esclarecimento de dúvidas. Porém, cabe aos profissionais que assistem a esta população a avaliação constante dessa estratégia, a fim de controlar a efetividade das orientações dadas, uma vez que a qualidade do serviço prestado é fator importante (BRASIL, 2015).

A atenção à Saúde da Mulher, no decorrer do ciclo gravídico-puerperal, é um desafio para as autoridades em saúde de todo o mundo, no que diz respeito à qualidade da assistência ofertada e marcos conceituais. É necessário que o ciclo gestatório seja acompanhado de maneira satisfatória durante suas três fases: gravidez, parto e puerpério, para que a gestante receba uma assistência individual, integral e de melhor qualidade. Dessa maneira, enfatiza-se a relevância da efetivação de estratégias pelos gestores e profissionais com o intuito de assegurar o acesso à saúde, assim como a qualidade e responsabilidade do serviço prestado (BALSELLS et al., 2018).

Por compreender que os fatores sociais, afetivos e espirituais irão repercutir no desenvolvimento da gestação, um bom profissional de saúde estará sempre atento a qualquer queixa por entender em como essa gestante se vê e em como ela sente-se em relação as transformações que acontecem no período gravídico e, posteriormente, ao 
período puerperal. Por esse motivo, não pode-se perder essa questão de vista, para tornar o pré-natal um momento de criação de vínculo entre os profissionais de saúde e as gestantes. E com isso, iremos ter um cuidado para além do biológico. Em seu objetivo principal, o pré-natal busca o bem estar do binômio mãe-bebê no decorrer de toda a gestação, buscando o desfecho apropriado (OLIVEIRA et al., 2017).

O pré-natal torna-se dessa maneira, um objeto indispensável, tanto pela consulta em si quanto pela preparação da gestante para os momentos posteriores deste período. Cabe ao profissional, desse modo, apoiar e preservar a saúde das gestantes, realizando suas orientações e condutas com embasamento teórico e prático, buscando sempre satisfazer às expectativas dessas gestantes e familiares, respeitando e compreendendo suas escolhas e preferências (SILVA et al., 2017).

Comprovou-se a relação entre a adesão das gestantes nas consultas de pré-natal e complicações na saúde materno-infantil, houve uma grande procura dessas usuárias pelo serviço na Unidade Básica de Saúde, e ainda demonstra que a assistência prestada é de boa qualidade, o que reflete diretamente na aprovação da mãe e seus familiares e como consequência, evita os acontecimentos indesejáveis durante a gestação, parto e puerpério. Sendo assim, é de suma relevância que o serviço que as usuárias busquem seja de fácil acesso, e também, que os profissionais de saúde estejam habilitados e dedicados para desempenharem uma assistência humanizada e de qualidade para a gestante (GUIMARÃES et al., 2018).

O acontecimento de ser mãe é considerado como uma das atribuições da mulher na sociedade, neste momento da vida, a mulher tem sua feminilidade aumentada, e uma das principais necessidades são os cuidados e as orientações que precisam ser realizadas na gestação e puerpério, transmitidas no decorrer das consultas de pré-natal no âmbito da APS. Dessa maneira, as gestantes possuem em sua comunidade as consultas de pré-natal, como um momento essencial e necessário para que as mesmas e seus familiares possam apontar seu medos, inseguranças e dúvidas sobre esse momento único na mulher e seu feto, sem receio de nenhum julgamento por parte do profissional (PEREIRA et al., 2017).

Através dos resultados encontrados, verificou-se que alguns pontos impossibilitavam os enfermeiros de efetuar as ações no pré-natal, os quais são necessário recursos para deliberação. Dentre esses recursos encaixam-se: o 
desenvolvimento de capacitações teóricas e práticas específicas, o fornecimento de informações em relação a importância da inserção e uso dos protocolos assistenciais e a elaboração de protocolos que fomentem a relação do trabalho médico e de enfermagem com objetivo da melhoria da qualidade da assistência (SCHMITT et al., 2018).

Neste sentido, nota-se a relevância do profissional habilitado e engajado com o serviço que o mesmo oferta, sempre alerta ao quadro clínico que as gestantes apresentam e realizando as orientações necessárias para que a mesma obtenha uma vida saudável para dar continuidade à gestação sem intercorrências. (PEREIRA et al., 2017). Neste momento, é importante que o profissional ajuste suas orientações ao mais próximo possível da realidade que gestante está inserida, pois assim haverá maior probabilidade da mesma em ouvir e seguir as orientações realizadas.

Em relação ao esclarecimento de dúvidas durante o pré-natal, evidenciou-se que o enfermeiro é o principal responsável por propagar as informações e elucidar os conhecimentos com relação a gravidez e ao parto. Compreende-se que o enfermeiro possui grande importância na transmissão de conhecimentos sobre o momento da parturição e cuidados necessários, e no fortalecimento da gestante como a protagonista da sua história.

Evidenciou-se o reconhecimento sobre as contribuições do enfermeiro no prénatal, descrito pelo acompanhamento, orientação, explanação de dúvidas e a extensão da segurança na gestação. Características estas, relacionadas à formação holística e humanística desse profissional, a qual proporciona uma atenção minuciosa, qualificada e imersa nas reais necessidades e vontades da gestante (JARDIM et al., 2019).

Dessa maneira, a gestação é aponta como um momento singular na vida de uma mulher, no qual o ideal é que esse período aconteça de maneira saudável, sem intercorrências e que haja somente as alterações fisiológicas habitualmente, sem ofertar nenhum risco à mãe e a seu concepto, precisando desta maneira, de um cuidado de qualidade e responsável à saúde dos mesmos (MARQUES et al., 2021).

O pré-natal é a mais importante das assistências ofertadas na unidade de saúde à mulher durante a gestação, no qual é possível realizar um acompanhamento minucioso e saudável da gestante e seu filho, prevenindo e/ou tratando as complicações 
que podem acontecer nesse momento, favorecendo, assim, para a redução dos indicadores de morbimortalidade materna e infantil.

\section{CONSIDERAÇÔES FInAIS}

Comprovou-se através deste estudo que o período gravídico puerperal é um momento singular na vida da mulher e de seus familiares os quais acompanham a mesma, período este no qual acontece inúmeras mudanças físicas e psicológicas e é de suma importância que esta mulher esteja preparada para vivenciar esse período da maneira mais prazerosa possível, sendo valorizada enquanto protagonista deste momento único e especial em sua vida.

Ficou evidente relevância da atuação do profissional enfermeiro no que diz respeito a assistência prestada para as mulheres no período gestacional, através da realização das CE no pré-natal, pois esta é uma atuação que acontece de maneira a prevenir agravos e promover saúde para contribuir em uma adequada qualidade de vida durante esse momento singular na vida da mulher.

Neste sentido, é necessário que a mulher/gestante tenha todo auxílio necessário no decorrer da gestação, realizando as consultas rotineiras de pré-natal com o profissional enfermeiro fim de prevenir agravos, promover saúde e intervir de maneira precoce diante de qualquer sinal de alteração identificado durante a assistência prestada.

O enfermeiro, por ser o profissional que está mais próximos da comunidade no âmbito da APS torna-se um agente transformador para prestar essa assistência de maneira qualificada e responsável, realizando suas orientações sempre levando em consideração o contexto em que a gestante está inserida e buscando explanar todas as dúvidas da mesma com autonomia e embasamento teórico, estimulando assim, a confiança e segurança das gestantes para vivenciar esse momento da maneira mais agradável possível e prepara-las para o momento do pós-parto, colocando-se à disposição da gestante sempre que a mesma necessitar.

\section{REFERÊกCIAS}

BALSELLS, M. M. D. et al., Avaliação do processo na assistência prénatal de gestantes com risco habitual. Acta Paul Enfermagem. v. 31, n. 3, p. 247-54, 2018. 
BARDI LAURENCE. Analise de conteúdo. Tradução Luis Reto e Augusto Pinheiro.

BARRETO, C. N. et al. "O Sistema Único de Saúde que dá certo": ações de humanização no pré-natal. Revista Gaúcha de Enfermagem, v. 36, p. 168-176, 2015.

BORTOLI, C. F. C. et al. que possibilitam a atuação do enfermeiro na atenção pré-natal. Rev Fun Care Online. v. 9, n. 4, p. 978-983, 2017.

BRASIL. Ministério da Saúde. Atenção ao pré-natal de baixo risco. Brasília: Ministério da Saúde, 2012.

Conselho Federal de Enfermagem (BR). Resolução n. 358, de 15 de outubro de 2009. Dispõe sobre a Sistematização da Assistência de Enfermagem e a implementação do Processo de Enfermagem em ambientes, públicos ou privados, em que ocorre o cuidado profissional de Enfermagem, e dá outras providências. Brasília (DF): COFEN; 2009.

GUIMARAES, W. S. G. et al., Acesso e qualidade da atenção pré-natal na Estratégia Saúde da Família: infraestrutura, cuidado e gestão, Cad. Saúde Pública, v. 34, n. 5, 2018.

JARDIM M. J. A. et al., Contribuições do Enfermeiro no Pré-Natal para a Conquista do Empoderamento da Gestante. Rev Fund Care Online. v. 11, p. 432-440, 2019.

LIVRAMENTO, D. V. P. et al., Percepções de gestantes acerca do cuidado pré-natal na atenção primária à saúde. Rev Gaúcha Enfermagem, v. 40, 2019.

MACHADO, L. B.; ANDRES, S. C. A consulta de enfermagem no contexto da Atenção Primaria em Saúde: Relato de experiência. Research, Society and Development, v. 10, n.1, 2021.

MARQUES, B. L. et al. Orientações às gestantes no pré-natal: a importância do cuidado compartilhado na atenção primária em saúde. Escola Anna Nery, v. 25, n. 1, 2021.

MATOS, D. S. et al. Atuação do enfermeiro na assistência ao pré-natal de baixo risco na estratégia saúde da família em um município de Minas Gerais. Rev. Enfermagem Revista, v. 16. n. 1, 2013.

MEIER, M. J. et., al. O processo de enfermagem como uma tecnologia para o cuidado: um instrumento para a prática. In: Anais do 2o Seminário Internacional de Trabalho em Enfermagem. Curitiba, 2008.

Ministério da Saúde (BR) Atenção ao Pré-natal de baixo risco. Brasília. 2013.

Ministério da Saúde (BR). Departamento de Informática do Sistema Único de Saúde. Sisprenatal. Brasília (DF): Ministério da Saúde; 2015.

OLIVEIRA, A. C. et al. AS PROPORÇÕES DO CUIDADO PRE NATAL NA CONSULTA DE ENFERMAGEM. Rev. UNINGÁ, Maringá, v. 54, n. 1, p. 176-184, 2017. 
PEREIRA, A. A. et. al. Percepções de gestantes ribeirinhas sobre a assistência pré-natal. Revista Cogitare Enfermagem, v. 23, n. 4, 2018.

PEREIRA, D. O. et al., AVALIAÇÃO DAS CONSULTAS DE PRÉ-NATAL: ADESÃO DO PRÉNATAL E COMPLICAÇÕES NA SAÚDE MATERNO-INFANTIL. Revista Ciência Plural. v. 3, n. 3, 2017.

RAMOS, A. S. M. B., et al. Assistência de enfermagem no pré-natal de baixo risco na atenção primária. J Manag Prim Health Care, v. 9, n.3, 2018.

ROCHA, A. C; ANDRADE, G. S, et al. Atenção da equipe de enfermagem durante o prénatal: Percepção das gestantes atendidas na rede básica de Itapuranga - go em diferentes contextos sociais. Revista Enfermagem Contemporânea, v. 6, n. 1, p. 30-41, abr. 2017.

São Paulo. Edição 70. 2011.

SCHMITT, P. M. et al., A REVELAÇÃO DE PUÉRPERAS NA ASSISTÊNCIA PRÉ-NATAL EM ESTRATÉGIAS DE SAÚDE DA FAMÍLIA. Revista Saúde e Pesquisa, v. 11, n. 1, p. 129-137, 2018.

SILVA, L. A. et. al., O CUIDADO NO PRÉ-NATAL: UM VALOR EM QUESTÃO. Cogitare Enfermagem. v. 22, n. 2, 2017. 


\title{
CAPITULO XV
}

\section{ATUAÇÃO DO ENFERTEEIRO NA PREUERÇÃO E COMBBATE À DESกUTRIÇÃO IחFAחTIL MAESTRATÉGIA SAÍLE DA FAMIIILIA}

\author{
DDI: 10.51859/AMPLLA.APS276.1121-15
}

\begin{abstract}
Francisca Paula de Lacerda Furtado ${ }^{1}$
Caio Ramon Queiroz ${ }^{2}$

Camilly Rodrigues Zaranza ${ }^{3}$

Flávia Raquel Miranda Vasconcelos ${ }^{4}$

Miryan Carla Beviláqua Nascimento ${ }^{5}$

Jose Henrique de Lacerda Furtado ${ }^{6}$
\end{abstract}

Especialista em Gestão de Saúde Pública (UFF). Graduada em Enfermagem (UBM). Técnica Administrativa em Educação/Enfermagem no Instituto Federal do Rio de janeiro (IFRJ-Campus Volta Redonda).

2 Mestrando em Ensino em Ciências da Saúde e do Meio Ambiente (UNIFOA). Graduado em Fisioterapia (ESTÁCIO/FIC). Fisioterapeuta da Prefeitura Municipal de Volta Redonda-RJ.

${ }^{3}$ Fisioterapeuta (ESTÁCIO/FIC). Pós-graduada em Traumato-Ortopedia com Ênfase em Terapia Manual (ESTACIO/FIC).

${ }^{4}$ Fisioterapeuta (ESTÁCIO/FIC). Pós-graduada em Fisioterapia Cardiorrespiratória (ESTÁCIO/FIC).

${ }^{5}$ Fisioterapeuta (ESTÁCIO/FIC). Pós-graduada em Fisioterapia Dermatofuncional (ESTÁCIO/FIC).

${ }^{6}$ Doutorando em Saúde Pública (ENSP/FIOCRUZ). Mestre em Educação Profissional em Saúde (EPSJV/FIOCRUZ). Graduado em Enfermagem (UBM). Técnico Administrativo em Educação/Enfermagem no Instituto Federal do Rio de janeiro (IFRJ-Campus Pinheiral).

\section{RESUTIO}

Embora a prevalência da desnutrição infantil tenha diminuído no Brasil ao longo dos anos, ela continua sendo um grave problema de saúde pública, sendo considerada de difícil solução devido à sua multicausalidade. Sobretudo no contexto pandêmico atual, em que além do avanço da conjuntura de desmonte das políticas públicas no cenário brasileiro, vivenciamos o aumento das desigualdades sociais, que podem implicar no ressurgimento de diversas condições que dificultam o acesso a condições dignas de vida e saúde da população mais vulnerável. Diante disso, o objetivo central do presente capítulo, construído a partir de uma revisão bibliográfica, foi refletir acerca da importância da atuação do (a) Enfermeiro (a) inserido (a) na Estratégia Saúde da Família (ESF) para promoção à saúde da criança e na prevenção e combate à desnutrição infantil, descrevendo as principais ações e estratégias a serem utilizadas por esses enfermeiros em seu cotidiano de trabalho. Dentro desse contexto, o profissional enfermeiro exerce um papel de extrema importância nessas atividades desenvolvidas na ESF, sejam elas gerenciais, no planejamento organizacional das ações, ou assistenciais, no planejamento e implementação do cuidado à essas crianças. Dessa forma, o contexto adverso em que vivenciamos na atualidade exige um esforço coletivo no combate a situações de saúde que, volta e meia, voltam a assolar os grupos mais vulneráveis, sendo de suma importância o desenvolvimento de estudos científicos que investiguem os aspectos que interferem nesse processo, para que sejam construídas novas propostas de enfrentamento eficaz. 
Palavras-chave: Transtornos da Nutrição Infantil. Cuidados de Enfermagem. Estratégia Saúde da Família. Promoção da Saúde. Prevenção e mitigação.

\section{IกTRODUÇก̃O}

De acordo com Marcondes et al. (2003), a desnutrição constitui um problema universal de Saúde Pública em países subdesenvolvidos. O autor ressalta ainda que sua forma primária resulta da pobreza, das más condições ambientais e da marginalização social em que vivem certas populações de áreas urbanas periféricas e/ou rurais, afetando principalmente as crianças com idade inferior a 5 anos.

Segundo Sawaya (1997, p. 21):

[...] a DEP é um problema chocante, tanto em escala, quanto em gravidade; cúmplice secreto da pobreza que impede o crescimento físico e mental de uma em cada três crianças nos países em desenvolvimento. Caracteriza-se como uma doença social, responsável por um elevado número de mortes de crianças. Tem como causa três fatores essenciais: pobreza, múltiplos processos infecciosos e baixa ingestão calórica.

A desnutrição ou, mais corretamente, as deficiências nutricionais, são doenças que decorrem do aporte alimentar insuficiente em energia e nutrientes ou, ainda, com alguma frequência, do inadequado aproveitamento biológico dos alimentos ingeridos, geralmente motivado pela presença de doenças, em particular doenças infecciosas (MONTEIRO, 2003).

Nos organismos desnutridos os processos infecciosos (diarreias, doenças respiratórias, sarampo, parasitoses) apresentam-se com um curso mais prolongado e ficando mais vulneráveis a doenças oportunistas. Faz-se oportuno salientar também, que a falta de nutrientes no organismo (energia, proteínas, vitaminas, ferro, zinco), também contribui para o atraso no desenvolvimento sadio das crianças (FERRARI, 1997).

Em relação à fisiopatologia da desnutrição, Monte (2000) destaca que esta patologia afeta todos os sistemas e órgãos das crianças gravemente desnutridas. O autor sugere ainda que todos os processos do organismo entram em uma redução funcional adaptativa, como estratégia para garantir a sobrevivência. 
Ratificando o que é descrito por Monte (2000), Marcondes et al. (2003) ressaltam que a diferença entre a desnutrição e outros agravos à saúde é que ela gera uma série de respostas clínico adaptativas. Somente mais tarde, pela persistência das condições adversas em seus mais variados graus, é que a adaptação se transforma em má adaptação, deixando em evidência as manifestações clínicas decorrentes. Concomitantemente, vários mecanismos fisiopatológicos são instalados, determinando adaptações metabólicas de variadas intensidades, desencadeados e mantidos por controles hormonais que, se não reconhecidos e tratados precocemente, podem desencadear uma série de prejuízos irreversíveis no crescimento e desenvolvimento desses indivíduos.

Diante disso, a Política Nacional de Alimentação e Nutrição, por meio da diretriz de prevenção e controle dos distúrbios nutricionais e doenças relacionadas à alimentação e nutrição se propõe a implementar ações específicas para o combate ao binômio infecção/desnutrição, que afeta principalmente crianças provenientes de classes econômicas com reduzido poder aquisitivo, em regiões com baixos índices de desenvolvimento econômico e social (BRASIL, 2005).

É válido pontuarmos ainda a complexidade em torno desse processo, tendo em vista que a prevenção e o controle da desnutrição dependem também, de medidas mais amplas e eficientes de combate à pobreza e à fome e políticas de inclusão social.

Conforme descrito por Monte (2000), apesar do direito inalienável de todo ser humano não padecer de fome e desnutrição ter sido reafirmado sucessivamente em conferências dos países membros das Nações Unidas em 1948 (Declaração Universal dos Direitos Humanos), em 1974 (Conferência Mundial de Alimentação das Nações Unidas), em 1978 (Pacto Internacional de Direitos Econômicos e Declaração da Organização Mundial da Saúde (OMS) sobre "Saúde para todos no ano 2000", em 1989 (Convenção sobre os Direitos da Criança) e, mais recentemente, promovida pela OMS como sendo um direito humano, a desnutrição infantil continua a figurar como um importante desafio para a saúde pública na contemporaneidade, devido a sua magnitude e potenciais consequências desastrosas para o crescimento, desenvolvimento e sobrevivência das crianças.

No Brasil, embora a prevalência da desnutrição na infância tenha caído nas últimas décadas, o percentual de óbitos por desnutrição grave em nível hospitalar, se 
manteve em torno de $20 \%$ em 2005, muito acima dos valores recomendados pela OMS (inferiores a 5\%) (BRASIL, 2005).

No mundo contemporâneo, em que várias descobertas já foram feitas e diversas tecnologias desenvolvidas, observa-se que problemas antigos ainda assolam a população, em especial, a dos países em desenvolvimento. É notável o paradoxo existente entre o desenvolvimento e o progresso técnico-científico e, em contrapartida, a persistência de problemas sociais como a fome e a pobreza que oprimem cada vez mais as camadas mais pobres da sociedade (PAULILO, RODOLPHO, 2003).

Embora a prevalência da desnutrição infantil tenha diminuído no Brasil, ela continua a ser um grave problema de saúde pública, sendo considerada de difícil solução devido à sua multicausalidade. Conforme apresentado em um dos documentos editados pelo Ministério da Saúde (MS) brasileiro em 2005, a desnutrição constitui-se como

[...] uma doença de natureza clínico-social multifatorial cujas raízes se encontram na pobreza. A desnutrição grave acomete todos os órgãos da criança, tornando-se crônica e levando a óbito, caso não seja tratada adequadamente. Pode começar precocemente na vida intra-uterina (baixo peso ao nascer) e freqüentemente cedo na infância, em decorrência da interrupção precoce do aleitamento materno exclusivo e da alimentação complementar inadequada nos primeiros 2 anos de vida, associada, muitas vezes, à privação alimentar ao longo da vida e à ocorrência de repetidos episódios de doenças infecciosas (diarréias e respiratórias). Isso gera a desnutrição primária. Outros fatores de risco na gênese da desnutrição incluem problemas familiares relacionados com a situação sócioeconômica, precário conhecimento das mães sobre os cuidados com a criança pequena (alimentação, higiene e cuidados com a saúde de modo geral) e o fraco vínculo mãe e filho (BRASIL, 2005, p. 13)

Porém, mesmo diante da dificuldade encontrada no combate à desnutrição, dados do Sistema de Vigilância Alimentar e Nutricional (SISVAN) do Ministério da Saúde que houve uma redução significativa da desnutrição em crianças menores de cinco anos no Brasil, entre os anos de 2003 e 2008. Muitos destes êxitos obtidos, no que diz respeito à diminuição da desnutrição infantil, vêm sendo correlacionado à ampliação 
da cobertura da Estratégia Saúde da Família (ESF), responsável pela principal porta de entrada do Sistema Único de Saúde (SUS) (BRASIL, 2009).

Na área da Atenção Primária à Saúde (APS), a ESF, desde a sua criação e expansão no decorrer da década de 1990, vem se consolidando como um dos eixos estruturantes do SUS, por meio de um movimento de expressiva expansão de cobertura populacional, aprimorando em muito o acesso da população às ações de saúde (BRASIL, 2009).

Conforme destacam Melo et al. (2018), objetivando a implementação dos princípios e diretrizes formulados pela Reforma Sanitária Brasileira (RSB), o esforço de construção de um novo modelo de atenção à saúde foi materializado na APS, através da implementação do Programa de Agentes Comunitários de Saúde (PACS) e da ESF, ao longo da década de 1990.

Nesse novo modelo de atenção que foi ganhando espaço nas agendas de governo, a prática de enfermagem se insere buscando a reformulação e a integração de ações com os demais trabalhadores da equipe de saúde. Esta reformulação e integração acontecem, principalmente, através de um processo de articulação das intervenções técnicas e da interação entre os outros profissionais da equipe de saúde da família, favorecendo não só a interprofissionalidade como também, viabilizando a articulação intersetorial tão necessária, considerando a saúde como expressão de suas múltiplas determinações, dentre elas o seu processo de determinação social (PEDUZZI, 2000; FURTADO, 2020).

A partir disso, pode-se depreender que o profissional enfermeiro inserido em uma equipe da ESF, tem a oportunidade de intervir de forma significativa nesse processo. Além do desenvolvimento de ações diretas relacionadas à assistência de enfermagem integral e de qualidade às crianças nessas unidades, a busca pelo desenvolvimento de ações intersetoriais e multidisciplinares pode contribuir de forma efetiva para prevenção e o combate à desnutrição infantil.

Diante do exposto, o presente estudo apresenta como objeto de estudo a atuação do profissional Enfermeiro da ESF na prevenção e combate à desnutrição infantil. Dessa forma, o mesmo se propõe a refletir acerca da importância da atuação do (a) Enfermeiro (a) inserido (a) na ESF para promoção à saúde da criança e na prevenção e combate à desnutrição infantil, descrevendo as principais ações e estratégias a serem utilizadas por esses enfermeiros em seu cotidiano de trabalho. 


\section{DESENUULUIIIERTO}

Trata-se de um estudo construído a partir de uma pesquisa bibliográfica, realizada no período de Setembro a Novembro de 2014, nos moldes propostos por Gil (2008), que descreve que a pesquisa bibliográfica pode ser elaborada a partir de material já publicado, constituído principalmente de livros, artigos periódicos e atualmente, com material disponibilizado na internet.

Optou-se pelo resgate dos dados obtidos na pesquisa realizada anteriormente, considerando a relevância da temática no contexto pandêmico atual, em que além do avanço da conjuntura de desmonte das políticas públicas no cenário brasileiro, vivenciamos o aumento das desigualdades sociais, que podem implicar no ressurgimento de diversas condições que dificultam o acesso a condições dignas de vida e saúde da população mais vulnerável.

De acordo com o expresso na primeira Política Nacional de Atenção Básica (PNAB), editada pelo MS em 2006, a Saúde da Família constitui-se enquanto estratégia prioritária para organização da APS, de acordo com os preceitos do SUS e também, visando a sua operacionalização, cita a eliminação da desnutrição infantil como uma de suas áreas estratégicas para atuação em todo o território nacional (BRASIL, 2006).

Ratificando a importância da ESF para a prevenção da desnutrição infantil, a Unicef, reconheceu em 2008, em sua publicação "Situação Mundial da Infância 2008 Sobrevivência Infantil", a ESF como uma das principais políticas adotadas pelo país, responsável pela redução da mortalidade infantil nos últimos anos (BRASIL, 2009).

Diante disso, é possível destacar a grande importância desta estratégia como ferramenta para a prevenção e combate à desnutrição infantil visto que além de ser a principal porta de entrada do sistema público de saúde brasileiro, permite o reconhecimento dos problemas mais relevantes e das reais necessidades da população da sua área de abrangência.

Apesar disso, faz-se oportuno salientar que, ao longo dos anos, um verdadeiro desmonte dessa política foi sendo empreendido no país. Sobretudo, nos últimos anos, com a revisão da PNAB em 2017 (BRASIL, 2017), que além de propor novos arranjos para a organização da APS no país, relativizam o caráter universal do sistema público de saúde brasileiro. 
Ademais, apesar dos entraves e desafios vivenciados pela APS no contexto atual, faz-se oportuno o resgate do exposto por Chiesa, Fracolli e Sousa. (2004) que ressaltam o trabalho interdisciplinar e multidisciplinar como uma importante característica da ESF, pois não se trata apenas de médico de família, mas de uma equipe de saúde da família. Nesse contexto de atuação, embora exista uma definição de competências predefinidas, são muitas as corresponsabilidades entre seus membros, trazendo um novo desafio para os trabalhadores de saúde, o de rever sua prática diante de novos paradigmas, repensando o processo de trabalho em saúde, adotando novas metodologias, novos instrumentos de trabalho e conhecimentos.

\subsection{0 enfermeiro e as estratégias de prevenção e combate à desnutrição infantil} กล ESF

De acordo com Monteiro, Caetano e Araújo (2010, p. 407):

Em suas diferentes abordagens de cuidado, o enfermeiro exerce papel fundamental na assistência à criança, iniciado na fase da vida uterina, durante as consultas de enfermagem no pré-natal e por meio do exame físico materno, quando é possível identificar anormalidades e viabilizar condutas com vistas ao crescimento e desenvolvimento do concepto. Tais condutas, em caso de alterações, podem salvar a vida de ambos, mãe e filho.

Diante disso, surge a puericultura como ferramenta oportuna no acompanhamento integral do crescimento e desenvolvimento infantil. Área da pediatria voltada principalmente para os aspectos de prevenção e de promoção da saúde, a puericultura atua no sentido de manter a criança saudável para garantir seu pleno desenvolvimento, de modo que atinja a vida adulta sem influências desfavoráveis e problemas trazidos da infância (RICCO; CIAMPO; ALMEIDA, 2005).

Telles e Barros Filho (2003) acreditam que o enfermeiro, dentro da lógica da puericultura, possui ferramentas/metodologias assistenciais capazes de contribuir para a promoção da adequada nutrição infantil.

Para Monteiro, Caetano e Araújo (2010), a avaliação nutricional é parte integrante dessas consultas de acompanhamento do crescimento e desenvolvimento infantil realizadas pelo enfermeiro na APS, tendo como principal objetivo verificar o 
crescimento e as proporções corporais em um indivíduo ou em uma comunidade, no intuito de estabelecer atitudes de intervenção.

De acordo com Fracolli e Bertolozzi. (2001), a ESF nos propicia maior proximidade com as pessoas e seus modos de "andar na vida", principalmente através das visitas domiciliares (VD). A VD é o melhor instrumento a ser utilizado a fim de avaliar o contexto familiar em que vivem essas pessoas. Além disso, a VD favorece, não só o estabelecimento do vínculo com os usuários da unidade como, também, oportuniza um mecanismo para a realização da captação das crianças faltosas às consultas de puericultura, sendo uma ferramenta de grande valia na realização da busca ativa destas, possibilitando a realização de orientações aos familiares e conscientização à respeito da importância do acompanhamento periódico da criança.

É importante ressaltar que de acordo com Brasil (2002, p. 03):

Uma das estratégias adotadas pelo Ministério da Saúde, a partir de 1984, visando a incrementar a capacidade resolutiva dos serviços de saúde na atenção à criança, foi a de priorizar cinco ações básicas de saúde que possuem comprovada eficácia (promoção do aleitamento materno, acompanhamento do crescimento e desenvolvimento, imunizações, prevenção e controle das doenças diarréicas e das infecções respiratórias agudas). Tais ações devem constituir o centro da atenção a ser prestada em toda a rede básica de serviços de saúde. $E$, nesse sentido, o Ministério da Saúde estabeleceu normas técnicas, definiu instrumentos operacionais e promoveu a capacitação de recursos humanos.

Para que isso fosse possível a partir da nova forma de organização dos serviços com a conquista do SUS, as normas para o acompanhamento do crescimento e desenvolvimento foram gradativamente incorporadas às atividades do Programa dos Agentes Comunitários de Saúde (PACS) e da ESF. Além disso, na década de 2000, foi lançado o Programa Bolsa-Alimentação, o qual, foi substituído pelo Programa Bolsa Família, que foi criado incorporando todos os benefícios para apoiar as famílias mais pobres e garantir a elas o direito à alimentação e o acesso à educação e à saúde. Considerando o complexo contexto social em que a maioria dos casos de desnutrição infantil estão inseridos, a adoção dessas iniciativas de assistência social é imprescindível, 
no sentido de garantia de direitos a condições de vida mais dignas às populações mais vulneráveis (BRASIL, 2002).

De acordo com o Manual de acompanhamento de crescimento e desenvolvimento infantil do MS, a forma mais adequada para o acompanhamento do crescimento de uma criança, nos serviços básicos de saúde, é o registro periódico do peso no Gráfico Peso/Idade do Cartão da Criança, este cartão é um documento importante para acompanhar a saúde, o crescimento e o desenvolvimento da criança, devendo ser entregue às mães ainda na maternidade (BRASIL, 2002).

Nóbrega (2007) acrescenta ainda que, embora a avaliação da condição nutricional aplicada em estudos populacionais quase sempre utilize apenas a antropometria, na avaliação individual, alguns parâmetros devem ser levados em conta como a anamnese clínica e alimentar (quantitativa e qualitativa), o exame físico detalhado (busca de sinais clínicos e carências específicas), a própria antropometria, a avaliação da composição corporal e, por fim, os exames laboratoriais e de imagem.

Monte (2000) destaca também que, a efetiva prevenção da desnutrição infantil não pode ser um objetivo isolado em relação a medidas gerais que visem atender às necessidades básicas das populações mais vulneráveis, sendo o papel do Estado imprescindível para a garantia de direitos básicos legalmente constituídos.

Além disso, faz-se oportuno chamarmos a atenção para outra estratégia de suma importância, que pode contribuir de forma significativa nesse contexto, que consiste no desenvolvimento de ações de educação em saúde, realizadas todos os trabalhadores inseridos no contexto da ESF, em especial o enfermeiro, visto que segundo Xavier (2001, p. 12):

[...] uma das características mais exaltadas do enfermeiro durante a sua formação, diz respeito a seu papel de educador, sendo este considerado o profissional ideal para comandar atividades de cunho educativo e preventivo de várias doenças.

Portanto, o enfermeiro tem papel essencial na conscientização das famílias sobre a importância do aleitamento materno, terapia de reidratação oral, imunização, suplementação alimentar adequada, alimentações alternativas, entre outras medidas simples, de custo baixo e alto impacto na promoção da saúde das crianças. 
Porém, conforme defende Monte (2000), considerando o reconhecimento da sua multicausalidade, a desnutrição passou a ser frequentemente, preocupação de muitos, mas sem que alguém assumisse, de fato, como responsabilidade. Em diversas situações, profissionais de saúde acabam por rotular a desnutrição infantil como sendo um "problema social", adotando, por vezes, uma atitude de descaso, de pouca importância ou derrotista face à criança desnutrida ou em risco de desnutrição, e de menos valia em relação à promoção da nutrição para a saúde da criança (MONTE, 2000).

Na tentativa de ampliar o acesso da população brasileira às ações de saúde, foram implantados sucessivamente, a partir dos anos 1980, com PACS e o PSF nos anos 1990 e também, em conjunto com a OMS, com a iniciativa Atenção Integral às Doenças Prevalentes da Infância (AIDIPI), que ainda na década de 1990, já incluía ações para a promoção da nutrição infantil em nível ambulatorial (MONTE, 2000).

O enfermeiro, portanto, como profissional integrante da ESF, possui conforme já foi citado anteriormente por Teles (2003), ferramentas/metodologias assistenciais capazes de promover a nutrição infantil. Ferramentas essas de grande valia para a prevenção da desnutrição infantil. Além de promover ações de manejo dietético em parceria com outros profissionais da ESF, é capaz de prestar orientação direta às mães sobre aleitamento materno, alimentação complementar para crianças a partir de 6 meses, incluindo alimentos ricos em vitamina A, ferro, zinco, vitamina B6, incluindo ainda orientações relacionadas à alimentação da criança doente e terapia de reidratação oral, quando necessário.

Sendo assim, apesar da complexidade que envolve o processo de prevenção da desnutrição infantil, considerando a sua multicausalidade, faz-se extremamente necessário e oportuno que o profissional enfermeiro invista em ações no nível da APS em prol da adoção de hábitos alimentares saudáveis por toda a população, dentro de uma perspectiva que respeite a cultura e as condições materiais das pessoas além de, é claro, intervir de forma eficaz e articulada a fim buscar a diminuição da desigualdade social no Brasil (SILVA; ROCHA; SILVA, 2009). 


\section{CONSIDERAÇÔES FInHIS}

Diante disso, a partir do exposto, é possível identificar algumas ferramentas que facilitam o trabalho de prevenção e combate à desnutrição infantil na ESF, sendo o trabalho multidisciplinar desenvolvido nesse contexto de atuação imprescindível.

As características do trabalho desenvolvido pelas equipes interdisciplinares das Unidades de Saúde da Família permitem não só, o estabelecimento do vínculo com as famílias, facilitando assim, o reconhecimento das condições em que vivem e, consequentemente, o reconhecimento das possíveis causas dos processos carenciais como, também, a criação de uma porta de entrada para esses usuários ao sistema de saúde do município.

Além disso, considerando que a questão socioeconômica é fator preponderante entre as causas da desnutrição infantil, os profissionais da ESF, em especial, o enfermeiro em parceria com os Agentes Comunitários de Saúde (ACS), tem papel imprescindível na realização de uma avaliação criteriosa do ambiente em que vivem essas crianças, a fim de conhecer a fundo a realidade dessas famílias para, então, realizar parcerias e planejar ações que sejam, de fato, eficazes.

Dentro desse contexto, o profissional enfermeiro exerce um papel de extrema importância nessas atividades desenvolvidas na ESF, sejam elas gerenciais, no planejamento organizacional das ações, ou assistenciais, no planejamento e implementação do cuidado à essas crianças.

O cuidado dispensado pelos enfermeiros às crianças deve ser realizado de forma planejada, integrada e articulada objetivando não só, a continuidade da assistência, mas também, a integralidade e resolutividade da mesma. Para isso, é de extrema importância a criação de parcerias com instituições, sejam elas, governamentais ou não, a existência de uma rede de suporte bem articulada, em que os mecanismos de referência e contrarreferência garantam a troca de informações e, consequentemente, a integralidade da assistência e, principalmente, a existência da vontade da gestão pública em amparar e apoiar a prática do profissional enfermeiro através do estabelecimento de protocolos municipais que assegurem o exercício pleno de sua profissão. 
Portanto, a partir do exposto, recomenda-se a criação de um protocolo de ação municipal o qual, deve ser embasado nas normas preconizadas pelo MS e evidências científicas acuradas. Neste protocolo deve ser estabelecido as ações a serem realizadas, as rotinas a serem implementadas e as normas a serem seguidas, inserindo o enfermeiro como profissional ativo no processo de prevenção e combate à desnutrição infantil, com ações de acompanhamento do crescimento e desenvolvimento infantil através da consulta de enfermagem e, consequentemente, da aplicação do seu processo de trabalho.

É válido salientar ainda, que a desnutrição infantil é um problema complexo, de difícil solução devido à sua multicausalidade devendo, portanto, haver também a articulação e integração de todos os setores da sociedade, governo e dos serviços de saúde, a fim de implementar ações que visem a redução da fome, da pobreza, das desigualdades sociais e se consiga então, intervir de forma eficaz nesse contexto.

Dessa forma, o contexto adverso em que vivenciamos na atualidade exige um esforço coletivo no combate a situações de saúde que, volta e meia, voltam a assolar os grupos mais vulneráveis, sendo de suma importância o desenvolvimento de estudos científicos que investiguem os aspectos que interferem nesse processo, para que sejam construídas novas propostas de enfrentamento eficaz.

\section{REFERÊกCIAS}

BRASIL. Ministério da Saúde. Portaria n. 648, de 28 de março de 2006. Aprova a Política Nacional de Atenção Básica, estabelecendo a revisão de diretrizes e normas para a organização da Atenção Básica para o Programa Saúde da Família (PSF) e o Programa Agentes Comunitários de Saúde (PACS). Brasília, 2006c. Disponível em:<

http://bvsms.saude.gov.br/bvs/saudelegis/gm/2006/prt0648_28_03_2006_co mp.html>. Acesso em: 01 de ago. 2018.

BRASIL. Ministério da Saúde. Portaria no 2.436, de 21 de setembro de 2017. Aprova a Política Nacional de Atenção Básica, estabelecendo a revisão de diretrizes para a organização da Atenção Básica, no âmbito do Sistema Único de Saúde (SUS). Brasília, DF: Ministério da Saúde, 2017. Disponível em: <http://www.brasilsus.com.br/index.php/legislacoes/gabinete -do-ministro/16247-portaria-n-2436-de-21-de-setembro-de-2017>. Acesso em 30 jul. 2018.

BRASIL. Ministério da Saúde. Secretaria de Atenção à Saúde. Coordenação Geral da Política de Alimentação e Nutrição. Manual de atendimento da criança com 
desnutrição grave em nível hospitalar / Ministério da Saúde, Secretaria de Atenção à Saúde, Coordenação Geral da Política de Alimentação e Nutrição Brasília: Ministério da Saúde, 2005.

BRASIL. Ministério da Saúde. Secretaria de Atenção À Saúde. Departamento de Atenção Básica. Saúde da criança: nutrição infantil: aleitamento materno e alimentação complementar / Ministério da Saúde, Secretaria de Atenção à Saúde, Departamento de Atenção Básica. - Brasília: Editora do Ministério da Saúde, 2009. 112 p. - (Série A. Normas e Manuais Técnicos) (Cadernos de Atenção Básica, n.23)

BRASIL. Ministério da Saúde. Secretaria de Políticas de Saúde. Departamento de Atenção Básica. Saúde da criança: acompanhamento do crescimento e desenvolvimento infantil / Ministério da Saúde. Secretaria de Políticas de Saúde. Brasília: Ministério da Saúde, 2002.

CHIESA, A. M.; FRACOLLI, L. A.; SOUSA, M. F. Enfermeiros capacitados para atuar no Programa Saúde da Família de São Paulo: relato de experiência. Saúde em Debate, Rio de Janeiro, v. 28, n.67, p. 91-99. maio/ago. 2004.

FERRARI, A. A. Fatores de risco para desnutrição energético-protéica como base para programas de prevenção na comunidade. In: Desnutrição Urbana no Brasil em um período de transição. São Paulo: Cortez, 1997.

FRACOLLI, L. A.; BERTOLOZZI, M. A abordagem do processo saúde-doença das famílias e do coletivo. In: Manual de enfermagem[S.I: s.n.], 2001. Disponível em: $<$ https://repositorio.usp.br/directbitstream/c0a4802c-d05b-442d-87d03859fdf59d20/FRACOLLI,\%20L\%20A\%20doc\%20107.pdf >. Acesso em 14 mar. 2014.

FURTADO, J. H. L. Dilemas e contradições da reestruturação do processo de trabalho dos agentes comunitários de saúde e seus efeitos para atenção primária à saúde. 174 f. Dissertação. (Mestrado em Educação profissional em Saúde), Escola Politécnica de Saúde Joaquim Venâncio, Fundação Oswaldo Cruz, Rio de Janeiro, 2020.

GIL, A. C. Métodos e técnicas de pesquisa social. 6. ed. São Paulo: Atlas, 2008.

MARCONDES, E. et al. Pediatria Básica: pediatria clínica geral. 9a ed. São Paulo: Sarvier, 20036.

MELO, E. A. M. et al. Mudanças na Política Nacional de Atenção Básica: entre retrocessos e desafios. Saúde Debate. Rio De Janeiro, v. 42, Número Especial 1, pp. 38-51, setembro 2018.

MONTE, C. M. G. Desnutrição: um desafio secular à nutrição infantil. J. Pediatr (Rio de Janeiro), v. 76, Supl. 3, 2000. 
MONTEIRO, C. A. A dimensão da pobreza, da desnutrição e da fome no Brasil. Estudos Avançados, v.17, n. 48, São Paulo, 2003.

MONTEIRO, F. P. M.; CAETANO, J. A.; ARAÚJO, T. L. Enfermagem na saúde da criança: estudo bibliográfico acerca da avaliação nutricional. Esc Anna Nery Rev Enferm, v. 14, n. 2, p. 406-411, 2010.

NOBREGA, F. J. Distúrbios da nutrição: na infância e na adolescência. 2.ed. Rio de Janeiro: Revinter, 2007.

PAULILO, M. A. S., RODOLPHO, I. P. F. A Desnutrição Infantil e seu Significado Social. Serviço social em revista, v. 5, n.2, Jan/Jun 2003.

PEDUZZI, M. A inserção do enfermeiro na equipe de saúde da família na perspectiva de promoção de saúde. In: Anais do 1o Seminário Estadual: o enfermeiro no programa de saúde da família; 2000 nov. 9-11; São Paulo. São Paulo: Secretaria de Estado da Saúde; 2000.

RICCO, R. G; CIAMPO, L. A.; ALMEIDA, C. A. N. Puericultura: princípios e praticas atenção integral a saúde da criança. São Paulo: Atheneu, 2001

SAWAYA, A. L. Desnutrição Energético-Protéica. In: Desnutrição Urbana no Brasil em um período de transição. São Paulo: Cortez, 1997.

SILVA, M. M.; ROCHA L.; SILVA, S. O. Enfermagem em puericultura: unindo metodologias assistenciais para promover a saúde nutricional da criança. Rev Gaúcha Enferm., Porto Alegre (RS), v. 30, n. 1, p. 141-4, 2009.

TELLES, R. K.; BARROS FILHO, A. A. O uso da antropometria como método de avaliação da composição corporal em pediatria. Rev Cienc, v. 12, n. 4, p. 351-63, 2003.

XAVIER, S. O. O papel do enfermeiro educador frente à problemática do câncer de próstata. 2001. Trabalho de Conclusão de Curso (Graduação em Enfermagem) Curso de Enfermagem, Universidade Federal Fluminense, Niterói, 2001. 


\title{
CAPITULO XVI
}

\section{MULLHERES RO CLITIATÉRID E SUA SEKUALIDADE: UTMA PERSPECTIUA BIOPSICOSSOCIAL}

\author{
DDI: 10.51859/AMPLLA.APS276.1121-16
}

\author{
Gabrielli dos Santos Netto de Melo ${ }^{1}$ \\ Juliana Rodrigues Cardoso Langsdorff ${ }^{2}$ \\ Lays Araújo Lessa Falcão ${ }^{3}$ \\ Natália Carvalho do Ó Santos 4
}

\footnotetext{
${ }^{1}$ Enfermeira. Pós-graduanda em estratégia de Saúde da Família na Faculdade Souza Marques.

${ }^{2}$ Enfermeira. Mestre em Saúde Pública. Sanitarista. Professora do Centro Universitário São José

${ }^{3}$ Enfermeira.

${ }^{4}$ Enfermeira.
}

\section{RESUMO}

Cada indivíduo tem uma forma singular de expressão da sexualidade e do envelhecimento. O climatério representa uma etapa de autoconhecimento e redescoberta importante de sua sexualidade. Objetivos do estudo a) discutir sobre o desejo sexual, beleza e feminilidade no climatério sob a ótica da mulher que vivenciou/vivencia esse período do ciclo de vida; b) identificar fatores/alterações de ordem biopsicossocial relacionados a sexualidade da mulher que vivenciou/vivencia o período climatério. Metodologia: Entrevistas com 30 mulheres de 45 a 65 anos que vivenciam ou vivenciaram o climatério, moradoras do município do Rio de Janeiro. 0 levantamento de dados, foi realizado através do formulário digital, Google Forms, com elaboração semiestruturada, para caracterização da população investigada (Bloco I) e a coleta de dados referentes ao desejo sexual, beleza e feminilidade (Bloco II). Discussão: compreendemos a importância do apoio dos parceiros e familiares para 0 enfrentamento dos novos sentimentos e inseguranças dessas mulheres. As mudanças físicas e a ressignificação de sua sexualidade e do sexo, também são desafios expressos pelas entrevistadas. Conclusão: As mulheres expressaram essa fase da vida como de novas liberdades, mas também de novas limitações. O novo nos impõe que apesar de cronológico e natural, há necessidade do acolher e do olhar direcionado para essa fase, com a mulher no centro do processo, considerando seus sentimentos acerca do climatério.

Palavras-chave: Climatério. Sexualidade. Cuidados de Enfermagem.

\section{IกTRODUÇÃO}

O climatério não é uma doença e sim uma fase biológica da vida de toda mulher.

E a reação de uma mulher ao climatério, pode variar muito. Algumas podem necessitar 
de medicamentos, já outras podem apresentar somente alguns sintomas leves, como a falta de lubrificação vaginal. Nessa fase, as mulheres apresentam mudanças corporais e começa a surgir uma insegurança sob o próprio corpo, o que leva a diminuição do desejo sexual, insônia, perda de peso e baixa lubrificação vaginal. Além do climatério ser um tabu, ser um assunto que não é discutido, as mulheres não sabem o que fazer nesse período, principalmente como dar continuidade a sua vida sexual. Consequentemente gerando problemas fisiológicos e psicológicos.

As demandas para o atendimento às necessidades dessas mulheres têm requerido um olhar criterioso e atencioso dos profissionais de enfermagem, visto que as queixas relacionadas ao climatério no cotidiano das consultas são cada vez mais frequentes. Embora a Política Nacional de Atenção Integral à Saúde da Mulher tenha em seus objetivos a implementação da atenção à saúde da mulher neste período, ainda persiste a pouca qualificação dos profissionais de saúde, a falta de acolhimento e a resolutividade voltada para essa parcela da população (GERMANO, 2010). Em 1999, a Área Técnica de Saúde da Mulher do Ministério da Saúde incorporou no seu planejamento a atenção à saúde da mulher acima de 50 anos (BRASIL, 2008).

Em 2004 o documento intitulado Política Nacional de Atenção Integral à Saúde da Mulher - Princípios e Diretrizes, incluiu um capítulo sobre a atenção à saúde da mulher no climatério e menopausa instituindo assim diretrizes nacionais para o cuidado à saúde das mulheres nesta faixa etária (BRASIL, 2008).

As mulheres na fase do climatério apresentam uma resposta a estímulos sexuais mais lenta, por conta da alteração dos hormônios, do corpo e de como aquela mulher está se sentindo diante a isso. Também existe a questão do parceiro muitas vezes não entender, que nesse período a mulher não se sente tão bem e procura não querer relações (BRASIL, 2008).

Mediante esse cenário, emergiram questões que culminaram no nosso interesse de estudo: o desejo sexual, a beleza e a feminilidade sob a ótica da mulher que vivenciou/vivencia o período do climatério. 


\section{REUISÃO BIBLIOGRÁFICA}

\subsection{Breve histórico}

A feminização do envelhecimento se dá pela grande abertura de um espaço diferente para convivência das mulheres com a sociedade, com objetivo de evitar o isolamento e melhorar a autoestima, dando uma maior autonomia a essa mulher. 0 declínio das taxas de fecundidade no Brasil na última década tem implicações profundas sobre a tendência demográfica de sua estrutura histórica.

A forma da pirâmide demográfica do Brasil muda de 1970 para o ano 2000, transformando-se de forma piramidal para uma retangularização progressiva, e os dados em crescimento do número de pessoas idosas (Veras, 1995)

A palavra climatério se origina do grego klimacter cujo significado é período crítico. Trench (2005), sobre a origem dos conceitos de climatério e menopausa, discorre que o conceito de menopausa surgiu a partir de um artigo publicado em 1816, denominado La menopausie. Menopausa é a soma de duas palavras gregas que significam mês e fim. A realidade feminina modifica-se bastante com a chegada da menopausa e com os aspectos relacionados à saúde. (FERREIRA, 2013).

O climatério corresponde a uma fase da mulher do período reprodutivo para o não reprodutivo (BRASIL, 2016). A menopausa acontece por volta dos 48 e 50 anos, tendo um período de basicamente 12 meses consecutivos de amenorreia, resultando uma interrupção definitiva do período menstrual, que é o fim do período reprodutivo.

De acordo com estimativas do DATASUS, em 2007, a população feminina brasileira totaliza mais de 98 milhões de mulheres. Nesse universo, cerca de 30 milhões têm entre 35 e 65 anos, o que significa que 32\% das mulheres no Brasil estão na faixa etária em que ocorre o climatério (BRASIL, 2008).

Segundo Valença (2010), às demandas para o atendimento às necessidades dessas mulheres têm requerido um olhar criterioso e atencioso dos profissionais de saúde visto que as queixas relacionadas ao climatério são frequentes. Embora a Política Nacional de Atenção Integral à Saúde da Mulher tenha em seus objetivos a implementação da atenção à saúde da mulher neste período, ainda persiste a pouca qualificação dos profissionais de saúde, a falta de acolhimento e a resolutividade voltada para essa parcela da população. 
Entende-se que cada vez mais é de extremamente importante a atenção nas consultas quanto às queixas das mulheres climatéricas e ao fortalecimento de uma base de estudo aos profissionais da saúde sobre a relação dos mesmos com essas mulheres.

De acordo com a OMS, estima-se que até 2025 o Brasil era o 6ำ país com o maior número de idosos, com isso o número de mulheres idosas também será maior. Quando a mulher atinge a "velhice" a sociedade ver essa mulher como uma pessoa do lar, a mulher que criou seus filhos, cuidou de seu marido, a mulher que vai ficar fazendo crochê na parte da tarde. Como a sociedade escolheu esteticamente o jovem, o homem idoso que vive essa sexualidade volta os olhos para a mulher jovem. A mulher idosa não deseja, e não está também no alvo do desejo. A mulher idosa é a viúva, ou a mãe solteira e solitária." (RODRIGUES, 2018).

A mulher no climatério é uma mulher saudável, uma mulher cuidada e ainda sim com muito fôlego para viver essa nova etapa de sua vida, com a ajuda dos profissionais de saúde sempre orientando e buscando a melhor forma de conversar, falar mais sobre o período climatérico.

\subsection{As principais alterações sekuais na mulher no climatério e a questão do} parceiro.

No período do climatério existem muitos tipos de mudanças, principalmente às hormonais, uma delas é a diminuição de libido e, até o canal vaginal fica com menos lubrificação, mas não impede essa mulher de ter relações, então sempre se é recomendado a essa mulher um tipo de lubrificante a base de água, conversar com parceiros para estimular essa mulher, para que ela se sinta mais confortável e bem (BRASIL, 2008).

A fase de excitação fica ainda mais dependente do nível de estimulação e a resposta sexual satisfatória precisa de mais "cumplicidade" da parceria sexual para ajudar o relaxamento e a entrega por parte da mulher (BRASIL, 2013). Muitas das vezes esse parceiro não entende e pode ser até ríspido em não se importar, também é dever do enfermeiro informar a esta paciente que o ato sexual sem nenhum tipo de lubrificação além de ser um incômodo e doloroso é prejudicial para a saúde da mesma.

Muitas mulheres passam por essa fase, sem nenhuma queixa proeminente, já outras tem queixas diversas como suores noturno e fogachos. Ao realizar consulta a uma 
paciente que está nesse período, devemos sempre dialogar, e procurar saber sobre as queixas da mesma, já que cada atendimento deve ser humanizado, pois seus sintomas variam de mulher para mulher.

O climatério tem diversas mudanças, contando com elas as mudanças hormonais, fisiológicas e psicológicas, também conhecido como um período de transição do período reprodutivo para o não reprodutivo. De acordo com o Ministério de Saúde as principais mudanças são ondas de calor, alterações nos órgãos sexuais, como coceira, secura da mucosa vaginal; distúrbios menstruais; diminuição da libido; desconforto durante as relações sexuais, suores noturnos prejudicando o sono.

Por ser um processo de suma importância na vida de toda a mulher, o climatério é caracterizado pela diminuição gradual da produção de hormônios sexuais femininos a partir dos ovários. Devido a hipoestrogenismo, alguns especialistas indicam a reposição desse hormônio de forma individual e com acompanhamento, para o alívio dos sintomas (BRASIL, 2008)

A discriminação geracional, com base na idade cronológica, ocorre na nossa sociedade como algo naturalizado. Para as mulheres esta discriminação é mais intensa e evidente. O mito da eterna juventude, a supervalorização da beleza física padronizada e a relação entre o sucesso e a juventude são fatores de tensionamento que interferem na auto-estima e repercutem na saúde física, mental, emocional e nas relações familiares e sociais. (BRASIL, 2008).

\subsection{Serualidade e climatério}

A sexualidade da mulher no climatério é carregada de muitos preconceitos e tabus. Isso porque existem vários mitos que reforçam a ideia de que, nesse período, a mulher fica assexuada. Discutir sexualidade, mesmo na atualidade ainda é presente tabus que pode ser decorrente da educação recebida, bem como a falta de informações.

As mulheres no climatério, mais frequentemente após a menopausa, podem apresentar uma lubrificação vaginal menos intensa e mais demorada, sendo necessário, às vezes, um maior estímulo sexual. É possível ocorrer também um adelgaçamento dos tecidos vaginais, que pode levar à dor nas relações sexuais, tornando a perspectiva do sexo com penetração, motivo de ansiedade e de falta de satisfação (BRASIL, 2008) 
A vida sexual nesse período necessita ser compreendida de maneira mais ampla, levando em consideração o contexto histórico, a prática sexual, os fatores econômicos, sociais e culturais em que a mulher esteja envolvida. No que diz respeito à vida sexual do indivíduo é necessário compreendê-la como sendo multifatorial (ARAUJO et al, 2013).

A mulher na fase do climatério tem alterações substanciais no tocante à sua sexualidade. Tais alterações são determinadas e justificadas, pela mulher, como determinantes desse período do ciclo vital. (OLIVEIRA; JESUS; MERIGHI, 2008).

O climatério é pouco mencionado pelos profissionais de enfermagem, dessa maneira, é necessário que o enfermeiro interfira neste sentido adequando seus conhecimentos profissionais e pessoais sobre a grandiosidade do ser mulher, efetivando a recuperação da autoestima, crescimento e maior enfrentamento (REIS; ANDRADE, 2008).

\subsection{0 enfermeiro e a paciente que viuencia o climatério}

Após leitura dos artigos pesquisados e analisados, observou-se nos estudos que a atividade assistencial em saúde da mulher no âmbito climatério e sexualidade ainda atuam de maneira fragmentada.

Milanez et al. (2004) descreve que a assistência à saúde da mulher no climatério deve ser realizada através dos determinados métodos: programas institucionalizados educativos para a população feminina; dos serviços de saúde, preferência para assistência em grupos de autoajuda, parcerias para as ações preventivas, curativas e de reabilitação dos agravos, apoio psicológico, assim como atualização dos profissionais de enfermagem para melhor atender as mulheres na fase do climatério.

Assim, destaca-se que a equipe de saúde, especialmente a enfermagem, tem função elementar na adesão de atividades que proporcionem uma boa qualidade de vida durante e após o climatério a essas mulheres. Considera-se que a enfermagem pode colaborar para eliminar mitos e superstições que permeiam a sexualidade no âmbito cultural e biológico. Portanto, é aconselhável a investidura em planos, como a educação em saúde, que estimulem entre homens e mulheres a reflexão de temas relacionados à sexualidade, dentre eles, gênero, corpo e violência, planejando estimular 
reflexões que desconstrua preconceitos sólidos de masculinidade e feminilidade e que estabelecem a vivência da sexualidade (SANTOS et al, 2014).

Aponta ainda que a consulta de enfermagem é uma das práticas fundamentais ao conhecimento individual das mulheres nessa fase de vida. Descreve como método que necessita ser empregado pelo enfermeiro, à criação de grupos, que permitem o agrupamento do companheiro e da família, grupo de convivência entre mulheres climatéricas, que possibilitem discussão e maior compreensão das inúmeras mudanças vivenciadas por mulheres que enfrentam o climatério (NASCIMENTO et al, 2010).

A assistência de enfermagem é essencial durante essa fase na vida da mulher, pois seu papel juntamente com os demais profissionais de saúde, deve ser repensado, articulado, para que juntos estabeleçam medidas de prevenção, atendendo as necessidades da mulher no climatério e sua sexualidade. Sendo uma prática educativa baseando em suas concepções e experiências de maneira a assegurar-lhes interação, convivência afetiva e compromisso com transformação adequado à existência, para que tenham uma vida ativa, saudável, com bem-estar e qualidade (FREITAS et al 2004).

O enfermeiro necessita acompanhar ao indivíduo como ser sexual, almejando contribuir para o conhecimento de si próprio e acompanhá-lo no atendimento de suas prioridades para inseri-lo em uma relação harmoniosa dentro do âmbito familiar e social atuando de forma articulada, com uma equipe de multiprofissionais, para que assim possam programar medidas estratégicas atendendo às suas necessidades (FERNANDEZ; HAYASHIDA, 2005).

É dever do enfermeiro aproveitar o momento da sua consulta de enfermagem para orientar quanto aos sintomas, os métodos para uma melhora na vida sexual, sobre uso de lubrificantes e o auxílio do parceiro nessa hora. Já que nesse período o seu maior sintoma é a redução da libido, necessitando de um estímulo maior na hora da relação. É importante também explica-la sobre a associação de atividade física e alimentação saudável, que juntos ajudam na melhora dos sintomas do climatério.

Pensando especificamente na mulher que está no período do climatério, a atividade física, além de proporcionar melhora na forma física, redução do risco de osteoporose, de obesidade, de diabetes e doenças cardíacas e também melhora o estado emocional. (SILVA, 2000). E Camargo, (2000) afirma que os fogachos e sudorese podem melhorar com a prática de exercícios físicos. 


\section{DISCUSSก̃O}

Segundo o IBGE (2016) a vida de uma mulher gira em torno de 79,9 anos, ou seja, ela passará uma grande parte de sua vida no climatério e menopausa. Entender e compreender essas mulheres entrevistadas nos apoiará ao adotar medidas que visam uma melhor qualidade de vida durante e após o climatério. O nosso estudo trouxe como resultados aspectos demográficos, sociais e individuais das mulheres entrevistadas.

Das 30 mulheres que participaram da nossa pesquisa, na faixa etária de 45 a 65 anos, todas residiam na zona oeste do estado do Rio de Janeiro. Sendo $46,7 \%$ das mulheres declaradas (brancas), 46,7\% (pardas) e 6,7\% (pretas).

Em relação ao estado civil das participantes, 36,7\% são casadas, 30,0\% são solteiras, $16,7 \%$ são divorciadas, $16,7 \%$ são viúvas. Nenhuma participante relatou deficiência. O grau de escolaridade, podemos ver que a maioria das participantes tem o ensino médio completo.

Cruzando os dados de grau de escolaridade e cor da pele, analisamos que dos $46,7 \%$ das mulheres brancas apenas $7,1 \%$ tem ensino fundamental completo, $21,4 \%$ tem o ensino médio completo, $28,6 \%$ ensino superior completo e os outros $35.6 \%$ não possui nenhum grau de escolaridade completo. Já os $46,7 \%$ das mulheres pardas, $7,1 \%$ delas tem ensino fundamental completo, $50 \%$ tem o ensino médio completo, $7,1 \%$ ensino superior completo e $35,6 \%$ não possui nenhum grau de ensino completo. Já os $6,7 \%$ das mulheres pretas, $50 \%$ possuem ensino fundamental completo e $50 \%$ possuem ensino médio completo.

No terceiro bloco de perguntas da pesquisa, criamos 3 tópicos relacionados ao climatério: Sentimentos, hábitos de vida e compreensão familiar/parceiro. Segundo Porto, Roecker e Salvagioni, (2012), para muitos essa fase é permeada por sentimentos de angústia, desespero, medo e abandono. Relacionando a afirmação da autora com o relato de uma das participantes percebe-se que o envelhecimento pode causar medo e preocupação em algumas mulheres. Como nesses relatos:

"Preocupação com as possíveis doenças do envelhecimento." M1

"Preocupação com a minha saúde." M2

Outras mulheres recebem o envelhecer com tranquilidade, porém, com preocupação de ser mais vaidosa e se cuidar mais, como podemos ver a seguir: 
“Isso faz parte do ciclo da vida, o que não pode deixar acontecer é com a idade chegando você achar que não pode ser feliz." M3

Sad (2001) relata que a vida de uma pessoa idosa pode vir a ser de grande riqueza interior, no que concerne ao encontro com sua própria essência. Dessa forma, pode-se chegar à plenitude, com modos mais positivos de ser e apreciação da vida. Observamos essa visão nessa fala:

"Satisfação! Esse é o momento na minha vida em que estou empenhada colecionar apenas afetos e tudo o que me traga serenidade e sabedoria." M4

Segundo Andrade (2010), saúde e beleza sempre estão interligadas, mas este laço se torna mais forte na terceira idade, quando o bem-estar com a própria aparência pode ser um impulso para cuidar melhor da saúde e ter mais energia para viver. Como podemos ver neste relato:

"Busco encarar naturalmente, porém sou vaidosa e me cuido." M5

Dados atuais têm mostrado que o aumento dos sintomas e problemas da mulher neste período reflete em circunstâncias sociais e pessoais, e não somente eventos endócrinos do climatério e menopausa (BRASIL, 2008)

Segundo Valença, Nascimento e Germano (2010): As demandas para o atendimento às necessidades dessas mulheres têm requerido um olhar criterioso e atencioso dos profissionais de saúde visto que as queixas relacionadas ao climatério são frequentes.

O mesmo autor relata que, embora a Política Nacional de Atenção Integral à Saúde da Mulher tenha em seus objetivos a implementação da atenção à saúde da mulher neste período, ainda persiste a pouca qualificação dos profissionais de saúde, a falta de acolhimento e a resolutividade voltada para essa parcela da população.

As mulheres no climatério e especialmente após a menopausa venham a se sentir incompetentes e incapazes de desempenhar normalmente suas atividades ou empreenderem-se em novos projetos de vida. Podem também vir a desenvolver alguma insegurança quando atingem a menopausa, seja pelo medo de adoecer ou pela maior consciência do processo de envelhecimento. (BRASIL, 2008)

No climatério, as alterações hormonais, acompanhadas pela desvalorização estética do corpo e por toda uma sintomatologia de intensidade variável - que no limite aparece como sofrimento depressivo - sinalizam o envelhecimento inevitável 
(BRASIL,2008). Com tantos sintomas surgindo, as mulheres se dão conta que a vida tem um fim e começam a entender que a fase climatérica já chegou em suas vidas.

Quando perguntado a elas se sentiram alguma diferença ao perceber que estava no climatério, 83,3\% responderam que SIM. E foi disponibilizada uma lista de sintomas mais frequentes, para que cada uma delas sinalizasse no formulário, qual sintoma ela apresentou ou que foi mais forte nesse período. No total a maioria sinalizou os fogachos, estresse e a sudorese que de acordo com os protocolos da Atenção Básica de Saúde da mulher, esses são os principais sintomas que levam essa mulher a procurar uma unidade de saúde, muitas das vezes por não entender o que está acontecendo ou para saber se realmente estão entrando no climatério. (BRASIL,2016)

Os enfermeiros exercem um importante papel quando relacionados à saúde reprodutiva e coletiva. Na atenção básica, é primordial a atuação profissional na saúde da mulher, seja durante o período reprodutivo ou na passagem para a fase não reprodutiva (climatério e pós-menopausa).

A consulta de enfermagem nesse período é muito importante, pois o climatério é um momento muito delicado na vida da mulher, pois ela está passando por mudanças não só hormonais, mas física e muita das vezes psicológica.

Por esse motivo, é importante sempre conversar com essa mulher, saber mais sobre a vida e práticas sexuais. Por que sabemos que nesse período a mulher tem a diminuição de libido, e tentar ajudá-la a melhorar as práticas sexuais com algo que não seja incômodo e desconfortável para ela.

Segundo o Manual de Atenção à Mulher no Climatério de 2008, os profissionais devem incluir diversas ações, tais como: Estimular o autocuidado, para melhora da autoestima e a paciente se sentir mais segura nessa fase. Influenciar a paciente a procurar algo que a estimule quanto a sexualidade, recursos como: revistas, livros e outros artigos. Ajudá-la a encontrar algo que alivie os sintomas do climatério e esclarecer suas dúvidas sobre masturbação ou meios que ajudem a melhorar a lubrificação vaginal durante o ato sexual, uma prática normal e saudável que deve ser feita independentemente da idade. Mas também há casos de ter o aumento da lubrificação.

Envelhecer não significa tornar-se assexuado, porém, mitos e tabus socioculturais acerca da sexualidade na terceira idade inibem os idosos de exercer a sua 
vida de forma integral, uma vez que as alterações fisiológicas do envelhecimento, preceitos religiosos, opressões familiares e aspectos individuais fortalecem esse estigma social (UCHOA, COSTA, JUNIOR, SILVA, FREITAS E SOARES, 2016).

Foi perguntado também quanto ao ato sexual, o que essa mulher sentiu ao praticar relações sexuais após se identificar nesse período: $60 \%$ disseram que sentiram uma diferença e a maioria respondeu que apresenta falta da lubrificação/secura vaginal, menos desejo sexual e até mesmo aversão ao sexo. Como podemos ver nesses depoimentos:

"Dor, devido ao ressecamento vaginal." M6.

"Menos desejo sexual." M7

Esses sintomas são totalmente ligados ao climatério, são os mais frequentes e comuns entre as mulheres. Isso acontece devido ao maior efeito da deficiência estrogênica sobre a pelve e a diminuição do fluxo sanguíneo, que pode promover alterações no aparelho genital (BRASIL, 2008).

Com relação a compreensão de parceiros ou familiares que estariam sabendo das mudanças corporais e hormonais do climatério, 21 das mulheres entrevistadas responderam que estão recebendo esse apoio. Já 9 entrevistadas responderam que seus parceiros ou familiares não sabem que ela está passando por essa fase, que pode ser um período muito complicado para elas, onde qualquer incentivo positivo é bem-vindo.

“Frigidez, indiferença e aversão ao sexo! Ocasionado também pela incompreensão do meu ex-marido, por achar que todos os sintomas eram "frescuras", por mais que tenha tentado dialogar a respeito, infelizmente." M8

A sexualidade pode ser entendida como uma dimensão pessoal e humana que supera os extremos do impulso genital e avança para um aspecto profundo da personalidade, presente desde a concepção até a morte e inclui tudo o que se é e o que se faz, inter-relacionada de forma inseparável aos papéis biológico, psicológico e social (MELO; CARVALHO; PELÁ, 2006).

A sexualidade influência de forma importante a qualidade de vida das pessoas, desde que não um aspecto isolado da vida delas. Ela é constantemente construída não se restringindo apenas a uma visão biológica (GOMES, 2007). 
É importante assegurar que apesar de algumas vezes apresentar dificuldades, o climatério é um período importante e inevitável na vida, devendo ser encarado como um processo natural, e não como doença como já relatado nesse estudo.

\section{COMSIDERACỐES FIIRIS}

O estudo pode colaborar com mais informações sobre a temática, visto que notamos durante a pesquisa ser um assunto escasso, na perspectiva da sexualidade, porém, necessário para agregar conhecimento aos profissionais da saúde. Além de quebrar um grande tabu quanto aos mitos que envolvem o climatério perante a sociedade.

Quando damos voz a essas mulheres, ao compartilhar sobre a sua visão e percepção sobre como foi viver o climatério. Conseguimos compreender que mesmo com todos os sentimentos e inseguranças a maioria das entrevistadas tiveram o apoio de seus parceiros e familiares e que isso foi fundamental para essa fase. Elas se sentem otimistas em lidar com as mudanças e sintomas sentidos nesse período. Porém, também relataram sentir diferença na hora do ato sexual como o desconforto e a insegurança. Por outro lado, entendem que isso faz parte do ciclo da vida e que elas precisam se adaptar e aumentar os cuidados em relação a sua saúde.

Por esse motivo, é fundamental a participação da enfermagem, no apoio a essas mulheres nas unidades de saúde. A consulta de enfermagem é o espaço potente para discussão das inseguranças e medos que rondam a vida sexual, impedindo a real expressão de sua sexualidade e feminilidade. $O$ enfermeiro deve estar sempre preparado para entender como acolher suas queixas e dúvidas.

A utilização da abordagem qualitativa, juntamente com a pesquisa de campo através da plataforma Google Forms, foi extremamente satisfatória, pois conseguimos compreender a vivência de cada mulher pesquisada, considerando suas especificidades. A inserção da tecnologia na coleta de dados nos permitiu a aproximação e a escuta dessas mulheres em meio uma pandemia (COVID-19) e nos fez também refletir sobre novas formas de pesquisa, inovações e aproximações que possibilitam ecoar a voz e os sentimentos da nossa população.

Nesse estudo podemos reafirmar que a sexualidade tem relação com a libido e inclui todo corpo e não apenas os genitais, ou período reprodutivo. Está intimamente 
ligado aos sentimentos e sensações e cada indivíduo tem uma forma singular de expressão da sua sexualidade. O envelhecimento e o climatério nas mulheres representam uma etapa de autoconhecimento e redescoberta de sua sexualidade.

\section{REFERÊCCIAS}

ANDRADE, Naif Thadeu. Saúde \& Beleza na terceira idade. 2010. Disponível em: $<$ http//naifthadeu.com.br/indez.php?option=com.content\&view=artide\&id=95 $<$ emid=87\&l ang=pt $>$. Acesso em: 22 set 2019.

ARAUJO, Ivonete Alves de et al. Representações sociais da vida sexual de mulheres no climatério atendidas em serviços públicos de saúde. 2013. Disponível em: $<$ http://www.scielo.br/scielo.php?pid=S0104-

07072013000100014\&script=sci_arttext\&tlng=pt >. Acesso em: 18 nov. 2019.

BRASIL, Ministério da Saúde. Manual de Atenção à Mulher no Climatério / Menopausa. 2008. <http://bvsms.saude.gov.br/bvs/publicacoes/manual_atencao_mulher_climate rio.pdf>. Acesso em: 03 set. 2020.

BRASIL. Ministério da Saúde. Secretaria de Atenção à Saúde. Departamento de Atenção Básica. Caderno de Atenção Básica no 26. Saúde sexual e saúde reprodutiva. Brasília: Ministério da Saúde; 2013. Disponível em: <http://bvsms.saude.gov.br/bvs/publicacoes/saude_sexual_saude_reprodutiva .pdf> Acesso em 20 set. 2019.

BRASIL. Ministério da Saúde. Protocolos da Atenção Básica- Saúde das Mulheres. Cadernos de Atenção Básica. Brasília, 2016. Disponível em: <http://bvsms.saude.gov.br/bvs/publicacoes/protocolos_atencao_basica_saud e_mulheres.pdf $>$. Acesso em 8 set. 2020.

CAMARGO, Eduardo. Atividade física no climatério. Disponível em: < http://camargo.med.br/artigos leigos/Atividade climaterio.html> Acesso 25 ago. 2020

FEBRASGO, Federação Brasileira de Ginecologia e Obstetrícia. Manual de Orientação ao Climatério. $2010 . \quad$ Disponível em: $<$ https://www.febrasgo.org.br/images/arquivos/manuais/Manuais_Novos/Man ual_Climaterio.pdf> Acesso em: 01 nov. 2020.

FERNANDEZ, Márcia Rodrigues; HAYASHIDA, Miyeko. Sexualidade no período climatérico: situações vivenciadas pela mulher. Sexuality in the climateric period: situations experienced by women, [s. I.] Acesso em: 01 nov. 2020

FERREIRA, Vanessa Nolasco et al. Menopausa: marco biopsicossocial do envelhecimento feminino. 2013. Disponível em: Acesso em: 18 nov. 2019. 
FREITAS, K. M.; SILVA, A. R. V; SILVA, R. M. Mulheres vivenciando o climatério. Acta Scientiarum Health Sciens. Maringá (PR), 26 (10, jan/jun. 2004. p.121-28. Disponível em: <http://www.scielo.br/pdf/reeusp/v39n2/02.pdf>. Acesso em: 14 mar 2020

GOMES, M. E. A. A Sexualidade das Mulheres Atendidas no PSF: uma produção sociopoética. 2007. Dissertação (Mestrado em Cuidados Clínicos em Saúde). Universidade Estadual do Ceará, Fortaleza, 2007. Acesso em 20 jun. 2020.

IBGE. Simões, Celso Cardoso da Silva Relações entre as alterações históricas na dinâmica demográfica brasileira e os impactos decorrentes do processo de envelhecimento da população. Celso Cardoso da Silva Simões. - Rio de Janeiro: Coordenação de População e Indicadores Sociais, 2016. Acesso em: 20 jun. 2020.

Melo, A. S.; CARVALHO, E. C.; PELÁ, N. T. R. A sexualidade do paciente portador de doenças onco-hematológicas. Rev. latinoam. Enfermagem; v. 14, n. 2, p. 227-32, mar./abr. 2006. Acesso em: 8 mar. 2020.

MILANEZ, M. R. de M. et al. Percepção das mulheres sobre o climatério. Pelotas. Esc. Anna Nery R. Enferm. 8 (2): 198-204, 2004. Disponível em: $<$ http://bases.bireme.br/cgi-

bin/wxislind.exe/iah/online/?IsisScript=iah/iah.xis\&src=google\&base=LILACS\&la $\mathrm{ng}=\mathrm{p} \&$ nextAction=Ink\&exprSearc $\mathrm{h}=446994$ \&indexSearch=ID>. Acesso em 18 nov. 2019

NASCIMENTO, K. B.; GONÇALVES, M. M. F.; SOUZA, M. G.; MELO R. V.; FIGUEIREDO, Y. M. D. Assistência de enfermagem no climatério: revisão da literatura no período de 2000 a 2010. [Periódico da internet]. Disponível em: $<$ http://www.pergamum.univale.br/pergamum/tcc/Assistenciadeenfermegemn ocim ateriorevisaodaliteraturanoperiodode2000a2010.pdf>. Acesso em 18 nov. 2019

PORTO, A R.; ROECKER S.; SALVAGIONI, D A J.; O envelhecer e a morte: compreendendo os sentimentos de idosos institucionalizados. Rev Enferm UFSM 2013 Jan/Abril;3(1):35-43; Londrina, 2012. Doi:10.5902/217976927205. Acesso em: 22 set. 2020

REIS C. B.; ANDRADE, S. M. O. Representações sociais das enfermeiras sobre a integralidade na assistência à saúde da mulher na rede básica. Ciência e Saúde coletiva. Rio de Janeiro (RJ), 2008, P.61-70. Disponível em: <http://www.scielosp.org/pdf/csc/v13n1/10.pdf>. Acesso em 18 nov. 2019

RODRIGUES, M. País não está pronto para uma 'sociedade de idosos', 2018. Disponível em: < https://g1.globo.com/df/distrito-federal/noticia/2018/08/05/pais-naoesta-pronto-para-uma-sociedade-de-idosos-diz-especialista-leiaentrevista.ghtml> Acesso em: 14 out 2019.

SAD, I. Revisão de vida, autoconhecimento e auto-aceitação: tarefas da maturidade. In A. L. Neri. Desenvolvimento e envelhecimento: perspectivas biológicas, 
psicológicas e sociológicas. São Paulo, 2001: Papirus. <https://www.scielo.br/scielo.php?script=sci_nlinks\&ref=000094\&pid=S0103166X200800020001400013\&lng=en >. Acesso em: 14 out. 2019.

SANTOS, S. M. P.; GOLÇALVES, R. L.; AZEVEDO, E. B.; PINHEIRO, A. K. D.; BARBOSA, C. A.; COSTA, K. N. F. A vivência da sexualidade por mulheres no climatério. Rev Enferm UFSM 2014 jan/mar; 4 (1):113-122. Disponível em: <http://cascavel.ufsm.br/revistas/ojs-

2.2.2/index.php/reufsm/article/view/8819>. Acesso em: 01 de nov. de 2020.

SILVA, Rafaela Oselame. A importância da prática de atividade física no período do climatério. $<$ https://acervodigital.ufpr.br/bitstream/handle/1884/59798/RAFAELA\%20OSE LAME\%20DA\%20SILVA.pdf?sequence=1\&isAllowed=y > Acesso em: 20 set. 2020

TRENCH, Belkis; SANTOS, Claudete Gomes dos. Menopausa ou Menopausas? 2005. Disponível em: Acesso em: 18 nov. 2019.

UCHÔA, Y; Costa, D; Junior, I; Silva, S; Freitas, W; Soares, S; Sexuality through the eyes of the elderly. Centro Universitário do Pará (CESUPA), Belém, 2016; Rev. Bras. Geriatr. Gerontol., Rio de Janeiro, 2016; 19(6): 939-949. Acesso em: 22 set. 2020

VALENÇA, Cecília Nogueira; NASCIMENTO FILHO, José Medeiros do; GERMANO, Raimunda Medeiros. Mulher no Climatério: reflexões sobre desejo sexual, beleza e feminilidade. 2010. Disponível em: Acesso em: 17 ago. 2019

VERAS, R.; CAMARGO JR., K. R. Idosos e universidades: parceria para a qualidade de vida. In: R. Veras, R. (et al) Terceira idade: um envelhecimento digno para o cidadão do futuro. Rio de Janeiro: Relume - Dumará, UnATI/ UERJ, 1995. Acesso em: 17 ago. 2019 


\title{
PERFLL SOCIOECONÔTIICOE CLÍIICO DE MULHERES CADASTRADAS Em UNIIDADE DE SAÚDE COM CITOPATOLOGIA OחCÓTICA RLTERADA
}

\author{
DII: 10.51859/AMPLLA.APS276.|I21-17
}

\author{
Patrick Leonardo Nogueira da Silva ${ }^{1}$ \\ Brenda Oliveira Nascimento Pinto ${ }^{2}$ \\ Luís Cláudio Cardoso Fonseca ${ }^{3}$ \\ Cláudio Luís de Souza Santos ${ }^{4}$ \\ Valdira Vieira de Oliveira ${ }^{5}$ \\ Carolina dos Reis Alves ${ }^{6}$
}

\footnotetext{
${ }^{1}$ Mestrando em Cuidado Primário em Saúde. Universidade Estadual de Montes Claros - UNIMONTES.

2 Graduação em Enfermagem. Faculdade Santo Agostinho - FASA.

${ }^{3}$ Graduação em Enfermagem. Faculdade Santo Agostinho - FASA.

${ }^{4}$ Especialista em Saúde Mental. Universidade Estadual de Montes Claros - UNIMONTES.

${ }^{5}$ Mestre em Enfermagem. Faculdade Santo Agostinho - FASA.

${ }^{6}$ Doutora em Ciências da Saúde. Faculdade Santo Agostinho - FASA.
}

\section{RESUITO}

Objetivo: identificar o perfil socioeconômico, demográfico e clínico de mulheres cadastradas em uma Unidade de Saúde com citopatologia oncótica alterada. Métodos: trata-se de um estudo descritivo, exploratório, retrospectivo, com abordagem quantitativa, realizado no Sistema de Informação do Câncer e em prontuários de mulheres que realizaram o rastreamento do câncer de colo uterino em uma Unidade de Saúde no período de 2014 a 2019 cujos resultados apresentaram alterações. Foram realizadas 1003 coletas neste período, porém a amostra foi constituída por 21 exames citopatológicos alterados. Utilizou-se um formulário como instrumento de coleta de dados. O tratamento dos dados se deu por meio de análise descritiva. Resultados: observou-se que $47,6 \%$ das mulheres investigadas apresentaram lesões intraepiteliais de baixo grau; 9,5\% tiveram lesões intraepiteliais de alto grau; 33,3\% desenvolveram atipias de significado indeterminado (escamosas e glandulares); $4,8 \%$ foi detectado adenocarcinoma invasor (cervical); e outros 4,8\% detectou-se adenocarcinoma invasor (endometrial). Conclusão: as alterações cervicais estiveram concentradas nas mulheres com poucos filhos, casadas, com maior nível de escolaridade e sem queixas de dispareunia.

Palavras-chave: Neoplasias do Colo do Útero. Programas de Rastreamento. Prevenção Primária. 


\section{IกTRODUÇÃO}

O câncer de colo do útero (CCU) caracteriza-se como uma alteração nas células que compõem o colo uterino, ocasionado por lesões não-tratadas decorrentes da infecção persistente pelos tipos de Human Papillomavirus (HPV). Essas lesões possuem um desenvolvimento lento para se tornarem invasivas o qual favorece sua identificação e tratamento (ORGANIZAÇÃO PAN-AMERICANA DA SAÚDE [OPAS], 2016). Assim sendo, a realização do rastreamento do CCU é preponderante para a sua detecção prévia (RIBEIRO et al., 2016; SANTOS; VARELA, 2015; BORGES et al., 2012).

O Preventivo de Câncer de Colo Uterino (PCCU), também conhecido como Exame de Papanicolau, é utilizado no Brasil como recurso para identificar as lesões sugestivas de câncer. Este exame é recomendado para mulheres a partir dos 25 anos de idade que já tiveram relação sexual ou mulheres com início da atividade sexual (IAS) anterior aos 25 anos, seguindo um intervalo de um ano para os dois primeiros exames e posteriormente um intervalo de três anos para dois exames com resultados negativos subseqüentes e finaliza aos 64 anos para as mulheres com dois exames subseqüentes sem alteração nos últimos cinco anos (SANTOS, 2018). No entanto, para ter uma redução significativa nos impactos negativos que este câncer ocasiona é necessário haver uma junção da oferta dos exames à população-alvo e ações planejadas a partir dos resultados dos exames (SANTOS, 2018; OPAS, 2016; RIBEIRO et al., 2016; SANTOS; VARELA, 2015; BORGES et al., 2012).

A gênese do CCU está ligada com fatores importantes no qual destacam o comportamento sexual, tal como a multiplicidade de parceiros, IAS precoce, além de hábitos relacionados ao estilo de vida, como por exemplo, o tabagismo, e condições socioeconômicas (ÁVILA et al., 2016; TELES; MUNIZ; FERRARI, 2013). No que diz respeito ao fator socioeconômico, esta neoplasia está ligada diretamente com regiões que possuem níveis de socioeconômicos e de desenvolvimento relativamente baixos (BARBOSA et al., 2016).

O crescimento significativo dos casos de $\mathrm{CCU}$, bem como a necessidade de criação dos sistemas de informação e vigilância do câncer, foram um dos motivos que convergiram para o desenvolvimento do Sistema de Informação do Câncer (SISCAN), implantado no Brasil em 2012. Este sistema integra os sistemas oficiais de informação 
do Programa Nacional de Controle do Câncer do Colo do Útero e de Mama (PNCCCUM), sendo esses o Sistema de Informação do Controle do Câncer do Colo do Útero (SISCOLO) e de Mama (SISMAMA), e tem seu diferencial por ser acessível nas Unidades Básicas de Saúde (UBS) por meio do acesso à internet, para a realização de serviços como requisição de exames, monitoramento e seguimento das mulheres no presente momento (INSTITUTO NACIONAL DE CÂNCER [INCA], 2013).

O gerenciamento das informações do SISCOLO de forma consecutiva é uma atividade pertinente, visto que permite aos profissionais e gestores uma visão holística das dificuldades no âmbito da saúde vivenciadas pela população e viabiliza possibilidades de modificações positivas constantes (SILVA NETO et al., 2017). Para a prevenção do CCU, assim como para promoção da saúde, são fundamentais as práticas educativas direcionadas à população, visto que constrói um conhecimento sobre as formas de transmissão do HPV, sua ligação com o câncer e as medidas de proteção existentes. Os saberes adquiridos pelas mulheres estimulam o seu autocuidado e proporciona comportamentos saudáveis que contribui na prevenção do câncer (SILVEIRA et al., 2015). Todas as formas de intervenção oportunizam impacto relevante na deteç̧ão hábil do CCU, no qual aumentam as chances quando oferecidos em combinações (BARBOSA et al., 2016).

Sendo assim, este artigo teve como objetivo identificar o perfil socioeconômico, demográfico e clínico de mulheres cadastradas em uma Unidade de Saúde com citopatologia oncótica alterada.

\section{MATERIAISE MÉTODOS}

Trata-se de um estudo descritivo, exploratório, documental, retrospectivo, com abordagem quantitativa. Foi realizada na Estratégia de Saúde da Família (ESF) do bairro Vila Anália, localizada na região leste do município de Montes Claros, Minas Gerais. A amostra foi composta pelos dados de exames de citopatologia oncótica alterada contida no Sistema de Informação do Câncer (SISCAN), bem como de prontuários, das mulheres que realizaram o rastreamento para o CCU durante o período de 2014 a 2019.

Foram adotados os seguintes critérios de inclusão para participação do estudo: (1) amostras coletadas de mulheres que tenham realizado o exame preventivo durante período de 2014-2019; (2) mulheres com prontuários arquivados na respectiva ESF. 
Ainda, foram estipulados os seguintes critérios de exclusão: (1) mulheres com prontuários clínicos com menos de $80 \%$ dos dados legíveis e preenchidos cujas informações não possam ser obtidas de outras fontes de informação; e (2) mulheres cujos prontuários não puderam ser localizados pela ESF.

Foi enviada uma carta de apresentação, juntamente com uma cópia do projeto de pesquisa, e um Termo de Consentimento Institucional (TCl) à Coordenação da Atenção Primária à Saúde (APS) da Secretaria Municipal de Saúde de Montes Claros (SMS-MOC) para autorização do estudo. A instituição foi devidamente orientada quanto às diretrizes da pesquisa e autorizou a realização do estudo por meio da assinatura do $\mathrm{TCl}$ de modo a estar ciente. A coleta de dados foi realizada no segundo semestre de 2019, durante os meses de outubro e novembro, pelo pesquisador responsável.

Foi utilizado um formulário estruturado, de elaboração própria pelos pesquisadores do estudo, como instrumento de coleta de dados. O mesmo foi fundamentado no formulário de requisição do exame citopatológico do colo do útero do Ministério da Saúde (MS) contendo as seguintes variáveis: socioeconômicas e demográficas (idade, cor, escolaridade, renda); dados da anamnese (motivo do exame, história familiar de CCU, história de preventivo, gestações, utilização de dispositivo intra-uterino [DIU], presença de gravidez, uso de pílula anticoncepcional [PAC], história de radioterapia, presença de sangramento nas relações sexuais, presença de sangramento após a menopausa); estilo de vida (tabagismo); comportamentos sexuais (número de parceiros, início precoce da sexarca e uso de preservativos); exame clínico (alterações do colo, sinais sugestivos de infecções sexualmente transmissíveis [IST]) e resultados do exame.

Os dados foram armazenados e tabulados por meio do programa estatístico Statistical Package for the Social Sciences (SPSS), bem como apresentados em tabelas com freqüências absolutas ( $n$ ), percentuais (\%) e medidas de tendência central (MTC), sendo estas a média aritmética ponderada (MAP) e o desvio padrão (DP), e foram elaboradas por meio do Microsoft Excel ${ }^{\circledR}$, versão 2010. O tratamento dos dados foi feito por meio de análise descritiva simples univariada não-paramétrica e não-probabilística.

O estudo obedeceu aos preceitos éticos estabelecidos pela Resolução $n=510$, de 7 de abril de 2016, do Conselho Nacional de Saúde (CNS), o qual regulamenta a realização da pesquisa envolvendo seres humanos (BRASIL, 2016a). O projeto de 
pesquisa foi apreciado e aprovado pelo Comitê de Ética em Pesquisa da Faculdade de Saúde e Desenvolvimento Humano Santo Agostinho (CEP FASA), via Plataforma Brasil, sob parecer consubstanciado ํo 396.876 .

\section{RESULTADOS}

Quanto ao perfil socioeconômico e clínico, a amostra é composta por predomínio de mulheres adultas jovens, em idade fértil, correspondendo à faixa etária de 25-45 anos

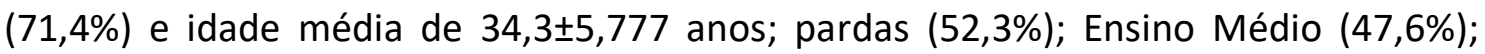
casadas ou em união estável (52,3\%); renda familiar não declarada pela maioria $(66,6 \%)$; predomínio da menarca entre 10-13 anos (71,6\%) e da sexarca entre 15-17 anos (38,0\%); $38,0 \%$ da amostra não possuíam registro do número de parceiros, em contrapartida, outros 38,0\% declararam ter apenas um parceiro; uso de pílula anticoncepcional (PAC) por $57,1 \%$ das mulheres; apresentavam entre um e dois filhos na data do rastreamento (57,1\%); histórico positivo para infecções sexualmente transmissíveis (IST) (61,9\%), bem como infecção pelo HPV (47,6\%). Negam tabagismo $(57,1 \%)$ e dispareunia $(57,1 \%)$ (Tabela 1).

Tabela 1 - Perfil socioeconômico e clínico das mulheres com alterações citopatológicas. Montes Claros, MG, 2019. $(n=21)$

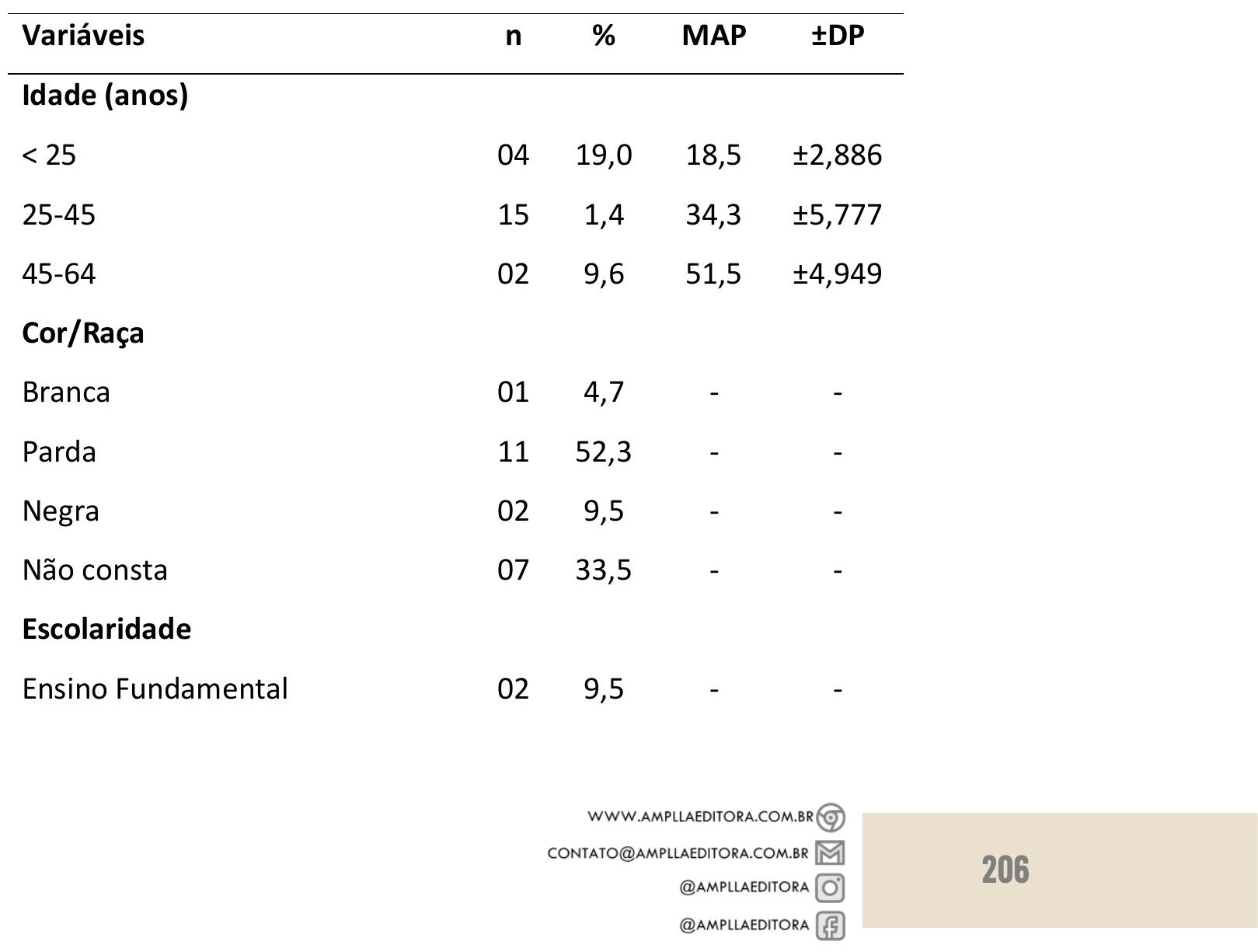


Ensino Médio

Ensino Superior

Não consta

Estado civil

Solteira

Casada/União estável

Viúva

Não consta

\section{Renda familiar (SM)}

$<1$

1

$2-3$

Não consta

Menarca (anos)

$<10$

$10-13$

$\geq 14$

Não consta

Sexarca (anos)

$<15$

15-17

$>17$

Não consta

№ de parceiros

1

2-3

$\geq 4$

Não consta

Uso de PAC

Sim

Não

$\begin{array}{cc}10 & 47,6 \\ 02 & 9,5 \\ 07 & 33,4\end{array}$

$03 \quad 14,2$

1152,3

029,5

$05 \quad 24,0$

$00 \quad 0,0 \quad 0,0 \quad \pm 0,0$

$04 \quad 19,2 \quad 1,0 \quad \pm 0,0$

$03 \quad 14,2 \quad 2,3 \quad \pm 0,577$

1466,6

$\begin{array}{cccc}01 & 4,7 & 9,0 & \pm 0,0 \\ 15 & 71,6 & 11,6 & \pm 1,242 \\ 02 & 9,5 & 14,5 & \pm 0,707 \\ 03 & 14,2 & - & -\end{array}$

$02 \quad 9,5 \quad 13,5 \quad \pm 0,707$

$08 \quad 38,0 \quad 15,75 \quad \pm 0,886$

$06 \quad 28,5 \quad 19,0 \quad \pm 1,264$

$05 \quad 24,0$

$\begin{array}{cccc}08 & 38,0 & 1,0 & \pm 0,0 \\ 05 & 24,0 & 2,4 & \pm 0,547 \\ 00 & 0,0 & 0,0 & \pm 0,0\end{array}$

0838,0

1257,1

0419,0 


\begin{tabular}{|c|c|c|c|c|}
\hline Não consta & 05 & 23,9 & - & - \\
\hline \multicolumn{5}{|c|}{ № de gestações } \\
\hline Nenhuma & 01 & 4,7 & 0,0 & $\pm 0,0$ \\
\hline $1-2$ & 12 & 57,1 & 1,25 & $\pm 0,452$ \\
\hline $3-5$ & 03 & 14,2 & 3,66 & $\pm 0,577$ \\
\hline$>5$ & 00 & 0,0 & 0,0 & $\pm 0,0$ \\
\hline Não consta & 05 & 24,0 & - & - \\
\hline \multicolumn{5}{|c|}{ Histórico de IST } \\
\hline Sim & 13 & 61,9 & - & - \\
\hline Não & 00 & 0,0 & - & - \\
\hline Não consta & 08 & 38,1 & - & - \\
\hline \multicolumn{5}{|l|}{ Tabagismo } \\
\hline Sim & 02 & 9,5 & - & - \\
\hline Não & 12 & 57,1 & - & - \\
\hline Não consta & 07 & 33,4 & - & - \\
\hline \multicolumn{5}{|l|}{ Dispareunia } \\
\hline Sim & 05 & 23,8 & - & - \\
\hline Não & 12 & 57,1 & - & - \\
\hline Não consta & 04 & 19,1 & - & - \\
\hline \multicolumn{5}{|c|}{ Histórico de infecção por HPV } \\
\hline Sim & 10 & 47,6 & - & - \\
\hline Não & 02 & 9,5 & - & - \\
\hline Não consta & 09 & 42,9 & - & - \\
\hline
\end{tabular}

Fonte: SISCAN, 2019.

SM: Salário Mínimo. PAC: Pílula Anticoncepcional. IST: Infecção Sexualmente Transmissível. HPV: Human Papillomavirus.

No período de junho 2014 a Maio de 2019, foram realizados 1003 exames citopatológicos, sendo que $2,1 \%$ das amostras $(n=21)$ apresentaram resultados positivos para ASCUS/AGC (Atypical Squamous Cells of Undetermined Significance/Células Glandulares), LSIL (Low-grade Squamous Intraepithelial Lesion), HSIL (High-grade Squamous Intraepithelial Lesion) e câncer. Das amostras com alteração detectada, 
houve prevalência de amostras com LSIL (47,6\%), seguidas de amostras com ASCUS/AGC $(33,3 \%)$ (Tabela 2$)$.

Tabela 2 - Perfil laboratorial e das alterações dos exames citopatológicos realizados durante o período de 2014-2019. Montes Claros, MG, 2019.

\begin{tabular}{lcc}
\hline Variável & $\mathbf{n}$ & \% \\
\hline Resultado da citopatologia oncótica & & \\
Positivo & 21 & 2,1 \\
Negativo & 982 & 97,9 \\
Tipos de alterações (n=21) & & \\
LSIL & 10 & 47,6 \\
HSIL & 02 & 9,5 \\
ASCUS/AGC & 07 & 33,3 \\
Al-Cervical & 01 & 4,8 \\
Al - Endometrial & 01 & 4,8 \\
\hline
\end{tabular}

Fonte: SISCAN, 2019.

LSIL: Low-grade Squamous Intraepithelial Lesion (Lesão Intra-Epitelial Escamosa de Baixo Grau). HSIL:

High-grade Squamous Intraepithelial Lesion (Lesão Intra-Epitelial Escamosa de Alto Grau). ASCUS: Atypical Squamous Cells of Undetermined Significance. AGC: Células glandulares. Al: Adenocarcinoma invasor.

Com relação à distribuição das alterações citopatológicas do colo do útero por idade, houve predominância de LSIL (47,6\%), seguido de ASCUS/AGC (33,3\%), com maior índice de acometimento entre a faixa etária de 25 a 35 anos de idade (47,55\%). As HSIL tiveram menor prevalência nas amostras de modo a manifestar-se em mulheres entre 25 a 49 anos (9,5\%). No entanto, o diagnóstico de Al ocorreu apenas em mulheres abaixo dos 25 anos (9,6\%) (Tabela 3). 
Tabela 3 - Perfil das alterações dos exames citopatológicos realizados durante o período de 2014-2019 distribuídos por idade. Montes Claros, MG, 2019. (n=21)

\begin{tabular}{lcccccccccc}
\hline \multirow{2}{*}{ Idade (anos) } & \multicolumn{2}{c}{ LSIL } & \multicolumn{2}{c}{ HSIL } & \multicolumn{2}{c}{ ASCUS/AGC } & \multicolumn{2}{c}{ AI } & \multicolumn{2}{c}{ Total } \\
\cline { 2 - 11 } & $\mathbf{n}$ & $\mathbf{\%}$ & $\mathbf{n}$ & $\mathbf{\%}$ & $\mathbf{n}$ & $\mathbf{\%}$ & $\mathbf{n}$ & $\mathbf{\%}$ & $\mathbf{n}$ & $\mathbf{\%}$ \\
\hline$<25$ & 02 & 9,5 & 00 & 0,0 & 00 & 0,0 & 02 & 9,6 & 04 & 19,1 \\
$25-35$ & 03 & 14,3 & 01 & 4,75 & 06 & 28,5 & 00 & 0,0 & 10 & 47,55 \\
$36-49$ & 03 & 14,3 & 01 & 4,75 & 01 & 4,8 & 00 & 0,0 & 05 & 23,85 \\
$>50$ & 02 & 9,5 & 00 & 0,0 & 00 & 0,0 & 00 & 0,0 & 02 & 9,5 \\
Total & $\mathbf{1 0}$ & $\mathbf{4 7 , 6}$ & $\mathbf{0 2}$ & $\mathbf{9 , 5}$ & $\mathbf{0 7}$ & $\mathbf{3 3 , 3}$ & $\mathbf{0 2}$ & $\mathbf{9 , 6}$ & $\mathbf{2 1}$ & $\mathbf{1 0 0 , 0}$ \\
\hline
\end{tabular}

Fonte: SISCAN, 2019.

LSIL: Low-grade Squamous Intraepithelial Lesion (Lesão Intra-Epitelial Escamosa de Baixo Grau). HSIL:

High-grade Squamous Intraepithelial Lesion (Lesão Intra-Epitelial Escamosa de Alto Grau). ASCUS: Atypical Squamous Cells of Undetermined Significance. AGC: Células glandulares. Al: Adenocarcinoma invasor.

\section{DISCUSSÃO}

O presente estudo mostra que os resultados citopatológicos de ASCUS/AGC, LSIL, HSIL e Al, apontaram prevalência em mulheres casadas e de cor parda. Resultados similares também foram encontrados em outros estudos científicos realizados na região sudeste do Brasil (THULER; AGUIAR; BERGMANN, 2014; MASCARELLO et al., 2012). Dois estudos realizados na região Nordeste do país apontaram frequência significativa de cor de pele não branca, respectivamente 91,75\% e 82,1\% (SILVA et al., 2018; RIBEIRO et al., 2014). Essa realidade difere de um estudo realizado em Santa Catarina ao revelar que $94,2 \%$ das mulheres com neoplasias malignas no trato genital, submetidas à radioterapia eram de cor branca, produzido pelo histórico de colonização predominantemente com cor de pele branca (SILVA et al., 2019).

As recomendações atuais para rastreamento do CCU do MS, preconizam a realização em mulheres na faixa etária entre 25 a 64 anos de idade que já tiveram ou mantêm atividade sexual (BRASIL, 2016b). Embora a idade média das mulheres no momento da coleta foi de 34,3 anos, sendo $71,5 \%$ entre 25 a 45 anos, a faixa etária inferior a mínima recomendada foi significativa, quando relacionada ao diagnóstico avançado, representando 9,5\% em idade entre 20 e 21 anos de idade, observância que 
confronta com os achados de outro estudo (MASCARELLO et al., 2012) ao revelar a idade avançada como um fator prepotente para estadiamento avançado da doença.

Estudos ainda indicam que a probabilidade para desenvolver a doença em estágios avançados em mulheres com idade entre 30 e 39 é $10 \%$ maior do que nas mais jovens, aumentando gradativamente até duas vezes para a faixa etária igual ou maior de 60 anos (THULER; AGUIAR; BERGMANN, 2014). No entanto mulheres com mais idade foram referidas com maiores chances de realizarem o exame citopatológico em relação as mais jovens, conseqüentemente relacionadas à identificação e tratamento precoce (SILVA, 2018; OPAS, 2016; MASCARELLO et al., 2012). No estudo envolvendo registro automatizado de mulheres submetidas ao rastreio cervical em Ontário no Canadá, ao comparar testes de Papanicolau entre mulheres mais jovens (menores de 50 anos) e maduras (maiores de 50 anos), obteve resultados de maiores anormalidades cervicais em mulheres mais jovens, respectivamente $88,6 \% \mathrm{HSIL} /$ carcinoma invasivo de qualquer tipo em 86,7\% representava LSIL + e AGUS (MENDES, 2014; COLGAN et al., 2002).

Os achados do presente estudo corroboram com estes resultados, ao revelar que mais de $90 \%$ das mulheres com resultados citopatológicos estavam abaixo dos 50 anos. Tal fato também foi identificado por Leyden et al. (2005) e Mendes (2014) ao verificarem prevalência de Câncer Cervical invasivo em mulheres com acesso integral à saúde abaixo dos 49 anos.

A posição socioeconômica desfavorável, menor nível educacional além da cor de pele não branca sido relatado como um indicador expressivo para a não aderência ao exame citopatológico pelas mulheres, conseqüentemente exposição à maior risco de terem diagnóstico tardio (RENNA JUNIOR; SILVA, 2018; CESAR et al., 2012). Todavia, os dados obtidos apresentam um marco de heterogeneidade, denotando transição dos achados supracitados com representatividade predominante das mulheres com ensino médio, consistindo com análise realizada em um município do Sul do país, o que sugere um contraponto positivo (SOARES et al., 2010).

A infecção pelo HPV é a causa necessária para a gênese do câncer cervical, no entanto sabe-se que outros fatores, tais como o uso de contraceptivos orais, início precoce da atividade sexual estão atribuídos ao seu desenvolvimento (SILVA et al., 2018; SILVA NETO et al., 2017; NOGUEIRA; MORAES, 2017; UCHIMURA et al., 2005). A frequência referente ao histórico para IST evidenciada neste estudo corrobora com essa 
hipótese, ao indicar predominância em $62 \%$ das mulheres, sendo 47,6\% infecções por HPV. A menarca mostrou-se aparente na faixa etária entre 10 a 13 anos, já o início da atividade sexual mostrou-se predominante na faixa etária entre 15 a 17 anos, a exemplos das participantes de um estudo feito no Acre (PRADO et al., 2012).

Em um estudo multicêntrico denominado Latin America Screening (LAMS), envolvendo mulheres usuárias do Sistema Único de Saúde (SUS) das cidades de São Paulo, Campinas e Porto Alegre, Roteli-Martins et al. (2007) dão suporte aos achados encontrados neste estudo, concluindo que o início precoce da atividade sexual correlaciona ao acréscimo da prevalência de infecções pelo HPV e suas lesões.

O uso de contraceptivo oral tem sido relacionado a transcrição do HPV e conseqüentemente ao acrescido risco de desenvolvimento de câncer cervical, tanto por repercussão social como também ter influência sobre a imunidade (MENDES, 2014; UCHIMURA et al., 2005; COELHO et al., 2004). Consistente com essa hipótese os dados encontrados refletem uso de contraceptivo oral em $57,2 \%$ das mulheres analisadas.

\section{COกCLUSÃO}

Ao interpretar os resultados, há que se considerar que as alterações cervicais estiveram concentradas nas mulheres com poucos filhos, casadas, com maior nível de escolaridade e sem queixas de dispareunia. Há também que as mulheres em idade fora da recomendada para rastreamento do câncer cervical apresentaram estágios mais avançados se comparadas às outras idades, sugerindo heterogeneidade entre os fatores de risco já consolidado. Dessa forma propõe-se a identificação dos fatores de risco para cada região, para subsidiar o delineamento das ações.

\section{REFERÊกCIAS}

ÁVILA, F. A. et al. A importância do exame Papanicolau na prevenção e manutenção da saúde da mulher. In: Anais do IV Seminário de Enfermagem, Universidade Feevale, Novo Hamburgo, 2016. Disponível em: https://www.feevale.br/hotsites/seminarioenfermagem/edicoesanteriores/2016. Acesso em: 18 mai 2018.

BARBOSA, I. R. et al. Desigualdades regionais na mortalidade por câncer de colo de útero no Brasil: tendências e projeções até o ano 2030. Ciência \& Saúde Coletiva. Rio de Janeiro, v. 21, n. 1, p. 253-262, 2016 . Disponível em: 
http://dx.doi.org/10.1590/1413-81232015211.03662015. Acesso em: 18 mai 2018.

BORGES, M. F. S. O. et al. Prevalência do exame preventivo de câncer do colo do útero em Rio Branco, Acre, Brasil, e fatores associados à não-realização do exame. Cadernos de Saúde Pública. Rio de Janeiro, v. 28, n. 6, p. 1156-1166, 2012. Disponível em: https://doi.org/10.1590/S0102-311X2012000600014. Acesso em: 21 out 2019.

BRASIL. Ministério da Saúde. Conselho Nacional de Saúde. Resolução no 510, de 7 de abril de 2016. Regulamenta a realização de pesquisas envolvendo seres humanos e dá outras providências. Brasília: CNS, 2016a. Disponível em: https://bvsms.saude.gov.br/bvs/saudelegis/cns/2016/res0510_07_04_2016.ht ml. Acesso em: 18 mai 2018.

BRASIL. Ministério da Saúde. Instituto Nacional de Câncer José Alencar Gomes da Silva. Diretrizes brasileiras para o rastreamento do câncer do colo do útero. 2aㅡ. ed. Rio de Janeiro: INCA, 2016b. 114p. Disponível em: https://www.inca.gov.br/publicacoes/livros/diretrizes-brasileiras-para-orastreamento-do-cancer-do-colo-do-utero. Acesso em: 29 set 2019.

CESAR, J. A. et al. Citopatológico de colo uterino entre gestantes no Sul do Brasil: um estudo transversal de base populacional. Revista Brasileira de Ginecologia e Obstetrícia. Rio de Janeiro, v. 34, n. 11, p. 518-523, 2012. Disponível em: http://dx.doi.org/10.1590/S0100-72032012001100007. Acesso em: 2 jan 2020.

COELHO, F. R. G. et al. Estrogen and progesterone receptors in human papilloma virus related cervical neoplasia. Brazilian Journal of Medical and Biological Research. Ribeirão Preto, v. 37, n. 1, p. 83-88, 2004 . Disponível em: http://dx.doi.org/10.1590/S0100-879X2004000100012. Acesso em: 22 nov 2019.

COLGAN, T. J. et al. Screening for cervical disease in mature women. Cancer. Atlanta (Geórgia), v. 96, n. 4, p. 195-203, 2002. Disponível em: http://doi.org/10.1002/cncr.10723. Acesso em: 19 ago 2020.

INSTITUTO NACIONAL DE CÂNCER JOSÉ ALENCAR GOMES DA SILVA. Sistema de informação do câncer: manual preliminar para apoio à implantação. Rio de Janeiro: INCA, 2013. 143p. Disponível em: https://www.inca.gov.br/sites/ufu.sti.inca.local/files//media/document//siste ma-informacao-cancer-manual.pdf. Acesso em: 18 mai 2018.

LEYDEN, W. A. et al. Cervical cancer in women with comprehensive health care access: attributable factors in the screening process. Journal of the National Cancer Institute. Oxford, v. 97, n. 9, p. 675-683, 2005. Disponível em: http://doi.org/10.1093/jnci/dji115. Acesso em: 12 jan 2020.

MASCARELLO, K. C. et al. Perfil sociodemográfico e clínico de mulheres com câncer do colo do útero associado ao estadiamento inicial. Revista Brasileira de 
Cancerologia. Rio de Janeiro, v. 58, n. 3, p. 417-426, 2012. Disponível em: https://doi.org/10.32635/2176-9745.RBC.2012v58n3.594. Acesso em: 18 mai 2018.

MENDES, T. L. T. Fatores relacionados com a ocorrência de lesões intraepiteliais cervicais em mulheres adolescentes. 23 fls. Pompéu. Monografia (Especialização em Atenção Básica em Saúde da Família) - Faculdade de Medicina, Núcleo de Educação em Saúde Coletiva, Universidade Federal de Minas Gerais, 2014. Disponível

em: https://www.nescon.medicina.ufmg.br/biblioteca/imagem/4615.pdf. Acesso em: 19 fev 2019.

NOGUEIRA, K. R. C.; MORAES, M. M. Prevenção do câncer cervical: o conhecimento das usuárias em uma equipe de saúde da família. Revista de Enfermagem UFPE on line. Recife, v. 11, n. 5, p. 1892-1901, 2017. Disponível em: http://doi.org/10.5205/reuol.11077-98857-1-SM.1105201719. Acesso em: 9 dez 2019.

ORGANIZAÇÃO PAN-AMERICANA DA SAÚDE. Controle integral do câncer de colo de útero: guia de práticas essenciais. Washington, DC: OPAS, 2016. Disponível em: http://iris.paho.org/xmlui/bitstream/handle/123456789/31403/978927571879 7-por.pdf? sequence=1\&isAllowed=y\&ua=1. Acesso em: 18 mai 2018.

PRADO, P. R. et al. Caracterização do perfil das mulheres com resultado citopatológico ASCUS/AGC, LSIL e HSIL segundo fatores sociodemográficos, epidemiológicos e reprodutivos em Rio Branco - AC, Brasil. Revista Brasileira de Cancerologia. Rio de Janeiro, v. 58, n. 3, p. 471-479, 2012. Disponível em: http://doi.org/10.32635/2176-9745.RBC.2012v58n3.604. Acesso em: $10 \mathrm{abr}$ 2019.

RENNA JUNIOR, N. L.; SILVA, G. A. Tendências temporais e fatores associados ao diagnóstico em estágio avançado de câncer do colo uterino: análise dos dados dos registros hospitalares de câncer no Brasil, 2000-2012. Epidemiologia \& Serviços de Saúde. Brasília, v. 27, n. 2, p. e2017285, 2018. Disponível em: https://doi.org/10.5123/s1679-49742018000200003. Acesso em: 13 ago 2019.

RIBEIRO, J. F. et al. Perfil sociodemográfico e clínico de mulheres com câncer do colo do útero em uma cidade do Nordeste. Revista Eletrônica Gestão \& Saúde. Brasília, v. 5, n. 4, p. 1367-1381, 2014. Disponível em: https://periodicos.unb.br/index.php/rgs/article/view/2921/2624. Acesso em: 21 jun 2018.

RIBEIRO, L. et al. Rastreamento oportunístico versus perdas de oportunidade: não realização do exame de Papanicolaou entre mulheres que frequentaram o prénatal. Cadernos de Saúde Pública. Rio de Janeiro, v. 32, n. 6, p. e00001415, 2016. Disponível em: http://dx.doi.org/10.1590/0102-311X00001415. Acesso em: 20 mai 2019. 
ROTELI-MARTINS, C. M. et al. Associação entre idade ao início da atividade sexual e subseqüente infecção por papilomavírus humano: resultados de um programa de rastreamento brasileiro. Revista Brasileira de Ginecologia e Obstetrícia. Rio de Janeiro, v. 29, n. 11, p. 580-587, 2007. Disponível em: https://doi.org/10.1590/S0100-72032007001100006. Acesso em: 13 dez 2019.

SANTOS, M. O. Estimativa 2018: incidência de câncer no Brasil. Revista Brasileira de Cancerologia. Rio de Janeiro, v. 64, n. 1, p. 119-120, 2018. Disponível em: https://doi.org/10.32635/2176-9745.RBC.2018v64n1.115. Acesso em: 18 mai 2018.

SANTOS, A. C. S.; VARELA, C. D. S. Prevenção do câncer de colo uterino: motivos que influenciam a não realização do exame de Papanicolau. Revista Enfermagem Contemporânea. Salvador, v. 4, n. 2, p. 179-188, 2015. Disponível em: http://dx.doi.org/10.17267/2317-3378rec.v4i2.692. Acesso em: 18 mai 2018.

SILVA, P. L. N. Perfil epidemiológico, clínico e laboratorial do exame citopatológico realizado em Espinosa, Minas Gerais, durante o ano de 2014. SUSTINERE Revista de Saúde e Educação. Rio de Janeiro, v. 6, n. 2, p. 239-249, 2018. Disponível em: https://doi.org/10.12957/sustinere.2018.32949. Acesso em: 2 jan 2020.

SILVA, A. A. L. et al. Perfil sociodemográfico e clínico de mulheres com câncer no trato genital submetidas a radioterapia. Cogitare Enfermagem. Curitiba, v. 2, n. 10, p. e58467, 2019. Disponível em: http://dx.doi.org/10.5380/ce.v24i0.58467. Acesso em: 20 jun 2018.

SILVA, R. C. G. et al. Perfil de mulheres com câncer de colo do útero atendidas para tratamento em centro de oncologia. Revista Brasileira de Saúde MaternoInfantil. Recife, v. 18, n. 4, p. 703-710, 2018. Disponível em: https://doi.org/10.1590/1806-93042018000400002. Acesso em: 20 mai 2018.

SILVA NETO et al. Rastreamento do câncer do colo do útero no município de Caxias, Estado do Maranhão. Revista Ciência \& Saberes. São Luís, v. 3, n. 1, p. 361-365, $2017 . \quad$ Disponível em: https://www.facema.edu.br/ojs/index.php/ReOnFacema/article/view/164/98. Acesso em: 18 mai 2018.

SILVEIRA, R. S. et al. Uma abordagem preventiva do câncer cérvico-uterino com mulheres em idade fértil. SANARE - Revista de Políticas Públicas. Sobral, v. 14, n. $1, \quad$ p. 58-64, 2015. Disponível em: https://sanare.emnuvens.com.br/sanare/article/view/609/326. Acesso em: 18 mai 2018.

SOARES, M. C. et al. Câncer de colo uterino: caracterização das mulheres em um município do sul do Brasil. Escola Anna Nery. Rio de Janeiro, v. 14, n. 1, p. 90-96, 2010. Disponível em: https://doi.org/10.1590/\$1414-81452010000100014. Acesso em: 7 jul 2019. 
TELES, C. C. G. D.; MUNIZ, M. C. V.; FERRARI, R. Tabagismo associado as lesões precursoras para o câncer de colo uterino. Revista de Enfermagem UFPE on line. Recife, v. 7, n. 9, p. 5427-5434, 2013. Disponível em: http://doi.org/10.5205/reuol.3529-29105-1-SM.0709201309. Acesso em: 23 ago 2019.

THULER, L. C. S.; AGUIAR, S. S.; BERGMANN, A. Determinantes do diagnóstico em estadio avançado do câncer do colo do útero no Brasil. Revista Brasileira de Ginecologia e Obstetrícia. Rio de Janeiro, v. 36, n. 6, p. 237-243, 2014. Disponível em: https://doi.org/10.1590/S0100-720320140005010. Acesso em: 18 mai 2018.

UCHIMURA, N. S. et al. Influência do uso de anticoncepcionais hormonais orais sobre o número de células de Langerhans em mulheres com captura híbrida negativa para papilomavírus humano. Revista Brasileira de Ginecologia e Obstetrícia. Rio de Janeiro, v. 27, n. 12, p. 726-730, 2005 . Disponível em: http://dx.doi.org/10.1590/S0100-72032005001200004. Acesso em: 21 mai 2019. 


\title{
CAPÍTULO XVIII
}

\section{PERCEPÇÃO DE GESTARTES QQUARTO AO USO DO SULFATO FERROSO}

\author{
DDI: 10.51859/AMPLLA.APS276.|121-18
}

Franciely Alves da Silva ${ }^{1}$

Higo Oliveira Inocêncio ${ }^{2}$

Edson Fredulin Scherer ${ }^{2}$

\footnotetext{
1 Mestre em Nutrição. Programa de Pós-Graduação em nutrição, alimentos e metabolismo - UFMT

2 Professor Docente do Centro Universitário do Vale do Araguaia - UNIVAR
}

\section{RESUMO}

Averiguar a percepção das gestantes acerca da importância do uso do sulfato ferroso na gestação. Métodos: Trata-se de um estudo descritivo com abordagem qualitativa conduzido com 45 gestantes com idade de 18-30 anos. As gestantes foram questionadas quanto a percepção das mesmas em relação ao uso do sulfato ferroso durante o atendimento do pré-natal em uma Unidades Básicas de Saúde (UBS) e no Centro de Referência de Assistência Social (CRAS) de Aragarças-GO, além da identificação da atuação do nutricionista durante esse período. Os dados foram coletados mediante um questionário individual semi-estruturado para seres analisados. Estabeleceu-se como critério de inclusão gestantes com 18 anos ou mais que foram atendidas na UBS e CRAS. Foram excluídas gestantes que não sabiam escrever o nome. Os dados obtidos foram analisados por estatística descritiva simples com auxílio do Microsoft Office Excel 2010. Resultados: Observou-se um desconhecimento por parte das gestantes em relação ao uso do sulfato ferroso, além disso, nota-se a ausência do acompanhamento nutricional adequado por parte de um profissional durante a gestação. Conclusão: conclui se que as gestantes possuem uma percepção deficiente em relação ao uso do sulfato ferro na gestação, no qual poderiam ser evitadas com o acompanhamento de um profissional de nutrição.

Palavras-chave: Sulfato ferroso. Gestante. Nutricionista.

\section{IกTRODUÇÃO}

A gestação é uma fase de vulnerabilidade biológica, envolvendo mãe-feto, período esse que necessita de aporte nutricional maior devido ao grau elevado de desenvolvimento e crescimento fisiológico (ANDRADE; SILVA; SANTOS; CAMPOS et al., 2015). Além das alterações fisiológicas, a carência de ferro denominada anemia ferropriva é uma das complicações comuns durante este período, podendo ocasionar danos à saúde materno-fetal (MODOTTI; MODOTTI; MARCELINO; DE OLIVA et al., 2015). 
Dessa forma, é de suma importância o desenvolvimento de uma assistência pré-natal de forma tranquila, digna e humano, com medidas que possibilita as gestantes a compreensão destas mudanças fisiológicas características (BRASIL; SAÚDE, 2005).

A anemia ferropriva na gestação é definida como aumento ou redução do tamanho das hemácias acompanhada da diminuição ou não da concentração de hemoglobina, obtendo níveis de hemoglobina menores que $11 \mathrm{~g} / \mathrm{dL}$ nas gestantes (SANTOS, 2009). O ferro é um mineral fundamental em várias atividades do organismo, como produção de energia para as células (SUBSTITUTO; TORRES; DIRETORIA; TORRES et al.) brasil essencial ao transporte de oxigênio e dióxido de carbono, envolvido diretamente na respiração celular (GUYTON, 2006).

A necessidade deste mineral durante a gestação é triplicada devido a demanda da placenta e do feto em crescimento, da volemia materna em evolução, assim como da multiplicação da massa de eritrócitos e das perdas sanguíneas do pardo. Para o feto também é essencial na formação da hemoglobina e constituição de deposito do mineral para os três meses após o nascimento (DOS SANTOS). Segundo a Organização Mundial da Saúde 2001 22,7\% das gestantes em países desenvolvidos apresentam anemia por deficiência de ferro, entretanto, nos países considerados subdesenvolvidos o número eleva para 52\%. Na África, por exemplo, cerca de $50 \%$ das gestantes são afetas por este tipo de anemia (WHO) 2001.

Dados epidemiológicos dessa anemia acometendo gestantes no Brasil são escassos, de acordo com Fujimori e colaboradores 2000 estimam se que a anemia acomete cerca de $30 \%$ a $40 \%$ das gestantes no país (FUJIMORI; LAURENTI; NÚÑEZ DE CASSANA; OLIVEIRA et al., 2000). Nesse sentido, em torno de $40 \%$ das mortes maternoperinatal estão relacionados com a anemia ferropriva. Os agravos a saúde desta anemia são: queda de cabelos, enfraquecimento de unhas, alterações cardiovasculares, baixa imunidade, pré-eclâmpsia entre outros (RODRIGUES; JORGE, 2010). Entretanto, objetivando reduzir os efeitos ocasionados pela a anemia durante a fase gestacional, 0 Ministério da Saúde recomenda desde os anos de 1980 a suplementação medicamentosa de ferro, e em 2005 inseriu o Programa Nacional de Suplementação de Ferro (FUJIMORI; SATO; SZARFARC; VEIGA et al., 2011).

Por isso, a fortificação obrigatória de ferro nas farinhas de trigo e milho também é uma ação do governo como medida profilática, bem como a promoção a alimentação 
saudável e adequada com refeições contendo fontes de ferro. As ações de alimentação saudável cabem ao nutricionista, profissional que está intimamente ligado à alimentação e nutrição em qualquer fase da vida (SUBSTITUTO; TORRES; DIRETORIA; TORRES et al.) BRASIL, 2013. Nesse sentido, a orientação nutricional deve ocorrer durante todo o acompanhamento gestacional e se possível já no período antenatal (RODRIGUES; JORGE, 2010). Porém, vários fatores de ordem política, administrativo, gestão, planejamento, entre outros reduzem sua efetividade. Outros fatores são os efeitos adversos pelo uso do suplemento interferem também no resultado positivo da medicação, tais como: náuseas, diarreia, dor abdominal, constipação e vômitos (FUJIMORI; SATO; SZARFARC; VEIGA et al., 2011).

Estudos de COSTA e MADEIRA 2007 relatam que estes efeitos adversos ao organismo das gestantes é fator causal para que muitas deixem de utilizar o suplemento, abandonando o tratamento, ocasionando um desperdício na rede de saúde pública, além de aumentar a probabilidade de obter anemia (COSTA; MADEIRA, 2007). Dessa forma, faz se necessário um acompanhamento preventivo de modo a evitar a ocorrência dessa anemia na gestação (TAPIA; FALEIRO; ZILLE; GONTIJO et al., 2010).

O profissional responsável pela distribuição bem como orientações relacionadas ao suplemento de sulfato ferroso dever capacitado, e de preferência designado aos serviços de alimentação e nutrição no município, ou seja, o profissional de nutrição (BRASIL, 2014). Entretanto a atuação deste profissional está ausente na Estratégia Saúde da Família, ou seja, não prestando serviços relacionados à alimentação saudável, não promovendo a prevenção, promoção e recuperação da saúde (GEUS et al., 2011).

Este tipo de suplemento deve ser ofertado gratuitamente, para as gestantes a partir da 20a semana até o final da gestação, consumindo diariamente cerca de $40 \mathrm{mg}$ de ferro, sendo distribuídos através das unidades de saúde que resignam a rede do SUS em todos os municípios brasileiros. Além da oferta do suplemento como medida preventiva é essencial exercer ações educativas em relação a alimentação saudável, principalmente enfatizar a importância do consumo de alimentos fontes de ferro (BRASIL, 2005).

Portanto, as medidas para a prevenção da anemia, durante o período gestacional, incluem não somente a fortificação de alimentos (SATO; FUJIMORI; SZARFARC; BORGES et al., 2010) e uso de sulfato ferroso (BRANDÃO; CABRAL; CABRAL, 
2011) mas da mesma forma, orientações referentes ao aumento do consumo de fontes naturais de ferro e de alimentos que auxiliam a absorção do mineral e redução daqueles que inibem sua absorção (SATO; FUJIMORI; SZARFARC; BORGES et al., 2010). A partir das exposições percebe-se a importância de se conhecer como ocorre a distribuição de sulfato ferroso durante o pré-natal, além de se observar a atuação do profissional nutricionista, a fim de se garantir a integralidade no atendimento à gestante. Portanto, o objetivo principal dessa pesquisa foi analisar se as gestantes possuem orientação do uso correto do sulfato ferroso durante sua distribuição, bem como, se existe um acompanhamento neste período do profissional de nutrição.

\section{METODOLOGIA}

Realizou se estudo transversal, exploratório, descritivo com abordagem qualitativa, no qual foi aplicado um questionário semiestruturado (contendo o Termo de Consentimento Livre e Esclarecido de acordo com a Resolução 466/12 que regulamenta pesquisa envolvendo seres humanos, garantindo segurança quanto ao anonimato, a privacidade e a desistência em qualquer etapa da pesquisa), buscando identificar qual a percepção das gestantes quanto ao uso do sulfato ferroso nesse período gravídico. A coleta de dados foi realizada em uma unidade UBS e no CRAS situado no município de Aragarças-Goiás. Constituíram da amostra todas as gestantes que se dispuserem a participar da pesquisa e as que se enquadraram nos critérios de inclusão: gestante maiores de 18 anos e foram excluídas as gestantes que não conseguiam fazer assinatura. Depois de obtido os dados, estes seguiram uma estatística simples, no qual os resultados foram expostos na forma de gráficos através de Microsoft Office Excel 2010.

\section{RESULTADOS E DISCUSSÃO}

Participaram dessa pesquisa 45 gestantes com idade entre dezoito e trinta anos, onde $13,5(\mathrm{~N}=30)$ concluíram o ensino médio e 6,75\% $(\mathrm{N}=15)$ relataram que concluíram o ensino superior. Fatores como idade e escolaridade podem influenciar o entendimento quanto ao uso do medicamento que é de suma importância durante o período gestacional (VITOLO; BOSCAINI, 2008). As mulheres com ensino superior 
demonstravam ter conhecimento maior em relação ao uso sulfato ferroso, comparado com as que concluíram apenas o ensino médio.

Aos serem questionadas em relação a função do sulfato ferroso, observamos que no gráfico 1, 24\% ( $N=11$ ) sabiam relatar algum conhecimento sobre a função do mesmo, em contraposição, 76\% ( $N=34)$ não souberam relatar á importância do suplemento. Resultado diferente foi encontrado no estudo de Ferreira e Gama 2010, no qual 23,81\% $(\mathrm{N}=5)$ das 21 gestantes relaram não ter conhecimento relacionados ao medicamento, contudo 80,95\% ( $N=18$ ) demonstravam algum conhecimento (FERREIRA; GAMA, 2010).

Obter conhecimentos relacionados aos medicamentos designados durante a gestação possibilita um planejamento e aceitação do tratamento, obtendo assim bons resultados dos seus propósitos, tornando esse processo saudável (FONSECA; FONSECA; BERGSTEN-MENDES, 2002).

Gráfico 1 - Percentual de grávidas que tinham conhecimento da função do sulfato ferroso.

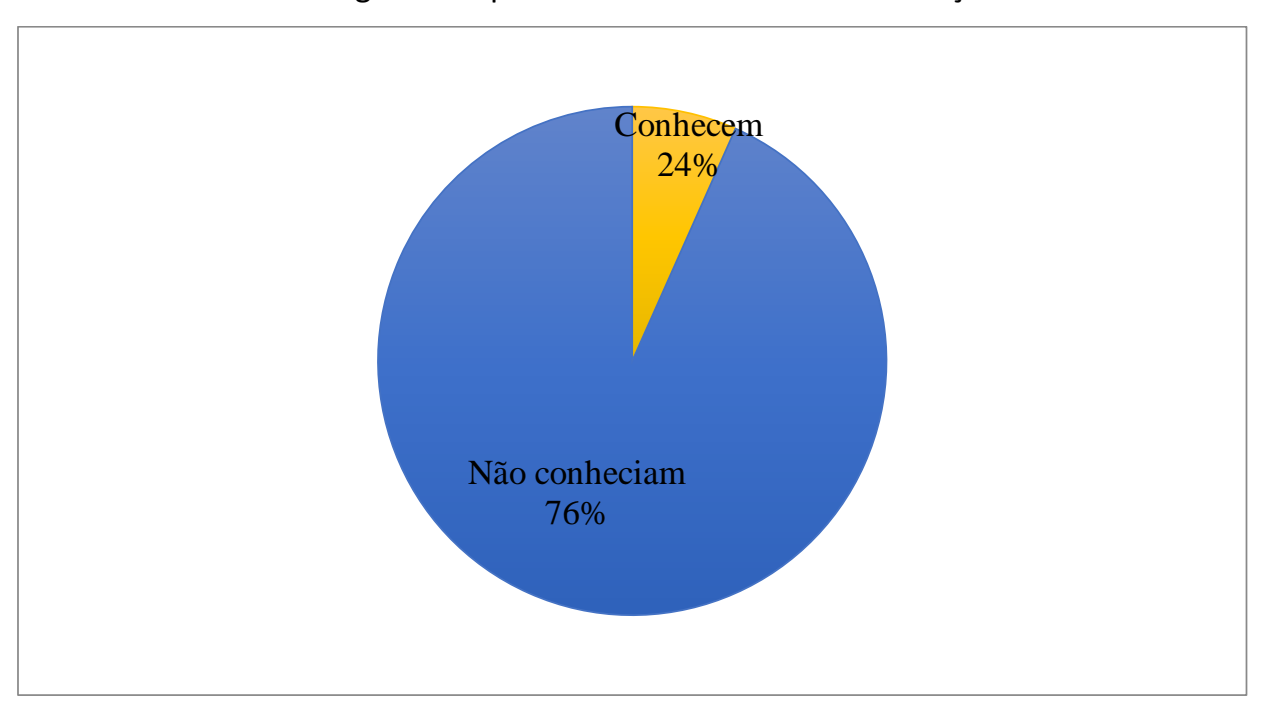

Fonte: Autoria própria

Sobre os tipos de alimentos que poderiam consumir durante a ingesta do fármaco, destacado no gráfico 2 , que $6,66 \%(\mathrm{~N}=3)$ souberam falar corretamente em relação a esses alimentos, porém 93,34\% (N=42) não demonstraram terem conhecimento sobre esse aspecto. Na alimentação encontra se dois tipos de ferro, o de origem animal denominado de ferro heme, encontrado, por exemplo, nas carnes vermelhas, peixe, aves entre outros. Outra classificação é o ferro não heme de origem vegetal, contendo nas hortaliças folhosas verdes escuras, leguminosas, grãos e etc, 
devendo se orientar o consumo desses alimentos de modo a prevenir anemia, bem como, auxiliar na demanda de ferro durante a gestação (BRASIL, 2013).

Gráfico 2: frequência de gestantes que conheciam os alimentos que podem ser consumidos durante o uso do medicamento (sulfato ferroso).

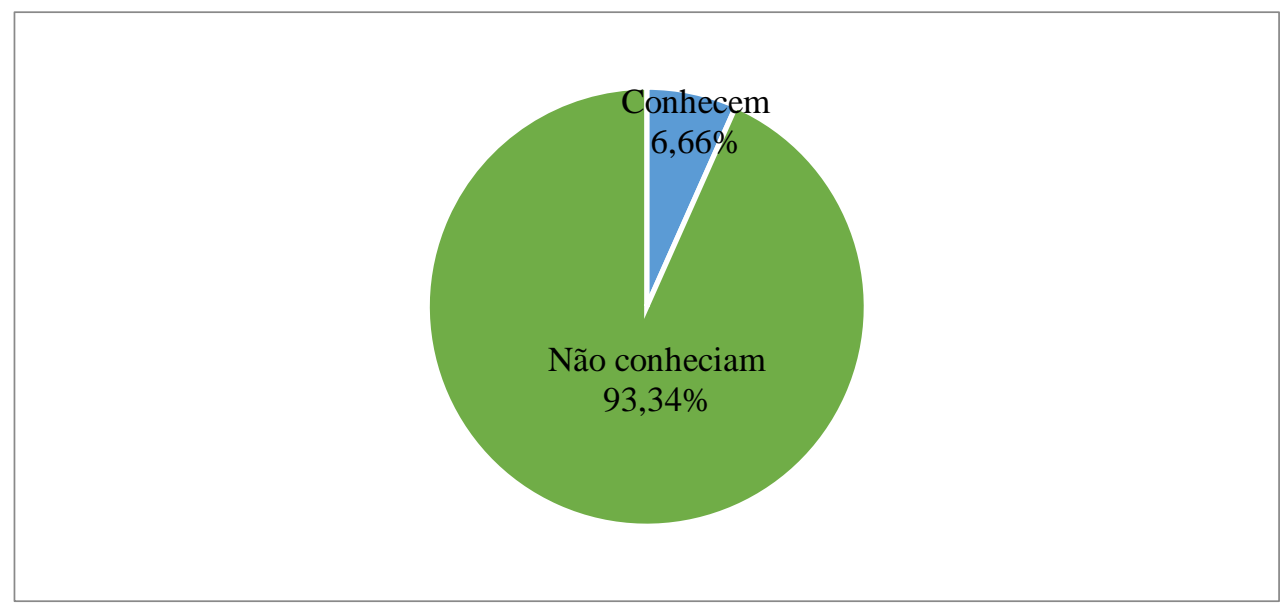

Fonte: Autoria própria

Em relação ao uso do suplemento $84,44 \%(\mathrm{~N}=38)$ faziam o consumo com água, $13,32 \%(\mathrm{~N}=6)$ com suco artificial e $2,22 \%(\mathrm{~N}=1)$ com leite de vaca. De acordo com SANTOS 2010 (SANTOS; DONADIA; SANTOS, 2010), a vitamina C denominado de ácido ascórbico aumenta a absorção do ferro, principalmente o ferro não heme, devido a redução da captação no organismo, em contrapartida, segundo OLIVEIRA e OSÓRIO 2005 o consumo de leite após as principais refeições diminui a biodisponibilidade do ferro contido no alimento, ou seja, ocasionando baixa absorção (OLIVEIRA; OSÓRIO, 2005). 
Gráfico 4: Porcentagem de gestantes que consomem o medicamento associando a alguma ingesta hídrica.

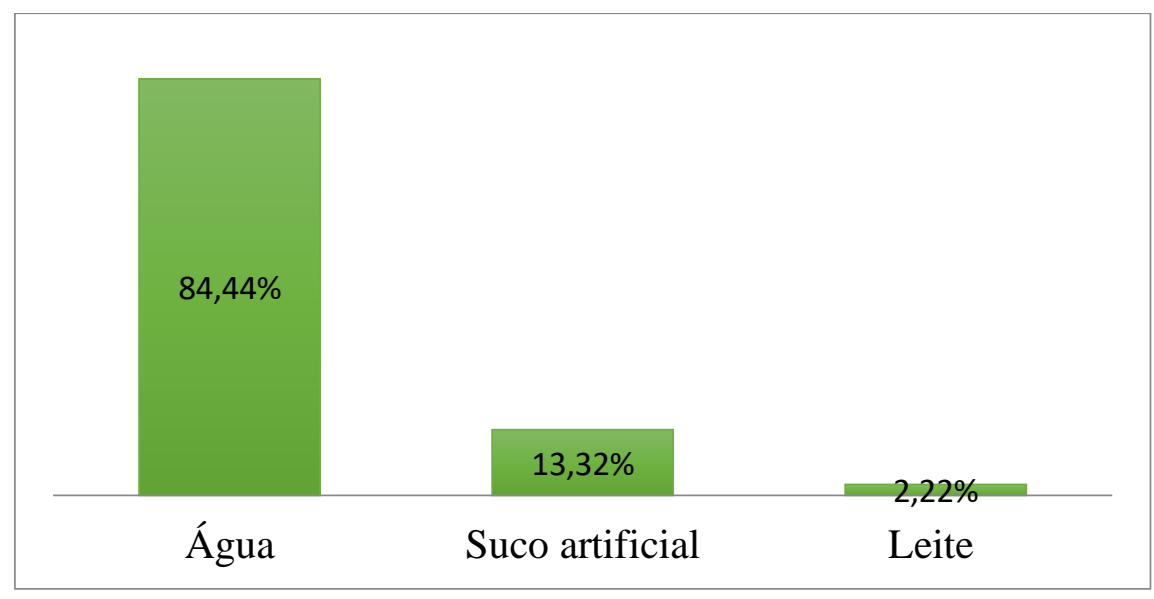

Fonte: Autoria própria

Destas gestantes $80 \%(\mathrm{~N}=36)$ faziam acompanhamento com a equipe de enfermagem durante o uso do sulfato ferroso e $20 \%(N=9)$ com médicos, eventualmente nenhuma delas obteve suporte de um profissional de nutrição durante a distribuição do suplemento. Segundo o Ministério da Saúde (2005) o Programa Nacional de Sulfato Ferroso deve ser acompanhado por um responsável técnico de preferência aquele já responsável pelas ações de alimentação e nutrição do município, ou seja, o profissional de nutrição.

Gráfico 4: Percentual de gestantes que faziam acompanhamento com algum profissional da saúde

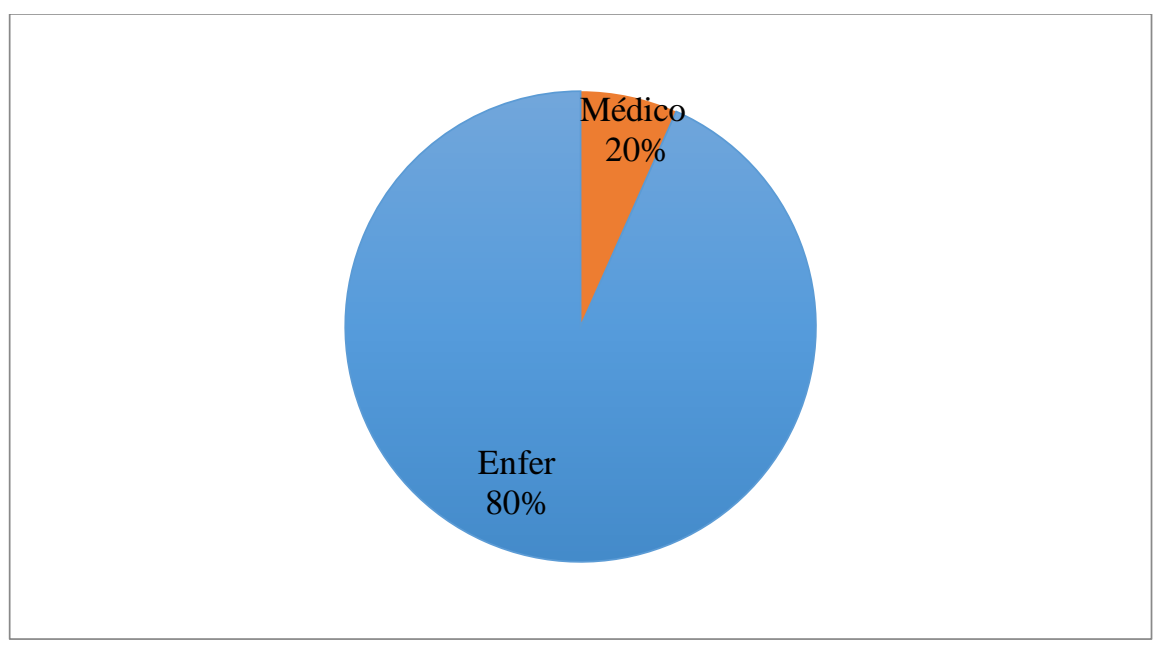

Fonte: Autoria própria 
O nutricionista é o profissional adequado para essas funções, pois possui pleno conhecimento das necessidades alimentares durante a vida principalmente na gestação, podendo assim orientar acerca da funcionalidade, benefícios, alimentos que auxiliam ou os que inibem sua absorção.

\section{CONSIDERAÇÔES FInRIS}

Baseado em conjunto de análises verificou se que, a partir dos relatos das gestantes obtidos pelo questionário o desconhecimento das mesmas em relação ao medicamento é visível. Mediante essa situação observa se a importância do acompanhamento do profissional de nutrição durante a oferta do suplemento, visto que é o profissional capacitado para orientar na questão alimentar, bem como, o seu devido uso.

\section{REFERÊRCIAS}

ANDRADE, B. D.; SILVA, A. C. P.; SANTOS, M. T. M. d.; CAMPOS, T. et al. Fatores nutricionais e sociais de importância para o resultado da gestação, em mulheres em acompanhamento na rede de atenção primária de Juiz de Fora. Rev Med Minas Gerais, 25, n. 3, p. 344-352, 2015.

BRANDÃO, A. H. F.; CABRAL, M. A.; CABRAL, A. C. V. A suplementação de ferro na gravidez: orientações atuais. Femina, 2011.

BRASIL; SAÚDE, d. d. Pré-natal e puerpério: atenção qualificada e humanizada: manual técnico. : Ministério da Saúde Brasília 2005.

COSTA, A. V. S.; MADEIRA, L. M. O uso do sulfato ferroso durante a gravidez: reflexões à luz da literatura. Revista Mineira de Enfermagem, 11, n. 2, p. 196-200, 2007.

DOS SANTOS, P. B. ANEMIA FERROPRIVA NA GESTAÇÃO.

FERREIRA, A.; GAMA, N. Percepção de gestantes quanto o ácido fólico e sulfato ferroso durante o pré natal. Rev Enferm Integr, 3, n. 2, p. 578-589, 2010.

FONSECA, M. R. C. C. d.; FONSECA, E. d.; BERGSTEN-MENDES, G. Prevalência do uso de medicamentos na gravidez: uma abordagem farmacoepidemiológica. Revista de Saúde Pública, 36, p. 205-212, 2002.

FUJIMORI, E.; LAURENTI, D.; NÚÑEZ DE CASSANA, L. M.; OLIVEIRA, I. M. V. d. et al. Anemia e deficiência de ferro em gestantes adolescentes. Revista de Nutrição, 13, n. 3, p. 177-184, 2000. 
FUJIMORI, E.; SATO, A. P. S.; SZARFARC, S. C.; VEIGA, G. V. d. et al. Anemia em gestantes brasileiras antes e após a fortificação das farinhas com ferro. Revista de Saúde Pública, 45, p. 1027-1035, 2011.

GUYTON, A. C. Tratado de fisiologia médica. Elsevier Brasil, 2006. 8535216413.

MODOTTI, M.; MODOTTI, C.; MARCELINO, M.; DE OLIVA, T. et al. Anemia ferropriva na gestação: controvérsias na suplementação do ferro. Med Rib Preto Online, 48, n. 4, p. 401-407, 2015.

OLIVEIRA, M. A.; OSÓRIO, M. M. Consumo de leite de vaca e anemia ferropriva na infância. J Pediatr, 81, n. 5, p. 361-367, 2005.

RODRIGUES, L. P.; JORGE, S. R. P. Deficiência de ferro na gestação, parto e puerpério. Revista Brasileira de Hematologia e Hemoterapia, 32, p. 53-56, 2010.

SANTOS, A. F. S.; DONADIA, J. T.; SANTOS, L. Ferro: Benefícios a saúde. MOSTRA ACADÊMICA UNIMEP, 8, 2010.

SANTOS, A. U. Prevalência de anemia em gestantes atendidas em uma maternidade social: antes e após a fortificação das farinhas com ferro. 2009. -, Universidade de São Paulo.

SATO, A. P. S.; FUJIMORI, E.; SZARFARC, S. C.; BORGES, A. L. V. et al. Consumo alimentar e ingestão de ferro de gestantes e mulheres em idade reprodutiva. Revista Latino-Americana de Enfermagem, 18, n. 2, p. Tela 113-Tela 121, 2010.

SUBSTITUTO, D. P.; TORRES, A. B.; DIRETORIA, P.; TORRES, D.-A. B. et al. Agência Nacional de Vigilância Sanitária-Anvisa.

TAPIA, M. E. L.; FALEIRO, M. L. S.; ZILLE, M. d. L. B.; GONTIJO, C. S. et al. Prevalência de anemia nas gestantes atendidas no Sistema Único de Saúde-Secretaria Municipal de Saúde-Prefeitura de Belo Horizonte. RBAC, 42, n. 4, p. 277-281, 2010.

WHO. United Nations Children's Fund/United Nations University 2001 Iron deficiency anaemia. Assessment, prevention and control: a guide for programme managers. Geneva: World Health Organization. 


\title{
CAPITULO XIX
}

\section{COחCEPÇÔES E DESAFIOS DA ATUAÇ̃̃O FOกOAUDIOLĹGICA חO NÚCLEO AMTPLIADO DE SAÚDE DA FATIÍLIAE ATERÇÃO PRIIÍ́RRIA}

\author{
DDI: 10.51859/AMPLLA.APS276.1121-19
}

Rodrigo Oliveira da Fonsêca ${ }^{1}$ Sâmara Danielly de Medeiros Alves ${ }^{2}$

\footnotetext{
${ }^{1}$ Mestre em Fonoaudiologia. Universidade Federal do Rio Grande do Norte - UFRN

${ }^{2}$ Especialista em Gestão de Programas de Saúde da Família. Universidade Candido Mendes - UCAM
}

\section{RESUTO}

O Núcleo Ampliado de Saúde da Família e Atenção Primária (NASF-AP) representa o principal espaço de atuação fonoaudiológica na Atenção Primária à Saúde (APS), oportunizando um amplo escopo para o desenvolvimento de práticas fonoaudiológicas coletivas e interdisciplinares. No entanto, ainda há uma limitação na compreensão do exercício fonoaudiológico e das suas contribuições no NASF-AP. Sendo assim, o objetivo deste estudo é analisar as informações existentes na literatura acerca da atuação fonoaudiológica no NASF-AP, identificando desafios presentes na prática profissional. Com a implantação do NASF-AP, houve um aumento no quantitativo de fonoaudiólogos na APS, atravessado por discrepâncias na distribuição destes profissionais e no acesso oportuno pelos usuários. Ademais, no decorrer do tempo, incorporaram-se ao processo de trabalho fonoaudiológico a presença maciça da dimensão clínico-assistencial, lacuna no conhecimento de gestores sobre o papel do profissional, limitação na oferta de recursos humanos e materiais e aspectos curriculares insuficientes. Paralelamente, há restrição de subsídios voltados ao processo de trabalho do fonoaudiólogo no âmbito do NASF-AP, demandando a ampliação de estudos acerca desta atuação.

Palavras-chave: Fonoaudiologia. Atenção Primária à Saúde. Sistema Único de Saúde.

\section{IกTRODUÇก̃O}

O Núcleo de Apoio à Saúde da Família (NASF) foi instituído em 2008, pela Portaria GM/MS no 154, para apoiar a Estratégia de Saúde da Família (ESF) e ampliar a resolutividade e o escopo de ações na Atenção Primária à Saúde (APS) (BRASIL, 2008). Em 2017, com a implantação da nova versão da Política Nacional de Atenção Básica, por meio da Portaria GM/MS no 2.436, o NASF foi designado como Núcleo Ampliado de Saúde da Família e Atenção Básica (BRASIL, 2017). Já em 2020, houve uma redefinição 
no registro das equipes de APS, alterando-o para Núcleo Ampliado de Saúde da Família e Atenção Primária (NASF-AP) (BRASIL, 2020).

No NASF-AP, o processo de trabalho baseia-se no conjunto das necessidades sociais e de saúde da população, no perfil epidemiológico do território, nos recursos disponíveis e no planejamento das ações por todos os atores envolvidos (ORUÉ et al., 2018). Segundo Nascimento et al. (2018), diferentes categorias profissionais podem compor o NASF-AP, as quais, conjuntamente, são capazes de repensar, transformar e subsidiar a mudança das práticas desenvolvidas, por muitos anos, na ESF.

Por meio de uma relação interativa, os profissionais componentes do Núcleo podem trocar conhecimentos de cada área na perspectiva do trabalho em rede (CASTRO; NIGRO; CAMPOS, 2018). Com o surgimento do NASF-AP, houve um aumento substancial no quantitativo de alguns profissionais de saúde na APS, incluindo o fonoaudiólogo, uma vez que a sua atuação engloba ações de promoção, proteção, recuperação e reabilitação da saúde da comunicação humana (SOUSA et al., 2017).

No NASF-AP, o fonoaudiólogo encontra o seu principal espaço de trabalho na APS, oportunizando o seu exercício sob um modelo interdisciplinar e comunitário (SOLEMAN; MARTINS, 2015). Medeiros et al. (2021) salientaram que o fonoaudiólogo apresenta uma grande potencialidade na APS, sendo capaz de detectar e solucionar os distúrbios da comunicação humana neste nível de atenção.

Apesar da tendência de consolidação da Fonoaudiologia na APS, existem ofertas e coberturas insuficientes e desiguais de serviços fonoaudiológicos, dificultando o acesso oportuno pelos usuários (VIÉGAS et al., 2018). Ademais, mesmo com o variado leque de possibilidades da atuação fonoaudiológica no NASF-AP, ainda há uma limitação na percepção acerca do exercício deste profissional e das suas contribuições interdisciplinares e intersetoriais (GUCKERT; SOUZA; ARAKAWA-BELAUNDE, 2020).

Face ao exposto, este estudo tem por objetivo analisar as informações existentes na literatura acerca da atuação fonoaudiológica no NASF-AP, identificando desafios presentes na prática profissional. 


\section{REUISÃO BIBLIOGRÁFICA}

\subsection{0 percurso fonoaudiológico na APS}

No período de 1970 a 1980, por meio das Secretarias de Saúde e Educação dos estados e municípios, a Fonoaudiologia ingressou no serviço público brasileiro. A prática fonoaudiológica realizada nesta época direcionava-se para a reabilitação do sujeito, com a ampla realização de atendimentos clínicos individuais (BEFI, 1997).

Gurgueira (2009) afirmou que com a implantação do Sistema Único de Saúde (SUS), ao final da década de 1980, os fonoaudiólogos começaram a atuar diretamente na APS. Contudo, a profissão estava atrelada à ótica clínica-reabilitadora. Sendo assim, os profissionais e as instituições de ensino buscaram revisitar a presença do fonoaudiólogo na APS. Segundo Cavalheiro (1996), a Fonoaudiologia precisou adequarse à uma perspectiva social, coletiva e preventiva, de modo que muitos fonoaudiólogos passaram a escrever e publicar vários relatos de experiências que contemplavam o modelo preventivo-comunitário.

Lemos e Bazzo (2010) afirmaram que tal conjuntura seria passível de superar a reprodução de um modelo pautado na reabilitação, à luz do desenvolvimento de cuidados interdisciplinares e coletivos relacionados aos aspectos da comunicação humana. No entanto, desde o surgimento da Fonoaudiologia no Brasil, é sabido que as ações de caráter terapêutico-reabilitador ainda são amplamente reproduzidas (CASTRO et al., 2020), tendo em vista que os fonoaudiólogos são convencionalmente formados e atuantes para as especialidades (SILVA et al., 2019).

Ainda assim, merece destaque o fato de que a inserção do fonoaudiólogo no NASF-AP, em 2008, foi crucial para a atuação do profissional no campo da Saúde Coletiva (MIRANDA et al., 2015). O NASF-AP representa o principal campo de atuação para o fonoaudiólogo na APS, desafiando-o a ir além de suas atividades clínicas tradicionais, no intento de promover práticas que lidem com o complexo processo saúde-doença (MOLINI-AVEJONAS; MENDES; AMATO, 2010). Soleman e Martins (2015) pontuaram que, partindo das demandas mais prevalentes no território, o profissional, ao efetuar ações de promoção e prevenção ou articulação intersetorial, auxilia na diminuição das demandas a médio e longo prazo. 
Em adição, Rech et al. (2019) atestaram que é evidente a heterogeneidade na oferta de serviços fonoaudiológicos públicos, intra e interregionalmente, no Brasil. A desigualdade na distribuição de fonoaudiólogos e o atendimento fonoaudiológico insuficiente no NASF-AP torna a oferta de ações reduzida, obstaculizando o processo de cuidado quanto aos distúrbios da comunicação humana.

Por outro lado, para solidificar a presença de fonoaudiólogos no NASF-AP, não basta apenas a apropriação de novos saberes e práticas por parte dos fonoaudiólogos e tampouco a abertura de espaços de atuação. Primordialmente, é necessário que ocorram investimentos concretos na formação do profissional, fazendo com que o mesmo esteja mais preparado para lidar e atuar no SUS (GURGUEIRA, 2009).

\subsection{0 fonoaudiólogo na dimensão do apoio matricial}

O apoio matricial é uma forma de trabalho colaborativa baseada nas dimensões técnico-pedagógica e clínico-assistencial, diferenciando-se das formas tradicionais de organização da atenção à saúde e da assistência. Nesta proposta, diversas ferramentas são integradas para a produção de uma clínica ampliada e compartilhada (CAMPOS; DOMITTI, 2007). No entanto, mesmo com as potencialidades do NASF-AP na qualificação do cuidado em saúde, a incorporação do apoio matricial no trabalho da equipe pode ser entravada, uma vez que há dificuldade na compreensão e aceitação deste tipo de trabalho (ORUÉ et al., 2018).

O conhecimento das atividades desenvolvidas no NASF-AP é uma condição elementar para adequações e mudanças no processo de trabalho (ARCE; TEIXEIRA, 2018). Segundo Castro et al. (2020), é necessário que o fonoaudiólogo exercite um pensamento crítico e reflexivo baseado em perspectivas que potencializem o seu exercício no contexto do SUS.

Fonsêca e Cruz (2020) apontaram, entretanto, que ainda há um desconhecimento acerca do apoio matricial na Fonoaudiologia, o que pode gerar prejuízos na inserção do fonoaudiólogo, que, por sua vez, é constantemente direcionado para a realização de atividades clínico-assistenciais, fragilizando o trabalho interdisciplinar. Em virtude disto, a prática fonoaudiológica no NASF-AP deve compreender o equilíbrio de atividades clínico-assistenciais e técnico-pedagógicas, para 
que, assim, o aspecto clínico-assistencial, que limita a profissão no campo coletivo, atenda às preconizações (FONSÊCA et al. 2020).

É contundente, também, que o fonoaudiólogo atue de forma direcionada à realidade de vida da população, às políticas públicas e ao perfil sociodemográfico e epidemiológico do território (SILVA et al., 2017). Para além desta atuação, é válido ponderar que fatores como a organização e o desenvolvimento do processo de trabalho são distintos entre as localidades, sendo que diversos quesitos podem influenciar na configuração do NASF-AP, como as características do território implantado, as equipes que compõem a saúde da família e o NASF-AP, a política municipal, entre outros (NASCIMENTO et al., 2018).

Na região Nordeste, por exemplo, estudiosos verificaram, por meio da análise da produção fonoaudiológica no NASF-AP, discrepâncias entre os estados, com marcantes desigualdades nas taxas de atendimentos fonoaudiológicos individuais e heterogeneidade entre as práticas de atividades coletivas (FONSÊCA et al., 2020). No estado de São Paulo, constatou-se que, houve um crescimento expressivo das taxas de atendimentos fonoaudiológicos individuais, ao passo que a produção de atividades coletivas evidenciou disparidades entre as modalidades existentes, refletidas pelo predomínio de atendimentos em grupo e pela menor ocorrência de ações essenciais, como a mobilização social (FONSÊCA; ALVES; FREITAS, 2020).

No estudo de Medeiros et al. (2021), constatou-se que a maior parte das atividades efetuadas pelos fonoaudiólogos entrevistados configuravam-se como atendimentos individuais, seguidos de atividades coletivas compartilhadas e reuniões de equipe. Embora tenham sido realçadas diversas ações no âmbito técnico-pedagógico e conhecimento dos entrevistados sobre o conceito de apoio matricial, o estudo alertou para a priorização da dimensão clínico-assistencial.

Similarmente, em um serviço da Atenção Especializada do Rio Grande do Norte, as práticas fonoaudiológicas também foram recorrentes na reabilitação e na cura dos pacientes, distanciando-se da necessidade de um olhar ampliado no SUS e da compreensão do seu funcionamento (CASTRO et al., 2020).

Para Guckert, Souza e Arakawa-Belaunde (2020), o desenvolvimento de ações coletivas e compartilhadas na APS favorece com que a população consiga ter maior acesso às ações fonoaudiológicas, reduzindo, assim, o fluxo de atendimentos na atenção 
secundária e auxiliando na organização da rede em saúde e na otimização dos recursos humanos e materiais. Na dimensão técnico-pedagógica, as atividades de educação em saúde, por sua vez, apresentam uma posição destacada, tendo em vista que são as principais ações coletivas do Núcleo nos territórios (ARCE; TEIXEIRA, 2018).

\subsection{Entraves do processo de trabalho fonoaudiológico no nASF-AP}

O NASF-AP foi elaborado sob uma perspectiva de trabalho clara, conivente com diretrizes e ações interdisciplinares, visando superar empecilhos da APS. Todavia, ao longo do tempo, o processo de trabalho do Núcleo foi atravessado por diversidades na configuração, questionamentos, incompreensões e distorções (NASCIMENTO et al., 2018). Conforme expuseram Arce e Teixeira (2018), no NASF-AP ainda prevalece uma tendência voltada à perspectiva assistencial hegemônica, embasada em um modelo de atenção com foco no cuidado clínico.

No que concerne à Fonoaudiologia no NASF-AP, é possível inferir que o fonoaudiólogo encontra intensos desafios no seu processo de trabalho, dificultando o atendimento às recomendações estabelecidas (FONSÊCA; ALVES; FREITAS, 2020). Com a desigualdade da distribuição de fonoaudiólogos no Brasil, a oferta de ações fonoaudiológicas torna-se reduzida, especialmente em áreas remotas (FONSÊCA; BRAZOROTTO; BALEN, 2015).

Na pesquisa desenvolvida por Fernandes, Nascimento e Sousa (2013), discorreuse que o quantitativo de fonoaudiólogos nas equipes era inferior ao das demais profissões, o que poderia estar relacionado ao conhecimento incipiente dos gestores sobre a importância da atuação fonoaudiológica na APS, repercutindo na oferta de empregos. Igualmente, Costa et al. (2013) associaram a predominância da realização dos atendimentos clínicos-assistenciais com a postura dos gestores municipais para que as atribuições fonoaudiológicas fossem baseadas na perspectiva de núcleo do saber.

As deficiências de infraestrutura despontam como outro aspecto interferente para o processo de trabalho fonoaudiológico (ZANIN; ALBUQUERQUE; MELO, 2015). Andrade et al. (2014) e Molini-Avejonas et al. (2014) expuseram que os fonoaudiólogos desempenhavam satisfatoriamente as suas funções no NASF-AP, mas encontravam precariedades na infraestrutura de trabalho. 
Silva et al. (2019) verificaram, também, dificuldades na infraestrutura de trabalho dos fonoaudiólogos, assim como a necessidade da contratação de mais profissionais. A despeito disto, as fonoaudiólogas contatadas no estudo realizavam adequadamente diversas ações, como atividades no Programa Saúde na Escola, visita domiciliar, capacitação e suporte aos Agentes Comunitários de Saúde, ações conjuntas com a ESF, orientações e atendimento individual.

Um estudo conduzido em São Paulo (SP), identificou que 55,3\% dos fonoaudiólogos entrevistados referiram conhecer e utilizar a ferramenta de apoio matricial, $46,8 \%$ a clínica ampliada, $46,8 \%$ o projeto terapêutico singular, $12,7 \%$ o projeto saúde no território e $2 \%$ a pactuação de apoio. Entre os contatados, $51 \%$ já haviam cursado pós-graduação em saúde coletiva e 66\% já apresentavam tempo superior a dois anos de experiência trabalhando na área (SOLEMAN; MARTINS, 2015).

Advoga-se que o tempo de serviço no NASF-AP, as competências pessoais e a formação profissional influenciam diretamente na atividade laboral (ANDRADE et al., 2014). Para Zanin, Albuquerque e Melo (2015), os investimentos em recursos humanos são necessários para uma atuação mais adequada, já que as grades curriculares dos cursos de graduação não abordam este campo de maneira mais aprofundada. Além disto, o perfil de cada membro e as suas aptidões para realizarem trabalhos interdisciplinares e coletivos podem interferir significativamente no desempenho da equipe (MOLINI-AVEJONAS; MENDES; AMATO, 2010).

A satisfação dos fonoaudiólogos no NASF-AP também deve ser lembrada. MoliniAvejonas et al. (2014), ao analisaram a estrutura dos NASF-AP no Brasil, elucidaram que para $40 \%$ dos fonoaudiólogos entrevistados as ações estavam abaixo do esperado. Ainda na ótica de fonoaudiólogos no NASF-AP, Braga et al. (2019) observaram que a maioria dos profissionais não notavam os riscos ocupacionais presentes, apesar de reconhecerem aspectos como a sobrecarga laboral, desvio das funções de ofício, localização das UBS, inadequações na infraestrutura, presença de ruídos ambientais, insegurança, assédio moral e a contaminação por agentes biológicos.

\section{COMSIDERAÇÔES FInRIS}

Com a implantação do NASF-AP, a Fonoaudiologia ampliou o seu espaço de atuação na APS. Entretanto, denota-se que existem diversos percalços capazes de 
dificultar o trabalho do fonoaudiólogo, os quais perpassam pela presença maciça da dimensão clínico-assistencial, lacuna no conhecimento de gestores sobre o papel do profissional, limitação na oferta de recursos humanos e materiais e aspectos curriculares insuficientes. Logo, considerando-se a restrição de pesquisas abarcando a prática fonoaudiológica no NASF-AP, torna-se necessário o desenvolvimento de estudos relacionados à temática.

\section{REFERÊCCIAS}

ANDRADE, A. F. et al. Avaliação das ações da Fonoaudiologia no NASF da cidade do Recife. Audiology Communication Research, v. 19, n. 1, p. 52-60, 2014.

ARCE, V. A. R.; TEIXEIRA, C. F. Atividades desenvolvidas por profissionais de Núcleos de Apoio à Saúde da Família: revisão da literatura. Trabalho, Educação e Saúde, v. 16, n. 3, p. 1443-1464, 2018.

BEFI, D. Fonoaudiologia em Atenção Primária à Saúde. São Paulo: Lovise, 1997.

BRAGA, B. A. C. et al. Riscos ocupacionais da prática fonoaudiológica na Atenção Básica. Revista Brasileira de Ciências da Saúde, v. 23, n. 2, p. 41-52, 2019.

BRASIL, Ministério da Saúde. Portaria no 154, de 24 de janeiro de 2008. Cria os Núcleos de Apoio à Saúde da Família. Diário Oficial da União, Brasília, DF, 04 mar. 2008.

BRASIL, Ministério da Saúde. Portaria no 2.436, de 21 de setembro de 2017. Aprova a Política Nacional de Atenção Básica, estabelecendo a revisão de diretrizes para a organização da Atenção Básica, no âmbito do Sistema Único de Saúde (SUS). Diário Oficial da União, Brasília, DF, 21 set. 2017.

BRASIL, Ministério da Saúde. Portaria no 99, de 07 de fevereiro de 2020. Redefine registro das Equipes de Atenção Primária e Saúde Mental no Cadastro Nacional de Estabelecimentos de Saúde (CNES). Diário Oficial da União, Brasília, DF, 11 fev. 2020.

CAMPOS, G. W. S.; DOMITTI, A. C. Apoio matricial e equipe de referência: uma metodologia para a gestão do trabalho interdisciplinar em saúde. Cadernos de Saúde Pública, v. 23, n. 2, p. 399-407, 2007.

CASTRO, C. P.; NIGRO, D. S.; CAMPOS, G. W. S. Núcleo de Apoio à Saúde da Família e Trabalho Interprofissional: a experiência do município de Campinas (SP). Trabalho, educação e saúde, v. 16, n. 3, p. 1113-1134, 2018.

CASTRO, E. G. P. et al. Práticas de saúde de fonoaudiólogos na Atenção Especializada no Rio Grande do Norte. Distúrbios da Comunicação, v. 32, n. 3, p. 500-509, 2020. 
CAVALHEIRO, M. T. P. Formação do fonoaudiólogo no Brasil: estrutura curricular e enfoque preventivo. 1996. 158f. Dissertação (Mestrado em Psicologia) Pontifícia Universidade Católica de Campinas, Campinas, 1996.

COSTA, L. S. et al. A prática do fonoaudiólogo nos Núcleos de Apoio à Saúde da Família em municípios paraibanos. CoDAS, v. 25, n. 4, p. 381-387, 2013.

FERNANDES, T. L.; NASCIMENTO, C. M. B.; SOUSA, F. O. S. Análise das atribuições dos fonoaudiólogos do NASF em municípios da região metropolitana do Recife. Revista CEFAC, v. 15, n. 1, p. 153-159, 2013.

FONSÊCA, R. O.; BRAZOROTTO, J. S.; BALEN, S. A. Telessaúde em fonoaudiologia no Brasil: revisão sistemática. Revista CEFAC, v. 17, n. 6, p. 2033-2043, 2015.

FONSÊCA, R. O.; CRUZ, P. O. A prática fonoaudiológica nos Nasf-AB na região Nordeste: revisão Integrativa. In: I Congresso Norte-Nordeste de Saúde Pública (online), 2020. Anais do I Congresso Norte-Nordeste de Saúde Pública (online): trabalhos completos. Triunfo, PE: Editora Omnis Scientia, 2020. p. 2784-2791.

FONSÊCA, R. O. et al. A prática fonoaudiológica no Núcleo Ampliado de Saúde da Família e Atenção Básica na região Nordeste. In: ANDRADE, J. V.; TOLEDO, L. V.; DOMINGOS, C. S.; BACHUR, T. P. R. (Org.). Geração de conhecimento nas ciências médicas: impactos científicos e sociais. 1aㅡ. ed. Campina Grande: Editora Amplla, 2020. p. 413-424.

FONSÊCA, R. O.; ALVES, S. D. M.; FREITAS, R. D. S. O processo de trabalho fonoaudiológico no Núcleo Ampliado de Saúde da Família e Atenção Básica no Estado de São Paulo. In: FEITOSA, A. K. (Org.). Estudos e Pesquisas: saberes multidisciplinares. 1a ed. Iguatu: Quipá Editora, 2020. p. 90-101.

GUCKERT, S. B.; SOUZA, C. R.; ARAKAWA-BELAUNDE, A. M. Atuação fonoaudiológica na Atenção Básica na perspectiva de profissionais dos Núcleos de Apoio à Saúde da Família. CoDAS, v. 32, n. 5, e20190102, 2020.

GURGUEIRA, A. L. Fonoaudiologia no Sistema Único de Saúde. In: FERNANDES, F. D. M.; MENDES, B. C. A.; NAVAS, A. L. (Org.). Tratado de Fonoaudiologia. 2a ed. São Paulo: Roca, 2009. p. 619-626.

LEMOS, M.; BAZZO, L. M. F. Formação do fonoaudiólogo no município de Salvador e consolidação do SUS. Ciência \& Saúde Coletiva, v. 15, n. 5, p. 2563-8, 2010.

MEDEIROS, Y. P. O. et al. Atividades do fonoaudiólogo do Núcleo Ampliado de Saúde da Família e Atenção Primária (NASF-AP) na perspectiva do apoio matricial. Revista CEFAC, v. 23, n. 2, e7220, 2021. 
MIRANDA, G. M. D. et al. Assistência Fonoaudiológica no SUS: A ampliação do acesso e o desafio de superação das desigualdades. Revista CEFAC, v. 17, n. 1, p. 71-79, 2015.

MOLINI-AVEJONAS, D. R.; MENDES, V. L. F; AMATO, C. A. H. Fonoaudiologia e Núcleos de Apoio à Saúde da Família: conceitos e referências. Revista da Sociedade Brasileira de Fonoaudiologia, v. 15, n. 3, p. 465-474, 2010.

MOLINI-AVEJONAS, D. R. et al. Inserção e atuação da Fonoaudiologia nos Núcleos de Apoio à Saúde da Família. CoDAS, v. 26, n. 2, p. 148-154, 2014.

NASCIMENTO, C. M. B. et al. Configurações do processo de trabalho em Núcleos de Apoio à Saúde da Família e o cuidado integral. Trabalho, Educação e Saúde, v. 16, n. 3, p. 1135-1156, 2018.

ORUÉ, A. L. et al. Núcleo Ampliado de Saúde da Família e Atenção Básica: revisão integrativa da literatura. Saúde em Redes, v. 4, n. 3, p. 159-177, 2018.

RECH, R. S. et al. Speech-language therapy offer and primary health care in Brazil: an analysis based on socioeconomic development. CoDAS, v. 31, n. 1, p. 1-6, 2019.

SILVA, L. J. M. et al. Distribuição dos Fonoaudiólogos que Atendem ao SUS no Estado da Paraíba, Brasil. Revista Brasileira de Ciências da Saúde, v. 21, n. 4, p. 299-306, 2017.

SILVA, N. C. et al. Atuação fonoaudiológica no NASF do município de Santa Rita - PB. Distúrbios da Comunicação, v. 31, n. 1, p. 170-178, 2019.

SOLEMAN, C.; MARTINS, C. L. O trabalho do fonoaudiólogo no Núcleo de Apoio à Saúde da Família (NASF) - especificidades do trabalho em equipe na atenção básica. Revista CEFAC, v. 17, n. 4, p. 1241-1253, 2015.

SOUSA, M. F. S. et al. Evolução da oferta de fonoaudiólogos no SUS e na atenção primária à saúde, no Brasil. Revista CEFAC, v. 19, n. 2, p. 213-220, 2017.

VIÉGAS, L. H. T. et al. Fonoaudiologia na Atenção Básica no Brasil: análise da oferta e estimativa do déficit, 2005-2015. Revista CEFAC, v. 20, n. 3, p. 353-362, 2018.

ZANIN, L. E.; ALBUQUERQUE, I. M. N.; MELO, D. H. Fonoaudiologia e estratégia de saúde da família: implicação da dimensão estrutural na qualidade da atenção à saúde fonoaudiológica. Audiology Communication Research, v. 20, n. 3, p. 255-261, 2015. 


\title{
CAPITULO XX
}

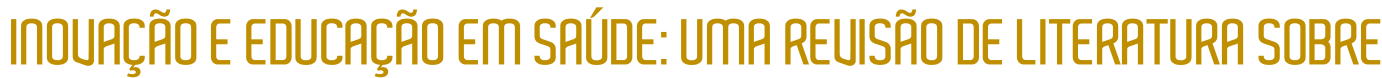

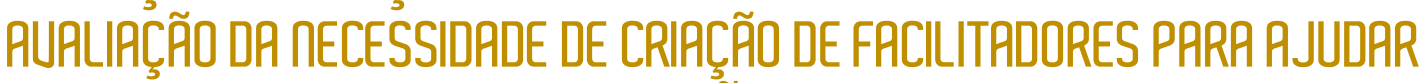 IDOSOS NA AUTOGESTR̃̃O MEDICAMTERTOSA}

\author{
DDI: 10.51859/AMPLLA.APS276.|II1-20
}

\author{
Israel Lucas dos Santos Fernandes ${ }^{1}$ \\ Natália Alves de Carvalho ${ }^{2}$ \\ Brenda Linique Sousa da $\mathrm{Cruz}^{3}$ \\ Cleydson Rodrigues de Oliveira ${ }^{4}$
}

\footnotetext{
${ }^{1}$ Graduando do curso de Enfermagem. Faculdade de Minas de Belo Horizonte - FAMINAS BH

${ }^{2}$ Graduando do curso de Enfermagem. Faculdade de Minas de Belo Horizonte - FAMINAS BH

${ }^{3}$ Graduando do curso de Enfermagem. Faculdade de Minas de Belo Horizonte - FAMINAS BH

${ }^{4}$ Professor Adjunto do Departamento de Enfermagem. Faculdade de Minas de Belo Horizonte - FAMINAS BH
}

\section{RESUITO}

Com um alto índice de doentes crônicos, um aumento constante da população idosa (podendo apresentar incapacidade cognitiva) e uma alta taxa de não letrados no Brasil se tornam relevante os estudos para ajudar essa população, principalmente, em relação a saúde e longevidade, a fim de mudar o perfil da morbimortalidade. O trabalho visa identificar através da literatura científica os empecilhos que levam a população idosa a seguir corretamente uma prescrição medicamentosa em horário correto com o intuito de avaliar a necessidade de desenvolver um material inovador para a saúde. A investigação teórica foi realizada por uma pesquisa de caráter descritivo e exploratório, sendo uma revisão de literatura. Conclui-se que através da literatura científica os empecilhos que levam a população idosa a seguir corretamente uma prescrição medicamentosa com os remédios e horário correto. A revisão da literatura evidenciou a necessidade de ajudar a população idosa com o desenvolvimento de um material inovador para a saúde.

Palavras-chave: Saúde do idoso. Doenças crônicas. Adesão. Uso de medicamentos.

\section{IกTRODUÇก̃O}

O Brasil contempla uma população de aproximadamente 210 milhões onde existe em média 11,3 milhões de analfabetos, 52,6 milhões de pessoas com doenças crônicas e mais de 30 milhões (crescendo 3,6\% ao ano) encontram-se na faixa etária superior aos 60 anos sendo que aproximadamente 5-30\% estão desenvolvendo incapacidade cognitiva progressiva (BRASIL,2018; ZORTEA et al., 2015). Com um alto 
índice de doentes crônicos, um aumento constante da população idosa (podendo apresentar incapacidade cognitiva) e uma alta taxa de não letrados no Brasil se tornam relevante os estudos para ajudar essa população, principalmente, em relação à saúde e à longevidade, tentando mudar o perfil da morbimortalidade.

Doenças cardiovasculares, respiratórias crônicas, diabetes, câncer e doenças renais são os principais tipos de Doenças Crônicas Não Transmissíveis (DCNT), que apesar de ser um quadro crônico, devem ser tratadas com tratamentos não farmacológicos e farmacológicos (não medicamentosa e medicamentosa), para que não ocorra o agravamento piorando o estado do paciente (MELO et al., 2019; DA SILVA et al., 2016).

Para a realização do tratamento não medicamentoso é necessário que a pessoa modifique o seu estilo de vida realizando uma alimentação adequada, pobre em gorduras, rica em frutas, legumes e verduras, pratique atividade física e diminui consumo de álcool. Entretanto, os brasileiros que se encontram na população de classe média e baixa apresentam dificuldade na adesão aos tratamentos não farmacológicos, pois se aderem à cultura alimentar rica em alimentos gordurosos, elevada ingestão de bebidas alcoólicas e padrão de vida sedentário (CUNHA et al., 2012; DE GUSMÃO et al., 2009; DA SILVA et al., 2016; MELO et al., 2019). Tendo assim, os medicamentos, infelizmente, como escolha principal para o tratamento.

Apesar de ser a forma mais utilizada como tratamento, devido ao comodismo de “apenas tomar a medicação" a terapia medicamentosa, geralmente, ocorre de maneira inadequada em função de um regime terapêutico que contém uma quantidade alta de medicamentos prescritos, esquema terapêutico complexos, efeitos adversos, nomenclatura difícil e por ser prescrita para uma população geralmente idosa, não letrada e com dificuldades cognitivas (TAVARES et al., 2016; MELO et al., 2019). Em virtude da gravidade desses fatores é essencial que seja realizado diversas pesquisas ajudar a população idosa dependente (VASCONCELOS et al., 2005).

Partindo do ponto de vista da literatura que mostra a dificuldade das pessoas idosas/analfabetas em realizar um tratamento farmacológico de maneira adequada foi realizada a seguinte pergunta norteadora com foco na possível causa do problema para guiar o trabalho: qual a necessidade da criação de um facilitador para melhorar a adesão à terapia farmacológica de idosos com DCNT? 
A partir da pergunta de base surgiram duas hipóteses diagnósticas. A primeira afirmava que não é necessária a criação de facilitadores para colaborar no tratamento farmacológico de idosos com DCNT, já que mesmo com as devidas dificuldades os idosos conseguem realizar a terapia medicamentosa no horário correto. A segunda, por sua vez, relatava que é necessária a criação de facilitadores para colaborar no tratamento uma vez que a população idosa em sua maioria não consegue administrar as medicações no horário correto, necessitando da criação de um ampliador para ajudar na administração.

Assim, o trabalho tem o objetivo de conhecer melhor a população idosa para identificar qual é a real adesão na terapia medicamentosa, entendendo se existe uma necessidade de criar um facilitador para contribuir e melhorar o padrão de vida do público alvo, já que algumas pessoas possuem dependência de familiares, mas buscam a independência.

O trabalho se justifica pelo fato do Brasil ser um país com aproximadamente 30 milhões de idosos que podem possuir problemas cognitivos e serem analfabetos (BRASIL, 2018), onde uma pequena parte possui um determinado grau de conhecimento sobre as doenças crônicas e grande parte opta por um tratamento farmacológico (DA SILVA et al., 2016; MELO et al, 2019).

Com isso, a administração dos medicamentos de maneira incorreta pode ser recorrente por confundir as medicações e não conseguir distinguir os horários de realização e via de utilização (TAVARES et al., 2016). Sendo assim, é de extrema importância a identificação na real adesão ao tratamento não farmacológico desta população que cresce cada vez mais no Brasil para que posteriormente possamos ajudar.

\section{METODOLOGIA}

O texto foi construído a partir de uma revisão integrativa com o intuito de usar uma forma ordenada para buscar, reunir, ler, entender e simplificar em um resumo as pesquisas mais atuais e que se envolvem melhor com a temática (MENDES et al., 2008), mostrando, assim, as dificuldades da população idosa em administrar os medicamentos em horários corretos. 
Geralmente, para a realização deste tipo de pesquisa utiliza-se fases separadas de forma sequencial: na primeira, ocorre identificação do tema e seleção da hipótese ou de pesquisa; na segunda, acontece o estabelecimento de critérios para inclusão e exclusão de estudos; durante a terceira, busca-se a definição das informações a serem extraídas dos estudos selecionados sendo uma categorização dos estudos; seguidamente na quarta fase é realizada a avaliação dos estudos incluídos na revisão integrativa; na penúltima, a quinta etapa, acontece uma interpretação dos resultados; e na última, a sexta, apresentação da revisão/síntese do conhecimento (MENDES et al., 2008).

Parte da investigação foi realizada por uma pesquisa do Instituto Brasileiro de Geografia e Estatística (IBGE) para compreender os dados demográficos atuais do Brasil, e a outra parte uma busca por literatura científica na SciELO (Scientific Eletonic Librany Online) e BVS (Biblioteca Virtual em Saúde Brasil), que possuem acesso a base de dados como a BDENF (Específica da Enfermagem); LILACS (Literatura Latino-Americana e do Caribe em Ciências da Saúde); entre outras, e utilizando os seguintes descritores: "saúde do idoso", "doenças crônicas" e "uso de medicamentos" durante o segundo semestre de 2020.

Efetuou-se, inicialmente, uma seleção de textos em português (afim de conhecer melhor a população do Brasil), artigos publicados na íntegra, entre 2010 a 2020 (com o intuito de filtrar uma geração de pessoas) e artigos que abordassem a temática do idoso. Como critério de exclusão optou-se por não utilizar: textos incompletos realizados antes de 2010, que não fossem do Brasil e que não tivesse relação com o tema após a leitura do título e/ou resumo e/ou texto integro (Tabela 1 ).

Tabela 1 - Critérios de Inclusão e Exclusão

\begin{tabular}{|c|c|}
\hline Critérios de Inclusão & Critérios de Exclusão \\
\hline Texto em Português & Texto incompletos \\
Publicados entre 2010 e 2020 & Publicações que não tivessem relação com \\
Publicados na Íntegra & Brasil \\
& Artigos que não abordasse “Adesão a \\
& medicamentos" \\
\hline
\end{tabular}

Fonte: Autoria própria. 
Encontrou-se, após as filtragens e leitura, 7 textos na BVS e 1 na SciELO, sendo que os artigos que estavam presentes em mais de uma base de dados foram contabilizados somente uma vez (Figura 1). Alguns artigos da pesquisa foram encontrados através de busca secundária durante a leitura dos artigos principais e alguns artigos encontrados foram utilizados somente para realizar a busca secundária.

Figura 1- Fluxograma de seleção dos artigos.

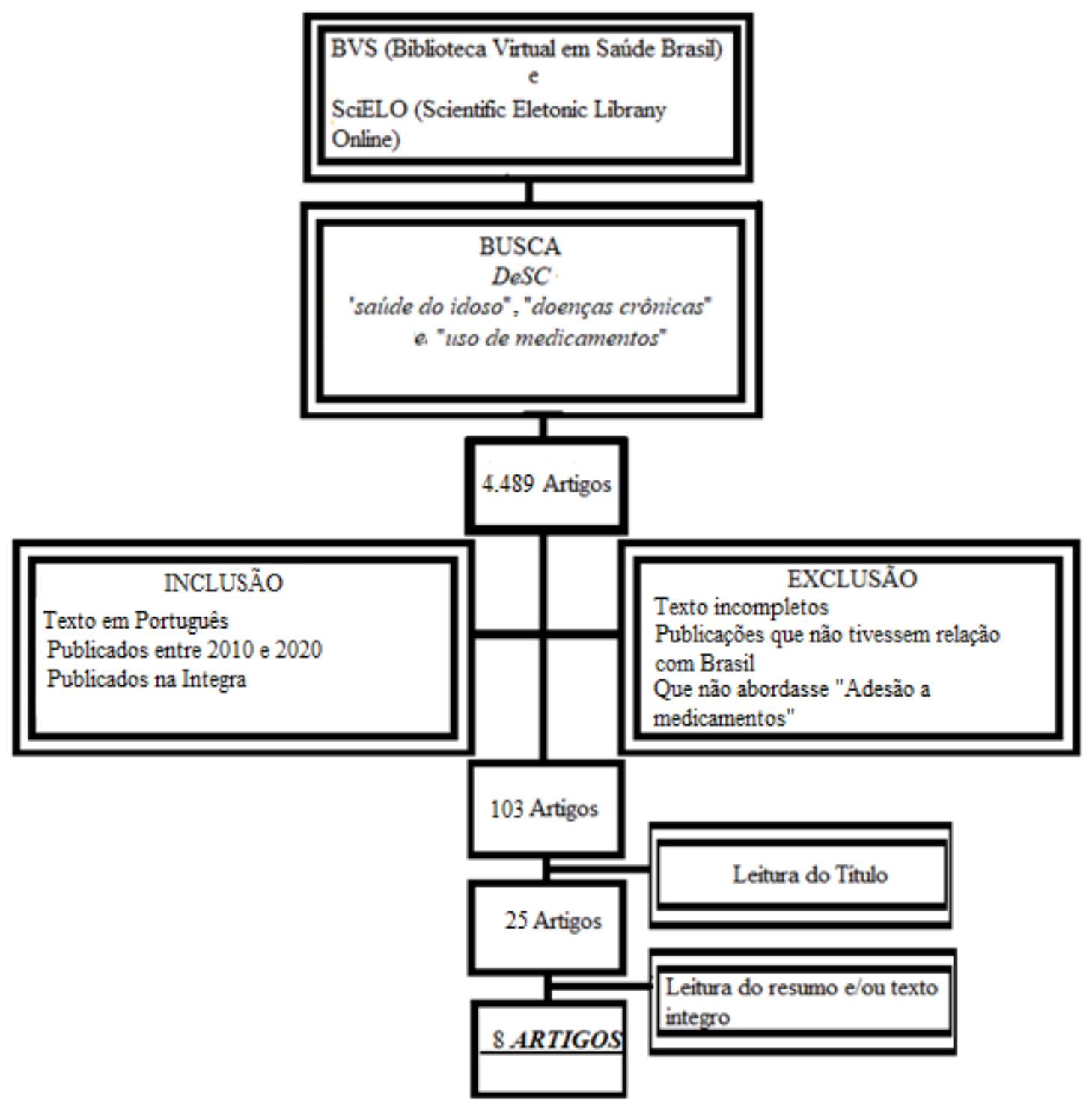

Fonte: Autoria própria 


\section{RESULTADOS}

O estudo foi composto por 8 trabalhos que ao examinar o ano de publicação foi possível perceber que 25\% são de 2014, 25\% são de 2015, 37,5\% são de 2016 e 12,5\% são de 2019. Dessa forma, foi possível perceber que $87,5 \%$ das pesquisas foram publicadas entre 2015 e 2016, o que reflete a necessidade de mais pesquisas atuais sobre o tema. Após a leitura dos trabalhos selecionados foram encontrados mais 10 textos por busca secundária que foram essenciais para a construção do presente estudo.

Todos os artigos pesquisados estão em português e foram realizados no Brasil. Esta estratégia foi utilizada afim de compreender minuciosamente a população brasileira observando cultura, rotinas, nível de atividades físicas, DCNT da população, dentre outros fatores primordiais que caracterizam os idosos brasileiros.

Os estudos foram extraídos de 8 revistas diferentes sendo elas: "Revista da Escola de Enfermagem da USP", "Revista de Saúde Pública", "Cadernos de Saúde Pública", "Revista Rene", "Cadernos de Saúde Coletiva", "Ciência \& Saúde Coletiva", "Revista Brasileira de Geriatria e Gerontologia" e "Health Informatics Journal”, o Qualis Caps variaram entre A2 e B3. Observou-se que $75 \%$ são estudos transversais, $12,5 \%$ são do tipo longitudinal e $12,5 \%$ são do tipo de revisão de literatura. Em relação a força/nível de evidência, 12,5\% pertencem ao "nível 1", 12,5\% pertencem ao "nível 4" e 75\% pertencem ao "nível 5" apresentando, dessa forma, prevalência de estudos do nível 5.

Para categorizar e avaliar as pesquisas, foi utilizado constantemente o "brainstorming", uma técnica, muito utilizada pela enfermagem, que incentiva o trabalho em grupo e estimula o pensamento em conjunto de cada integrante, sendo realizada uma "tempestade de ideias" sobre os artigos selecionados e lidos (FONSECA et al., 2015). Assim, para facilitar o entendimento dos artigos que compõem essa literatura, foi criado um quadro sinóptico que contém como informações o Título, o Ano de Publicação, a Revista, o Qualis Caps Referente à Revista, o Objetivo do estudo, o Tipo de abordagem com nível de evidência e a Conclusão do trabalho (Tabela 2). 
Tabela 2- Quadro Sinóptico dos artigos.

\begin{tabular}{|c|c|c|c|c|}
\hline $\begin{array}{l}\text { Revista/ } \\
\text { Qualis }\end{array}$ & $\begin{array}{c}\text { Título/ } \\
\text { Ano de Publicação }\end{array}$ & $\begin{array}{c}\text { Tipo de } \\
\text { Estudo/ Nível } \\
\text { de Evidência }\end{array}$ & Objetivo & Conclusão \\
\hline $\begin{array}{c}\text { Revista da } \\
\text { Escola de } \\
\text { Enfermagem } \\
\text { da USP/ } \\
\text { A2. }\end{array}$ & $\begin{array}{c}\text { Adesão ao } \\
\text { tratamento de } \\
\text { hipertensos em um } \\
\text { programa de gestão } \\
\text { de doenças crônicas: } \\
\text { estudo longitudinal } \\
\text { retrospectivo/2014. }\end{array}$ & $\begin{array}{c}\text { Estudo } \\
\text { Longitudinal/ } \\
\text { Nível } 4 .\end{array}$ & $\begin{array}{c}\text { Avaliar a adesão ao } \\
\text { tratamento } \\
\text { farmacológico pelo teste } \\
\text { de Morisky-Green e } \\
\text { identificou variáveis } \\
\text { relacionadas. }\end{array}$ & $\begin{array}{c}\text { Estratégias como o } \\
\text { gerenciamento de doenças } \\
\text { crônicas realizadas por } \\
\text { enfermeiros podem aumentar a } \\
\text { adesão ao tratamento anti- } \\
\text { hipertensivo e, portanto, } \\
\text { contribuir para o controle da } \\
\text { pressão arterial, minimizando o } \\
\text { perfil de morbidade dos } \\
\text { pacientes com hipertensão. }\end{array}$ \\
\hline $\begin{array}{c}\text { Revista de } \\
\text { Saúde } \\
\text { Pública/A2. }\end{array}$ & $\begin{array}{l}\text { Fatores associados à } \\
\text { baixa adesão ao } \\
\text { tratamento } \\
\text { farmacológico de } \\
\text { doenças crônicas no } \\
\text { Brasil/2016. }\end{array}$ & $\begin{array}{c}\text { Estudo } \\
\text { transversal/ } \\
\text { Nível } 5 .\end{array}$ & $\begin{array}{c}\text { Analisar fatores } \\
\text { associados à baixa } \\
\text { adesão ao tratamento } \\
\text { farmacológico de } \\
\text { doenças crônicas no } \\
\text { Brasil. }\end{array}$ & $\begin{array}{l}\text { A baixa adesão ao tratamento } \\
\text { medicamentoso para doenças } \\
\text { crônicas no Brasil é relevante e } \\
\text { as diferenças regionais, } \\
\text { demográficas e aquelas } \\
\text { relacionadas à atenção à saúde } \\
\text { do paciente e ao regime } \\
\text { terapêutico requerem ações } \\
\text { coordenadas entre profissionais } \\
\text { de saúde, pesquisadores, } \\
\text { gestores e formuladores de } \\
\text { políticas para o seu } \\
\text { enfrentamento. }\end{array}$ \\
\hline $\begin{array}{l}\text { Cadernos de } \\
\text { Saúde } \\
\text { Pública/B1. }\end{array}$ & $\begin{array}{l}\text { Hipertensão arterial } \\
\text { referida e utilização } \\
\text { de medicamentos de } \\
\text { uso contínuo no } \\
\text { Brasil: um estudo de } \\
\text { base } \\
\text { populacional/2014. }\end{array}$ & $\begin{array}{c}\text { Estudo } \\
\text { transversal/ } \\
\text { Nível } 5 .\end{array}$ & $\begin{array}{c}\text { Estimar a prevalência e } \\
\text { fatores associados a não } \\
\text { utilização de algum } \\
\text { medicamento de uso } \\
\text { contínuo nos indivíduos } \\
\text { de } 30-79 \text { anos que } \\
\text { referiram hipertensão } \\
\text { arterial na Pesquisa } \\
\text { Nacional por Amostra de } \\
\text { Domicílios. }\end{array}$ & $\begin{array}{c}\text { A adesão à terapia } \\
\text { medicamentosa no controle de } \\
\text { hipertensão arterial é } \\
\text { necessária e requer } \\
\text { investimento na atenção } \\
\text { primária, na melhoria, no } \\
\text { acesso aos serviços de saúde e } \\
\text { no enfretamento das } \\
\text { desigualdades regionais, sociais } \\
\text { e de gênero. }\end{array}$ \\
\hline
\end{tabular}




\begin{tabular}{|c|c|c|c|c|}
\hline $\begin{array}{l}\text { Revista } \\
\text { Rene/B1. }\end{array}$ & $\begin{array}{c}\text { Avaliação cognitiva de } \\
\text { pessoas idosas em } \\
\text { atendimento } \\
\text { ambulatorial/2015. }\end{array}$ & $\begin{array}{c}\text { Estudo } \\
\text { transversal/ } \\
\text { Nível } 5 .\end{array}$ & \begin{tabular}{|} 
Identificar o estado \\
cognitivo de pessoas \\
idosas em atendimento \\
ambulatorial, investigar a \\
associação entre o \\
estado cognitivo e as \\
variáveis \\
sociodemográficas, \\
condições de saúde, \\
número de \\
medicamentos e adesão \\
aos medicamentos.
\end{tabular} & $\begin{array}{c}\text { O Enfermeiro pode intervir para } \\
\text { evitar o aumento do déficit } \\
\text { cognitivo com uma avaliação da } \\
\text { pessoa idosa, direcionada às } \\
\text { estratégias facilitadoras para o } \\
\text { amenizar. }\end{array}$ \\
\hline $\begin{array}{c}\text { Cadernos de } \\
\text { Saúde } \\
\text { Coletiva/B1. }\end{array}$ & $\begin{array}{c}\text { Prevalência de } \\
\text { diabetes mellitus e } \\
\text { adesão } \\
\text { medicamentosa em } \\
\text { idosos da Estratégia } \\
\text { Saúde da Família de } \\
\text { Porto Alegre/RS } \\
\text { /2016. }\end{array}$ & $\begin{array}{c}\text { Estudo } \\
\text { transversal/ } \\
\text { Nível } 5 .\end{array}$ & $\begin{array}{c}\text { O objetivo do estudo é } \\
\text { descrever a prevalência } \\
\text { de DM em idosos da } \\
\text { Estratégia Saúde da } \\
\text { Família (ESF) de Porto } \\
\text { Alegre, no Estado do Rio } \\
\text { Grande do Sul, de acordo } \\
\text { com o tratamento, a } \\
\text { adesão medicamentosa e } \\
\text { variáveis } \\
\text { sociodemográficas e de } \\
\text { saúde. }\end{array}$ & $\begin{array}{c}\text { A atenção ao idoso diabético } \\
\text { vem crescendo nas ESF, por isso } \\
\text { este estudo contribuirá para o } \\
\text { desenvolvimento de estratégias } \\
\text { para melhor atenção a essa } \\
\text { população. }\end{array}$ \\
\hline $\begin{array}{c}\text { Ciência \& } \\
\text { Saúde } \\
\text { Coletiva/B1. }\end{array}$ & $\begin{array}{c}\text { Doenças crônicas não } \\
\text { transmissíveis e } \\
\text { fatores associados em } \\
\text { adultos numa área } \\
\text { urbana de pobreza do } \\
\text { nordeste } \\
\text { brasileiro/2019. }\end{array}$ & $\begin{array}{c}\text { Estudo } \\
\text { transversal/ } \\
\text { Nível } 5 .\end{array}$ & $\begin{array}{c}\text { Objetiva-se analisar a } \\
\text { prevalência e os fatores } \\
\text { associados às Doenças } \\
\text { Crônicas não } \\
\text { Transmissíveis (DCNT), } \\
\text { em adultos residentes } \\
\text { numa área urbana de } \\
\text { pobreza situada em } \\
\text { Recife, Nordeste do } \\
\text { Brasil. }\end{array}$ & $\begin{array}{c}\text { Observou-se, neste estudo, uma } \\
\text { elevada prevalência de pelo } \\
\text { menos uma DCNT, bem como, } \\
\text { associação estatisticamente } \\
\text { significante entre DCNT e as } \\
\text { variáveis: escolaridade, IMC, } \\
\text { percepção da própria saúde, } \\
\text { sexo e faixa etária. Estes } \\
\text { resultados sugerem a } \\
\text { necessidade de se intensificar } \\
\text { as ações de promoção à saúde, } \\
\text { em comunidades carentes, com } \\
\text { vistas ao seu melhor controle. }\end{array}$ \\
\hline
\end{tabular}




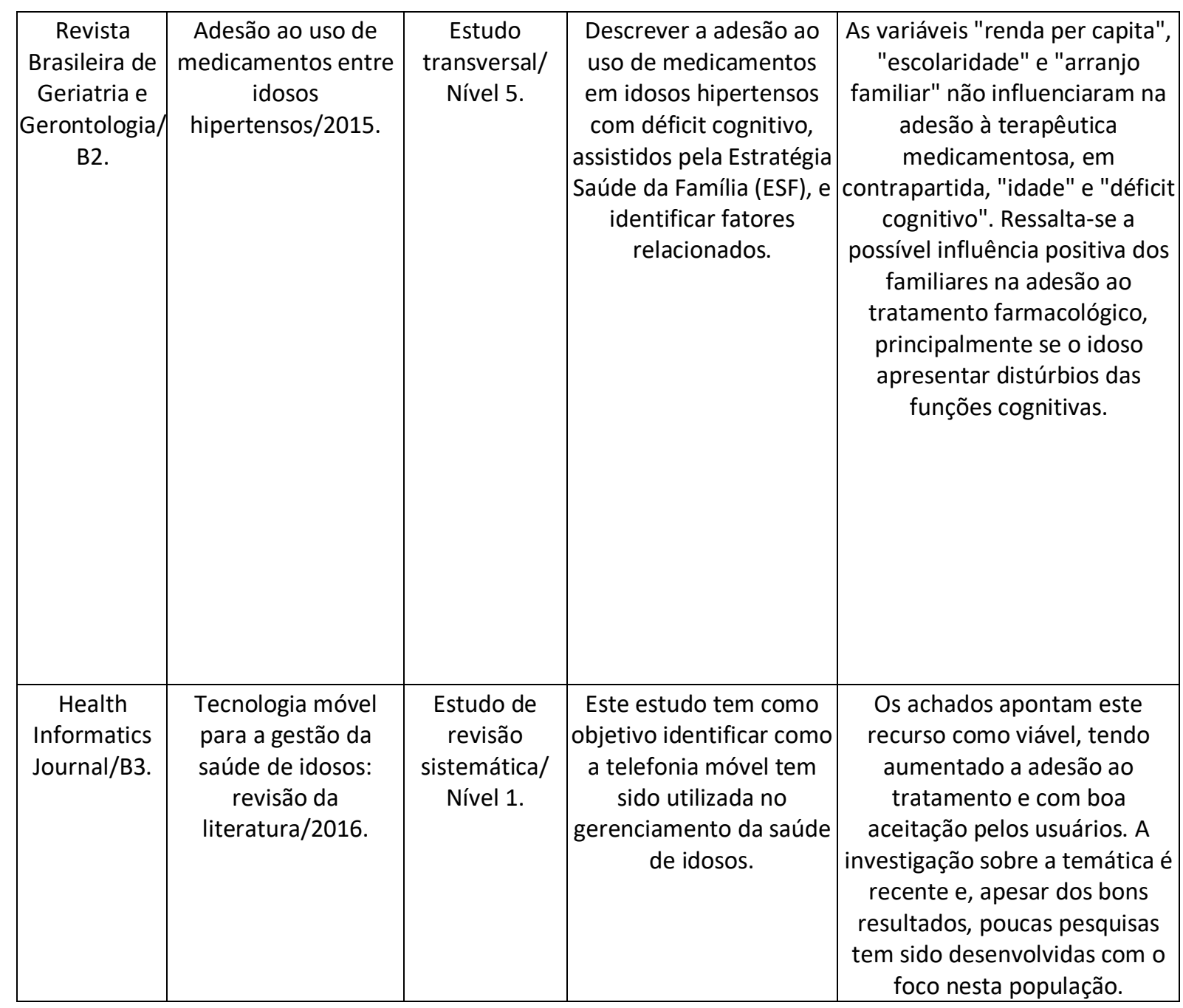

Fonte: Próprio autor.

Apesar de ser uma revisão integrativa, esta pesquisa não contempla todas as publicações sobre a adesão medicamentosa. Entretanto, a análise dos textos nacionais selecionados possibilitou traçar um estudo extensivo da temática.

\section{DISCUSSÃO}

Com o envelhecimento, os fatores genéticos, culturais, hábitos de vida e presença de outras patologias podem afetar a saúde principalmente na velhice (ZORTEA et al., 2015). Devido a este fator, no Brasil, o Estatuto do Idoso - Lei 10741/03, no art.9, relata que é "obrigação do Estado, garantir à pessoa idosa a proteção à vida e à saúde, mediante efetivação de políticas sociais públicas que permitam um envelhecimento saudável e em condições de dignidade" (BRASIL, 2004). 
A pessoa idosa deve receber cuidados que visem à manutenção de seu estado de saúde, buscando uma expectativa de vida ativa ao máximo possível, com independência funcional e autonomia, junto com seus familiares (SILVESTRE; COSTA NETO, 2003), proporcionando ao idoso um real domínio das Atividades Básicas da Vida Diária (ABVD) e o máximo possível de atuação nas Atividades Instrumentais de Vida Diária (AIVD). Dentro desses cuidados devemos atentar às doenças crônicas e à dificuldade cognitiva que afeta grande parte da população idosa (OLIVEIRA; MILECH, 2004).

O déficit cognitivo é duas vezes maior em pessoas com 0-4 anos de escolaridade, acima de $90 \%$ maior em pessoas que recebem aproximadamente um salário mínimo e acima de $40 \%$ menor nos que moram com companheiro ${ }^{2}$. Assim, no Brasil onde a maioria da população apresenta baixa renda, escolaridade e socialização é comum encontrar pessoas com déficits de cognição (BRASIL, 2018; ZORTEA et al., 2015). Além dos fatores socioeconômicos, como por exemplo: escolaridade, renda, condição civil e socialização que apresentam forte ligação com capacidade cognitiva da pessoa, a polifarmácia é notada em grande parte dos idosos com baixa capacidade cognitiva, sendo uma causa e também uma consequência (ZORTEA et al., 2015).

O declínio da cognitividade pode acarretar em mudanças nas ABVD e AIVD, alterando a funcionalidade do idoso, ocasionando dificuldades na leitura, mudanças no padrão emocional, dificuldades para o relacionamento, déficits na autogestão e no autocuidado, principalmente na farmacoterapia quando ocorre a utilização de vários fármacos devido a diversas DCNT (DA SILVA et al., 2016; ZORTEA et al., 2015). Este fato pode prejudicar o tratamento e o cumprimento da prescrição de medicamentos devido à leitura, aos horários e ao lembrar de utilizar o fármaco.

Um estudo que avaliava a adesão no tratamento de pessoas com Hipertensão Arterial Sistêmica (HAS) apresentou que apenas $25,1 \%$ da população estudada era aderente ao tratamento medicamentoso de forma correta e os outros $74,9 \%$ não preferiram a terapia farmacológica e não tinham uma fidedignidade sentindo, constantemente, sinais e sintomas relacionados aos picos pressóricos (RAYMUNDO; PIERIN, 2014). Em 2016, um estudo com portadores de Diabetes Mellitus (DM) apresentou que $32,3 \%$ da amostra eram aderentes ao tratamento medicamentos de 
forma correta, onde a principal causa de não aderência foi por "esquecer-se de tomar o medicamento" (SILVA et al., 2016).

Apesar dos estudos não apresentarem relação, os dados apresentados são similares em relação à adesão correta e chegam bem próximo a um estudo realizado com portadores de diversas DCNT's, que relatou que apenas $30,8 \%$ da população brasileira seguia o tratamento correto para a devida doença (TAVARES et al., 2016).

Quando uma doença crônica, como DM ou HAS, não é tratada adequadamente, os sintomas podem se agravar e contribuir para a manifestação de outras doenças, como diversas outras patologias cardíacas, visuais, cerebrais, renais, lesões de difícil cicatrização, comprometendo o padrão de saúde da pessoa que é portadora da doença (DA SILVA et al., 2016; VASCONCELOS; MOREIRA; ARAUJO,2005). Para que se possa atingir e manter a doença controlada, o idoso requer estímulo constante para as mudanças de estilos de vida e ajustes ao tratamento (DA SILVA et al., 2016; FERREIRA; BARRETO; GIATTI, 2014; OLIVEIRA; FRANCO, 2014; OLIVEIRA; MILECH, 2014).

A partir da década de 90, ocorreu no Brasil uma expansão tecnológica, que vem promovendo, até os dias de hoje, mudanças na rotina da população ajudando nos cuidados da saúde e colaborando para a gestão e tratamento de enfermidades ajudando, indiretamente, na evolução do cuidado principalmente com a população (FERREIRA; BARRETO; GIATTI, 2014; MELO et al., 2019; RAYMUNDO; PIERIN, 2014; ZORTEA et al., 2015). Mas, mesmo com o avanço tecnológico essa expansão não chegou para todas as pessoas principalmente para a população idosa que necessita de constante ajuda.

Devido às limitações e dificuldades, durante o dia a dia o idoso muitas vezes necessita da ajuda de terceiros para realização de tarefas. Esse fato ocorre não somente pelas patologias que agrega dificuldades físicas, mas pela dificuldade cognitiva que se progride com o envelhecimento (AIOLFI et al., 2015). Assim, esses fatores geram o aumento da mortalidade, devido a incapacidade de progredir em situações rotineiras do dia a dia, como tomar a medicação correta.

A administração de fármacos é uma técnica rotineira para a maior população idosa devido às DCNTs, mas também é uma das maiores dificuldades que a população idosa enfrenta pelo fato de existir dificultadores como: leitura de bulas e instruções das medicações, compreensão da linguagem proposta, cumprimento do esquema 
medicamentoso, planejamento do acesso a medicamentos e o manejo em situações de esquecimento de doses (tudo sempre ocorrendo com diversos fármacos para serem administrados em horários diferentes) (AIOLFI et al., 2015; DA SILVA et al., 2016; RAYMUNDO; PIERIN, 2014).

Dessa forma, é necessária uma constante ajuda para realizar um tratamento farmacológico com adesão fidedigna (AIOLFI et al., 2015; DA SILVA et al., 2016). O esquecimento da dose é um fator preocupante entre a população idosa e que pode levar a uma descontinuação do tratamento farmacológico na qual a fidelidade ao tratamento é fundamental para o controle dos efeitos das doenças (FERREIRA; BARRETO; GIATTI, 2014; MELLO et al., 2016).

Com a evolução do cuidado surgem novas estratégias utilizando de alguns materiais inovadores e/ou tecnológicos que ajudam a população idosa a gerenciar melhor sua saúde de maneira autônoma e correta (BERNARDES et al., 2015; FERREIRA; BARRETO; GIATTI, 2014). É necessário atentar-se à realidade do Brasil onde a introdução ao mundo tecnológico aconteceu há pouco tempo e a população idosa apresenta dificuldades em lidar com algumas tecnologias da era digital. Vale ressaltar que esse cenário vem sendo modificado e alguns métodos já são incorporados no dia a dia de grande parte da população idosa, como meios de comunicação, lazer, dentre outros. Isso é importante já que a população idosa é uma das que mais consomem medicamentos e pode ser beneficiada pelos facilitadores que a tecnologia oferece (BERNARDES et al., 2016).

\section{COกCLUSÃO}

O presente estudo proporcionou verificar que existe um alto grau de dificuldade com a administração de medicamento e muitos fatores contribuem para diminuir a adesão do idoso ao tratamento, incluindo as dificuldades cognitivas e de recordar informações previamente apresentadas, o analfabetismo, a existência de duas ou mais doenças crônicas concomitantes e a falta de um cuidador para auxiliar na tarefa. Com o envelhecimento, a capacidade física e cognitiva das pessoas diminui e essas mudanças podem ser impulsionadas por fatores genéticos, culturais, bem como por hábitos de vida e presença de outras patologias. 
Assim, a partir da identificação da dificuldade, o enfermeiro pode atuar junto à família com intervenções que diminuem esse fato. Dessa forma, passam a envolver os entes dos idosos nas atividades, discutir com eles os sinais/sintomas da doença e a forma como influenciam o cotidiano da família, informar sobre estilos de vida e gestão do regime terapêutico, abordar os déficits de memória e as influências nas atividades de vida diária das pessoas idosas e podem criar novos facilitadores para ajudar o idoso principalmente na administração de medicamentos.

\section{REFERÊกCIAS}

AlOLFI, Claucia Raquel et al . Adesão ao uso de medicamentos entre idosos hipertensos. Rev. bras. geriatr. gerontol., Rio de Janeiro , v. 18, n. 2, p. 397404, June 2015 Available from $<$ http://www.scielo.br/scielo.php?script=sci_arttext\&pid=S180998232015000200397\&Ing=en\&nrm=iso>. Acesso em 04 Mar. 2021

BERNARDES, Marina Soares et al. Tecnologia móvel para a gestão da saúde de idosos: revisão da literatura. J. health inform, p. 1081-1088, 2016. Disponível em: < https://pesquisa.bvsalud.org/ripsa/resource/pt/biblio-906823>. Acesso em 04 Mar. 2021

BRASIL. Lei federal no 10.741, de 01 de outubro de 2003. Estatuto do idoso. Brasília, DF: Secretaria Especial dos Direitos Humanos, 2004.

CUNHA, Paulo Renan Matos Sucupira et al. PREVALÊNCIA E CAUSAS DE NÃO ADESÃO AO TRATAMENTO ANTI-HIPERTENSIVO DE IDOSOS NA ATENÇÃO BÁSICA/PREVALENCE AND CAUSES OF NONADHERENCE TO ANTIHYPERTENSIVE TREATMENT OF THE ELDERLY IN PRIMARY CARE. Revista de Pesquisa em Saúde, v. 13, n. 3, 2012.Disponível em: < http://www.periodicoseletronicos.ufma.br/index.php/revistahuufma/article/vi ew/1455>. Acesso em 04 Mar. 2021.

SILVA, Aline Bueno da et al. Prevalência de diabetes mellitus e adesão medicamentosa em idosos da Estratégia Saúde da Família de Porto Alegre/RS. Cadernos Saúde Coletiva, v. 24, n. 3, p. 308-316, 2016. Disponível em: < https://web.b.ebscohost.com/abstract?direct=true\&profile=ehost\&scope=site \&authtype $=$ crawler\&jrnl $=1414462 X \& A N=120711446 \& h=$ sveEBNJCB4RzCNoOB0 KZh7eischugfbsmqFl\%2frbV5D4MvnpWKuDdy9TWWawpTILzv7\%2b\%2f9iZsXxIn iv5NBsSfag\%3d\%3d\&crl=c\&resultNs=AdminWebAuth\&resultLocal=ErrCrINotAu th\&crlhashurl=login.aspx\%3fdirect\%3dtrue\%26profile\%3dehost\%26scope\%3dsi te\%26authtype\%3dcrawler\%26jrnl\%3d1414462X\%26AN\%3d120711446 >. Acesso em 04 Mar. 2021. 
DE GUSMÃO, Josiane Lima et al. Adesão ao tratamento em hipertensão arterial sistólica isolada. Rev Bras Hipertens, v. 16, n. 1, p. 38-43, 2009.. Disponível em: < http://www.saudedireta.com.br/docsupload/134010539911-adesao.pdf>. Acesso em 04 Mar. 2021

FERREIRA, Reginara Alves; BARRETO, Sandhi Maria; GIATTI, Luana. Hipertensão arterial referida e utilização de medicamentos de uso contínuo no Brasil: um estudo de base populacional. Cadernos de Saúde Pública, v. 30, p. 815-826, 2014. Disponível em: < https://www.scielosp.org/article/csp/2014.v30n4/815-826/ >. Acesso em 04 Mar. 2021

FONSECA, Rachel Cavalcanti et al. Metodologias ativas facilitando o processo de ensino na fisioterapia: um relato através do brainstorming. Cadernos de Educação, Saude e Fioterapia, v. 2, n. 3, 2015. Disponível em: <http://revista.redeunida.org.br/ojs/index.php/cadernos-educacao-saudefisioter/article/view/552>. Acesso em 04 Mar. 2021

IBGE - Instituto Brasileiro de Geografia e Estatística. Censo Demográfico, 2018. Disponível em: <https://www.ibge.gov.br/apps/populacao/projecao/index.html >. Acesso em 04 Mar. 2021

MELO, Silvia Pereira da Silva de et al. Doenças crônicas não transmissíveis e fatores associados em adultos numa área urbana de pobreza do nordeste brasileiro. Ciência \& Saúde Coletiva, v. 24, p. 3159-3168, 2019. Disponível em: https://www.scielosp.org/article/csc/2019.v24n8/3159-3168/pt/ . Acesso em 04 Mar. 2021

MENDES, Karina Dal Sasso; SILVEIRA, Renata Cristina de Campos Pereira; GALVÃO, Cristina Maria. Revisão integrativa: método de pesquisa para a incorporação de evidências na saúde e na enfermagem. Texto \& contexto enfermagem, v. 17, n. 4, p. 758-764, 2008. Disponível em: < https://www.redalyc.org/pdf/714/71411240017.pdf>. Acesso em 04 Mar. 2021.

OLIVEIRA, José Egídio Paulo de; MILECH, Adolpho. Diabetes mellitus: clínica, diagnóstico, tratamento multidisciplinar. São Paulo: Atheneu, p. 39, 2004. Disponível em: <http://www.scielo.br/scielo.php?script=sci_arttext\&pid=S1414462X2016000300308>. Acesso em 04 Mar. 2021

OLIVEIRA, Paula Barbosa, FRANCO, Laercio Jael. Consumo de adoçantes e produtos dietéticos por indivíduos com diabetes melito tipo 2, atendidos pelo Sistema Único de Saúde em Ribeirão Preto, SP. Arq Bras Endocrinol Metabol. 2014. Disponível em: http://dx.doi.org/10.1590/S0004-27302010000500005. Acesso em 04 Mar. 2021

RAYMUNDO, Ana Carolina Nascimento; PIERIN, Angela Maria Geraldo. Adesão ao tratamento de hipertensos em um programa de gestão de doenças crônicas: estudo longitudinal retrospectivo. Revista da Escola de Enfermagem da USP, v. 48, n. 5, p. 811-819, 2014. 
VASCONCELOS, Francisca de Fátima et al . Utilização medicamentosa por idosos de uma Unidade Básica de Saúde da Família de Fortaleza - CE. Acta paul. enferm., São Paulo , v. 18, n. 2, p. 178-183, June 2005 . Disponível em: $<$ http://www.scielo.br/scielo.php?script=sci_arttext\&pid=S010321002005000200010\&Ing=en\&nrm=iso>. Acesso em 04 Mar. 2021

TAVARES, Noemia Urruth Leão et al. Fatores associados à baixa adesão ao tratamento farmacológico de doenças crônicas no Brasil. Revista de Saúde Pública, v. 50, n. 2. $\quad$ p. 1s-11s, 2016. Disponível em: < https://www.redalyc.org/pdf/672/67248914009.pdf>. Acesso em 04 Mar. 2021.

ZORTEA, Bruna et al. Avaliação cognitiva de pessoas idosas em atendimento ambulatorial. Revista da Rede de Enfermagem do Nordeste, v. 16, n. 1, p. 123131, 2015.

Disponível em: https://www.redalyc.org/pdf/3240/324036185015.pdf >. Acesso em 04 Mar. 2021. 


\title{
CAPITULO XXI
}

\section{MEDICINA POPUL AR RA ATERÇÃO BÁSICA: UTILIZAÇÃO DAS PLARTAS MEDICIMAIS PELOS RESIDERTES DA ÁREA FITOGEOGRÉFICA DO CERRADO BRASILEIRO}

\author{
DDI: 10.51859/AMPLLA.APS276.1121-21
}

Rubens Barbosa Rezende ${ }^{1}$

${ }^{1}$ Graduando do curso de Biomedicina. Departamento de Biomedicina. Faculdade Santa Rita - FASAR. Conselheiro Lafaiete - MG, Brasil.

\section{RESUMO}

As plantas têm sido usadas para tratar diferentes tipos de feridas, e muitas destas descobertas foram empíricas. Os residentes da área fitogeográfica do Cerrado utilizam diversas plantas medicinais para fins terapêuticos. Dessa forma, objetivou-se compilar as principais plantas medicinais utilizadas por moradores do bioma Cerrado brasileiro, suas formas de uso, indicações e partes utilizadas. Por meio de uma revisão de literatura de natureza qualitativa e de cunho descritivo e exploratório, tendo como questão norteadora: Quais plantas medicinais os moradores do bioma Cerrado fazem uso? A busca foi realizada nos bancos de dados: SciELO e PubMed, como também no site do Google Acadêmico. A flora do cerrado é extraordinariamente rica em espécies vegetais, sendo utilizadas como medicamentos, ornamentos e alimentos. A literatura reporta que as principais famílias de plantas utilizadas pelos moradores do Cerrado eram: Sapotaceae, Tiliaceae, Bromeliaceae, Colchospermaceae, Cucurbitaceae, Gentianaceae, Guttiferae, Dilleniaceae, Moraceae, Boraginaceae, Convolvulaceae, Myrtaceae, Sapindaceae, Annoceae, Vochysiaceae, Asteraceae, Bignoniaceae, Euphorbiaceae, Anacardiaceae, Solanaceae, Apocynaceae, Palmae e Leguminosae. O bioma Cerrado possui uma vasta biodiversidade, como também uma enorme riqueza no que diz respeito a conhecimento popular ligada ao uso de plantas. É essencial ter o resgate cultural ligado ao conhecimento científico, sobre o potencial das plantas utilizadas popularmente como medicinais.

Palavras-chave: Brasil. Etnobotânica. Fitoterapia. Plantas medicinais.

\section{IกTRODUÇก̃O}

Desde o início da história, as plantas têm sido usadas para tratar diferentes tipos de feridas, e muitas das descobertas são empíricas. Diante disso, o ser humano foi impulsionado a aprofundar seus conhecimentos sobre o assunto e desenvolver 
produtos com o mais alto conteúdo técnico (MERCÊS et al., 2017; GAZOLA; FREITAS; COIMBRA, 2018).

Com o conhecimento passado de geração em geração, o uso desses produtos tem sido amplamente utilizado por toda a população. No Brasil, as culturas que mais influenciaram na disseminação desse conhecimento popular foram principalmente a indígena, europeia e africana (LEMOS et al., 2015; MERCÊS et al., 2017).

O Cerrado brasileiro abrange uma área de aproximadamente de 2 milhões de quilômetros quadrados, na qual ocupa o centro da América do Sul. Em sua área total, cerca de $20 \%$ não sofreu qualquer perturbação humana, e 1,5\% está protegida, em local de conservação (RODRIGUES, 2005). O Cerrado é considerado um dos 25 locais com alta biodiversidade do planeta e sendo também um dos mais ameaçados. Existem aproximadamente 7 mil espécies de angiospermas no Cerrado, nas quais 10\% não foram classificadas ainda, e as espécies vegetais dos biomas em diferentes regiões estão sub documentadas (PAGOTTO et al., 2006).

Os residentes da área fitogeográfica do Cerrado utilizam diversas plantas medicinais para fins terapêuticos. No entanto, devido às intensas atividades de escavação/extrativista dos próprios moradores e do setor industrial (especialmente o farmacêutico), muitas espécies correm o risco de desaparecer ou diminuir drasticamente suas populações (NETO e MORAIS, 2003). Dessa forma, objetivou-se compilar as principais plantas medicinais utilizadas por moradores do bioma Cerrado brasileiro, suas formas de uso, indicações e partes utilizadas.

\section{MATERIAL E MÉTODOS}

Trata-se de uma revisão de literatura de natureza qualitativa e de cunho descritivo e exploratório, tendo como questão norteadora: Quais plantas medicinais os moradores do bioma Cerrado fazem uso? A busca foi realizada nos bancos de dados: SciELO e PubMed, como também no site do Google Acadêmico, utilizando os descritores: "plantas medicinais" e "flora do cerrado". Empregando o operador booleano AND, respeitando os critérios de inclusão: artigos nacionais e internacionais, publicados de janeiro de 2000 a janeiro de 2021 em português, espanhol e inglês e nos quais abordavam o uso de plantas medicinais por moradores do bioma cerrado. Como também os critérios de exclusão foram: artigos nos quais não abordavam uso de plantas

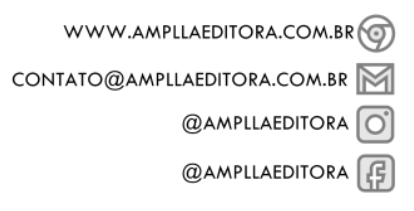


medicinais para tratamento, resumos e artigos duplicados e não disponibilizados de forma gratuita.

Foram encontradas 1961 publicações, e após a primeira análise, avaliando título e resumos, foram excluídas 1795 publicações. No segundo momento foram avaliados os conteúdos das publicações, e se coincidiam com os critérios de inclusão, com isso foram excluídas mais 136 publicações e incluídas no final 30 publicações para o presente estudo.

\section{REUISÃO DE LITERATURA}

\subsection{Plantas medicinais}

A aplicação de fitoterápicos e plantas medicinais ainda é bastante utilizada pela população devido, principalmente, aos efeitos colaterais ocasionados pelos fármacos sintéticos, indicando melhor aderência ao consumo de produtos naturais, bem como as PICS, aplicam uma abordagem holística aos conceitos de saúde e bem-estar (MASCARENHAS e JACOBSEN, 2017).

A utilização das plantas medicinais na arte da cura é um tratamento muito antigo, relacionado ao início da medicina e baseado no acúmulo de informações por muitas gerações. Durante séculos, os produtos derivados de plantas se tornaram a base para o tratamento de várias doenças (BRASIL, 2015). A fitoterapia é designada pelo uso de plantas medicinais em diferentes formas farmacêuticas, porém sem a utilização de substâncias ativas isoladas, ainda que de origem vegetal (MONTEIRO, 2017).

E no Brasil o uso de plantas medicinais vem se consolidando nas últimas décadas, principalmente com a divulgação da Política Nacional de Plantas Medicinais e Fitoterápicos (BRASIL, 2004), na qual visa ampliar as opções terapêuticas oferecidas aos usuários do Sistema Único de Saúde (SUS), e por meio dos diferentes níveis de complexidade do sistema, garante o acesso à segurança, eficácia e qualidade das plantas medicinais e fitoterápicos, com foco na atenção básica. Com intuito de prevenir doenças, promover e restaurar a saúde, sendo assim uma estratégia importante que objetiva a melhoria da atenção à saúde das pessoas e à inclusão social (BRASIL, 2009).

A utilização de plantas medicinais ao longo do tempo, foi o meio terapêutico primordial adotado para cuidar da saúde das pessoas e de suas famílias, usada para 
aliviar ou mesmo curar algumas enfermidades (BADKE et al., 2011). Nas últimas décadas o uso de plantas medicinais para o tratamento de algumas doenças comuns tem sido apoiado pela classe médica e por programas oficiais de saúde (STEFANELLO et al., 2006). O Brasil possui um acervo enorme de espécies vegetais nativas que são consideradas medicinais (MORS, RIZZINI, PEREIRA, 2000; BARBOSA-FILHO et al., 2005; LIMA et al., 2006; BRANDÃO et al., 2006).

Desde 1978, os fitoterápicos são reconhecidos pela Organização Mundial da Saúde (OMS), e são utilizados para fins de prevenção, paliativo e curativo. Existem diversos medicamentos fitoterápicos com múltiplas finalidades (MARTINS et al., 2009), com isso as pesquisas empregando plantas medicinais vem sendo realizadas com maior intensidade, graças ao avanço da tecnologia e a relevância em comprovar o seu uso empírico (ARNOUS et al., 2005).

Diferentes espécies medicinais são utilizadas para fins terapêuticos por moradores que vivem as regiões do domínio fitogeográfico do Cerrado, sendo possível haver maior risco de sumir ou sofrer drástica diminuição populacional, em consequência da intensa atividade extrativista da comunidade local, e até mesmo, da indústria farmacêutica (NETO e MORAIS, 2003).

\subsubsection{Plantas medicinais utilizadas na medicina popular}

O Brasil é o país com a maior biodiversidade do planeta tendo uma flora altamente diversificada incluindo espécies que ainda não foram pesquisadas cientificamente quanto a sua ação na saúde humana (SIMÕES et al., 2000; AURICCHIO \& BACCHI, 2003). Dessa forma, as descobertas dos princípios ativos em plantas impulsionaram um avanço cientifico e tecnológico e os medicamentos de base vegetal vem sendo gradativamente substituídos por fármacos sintéticos. Sendo assim, houve maior interesse pela investigação científica de materiais naturais como agentes antimicrobianos com potencial terapêutico, onde diferentes extratos de plantas medicinais, condimentares ou aromáticas têm sido testadas em prol da sociedade (ALBUQUERQUE \& HANAZAKI, 2006; OLIVEIRA et al., 2007).

Askari e colaboradores (2012) diz que compostos provenientes das plantas medicinais tem a capacidade de inibir o crescimento de patógenos ou matá-los, além de demonstrar toxicidade mínima para as células hospedeiras, sendo estas consideradas candidatas para a criação de novos antimicrobianos. 
$\mathrm{Na}$ busca pela obtenção de princípios ativos em plantas, o aspecto relevante principal tem como base as informações na medicina popular, uma vez que, há uma possibilidade maior de encontrar atividade biológica em espécies vegetais já utilizadas pela população, em vez de plantas selecionadas ao acaso (YUNES E CALIXTO, 2001). A maioria dos medicamentos em uso derivam direta ou indiretamente de princípios ativos originalmente isolados de plantas. E grande parte desses princípios, possuem ação farmacológica rápida e eficaz (VANACLOCHA E FOLCARÁ, 2003).

Têm se gerado uma preocupação emergente no que diz respeito a farmacovigilância de plantas medicinais e fitoterápicos, pois é necessária a avaliação dos riscos e benefícios destes produtos, visando a segurança, qualidade e eficácia conciliada ao seu uso de forma racional (SILVEIRA, BANDEIRA E ARRAIS, 2008). A realidade é que a identificação das espécies vegetais de forma errônea e sua utilização diferente da forma tradicional, podem ser graves, o que leva a uma alta dose ingerida, ineficácia do tratamento e consequente presença de efeitos adversos (WHO, 2002).

Geralmente, a espécie vegetal na medicina popular é considerada terapêutica, no entanto, podem apresentar toxicidade desconhecida pela população. Portanto, a pesquisa com plantas e suas aplicações clínicas para fins terapêuticos são fundamentais, pois tem-se que saber distinguir os benefícios e os mitos relacionados a fitoterapia, (Quadro 1) (MARQUES et al., 2019).

Quadro 1 - Plantas medicinais com indicações e respectivas restrições de uso.

\begin{tabular}{|c|c|c|}
\hline Plantas medicinais & Indicações & Restrições \\
\hline $\begin{array}{c}\text { Aesculus hippocastanum } \\
\text { (Castanha da índia) }\end{array}$ & Insuficiência venosa & - \\
\hline Allium sativum (Alho) & $\begin{array}{c}\text { Hiperlipidemia e hipertensão } \\
\text { arterial leve a moderada }\end{array}$ & \\
\hline $\begin{array}{c}\text { Centella asiatica (Centela/ } \\
\text { Centela-asiática) }\end{array}$ & $\begin{array}{c}\text { Insuficiência venosa dos } \\
\text { membros inferiores }\end{array}$ & \\
\hline $\begin{array}{c}\text { Cynara scolymus (Alcachofra) } \\
\text { Glycine max (Soja) }\end{array}$ & $\begin{array}{c}\text { Antidispéptico, antiflatulento, } \\
\text { diurético }\end{array}$ & \\
\hline Glycyrrhiza glabra (Alcaçuz) & Úlceras gástricas e duodenais & Não recomendado uso \\
\hline
\end{tabular}




\begin{tabular}{|c|c|c|}
\hline & & $\begin{array}{l}\text { contínuo por mais de seis } \\
\text { semanas, sem } \\
\text { acompanhamento médico }\end{array}$ \\
\hline $\begin{array}{l}\text { Mentha } x \text { piperita (Hortelã- } \\
\text { pimenta) }\end{array}$ & $\begin{array}{l}\text { Expectorante, carminativo e } \\
\text { antiespasmódico e síndrome do } \\
\text { cólon irritável }\end{array}$ & $\begin{array}{c}\text { Venda livre para ação } \\
\text { expectorante, carminativo e } \\
\text { antiespasmódico }\end{array}$ \\
\hline Panax ginseng (Ginseng) & $\begin{array}{l}\text { Estado de fadiga física e mental, } \\
\text { adaptógeno }\end{array}$ & $\begin{array}{l}\text { Utilizar por no máximo três } \\
\text { meses }\end{array}$ \\
\hline Paullinia cupana (Guaraná) & Psicoestimulante e astenia & - \\
\hline $\begin{array}{c}\text { Pimpinella anisum (Erva-doce/ } \\
\text { Anis) }\end{array}$ & $\begin{array}{c}\text { Expectorante, antiespasmódico, } \\
\text { carminativo e dispepsias } \\
\text { funcionais }\end{array}$ & - \\
\hline Plantago ovata (Plantago) & $\begin{array}{l}\text { Obstipação intestinal e síndrome } \\
\text { do cólon irritável }\end{array}$ & $\begin{array}{c}\text { Venda livre como coadjuvante } \\
\text { nos casos de obstipação } \\
\text { intestinal }\end{array}$ \\
\hline Polygala senega (Polígala) & Bronquite crônica, faringite & - \\
\hline $\begin{array}{c}\text { Frangula purshiana (Cáscara } \\
\text { Sagrada) }\end{array}$ & Constipação ocasional & $\begin{array}{l}\text { Não recomendado uso } \\
\text { contínuo por mais de uma } \\
\text { semana }\end{array}$ \\
\hline Salix alba (Salgueiro Branco) & $\begin{array}{l}\text { Antitérmico, anti-inflamatório e } \\
\text { analgésico }\end{array}$ & - \\
\hline Senna alexandrina (Sene) & Laxativo & - \\
\hline Vaccinium myrtillus (Mirtilo) & Insuficiência venosa periférica & - \\
\hline $\begin{array}{c}\text { Zingiber officinale Roscoe } \\
\text { (Gengibre) }\end{array}$ & $\begin{array}{c}\text { Náuseas causadas por } \\
\text { movimento (cinetose) e pós- } \\
\text { cirúrgicas }\end{array}$ & - \\
\hline Arnica montana (Arnica) & $\begin{array}{c}\text { Equimoses, hematomas e } \\
\text { contusões }\end{array}$ & $\begin{array}{l}\text { Não usar em ferimentos } \\
\text { abertos }\end{array}$ \\
\hline $\begin{array}{l}\text { Calendula officinalis } \\
\text { (Calêndula) }\end{array}$ & Cicatrizante, anti-inflamatório & - \\
\hline Eucalyptus globulus (Eucalipto) & $\begin{array}{l}\text { Antisséptico das vias aéreas } \\
\text { superiores e expectorante }\end{array}$ & - \\
\hline $\begin{array}{l}\text { Hamamelis virginiana } \\
\text { (Hamamélis) }\end{array}$ & Antihemorroidal e equimoses & - \\
\hline $\begin{array}{c}\text { Harpagophytum procumbens } \\
\text { (Garra do diabo) }\end{array}$ & $\begin{array}{c}\text { Dores articulares moderadas e } \\
\text { dor lombar baixa aguda }\end{array}$ & - \\
\hline Matricaria recutita (Camomila) & $\begin{array}{l}\text { Antiespasmódico intestinal, } \\
\text { dispepsias funcionais }\end{array}$ & - \\
\hline $\begin{array}{c}\text { Maytenus ilicifolia (Espinheira- } \\
\text { santa) }\end{array}$ & $\begin{array}{c}\text { Dispepsias, gastrite e úlcera } \\
\text { gastroduodenal }\end{array}$ & - \\
\hline $\begin{array}{c}\text { Melissa officinalis (Melissa/ } \\
\text { Erva Cidreira) }\end{array}$ & $\begin{array}{c}\text { Carminativo, antiespasmódico e } \\
\text { ansiolítico leve }\end{array}$ & - \\
\hline Mikania glomerata (Guaco) & Expectorante e broncodilatador & - \\
\hline Passiflora edulis (Maracujá) & Ansiolítico leve & - \\
\hline
\end{tabular}




\begin{tabular}{|c|c|c|}
\hline $\begin{array}{c}\text { Peumus boldus Molina (Boldo/ } \\
\text { Boldo-do-Chile) }\end{array}$ & $\begin{array}{c}\text { Dispepsias funcionais e } \\
\text { distúrbios gastrointestinais } \\
\text { espásticos }\end{array}$ & - \\
\hline Sambucus nigra (Sabugueiro) & Mucolítico/expectorante & - \\
\hline $\begin{array}{c}\text { Silybum marianum (Cardo } \\
\text { mariano) }\end{array}$ & Hepatoprotetores & - \\
\hline Symphytum officinale (Confrei) & $\begin{array}{l}\text { Cicatrizante, equimoses, } \\
\text { hematomas e contusões }\end{array}$ & $\begin{array}{c}\text { Utilização por no máximo } 4 \text { a } 6 \\
\text { semanas/ano. Não utilizar em } \\
\text { lesões abertas }\end{array}$ \\
\hline $\begin{array}{l}\text { Uncaria tomentosa (Unha de } \\
\text { gato) }\end{array}$ & Anti-inflamatório & $\begin{array}{c}\text { Não recomendado para } \\
\text { gestantes, lactantes e lactentes }\end{array}$ \\
\hline
\end{tabular}

Fonte: adaptado de MARQUES et al., 2019, p. 5-6.

Uma vez que, corre-se o risco de consequências às vezes irreparáveis, pois o uso de fitoterápicos está no paradigma "Se é natural não vai fazer mal", que se estabeleceu por falta de informação ou conhecimento popular, que se disseminou com o tempo e contribuiu para o uso de forma indiscriminada (ROSSATO et al., 2012). A hipersensibilidade pode ser um dos efeitos colaterais mais comuns. Geralmente, é causada pelo uso irracional de plantas medicinais e seus efeitos podem se diferenciar entre dermatite temporária a choque anafilático (CUNHA, 2004).

\subsubsection{Plantas medicinais mais utilizadas da flora do cerrado}

O cerrado está localizado essencialmente no Planalto Central do Brasil, e é o segundo maior bioma do Brasil, dispondo de características em razão da ação climática, geológica e antrópica. Como área contínua, este bioma abrange os estados de Goiás, Tocantins e Distrito Federal, além de parte dos estados do Mato Grosso, Mato Grosso do Sul, Minas Gerais, Piauí, Rondônia e São Paulo. Além do clima regional, a distribuição da flora é dependente da latitude, profundidade do lençol freático e por fatores antrópicos como atividade agropecuária e queimadas (RIBEIRO e WALTER, 2008).

O cerrado é denominado como um complexo fisionômico onde as diferentes graduações entre o herbáceo e os extratos arbóreos estabelecem diversas paisagens, tendo diferentes formas de cerrado: campo sujo e limpo, campo cerrado, cerrado, cerradão, matas de galerias e veredas (MATTEUCCI et al., 2007).

A flora do cerrado é extraordinariamente rica em espécies vegetais, sendo utilizadas como medicamentos, ornamentos e alimentos. Porém, com a apropriação caótica e a mudança da pecuária à agricultura intensiva arriscou-se espécies já catalogadas e desconhecidas (MATTEUCCI et al., 2007). 
Matteucci e colaboradores (2007) em seu trabalho, apresentaram o levantamento de espécies identificadas e posteriormente catalogadas da flora do cerrado nas quais eram mais utilizadas, (Quadro 2). As principais famílias encontradas em ordem crescente foram: Sapotaceae, Tiliaceae, Bromeliaceae, Colchospermaceae, Cucurbitaceae, Gentianaceae, Guttiferae, Dilleniaceae, Moraceae, Boraginaceae, Convolvulaceae, Myrtaceae, Sapindaceae, Annoceae, Vochysiaceae, Asteraceae, Bignoniaceae, Euphorbiaceae, Anacardiaceae, Solanaceae, Apocynaceae, Palmae e Leguminosae.

Quadro 2 - Plantas medicinais mais utilizadas da flora do cerrado.

\begin{tabular}{|c|c|c|c|c|}
\hline Família/Espécie & Nome polular & Ocorrência & $\begin{array}{c}\text { Partes } \\
\text { utilizadas }\end{array}$ & Aproveitamento \\
\hline \multicolumn{5}{|l|}{ ANACARDIACEAE } \\
\hline Lithraea araeirinha & aroerinha & cerrado & casca & $\begin{array}{l}\text { antidiarreico, } \\
\text { balsâmico }\end{array}$ \\
\hline Lithraea molleoides & aroerinha & cerrado & casca & balsâmico \\
\hline Schinous molleoides & aroerinha & cerrado & casca, folha & vias respiratórias \\
\hline Schinous molleoides & aroerinha & cerrado & casca & tanífera, tintura \\
\hline \multicolumn{5}{|l|}{ ANNONACEAE } \\
\hline Xilopia aromatica & $\begin{array}{c}\text { pimenta de } \\
\text { macaco }\end{array}$ & cerrado & fruto & gases intestinais \\
\hline \multicolumn{5}{|l|}{ APOCYNACEAE } \\
\hline $\begin{array}{l}\text { Apidosperma } \\
\text { macrocarpon }\end{array}$ & guatambu & cerrado & casca & disgestivo \\
\hline Peschiera fuchsiaefolia & leiteira & $\begin{array}{l}\text { campo, } \\
\text { cerrado }\end{array}$ & folhas & $\begin{array}{l}\text { desinfecção de } \\
\text { feridas }\end{array}$ \\
\hline $\begin{array}{c}\text { Tabernaemontana } \\
\text { laeta }\end{array}$ & grão-de-galo & $\begin{array}{l}\text { campo, } \\
\text { cerrado }\end{array}$ & casca & látex, antiverrugas \\
\hline \multicolumn{5}{|l|}{ ARISTOLOCHIACEAE } \\
\hline Aristolochia simbifera & jarrinha & cerrado & raíz & histeria, arbotiva \\
\hline \multicolumn{5}{|l|}{ ASTERACEAE } \\
\hline Lychnophora ericoides & arnica & cerrado & $\begin{array}{l}\text { folhas e } \\
\text { raízes }\end{array}$ & $\begin{array}{l}\text { cicatrizantes, } \\
\text { contusões }\end{array}$ \\
\hline Lychnophora passerina & $\begin{array}{c}\text { arnica, falsa } \\
\text { arnica ou arnica } \\
\text { da serra }\end{array}$ & cerrado & $\begin{array}{l}\text { folhas e } \\
\text { raízes }\end{array}$ & $\begin{array}{c}\text { anti-inflamatória, } \\
\text { analgésico, } \\
\text { cicatrizante }\end{array}$ \\
\hline
\end{tabular}




\begin{tabular}{|c|c|c|c|c|}
\hline Chromolaena odorata & arnica & cerrado & raízes & contusões, dores \\
\hline Veronia ferruginea & assa-peixe & cerrado & folhas & $\begin{array}{c}\text { dores no peito, } \\
\text { pneumonia, gripe, } \\
\text { depurativo }\end{array}$ \\
\hline Veronica sp. & assa-peixe & cerrado & flores & $\begin{array}{l}\text { diurético, anti- } \\
\text { inflamatório }\end{array}$ \\
\hline \multicolumn{5}{|l|}{ BIGNONIACEAE } \\
\hline Jacaranda cuspidofolia & caroba & campo & casca fervida & infecções e feridas \\
\hline Jacaranda micrantha & carobinha & cerradão & casca fervida & infecções e feridas \\
\hline $\begin{array}{l}\text { Sparattosperma } \\
\text { leucanthum }\end{array}$ & ipê branco & cerrado & casca & $\begin{array}{l}\text { afecções cutâneas, } \\
\text { reumatismo, ameba }\end{array}$ \\
\hline Anemopaegma arvense & catuaba & cerrado & $\begin{array}{l}\text { folhas e } \\
\text { cascas }\end{array}$ & $\begin{array}{l}\text { revigorante, } \\
\text { afrodisíaco }\end{array}$ \\
\hline Tabebuia impetiginosa & ipê roxo & cerrado & casca & $\begin{array}{l}\text { impígens, coceira, } \\
\text { sarnas }\end{array}$ \\
\hline Tabeuia avelianedae & ipê roxo & cerrado & casca & $\begin{array}{l}\text { inflamações } \\
\text { artríticas, diabetes }\end{array}$ \\
\hline Tabeluia caraiba & ipê amarelo & cerrado & $\begin{array}{l}\text { casca e } \\
\text { raízes }\end{array}$ & diurético, gripe \\
\hline Zeyheria digitalis & chá de frade & cerrado & folhas & cicatrizante \\
\hline \multicolumn{5}{|l|}{ BORAGINACEAE } \\
\hline $\begin{array}{c}\text { Cordia superba var. } \\
\text { cuneata }\end{array}$ & babosa branca & cerrado & tubérculo & gripe, dor de dente \\
\hline C. superba var. elliptica & grão de galo & cerrado & tubérculo & dores artríticas \\
\hline C. blanchetil & grão de porco & cerrado & pó da raíz & sinusite \\
\hline C. affusea & $\begin{array}{l}\text { jangada do } \\
\text { campo }\end{array}$ & cerrado & pó da raíz & sinusite \\
\hline C. glabrata & sete sangria & $\begin{array}{l}\text { campo, } \\
\text { cerrado }\end{array}$ & raíz & $\begin{array}{l}\text { resfriados, diurético, } \\
\text { hipertensão arterial }\end{array}$ \\
\hline \multicolumn{5}{|l|}{ CARYOCARACEAE } \\
\hline Caryocar brasiliense & pequi & cerrado & fruto & $\begin{array}{l}\text { tônico, afecções } \\
\text { respiratórias }\end{array}$ \\
\hline \multicolumn{5}{|l|}{ COLCHOSPERMACEAE } \\
\hline $\begin{array}{c}\text { Colchospermum } \\
\text { vitifolium }\end{array}$ & algodãozinho & cerrado & raízes & útero e bexiga \\
\hline \multicolumn{5}{|l|}{ CONVOLVULACEAE } \\
\hline Convolvus sp. & amaro leite & cerrado & tubérculos & depurativo \\
\hline Operculina macrocarpa & batata-do-mato & cerrado & - & - \\
\hline Ipomoea operculata & batata-purga & cerrado & $\begin{array}{l}\text { raízes e } \\
\text { sementes }\end{array}$ & $\begin{array}{c}\text { vermes, depurativo, } \\
\text { constipação } \\
\text { intestinal, sífilis, }\end{array}$ \\
\hline
\end{tabular}




\begin{tabular}{|c|c|c|c|c|}
\hline & & & & regulador menstrual \\
\hline Cuscuta umbelato & cipó-chumbo & cerrado & casca & cicatrizante, diarréia \\
\hline Convolvusoperculata & jaiapa & cerrado & raíz & $\begin{array}{c}\text { preventivo de } \\
\text { meningite, purgante }\end{array}$ \\
\hline \multicolumn{5}{|l|}{ CUCURBITACEAE } \\
\hline Cayaponia tayuyá & taiuiá & cerrado & raiz & dores ciáticas \\
\hline \multicolumn{5}{|l|}{ DILLENIACEAE } \\
\hline Curatella americana & lixeira & $\begin{array}{l}\text { campo, } \\
\text { cerrado }\end{array}$ & folhas & $\begin{array}{c}\text { tratamento de } \\
\text { feridas }\end{array}$ \\
\hline \multicolumn{5}{|l|}{ EUPHORBIACEAE } \\
\hline Croton antysiphiliticus & curraleira & cerrado & folhas, raízes & $\begin{array}{l}\text { sífilis, úlceras, } \\
\text { ovários }\end{array}$ \\
\hline Croton campestris & $\begin{array}{l}\text { velame-do- } \\
\text { campo }\end{array}$ & cerrado & raízes & digestão, aerofagia \\
\hline \multicolumn{5}{|l|}{ EQUISETACEAE } \\
\hline Equisetum pyramidale & carobinha & cerrado & planta toda & $\begin{array}{l}\text { rins, bexiga, } \\
\text { hemorragias }\end{array}$ \\
\hline \multicolumn{5}{|l|}{ FABACEAE } \\
\hline Andira humilis & $\begin{array}{l}\text { maminha-de- } \\
\text { porca }\end{array}$ & $\begin{array}{l}\text { cerrado, } \\
\text { cerradão }\end{array}$ & folhas & $\begin{array}{l}\text { cólicas, dores de } \\
\text { dente, piolhos }\end{array}$ \\
\hline Galactia sp. & rabo-de-tatu & $\begin{array}{l}\text { cerrado, } \\
\text { campo } \\
\end{array}$ & raíz, caule & estômago, fígado \\
\hline \multicolumn{5}{|l|}{ GENTINIACEAE } \\
\hline Delanira erubecens & fel-da-terra & cerrado & planta toda & $\begin{array}{l}\text { raízes, vermifugo, } \\
\text { febre }\end{array}$ \\
\hline \multicolumn{5}{|l|}{ GUTTIFERAE } \\
\hline Rheedia gardenaria & bacupari & cerrado & fruto, casca & sarnicida, digestivo \\
\hline \multicolumn{5}{|l|}{ LECYTHIDACEAE } \\
\hline Cariniana estreliensis & jequitibá & cerradão & casca & distúrbios digestivos \\
\hline \multicolumn{5}{|l|}{ LEGUMINOSAE } \\
\hline Apuleta lelocarpa & amarelinho & $\begin{array}{l}\text { cerradão, } \\
\text { mata }\end{array}$ & casca & cicatrizante \\
\hline Amburana copubrina & imburana & $\begin{array}{l}\text { campo, } \\
\text { cerrado }\end{array}$ & $\begin{array}{l}\text { casca, } \\
\text { semente }\end{array}$ & $\begin{array}{c}\text { gripe, prisão de } \\
\text { ventre, dor de } \\
\text { cabeça }\end{array}$ \\
\hline $\begin{array}{c}\text { Anadenanthera } \\
\text { colubrina }\end{array}$ & angico-branco & $\begin{array}{l}\text { campo, } \\
\text { cerrado }\end{array}$ & casca & $\begin{array}{c}\text { bicheira, } \\
\text { aftosa,frieiras, } \\
\text { coceiras, angina, } \\
\text { leucorréia, úlcera }\end{array}$ \\
\hline
\end{tabular}




\begin{tabular}{|c|c|c|c|c|}
\hline Bauhinia rufa & $\begin{array}{l}\text { pata-de-vaca, } \\
\text { unha-de-vaca }\end{array}$ & cerrado & folhas, raíz & diabetes, rins \\
\hline Bowdichia virgilioides & sucupira preta & $\begin{array}{l}\text { cerrado, } \\
\text { cerradão }\end{array}$ & sementes & garganta, faringe \\
\hline $\begin{array}{l}\text { Dimorphandra } \\
\text { gardenaria }\end{array}$ & faveira & cerrado & cascas & $\begin{array}{c}\text { cicatrizante, provoca } \\
\text { abortos em vacas } \\
\text { prenhas }\end{array}$ \\
\hline $\begin{array}{l}\text { Hymenaea } \\
\text { stigonocarpa }\end{array}$ & jatobá & cerrado & cascas & $\begin{array}{l}\text { dores de barriga, } \\
\text { lesões internas, } \\
\text { estômago, diabete, } \\
\text { rins }\end{array}$ \\
\hline Pterodon pubecens & sucupira-branca & $\begin{array}{l}\text { cerrado, } \\
\text { cerradão }\end{array}$ & sementes & garganta, faringe \\
\hline $\begin{array}{l}\text { Stryphnodendron } \\
\text { barbatiman }\end{array}$ & barbatimão & cerrado, mata & $\begin{array}{l}\text { folhas, } \\
\text { cascas }\end{array}$ & $\begin{array}{l}\text { infecções, úlceras, } \\
\text { hemorragias, } \\
\text { adstringente, } \\
\text { cicatrizante, } \\
\text { expectorante }\end{array}$ \\
\hline Copaifera langsdorffit & copaíba & cerrado & tronco, óleo & $\begin{array}{l}\text { garganta, feridas, } \\
\text { inflamações, } \\
\text { bernicida }\end{array}$ \\
\hline Mimosa humilis & sensitiva & cerrado & planta toda & fígado \\
\hline \multicolumn{5}{|l|}{ LONGANIACEAE } \\
\hline Strychnos pseudoquina & quina & cerrado & casca & estômago, fígado \\
\hline \multicolumn{5}{|l|}{ MORACEAE } \\
\hline Ficus dolaria & gameleira & cerrado, mata & casca, látex & vermifugo \\
\hline \multicolumn{5}{|l|}{ MUSACEAE } \\
\hline Heliconia caribaea & banana-brava & cerrado & casca,raíz & fígado, estômago \\
\hline \multicolumn{5}{|l|}{ PIPEACEAE } \\
\hline Piper aduncum & jaborandi & cerrado & folhas & $\begin{array}{c}\text { diaforético, hálito, } \\
\text { tônico capilar, } \\
\text { adstringente } \\
\end{array}$ \\
\hline \multicolumn{5}{|l|}{ RUBIACEAE } \\
\hline $\begin{array}{l}\text { Ipecacuanha } \\
\text { brasiliensis }\end{array}$ & poaia & cerrado & raíz & $\begin{array}{l}\text { bronquite, } \\
\text { coqueluche }\end{array}$ \\
\hline Chiococca brachiata & cainca & cerrado & raíz & $\begin{array}{c}\text { antiofidica, sífilis, } \\
\text { angina }\end{array}$ \\
\hline Palicourea xanthophyla & douradinha & campo & ramos & $\begin{array}{l}\text { diurético, } \\
\text { reumatismo }\end{array}$ \\
\hline Rudgea viburnioides & chá-de-bugre & cerrado & planta toda & estômago \\
\hline
\end{tabular}




\begin{tabular}{|c|c|c|c|c|}
\hline \multicolumn{5}{|l|}{ RUTACEA } \\
\hline Zamfoxylum tinguaciba & tinguaciba & cerrado & casca e raíz & cólicas intestinais \\
\hline \multicolumn{5}{|l|}{ STERCULIACEAE } \\
\hline Waltheria communis & $\begin{array}{l}\text { douradinha-do- } \\
\text { campo }\end{array}$ & $\begin{array}{l}\text { carrado, } \\
\text { campo }\end{array}$ & ramos & $\begin{array}{l}\text { diurético, bexiga, } \\
\text { sífilis, gota e } \\
\text { diarréias }\end{array}$ \\
\hline \multicolumn{5}{|l|}{ SIMARAUBACEAE } \\
\hline Simaruba brasilienses & $\begin{array}{c}\text { marubá, mata- } \\
\text { barata }\end{array}$ & cerrado & folhas & inseticida \\
\hline \multicolumn{5}{|l|}{ SOLANACEAE } \\
\hline Penax quinquefolium & cinco-folhas & $\begin{array}{l}\text { campo, } \\
\text { cerrado }\end{array}$ & raíz & $\begin{array}{c}\text { depurativo, coração } \\
\text { e pele }\end{array}$ \\
\hline Solanum paniculatum & jurubebinha & cerrado & $\begin{array}{l}\text { raízes, folhas } \\
\text { e frutos }\end{array}$ & $\begin{array}{c}\text { fígado, baço, tônico, } \\
\text { diurético, tônico } \\
\text { capilar e pele }\end{array}$ \\
\hline Cesirum lavigatum & coerana & $\begin{array}{l}\text { campo, } \\
\text { cerrado }\end{array}$ & ramos & $\begin{array}{c}\text { anti-séptico, } \\
\text { sedativo, fígado }\end{array}$ \\
\hline \multicolumn{5}{|l|}{ TILIACEAE } \\
\hline Lueheae grandiflora & mutamba-preta & cerrado & entre-casca & $\begin{array}{l}\text { hemorragia, } \\
\text { adstringente }\end{array}$ \\
\hline \multicolumn{5}{|l|}{ URTICACEAE } \\
\hline Urera baccifera & urtiguinha & cerrado & folhas & $\begin{array}{c}\text { rins, aumenta leite } \\
\text { da lactante }\end{array}$ \\
\hline \multicolumn{5}{|l|}{ VELLOZIACEAE } \\
\hline Vellozia favicans & canela-de-ema & $\begin{array}{l}\text { campo, } \\
\text { cerrado }\end{array}$ & $\begin{array}{c}\text { caule } \\
\text { (infusão) }\end{array}$ & luxações \\
\hline \multicolumn{5}{|l|}{ VOCHYSIACEAE } \\
\hline Quelea grandiflora & pau-terra & cerrado & folhas & $\begin{array}{c}\text { digestivo e anti- } \\
\text { gripal }\end{array}$ \\
\hline Quela parviflora & pau-terra & cerrado & casca & $\begin{array}{l}\text { infecção intestinal, } \\
\text { úlcera, depurativo, } \\
\text { chá anti-séptico, } \\
\text { digestivo, calmante, } \\
\text { infecções } \\
\text { respiratórias }\end{array}$ \\
\hline
\end{tabular}

Fonte: adaptado de MATTEUCCI et al., 2007, p. 16-21.

\section{CONSIDERAÇÔES FInAIS}

O bioma Cerrado possui uma vasta biodiversidade, como também uma enorme riqueza no que diz respeito a conhecimento popular ligada ao uso de plantas. É essencial 
ter o resgate cultural ligado ao conhecimento científico, sobre o potencial das plantas utilizadas popularmente como medicinais.

Foi demonstrada a diversidade de plantas utilizadas de forma medicinal pelos moradores, sendo verificado um rico acervo botânico na região. E com isso se faz necessário mais estudos relacionados a identificação das espécies vegetais, pois a identificação de forma errônea e sua utilização diferente da forma tradicional, podem ser graves, levando a uma alta dose ingerida, ineficácia no tratamento e consequente presença de efeitos adversos, podendo ocasionar uma intoxicação ou mesmo levando a morte.

\section{REFERÊRCIAS}

ALBUQUERQUE, U. P.; HANAZAKI, N. As pesquisas etnodirigidas na descoberta de novos fármacos de interesse médico e farmacêutico: fragilidades e perspectivas. Revista Brasileira de Farmacognosia, v.16, supl., p.678-89, 2006.

ARNOUS, A. H.; SANTOS, A. S.; BEINNER, R. P. C. Plantas medicinais de uso caseiro conhecimento popular e interesse por cultivo comunitário. Revista Espaço para a Saúde, Londrina, v.6, n.2, p.1-6, jun. 2005.

ASKARI, G. A. et al. Evaluation of Antimicrobial Activity of Aqueous and Ethanolic Extracts of Leaves of Vitis vinifera Collected from Different Regions in Morocco. American-Eurasian Journal of Agricultural \& Environmental Sciences. v.12, n.1, p.85-90, 2012.

AURICCHIO, M. T.; BACCHI, E. M. Folhas de Eugenia uniflora L. (pitanga): propriedades farmacobotânicas, químicas e farmacológicas. Revista do Instituto Adolfo Lutz, v.62, 55-61, 2003.

BADKE MR. Significado do uso de plantas em práticas de autoatenção em situações de padecimento [tese]. Pelotas: Universidade Federal de Pelotas; 2011. Disponível em: $\quad$ https://wp.ufpel.edu.br/pgenfermagem/files/2017/04/TESE-MarcioRossato-Badke.pdf Acesso em: 11 de janeiro de 2021.

BARBOSA-FILHO, J. M., et al. Plants and their active constituents from South, Central, and North America with hypoglycemic activity. Rev Bras Farmacognosia, 15: 392413, 2005.

BRANDÃO, M. G. L. et al. Medicinal plants and other botanical products from the Brazilian Official Pharmacopoeia. Rev Bras Farmacogn 16: 408-420, 2006.

BRASIL, 2004. Ministério da Saúde, Agência Nacional de Vigilância Sanitária. Resolução Diretora Colegiada $\mathrm{n}^{\circ} \mathbf{4 8}$ de $\mathbf{1 6}$ de março de 2004. Aprova o regulamento técnico 
sobre registro de medicamentos fitoterápicos. Diário Oficial da República Federativa do Brasil, Brasília/DF.

BRASIL. Ministério da Saúde. Secretaria de Atenção à Saúde. Departamento de Atenção Básica. Política nacional de práticas integrativas e complementares no SUS: atitude de ampliação de acesso / Ministério da Saúde. Secretaria de Atenção à Saúde. Departamento de Atenção Básica. - 2. ed. - Brasília: Ministério da Saúde, 2015. 96 p.: il. Disponivel em: http://bvsms.saude.gov.br/bvs/publicacoes/politica_nacional_praticas_integrat ivas_complementares_2ed.pdf Acesso em: 11 de janeiro de 2021.

BRASIL. Ministério da Saúde. Secretaria de Ciência, Tecnologia e Insumos Estratégicos. Departamento de Assistência Farmacêutica e Insumos Estratégicos. Programa Nacional de Plantas Medicinais e Fitoterápicos / Ministério da Saúde, Secretaria de Ciência, Tecnologia e Insumos Estratégicos, Departamento de Assistência Farmacêutica e Insumos Estratégicos. - Brasília: Ministério da Saúde, 2009. 136 p.: il. Disponível em: http://bvsms.saude.gov.br/bvs/publicacoes/programa_nacional_plantas_medic inais_fitoterapicos.pdf Acesso em: 11 de janeiro de 2021.

CUNHA A. P. Plantas e produtos vegetais em cosmética e dermatologia. Lisboa: Fundação Calous-te Gulbenkian, p. 310, 2004.

GAZOLA, A. M.; FREITAS, G.; COIMBRA, C. C. B. E. O uso da Calendula officinalis no tratamento da reepitelização e regeneração tecidual. Revista Uningá Review, v. 20, n. 3, p. 54-59, 2018.

LEMOS, I. C. S. et al. Uso de plantas medicinais para o tratamento de feridas. Revista Interdisciplinar, v. 8, n. 2, p. 60-67, 2015.

LIMA, M. R. F. et al. The antibiotic activity of some Brazilian medicinal plants. Rev Bras Farmacogn 16: 300-306, 2006.

MARQUES, P. et al. Prescrição farmacêutica de medicamentos fitoterápicos. Brazilian Journal of Natural Sciences, v. 2, n. 1, p. 15, 11 jan. 2019.

MARTINS, M. B. G. et al. Caracterização anatômica, química e antibacteriana de folhas de Brunfelsia uniflora (manacá) presentes na Mata Atlântica. Rev. bras. Farmacogonosia. vol.19, n.1a, pp. 106-114, 2009.

MASCARENHAS MA, JACOBSEN MS, organizadores. Práticas integrativas e complementares em saúde: fundamentos e aplicabilidades. Porto Alegre: Ed. Universitária Metodista IPA; 2017.

MATTEUCCI, M. B. DE A. et al. A flora do cerrado e suas formas de aproveitamento. Pesquisa Agropecuária Tropical, v. 25, n. 1, p. 13-30, 12 dez. 2007.

MERCÊS, P. L. et al. Avaliação da Atividade Cicatricial do Aloe vera em Feridas em Dorso de Ratos. Revista Estima, v. 15, n. 1, p. 35-42, 2017. 
MONTEIRO S. C. Farmacobotânica: aspectos teóricos e aplicação. Porto Alegre: Artmed; 2017.

MORS, W. B. RIZZINI, C. T., PEREIRA, N. A. Medicinal plants of Brazil. Michigan: Reference Publications Inc, 2000.

NETO, G. G.; MORAIS R. G. de. Recursos medicinais de espécies do Cerrado de Mato Grosso: um estudo bibliográfico. Acta Botanica Brasilica, São Paulo, v. 17, n. 4, p. 561-584, 2003.

OLIVEIRA, R.A.G. et al. Interference of Plectranthus amboinicus (Lour.) Spreng essential oil on the anti-Candida activity of some clinically used antifungals. Revista Brasileira de Farmacognosia, v.17, n.2, p.186-90, 2007.

PAGOTTO, T. C. S. et al. Bioma cerrado e área estudada. In: PAGOTTO, T. C. S.; SOUZA, P. R. Biodiversidade do complexo Aporé-Sucuriú : subsídios à conservação e ao manejo do cerrado: área prioritária 316-Jauru. Campo Grande: UFMS, p. 18- 30, 2006.

RIBEIRO, J. F. \& WALTER, B. M. T. As principais fitofisionomias do bioma Cerrado. Pp. 153- 212. 2008. In: S.M. Sano; S.P. Almeida \& J.F. Ribeiro (eds.). Cerrado: ecologia e flora. v. 1. Brasília, Embrapa Informação Tecnológica.

RODRIGUES, M. T. A biodiversidade dos cerrados: conhecimento atual e perspectivas, com uma hipótese sobre o papel das matas de galeria na troca faunística durante o ciclo climático. In: SCARIOT, A.; SOUSA-SILVA, J. C.; FELFILI, J. M. (Orgs.) Cerrado: ecologia, biodiversidade e conservação. Brasília: Ministério do Meio Ambiente, p.237-246, 2005.

ROSSATO M. B. et al. Saberes e práticas populares de cuidado em saúde com o uso de plantas medicinais. Texto Contexto Enferm, Abr-Jun; 21(2): 363-370, 2012.

SILVEIRA P. F., BANDEIRA M. A. M., ARRAIS P. S. D. Farmacovigilância e reações adversas às plantas medicinais e fitoterápicos: uma realidade. Rev. Bras. Far-macogn. João Pessoa, 2008.

SIMÕES, C. M. O. et al. Farmacognosia: da planta ao medicamento. 2.ed. Porto Alegre: Universidade Federal do Rio Grande do Sul, p.1104, 2000.

STEFANELLO, M. E. A., SALVADOR, M. J., ITO, I. Y., MACARI, P.A T. Avaliação da atividade antimicrobiana e citotóxica de extratos de Gochnatia polymorpha ssp floccosa. Revista Brasileira de Farmacognosia, 16(4), 525-530, 2006.

VANACLOCHA B. V., FOLCARÁ S. C. Fitoterapia: vade-mécum de prescripción. 4. ed. Barcelona: Masson, 2003.

WORLD HEALTH ORGANIZATION - WHO. The importance of pharmacovigilance safety monitoring of medicinal products. Geneva. 2002. 
YUNES R. A., CALIXTO J. B. Plantas medicinais sob a ótica da moderna química medicinal. Chapecó: Argos, 2001. 


\title{
CAPITULO XXII
}

\section{O CONHECIMEETTO BÁSICO EET SAÚDE BUCAL COMO FATOR QUARTIOSO PARA O BET-ESTRR GERPL}

\author{
DDI: 10.51859/AMPLLA.APS276.1121-22
}

\author{
Julio Cesar Ramos Cadilho ${ }^{1}$ \\ Cláudia Maria Pereira ${ }^{2}$ \\ Tatiane Azeredo Omena ${ }^{3}$
}

\begin{abstract}
${ }^{1}$ Graduando do curso de Odontologia. Universidade do Grande Rio - UNIGRANRIO
2 Professor Adjunto Doutor. Universidade do Grande Rio - UNIGRANRIO

${ }^{3}$ Professor Mestre. Universidade do Grande Rio - UNIGRANRIO
\end{abstract}

\section{RESUTO}

A educação em saúde bucal é considerada um importante prenunciador das condições e comportamentos em saúde coletiva. Dessa forma, este estudo teve por finalidade realizar uma revisão expositiva acerca da importância do conhecimento sobre os princípios básicos de higiene oral e as principais afecções em condições precárias. Para isso foi realizada uma busca na literatura com consulta a bases de dados SCIELO e Portais de Saúde. Métodos: A metodologia utilizada foi a bibliográfica, somada a uma contextualização dos dados, tendo como precípuo a informação. Onde os critérios de inclusão foram textos com linguagem inteligível, demonstrar clareza no detalhamento metodológico utilizado e estar disponível em língua portuguesa ou inglesa. Conclusão: Através da argumentação realizada no presente estudo, foi possível discorrer de forma enriquecedora a temática proposta, englobando diversos aspectos fisiológicos, históricos e sociais, enquanto agentes diretos no processo de saúde e bem-estar pessoal.

Palavras-chave: Higiene oral. Saúde bucal. Atenção básica em saúde.

\section{IกTRODUÇÃO}

A atenção primária à Saúde geral é um norteador do princípio precatório no âmbito dos cuidados em saúde, enquanto espaço privilegiado, para o desenvolvimento de ações de educação e conscientização no campo da saúde bucal coletiva. A inter relação das condições de saúde bucal e o bem estar geral do indivíduo devem ser constantemente salientadas em debates e projetos, bem como os métodos diários de cuidados individuais para manutenção da plenitude oral, dentre os quais podem ser 
citados a escovação dentária, o uso de fio dental diariamente, limpeza da língua e uso de colutórios. Além, evidentemente, da visita periódica ao consultório odontológico.

A escovação dentária é a principal forma mecânica que o indivíduo tem de ação para o controle da placa dental e manutenção geral da condição adequada de saúde oral. O hábito de escovar os dentes passou a receber destaque especial nas últimas três décadas, também por ser um dos métodos mais eficientes de se levar flúor aos dentes, tornando-se então, a forma mais simples de prevenir a cárie dentária (AXELSSON, 1999), além do uso do fio dental, que viabiliza a limpeza entre os dentes, em áreas onde as cerdas da escova possuem maior dificuldade em ter contato.Uma boa higiene oral é parte fundamental e indispensável quando fala-se das práticas de saúde geral, é errôneo tratar a saúde bucal como fator isolado, trata-se de um sistema altamente conectado com os demais e seu mau funcionamento impacta de forma direta o estado de saúde do indivíduo. Para a população geral, hábitos de higiene bucal estão mais vinculados ao estilo de vida, gênero, com caráter socioeconômico tendendo a ser o de menor escala (FISCHER., 1999). O que pode tender a distanciar essa perspectiva precatória do pensamento geral, fazendo com que a maioria dos indivíduos só deem atenção a boca e suas estruturas quando estas estão deveras debilitadas e enfraquecidas.

Esse fenômeno se dá parcialmente pela falta de conscientização da população sobre a importância da higiene básica em saúde bucal como fator primordial, fazendose então extremamente necessário reforçar o ensino à tais práticas de conscientização e ensino em saúde. Logo, no presente estudo a temática abordada será evidenciada de maneira simples e inteligível, a fim de esclarecer dúvidas de todos os públicos. Fomentando ainda possíveis debates sobre a importância da odontologia no atual cenário nacional.

\section{UIT BREUE HISTÓRICO}

O modo de viver do ser humano e a forma como essa interação ocorre vai construindo seu cotidiano. E a higiene está intimamente conectada a este cotidiano. A higiene bucal tem como parte fundamental a limpeza oral de forma correta, que é executada com o auxílio da escova dental. A escova dental, como a conhecemos na atualidade, é uma invenção recente da humanidade. Segundo manuscritos encontrados em diversas escavações feitas na Babilônia, o meio utilizado para a limpeza dos dentes 
em cerca de 3.500 AC eram palitos feitos de ouro. Contudo, os principais mecanismos que ajudavam na limpeza dos dentes foram pedaços de ramos e gravetos, que eram atritados sobre as superfícies dentárias e estruturas bucais, como mostraram os achados em tumbas etruscas e egípcias (MACCAULEY; 1946). Possivelmente utilizando substâncias de limpeza da época, como ervas e substâncias extraídas de sementes e árvores.

No início da Era Cristã, os romanos demonstravam preocupação com a higiene da bucal e, por volta do ano 100 d.C., Plínio, o Jovem, resolveu que deveria estabelecer uma série de conceitos sobre o tipo de material usado e a forma de confecção da primeira escova dental. Uma das normas deixava claro que que escovas confeccionadas com penas de urubu não eram aconselháveis, por causar mau hálito que estas poderiam proporcionar, provavelmente devido a alta população microbiológica presente nas penas, sendo o aconselhável a confecção de escovas com cerdas de porco-espinho (GARFIN; 1964).

Provavelmente, a escova dental que antecedeu as escovas dentais que temos hoje foi a produzida na Inglaterra, em 1780, por Addis. Era composta por um cabo de osso fino, com pelos naturais presos por arame em buracos feitos em uma das extremidades do osso. (CUNHA \& CARVALHO ;1993). Em 1840, as escovas passam a ser fabricadas na Inglaterra, França e Alemanha (CUNHA \& CARVALHO ;1993), mas somente a partir de 1880 foram feitas inovações no processo industrial de confecção e design de escovas, com a introdução de plástico para a confecção dos cabos, sendo usado o acetato de celulose em 1930 em diante, e no ano de 1938 com o surgimento do nylon para substituir as cerdas de pelos naturais, tornando-se esse o material de eleição para confecção de cerdas na época.

\section{ESCOUAÇ̃̃O E DESORGAกIZAÇÃO DO BIOFILTE DERTHL}

O biofilme dental é uma massa constituída de diversos componentes, dentre os quais estão restos alimentares e bactérias de diferentes espécies, que vivem em comunidade, onde estas desenvolve-se de forma constante e num processo bem dinâmico de adesão bacteriana, crescimento populacional e maturação (MARSH \& BRADSHAW; 1995). A escova dental é o instrumento de eleição para a remoção desse 
biofilme nas superfícies livres dos dentes, enquanto o fio dental é mais adequado na limpeza das superfícies interproximais dos dentes (HANCOK \& NEWELL;2001).

A escovação está relacionada intimamente com a Promoção da Saúde onde procura-se criar condições mais favoráveis para que o indivíduo não desenvolva o processo da cárie, bem como doenças periodontais e mau hálito ,aumentando a sua resistência, restaurando a qualidade de vida e colocando-o num ambiente favorável à saúde bucal plena( Chaves MM;1986). Essa limpeza dos dentes com escova dental deve ser feita com uma força média tendendo à leve , com uma quantidade de dentifrício , para adultos ,com cerca de centímetro, se assemelhando a forma de uma ervilha, já para crianças uma quantidade deve se assemelhar à de um grão de arroz. Independente do risco de cárie e doença periodontal, indica-se a escovação dos dentes três vezes ao dia. A escovação deve ser realizada sem pressa, contemplando todas as superfícies dentárias e higienizando a língua de forma minuciosa. A língua é o principal responsável, na maioria das vezes pelo mau hálito, é nela que se acumulam fluidos, restos alimentares minúsculos, baterias e até mesmo fungos. Esse mau odor bucal constitui uma queixa comum, e que afeta adultos de ambos os sexos e em qualquer idade, apresentando uma etiologia multifatorial, porém seu principal fator causal seja a decomposição de matéria orgânica (TARZIA ,2005), provocada por bactérias anaeróbias proteolíticas da cavidade bucal (RIO et al., 2007).

\section{MALEFÍCIOS DE UMTA HIGIENE ORAL PRECÉRIA}

São muitos os malefícios decorrentes de uma higiene bucal precária. Dentre eles está a Cárie dentária. Trata-se de uma doença infecciosa que progride de forma gradual e lenta nos elementos dentários, na ausência de tratamento, progride até destruir totalmente a estrutura dentária (FEJERSKOV \& KIDD., 2005). Além dos fatores determinantes para a doença que são: interação entre hospedeiro, uma dieta rica em carboidratos, a presença biofilme dental e de tempo para que a lesão se estabeleça, é notório que fatores sociais, econômicos e comportamentais influenciam diretamente no desenvolvimento da doença cárie. (ANTUNES ET AL., 2004)

Um fator negativo importante é a Halitose, que em sociedade tende a causar um distanciamento social e desconforto. Essa condição pode ser definida como uma condição ou alteração do hálito, sendo de característica fisiológica ou patológica, ambas 
se apresentam através de um hálito bucal desagradável emitido pela expiração durante a fala (BUTZE ET AL., 2015). A higienização da cavidade bucal tem como intuito diminuir consideravelmente colônias de bactérias, fungos e restos alimentares que podem estar presentes na boca. Sabe-se hoje que a formação da cárie é um processo multifatorial, e como tal, depende de bactérias, higiene oral precária, restos alimentares e tempo. Segundo estudos o tempo mínimo para que se instale o início de um processo carioso de desmineralização do esmalte é de cerca de dois dias corridos, ou quarenta e oito horas corridas, por isso a importância da escovação e desorganização do biofilme dental, o popular Tártaro. Uma vez que esse biofilme é desfeito as diferentes bactérias são retiradas da área, fazendo com que não haja liberação de ácidos por essas bactérias, impedindo assim o processo de desmineralização do esmalte dentário, não ocorrendo o processo de cárie.

\section{PROMOÇÃO ETI SAÍDE BUCAL}

O século XX foi um marco histórico quando trata-se da saúde bucal, houve uma redução gigantesca na incidência de cárie dentária. A fluoretação das águas de abastecimento público, a adição de flúor nos dentifrícios, e o maior acesso à informação e conscientização dos fatores ligados à promoção em saúde foram essenciais para a queda brusca da prevalência de cárie. De acordo com os preceitos de Promoção de Saúde, os órgãos competentes bem como as equipes que atuam na área, enquanto atores sociais, visam restabelecer o equilíbrio e a saúde bucal do indivíduo através de um controle dos fatores etiológicos, como a remoção do biofilme, educação e instrução de higiene e dieta adequada, além do uso de fluoretos.

As ações de saúde bucal devem se inserir na estratégia planejada pela equipe de saúde onde haja uma relação pautada no bem comum e interdependente permanentemente com as demais ações da Unidade de Saúde (BRASIL, 2004). A construção de políticas públicas saudáveis, políticas que gerem oportunidades de acesso à água tratada e saneamento básico, ações que incentivem a fluoretação das águas para todos, o uso de dentifrício fluoretado e que garantam a disponibilidade de cuidados odontológicos básicos apropriados, bem como; propagação de políticas de alimentação saudável com menor ingestão de alimentos ricos em açucares, fator esse que impactará diretamente na prevenção da doença cárie, obesidade e diabetes, além de uma 
abordagem comunitária para aumentar o autocuidado com a higiene corporal e bucal geral dos indivíduos (BRASIL, 2004). Os fatores sociais aparecem como os principais fatores explicativos da doença na população em geral. Então, toda e qualquer ação social que busque a promoção de fatores saudáveis se mostram como a melhor estratégia para reduzir significativamente a iniquidade da saúde (BRAGA ET AL., 2008).

\section{QUALIDADE DE UIDA}

Quando fala-se em conceito de qualidade de vida esse tende a variar bastante, mas no geral está relacionado à autoestima e ao bem-estar do indivíduo, e contempla diversos aspectos como a capacidade funcional, o estado emocional, as formas diversas de interação social, o autocuidado, o próprio estado de saúde, os valores culturais, éticos e a religiosidade, o estilo de vida geral, bem como a satisfação com o emprego e/ou atividades diárias e o ambiente em que se vive (VECCHIA et al.; 2005).

Há a associação de uma pior percepção de qualidade de vida em indivíduos portadores de periodontite, ao que os estudos indicaram é que as periodontites moderadas e severas estavam negativamente associadas à qualidade de vida quando comparadas com indivíduos com periodonto saudável (SANTANA et al;2007).

Piores níveis de qualidade de vida também podem ser considerados em pacientes edêntulos parciais ou totais, onde o sorriso se torna algo mais dificultoso. Além destes efeitos de caráter biológico, a literatura tem mostrado que a cárie dentária interfere em aspectos psicológicos associados com a autoestima de crianças e adolescentes (FERNANDES et al; 2013). A autocrítica nesses casos com relação a imagem se torna um fator importante quando se fala de saúde coletiva, pois estes relacionamse diretamente à qualidade de saúde mental e autoestima.

\section{?. DISCUSSก̃O}

A higiene bucal é um importante fator de prevenção das doenças cárie e periodontal. A odontologia atual tem visado a orientação nos cuidados com a saúde bucal, enfatizando a importância de se utilizar uma escova dental e fio dental que permitam a aplicação de métodos preventivos eficazes, com alcance coletivo e impacto social. 
A promoção em saúde além de proporcionar um restabelecimento da saúde dos pacientes e prevenção, também deverá proporcionar ações de conscientização, tornando possível a apropriação do conhecimento sobre o processo saúde-doença, incluindo fatores de risco e de proteção à saúde bucal, com e educação na área tornase possível que o indivíduo mude seus hábitos de higiene oral apoiando-o na conquista de sua autonomia. Esse empoderamento social e conscientização de aspectos básicos em saúde deveria ser melhor discutido tanto ao longo da formação básica de ensino quanto em ações sociais. Consciência favorece a mudança.

\section{COกCLUSค̃O}

A atenção primária em saúde bucal está ligado a fatores sociodemográficos e que tende a expor a falta de conhecimento na importância dos fatores biológicos. A maioria das pessoas não mantém uma rotina de higiene bucal adequada, onde a escovação diária dos dentes é bem aceita, contudo são poucos indivíduos utilizam o fio dental diariamente, e são menores ainda o número de pessoas conscientes acerca da importância da atenção primária em saúde. O impacto da saúde bucal na qualidade de vida é imensurável e merece importância, fazendo-se importante então o debate acerca da temática e medidas de conscientização e restabelecimento da saúde bucal a fim de discutir, conscientizar as massas e diminuir a iniquidade em saúde no Brasil.

\section{REFERÊกCIAS}

ANTUNES, J. L. F.; NARVAI, P. C.; NUGENT, Z. J..Measuring inequalities in the distribution of dental caries. Community Dent Oral Epidemiol, v. 32, n. 1, p. 4148,2004 .

AXELSSON P. An introduction to risk prediction and preventive dentistry. Karsltad, Sweden: Quintessence Publishing.1999.

BRASIL. Ministério da Saúde. Secretaria de Atenção à Saúde. Departamento de Atenção Básica. Coordenação Nacional de Saúde Bucal. Brasília: MS-CNSB.

BRAGA, M. M.; MENDES, F. M.; IMPARATO, J. C. P. A doença Cárie Dentária. In: Imparato, J. C. P.; RAGGIO, D. P.; MENDES, F. M.(2004) Selantes de fossas e fissuras: quando como e por quê? 1. ed. São Paulo: Livraria Santos Editora, 2008.

BUTZE, J., ANGST, P. E GOMES, S.. Current perspectives on oral halitosis: a literature review. Brazilian journal periodontology, Junho, 25(02), pp. 48- 54. 2015. 
CHAVES, M. M. Odontologia Social. 3.ed. São Paulo: Artes Médicas.1986.

CUNHA, T.C.R., CARVALHO; L.A. Avaliação da efetividade de uma escova dental modificada em comparação a uma tradicional no controle da placa bacteriana e índice gengival em pacientes com aparatologia ortodôntica fixa. Rev Bras Ortod, v.26, n.1, p.58-69, jan./abr.1993.

FEJERSKOV, O.; KIDD, E. Cárie dentária: a doença e seu tratamento clínico. 1. ed. São Paulo: Santos. 2005.

FERNANDES MLMF, MOURA FMP, GAMALIEL KS, CORRÊA-FARIA P..Cárie dentária e necessidade de tratamento ortodôntico: impacto na qualidade de vida de escolares. Pesqui Bras Odontopediatria Clin Integr. 2013 Mar;13(1):37-43. http://dx.doi.org/10.4034/PBOCI.131.06.2013.

FISCHER RG. Controle mecânico e químico do biofilme dental. In: Tunes UR, Rapp GE. Atualização em Periodontia e Implantodologia. São Paulo: Artes Médicas.1999.

GARFIN, L.A. Tooth picks and tooth brushes. Dental Survey, n.40, p. 102-8, Jan./June .1964 .

HANCOCK EB, NEWELL DH. Preventive strategies and supportive treatment. Periodontol.; 25: 59-76. 2000.

MACCAULEY, H.B. Toothbrush material and design. J Am Dent Assoc, n.5, p.283-93, Mar.1946.

MARSH PD, BRADSHAW DJ. Dental plaque as a biofilm. J Ind Microbiol.; 15:169-75.1995.

RIO ANCD, NICOLA EMD, TEIXEIRA ARF. Halitose: proposta de um protocolo de avaliação. Rev Bras Otorrinolaringol. 2007;73(6):24-8.

SANTANA TD, COSTA FO, ZENOBIO EG, SOARES RV, SANTANA TD. Impacto da doença periodontal na qualidade de vida de indivíduos diabéticos dentados. Cad Saúde Publica. ;23(3):637-44.2007.

TÁRZIA O. Halitose por saburra lingual. In: Paiva JS, Almeida RV. Peridontia: a atualização baseada em evidências científicas. São Paulo: Artes Médicas; 2005. p.543-61.

VECCHIA RD, RUIZ T, BOCCHI SCM, CORRENTE JE.Qualidade de vida na terceira idade: um conceito subjetivo. Rev Bras Epidemiol;8(3):246-52.2005. 


\title{
CAPITULO XXIII
}

\section{MARIFESTRÇÔES ORAIS DO DIRBETES MELLITUS}

\section{DDI: 10.51859/AMPLLA.APS276.1121-23}

\author{
Caroline Rodrigues Thomes ${ }^{1}$ \\ Maria Cecília Baratela ${ }^{2}$ \\ Jonata Leal dos Santos ${ }^{3}$ \\ David Wilkerson dos Santos Silva ${ }^{3}$ \\ Lara Victória Dittz de Abreu Costa ${ }^{1}$ \\ Alfredo Carlos Rodrigues Feitosa ${ }^{4}$
}

\footnotetext{
${ }^{1}$ Graduandas do curso de Odontologia. Universidade Federal do Espírito Santo - UFES.

${ }^{2}$ Graduanda do curso de Medicina. Universidade Federal do Espírito Santo - UFES.

${ }^{3}$ Graduandos do curso de Odontologia. Faculdade Pitágoras Imperatriz - MA.

${ }^{4}$ Professor Titular do Departamento de Clínica Odontológica. Universidade Federal do Espírito Santo- UFES.
}

\section{RESUMO}

O diabetes mellitus é o distúrbio metabólico mais comum e causador de repercussões multiviscerais, classificado em tipo 1 e tipo 2. Quando descontrolado pode gerar uma série de complicações renais, oculares e vasculares e outras sistêmicas, incluindo manifestações orais, às quais podem atingir uma ocorrência de $80 \%$. As lesões orais mais comuns incluem: xerostomia, cárie dentária, lesões periapicais, gengivite, doença periodontal, candidíase oral, síndrome da ardência bucal, alterações no paladar, língua geográfica, líquen plano oral e estomatite aftosa recorrente. O diabetes mellitus, assim como as suas complicações na cavidade oral, na maioria das vezes pode ser prevenido principalmente por meio do aumento da prática de atividades físicas, do controle da pressão arterial, dos níveis de colesterol, dos problemas emocionais, além da redução do peso corporal, enquanto, o tratamento tem como finalidade principal, a manutenção do controle metabólico e glicêmico do paciente. Constata-se que a plena compreensão e o domínio do conhecimento da fisiopatologia, das manifestações e do próprio manejo dos diferentes tipos de infecções orofaciais relacionadas ao diabetes mellitus pelo endocrinologista e pelo cirurgião dentista são essenciais para otimizar o atendimento dos pacientes diabéticos.

Palavras-chave: Boca. Diabetes mellitus. Odontologia.

\section{IกTRODUÇÃO}

O diabetes mellitus é definido como um dos distúrbios metabólicos mais comuns e causador de repercussões multiviscerais. É caracterizado pela presença de um quadro de hiperglicemia crônica que pode ser desencadeado por deficiência de secreção de insulina, por uma resistência à ação da insulina ou pelas duas simultaneamente, 
podendo ser acompanhada também pela presença de alterações metabólicas referentes ao metabolismo de carboidratos, proteínas e lipídios (NAZIR et al., 2018; ROHANI, 2019; MAURI-OBRADORS et al., 2017; TERNOIS, 2017; SOUSA; COSTA; RONCALLI, 2011).

A intensidade das complicações diabéticas geralmente acompanha o grau e a duração da hiperglicemia em proporcionalidade. Quando descontrolada pode gerar uma série de complicações renais, oculares e vasculares, sendo que os sintomas mais comumente encontrados nos portadores de diabetes mellitus incluem: quadros de polidipsia, poliúria-nictúria, polidipsia associada à xerostomia, polifagia, hálito cetônico, cãibras e emagrecimento rápido (ROHANI, 2019; YAMASHITA et al., 2013).

O número de pessoas portadoras de diabetes aumentou consideravelmente de 108 milhões em 1980 para 422 milhões em 2014. A prevalência geral de diabetes entre adultos maiores de 18 anos aumentou, portanto, de 4,7\% em 1980 para 8,5\% em 2014 e a Organização Mundial da Saúde (OMS) prevê que isso possa aumentar até para cerca de 439 milhões, quase 10\% dos adultos em 2030 (ORGANIZAÇÃO MUNDIAL DA SAÚDE, 2011).

Em relação a atenção básica de saúde de pessoas com diabetes, não foram encontrados estudos que permitissem avaliar se o Modelo de Atenção às Condições Crônicas (MACC), um modelo que vem sendo tomado como referência pelo Ministério da Saúde brasileiro para o estabelecimento das políticas de atenção às pessoas com doenças crônicas, como o desenvolvimento das Redes de Atenção à Saúde (RAS), vem servindo como referência para os profissionais da saúde e quais mudanças ele promoveu no oferecimento de uma estrutura específica para a atenção em saúde às pessoas em condição crônica (MENDES, 2013).

As duas formas mais comuns de classificação da doença são o diabetes mellitus tipo I e o diabetes mellitus tipo II. Além dessas, existem outras cujo uso é menos frequente, mas, que são igualmente importantes clinicamente: diabetes gestacional, diabetes associado a medicamentos; associado às doenças do pâncreas, como a fibrose cística; relacionado a infecções, como a rubéola congênita e outras relacionadas às síndromes genéticas (PRADO; VACCAREZZA, 2013).

De etiologia autoimune, o diabetes mellitus tipo I, conhecido também como diabetes mellitus insulino-dependente se caracteriza pela diminuição da secreção da insulina devido à destruição de células beta das ilhotas de Langherans pancreáticas que 
frequentemente leva à destruição completa de insulina. Ocorre principalmente nos pacientes pediátricos e constitui de $5 \%$ a $10 \%$ de todos os casos de diabetes mellitus (NAZIR et al., 2018; FARAG et al., 2017; YAMASHITA et al., 2013; PRESHAW; BISSETT, 2019).

O diabetes mellitus tipo II, tipo mais comumente encontrado ( $90 \%$ dos casos de DM) e relacionado a fatores genéticos e ambientais, é caracterizado pela resistência dos tecidos periféricos à insulina. Assim, o organismo é incapaz de utilizá-la mesmo com a presença dela no corpo. Essa forma também é conhecida como diabetes mellitus não insulino-dependente e, ocorre principalmente em adultos após os 40 anos de idade, sendo normalmente associada a um estilo de vida do tipo sedentário (YAMASHITA et al., 2013; SOUSA; COSTA; RONCALLI, 2011; SOBRINHO et al., 2014; PRESHAW; BISSETT, 2019).

Tanto o diabetes mellitus tipo I quanto o diabetes mellitus tipo II apresentam inúmeras complicações à longo prazo (MAURI-OBRADORS et al., 2017). Com repercussões multiviscerais, a mucosa oral e elementos dentários também constituem alvos dessa doença metabólica. As manifestações orais são dependentes do controle glicêmico do paciente e, mesmo aqueles que possuem uma boa higiene oral estão sujeitos às lesões, uma vez que a frequência de ocorrência delas pode chegar a $80 \%$. As complicações orais nesses indivíduos podem estar relacionadas à função neutrofílica deficiente, aumento de atividade da colagenase, redução da síntese de colágeno, microangiopatia e neuropatia (PRADO; VACCAREZZA, 2013; ROHANI, 2019).

A presente pesquisa bibliográfica teve como objetivo realizar um levantamento na literatura por meio da consulta às bases de dados PubMed e Google scholar tratandose das manifestações orais mais comuns ocasionadas pelo diabetes mellitus a fim enfatizar a necessidade da atenção, principalmente, dos cirurgiões-dentistas e dos médicos no diagnóstico dessa doença cuja prevalência só tem aumentado.

\section{REUISÃO BIBLIOGRÁFICA}

\subsection{Manifestações orais do diabetes mellitus}


As manifestações orais provenientes do quadro do diabetes mellitus são comuns e podem afetar tanto o controle metabólico da doença quanto o tratamento odontológico. É de extrema importância que os profissionais da área da saúde atuem no controle metabólico dos portadores dessa doença. As principais manifestações orais e complicações relacionadas ao quadro de diabetes mellitus incluem xerostomia, cárie dentária, lesões periapicais, doença periodontal, queimação na boca e alteração no paladar (MAURI-OBRADORS et al., 2017; PRADO; VACCAREZZA, 2013; ROHANI, 2019).

\subsubsection{Kerostomia}

Os pacientes portadores de diabetes mellitus geralmente apresentam disfunções relacionadas à saliva que podem reduzir o fluxo salivar, além de alterações relacionadas às mudanças na composição salivar. Sendo assim, a prevalência universal estimada de xerostomia em pacientes portadores da doença varia entre $34 \%$ e $51 \%$ (ROSAS et al., 2018; ROHANI, 2019).

O quadro de xerostomia pode ocasionar inúmeras problemáticas, como dificuldades na alimentação, no ato de engolir e até no falar, causando um impacto negativo significativo na qualidade de vida dos pacientes com diabetes mellitus. A etiologia dessa condição ainda é desconhecida, mas, pode se relacionar a poliúria, neuropatias autonômicas, alterações microvasculares e alterações nas membranas basais das glândulas salivares. Além disso, existe uma inter-relação significativa entre o grau de xerostomia e os níveis de glicose na saliva. Portanto, o nível mais alto de disfunção salivar geralmente é notado em diabéticos com pobre controle glicêmico (ROSAS et al., 2018; ROHANI, 2019).

\subsubsection{Cárie dentária}

Pacientes diabéticos encontram-se mais suscetíveis ao desenvolvimento de cáries dentárias novas e recorrentes. Essa incidência alta deve-se em grande parte pela redução da capacidade de limpeza e tamponamento da saliva, aumento de carboidratos presentes na saliva, além do aumento de leveduras orais, Streptococcus mutans e Lactobacilos. Além disso, o quadro hiperglicêmico crônico pode levar a pulpites crônicas irreversíveis, podendo progredir para casos de necroses pulpares (ROHANI, 2019). 


\subsubsection{Lesões periapicais}

Os pacientes diabéticos com o quadro da doença não controlada, apresentam maior prevalência de lesão periapical (MAURI-OBRADORS et al., 2017). Afirma-se que, se a hiperglicemia não estiver controlada, a cicatrização da lesão periapical não irá ocorrer e esta irá aumentar, mesmo com o tratamento endodôntico (FOUAD, 2003). Assim, a polpa que acaba não possuindo a circulação limitada irá causar comprometimentos na resposta imune, aumentando o risco destes à infecção ou necrose pulpar (MAURI-OBRADORS et al., 2017).

\section{1.4. Doença periodontal}

A deficiência do controle glicêmico pode estar associada ao aparecimento e a progressão do quadro de gengivite e periodontite. Nesse sentido, a doença periodontal tem tido uma maior prevalência e incidência em pacientes portadores de diabetes mellitus tipo I e tipo II e com prevalência grave em pacientes diabéticos (59\%) em comparação com os pacientes não diabéticos (39\%) (INDURKAR et al., 2016; SHIP, 2003; KHAN, 2018; DANIEL et al., 2012).

Dentro desse contexto, a doença periodontal expressa um impacto negativo sobre o diabetes, assim como o controle da doença periodontal exerce efeitos desejáveis em relação ao controle da glicemia. A própria eliminação de patógenos que ocorre na terapêutica periodontal leva a uma redução no quadro de inflamação, corroborando com a diminuição da resistência à insulina e assim, diminuindo os níveis de glicose (ROHANI, 2019).

\subsubsection{Queimação na boca}

A sensação de ardência na boca ou disestesia na cavidade oral de pacientes diabéticos se atribui ao próprio controle glicêmico ineficaz, alterações no metabolismo da mucosa oral, angiopatia, candidíase e neuropatia. Nesses pacientes, a dor neuropática pode se manifestar por meio de queimação, formigamentos ou até mesmo choque elétrico ou sensação de pontada que têm efeitos significativos nas próprias funções físicas e psicológicas associadas à distúrbios do sono, depressão e quadros de ansiedade (ROHANI, 2019). 


\subsubsection{Alterações no paladar}

A presença de disfunções relacionadas ao paladar pode atingir pacientes diabéticos sem o controle da doença, podendo ocasionar alterações da sensação do paladar ou até mesmo aumento dos limites de deteç̧ão por meio de quadros de neuropatia, sendo que essa alteração sensorial pode causar a inibição da capacidade de manter uma boa dieta, levando a uma regulação deficiente da glicose (ROHANI, 2019).

\subsubsection{Alterações na mucosa oral}

Pacientes com diabetes mellitus geralmente apresentam maior prevalência de distúrbios da mucosa oral possivelmente associados a quadros de imunossupressão crônica, retardo na cicatrização e/ou hipofunção salivar (KADIR et al., 2002). Essas alterações na mucosa oral incluem: infecções relacionadas aos fungos como a candidíase oral (GUGGENHEIMER et al., 2000), língua fissurada, fibroma de irritação, úlceras traumáticas além de líquen plano (PETROU-AMERIKANOU et al., 1998). É importante salientar que ainda existem controvérsias se tratando da relação dessas alterações na mucosa oral com o quadro de diabetes mellitus (MIRALLES et al., 2002).

\subsection{Diagnóstico}

O diagnóstico da diabetes mellitus para muitos pacientes têm um impacto psicossocial, ou seja, causa ansiedade, depressão, falta de energia, disfunções sexuais, dificuldades no trabalho e sensação de solidão. Então, para o paciente esse momento é importante, uma vez que marca uma nova etapa, a qual exige estilo de vida saudável, controle de peso e medicações (LAZO; DURÁN-AGÜERO, 2019). Entretanto, esse processo é extremamente necessário para o alcance da saúde e bem-estar do assistido; e deve ser precoce, eficaz e sustentado para prevenir complicações crônicas e evitar efeitos deletérios no metabolismo (ASCHNER et al., 2016). O rastreamento de diabetes deve ser realizado em todo indivíduo com mais de 45 anos de idade a cada 3 anos, ou mais precocemente e mais frequentemente em indivíduos assintomáticos quando apresentarem fatores de risco para o desenvolvimento da doença (GROSS et al., 2002). Atualmente, para realizá-lo são utilizados: glicemia plasmática em jejum; hemoglobina glicosilada; teste oral de tolerância à glicose (ADA, 2019; ASCHNER et al., 2016).

A glicemia plasmática em jejum mede a glicose no sangue após, no mínimo, 8 horas de jejum. Nesse exame para o paciente ser considerado diabético o valor da 
glicose plasmática deve ser superior a $126 \mathrm{mg} / \mathrm{dL}$ (7.0 mmol/L) (ADA, 2019). Quando comparada ao teste oral de tolerância à glicose, a glicemia plasmática em jejum é mais econômica, fácil execução, favorecendo a realização em um maior número de pessoas e apresenta um menor coeficiente de variação interindividual (GROSS et al., 2002).

A dosagem de hemoglobina glicosilada, também chamada de hemoglobina glicada, hemoglobina A1c ou simplesmente HbA1c, monitora a glicose média no sangue nos últimos 2-3 meses (NAYA; ÁLVAREZ, 2016). Para o paciente ser considerado diabético o valor de A1C deve ser superior a 6,5\% (48 mmol/mol) (ADA, 2019), entretanto existem alguns fatores que podem afetar a glicação da hemoglobina independentemente da glicemia. São eles: tratamento do HIV, idade, etnia (indivíduos asiáticos e afro descendentes apresentam níveis mais elevados de hemoglobina glicada quando comparados à caucasianos), gravidez, genética, hemoglobinopatias, anemias hemolíticas e ferropriva (Métodos e critérios para o diagnóstico do diabetes mellitus, 2014; ADA, 2019).

O teste oral de tolerância à glicose (TOTG), também conhecido como exame de curva glicêmica, determina a capacidade que um indivíduo tem de manter a homeostase da glicose sanguínea após uma sobrecarga de glicose. Para isso é realizada a medição em dois momentos: após jejum e após 2 horas da ingestão de $75 \mathrm{~g}$ de glicose dissolvida em água, segundo a OMS (NAYA; ÁLVAREZ, 2016). Para um diagnóstico de Diabetes Mellitus a glicemia plasmática deve ser igual ou superior a $200 \mathrm{mg} / \mathrm{dL}$ após duas horas da ingestão de glicose dissolvida (ADA, 2019).

\subsection{Prevenção}

O diabetes mellitus assim como as suas complicações manifestadas na cavidade oral, na maioria das vezes pode ser prevenido principalmente por meio do aumento da prática de atividades físicas, do controle da pressão arterial, dos níveis de colesterol, dos problemas emocionais, além da redução do peso corporal (NAZIR et al., 2018).

Nos indivíduos de alto risco, ou seja, mais suscetíveis a desenvolver o diabetes mellitus que possuem uma tolerância menor à glicose ou glicemia de jejum, os aspectos preventivos também incluem mudanças em relação ao estilo de vida padrão, a prática regular de exercícios físicos, dieta adequada e até mesmo o uso de medicamentos antidiabéticos quando indicados (NAZIR et al., 2018). 
Tendo em vista os aspectos observados anteriormente, infere-se que as manifestações orais do diabetes mellitus podem ser minimizadas por vários aspectos preventivos que se baseiam no controle da glicemia, na prática de autocuidado em relação à doença além da manutenção da saúde bucal de maneira consciente (NAZIR et al., 2018).

Sendo assim, o envolvimento de profissionais de saúde bucal em estratégias para identificar indivíduos em risco de diabetes estenderá os esforços preventivos e de triagem necessários para retardar o desenvolvimento dessas doenças (LEITE; MARLOW; FERNANDES, 2013).

\subsection{Tratamento}

O tratamento do diabetes mellitus tem como finalidade envolver principalmente a manutenção do controle metabólico e glicêmico do paciente (BERTONHI; DIAS, 2018). O diabetes mellitus é uma doença de caráter metabólico incurável, no entanto, pode ser controlada (COSTA, 2018).

Dentro desse contexto, é estritamente necessário que o médico oriente o paciente a seguir tanto as mudanças aplicadas em seu estilo de vida que se referem principalmente a prática regular de exercícios físicos e o seguimento de dieta específica quanto à prescrição de medicamentos (VILLAS BOAS et al., 2012).

A terapêutica medicamentosa do diabetes mellitus se baseia geralmente no uso de antidiabéticos orais e na insulinoterapia (PFEIFFER; KLEIN, 2014).

O uso da metformina geralmente é recomendado para o tratamento inicial com medicamentos. Se a metformina for contraindicada, mal tolerada ou inadequadamente eficaz, inúmeras alternativas terapêuticas e suplementos encontram-se disponíveis (PFEIFFER; KLEIN, 2014).

Grande parte dos ensaios clínicos sobre o assunto disponíveis demonstraram que as sulfonilureias e a insulina são benéficas em relação aos parâmetros de avaliação relevantes para o paciente, mas dados comparáveis de ensaios clínicos ainda não estão disponíveis para qualquer outro medicamento antidiabético (exceto metformina). Além disso, outros medicamentos podem ter vantagens, como menor risco de hipoglicemia, menor ganho de peso, administração oral e / ou aplicabilidade em casos de insuficiência renal (PFEIFFER; KLEIN, 2014). 
A terapêutica deve ser orientada de forma individual, tendo em vista a idade do paciente, o estágio da doença, peso corporal, comorbidades, situação de trabalho, adesão e prioridades pessoais. Portanto, a combinação de mais de dois antidiabéticos não é recomendada de acordo com esses parâmetros (PFEIFFER; KLEIN, 2014).

\section{CONSIDERAÇÔES FInAIS}

O diabetes mellitus tem tido uma prevalência crescente na população e pode ocasionar o surgimento de múltiplas complicações, que geralmente estão associadas à hiperglicemia, ou seja, aumentam quando o controle glicêmico do paciente se encontra inadequado.

As complicações orais em pacientes com diabetes mellitus são consideradas complicações maiores da doença e podem impactar na qualidade de vida dos pacientes. Há evidências de que complicações orais crônicas e persistentes nesses pacientes afetam adversamente o controle da glicemia. Portanto, a prevenção e o controle das complicações orais decorrentes do diabetes são consideráveis.

Isso torna o gerenciamento e a prevenção da doença fundamentais, levando em consideração que ela existe em uma relação bidirecional com a doença periodontal e pode levar a outras patologias orais. Por isso, os médicos e os cirurgiões-dentistas devem estar sempre atentos às diversas manifestações orais do diabetes com o intuito principalmente de realizar um diagnóstico precoce.

Constata-se que a plena compreensão e o domínio do conhecimento da fisiopatologia, das manifestações e do próprio manejo dos diferentes tipos de infecções orofaciais relacionadas ao diabetes mellitus pelo endocrinologista e pelo cirurgiãodentista são essenciais para otimizar o atendimento dos pacientes diabéticos.

Sendo assim, se o cirurgião-dentista suspeitar de diabetes, deve solicitar os exames laboratoriais com a finalidade de avaliar a glicemia e encaminhar o paciente para o tratamento médico. Caso já esteja diagnosticada, deve conscientizar o paciente das suas possíveis complicações. 


\section{REFERÊกCIAS}

AMERICAN DIABETES ASSOCIATION (ADA). 2. Classification and diagnosis of diabetes: standards of medical care in diabetes-2019. Diabetes Care, v. 42, n. Supplement 1, p. S13-S28, 2019.

ASCHNER, P., et al. Guía de práctica clínica para la prevención, diagnóstico, tratamiento y seguimiento de la diabetes mellitus tipo 2 en la población mayor de 18 años. Colombia Médica, v. 47, n. 2, p. 109-131, 2016.

BERTONHI, L.G; DIAS, J. C. R. Diabetes mellitus tipo 2: aspectos clínicos, tratamento e conduta dietoterápica. Revista Ciências Nutricionais. v.2, n.2, p. 1-10, 2018.

COSTA, A. C. Manifestações da Diabetes Mellitus na cavidade oral. Dissertação de mestrado, Mestre em Medicina Dentária, Universidade Fernando Pessoa, Porto, p. 26, 2018.

DANIEL. R. et al. Diabetes and periodontal disease. Journal of Pharmacy \& Bioallied Sciences, v.4, n.2, p. $280-282,2012$.

FARAG, A.M. et al. Head and Neck Manifestations of Endocrine Disorders. Atlas of the oral and Maxillofacial Surgery Clinics, v. 25, n. 2, p. 197-207, 2017.

Folha Informativa No.312. Diabetes. Organização Mundial da Saúde, 2011. Disponível em: http://www.who.int/mediacentre/factsh

FOUAD, A. F. Diabetes Mellitus as a Modulating Factor on Endodontic Infections. Journal of Dental Education, v.67, n.4, p. 459 - 467, 2003.

GROSS, Jorge L. et al. Diabetes Melito: Diagnóstico, Classificação e Avaliação do Controle Glicêmico. Arquivo Brasileiro Endocrinologia Metabólica, São Paulo, v. 46, n. 1, p. 16-26, 2002.

GUGGENHEIMER, J. et al. Diabetes mellitus insulino-dependente e patologias orais dos tecidos moles: II. Prevalência e características das lesões por Candida. Oral Surg Oral Med Oral Pathol Oral Radiol Endod, v.84, p. 570 - 576, 2000.

INDURKAR, M. S.; MAURYA A. S.; INDURKAR S. Oral manifestations of diabetes. American Diabetes Association, v.34, n.1, p. 54 - 57, 2016.

KADIR, T. et al. Exame micológico e citológico do transporte oral de cândidas em pacientes diabéticos e controles não diabéticos: Análise minuciosa de fatores etiológicos e sistêmicos locais. Journal of Oral Rehabilitation, v.29, p. 452 - 457, 2002.

KHAN, T. Oral manifestations and complications of diabetes mellitus: A review. International Journal of Medical Health, v.4, p. 50 - 52, 2018. 
LAZO, C.; DURÁN-AGÜERO, S. Efecto del diagnóstico de la diabetes mellitus y su complicación con los trastornos de la conducta alimentaria. Revista Chilena de Nutrición, Santiago, v. 46, n. 3, p. 352-360, junho, 2019.

LEITE, R.S.; MARLOW, NICOLE M.; FERNANDES, JYOTIKA K. Oral health and type 2 diabetes. The American Journal of the Medical Sciences, v.345, n.4, p.271 - 273, 2013.

MAURI-OBRADORS, E.; DEVESSA, A.E.; SALAS, E.J.; VIÑAS, M.; LÓPEZ, J.L. Oral Manifestations of Diabetes mellitus. A systematic review. Medicina Oral Patologia Oral y Cirurgia Bucal, v.22, n.5, p. 586 - 594, 2017.

MENDES, E.V. O cuidado das condições crônicas na atenção primária à saúde: o imperativo da consolidação da estratégia da saúde da família [Internet]. Brasília: OPAS; $2012 . \quad 512 \quad$ p. $\quad$ Disponível em: http://bvsms.saude.gov.br/bvs/publicacoes/cuidado_ condicoes_atencao_primaria_saude.pdf

MIRALLES, J. et al. Dental caries in type 1 diabetics: influence of Systemic factors of the disease upon the development of dental caries. Medicina Oral Patologia Oral y Cirurgia Bucal, v.11, n.3, p. 256 - 260, 2006.

NAYA, L. Díaz; ÁlVAREZ, E. Delgado. Diabetes mellitus. Criterios diagnósticos y clasificación. Epidemiología. Etiopatogenia. Evaluación inicial del paciente con diabetes. Medicine-Programa de Formación Médica Continuada Acreditado, v. 12, n. 17, p. 935-946, 2016.

NAZIR, M.A.; ALGHAMDI, L.; ALKADI, M.; ALBEAJAN, N.; ALRASHOUDI, L; ALHUSSAN, M. The burden of Diabetes, its oral complications and their prevention and management. Journal of Medical Sciences, v.6, n.8, p. 1545 - 1553, 2018.

PETROU-AMERIKANOU, $C$. et al. Prevalence of oral lichen planus in diabetes mellitus according to type of diabetes. Oral Disease, v.4, 1998.

PFEIFFER, A. F. H.; KLEIN, H. H. The treatment of Type 2 Diabetes. Deutsches Ärzteblatt International, v.111, n.5, p. 69 - 82, 2014.

PRADO, B.N.; VACCAREZZA, G.F. Alterações bucais em pacientes diabéticos. Revista de Odontologia da Universidade Cidade de São Paulo, v. 25, n. 2, p. 147, 2017.

PRESHAW, P.M.; BISSETT, S.M. Periodontitis and diabetes. British Dental Journal, v. 227, n. 7, p. 577-584, 2019.

ROSAS, C.Y et al. Dental, periodontal and salivary conditions in diabetic children associated with metabolic control variables and nutritional plan adherence. European Journal of Paedratic Dentistry, v.19, n.2, p.119 - 126, 2018. 
ROHANI, B. Oral Manifestations in patients with diabetes mellitus. World Journal of Diabetes, v.10, n.9, p. 485 - 489, 2019.

SOBRINHO, K.N.; DOMINGUES, J.E.G.; PEREIRA, J.V.; CONDE, N.C.O. Alterações em mucosa bucal de pacientes portadores de diabetes mellitus. Revista de Odontologia da Universidade Cidade de São Paulo, v. 26, n. 3, p. 204, 2017.

SOUSA, M.G.M.; COSTA, A.L.L.; RONCALLI, A.G. Clinical study of the oral Manifestations and Related factors in type 2 diabetics patients. Brazilian Journal of Otorhinolaryngology, v. 77, n. 2, p. 145-152, 2011.

VILLAS BOAS, L.C.G; FOSS, M.C; FREITAS, M.C.F; PACE, A.E. Relação entre apoio, adesão aos tratamentos e controle metabólico de pessoas com diabetes mellitus. Revista Latino-Americana de Enfermagem, v.20, ed.1, p.1-8, 2012.

TERNOIS, M. La bouche: un miroir du diabète. La Presse Médicale, v. 46, n. 9, p. 822830 , 2017.

YAMASHITA, J.M.; MOURA-GREC, P.G.; CAPELARI, M.M.; SALES-PERES, A.; SALES-PERES, S.H.C. Manifestações bucais em pacientes portadores de Diabetes Mellitus: uma revisão sistemática. Revista de Odontologia da UNESP, v. 42, n. 3, p. 211-220, 2013. 


\title{
CAPITTULO XXIV
}

\section{MARIFESTAÇÔES ORPIS DA DOERÇACELÍACA}

\section{DDI: 10.51859/AMPLLA.APS276.1121-24}

\author{
Lara Victória Dittz de Abreu Costa ${ }^{1}$ \\ Caroline Rodrigues Thomes ${ }^{1}$ \\ Lorraine Ribeiro Santana ${ }^{1}$ \\ Jonata Leal dos Santos ${ }^{2}$ \\ David Wilkerson dos Santos Silva ${ }^{2}$ \\ Alfredo Carlos Rodrigues Feitosa ${ }^{3}$
}

\footnotetext{
${ }^{1}$ Graduanda do curso de Odontologia. Universidade Federal do Espírito Santo - UFES.

${ }^{2}$ Graduando do curso de Odontologia. Faculdade Pitágoras Imperatriz - MA.

${ }^{3}$ Professor Titular do Departamento de Clínica Odontológica. Universidade Federal do Espírito Santo- UFES.
}

\section{RESUITO}

A doença celíaca é uma patologia autoimune em resposta à exposição ao glúten em indivíduos geneticamente predispostos. Pode ser classificada em clássica, não clássica, silenciosa e latente, nas quais as manifestações clínicas podem variar desde pacientes assintomáticos até envolvimento de múltiplos sistemas. Pode provocar lesões em cavidade oral, incluindo: cárie, líquen plano, glossite atrófica, úlceras aftosas recorrentes e hipoplasia do esmalte. O diagnóstico deve ser realizado minuciosamente, associando achados clínicos e laboratoriais devido a verossimilhança com outras condições de saúde. $O$ tratamento preconizado é a isenção do glúten na dieta. Em razão da doença celíaca ser um problema de saúde pública é necessário avaliar as demandas na atenção primária, incluindo cirurgiões-dentistas, endocrinologistas, nutricionistas, entre outros profissionais.

Palavras-chave: Doença Celíaca. Manifestações Bucais. Odontologia.

\section{IกTRODUÇก̃O}

A doença celíaca (DC) é uma enteropatia crônica do intestino delgado, de caráter autoimune, que se desencadeia em indivíduos propensos geneticamente ao serem expostos ao glúten presente no trigo, centeio, cevada e aveia. É caracterizada pela inflamação da mucosa do intestino, levando à atrofia das vilosidades intestinais (GUERRA et al., 2015; CAMPOS et al., 2018) e, assim, dificultando a absorção de água, medicamentos, vitaminas, minerais e macronutrientes (proteínas, carboidratos e lipídios) dos alimentos (DE PAULA; CRUCINSKY; BENATI, 2014). 
A doença celíaca possui alta prevalência, aproximadamente 1:100-300 pessoas em todo o mundo. Já no Brasil, a estatística oficial é desconhecida, porém estima-se que 300 mil brasileiros são portadores, com maior incidência na região sudeste. Estudos também indicam que a patologia atinge mulheres numa proporção de 2:1, além de predominar em pessoas de cor branca e, no Brasil, atingir mulatos. Essa prevalência em conjunto com as consequências da DC acusa a doença como um problema de saúde pública, principalmente na atenção primária, demandando adequação às necessidades da população celíaca (CAMPOS et al., 2018).

Em condições normais o glúten é degradado pelas enzimas pepsina, tripsina e quimiotripsina presentes no intestino, resultando nos peptídeos gliadina (principal causador da DC) e gluteína, sendo que o primeiro se divide em quatro porções: alfa (responsável pela ativação do sistema imune); beta; gama; e ômega. Entretanto, em pacientes celíacos partes da gliadina não são quebradas, provocando uma resposta exacerbada do sistema imune, uma vez que são reconhecidos como antígenos pelas células T. Dentro das células, as partículas de glúten sofrem ação da transglutaminase tecidual (tTG) que produz ácido glutâmico, aumentando ainda mais o potencial imunogênico e, consequentemente, resultando na destruição das vilosidades intestinais (GUERRA et al., 2015).

Os sintomas diferem conforme a apresentação da reação autoimune, sendo quatro tipos: clássica; atípica ou não clássica; silenciosa ou assintomática; latente. $\mathrm{A}$ primeira forma é caracterizada por sintomas gastrointestinais como má absorção de nutrientes, distensão abdominal, atrofia das vilosidades, constipação crônica, dor, vômito, anemia e perda de peso. Normalmente, é diagnosticada no segundo semestre de vida, coincidindo com a introdução dos cereais na alimentação (RAUEN; BACK; MOREIRA, 2005; GUERRA et al., 2015; CAMPOS et al., 2018).

A segunda forma é aquela em que os exames são positivos para doença celíaca, entretanto, os sinais não são gastrointestinais, como: infertilidade, osteoporose, artrite, diabetes mellitus tipo I, epilepsia, disfunção hepática, dermatite herpetiforme, manifestações bucais, distúrbios na tireoide, irregularidade do ciclo menstrual, miopatia e anemia que não responde a reposição de ferro ou anemia por deficiência de vitamina B12. A dermatite herpetiforme é uma manifestação atípica da doença celíaca, sendo um marcador desta, mesmo sem graves sintomas histológicos. No exame sorológico, 
caracteriza-se por depósitos de IgA nas papilas dérmicas. Sabe-se que em adultos apresenta-se na maioria dos casos e é descoberta em torno dos 45 anos de idade (JAMMA et al., 2010; RASHID et al., 2011; ROGRIGO-SÁEZ et al., 2011; GUERRA et al., 2015; CAMPOS et al., 2018).

Já a terceira forma apresenta sorologia e biópsia positiva, porém os sintomas são mínimos ou ausentes. A forma silenciosa passou a ser diagnosticada mais frequentemente nos últimos anos entre familiares de primeiro grau de pacientes celíacos por meio do desenvolvimento de marcadores sorológicos específicos. Por fim, a quarta forma é identificada pela biópsia jejunal inconclusiva e sorologia positiva, sendo que o paciente não apresenta sintomas (GUERRA et al., 2015; CAMPOS et al., 2018).

Diante de diferentes sinais e sintomas é necessário o acompanhamento por diferentes profissionais, incluindo cirurgiões-dentistas (GUERRA et al., 2015). Essa necessidade enfatiza a indispensabilidade da atenção multiprofissional e multidisciplinar na atenção primária. Assim, a presente pesquisa bibliográfica teve como objetivo realizar um levantamento na literatura por meio da consulta aos portais eletrônicos Bireme, Google Scholar e PubMed, abordando as manifestações orais mais comuns ocasionadas pela doença celíaca a fim de enfatizar a necessidade da atenção dos cirurgiões-dentistas e dos médicos no diagnóstico e tratamento dessa doença.

\section{REUISÃO BIBLIOGRÁFICA}

\subsection{Manifestações orais da doença celíaca}

A doença celíaca relaciona-se com a Odontologia pelas alterações nas estruturas bucais provenientes do quadro da doença, que são comuns, seja na infância ou no período adulto. É de extrema importância que os profissionais da área da saúde, principalmente o cirurgião-dentista, desempenhem um papel fundamental no diagnóstico precoce dessa condição, proporcionando aos portadores de DC um atendimento amplo e qualificado, além de valorizar a sua posição na área da saúde (RAUEN; BACK; MOREIRA, 2005; GUERRA et al., 2015).

Em alguns casos, a DC pode contribuir para o desenvolvimento da desnutrição proteico-calórica e esta, dependendo da idade em que se estabeleça, contribui para o aparecimento de alterações na saúde bucal, tais como atraso na erupção dental, 
diminuição do tamanho dos dentes, problemas na formação do esmalte e disfunção das glândulas salivares (MAKI et al., 1991; RAUEN; BACK; MOREIRA, 2005).

Dentro desse contexto, um profissional atento e bem inteirado sobre as manifestações dessa doença, encaminha corretamente esses pacientes e garante o sucesso de seus tratamentos. As principais manifestações orais e complicações relacionadas ao quadro de doença celíaca incluem úlceras aftosas recorrentes, hipoplasia do esmalte, cárie, glossite atrófica e líquen plano (GUERRA et al., 2015; CRUZ, 2016).

\subsection{1. Úlceras aftosas recorrentes}

A úlcera aftosa recorrente é uma das condições patológicas mais frequentes da cavidade oral. A sua etiologia é desconhecida, mas, parece estar atrelada a uma série de fatores como infecções, estresse, trauma, alergias alimentares, distúrbios nutricionais e hormonais, sendo muito habitual em crianças e adolescentes, sendo que sua frequência e gravidade tornam-se mais brandas com a idade. A localização geralmente é variável, podendo atingir na mucosa jugal, fundo de assoalho de boca e língua (SEDGHIZADEH et al., 2002; RASHID et al., 2011; GUERRA et al., 2015).

A prevalência dessa condição na população em geral varia de 5\% a 66\%, enquanto em pacientes celíacos, grande parte dos estudos aponta para uma prevalência de 9,66\% a 40,98\% (SEDGHIZADEH et al., 2002; PASTORE et al.,2008).

\subsubsection{Hipoplasia do esmalte}

A hipoplasia do esmalte é considerada o distúrbio mais comum no desenvolvimento do esmalte dentário. As manifestações incluem deformidades no esmalte provenientes de injúrias aos ameloblastos, decorrentes principalmente de alterações em níveis sistêmicos, dentre elas alterações nutricionais. Essas deformidades geralmente se caracterizam como uma faixa ou uma faixa com alterações e descontinuidades no esmalte, com fissuras, consistindo em cores amareladas ou amarronzadas pela deposição de pigmentos extrínsecos (NIKIFORVK, 1981; DE CASTRO, 2018). Em pacientes celíacos afeta principalmente primeiros molares e incisivos permanentes (DA CRUZ, 2016).

A hipoplasia do esmalte costuma ser um sinal bem comum na apresentação da doença celíaca e, em muitos casos é a única manifestação da doença em crianças e 
adolescentes celíacos (AINE, 1994). Além disso, essa condição tem maior prevalência em pacientes com doença celíaca, quando comparados a pacientes sem a doença, o que infere a importância e relevância dessas lesões para o diagnóstico da doença, especialmente em casos assintomáticos (PRIOVOLOU et al., 2004; DE CASTRO,2018).

\subsubsection{Cárie}

É estabelecido que a cárie dentária se apresenta como uma doença multifatorial, açúcar biofilme-dependente que leva a uma desmineralização das estruturas dentárias. Esta definição faz com que a compreensão destas lesões seja desafiadora (CAUFIELD; LI; DASANAYAKE, 2005; LUÍS, 2016).

A cárie teve maior prevalência em pacientes celíacos (COSTACURTA et al., 2010; LUís, 2016), no entanto ela pode estar relacionada a uma maior fragilidade do esmalte dental devido aos defeitos causados pela doença celíaca. Portanto, a lesão de cárie não é considerada uma manifestação da doença celíaca, mas sim uma consequência das condições causadas pela doença, como a fragilidade do esmalte, previamente referida, bem como alterações da secreção salivar (COSTACURTA et al., 2010; LUÍS, 2016).

\subsubsection{Glossite atrófica}

A glossite atrófica é uma condição caracterizada por uma atrofia das papilas da língua somada a um quadro de inflamação crônica local (CUNHA; BRAGA; CUNHA, 2012). Essa condição é um sinal clínico de inúmeras patologias, portanto, a identificação de sua etiologia é bastante complexa e geralmente permanece uma incógnita até que outras manifestações surjam para se concluir o diagnóstico (BYRD et al., 2003; LUís, 2016).

A glossite atrófica pode estar presente como manifestação no quadro de doença celíaca e constata-se que é recorrente vê-la associada à presença de uma má nutrição, sendo um dos sinais atrelados a distúrbios alimentares (BOHMER; MOWÉ, 2000; DA SILVA et al., 2010; GONÇALVES; BEZERRA JÚNIOR; CRUZ, 2010; PHILIP et al., 2012; LUÍS, 2016).

\subsubsection{Líquen plano}

O líquen plano é uma doença inflamatória crônica caracterizada por lesões atróficas, erosivas e ulcerativas. Essa condição pode afetar a mucosa oral, a pele, sendo que manifesta com maior frequência na cavidade oral, previamente ou posteriormente a se manifestar na pele. Além disso, essa doença tem sido associada a pacientes com 
doença celíaca e relacionada a presença de deficiências nutricionais (COMPILATO et al., 2010; GONÇALVES; BEZERRA JÚNIOR; CRUZ, 2010; TOSUN et al., 2012).

\subsection{Diagnóstico}

O processo de reação autoimune ao glúten pode assumir diversas formas, podendo-se encontrar em quatro tipos citados anteriormente e para exemplificar o panorama do diagnóstico foi criado um modelo utilizando um iceberg. A ponta representa a forma clássica, visível pelos sintomas intestinais e testes sorológicos compatíveis com a presença da DC. A porção logo abaixo da água representa a forma atípica, com o predomínio de sintomas extra intestinais e, consequentemente, um diagnóstico dificultado. A porção intermediária corresponde a doença na sua forma silenciosa, onde não temos sintomas, porém a mucosa intestinal é afetada. E, por fim, a mais profunda das partes é ocupada pela DC latente. Extremamente difícil de ser diagnosticada, somente detectável por testes sorológicos positivos. O paciente não possui sintomas extra ou intra-intestinais e suas vilosidades são normais (FEIGHERY et al., 1998).

\subsubsection{EKAMES LABORATORIAIS}

O primeiro passo para a análise da doença celíaca é determinar o nível da imunoglobulina A. Caso o paciente venha a apresentar números baixos pode-se ter um falso negativo. Como alternativa tem-se lgG que, mesmo não possuindo grande precisão no diagnóstico, possibilita a análise de anti-EMA (anticorpo anti endomísio) e anti-tTG (anticorpo anti-transglutaminase tecidual). $O$ anti-tTG destaca-se pela sensibilidade elevada, que chega a $97 \%$ contra $94 \%$ do anti-EMA e, o anti-EMA é mais específico, chegando à casa dos 100\% contra 91\% do anti-tTG (VILLANACCI et al., 2011; FASANO; CATASSI, 2012). Para pacientes menores de 2 anos, os exames anti-tTG e anti-EMA são negativos, sendo o anti-DGP (anticorpos para os peptídeos de gliadina desaminados), com sua alta sensibilidade em crianças desta faixa etária, decisivo para o diagnóstico. Para não ocorrer um falso negativo recomenda-se a introdução de uma alimentação saudável antes de iniciar o processo de diagnóstico (HUSBY et al., 2012). 


\subsubsection{BIÓPSIA}

A biópsia do intestino - com ênfase na região duodenal - revela o grau de atrofia das vilosidades sendo este padrão importante na definição do estágio e progressão da doença, sendo a classificação de Marsh-Oberhuber a mais difundida (VILLANACCI et al., 2011).

Evidencia-se que:

Tipo 0 - Mucosa normal.

Tipo I - Aumento do número de linfócitos intraepiteliais (LIE's).

Tipo II - Criptas hiperplásicas junto ao aumento de LIE's.

Tipo III - Atrofia das vilosidades junto as características do tipo II.

A-Atrofia parcial.

B - Atrofia subtotal.

C-Atrofia Total.

Tipo IV - Atrofia total das vilosidades, porém com ausência dos sintomas do tipo II.

\subsubsection{DIAGกÚSTICO DIFERERCIAL}

A doença celíaca possui algumas verossimilhanças em suas características clínicas, deste modo serão apresentadas as principais hipóteses diagnósticas diferenciais:

- Sprue Tropical: com etiologia desconhecida, causa atrofia das vilosidades, má absorção e diarreia. Presente em regiões tropicais a suspeita de sua transmissão recai sobre infecções bacterianas, virais ou parasitárias (WETERGAARD, 2004).

- Doença de Crohn: inflamação crônica do intestino e que ocasiona lesões orais na forma de inchaço firme e indolor em 0,5 a $20 \%$ dos pacientes. Ulcerações aftosas também podem estar presentes. Em geral, a magnitude da manifestação na cavidade oral condiz com o grau de inflamação da mucosa intestinal (PITTOCK et al., 2001).

- Sensibilidade ao glúten: os sintomas aparecem em horas ou dias após a exposição ao glúten, sendo que uma pequena reação do sistema imune é esperada, não produzindo auto anticorpos. Os sintomas estomacais não são 
distinguíveis da doença celíaca, porém a nível histológico ocorre um ligeiro aumento dos linfócitos intraepiteliais. As complicações sistêmicas geralmente são a longo prazo (FASANO; CATASSI, 2012).

- Alergia ao Trigo: os sintomas se manifestam em minutos ou horas após a ingestão do glúten. Uma resposta alérgica é ativada, não produzindo anticorpos ou sintomas intestinais significativos. As complicações sistêmicas não se acumulam e, se presentes, duram pouco tempo (FASANO; CATASSI, 2012).

\subsection{Prevenção}

A doença celíaca, pode não apresentar sintomas em alguns casos, mas os eventos inflamatórios desencadeados por ela podem trazer consequências aos órgãos, causando complicações a longo prazo. Medidas preventivas devem ser tomadas para o não agravamento no quadro dos pacientes, a fim de diminuir a incidência de pioras decorrentes da DC (NASCIMENTO et al., 2012).

A equipe de saúde responsável por esses pacientes deve orientá-los sobre essas manifestações, a fim de promover uma melhor qualidade de vida, estando atenta não somente à alimentação, mas também aos medicamentos prescritos (SARTORI et al., 2020). Sabe-se que a dieta isenta de glúten é a forma de tratamento mais eficaz da doença celíaca e que por ser restrita exige uma disciplina do celíaco (DA CRUZ, 2016). Quando esse paciente é bem orientado pelos profissionais que o atendem seu prognóstico tende a melhorar, pois quanto maior o grau de conhecimento da doença e de seu tratamento, maior a disciplina com a dieta (NASCIMENTO et al., 2012).

No Brasil, a Lei no 10.674 , de 16 de maio de 2003, obriga que os produtos alimentícios informem sobre a presença de glúten. Deve ser impressa nos rótulos e embalagens dos produtos respectivos assim como em cartazes e materiais de divulgação em caracteres com destaque, nítidos e de fácil leitura, como medida preventiva e de controle da doença celíaca (BRASIL, 2003). Entretanto, é necessária uma atenção especial aos ingredientes e sua procedência, uma vez que os produtos alimentícios possam conter traços desta proteína (RUBIO-TAPIA et al., 2009).

Grupos de risco para a doença celíaca incluem parentes de primeiro grau de indivíduos com DC, a literatura estima que aproximadamente $10,0 \%$ dos parentes dos celíacos podem apresentar essa condição devido ao caráter familiar da desordem 
(CAMPOS et al., 2018). Para esses indivíduos que apresentam alto risco de desenvolver a DC recomenda-se triagem sorológica a fim de obter um diagnóstico precoce, porém a realização desses testes ainda é restrita devido ao seu alto custo (DA CRUZ, 2016; CAMPOS et al.,2018).

O exame clínico bucal é uma ferramenta importante para a realização do diagnóstico precoce e o rastreamento de casos de doença celíaca. Salienta-se aqui a importância do profissional cirurgião-dentista na detecção de problemas que se caracterizam como sinais da DC (DA CRUZ, 2016). A respeito dos acometimentos bucais da doença celíaca, segundo a Sociedade Norte-Americana de Gastroenterologia Pediátrica, Hepatologia e Nutrição, os defeitos de esmalte apresentam-se como um fator associado à doença celíaca e é descrita como uma das principais características dos portadores da doença (GUERRA et al., 2015; LUís, 2016).

Os defeitos de esmalte necessitam de intervenção por motivos estéticos, funcionais e também como forma de prevenir agravos na dentição e possível perda dos elementos dentários. As irregularidades, cavidades e sulcos da superfície favorecem a retenção de bactérias, ou seja, risco de desenvolver lesão cariosa pela fragilidade do esmalte, somada a outras alterações como alterações na concentração salivar e diminuição do fluxo salivar (GUERRA et al., 2015; DE CASTRO, 2018). Vale salientar que a doença cárie é multifatorial e somente essa condição do esmalte isolada não é razão do desenvolvimento da lesão cariosa, também envolve outros fatores como dieta e frequência de escovação, por exemplo. Portanto, se faz necessário reabilitação dos elementos afetados, acompanhamento e orientação a respeito de higiene bucal, promovendo saúde para esses pacientes (GUERRA et al., 2015; LUíS, 2016).

\subsection{Tratamento}

Sabe-se que quanto mais precoce for o diagnóstico e deteç̧ão da patologia melhor será o prognóstico, pois permitirá o portador a aderir a dieta, prevenindo futuras complicações malignas e não malignas, evidenciando que será necessário o acompanhamento médico e odontológico regularmente (WORLD GASTROENTEROLOGY ORGANISATION GLOBAL GUIDELINES, 2012; PAUL et al., 2016). Assim, pesquisadores descreveram como o único tratamento eficaz o método nutritivo onde há uma alimentação isenta de glúten, onde será capaz de reduzir ou até mesmo eliminar os 
sintomas, devendo restabelecer fisiologia intestinal adequada, parâmetros bioquímicos e qualidade de vida (WORLD GASTROENTEROLOGY ORGANISATION GLOBAL GUIDELINES, 2012; SHTEYER et al., 2013; ADORNETTO et al., 2015).

Alguns dos exemplos de novas abordagens terapêuticas são:

\subsection{TERAPÊUTICAS ERZIMTÁTICAS}

Uma das abordagens terapêuticas fortemente estudada é a degradação do glúten ainda no trato gastrointestinal, onde os peptídeos de glúten funcionam como antígenos para o celíaco. A administração de enzimas por via oral, nomeadas de glutenases, são capazes de degradar os fragmentos de glúten não digeridos ao transformá-los em peptídeos de baixo peso molecular não imunogênicos. No entanto, para serem realmente eficazes, estas devem ser capazes de surtir atividade em ambientes com um baixo $\mathrm{pH}$, devendo também ser resistentes às proteases humanas (MCCARVILLE; CAMINERO; VERDU, 2015).

\subsubsection{UACIПA ПЕКUИАК2}

Com o intuito de restabelecer a tolerância oral aos efeitos tóxicos dos peptídeos de glúten está sendo estudado uma vacina composta por 3 peptídeos capazes de induzir uma resposta pró inflamatória, de reprogramar a resposta imune dos linfócitos T ao glúten, sendo a única abordagem terapêutica para a DC atualmente em desenvolvimento, que tem o potencial de vir a possibilitar ao doente celíaco a prática de uma alimentação normal (VEERARAGHAVAN et al., 2015).

\section{CONSIDERAÇÔES FInRIS}

A alta prevalência da doença celíaca assim como formas silenciosas e latentes da doença e as consequências que traz ao indivíduo acometido caracterizam a doença como um problema de saúde pública, sendo essencial uma abordagem multidisciplinar para diagnóstico, tratamento e acompanhamento desses pacientes. O conhecimento aprofundado por parte dos profissionais de saúde sobre o protocolo e diretrizes de assistência ao paciente é essencial, pois o entendimento superficial implica na demora da captação dos pacientes não diagnosticados bem como nas orientações ao paciente celíaco quanto ao tratamento a ser seguido. 


\section{REFERÊCCIAS}

ADORNETTO, G. et al. An electrochemical immunoassay for the screening of celiac disease in saliva samples. Analytical and Bioanalytical Chemistry, v. 407, n. 23, p. 7189-7196, 2015.

AINE, L. et al. Permanent tooth dental enamel defects leading to the diagnosis of coeliac disease. British Dentistry Journal., v. 7, p. 254-255, 1994.

BOHMER, T; MOWÉ, M. The association between atrophic glossitis and protein-calorie malnutrition in old age. Age and ageing, v.29, n.1, p. $47-50,2000$.

BRASIL. Lei no 10.674 , de 16 de maio de 2003. Obriga a que os produtos alimentícios comercializados informem sobre a presença de glúten, como medida preventiva e de controle da doença celíaca. Diário Oficial da União, Brasília, 2003.

BYRD, J. A.; BRUCE, A. J.; ROGERS, R. S. Glossitis and other tongue disorders. Dermatologic Clinics, 2003.

CAMPOS, C.G.P. et al. Doença celíaca e o conhecimento dos profissionais de saúde da atenção primária. Revista de Saúde Pública do Paraná, v. 1, n. 2, p. 54-62, 2018.

CAUFIELD, P. W.; DASANAYAKE A. Dental caries: an infectious and transmissible disease. Compedium of Continuing Education in Dentistry, v.26, n.5, p. $10-16,2005$.

COMPILATO, D. et al. The production of oral mucosa and antiendomysial and anti-tissuetransglutaminase antibodies in patients with celiac disease: a review. The Scientific World Journal, v.10, p. 2385 - 3394, 2010.

COSTACURTA, M. et al. Oral manifestations of coeliac disease: A clinical-statistic disease study. Oral and Implantology, v.3, n.1, p. $12-19$.

CUNHA, S. F. DE C. D.; BRAGA, C. B. M.; CUNHA, D. F. D. et al. Papillary atrophy of the tongue and nutritional status of hospitalized alcoholics. Anais Brasileiros de Dermatologia., Rio de Janeiro, v. 87, n. 1, p. 84-9, 2012.

DA CRUZ, I.T.S.A. Manifestações orais em pacientes com doença celíaca. Orientador: Luciana Reichert Assunção Zanon. 2016. 73 p. Dissertação (Mestre em Odontologia) - Universidade Federal do Paraná, Curitiba, 2016.

DA SILVA, P. et al. Oral manifestations of celiac diasease. A case report and review of the literature. Oral Medicine, Oral Pathology and Oral Surgery, v.13, n.69, p. $559-$ 562, 2008.

DE CASTRO, A.M. A relação da doença celíaca e a hipoplasia do esmalte dentário. Orientador: Maria Geruza Côrrea do Amaral Ribeiro. 2018. 22 p. Trabalho de Conclusão de Curso (Cirurgiã-dentista) - Centro Universitário São Lucas, Porto Velho, 2018. 
DE PAULA, F.A.; CRUCINSKY, J.; BENATI, R. FRAGILIDADES DA ATENÇÃO À SAÚDE DE PESSOAS CELÍACAS NO SUS: A PERSPECTIVA DO USUÁRIO. DEMETRA: Alimentação, Nutrição \& Saúde, [S. I.], v. 9, p. 311-328, 2014.

FASANO, A.; CATASSI, C. Celiac disease. New England Journal of Medicine, v. 367, n. 25, p. 2419-2426, 2012.

FEIGHERY, C. et al. Diagnosis of gluten-sensitive enteropathy: is exclusive reliance on histology appropriate? European Journal of Gastroenterology and Hepatology, France, n. 10, p. 919-25, 1998.

GONÇALVES, L. M.; BEZERRA JÚNIOR, J. R. S.; CRUZ, M.C.F.N.D. Clinical evaluation of oral lesions associated with dermatologic diseases. Anais Brasileiros de Dermatologia, v. 85, n.6, p. $150-156,2010$.

GUERRA, F.A. et al. MANIFESTAÇÕES ORAIS DA DOENÇA CELÍACA REVISTA DA LITERATURA. Revista Odontologia (ATO), v. 15, n. 2, p. 117-49, 2015.

HUSBY, S. et al. European Society for Pediatric Gastroenterology, Hepatology, and Nutrition guidelines for the diagnosis of coeliac disease. Journal of Pediatric Gastroenterology and Nutrition, v. 54, n. 1, p. 136-160, 2012.

JAMMA, $S$. et al. Celiac crisis is a rare but serious complication of celiac disease in adults. Clinical Gastroenterology and Hepatology, v. 8, n. 7, p. 587-590, 2010.

LUÍS, S.M. Alterações orais na doença celíaca. Orientador: Jorge Fonseca. 2016. 62 p. Dissertação (Mestre em Medicina Dentária) - Instituto Superior de Ciências da Saúde Egas Moniz, [S. I.], 2016.

MAKI et al. Dental enamel effects in first - degree relatives of coeliac disease pacients. Lancet, v.337, n.8744, p. 763-764, 1991.

MCCARVILLE, J.L.; CAMINERO, A.; VERDU, E.F. Pharmacological approaches in celiac disease. Current Opinion in Pharmacology, v. 25, p. 7-12, 2015.

NASCIMENTO, K.O. et al. Doença Celíaca: Sintomas, Diagnóstico e Tratamento Nutricional. Saúde em Revista, v. 12, n. 30, p. 53-63, 2012.

NIKIFORVK, G.; FRASER, D. The etiology of enamel hypoplasia: a unifying concept. Journal Pediatric, v. 6, p. 888-893, 1981.

PASTORE, L. et al. Oral manifestations of celiac disease. Journal of Clinical Gastroenterology, v.42, n.3, p. $224-232,2008$.

PAUL, S. P. et al. Coeliac disease in children-an update for general dental practitioners. British Dental Journal, v. 220, n. 9, p. 481-485, 2016.

PHILIP, R. et al. Endocrine manifestations of celiac disease. Indian Journal of Endocrinology and Metabolism, v.16, n.2, p. 506 - 508, 2012. 
PITTOCK, S. et al. The oral cavity in Crohn's disease. The Journal of Pediatrics, v. 138, n. 5, p. 767-771, 2001.

PRIOVOLOU, C. et al. A comparative study on the prevalence of enamel defects and dental caries in children and adolescents with and without coeliac disease. European Journal Pediatric Dentistry, v. 2, p. 102-106, 2004.

RASHID, $M$. et al. Oral manifestations of celiac disease: a clinical guide for dentists. Journal of Canadian Dental Association, v. 77, n. b39, p. 1-6, 2011.

RAUEN, M.S.; BACK, J.C.V.; MOREIRA, E.A.M. Doença celíaca: sua relação com a saúde bucal. Revista de Nutrição, v. 18, n. 2, p. 201-206, 2005.

RODRIGO-SÁEZ, L. et al. Differences between pediatric and adult celiac disease. Revista Espanola de Enfermedades Digestivas, v. 103, n. 5, p. 238, 2011.

RUBIO-TAPIA, A. et al. Increased prevalence and mortality in undiagnosed celiac disease. Gastroenterology, v. 137, n. 1, p. 88-93, 2009.

SARTORI, L.A. et al. A Doença Celíaca e as alterações Bucais: Revisão de Literatura. Revista CROMG, v. 19, n.1, p. 21-26, 2020.

SEDGHIZADEH, P.P. et al. Celiac disease and recurrent aphthous stomatitis: a report and review of the literature. Oral Surgery Oral Medicine Oral Pathology Oral Radiology and Endodontics, Chicago, n. 94, p. 474-8, 2002.

SHTEYER, E. et al. Oral health status and salivary properties in relation to gluten-free diet in children with celiac disease. Journal of Pediatric Gastroenterology and Nutrition, v. 57, n. 1, p. 49-52, 2013.

TOSUN, M. et al. Oral findings in children with celiac disease. Turkish Journal of Medical Sciences, v.42, n.4, p. $613-617,2012$.

VEERARAGHAVAN, G. et al. Celiac disease 2015 update: new therapies. Expert Review of Gastroenterology \& Hepatology, v. 9, n. 7, p. 913-927, 2015.

VILLANACCI, V. et al. Coeliac disease: the histology report. Digestive and Liver Disease, v. 43, p. S385-S395, 2011.

WETERGAARD, H. Tropical Sprue. Current Treatment Options in Gastroenterology, n. 7, p. 7-11, 2004.

WORLD GASTROENTEROLOGY ORGANISATION GLOBAL GUIDELINES. Doença celíaca. [s.l.]: [s.n.], 18p., 2012. Disponível em: https://www.worldgastroenterology.org/UserFiles/file/guidelines/celiacdisease-portuguese-2012.pdf. Acesso em: 20 fev. 2021. 


\title{
CAPITULO XXV
}

\section{IחTOKICAÇÃO POR MEDICAMEETTOS กO BRASIL: UMTA RELISÃO SISTEMT́́TICA}

\author{
DDI: 10.51859/AMPLLA.APS276.1121-25
}

\author{
Bruna Carla Costa Pinto ${ }^{1}$ \\ Danyelle Cristina Pereira Santos ${ }^{2}$ \\ Márcio Anderson Sousa Nunes ${ }^{3}$ \\ Wellyson da Cunha Araújo Firmo ${ }^{3,4}$
}

\footnotetext{
Bacharel em Biomedicina pela Universidade Ceuma.

${ }^{2}$ Bacharel em Biomedicina e Mestranda em Biologia Microbiana pela Universidade Ceuma.

${ }^{3}$ Docente do Curso de Biomedicina da Universidade Ceuma.

4 Doutor em Biotecnologia pela Universidade Federal do Maranhão e Docente dos Mestrados em Biologia Microbiana e Gestão de Programas e Serviços de Saúde da Universidade Ceuma
}

\section{RESUMO}

A população vem utilizando medicamentos sem orientação de um profissional da saúde, quase sempre acompanhado do desconhecimento dos prejuízos que isto pode causar. Este fato constitui o principal responsável pelas intoxicações humanas registradas no Brasil. Diante deste contexto, o presente trabalho tem como objetivo revisar a literatura de publicações científicas brasileiras sobre intoxicações oriundas de medicamentos. 0 estudo se trata de uma pesquisa documental, quantitativa e de revisão de literatura de trabalhos publicados durante os anos de 2014 a 2020. Os resultados indicaram que significante proporção da população brasileira se automedica podendo levar à ocorrência de intoxicações. As principais causas desse problema são o uso abusivo do medicamento decorrente à falta de conhecimento sobre a sua posologia e administração, erros de prescrição e automedicação. Os fármacos mais citados como causadores de intoxicação são: paracetamol, amoxicilina e diazepam. Por fim, pode-se concluir que são necessárias estratégias de promoção à saúde que orientem e eduquem a população sobre o uso consciente de medicamentos, assim como ações de prevenção ao suicídio; tendo em vista a quantidade de casos de intoxicações ocorridos no período estudado por este motivo.

Palavras-chave: Medicamentos. Automedicação. Intoxicação. Psicotróficos.

\section{IกTRODUÇก̃O}

Medicamentos são produtos farmacêuticos elaborados com finalidade profilática, curativa, paliativa ou para fins de diagnóstico (GONÇALVES et al., 2017). Não há dúvidas sobre as vantagens do tratamento medicamentoso no combate às diversas enfermidades que prejudicam o ser humano, no entanto, sabe-se que em algumas 
situações seu uso causa consequências indesejáveis promovendo riscos à saúde (SILVA; SOUZA; AOYAMA, 2020).

Para consumir cada vez mais os medicamentos existentes no mercado, a população sofre pressão de setores como a indústria farmacêutica e empresas de comunicação, o que leva a um excesso no consumo e consequentemente um aumento no número de intoxicações devido aos efeitos adversos dos fármacos, e por não terem sido usados somente quando prescritos por um profissional habilitado e sim na prática de automedicação (PAIM; MULLER, 2015).

A automedicação no Brasil vem crescendo devido à facilidade em adquirir medicamentos, como por exemplo os de venda livre, com o objetivo de aliviar sintomas mais brandos como dor de cabeça ou mal-estar em geral (GONÇALVES et al., 2017). Este aspecto contribui, juntamente com o uso indevido e indiscriminado de determinados fármacos como antibióticos e psicotrópicos, para que os medicamentos sejam o principal fator responsável pelas intoxicações (TAKAHAMA; TURINI; GIROTTO, 2015).

Intoxicação é a manifestação, através de sinais e sintomas, dos efeitos nocivos produzidos em um organismo vivo como resultado da sua interação com substância exógena de potencial tóxico (VIEIRA; CAVEIÃO, 2016). Fatores que estão geralmente relacionados a intoxicações medicamentosas são: automedicação, erros de prescrição, exposição acidental e, dentre esses fatores podemos destacar a utilização inadequada por tentativa de suicídio, aborto e homicídio (GONÇALVES et al., 2017).

O ambiente domiciliar apresenta uma grande variedade de agentes como plantas tóxicas, medicamentos, pesticidas, produtos de limpeza e higiene que quando não armazenados de forma correta podem apresentar risco de envenenamento e intoxicação. Diante disso as intoxicações acidentais em ambiente domiciliar são frequentes na população infantojuvenil, e ocupam uma posição de destaque nos atendimentos de serviços de urgência e emergência (BRITO; MARTINS, 2015).

No Brasil, as informações disponíveis sobre exposições e intoxicações relacionadas a medicamentos são limitadas aos dados do Sistema Nacional de Agravos de Notificação (SINAN), do Sistema Nacional de Informações Tóxico-Farmacológicas (SINITOX), e alguns estudos em grandes hospitais. O SINITOX aponta os medicamentos como os responsáveis pelo maior número de atendimentos entre os Centros de Informações Toxicológicas (CITs) (GERMANO; ALONZO, 2015). 
Sendo a intoxicação por medicações um agravo muito comum, é de extrema importância o conhecimento dos fatores que contribuem para que a automedicação seja um ato rotineiro, de que forma este ato pode ser nocivo à saúde e como CITs podem ajudar a prevenir a morbimortalidade relacionada a medicamentos. Desta forma, o presente trabalho teve como objetivo realizar uma revisão bibliográfica de publicações sobre intoxicações por medicamentos no Brasil, descrevendo os fatores e agravos da automedicação irracional.

\section{METODOLOGIA}

O presente trabalho tratou de uma pesquisa documental, quantitativa e de revisão de literatura. Para realizar este trabalho foram feitas buscas nas bases de dados eletrônicas em plataformas do Google acadêmico, Scielo e Biblioteca Virtual em Saúde (BVS), utilizando os descritores: medicamentos, intoxicação, automedicação e psicotrópicos; e que foram publicados durante os anos de 2014 a 2020.

Foram selecionados para a realização do trabalho, artigos na língua portuguesa que possuíam em seu título algum dos descritores utilizados e que abordavam as características de automedicação e fatores relacionados a intoxicações. Estes foram organizados em uma tabela feita no Programa Microsoft Excel ${ }^{\circledR} 2010$.

Figura 1 - Fluxograma das etapas de seleção dos artigos.
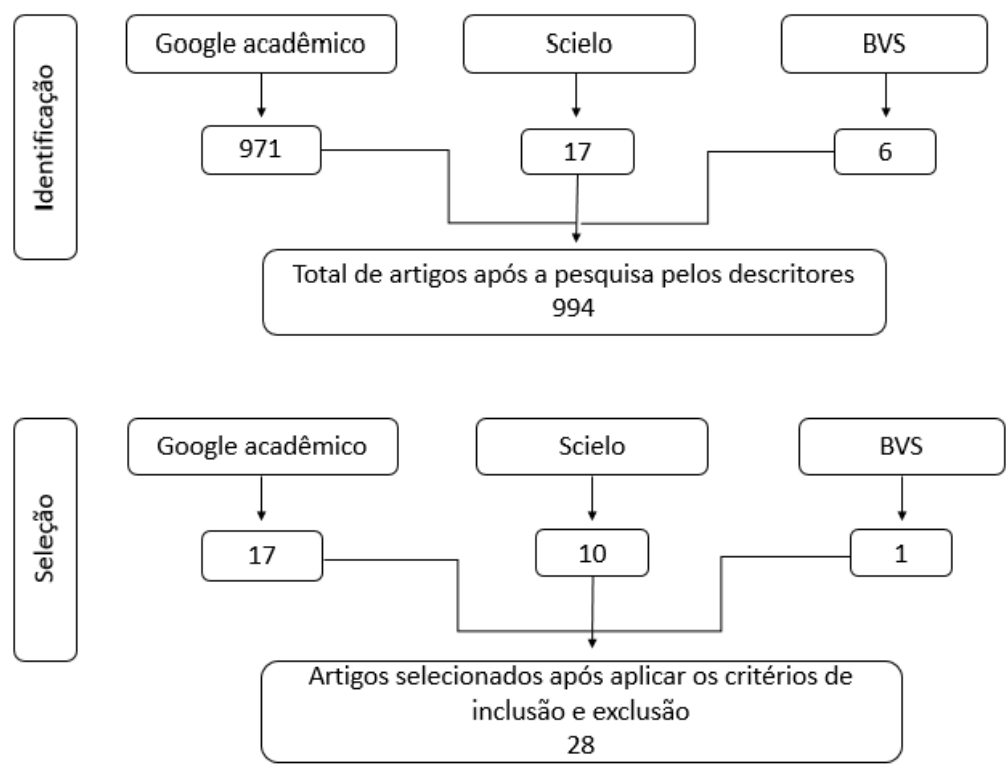

Fonte: Autoria própria. 


\section{RESULTADOS}

Depois de conhecer alguns fatores de riscos da intoxicação por medicamentos, vamos entender como esses dados foram analisados (Tabela 1).

Observou-se que a metodologia mais utilizada nos trabalhos foi descritiva, publicados mais em revistas de saúde pública e ciências da saúde no período de 2017 a 2018; cujo objetivo principal foi analisar os dados provenientes de intoxicação por medicamentos. O público-alvo das pesquisas foi pacientes vítimas de intoxicação, envolvendo crianças, adolescentes, adultos e idosos, em idade de 0 a 89 anos. Os fármacos mais citados como causadores de intoxicação foram: paracetamol, amoxicilina e diazepam.

São necessárias estratégias de promoção à saúde que orientem e eduquem a população sobre o uso consciente de medicamentos, assim como ações de prevenção ao suicídio; tendo em vista a quantidade de casos de intoxicações ocorridos no período estudado por este motivo.

Tabela 1 - Distribuição das variáveis quantas as análises dos artigos sobre intoxicação por medicamento

\begin{tabular}{|c|c|c|c|c|c|c|}
\hline TÍTULO/REVISTA/ANO & OBJETIVO & $\begin{array}{c}\text { METODOLOGIA/ } \\
\text { PERÍODO DE } \\
\text { ESTUDO }\end{array}$ & $\begin{array}{c}\text { PÚBLICO/ } \\
\text { GÊNERO/ IDADE }\end{array}$ & SUBSTÂNCIA & DESFECHO & \\
\hline $\begin{array}{c}\text { Fatores relacionados à } \\
\text { utilização de } \\
\text { flumazenil em } \\
\text { pacientes } \\
\text { hospitalizados / } \\
\text { Revista Enfermagem } \\
\text { UERJ / } 2014\end{array}$ & $\begin{array}{c}\text { Conhecer os } \\
\text { aspectos e } \\
\text { elementos } \\
\text { relacionados à } \\
\text { utilização de } \\
\text { flumazenil em } \\
\text { pacientes } \\
\text { internados em um } \\
\text { hospital geral } \\
\text { universitário } \\
\text { Estudar as } \\
\text { tentativas de } \\
\text { suicídio por } \\
\text { intoxicações } \\
\text { exógenas }\end{array}$ & $\begin{array}{l}\text { Epidemiológico, } \\
\text { descritivo e } \\
\text { transversal / } \\
\text { janeiro (2008) - } \\
\text { dezembro (2013) }\end{array}$ & $\begin{array}{c}\text { Todos os casos } \\
\text { notificados como } \\
\text { tentativa de } \\
\text { suicídio por } \\
\text { intoxicações } \\
\text { exógenas / } \\
\text { Masculino e } \\
\text { feminino / } 20 \text { a } 59 \\
\text { anos }\end{array}$ & Não relatado & $\begin{array}{c}\text { Campanhas de } \\
\text { conscientização } \\
\text { para o uso } \\
\text { nacional de } \\
\text { medicamentos e } \\
\text { controle sobre a } \\
\text { venda de } \\
\text { agrotóxicos } \\
\text { poderiam } \\
\text { contribuir para a } \\
\text { diminuição dos } \\
\text { casos }\end{array}$ & [1] \\
\hline
\end{tabular}




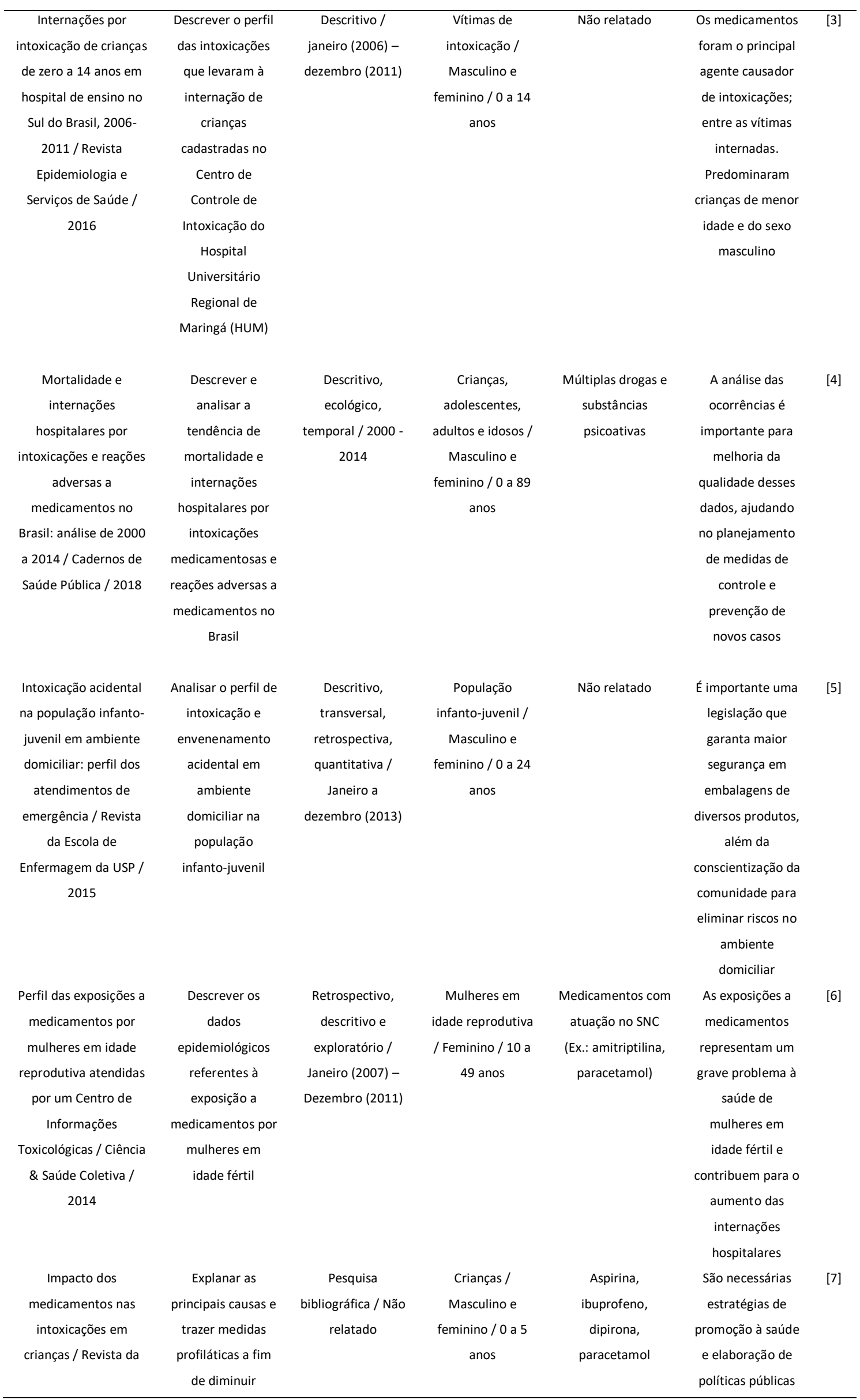




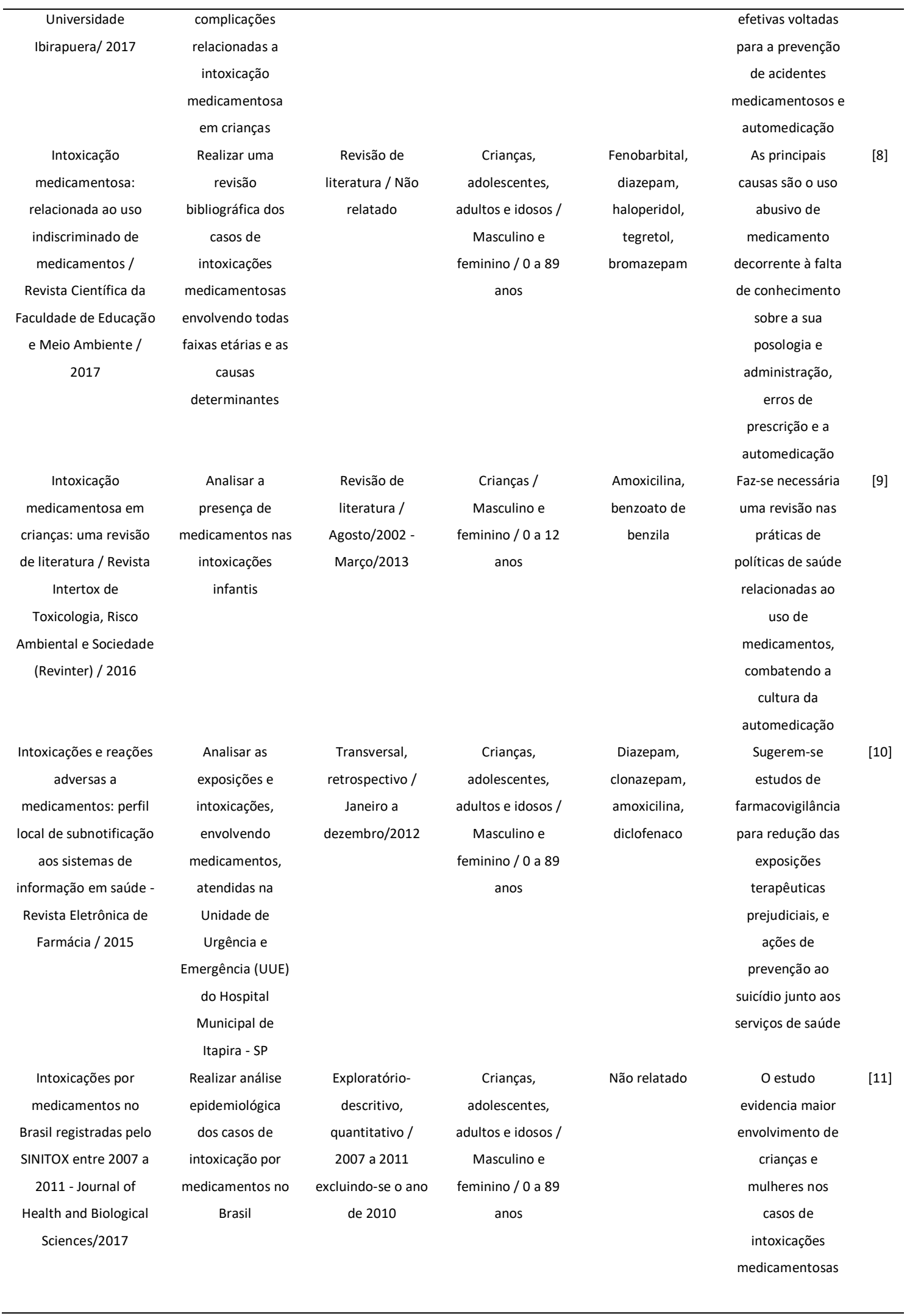




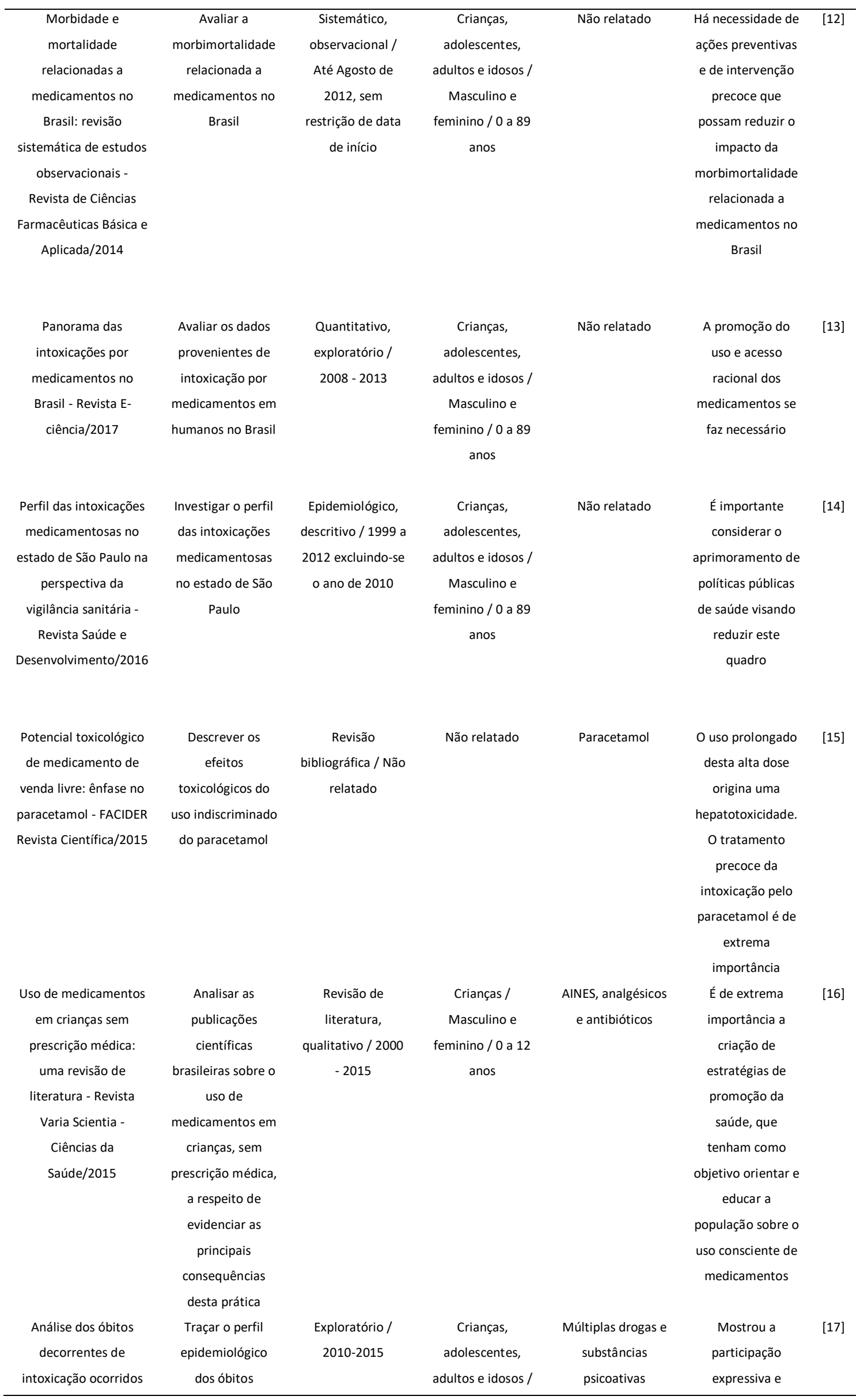




\begin{tabular}{|c|c|c|c|c|c|c|}
\hline no Brasil de 2010 a & decorrentes de & & Masculino e & & crescente das & \\
\hline 2015 com base no & intoxicação & & feminino / 10 a 89 & & drogas de abuso & \\
\hline Sistema de Informação & ocorridos de 2010 & & anos & & nos óbitos, em & \\
\hline sobre & a 2015 no Brasil, & & & & especial & \\
\hline Mortalidade (SIM) - & registrados pelo & & & & evidenciada pelos & \\
\hline Ciência \& Saúde & SIM & & & & APVP (Anos & \\
\hline \multirow[t]{2}{*}{ Coletiva/2020 } & & & & & Potenciais de Vida & \\
\hline & & & & & Perdido) & \\
\hline Demografia, óbitos e & Analisar as & Descritivo, & Crianças / & Não relatado & Recomenda-se a & [18] \\
\hline indicadores de & internações & retrospectivo / & Masculino e & & oferta de atenção & \\
\hline agravamento nas & hospitalares em & $2003-2012$ & feminino / 0 a 5 & & especializada às & \\
\hline internações por & razão de & & anos & & intoxicações & \\
\hline intoxicações & intoxicações & & & & medicamentosas, & \\
\hline medicamentosas entre & medicamentosas & & & & mapeando & \\
\hline menores de 5 anos no & no país, & & & & aqueles que & \\
\hline Brasil - Revista & envolvendo & & & & podem assistir & \\
\hline Brasileira de & menores de 5 & & & & pacientes & \\
\hline \multirow[t]{7}{*}{ Epidemiologia/2020 } & anos, entre 2003 e & & & & intoxicados, até & \\
\hline & 2012 , quanto aos & & & & mesmo ofertando & \\
\hline & aspectos & & & & leitos de UTI & \\
\hline & demográficos, & & & & & \\
\hline & óbitos e & & & & & \\
\hline & indicadores de & & & & & \\
\hline & agravamento & & & & & \\
\hline Intoxicações em & Analisar dados de & Transversal, & Crianças e & Não relatado & É necessário & [19] \\
\hline crianças e & intoxicações & analítico / 2012 - & adolescentes / & & instituir medidas & \\
\hline adolescentes & agudas em & 2014 & Masculino e & & educativas & \\
\hline notificados em um & crianças e & & feminino / 0 a 12 & & associadas às & \\
\hline centro de & adolescentes até & & anos & & legislativas & \\
\hline toxicologia no & 12 anos, & & & & visando à & \\
\hline nordeste do Brasil - & notificadas em um & & & & prevenção destes & \\
\hline Revista Brasileira de & centro de & & & & agravos & \\
\hline Saúde Materno & referência em & & & & & \\
\hline \multirow[t]{2}{*}{ Infantil/2017 } & toxicologia no & & & & & \\
\hline & nordeste do Brasil. & & & & & \\
\hline Tendência da & Apresentar a & Exploratório, & Crianças, & Narcóticos, & Ações educativas & [20] \\
\hline mortalidade por & avaliação da & temporal / 1996 - & adolescentes, & psicodisléptico, & e reguladoras & \\
\hline intoxicação & magnitude e da & 2012 & adultos e idosos / & anticonvulsivante, & devem ser & \\
\hline medicamentosa entre & tendência dos & & Masculino e & sedativos, & implementadas & \\
\hline gêneros e faixas etárias & óbitos por & & feminino / 0 a 89 & hipnóticos, & para colaborar & \\
\hline no Estado de São & intoxicação & & anos & antiparkinsoniano e & com a melhora no & \\
\hline Paulo, Brasil, 1996- & medicamentosa & & & psicotrópicos & impacto dos & \\
\hline 2012 - Ciência \& Saúde & no estado de São & & & & medicamentos na & \\
\hline \multirow[t]{9}{*}{ Coletiva/2017 } & Paulo, Brasil, no & & & & saúde & \\
\hline & período de 1996 a & & & & & \\
\hline & 2012, além de & & & & & \\
\hline & avaliar diferenças & & & & & \\
\hline & na mortalidade & & & & & \\
\hline & entre os sexos, & & & & & \\
\hline & faixas etárias e & & & & & \\
\hline & intenções & & & & & \\
\hline & envolvidas no & & & & & \\
\hline
\end{tabular}




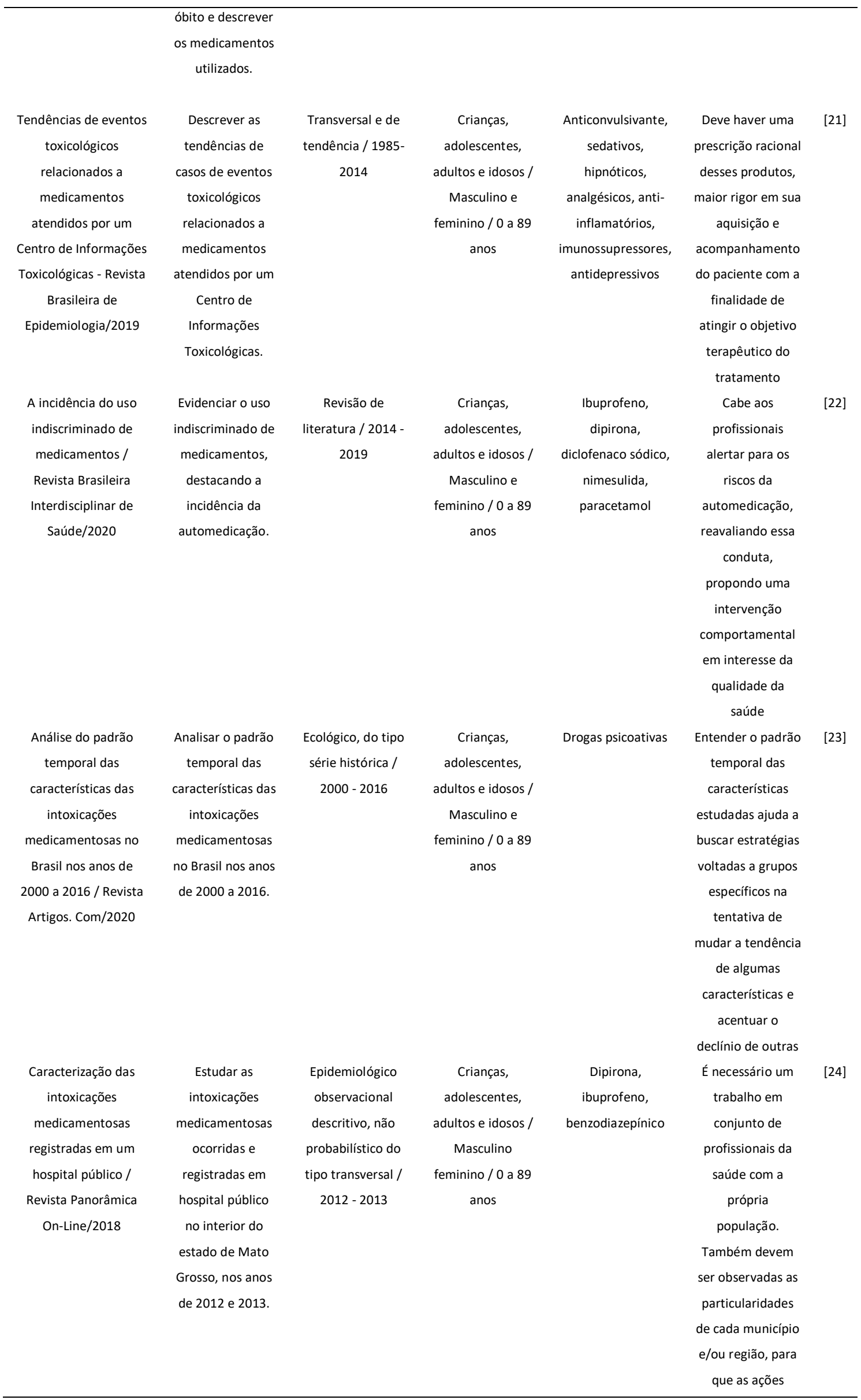




\begin{tabular}{|c|c|c|c|c|c|c|}
\hline & & & & & $\begin{array}{l}\text { sejam mais } \\
\text { eficientes }\end{array}$ & \\
\hline $\begin{array}{c}\text { Caracterização do } \\
\text { perfil das intoxicações } \\
\text { medicamentosas } \\
\text { no Brasil, durante } 2013 \\
\text { a } 2016 \text { / Id on Line } \\
\text { Revista Multidisciplinar } \\
\text { e de Psicologia/2018 }\end{array}$ & $\begin{array}{c}\text { Realizar um } \\
\text { levantamento } \\
\text { sobre a ocorrência } \\
\text { dos casos de } \\
\text { intoxicação } \\
\text { medicamentosa } \\
\text { no Brasil no } \\
\text { período de } 2013 \text { a } \\
2016 .\end{array}$ & $\begin{array}{c}\text { Pesquisa } \\
\text { documental, } \\
\text { quantitativa / } \\
2013 \text { - } 2016\end{array}$ & $\begin{array}{c}\text { Crianças, } \\
\text { adolescentes, } \\
\text { adultos e idosos / } \\
\text { Masculino e } \\
\text { feminino / } 0 \text { a } 89 \\
\text { anos }\end{array}$ & $\begin{array}{c}\text { Benzodiazepínico, } \\
\text { anticonvulsivante, } \\
\text { antidepressivos e } \\
\text { analgésicos }\end{array}$ & $\begin{array}{c}\text { Seria propício a } \\
\text { implantação de } \\
\text { um maior número } \\
\text { de Centros de } \\
\text { Informação e } \\
\text { Assistência } \\
\text { Toxicológica, pois } \\
\text { apenas analisando } \\
\text { quali- } \\
\text { quantitativamente } \\
\text { os dados sobre } \\
\text { intoxicações } \\
\text { medicamentosas, } \\
\text { poderemos propor } \\
\text { medidas } \\
\text { apropriadas para a } \\
\text { redução dos casos } \\
\text { desse tipo de } \\
\text { intoxicação }\end{array}$ & {$[25]$} \\
\hline $\begin{array}{c}\text { Intoxicação } \\
\text { medicamentosa } \\
\text { infantil no Paraná / } \\
\text { Revista Visão } \\
\text { Acadêmica / } 2018\end{array}$ & $\begin{array}{c}\text { Verificar por meio } \\
\text { de dados } \\
\text { disponibilizados } \\
\text { pelos órgãos } \\
\text { estaduais e } \\
\text { federais a } \\
\text { ocorrência de } \\
\text { intoxicações } \\
\text { medicamentosas } \\
\text { infantis no estado } \\
\text { do Paraná }\end{array}$ & $\begin{array}{l}\text { Revisão de } \\
\text { literatura / } 2012 \text { - } \\
2015\end{array}$ & $\begin{array}{c}\text { Crianças / } \\
\text { Masculino e } \\
\text { feminino / } 0 \text { a } 12 \\
\text { anos }\end{array}$ & Não relatado & $\begin{array}{l}\text { Cabe orientar os } \\
\text { pais e } \\
\text { responsáveis } \\
\text { sobre o perigo da } \\
\text { exposição } \\
\text { acidental das } \\
\text { crianças ao } \\
\text { medicamento, } \\
\text { evitando assim } \\
\text { casos de } \\
\text { intoxicação }\end{array}$ & [26] \\
\hline $\begin{array}{c}\text { Uma abordagem ao } \\
\text { uso indiscriminado de } \\
\text { medicamentos } \\
\text { benzodiazepíni-cos / } \\
\text { Revista Científica } \\
\text { FAEMA / } 2018\end{array}$ & $\begin{array}{c}\text { Reunir } \\
\text { conhecimentos } \\
\text { científicos por } \\
\text { intermédio de } \\
\text { revisão de } \\
\text { literatura acerca } \\
\text { das consequências } \\
\text { do uso } \\
\text { indiscriminado de } \\
\text { medicamentos } \\
\text { benzodiazepínicos }\end{array}$ & $\begin{array}{l}\text { Revisão de } \\
\text { literatura / } 2000 \text { - } \\
2018\end{array}$ & Não relatado & Benzodiazepínicos & $\begin{array}{c}\text { Destaca-se que o } \\
\text { uso indiscriminado } \\
\text { de medicamentos, } \\
\text { dentre eles os } \\
\text { BZD, constitui um } \\
\text { fenômeno social } \\
\text { que evidencia-nos } \\
\text { um grave } \\
\text { problema de } \\
\text { saúde pública }\end{array}$ & [27] \\
\hline $\begin{array}{c}\text { Estudo sobre a } \\
\text { automedicação, o uso } \\
\text { irracional de } \\
\text { medicamentos e o } \\
\text { papel do farmacêutico } \\
\text { na sua prevenção / } \\
\text { Revista Científica } \\
\text { FAEMA / } 2018\end{array}$ & $\begin{array}{c}\text { Demonstrar o } \\
\text { papel do } \\
\text { farmacêutico na } \\
\text { orientação e } \\
\text { conscientização } \\
\text { dos pacientes na } \\
\text { prática da } \\
\text { automedicação e } \\
\text { como a sua } \\
\text { influência na } \\
\text { correta utilização }\end{array}$ & $\begin{array}{c}\text { Revisão de } \\
\text { literatura / } 2000 \text { - } \\
2018\end{array}$ & Não relatado & Não relatado & $\begin{array}{l}\text { O farmacêutico } \\
\text { tem um papel } \\
\text { importante como } \\
\text { medida para evitar } \\
\text { a utilização } \\
\text { irracional dos } \\
\text { medicamentos }\end{array}$ & [28] \\
\hline
\end{tabular}




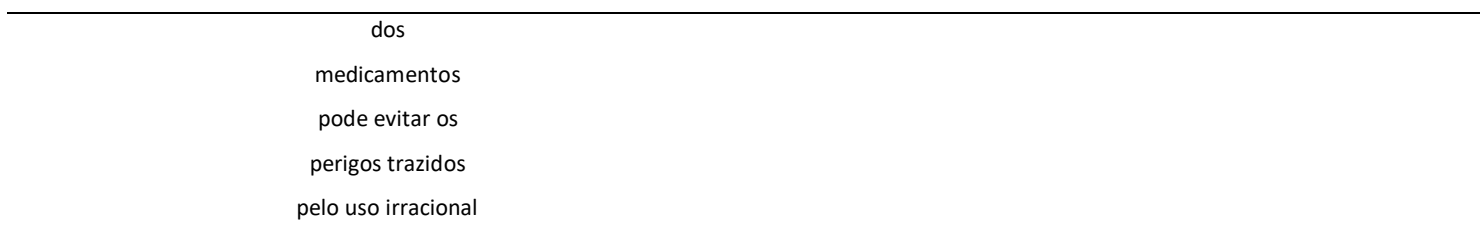

[1]: Sandes et al. (2014); [2]: Vieira, Santana e Suchara (2015); [3]: Domingos et al. (2016); [4]: Santos e Boing (2018); [5]: Brito e Martins (2015); [6]: Takahama, Turini e Girotto (2014); [7]: Paiva et al. (2017); [8]: Gonçalves et al. (2017); [9]: Witter et al. (2016); [10]: Germano e Alonzo (2015); [11]: Mendes e Pereira (2017); [12]: Souza et al. (2014); [13]: Nunes et al. (2017); [14]: Vieira e Caveião (2016); [15]: Terres (2015); [16]: Paim e Muller (2015); [17]: Bochner e Freire (2020); [18]: Maior, Castro e Andrade (2020); [19]: Amorim, Mello e Siqueira (2017); [20]: Oliveira et al. (2017); [21]: Mathias, Guidoni e Girotto (2019); [22]: Da Silva, Souza e Aoyama (2020); [23]: Silva, Rodrigues e Comarella (2020); [24]: Brito e Suchara (2018); [25]: Rangel e Francelino (2018); [26]: Silva e Oliveira (2018); [27]: Silva, Fernandes e Terra Júnior (2018); [28]: Ferreira e Terra Júnior (2018).

Fonte: Autoria própria.

\section{DISCUSSค̃O}

Medicamentos são produtos químicos utilizados com a finalidade de diminuir ou tratar as manifestações clínicas das patologias que nos cercam, mas que se utilizados de forma indevida, podem ter consequências que causam riscos à saúde. De acordo com Brito e Suchara (2018), a interação destas substâncias com o organismo pode resultar em reações esperadas ou adversas, e quando em doses inadequadas, podem levar a intoxicações.

Os dados encontrados na Tabela 1 , justificam-se pelo fato de que a automedicação é facilitada pelo acesso de forma indiscriminada ao medicamento. Como afirma Vieira e Caveião (2016), o ato de um indivíduo utilizar medicamentos sem a prescrição e orientação médica, e o fato de poder se adquirir um medicamento sem prescrição, facilita que o indivíduo faça uso indevido do mesmo, ou seja, o utiliza por indicação própria seguindo um esquema posológico pessoal.

De acordo com a Tabela 1, a maioria dos trabalhos teve como objetivo analisar os dados provenientes de intoxicação por medicamentos, pois de acordo com Germano e Alonzo (2015), as exposições tóxicas a agentes químicos compreendem um importante problema de saúde pública, e os medicamentos são os principais responsáveis pelos casos de intoxicações. Além disso, Gonçalves et al. (2017) afirmam que as principais causas desse problema são o uso abusivo de medicamento decorrente à falta de conhecimento sobre a sua posologia e administração, erros de prescrição e a automedicação.

Em relação ao tipo de pesquisa, é possível observar pelo estudos de Silva, Souza e Aoyama (2020), Silva e Oliveira (2018), Silva, Fernandes e Terra Júnior (2018), Ferreira 
e Terra Júnior (2018), Paiva et al. (2017), Gonçalves et al. (2017), Witter et al. (2016), Terres (2015) e Paim e Muller (2015), que constam na Tabela 1, que muitos trabalhos associados à intoxicação de medicamentos são difíceis de avaliar pois muitas vezes esses trabalhos estão mais voltados para pesquisa de revisão de literatura. Observa-se também que a maioria das pesquisas foi feita durante o período de um ano pois grande parte dos trabalhos são revisão de literatura, e assim acabam abrangendo uma temporalidade maior.

Vários casos de uso de medicamentos que podem levar à intoxicação estão associados ao ambiente domiciliar, como se evidenciam nos trabalhos de Silva e Oliveira (2018), Paiva et al. (2017), Witter et al. (2016) e Brito e Martins (2015) (Tabela 1).

A intoxicação dentro do domicílio é um fator preponderante pois a maioria dos medicamentos é armazenada de forma errada. De acordo com Nunes et al. (2017), a maioria desses casos acontece no ambiente doméstico devido a existência das "farmácias caseiras", que acabam aumentando o risco de ingestão acidental de medicamentos, principalmente por crianças; onde ocorre também o armazenamento inadequado destes, por estarem vencidos e/ou serem utilizados por conta própria sem a orientação de um profissional habilitado.

Nota-se ainda na Tabela 1, que os maiores grupos de intoxicação são crianças e idosos, como foi demonstrado nos estudos de Maior, Castro e Andrade (2020), Silva e Oliveira (2018), Paiva et al. (2017), Gonçalves et al. (2017), Nunes et al. (2017), Oliveira et al. (2017), Amorim, Mello e Siqueira (2017), Mendes e Pereira (2017), Domingos et al. (2016), Witter et al. (2016), Paim e Muller (2015) e Souza et al. (2014).

Crianças e idosos são mais fáceis de favorecer a intoxicação, pois crianças acabam ingerindo acidentalmente e idosos por utilizar muitos medicamentos. Esta informação corrobora com o estudo de Vieira e Caveião (2016), pois muitas vezes os medicamentos de uso pessoal da família são estocados em locais de fácil acesso, e somado a isso temos a apresentação dos medicamentos que podem ser coloridos e alguns de sabor palatável que acabam chamando a atenção das crianças que podem vir a ingeri-los. Além disso, o estudo de Paiva et al. (2017) mostram que no período infantil os riscos são maiores devido ao fato das crianças apresentarem características que as tornam mais vulneráveis, não somente pela susceptibilidade de ingestão de fármacos, mas também pelas diferenças farmacocinéticas e farmacodinâmicas, como também a 
ausência do desenvolvimento de fármacos específicos para este grupo, pois pacientes pediátricos estão excluídos do processo de pesquisa clínica de novas medicações por questões legais, éticas e econômicas.

Em relação aos idosos, Silva, Souza e Aoyama (2020) afirmam que eles podem ser mais suscetíveis a resultados indesejáveis referentes à utilização de fármacos, devido principalmente às variações fisiológicas provocadas pelo avanço da idade, da mesma maneira que, as potenciais interações medicamentosas, podem elevar a chance de mortalidade do paciente e estão diretamente relacionadas às situações clínicas do indivíduo.

A maior parte dos óbitos atribuídos a irregularidade de uso de substâncias é considerada acidental, mas existem vários casos de intoxicação que não são acidentais, são voluntários para tentativa de suicídio, principalmente. Observa-se na Tabela 1, que várias pesquisas apontam isso, como se evidenciam nos trabalhos de Mathias, Guidoni e Girotto (2019), Vieira, Santana e Suchara (2015) e Germano e Alonzo (2015), que utilizaram substâncias psicotrópicas e ansiolíticas para tentativa de suicídio. A explicação dessa situação pode ser observado no estudo de Rangel e Francelino (2018), que afirmam que no período de transição entre a juventude e a fase adulta, surgem aflições com questões relacionadas à consolidação de vida. Existe a pressão da sociedade com cobranças de sucesso em todos os âmbitos, podendo ocasionar o desenvolvimento de transtornos mentais, que muitas vezes levam às tentativas de suicídio. Estas tentativas podem ocorrer pela ingestão de altas doses de medicamentos, causando intoxicações que podem levar a pessoa até mesmo à óbito. Além disso, no estudo de Mendes e Pereira (2017), se destaca a população feminina por apresentar o maior número de casos registrados de tentativa de suicídio como principal circunstância associada aos casos de intoxicação.

Observa-se na Tabela 1, pelos trabalhos de Takahama, Turini e Girotto (2014), Paiva et al. (2017), Da Silva, De Souza e Aoyama (2020), Terres (2015), Gonçalves et al. (2017), Germano e Alonzo (2015) e Witter et al. (2016), que os fármacos mais citados como causadores de intoxicação são paracetamol, amoxicilina e diazepam. De acordo com Paim e Muller (2015), as motivações para a automedicação estão muitas vezes relacionadas à busca de alívio de sintomas como resfriado, febre e dor, e os principais medicamentos utilizados são o paracetamol e a amoxicilina. Esta informação corrobora 
com o estudo de Terres (2015) que afirma que o paracetamol em doses corretas é eficaz e seguro, e o uso prolongado desta alta dose origina uma hepatotoxicidade. Além disso, Gonçalves et al. (2017) afirma que apesar dos medicamentos psicotrópicos serem de uso controlado, são registrados muitos casos de intoxicações, pelo fato de serem medicamentos de uso diário agravando cada vez mais as intoxicações por medicamentos no Brasil.

\section{COISIDERAÇÔES FInAIS}

A predisposição pela automedicação se dá pela facilidade em se adquirir medicamentos, assim como seu armazenamento de forma errada. Nota-se ainda a pressão da sociedade com cobranças de sucesso em todos os âmbitos da vida, e isso pode levar algumas pessoas ao desenvolvimento de transtornos mentais. Dessa forma, a população também precisa ser conscientizada dos riscos dos medicamentos, desde seu uso sem devidas prescrições médicas até o abuso intencional.

A disponibilidade de informação com base em dados sólidos e confiáveis é condição essencial para a análise objetiva da situação sanitária de qualquer localidade, assim como para a tomada de decisão baseada em indicadores e para a elaboração de condutas na saúde. O conhecimento do perfil de intoxicações por medicamentos poderá direcionar estratégias de controle e de implementação de assistência adequada ao uso incorreto e indiscriminado desses recursos terapêuticos.

\section{REFERÊกCIAS}

AMORIM, Maria Lucineide Porto; MELLO, Maria Júlia Gonçalves de; SIQUEIRA, Marília Teixeira de. Intoxicações em crianças e adolescentes notificados em um centro de toxicologia no nordeste do Brasil. Rev. Bras. Saúde Mater. Infant., Recife, v. 17, n. 4, p. 765-772, dez. 2017.

ARRUÉ WITTER, Álvaro et al. Intoxicação medicamentosa em crianças: uma revisão de literatura. Revinter, v. 9, n. 3, 2016.

BOCHNER, Rosany; FREIRE, Marina Moreira. Análise dos óbitos decorrentes de intoxicação ocorridos no Brasil de 2010 a 2015 com base no Sistema de Informação sobre Mortalidade (SIM). Ciênc. Saúde Coletiva, Rio de Janeiro, v. 25, n. 2, p. 761-772, fev. 2020. 
BRITO, Eidiane Lopes Barros; SUCHARA, Eliane Aparecida. Caracterização das intoxicações medicamentosas registradas em um hospital público. Revista Panorâmica online, v. 1, 2019.

BRITO, Jackeline Gonçalves; MARTINS, Christine Baccarat de Godoy. Intoxicação acidental na população infanto-juvenil em ambiente domiciliar: perfil dos atendimentos de emergência. Revista da Escola de Enfermagem da USP, v. 49, n. 3, p. 372-379, 2015.

DA SILVA, Jairton Clebison Soares; DE SOUZA, Francisco das Chagas Rodrígues; AOYAMA, Elisângela de Andrade. A incidência do uso indiscriminado de medicamentos. ReBIS-Revista Brasileira Interdisciplinar de Saúde, v. 2, n. 1, 2020.

DE OLIVEIRA SILVA, Julio Cesar; RODRIGUES, Giovana Melo; COMARELLA, Larissa. Análise do padrão temporal das características das intoxicações medicamentosas no Brasil nos anos de 2000 a 2016. Revista Artigos. Com, v. 15, p. e3048-e3048, 2020.

DE SOUZA, Thais Teles et al. Morbidade e mortalidade relacionadas a medicamentos no Brasil: revisão sistemática de estudos observacionais. Journal of Basic and Applied Pharmaceutical Sciences, v. 35, n. 4, 2014.

DOMINGOS, Samara Messias et al. Internações por intoxicação de crianças de zero a 14 anos em hospital de ensino no Sul do Brasil, 2006-2011. Epidemiologia e Serviços de Saúde, v. 25, p. 343-350, 2016.

FERREIRA, Rogério Lobo; TERRA JÚNIOR, André Tomaz. Estudo sobre a automedicação, o uso irracional de medicamentos e o papel do farmacêutico na sua prevenção. Revista Científica da Faculdade de Educação e Meio Ambiente, v. 9, n. edesp, p. 570-576, 2018.

GERMANO, Lucas Coraça; ALONZO, Herling Gregório Aguilar. Intoxicações e reações adversas a medicamentos: perfil local de subnotificação aos sistemas de informação em saúde. Revista Eletrônica de Farmácia, v. 12, n. 4, 2015.

GONÇALVES, Claudiana Aguilar et al. Intoxicação medicamentosa: relacionada ao uso indiscriminado de medicamentos. Revista Científica da Faculdade de Educação e Meio Ambiente, v. 8, n. 1, 135-143, jan-jun, 2017.

MAIOR, Marta da Cunha Lobo Souto; OSORIO-DE-CASTRO, Claudia Garcia Serpa; ANDRADE, Carla Lourenço Tavares de. Demografia, óbitos e indicadores de agravamento nas internações por intoxicações medicamentosas entre menores de 5 anos no Brasil. Rev. Bras. Epidemiol., Rio de Janeiro, v. 23, e200016, 2020.

MATHIAS, Thays Lopes; GUIDONI, Camilo Molino; GIROTTO, Edmarlon. Tendências de eventos toxicológicos relacionados a medicamentos atendidos por um Centro de 
Informações Toxicológicas. Revista Brasileira de epidemiologia, v. 22, p. e190018, 2019.

MENDES, Lucas Alves; PEREIRA, Boscolli Barbosa. Intoxicações por medicamentos no Brasil registradas pelo SINITOX entre 2007 e 2011. Journal of Health \& Biological Sciences, v. 5, n. 2, p. 165-170, 2017.

NUNES, Caroliny Ribeiro de Melo et al. Panoramas das intoxicações por medicamentos no Brasil. Revista e-ciência, 5(2): 98-103, 2017.

OLIVEIRA, Janessa de Fátima Morgado de et al. Tendência da mortalidade por intoxicação medicamentosa entre gêneros e faixas etárias no Estado de São Paulo, Brasil, 1996-2012. Ciência \& Saúde Coletiva, v. 22, p. 3381-3391, 2017.

PAIM, Roberta Soldatelli Pagno; MULLER, Ana Claudia. Uso de medicamentos em crianças sem prescrição médica: uma revisão de literatura. Varia ScientiaCiências da Saúde, v. 1, n. 2, p. 149-155, 2015.

PAIVA, Andriely et al. Impacto dos medicamentos nas intoxicações em crianças. Revista Ibirapuera, São Paulo, n. 13, p. 8-16, jan/jun 2017.

RANGEL, Nayara Landim; FRANCELINO, Eudiana Vale. Caracterização do Perfil das Intoxicações Medicamentosas no Brasil, durante 2013 a 2016. Id on Line Revista De Psicologia, v. 12, n. 42, p. 121-135, 2018.

SANDES, Valcieny de Souza et al. Fatores relacionados à utilização de flumazenil em pacientes hospitalizados. Revista de Enfermagem UERJ, p. 589-596, 2014.

SANTOS, Guidyan Anne Silva; BOING, Alexandra Crispim. Mortalidade e internações hospitalares por intoxicações e reações adversas a medicamentos no Brasil: análise de 2000 a 2014. Cad. Saúde Pública, Rio de Janeiro, v. 34, n. 6, e00100917, 2018.

SILVA, Eduardo Gomes; FERNANDES, Dione Rodrigues; TERRA JÚNIOR, André Tomaz. Uma abordagem ao uso indiscriminado de medicamentos benzodiazepínicos. Revista Científica da Faculdade de Educação e Meio Ambiente, v. 9, n. edesp, p. 610-614, 2018.

SILVA, Thiago José; OLIVEIRA, Vinícius Bednarczuk. Intoxicação medicamentosa infantil no Paraná. Visão Acadêmica, v. 19, n. 1, 2018.

TAKAHAMA, Carina Harumi; TURINI, Conceição Aparecida; GIROTTO, Edmarlon. Perfil das exposições a medicamentos por mulheres em idade reprodutiva atendidas por um Centro de Informações Toxicológicas. Ciência \& Saúde Coletiva, v. 19, p. 1191-1199, 2014.

TERRES, Daniele Refatti. Potencial toxicológico de medicamento de venda livre: ênfase no paracetamol. Facider Revista Científica, Colider, n. 08, 2015. 
VIEIRA, Daniel Malingre; CAVEIÃO, Cristiano. Perfil das intoxicações medicamentosas no estado de São Paulo na perspectiva da vigilância sanitária. Revista Saúde e Desenvolvimento, v. 9, n. 5, jan/jun. 2016.

VIEIRA, Letícia Pereira; SANTANA, Vivian Tallita Pinheiro de; SUCHARA, Eliane Aparecida. Caracterização de tentativas de suicídios por substâncias exógenas. Cad. Saúde Colet., Rio de Janeiro, v. 23, n. 2, p. 118-123, jun. 2015. 


\title{
CAPÍTULO XXVI
}

\section{RESILIÊRCIA DA EQUUIPE DE ENFERTIAGET DIATTE DO PACIERTE ONCOLÓGICO PALIATIUO}

\author{
DDI: 10.51859/AMPLLA.APS276.1121-26
}

\author{
Wanuska Munique Portugal ${ }^{1}$ \\ Camila Alexandre De Araújo ${ }^{2}$ \\ Frederico Da Silva Barros ${ }^{2}$ \\ Luana Cristina Gabym Ferreira Da Silva ${ }^{2}$ \\ Raiza Rafaela Dos Santos Cruz ${ }^{2}$ \\ Giselda Bezerra Correia Neves ${ }^{3}$
}

\footnotetext{
${ }^{1}$ Coordenadora do curso de enfermagem do Centro Universitário Brasileiro - UNIBRA

2 Docentes do curso de enfermagem do Centro Universitário Brasileiro - UNIBRA

${ }^{3}$ Docente do curso de enfermagem do Centro Universitário Brasileiro - UNIBRA
}

\section{RESUITO}

Introdução: O câncer é considerado atualmente uma das mais graves doenças que pode acometer o ser humano, estando relacionado à possibilidade de morte. Objetivo: Descrever as atitudes resilientes da equipe de enfermagem perante as dificuldades vivenciadas por seus pacientes oncológicos paliativos. Metodologia: Trata-se de uma revisão integrativa de literatura, nas bases de dados da Literatura Latino americanae do Caribe em Ciências da Saúde (LILACS), Scientific Eletronic Libray Online (SciELO) e Banco de Dados em Enfermagem (BDENF), por meio das seguintes palavras-chave: Oncologia. Resiliência Pisicológica. Enfermeiro. Resultados e discussão: A equipe de Enfermagem é fundamental não só nas necessidades clínicas, mas também como conforto e suporte psicossocial, com todo conhecimento e habilidade técnica podendo assistir o paciente por inteiro. Apesar deexperimentar sentimentos de negação no cuidado do paciente paliativo por não conseguir fazer mais do que o necessário para salvar aquela vida sabendo que não haveria mais tratamento possível, a dedicação e o cuidado permanecem proporcionando conforto até o último dia. Conclusão: Embora a morte seja algo natural enfrenta-la todos os dias é uma tarefa difícil, manter a saúde mental é essencial para criar resiliência e se sentir a dor do outro e o mais apropriado nesta fase paliativa.

Palavras-chave: Oncologia. Resiliência Pisicológica. Enfermeiro.

\section{IกTRODUÇก̃O}

Câncer é o nome dado a um conjunto de mais de 100 doenças que têm em comum o crescimento desordenado de células, que invadem tecidos e órgãos. Dividindo-se rapidamente, estas células tendem a ser muito agressivas e incontroláveis, 
determinando a formação de tumores, que podem espalhar-se para outras regiões do corpo (INCA, 2019).

É considerado um problema de saúde pública e, na última década, o Brasil vem apresentando uma pequena queda na sua taxa de mortalidade por câncer. De 2003 a 2012, a variação anual das mortes relacionadas ao câncer entre homens caiu de 0,53\% e entre mulheres 0,37\% (BRASIL, 2019).

Existem os exames de rastreamento que podem ser realizados para alguns tipos de câncer, para que possa ser realizado o diagnóstico precoce da doença, tornando as chances de cura maiores do que quando é diagnosticada em estágios avançados. Milhões de pessoasas vivem atualmente com câncer ou curadas do mesmo.O risco de desenvolver vários tipos de neoplasias pode ser reduzido com mudanças no estilo de vida, por exemplo, não fumar, limitar o tempo de exposição ao sol, praticarexercícios físicos e manter uma alimentação saudável (INCA, 2019).

Os pacientes oncológicos podem apresentar sinais e sintomas, bem como: dor, fadiga, falta de apetite, febre (geralmente acontece com a disseminação da doença), náuseas e vômitos, edema, constipação intestinal. A maioria perderá peso em algum momento do desenvolvimento da doença (BRASIL, 2019).

Contudo, diante da magnitude do câncer e da possibilidade de alguns pacientes evoluírem para estágios terapeuticamente incontroláveis, é necessário identificar fatores que possam estar associados à melhora ou a piora de sua qualidade de vida (BRASIL, 2019).

$\mathrm{Na}$ fase final, em que o paciente tem pouco tempo de vida, pode ser oferecido o tratamento paliativo, o qual é voltado para qualidade de vida e controle dos sintomas, alívio do sofrimento humano (FROSSARD, 2018).

A abordagem paliativa visa promover qualidade aos dias de vida do paciente crônico, sem possibilidades terapêuticas, por meio de alívio da dor e de seu sofrimento biológico, psicológico. Trata-se de um tratamento humanizado, empregado desde o diagnóstico quando se encontra na sua fase avançada e progressiva. Deste modo cabe a equipe assistir o paciente e seus familiares, uma vez que participa diretamentedo seu processo de tratamento e encontra-se presente na sua fase terminal (SANTOS, 2017) 
O enfermeiro ocupa um lugar importante no dia a dia da desse processo terapêutico, sendo importante para o controle do medo, fragilidade, angústias e dificuldades encontradas na experiência da internação promovendo suporte psicossocial e conforto, é um profissional acessível para conversar e esclarecer dúvidas, na maioria das vezes é reconhecido como principal elo entre os membros daequipe. Para essa boa convivência é imprescindível que tenham um posicionamento diante da vida, dor e sofrimento do outro. Acredita-se que os cuidados da enfermagem nessa determinada fase da vida, deverão ser realizados de maneira humanizada, trazendo ao paciente e sua família consolo diante dessa situação agressiva e avassaladora que vivenciam (CRUZ; ROSSATO., 2015).

Desta forma a relevância da pesquisa está no fato de que o profissional de enfermagem está mais próximo do paciente e da família, como é o elo entre família e paciente precisa ser resiliente em prol do bem estar e do processo de aceitação de diagnóstico, com conhecimento e técnica principalmente na fase terminal onde se encontra fragilizado.Esse cuidado pressupõe em conhecer não só a patologia, mas saber lidar com os sentimentos dos outros, como com suas próprias emoções perante a doença, com ousem possibilidade de cura. Neste contexto, é fundamental uma atenção ao suporte emocional e social tanto para o doente como para família, para que ambos enfrentemesse processo com mais tranquilidade e dignidade, deixando de encarar a morte comoum fato desastroso (QUADROS, 2018).

Surge então a questão desta pesquisa, de que forma a resiliência da equipe de enfermagem influência no tratamento do paciente oncológico terminal? O pressuposto é que a resiliência da equipe de enfermagem na assistência aospacientes terminais é fundamental para compreensão e aceitação do diagnóstico, encontrando-se capacitados para identificarem situações de risco e tomarem medidasnecessárias. Sendo assim o objetivo deste estudo é descrever as atitudes resilientes da equipe de enfermagem perante as dificuldades vivenciadas por seus pacientes oncológicos terminais. 


\section{REFERERCIAL TEÓRICO}

\subsection{Câncer}

As células normais de um ser vivo em seu organismo se comportam em constante equilíbrio em seu meio. O crescimento celular dar-se de forma ordenada, dependente de fatores estimulantes e inibidores, que atuam na ativação da multiplicação celular que controlam sua função (INCA, 2019).

A carcinogênese é desenvolvimento de tumores malignos, que quebram o mecanismo de controle, a célula começa a se multiplicar desordenadamente. Resultando na formação de células defeituosas, anômalas que atacam o seu próprio sistema (INCA, 2019).

Resiliência da equipe de enfermagem ou adaptação da enfermagem diante ao paciente oncológico. Ou Afinal, o que é resiliência?

Pode-se falar que a resiliência: pertence à família dos mecanismos de defesa;(...) poderíamos exemplificar como uma "mola" ou "tecido". "Mola" porque, ao recebero impacto da adversidade a pessoa sofre e de certa maneira deforma-se, como a mola ao receber uma força: quando a mola é presa a um peso, por exemplo, ela estica, mas depois volta e depois supera o sofrimento, salta superando o fator que ameaça a pessoa. "Tecido' porque se configura no espaço entre a pessoa e seu entorno social, especialmente as pessoas significativas, com quem é possível estabelecer uma relação de apego seguro, como um mosaico" (QUADROS, 2018).

A palavra resiliência origina-se do latim (Resiliens) que significa "ser elástico" e têm diversas interpretações para diferentes campos de conhecimento, oportunos de resgatar na reflexão sobre o trabalho em saúde. Resiliência é um conceito fácil de entender, mas que apresenta dificuldade de precisão e, ainda mais, complicado de medir ou calcular com exatidão. É um tema muito visível no cotidiano, mas é preciso ter cautela para lidar com ele, principalmente quando se pretende fazer o uso no modode sentir e reagir das pessoas" (QUADROS, 2018).

Um dos conceitos da resiliência é a capacidade de voltar rapidamente para seu usual estado de saúde ou de espírito depois de passar por doenças ou dificuldades. A resiliência vem sendo estudada por diversos autores desde os meados da década de 1960 e início de 1970. Nesses estudos os autores buscam identificar fatores que 
pudessem auxiliar as pessoas a se manterem num processo saudável em meio às adversidades (NUNES et al., 2020).

O estudo da resiliência humana passou a ser explorado também nas ciências humanas e sociais. Por volta dos anos de 1966 o termo foi utilizado para descrever as "forças" psicológicas e biológicas que são mobilizadas para atravessar com êxito mudanças na vida das pessoas. Diante dessa abordagem, um indivíduo resiliente, teria a habilidade para reconhecer a dor e as situações que a produzem, constituir umsentido para essa situação e tolerá-la até o momento da resolução das condições que o mobilizam, de uma forma construtiva, com transformações favoráveis ao seu desenvolvimento (NUNES et al., 2020).

Com base nesses estudos a resiliência tem sido aprofundada na enfermagem, bem como em outras áreas do saber, com foco na compreensão do estabelecimentoda relação entre os fatores de risco, vulnerabilidade e de fatores de proteção inerentesao indivíduo e ao ambiente, frente às situações do cotidiano. Então é necessário oferecer uma abordagem educativa aos profissionais de saúde para que possam lidarcom esses pacientes em situações graves ou mesmo a formação de especialistas para o trabalho de promoção de saúde comunitária, considerando que a resiliência e seus fatores de proteção sejam passíveis de aprendizagem e têm efeitos singulares em cada pessoa ou grupo (NUNES et al, 2020).

Essa capacidade para enfrentar questões postas no local de trabalho em situações específicas precisa estar inclusa na formação dos profissionais de saúde no cotidiano do trabalho e como educação permanente em saúde, assim deixando os profissionais com abordagens mais amplas com relação a cultura sobre a morte e do morrer, no intuito de diminuir o sofrimento dos trabalhadores em dimensões cognitivase afetivas, seja em qualquer área da saúde e principalmente na oncológica (NUNES et al., 2020).

\subsection{Cuidados Paliativos e Cuidados no Fim da Vida}

Como parte integrante nos cuidados com o paciente oncológico tem o de suma importância, cuidados paliativos e cuidados no fim da vida. É preciso destacar a importância dos conceitos de prevenção e alívio do sofrimento humano em cuidados paliativos. De modo que ressalte o estudo promovido pela OMS em conjunto com a 
World Hospice Care Alliance, que define os objetivos dos cuidados paliativos, sejam eles: prevenir e aliviar o sofrimento humano nas dimensões física, psicológica, social e espiritual, em adultos ou em crianças com diferentes graus de comprometimento relacionados à saúde (crônicos, graves, complexos e limitantes). Esse estudo defendeuma visão de cuidados baseado em evidências, visando o aumento da qualidade de vida. A promoção entendida na perspectiva do respeito à dignidade humana. Ganhando centralidade no processo de vida das pessoas alinhando-se às doenças progressivas (MARKUS et al., 2017).

O modelo assistencial humanizado promove $\mathrm{o}$ atendimento às necessidades de usuários fora de possibilidades de cura buscando ofertar cuidados individualizados, assistindo tanto para quem precisa ser hospitalizado e para aqueles inseridos em programas de cuidados paliativos nas unidades de atenção primária ou em assistência domiciliar, com especial atenção aos seus desejos e escolhas (FRANCO et al., 2017).

Os cuidados paliativos devem ser ofertados para os pacientes desde o início da descoberta da doença até sua fase final, em conjunto com outras terapias destinadas a prolongar a vida do mesmo, como a quimioterapia e a radioterapia, e inclui as investigações necessárias para entender e controlar melhor as complicaçõesclínicas dolorosas. Já nos cuidados do FIM DA VIDA (CFV) da ênfase às providências tomadas nas últimas horas de vida, em que o paciente se encontra em estado de declínio progressivo e inexorável (FRANCO et al., 2017).

Deste modo os cuidados do fim da vida são de suma importância dentro dos cuidados paliativos, é o que assiste ao paciente a receber os cuidados durante a última etapa de sua vida (fase de terminalidade), ao se aproximar da finitude (NASCIMENTO; SANTOS, 2019).

É um momento muito delicado para quem está partindo, assim como para sua famíliae profissionais que o acompanham. Exige uma grande habilidade da equipe de multiprofissionais, uma vez em que todas as dimensões são contempladas, uma boa comunicação, prestação de cuidados individualizados e continuados e consequentemente, com a promoção da qualidade de vida. Uma vez que a maior preocupação e centro de atenção tem que ser dada ao paciente, levando em conta seus valores e preferências e que a dignidade e autonomia em questões do pacientesejam preservada (NASCIMENTO; SANTOS, 2019). 


\section{3. mÉTODO}

Trata-se de uma revisão integrativa da literatura, desenvolvida em seis etapas: elaboração da pergunta norteadora, busca na literatura, extração dos dados, avaliação dos estudos encontrados, análise e síntese dos resultados e, por último, a apresentação do trabalho final (MOHER ET AL., 2009). Para condução do estudo, formulou-se a seguinte questão de pesquisa: : Como a resiliência da equipe de enfermagem pode influenciar no tratamento do paciente oncológico paliativo? As buscas foram realizadas entre os meses de Agosto a Novembro de 2020, nas bases de dados da biblioteca virtual de saúde Ciências da Saúde (LILACS), Scientific Eletronic Libray Online (SciELO) e Banco de Dados em Enfermagem (BDENF), Utilizando dois descritores indexados Oncologia. Resiliência Pisicológica. Enfermeiro, com cruzamentos pelo operador booleano 'AND'. Consideraram-se, como critérios de inclusão: artigos originais em português com textos completos e abertos. Adotou-se, também, com critérios de exclusão os artigos nos idiomas inglês e Espanhol com mais de 5 anos de publicação, encontrados um total de 630 artigos. Aplicados os demais critérios de inclusão e exclusão ficando contabilizado um total de 08 artigos os quais estão descritos nos resultados e discussões. 0 procedimento efetuado está descrito na Tabela 1.

Tabela 1 - Composição do escopo

\begin{tabular}{cllc}
\hline ASE DEDADOS & $\begin{array}{l}\text { o de Artigos } \\
\text { encontrados }\end{array}$ & $\begin{array}{l}\text { № de Artigos excluídos } \\
\text { nforme critérios de inclusão e } \\
\text { exclusão }\end{array}$ & $\begin{array}{c}\text { № de Artigos } \\
\text { selecionados para estar } \\
\text { pesquisa }\end{array}$ \\
\hline SciELO & 282 & 622 & 08 \\
BDENF & 118 & & \\
LILACS & 230 & & \\
TOTAL & 630 & & \\
\hline
\end{tabular}

Fonte: Autoria própria.

\section{RESULTADOS E DISCUSSÃO}

Os resultado foram apresentados em fomato de quadro. O instrumento utilizado para analisar os artigos incluídos foi composto por: Autor / Anode publicação, Título, Objetivos e Principais Achados. 
Quadro 1-Resultados

\begin{tabular}{|c|c|c|c|}
\hline $\begin{array}{c}\text { Autor/ Ano de } \\
\text { publicação }\end{array}$ & Título & Objetivo & Principais achados \\
\hline $\begin{array}{l}\text { 1-Franco et al., } \\
2017\end{array}$ & $\begin{array}{l}\text { Papel da enfermagem na } \\
\text { equipe de cuidados } \\
\text { paliativos: a humanização } \\
\text { no processo da morte e } \\
\text { morrer }\end{array}$ & $\begin{array}{l}\text { Estabelecer o papel } \\
\text { do enfermeiro na } \\
\text { execução de Cuidados } \\
\text { Paliativos }\end{array}$ & $\begin{array}{l}\text { Está pesquisa identificou que: a } \\
\text { Enfermagem é responsável pelas } \\
\text { necessidades fisiológicas, psicossociais, } \\
\text { espirituais, afetuosas }\end{array}$ \\
\hline $\begin{array}{l}\text { 2-Silva et al., } \\
2020\end{array}$ & $\begin{array}{l}\text { Assistência de } \\
\text { enfermagem a pacientes } \\
\text { com câncer em cuidados } \\
\text { paliativos: revisão } \\
\text { integrativa }\end{array}$ & $\begin{array}{l}\text { Identificar na } \\
\text { literatura quais são as } \\
\text { evidências científicas } \\
\text { sobre os cuidados } \\
\text { paliativos realizados } \\
\text { pelos enfermeiros ao } \\
\text { paciente com câncer. }\end{array}$ & $\begin{array}{l}\text { O enfermeiro precisa ter } \\
\text { conhecimentos para assistir de forma } \\
\text { integral ao paciente com câncer sobre } \\
\text { cuidados paliativos apto/capacitado } \\
\text { para abordar, avaliar e cuidar com o } \\
\text { intuito de garantir uma assistência de } \\
\text { qualidade e efetiva ao paciente } \\
\end{array}$ \\
\hline $\begin{array}{l}\text { 3-Oliveira et } \\
\text { al., } 2020\end{array}$ & $\begin{array}{l}\text { Enfermeiros na } \\
\text { Assistência ao Paciente } \\
\text { em Cuidados Paliativos: } \\
\text { Uma revisão integrativa }\end{array}$ & $\begin{array}{l}\text { Realizar uma revisão } \\
\text { integrativa sobre o } \\
\text { sentimento dos } \\
\text { enfermeiros na } \\
\text { assistência ao } \\
\text { paciente em cuidados } \\
\text { paliativos. }\end{array}$ & $\begin{array}{l}\text { O sentimento gerado No profissional } \\
\text { É uma sensação de incapacidade, de } \\
\text { tristeza e frustação por não conseguir } \\
\text { fazer mais do que o necessário para } \\
\text { salvar aquela vida }\end{array}$ \\
\hline $\begin{array}{l}\text { 4-Santos et al., } \\
2017\end{array}$ & $\begin{array}{l}\text { Planejamento da } \\
\text { assistência ao paciente } \\
\text { em cuidados paliativos na } \\
\text { terapia intensiva } \\
\text { oncológica }\end{array}$ & $\begin{array}{l}\text { Analisar o } \\
\text { entendimento dos } \\
\text { profissionais de saúde } \\
\text { acerca da assistência } \\
\text { ao paciente em } \\
\text { cuidados ao fim da } \\
\text { vida na unidade de } \\
\text { terapia intensiva (UTI) } \\
\text { oncológica. }\end{array}$ & $\begin{array}{l}\text { Acostumar-se de uma certa forma com } \\
\text { o processo de morte e tendo que usar } \\
\text { da resiliência para lidar com essas } \\
\text { adversidades no local de trabalho que } \\
\text { tanto afetam o emocional. }\end{array}$ \\
\hline $\begin{array}{l}\text { 5-Magalhães } \\
\text { et al., } 2018\end{array}$ & $\begin{array}{l}\text { Assistência do enfermeiro } \\
\text { ao paciente oncológico } \\
\text { adulto fora de } \\
\text { possibilidade terapêutica }\end{array}$ & $\begin{array}{l}\text { Identificar a } \\
\text { importância das ações } \\
\text { de enfermagem nos } \\
\text { cuidados paliativos a } \\
\text { pacientes oncológicos } \\
\text { adultos internados na } \\
\text { UTI. }\end{array}$ & $\begin{array}{l}\text { O enfermeiro é o profissional de mais } \\
\text { acessibilidade ao paciente, buscando } \\
\text { ser um conforto na superação do } \\
\text { diagnóstico apresentado, no dia a dia } \\
\text { buscando e desenvolvendo ações de } \\
\text { acolhimento e bem estar do paciente. }\end{array}$ \\
\hline $\begin{array}{l}\text { 6-Melo et al., } \\
2020\end{array}$ & $\begin{array}{l}\text { Resiliência da equipe de } \\
\text { enfermagem diante do } \\
\text { paciente oncológico } \\
\text { terminal }\end{array}$ & $\begin{array}{l}\text { Identificar a resiliência } \\
\text { nos profissionais de } \\
\text { enfermagem que } \\
\text { lidam com frequência } \\
\text { com pacientes que } \\
\text { estão em fase } \\
\text { terminal de câncer. }\end{array}$ & $\begin{array}{l}\text { Manter a saúde mental é o fundamento } \\
\text { para criar resiliência emocional, na qual } \\
\text { o profissional vai condicionar a mente a } \\
\text { tolerar os pensamentos e consegue } \\
\text { esquivar-se do sofrimento ao entender } \\
\text { que a dor fará, inevitavelmente, parte } \\
\text { da trajetória de vida conseguindo } \\
\text { atingir uma percepção de possíveis } \\
\text { fatores de risco e proteção presentes } \\
\text { no cotidiano da equipe de } \\
\text { enfermagem. }\end{array}$ \\
\hline $\begin{array}{l}\text { 7-Markus et } \\
\text { al., } 2017\end{array}$ & $\begin{array}{l}\text { A atuação do enfermeiro } \\
\text { na assistência ao paciente } \\
\text { em cuidados paliativos }\end{array}$ & $\begin{array}{l}\text { Investigar a atuação } \\
\text { do enfermeiro na } \\
\text { assistência ao } \\
\text { paciente em Cuidados } \\
\text { Paliativos. }\end{array}$ & $\begin{array}{l}\text { Percebe-se a preocupação em realizar } \\
\text { cuidados com qualidade, respeito e } \\
\text { humanização, construindo uma relação } \\
\text { de confiança. A atuação do enfermeiro } \\
\text { na assistência ao paciente em cuidados } \\
\text { paliativos é extremamente relevante, } \\
\text { principalmente pela equipe de }\end{array}$ \\
\hline
\end{tabular}




\begin{tabular}{|l|l|l|l|} 
& & & $\begin{array}{l}\text { enfermagem que permanece ao lado } \\
\text { do paciente paliativa do em tempo } \\
\text { integral. }\end{array}$ \\
\hline \multirow{3}{*}{$\begin{array}{l}\text { 8-Nunes et al., } \\
2019\end{array}$} & $\begin{array}{l}\text { O cuidado da alma no } \\
\text { contexto hospitalar de } \\
\text { enfermagem: uma análise } \\
\text { fundamentada no Cuidado } \\
\text { Transpessoal }\end{array}$ & $\begin{array}{l}\text { Desvelar a } \\
\text { espiritualidade no } \\
\text { processo de cuidado } \\
\text { dos profissionais de } \\
\text { enfermagem no } \\
\text { contexto hospitalar } \\
\text { sob as lentes do } \\
\text { Cuidado Transpessoal }\end{array}$ & $\begin{array}{l}\text { Destacam-se, como dispositivos } \\
\text { oportunos a Sistematização da } \\
\text { Assistência Espiritual de Enfermagem e } \\
\text { o Cuidado Transpessoal, os quais } \\
\text { fornecem subsídios consistentes ao } \\
\text { empreendimento do cuidado espiritual. }\end{array}$ \\
\hline
\end{tabular}

Fonte: Autoria própria.

\section{DISCUSSค̃O}

Meireles et al. (2020) destaca que o enfermeiro é o profissional responsável pelo cuidado direto, porque permanece mais tempo próximo ao paciente, com isso, é atribuição deste profissional realizar a assistência que auxilie no controle da dor, garantindo a este paciente o alívio da dor, permitindo assim uma melhor qualidade de vida.

Franco et al. (2017) demonstra que para os cuidados paliativos são o oposto da medicina terapêutica tradicional, onde o cuidado paliativo enfoca o cuidado integral, por meio do controle dos sintomas diante de pacientes portadores de doenças crônicas e graves. Esse conceito se aplica, tanto ao paciente como para seus entes próximos, que adoece e sofre junto.

Silva et al. (2020) aponta que o profissional de enfermagem, em sua função, deve implementar a sua assistência de forma a impulsionar o paciente a manter umavida ativa, preservando a capacidade de realizar as suas atividades diárias, com a intenção de dar autonomia ao paciente em cuidados paliativos, diminuindo a sua incapacidade e independência

Oliveira et al. (2020) existem sensações que estão ligadas a questões éticas elegais vivenciadas pela equipe de saúde e pelos pacientes em relação até onde deveser estabelecido o tratamento e em que nível este deve ser realizado, posto não haver conceito único e universal de qualidade de vida, mas sim um conceito pessoal que varia entre indivíduos. Percebe-se que existem barreiras para encontrar o melhor momento para abordar junto aos pacientes e parentes, o emprego ou não de condutas, que 
incluem a adoção e/ou retirada de medidas de suporte de vida, ordemde não reanimar, interrupção de tratamento fútil, suspensão de cuidados ordinários ouextraordinários.

Melo et al. (2020) relata que um outro ponto a se destacar, é o déficit de profissionais, especificamente de enfermeiros, a sobrecarga de trabalho passa a ser uma consequência previsível, e estes acabam, a cargo de suas múltiplas atribuições, dispensando maior tempo com as atividades administrativas, que lhes são privativas, em sua maioria. Tais atividades distanciam os enfermeiros do cuidado direto, devidoao tempo que demandam para execução, sendo este mais um fator restritivo na prática junto às pessoas em cuidados paliativos oncológicos.

\section{COחSIDERAÇÔES FIחAIS}

No momento da terminalidade da vida do paciente oncológico, todos os esforços em busca da melhoria para o paciente e familiares. Portanto, ai está a grande opulência para o trabalho da equipe de enfermagem, na qual servir das palavras às atitudes humanizadas. Para o desenvolvimento de propostas que envolvem a resiliência da equipe de enfermagem diante do paciente oncológico paliativo, enfocam sua estrutura, não apenas aspectos técnicos, mas também aspectos humanos.Embora a morte seja descrita como natural e inevitável, falar sobre ela e enfrentá-la todos os dias não é uma tarefa fácil, para a equipe de enfermagem, contudo, é possível dialogar com respeito à dor do outro que ver a partir seu ente amado. Por isso, o que atendimento que promove a resiliência é por certo apropriado para está fase da vida.

\section{REFERÊRCIAS}

BRASIL, Ministério da Saúde. Como tratar o Câncer. Brasília, DF. Ministério da Saúde. Disponível em https://saude.gov.br/. Acesso em 03 de Março de 2021.

BRASIL, Instituto Nacional de Câncer - INCA. O que é Câncer. Rio de Janeiro, RJ. Insituto Nacional de Câncer Disponível em https://www.inca.gov.br/. Acesso em 03 de Março de 2021.

CRUZ, F.S; ROSSATO, L.G. Cuidados com o paciente oncológico em tratamento quimioterápico: o Conhecimento dos enfermeiros da estratégia saúde da família. Rev. Bras. de Cancerologia. Rio de Janeiro, RJ. v. 61, n. 4, p. 335-341, 2015. 
FRANCO, H.C.P; STIGAR, R; SOUZA, S.J.P. Papel da enfermagem na equipe de cuidados paliativos: a humanização no processo da morte e morrer. Rev Gestão\&Saúde. Brasília, DF, 17, n. 2, p. 48-61, 2017.

MAGALHÃES, R.R.P; PINHO, L.SF; VELASCO, E.S. Assistência do Enfermeiroao Paciente Oncológico Adulto Fora de Possibilidade Terapêutica. Biológicas \& Saúde. Campo dos Goytacazes, RJ. v. 8, n. 27, 2018.

MARKUS, L.A; BETIOLLI, S.E; SOUZA, S.J.P. A Atuação Do Enfermeiro Na Assistência Ao Paciente Em Cuidados Paliativos. Rev. Gestão\&Saúde. Rio de Janeiro, RJ. v. 71, n. 81, 2017.

MEIRELES, D.S; BITTENCOURT, G.K.G.C; MONTENEGRO, C.P.D. Assistência de enfermagem ao idoso em cuidados paliativos: um relato de experiência. Brazilian Journal of Development. Paraná, PA, v. 6, n. 6, p. 40854-40867, 2020.

MELO, A. A; OLIVEIRA, A.A; SILVA, A.P.J. Resiliência da equipe de enfermagem diante do paciente oncológico terminal. Rev. Bras. Interd. De Saúde. Brasília, DF, v.2, n. 1, p. 59-64, 2020.

NASCIMENTO, E.B.B; SANTOS, L.C. Qualidade de Vida dos Profissionais de Enfermagem que Atuam Em UTI: uma revisão bibliográfica. Revista Artigos. Com. São Paulo, SP, v.2, p. e1200-e1200, 2019.

NUNES, E.C.D.A; SANTOS, H.S; DUTRA, G.A. O cuidado da alma no contextohospitalar de enfermagem: uma análise fundamentada no Cuidado Transpessoal. Revista da Escola de Enfermagem da USP. São Paulo, SP. v. 54, 2020.

OLIVEIRA, A.P.R; FERREIRA, L.P; QUADRO, A. Sentimentos de Enfermeiros na Assistência ao Paciente em Cuidados Paliativos: Uma revisão integrativa. Brazilian Journal of Development. Paraná, PA, v. 6, n. 8, p. 63874-63890, 2020.

QUADROS, A. Resiliência no trabalho de enfermeiros em serviços de atenção oncológica: o desafio de desenvolver capacidades profissionais. Saúde em Redes, v.4, n. 2, p. 129-142, 2018.

SANTOS, D.C.L; SILVA, M.M; MOREIRA, M.C. Planejamento da assistência aopaciente em cuidados paliativos na terapia intensiva oncológica. Acta Paulista de Enfermagem. São Paulo, SP, v. 30, n. 3, p. 295-300, 2017.

SILVA, F.C.F; CUNHA, C.S; FEITOSA, T.S.R.G.T. Assistência de enfermagem a pacientes com câncer em cuidados paliativos: Revisão integrativa. Revista Enfermagem Atual In Derme, v. 91, n. 29, 2020.

SILVEIRA, N.R; NASCIMENTO, E.R.P; ROSA, L.M. et. al. Cuidado paliativo e enfermeiros de terapia intensiva: sentimentos que ficam. Revista Brasileira de Enfermagem, v. 69 , n. 6, p. 1074-1081, 2016. 


\title{
CAPITULO XXVII
}

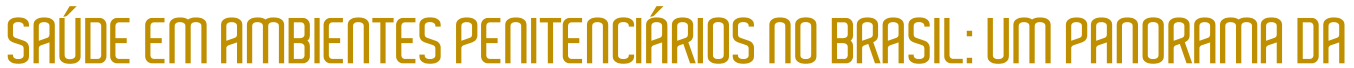

\section{ESTRUTURA FÍSICA E COMPOSIÇÃO}

\author{
DDI: 10.51859/AMPLLA.APS276.1121-27
}

\author{
Lara Kamylli Felismino Chagas ${ }^{1}$ \\ Lúcia Magnólia Albuquerque Soares de Camargo ${ }^{2}$
}

${ }^{1}$ Enfermeira. UNIFACISA.

${ }^{2}$ Mestre em Saúde Coletiva. Esp. em Gestão em Saúde e Adm. Hospitalar; e em Saúde Pública. Docente UNIFACISA.

\section{RESUMO}

As formulações específicas para a saúde da população penitenciária foram instauradas com o Plano Nacional de Saúde do Sistema Penitenciário pela Portaria Interministerial, e pela Política Nacional de Atenção Integral à Saúde das Pessoas Privadas de Liberdade no Sistema Prisional. Mesmo com políticas consolidadas, a realidade desses ambientes é altamente precária, com estruturas danificadas, úmidas, sem iluminação adequada e superlotadas. Deste modo objetivou-se investigar a estrutura física e composição profissional de saúde em ambientes penitenciários nacionais, e examinar os tipos de patologias acometidas pela população privada de liberdade e as suas causas de óbito. $O$ estudo realizado foi do tipo descritivo, com base nas informações estruturais e profissionais dos ambientes de saúde em penitenciárias brasileiras. Utilizando os dados de estrutura física de ambiente do saúde em geral, estrutura física de ambiente de maternidade, composição da equipe profissional de saúde da maternidade, número de profissionais de equipes em geral, procedimentos de saúde realizados, patologias da população em questão, e causas dos óbitos, nos ambientes penitenciários brasileiros, disponibilizados abertamente no Sistema de informações estatísticas do sistema penitenciário do Departamento Penitenciário Nacional, coletados em agosto de 2020. Concluiu-se que, a saúde das pessoas privadas de liberdade não estão preservadas, tampouco promovidas, sendo notória a incompatibilidade dos cenários descritos a depender da fonte manuseada, no tocante à patologias condicionadas a esta população. A composição profissional é desfalcada e simplista, suas ações não são pautadas em prevenção, cuidado e qualidade em saúde, apenas é realizado um modelo curativista precário.

Palavras-chave: Políticas Públicas de Saúde. População Privada de Liberdade. Penitenciárias. 


\section{IกTRODUÇÃO}

As legislações que abrangem a saúde da pessoa privada de liberdade reverberam desde a década de 80 com a Lei de Execução Penal no 7.210 de 11 de Julho de 1984 (BRASIL, 1984) e a Constituição Federal de 1988, que estabelece como o dever do Estado a garantia aos indivíduos o direito à saúde (BRASIL, 1988). A partir do ano de 2003 formulações específicas para a saúde da população penitenciária foram instauradas, como o Plano Nacional de Saúde do Sistema Penitenciário pela Portaria Interministerial no 1.777/2003 (BRASIL, 2003), e uma década após, com a Política Nacional de Atenção Integral à Saúde das Pessoas Privadas de Liberdade no Sistema Prisional - PNAISP, instituída pela Portaria interministerial no 1, de 02 de Janeiro de 2014 (BRASIL, 2014).

Na busca pela garantia de um direito básico como a saúde, entre as legislações é possível observar a extensiva evolução entre a Lei de Execução Penal e a PNAISP. A primeira designa à penitenciária a responsabilidade das ações de saúde para com o encarcerado, enquanto a PNAISP, globaliza a competência do cuidado às pessoas em situação de privação de liberdade, de forma que o indivíduo é inserido na Rede de Atenção à Saúde - RAS do Sistema Único de Saúde - SUS, prisionais torna-se porta de entrada e ponto de atenção, fazendo parte do ordenamento, o referenciamento em saúde pelas equipes de Atenção Básica Prisional - eABP, que é organizadora de ações promoção da saúde, prevenção de agravos, tratamento atendendo de acordo com os princípios do SUS (BRASIL, 2014).

Mesmo com políticas consolidadas, a realidade dos ambientes que comportam pessoas em privação de liberdade é altamente precária, com estruturas danificadas, úmidas, sem iluminação adequada e superlotadas (FILHO, et al., 2015). Com dados de 2019, o sistema carcerário brasileiro possui um déficit de 312,925 mil vagas, sendo uma população $70 \%$ maior que o ideal para a estrutura penitenciária. De acordo com o Departamento Penitenciário Nacional - DEPEN, esse percentual é o segundo maior em 20 anos, denunciando a crescente calamidade cada vez mais urgente em que vive essa população, ao perpassar os anos (DEPEN, 2019). Nessa composição, o ambiente somado a má-alimentação, sedentarismo, uso generalizado de drogas e falta de higiene criam 
condições propícias à aquisição e transmissão de doenças, e ao desenvolvimento de psicopatologias (FILHO, et al, 2015).

A Portaria de Consolidação no 2, de 28 de setembro de 2017 disciplina os tipos de equipes de saúde prisional e os profissionais que compõem essas equipes (BRASIL, 2017). De acordo com a PNAISP a composição das eABP's e os serviços desempenhados são definidos de acordo com número de pessoas privadas de liberdade por unidade prisional, vinculação dos serviços de saúde a uma unidade básica de saúde no território, e existência de demandas referentes à saúde mental (BRASIL, 2014). A eABp-I formada por 5 profissionais, sendo as mesmas categorias profissionais da Estratégia Saúde da Família (enfermeiro, médico, técnico ou auxiliar de enfermagem, cirurgião-dentista e técnico ou auxiliar de saúde bucal), com carga horária de seis horas semanais; eABp-II formada por oito profissionais: 5 profissionais da Estratégia Saúde da Família, um psicólogo, um assistente social e um profissional escolhido, podendo ser acrescida da equipe de saúde mental; eABp-III formada por 11 profissionais: cinco profissionais da Estratégia Saúde da Família, somada necessariamente à equipe de saúde mental, e três profissionais escolhidos. Tais equipes possuem jornada específica para o seu tipo, sendo entre 6 e 30 horas semanais, tendo capacidade de atender até 1.200 pessoas (BRASIL, 2017).

A amplitude da política de saúde voltada para pessoas privadas de liberdade discorre sobre as responsabilidades da Esfera Federal, dos Estados, do Distrito Federal e dos Municípios perante as necessidades da implantação, implementação, eficácia e manutenção da PNAISP. No que concerne a estrutura na unidade penitenciária, a mesma política penhora a garantia de espaços adequados, salubres, adaptados para atender às pessoas com deficiência, idosas e com doenças crônicas, além de apoio, técnico e financeiro, e aquisição de equipamentos e a adequação do espaço físico para implantar a ambiência necessária ao funcionamento dos serviços de saúde no sistema prisional, seguindo as normas, regulamentos e recomendações do SUS e do Conselho Nacional de Previdência Complementar - CNPCP, aos Estados e Distrito Federal, por meio da Secretaria Estadual de Justiça, de Administração Penitenciária ou congêneres (BRASIL, 2014).

Diante deste contexto, ressalta-se a necessidade do conhecimento particularizado dos ambientes de saúde existentes dentro das penitenciárias nacionais, 
como também a realidade da composição da equipe profissional de saúde, por haver legislação específica que exige e detalha cada componente. Considerando tal conjuntura, o objetivo principal do presente estudo foi investigar a estrutura física e composição profissional de saúde em ambientes penitenciários nacionais, e objetivos secundários examinar os tipos de patologias acometidas pela população privada de liberdade e as suas causas de óbito.

\section{MÉTODO}

Foi realizado um estudo descritivo, com base nas informações estruturais e profissionais dos ambientes de saúde em penitenciárias brasileiras. Utilizando os dados de estrutura física de ambiente do saúde em geral, estrutura física de ambiente de maternidade, composição da equipe profissional de saúde da maternidade, número de profissionais de equipes em geral, procedimentos de saúde realizados, patologias da população em questão, e causas dos óbitos intramuros, nos ambientes penitenciários brasileiros, disponibilizados abertamente no Sistema de informações estatísticas do sistema penitenciário brasileiro do Departamento Penitenciário Nacional - DEPEN, coletados 21 de Agosto de 2020.

Foram analisados as seguintes variáveis: estrutura física de ambiente de saúde em geral; estrutura física do ambiente de maternidade; composição da equipe profissional de saúde da maternidade; número de profissionais de enfermagem; psicólogos; psiquiatras; dentistas; técnicos odontólogos; terapeutas ocupacionais; médicos clínicos gerais; médicos especialistas; procedimentos de saúde realizados; patologias da população em questão; e causas dos óbitos intramuros. Os cálculos de média da porcentagem de procedimentos realizados, bem como a elaboração de gráficos e tabelas, foram processados usando o programa Excel for Windows 2010 e Google Planilhas. Tendo em vista que os dados utilizados são de domínio público e sem identificação de participantes, não foi necessário submeter o estudo para aprovação do Comitê de Ética em Pesquisa. 


\section{RESULTADOS}

\subsection{Estrutura física}

Foram dezenove ambientes citados como componentes da estrutura física dos ambientes de saúde dentro das penitenciárias nacionais como observado na Tabela 1. Tais ambientes são, Consultórios odontológicos; Celas de espera; Celas de enfermagem com solário; Salas de atendimento clínico multiprofissional; Depósitos de material de limpeza; Salas de raio X; Farmácias ou Salas de estoque; Laboratórios de diagnóstico; Salas de coleta de material para laboratório; Celas de observação; Centrais de material esterilizado; Salas de esterilização; Celas de lavagem e descontaminação; Sanitários para pacientes; Salas de procedimento; Consultórios médico; Sanitários para equipe de saúde; Solários para pacientes; Salas de curativos, suturas, vacinas e postos de enfermagem.

\subsubsection{Maternidade - Equipe e Estrutura Física}

Com apenas setenta dormitórios ou celas adequadas para gestantes, as equipes de composição de maternidade intramuros são compostas apenas por médicos pediatras e ginecologistas, nutricionistas, e cuidadores. Sendo os cuidadores apenas citados, porém, não há qualquer registro de atuação de algum profissional em atuação. Na estrutura de recepção dos bebês, há 55 berçários ou centros de referência maternoinfantil, com capacidade de receber 598 bebês, e 154 crianças em 13 creches, como detalhado na Tabela 2.

Tabela 1: Dados sobre a estrutura física dos ambientes de saúde nas penitenciárias do Brasil - 2019.

\begin{tabular}{|l|l|l|l|}
\hline Variáveis & $\mathbf{n}$ & Variáveis & $\mathbf{n}$ \\
\hline Consultório Odontológico & 752 & Sala de procedimento & 509 \\
\hline Consultório médico & 1022 & Sala de raio X & 31 \\
\hline Cela de lavagem e descontaminação & 229 & Central de material esterilizado & 299 \\
\hline Cela de Espera & 422 & Laboratório de diagnóstico & 13 \\
\hline Cela de observação & 1088 & Farmácia ou Sala de Estoque & 780 \\
\hline Cela de Enfermagem com Solário & 610 & Solário para pacientes & 254 \\
\hline $\begin{array}{l}\text { Sala de curativos, suturas, vacinas e posto de } \\
\text { enfermagem }\end{array}$ & 845 & Depósito de material de limpeza & 535 \\
\hline Sala de Atendimento Clínico Multiprofissional & 808 & Sanitário para pacientes & 1552 \\
\hline
\end{tabular}




\begin{tabular}{|l|l|l|l|}
\hline Sala de Coleta de Material para Laboratório & 470 & & \\
\cline { 1 - 2 } Sala de esterilização & 264 & Sanitário para equipe de saúde & 1112 \\
\hline
\end{tabular}

(Fonte: DEPEN, 2019)

Tabela 2: Dados da composição física e profissional das maternidades das Penitenciárias do Brasil 2019.

\begin{tabular}{|l|l|}
\hline Variáveis & $\mathbf{n}$ \\
\hline Equipe de Pediatria & 7 \\
\hline Equipe de Ginecologia & 5 \\
\hline Equipe de Nutricionista & 6 \\
\hline Equipe de Cuidadores & 0 \\
\hline Berçário ou Centro de Referência Materno-infantil & 55 \\
\hline Dormitórios ou Cela Adequada para Gestantes & 70 \\
\hline Creche & 13 \\
\hline Capacidade de Crianças na Creche & 154 \\
\hline Capacidade de Bebês no Berçário ou Centro & 598 \\
\hline
\end{tabular}

(Fonte: DEPEN, 2019)

\section{2. Пúmero de profissionais}

\subsubsection{Equipe de enfermagem: enfermeiros, aukiliares e técnicos de enfermagem}

A maioria dos profissionais de ensino superior nas subdivisões contratantes, entre efetivos, comissionados, temporários e terceirizados são compostas por profissionais femininos. Entre os profissionais masculinos os efetivos são os de maior número, seguidos de terceirizados, temporários e comissionados. A maior classe contratada, é a de nível médio, possui mulheres efetivas na composição profissional nacional, seguida por terceirizadas, profissionais homens efetivos, e menor número em homens comissionados, como mostra a Tabela 3. 
Tabela 3: Número de Profissionais da Equipe de Enfermagem nas Penitenciárias do Brasil - 2019.

\begin{tabular}{|c|c|c|c|}
\hline Variáveis & $\mathbf{n}$ & Variáveis & n \\
\hline Enfermeiros & & \multicolumn{2}{|c|}{ Aux. e Tec. de Enfermagem } \\
\hline \multicolumn{4}{|c|}{ Sexo Feminino } \\
\hline Efetivo & 587 & Efetivo & 1.142 \\
\hline Comissionado & 22 & Comissionado & 22 \\
\hline Temporário & 185 & Temporário & 276 \\
\hline Terceirização & 297 & Terceirização & 448 \\
\hline \multicolumn{4}{|c|}{ Sexo Masculino } \\
\hline Efetivo & 182 & Efetivo & 392 \\
\hline Comissionado & 8 & Comissionado & 6 \\
\hline Temporário & 40 & Temporário & 54 \\
\hline Terceirização & 74 & Terceirização & 133 \\
\hline Total & 1.395 & Total & 2.473 \\
\hline
\end{tabular}

(Fonte: DEPEN, 2019)

\subsubsection{Terapeutas ocupacionais}

Sendo a menor classe contratada, os terapeutas ocupacionais são em sua maioria terceirizados e efetivos, não havendo comissionados, sendo possível observar na Tabela 4.

Tabela 4: Número de Terapeutas Ocupacionais nas Penitenciárias do Brasil- 2019.

\begin{tabular}{|l|c|c|}
\hline \multicolumn{1}{|c|}{ Variáveis } & $\mathbf{n}$ \\
\hline & Sexo Feminino & Sexo Masculino \\
\hline Efetivo & 29 & 4 \\
\hline Comissionado & 1 & 0 \\
\hline Temporário & 25 & 8 \\
\hline Terceirização & 32 & 11 \\
\hline Total & & 110 \\
\hline
\end{tabular}

(Fonte: DEPEN, 2019)

\subsubsection{Equipe de saúde bucal: dentistas, técnicos odontolóbicos}

Os profissionais de ensino superior efetivos são maioria, e possuem quantidade semelhante em relação ao gênero. Seguido de terceirizados, tendo mais homens que 
mulheres, profissionais temporários, e com menor quantidade os comissionados. $\mathrm{Na}$ Tabela 5 explana que os técnicos em saúde bucal, os profissionais femininos terceirizados são a maioria, seguido das efetivas, sendo os comissionados masculinos com menor contratação.

Tabela 5: Número de Dentistas nas Penitenciárias do Brasil - 2019.

\begin{tabular}{|l|c|c|}
\hline \multicolumn{1}{|c|}{ Variáveis } & $\mathbf{n}$ \\
\hline & Sexo Feminino & Sexo Masculino \\
\hline Efetivo Feminino & 265 & 264 \\
\hline Comissionado Feminino & 3 & 12 \\
\hline Temporário Feminino & 55 & 39 \\
\hline Terceirização Feminino & 99 & 114 \\
\hline
\end{tabular}

(Fonte: DEPEN, 2019)

\subsubsection{Clínicos gerais}

Entre os médicos clínicos gerais, os profissionais do sexo masculino efetivos e terceirizados apresentam maiores números entre as subcontratações. Entre as mulheres, as profissionais terceirizadas são a maior parte, efetivas, temporárias e comissionadas subsequentemente, como mostra a tabela na Tabela 6 .

Tabela 6: Número de médicos clínicos gerais nas penitenciárias do Brasil - 2019.

\begin{tabular}{|l|c|c|}
\hline \multicolumn{2}{|c|}{ Variáveis } & $\mathbf{n}$ \\
\hline & Sexo Feminino & Sexo Masculino \\
\hline Efetivo & 89 & 222 \\
\hline Comissionado & 8 & 17 \\
\hline Temporário & 47 & 99 \\
\hline Terceirização & 97 & 225 \\
\hline Total & & 804 \\
\hline
\end{tabular}

(Fonte: DEPEN, 2019)

\subsubsection{Outros médicos especialistas}

Há expressão mínima de contratação de serviço médico especializado intramuros, com o total de setenta e nove profissionais em atuação, mostrado na Tabela 7. 
Tabela 7: Número de médicos especialistas nas penitenciárias do Brasil - 2019.

\begin{tabular}{|l|c|c|}
\hline \multicolumn{1}{|c|}{ Variáveis } & $\mathbf{n}$ \\
\hline & Sexo Feminino & Sexo Masculino \\
\hline Efetivo & 8 & 17 \\
\hline Comissionado & 0 & 3 \\
\hline Temporário & 2 & 17 \\
\hline Terceirização & 20 & 22 \\
\hline Total & & 79 \\
\hline
\end{tabular}

(Fonte: DEPEN, 2019)

\subsubsection{Equipe de saúde mental: psicólogos e psiquiatras}

A quantitativa de profissionais de psicologia é maior que do que médicos psiquiatras. Sendo a maior parte psicólogos efetivos, e no caso de contratações de profissionais psiquiatras, há maior terceirização do serviço, transparecido na Tabela 8.

Tabela 8: Dados do quantitativo de psicólogos e psiquiatras nas penitenciárias do Brasil - 2019.

\begin{tabular}{|c|c|c|c|}
\hline Variáveis & $n$ & Variáveis & $\mathbf{n}$ \\
\hline \multicolumn{2}{|c|}{ Psicólogos } & \multicolumn{2}{|c|}{ Psiquiatras } \\
\hline \multicolumn{4}{|c|}{ Sexo Feminino } \\
\hline Efetivo & 635 & Efetivo & 31 \\
\hline Comissionado & 44 & Comissionado & 1 \\
\hline Temporário & 173 & Temporário & 14 \\
\hline Terceirização & 151 & Terceirização & 30 \\
\hline \multicolumn{4}{|c|}{ Sexo Masculino } \\
\hline Efetivo & 152 & Efetivo & 91 \\
\hline Comissionado & 12 & Comissionado & 1 \\
\hline Temporário & 33 & Temporário & 25 \\
\hline Terceirização & 44 & Terceirização & 45 \\
\hline Total & 1.244 & Total & 238 \\
\hline
\end{tabular}

(Fonte: DEPEN, 2019) 


\subsection{Procedimentos de saúde}

Considerando $100 \%$ dos procedimentos realizados, a intervenção cirúrgica tem o menor percentual entre os procedimentos realizados pelos homens e mulheres privados de liberdade, com média de $0,66 \%$ de realização, tendo os homens representando $1,16 \%$ entre os procedimentos listados. Na Tabela 9 a vacina encontrase, com a terceira menor média de ação de saúde, 7,55\%, transparece o público feminino com menor aderente, com 6,05\%. Exames e testagem, consultas psicológicas, e consultas odontológicas, possuem média semelhante, e com predominância entre as mulheres, e homens, no caso de exames e testagem. Consultas médicas externas manifestam segunda menor média, 4,75\%, com maior procura entre as mulheres, $5,42 \%$, seguida das consultas médicas externas, onde as mulheres usam $18,46 \%$, mas, sendo a segunda maior média de procedimentos. Suturas, curativos e etc, mostram-se como os procedimentos mais realizados, mostrando média de $42,17 \%$ entre homens e mulheres, liderados também pelos homens privados de liberdade que realizam $43,58 \%$.

Tabela 9: Média da quantidade de procedimentos realizados nas penitenciárias do Brasil - 2019.

\begin{tabular}{|l|c|c|}
\hline Procedimentos & Homens & Mulheres \\
\hline Intervenção Cirúrgica & $1,16 \%$ & $0,16 \%$ \\
\hline Suturas, Curativos e etc & $43,58 \%$ & $40,75 \%$ \\
\hline Vacinas & $9,05 \%$ & $6,05 \%$ \\
\hline Exames e Testagem & $9,71 \%$ & $9,68 \%$ \\
\hline Consultas Psicológicas & $8,31 \%$ & $10,94 \%$ \\
\hline Consultas Odontológicas & $7,69 \%$ & $8,51 \%$ \\
\hline Consultas Médicas Externas & $4,08 \%$ & $5,42 \%$ \\
\hline Consultas Médicas Internas & $16,45 \%$ & $18,46 \%$ \\
\hline
\end{tabular}

(Fonte: DEPEN, 2019)

\subsection{Patologias}

As patologias citadas são doenças infectocontagiosas, com transmissão sexual e por contato próximo com indivíduos doentes. Sendo HIV com maior diagnóstico em ambos os sexos, sendo predominante em mulheres, o que também é observado nos casos diagnosticados como sífilis. Na Tabela 10 transparece um cenário dessemelhante 
nos dados da tuberculose, onde a grande maioria é manifestada na população masculina, e poucos casos em mulheres. Hepatite mostra-se equiparada entre os sexos, e com menor porcentagem diagnóstica perante as outras doenças. Não há especificação das doenças aplicadas como "outros", que expressam diagnóstico maior que a porcentagem de hepatite.

Tabela 10: Dados sobre as patologias diagnosticadas nas penitenciárias do Brasil - 2019.

\begin{tabular}{|l|c|c|}
\hline Patologias & Homens & Mulheres \\
\hline Hepatite & $9,75 \%$ & $7,35 \%$ \\
\hline HIV & $25,60 \%$ & $40,45 \%$ \\
\hline Sífilis & $20,66 \%$ & $34,12 \%$ \\
\hline Tuberculose & $30,88 \%$ & $5,15 \%$ \\
\hline Outros & $13,11 \%$ & $12.94 \%$ \\
\hline
\end{tabular}

(Fonte: DEPEN, 2019)

\subsection{Causa dos óbitos}

A maior porcentagem de óbitos expõe-se como natural por motivos de saúde, expressando $70,59 \%$ das causas de óbitos em mulheres privadas de liberdade, porém não há dados fracionados que possam definir tais motivos naturais de saúde. Os óbitos ocasionados por motivos acidentais, apresentam baixa porcentagem na população masculina, não havendo registros entre as mulheres de óbitos por motivos criminais ou acidentais. Desfechos por suicídios são maiores em mulheres, e baixo percentual no gênero masculino, e causas de morte desconhecidas externa exibe registro médio de 6,06\% das causas em ambos os sexos, como sinaliza a Tabela 11.

Tabela 11: Dados das causas dos óbitos nas penitenciárias do Brasil - 2019.

\begin{tabular}{|l|c|c|}
\hline Causas de Óbitos & Homens & Mulheres \\
\hline Acidentes & $1,61 \%$ & $0,00 \%$ \\
\hline Criminais & $17,79 \%$ & $0,00 \%$ \\
\hline Suicídios & $6,81 \%$ & $23,53 \%$ \\
\hline Naturais por Motivos de Saúde & $67,55 \%$ & $70,59 \%$ \\
\hline Desconhecidas & $6,24 \%$ & $5,88 \%$ \\
\hline
\end{tabular}

(Fonte: DEPEN, 2019) 


\section{DISCUSSก̃O}

A partir dos dados obtidos, observa-se a composição profissional de domínio das unidades penitenciárias como desprovida de equipe completa em profissionais essenciais para realização de assistência adequada ao binômio mãe-filho, como profissionais enfermeiros, fisioterapeutas e doulas. A falha em não haver enfermeiros obstétricos e neonatologistas impede que recém-nascidos, gestantes e tão logo puérperas, recebam cuidado humanizado, especializado e multidisciplinar, tendo em vista que cuidado é a ciência no qual está alicerçada as atribuições de enfermagem, no seu exercício, o qual durante o parto proporciona segurança e conforto para a parturiente, com olhar ampliado integral e humanístico, a fim de diminuir a ansiedade e oferecer a melhor assistência ao parto (SIQUEIRA, 2019).

A composição de profissionais de saúde atuantes atualmente nos ambientes penitenciários não coincide com o preconizado pela PNAISP, onde profissionais como fisioterapeutas, farmacêuticos, assistentes sociais e nutricionista (este, fora da maternidade) não são citados como efetivos, comissionados, temporários ou terceirizados. Sem o cuidado multidisciplinar, a lacuna deixada na atenção à saúde desta população pode resultar em sobrepeso, doenças relacionadas pela má alimentação, sequelas motoras após procedimentos cirúrgicos, má dispensação medicamentosa, e retrocessos na assistência social ao indivíduo já vulnerabilizado socialmente. Nesse cenário, é preciso ressaltar que apesar de todos os Estados aderirem à PNAISP, e haver 230 Municípios também aderidos, há apenas 26 eABp's habilitadas em todo país (BRASIL, 2019; BRASIL, 2020).

De acordo com o DEPEN (2019), 711.080 mil homens estão em situação prisional no país, sendo $95,06 \%$ do total da população atual, sendo 4,94\% apenas mulheres (BRASIL, 2019). Ao quantificar a presença de profissionais do ambos os gêneros em equipes de saúde prisionais, a presença de profissionais médicos é superior no sexo masculino, quando em todas as outras áreas prevalece profissionais mulheres. A maior classe profissional efetiva no serviço em questão, trata-se de técnicos e auxiliares de enfermagem, seguido de psicólogos, e enfermeiros.

No que concerne aos procedimentos realizados com e para as pessoas privadas de liberdade, é possível identificar a ausência de consultas de enfermagem, tratando-se 
de uma tecnologia leve que sistematiza o conhecimento técnico-científico e o relacionamento interpessoal, prestando assistência qualificada no cuidado ao indivíduo no contexto familiar e inserido em uma comunidade. Logo também não é possível identificar a realização de ações de educação em saúde, cuidados de promoção à saúde e prevenção de doenças, tendo em vista que é o enfermeiro o principal profissional que realizada o processo de Atenção Primária à Saúde, educando e cuidando no propósito de prevenir e proteger o indivíduo de qualquer agravo (DANTAS, 2016).

Em desequilíbrio, os comparativos entre consultas psicológicas e suicídios não estão equiparados. A porcentagem de consultas com o psicólogo é menor que as causas de óbitos por suicídios. Quando centralizado os valores das mesmas consultas e causas de óbitos em mulheres em privação de liberdade, a porcentagem de suicídio mostra-se com valor duas vez maior que consultas com o profissional psicólogo. Enquanto em homens, apesar de realizar menos consultas psicológicas do que a população feminina, a porcentagem de suicídio é menor até mesmo da porcentagem de consultas.

Tendo em vista que de cinco patologias presentes na população privada de liberdade, quatro são infectocontagiosas, a porcentagem de exame e testagem é considerada baixa, tendo média de $9,68 \%$ dos procedimentos realizados, para a porcentagem média de 33,02\% exibida pelo HIV entre as patologias, contando com os fatores agravantes da vivência em ambiente insalubre e superlotado, além de prática de sexo desprotegido, contribuem para propagação das doenças descritas, além de meningite, tuberculose, gonorreia, herpes genital, e HPV, revelando uma problemática de subnotificação por baixa testagem, e/ou desregulação no registro de evolução dos pacientes (SANTOS, 2019).

Dentre as patologias descritas como prevalentes na população intramuros, no que é definido como "outros", não é possível discutir por não haver fracionamento e definição desta porcentagem. Mas, podemos observar que não há pluralidade de patologias descritas, como doenças de ordem crônica, pregressa ou não, como doenças cardiovasculares e diabetes, tendo em vista que as pessoas privadas de liberdade em sua maioria não desenvolvem nenhum tipo de atividade física, são obesos, tabagistas e ingerem álcool, possuindo maiores chances de desenvolverem cardiopatias, aumentando de 20 a 30\% o risco de mortalidade. Conjuntamente, não há mensuração de psicopatologias, como depressão e ansiedade, onde se trata de um ambiente que 
favorece o desenvolvimento das mesmas, revelando mais uma vez a problemática de subnotificação dificultando com que a epidemiologia seja mensurada, consequentemente analisada e possibilitando mudanças no atendimento em saúde (CORDEIRO, 2019; SANTOS, 2019)

\section{CONSIDERAÇÔES FInHIS}

Na conjuntura analisada pode-se alcançar a conclusão que a saúde das pessoas privadas de liberdade não estão preservadas, tampouco promovidas. Acrescenta-se ainda que a prevenção de agravos no sistema de saúde é apenas intramuros. Subsequentemente, é notória a incompatibilidade dos cenários descritos a depender da fonte manuseada, no tocante à patologias condicionadas a esta população. A composição profissional é desfalcada e simplista, suas ações não são pautadas em prevenção, cuidado e qualidade em saúde, apenas é realizado um modelo curativista precário.

Uma realidade criticável, em uma nação que há uma política especializada e pautada nos princípios do SUS. A necessidade da popularização da PNAISP dentre oS Estados e Municípios, consequentemente habilitação das equipes de saúde de prestação de serviço a população em questão, torna-se uma alternativa plausível, já estruturada e consolidada nos termos da lei, capaz de converter o atual penoso sistema de saúde executado em ambientes penitenciários, em um sistema humanizado, digno e executor dos direitos garantidos constitucionalmente.

\section{REFERÊRCIAS}

BRASIL, Constituição da República Federativa do Brasil. Brasília, 1988. Brasília. Disponível em: <http://www.planalto.gov.br/ccivil_03/constituicao/constituicao.htm>.

BRASIL, Lei de Execução Penal. Brasília, 1984. Brasília, 1984. Disponível em: <https://www2.camara.leg.br/legin/fed/lei/1980-1987/lei-7210-11-julho-1984356938-norma-pl.html>.

BRASIL, Ministério da Justiça. Departamento Penitenciário Nacional. Brasília, 2019. Disponível em: <http://depen.gov.br/DEPEN/depen/sisdepen/infopen>. 
BRASIL, Ministério da Saúde e Ministério da Justiça. Portaria Interministerial no 1.777 de 09 de setembro de 2003. Brasília, 2003. Disponível em: <http://bvsms.saude.gov.br/bvs/saudelegis/gm/2003/pri1777_09_09_2003.ht $\mathrm{ml}>$.

BRASIL, Ministério da Saúde. Política Nacional de Atenção Integral à Saúde das Pessoas Privadas de Liberdade no Sistema Prisional (PNAISP). Brasília, 2014. Disponível em: <https://www.saude.gov.br/acoes-e-programas/pnaisp/politica-nacionalde-atencao-integral-a-saude-das-pessoas-privadas-de-liberdade-no-sistemaprisional>.

BRASIL, Ministério da Saúde. Portaria de Consolidação no 2, de 28 de Setembro de 2017. Brasília, $2017 . \quad$ Disponível em: <http://bvsms.saude.gov.br/bvs/saudelegis/gm/2017/prc0002_03_10_2017.ht $\mathrm{ml}>$.

BRASIL, Ministério da Saúde. Secretaria de Atenção Primária à Saúde. Brasília 2019. Disponível em: <https://aps.saude.gov.br/ape/pnaisp/monitoramento>.

BRASIL, Ministério da Saúde. Secretaria de Atenção Primária à Saúde. Brasília 2020. Disponível em: <https://aps.saude.gov.br/ape/pnaisp/monitoramento>.

CORDEIRO, Eliana Lessa; SILVA, Tânia Maria da; SILVA, Liniker Scolfild Rodrigues da; PEREIRA, Carlos Eduardo de Araújo, et al. Perfil epidemiológico dos detentos: patologias notificáveis. Avances en Enfermería, 2018. Disponível em: $<$ http://www.scielo.org.co/scielo.php?script=sci_abstract\&pid=S0121$45002018000200170 \&$ Ing=en\&nrm=iso\&tlng=pt>.

DANTAS, Cilene Nunes; SANTOS, Viviane Euzébia Pereira; TOURINHO, Francis Solange Vieira. A consulta de enfermagem como tecnologia do cuidado á luz dos pensamentos de bacon e galimberti. Texto \& Contexto - Enfermagem, 2016. Disponível em: <https://www.scielo.br/scielo.php?pid=S010407072016000100601\&script=sci_abstract $>$.

FILHO, Marden Marques Soares; BUENO, Paula Michele Martins Gomes; Demografia, vulnerabilidades e direito à saúde da população prisional brasileira. Ciência \& Saúde Coletiva. Disponível em: <https://scielosp.org/article/csc/2016.v21n7/1999-2010/pt/\#>.

SANTOS, Roberta Lopes; OLIVEIRA, Janine Melo de; OLIVEIRA, Andreza Mayara da Silva; MACÊDO, Amanda Cavalcante de, et al. Ocorrência de doenças infecciosas em pessoas privadas de liberdade no sistema prisional. Interfaces Científicas, 2019. Disponível em: <https://periodicos.set.edu.br/saude/article/view/5962>. 


\title{
CAPITULO XXVIII
}

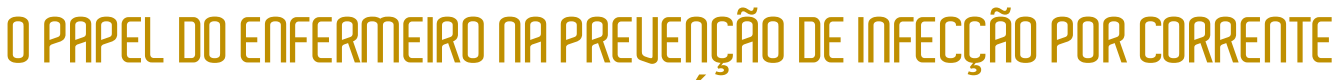 SATGUIÍTER}

\author{
DDI: 10.51859/AMPLLA.APS276.1121-28
}

\author{
Giselda Bezerra Correia Neves ${ }^{1}$ \\ Leandro Batista Wanderley ${ }^{2}$ \\ Bianca Ramos De Alcantara Pereira ${ }^{3}$ \\ Elianai Andre Da Silva De Melo ${ }^{3}$ \\ Fátima Barbosa Silva Dos Santos ${ }^{3}$ \\ Wanuska Munique Portugal ${ }^{4}$
}

\footnotetext{
${ }^{1}$ Docente da graduação de enfermagem -UNIBRA-PE

${ }^{2}$ Enfermeiro do Hospital Agamenon Magalhães -PE

${ }^{3}$ Discentes da graduação de enfermagem -UNIBRA-PE

${ }^{4}$ Coordenadora da Graduação de enfermagem-UNIBRA-PE
}

\section{RESUITO}

Introdução: As infecções representam um significativo percentual das mortes em pacientes hospitalizados, principalmente quando se refere a infecções de corrente sanguínea, cujo agravo pode gerar sepse. Objetivo: identificar o papel do enfermeiro na prevenção de infeç̧ões da corrente sanguínea. Metodologia: Trata-se de uma revisão integrativa de literatura, para seleção dos artigos foram executadas buscas nas bases de dados da Literatura Latino americana e do Caribe em Ciências da Saúde (LILACS), Scientific Eletronic Libray Online (SciELO) e Banco de Dados em Enfermagem (BDENF), por meio das seguintes descritores: infecções, circulação sanguínea, prevenção e enfermagem. Resultados e discussões: Foram incluídos 8 artigos publicados, em português, entre os anos de 2015 e 2020, relacionados à temática proposta. O uso prolongado de dispositivos intravenosos como cateter venoso central aumenta drasticamente a susceptibilidade à infecção da corrente sanguínea. Além disso, o enfermeiro, dentro as suas atribuições, deve preparar protocolos e treinamentos para o adequado manuseio de cateteres, evitando contaminação. Conclusão: Nesse sentido, o profissional de enfermagem detém o dever de gerenciar protocolos, cuidados e ações de combate e prevenção contra essas infecções. Através de medidas prevenção e redução da infecção de corrente sanguínea, tais como: Higienização das mãos e cuidados durante a manipulação do cateter com medidas assépticas.

Palavras-chave: Infecções. Circulação sanguínea. Prevenção e enfermeiro. 


\section{IกTRODUÇÃO}

Conhecer as medidas preventivas da Infeç̧ão de Corrente Sanguínea e de extrema importância para que o Enfermeiro possa evitar que ocorra esta infecção. Além disso, sabe-se que uma infecção pode prolongar o tempo de internamento, comprometendo a qualidades assistência à saúde. Vale ressaltar que o tempo prolongado dos pacientes nos serviços de saúde incrementa os custos e reduz a oportunidade de outros pacientes possam receber assistência (SILVA E OLIVEIRA, 2018).

As infecções de corrente sanguínea encontram-se entre as mais freqüentemente relacionadas à assistência à saúde, que são infecções adquiridas em virtude dos procedimentos necessários à monitorizarão e ao tratamento de pacientes. Essas infecções podem ocorrer em hospitais, ambulatórios, centros diagnósticos e outras unidades de saúde, entre as quais as infecções hospitalares destacam-se (PERIN et al., 2016).

Devido à variação e quantidade de micro-organismos, por muitas vezes multirresistentes, a prevenção de infecções hospitalares enfrenta grandes desafios na unidade de terapia intensiva (UTI). A realização de procedimentos invasivos para diagnosticar ou possibilitar a cura do paciente torna o controle de infecções complicado. Quando se trata de infecção da corrente sanguínea, isso é ainda mais complicado (BARROS, 2016).

Em torno de $60 \%$ das infecções relacionadas à saúde estejam diretamente associadas a algum tipo de dispositivo intravascular, como os que são utilizados para administração intravenosa de fluidos, hemoderivados, medicações, nutrição parenteral, hemodiálise ou monitorização hemodinâmica. Entre esses dispositivos, destaca-se o cateter venoso central (CVC), pois é amplamente utilizado em pacientes críticos, que demandam assistência à saúde de alta complexidade como nas UTIs (SANTOS et al., 2014).

Esses dispositivos podem permanecer implantados no paciente por vários dias (longa permanência), minimizando os traumas relacionados às repetidas, como é o caso do CVC. Apesar benefícios sua utilização, esses implantes podem gerar riscos aos pacientes, como a formação de trombos ou infecções da corrente sanguínea. Diante 
desse contexto, faz-se necessário uma série de cuidados preventivos que minimizem os riscos inerentes à utilização desses dispositivos (STOCCO et al., 2016).

Tendo em vista que os profissionais da enfermagem são os responsáveis legais pela inserção de grande parte dos dispositivos intravasculares, e o uso desses dispositivos representa um fator de risco para a infecção da corrente sanguínea, o objetivo deste trabalho foi explorar os cuidados do enfermeiro frente à prevenção da infecção de corrente sanguínea.

\section{REFERERCIAL TEÓRICO}

O papel do enfermeiro na prevenção de infecção por corrente sanguínea é reduzir ou eliminar as infecções relacionadas aos procedimentos realizados no paciente, o papel e conscientizar esses profissionais a conduta preventiva para redução dos riscos de infecção, temos o objetivo de descrever as suas principais causas, citar medidas preventivas que possam ser úteis diante dessas infecções, pontuarem as atribuições dos profissionais de enfermagem, de modo a minimizar os riscos do desenvolvimento de uma infecção da corrente sanguínea.

\subsection{Infecção de corrente sanguinea}

O sangue é estéril, porém no decorrer de algumas doenças infecciosas o sangue pode ser invadido por microorganismos, uma invasão na corrente sanguínea os microorganismos podem se multiplicar na corrente circulatória, a gravidade da infecção depende do microorganismo infectante e da resposta do organismo da pessoa infectada, já que pessoas com sistema imunológico comprometido são mais vulneráveis a esse tipo de infecção e os cuidados normalmente é bem mais complicado (PERIN et al., 2016).

A infecção ocorre quando alguns microorganismos possuem uma grande capacidade infecciosa, podendo se proliferar muito rápido e se espalhar pelo sangue podendo assim atingir outros órgãos e causando um quadro de choque séptico ou septicemia, se não identificar a infecção e tratar da mesma, pode haver falência de órgãos e o paciente pode vir a óbito (SOUZA et al., 2020).

Os microrganismos causadores da infecção atingem o acesso vascular de diversas formas: durante a inserção, contaminação das conexões, soluções contaminadas usadas 
para manter permeável o cateter ou em caso de monitorizarão hemodinâmica, como é o caso da averiguação da pressão arterial. Além disso, Os principais microrganismos causadores dessas infecções são provenientes das mãos dos profissionais que manipulam os diversos tipos de dispositivo. Portanto, a higienização das mãos é, sem dúvidas, uma das mais importantes formas de prevenção e redução das taxas de infecção (DANTAS et al., 2017).

Os dispositivos de acesso venoso central podem permanecer implantados no paciente por vários dias (longa permanência), minimizando os traumas relacionados às repetidas, como é o caso do CVC. Apesar benefícios sua utilização, esses implantes podem gerar riscos aos pacientes, como a formação de trombos ou infecções da corrente sanguínea. Diante desse contexto, faz-se necessário uma série de cuidados preventivos que minimizem os riscos inerentes à utilização desses dispositivos (SANTOS et al., 2014).

Os microrganismos causadores da infecção atingem o acesso vascular de diversas formas: durante a inserção, contaminação das conexões, soluções contaminadas usadas para manter permeável o cateter ou em caso de monitorizarão hemodinâmica, como é o caso da averiguação da pressão arterial. Além disso, Os principais microrganismos causadores dessas infecções são provenientes das mãos dos profissionais que manipulam os diversos tipos de dispositivo. Portanto, a higienização das mãos é, sem dúvidas, uma das mais importantes formas de prevenção e redução das taxas de infecção (SANTOS et al., 2014).

Alguns estudos apontam que, aproximadamente, 65 a 70\% dos casos de infecção da corrente sanguínea poderiam ser prevenidos por meio da adoção de medidas adequadas. Entre essas medidas, podem ser destacadas a adesão aos bundles de boas práticas de inserção propostas pelo Institute of Health care Improvement (IHI) e a adequada manutenção dos dispositivos. Os bundles caracterizam-se como um conjunto de práticas que, quando executadas coletivamente e de forma adequada, melhora os resultados para os pacientes (LAMY et al., 2016).

\subsection{Cuidados de enfermagem para preuenir infecção de corrente sanguínea}

É de extrema importância que o enfermeiro conheça as medidas preventivas da infecção por corrente sanguínea para que possam ser evitadas, as infecções ligadas aos 
cuidados é um enorme problema de saúde publica, essas infecções são decorrentes ao o uso de dispositivos invasivos devemos ter os cuidados nas praticas utilizadas e na prevenção da infecção no manuseio destes dispositivos invasivos, devemos utilizar técnicas assépticas (LUCAS et al., 2018).

Temos o papel de desenvolver algumas medidas preventivas como higienização das mãos observação de sinais flogísticos, realizar trocas de dispositivos higienizando sempre os conectores, considerarem a importância que tem a redução de infecções nos hospitais para a diminuição do risco de morbidade e mortalidade, no custo do tratamento e da média de permanência dos pacientes nos hospitais que resulta numa maior utilização de leitos hospitalares (MEDEIROS, 2010, p. 290).

O enfermeiro deve supervisionar o seu pessoal na desinfecção e esterilização de material e do ambiente, no tratamento e no processo de atenção de enfermagem ao paciente infectado, desenvolver cursos para o seu pessoal dando ênfase aos conteúdos relacionados com a atenção de enfermagem a pacientes infectados e à prevenção de infecções, procurarem ampliar seus conhecimentos sobre anticépticos e desinfetantes muito especialmente quando se responsabilizar pela indicação dos mesmos para os diversos fins no hospital (DANTAS et al., 2017).

Segundo a Lei 7.498 do Exercício Profissional de Enfermagem, em seu parágrafo único, inciso I do art. 11, o enfermeiro é responsável pela prevenção e pelo controle das infecções relacionadas à assistência à saúde. Os enfermeiros são os responsáveis legais pela inserção de grande parte desses dispositivos, logo deverão passar por adequado treinamento, de modo a manter a integridade do cateter em todos os níveis de cuidado. Esses cuidados podem ser colocados em prática seja na simples observação e inspeção ou na retirada do dispositivo por alguma complicação eminente, principalmente no que diz respeito ao risco de infecção (BARROS et al., 2016).

Algumas medidas podem ser tomadas para diminuir a ocorrência destas infecções principalmente, aquelas associadas à assistência à saúde. "Medidas de prevenção baseadas em conhecimento técnico adequado, a aplicação de protocolos e apoio administrativo podem prevenir parte considerável das infecções" (MEDEIROS, 2010, p. 290).

A equipe de enfermagem deve estar atenta para tais medidas, pois é o grupo profissional que mais realiza o manejo e a manutenção desta tecnologia. Estes 
profissionais têm um importante papel nos cuidados com os pacientes, sendo o mesmo responsável por cuidados diretos com a manutenção e a avaliação diária a fim de diminuir os riscos de infecção. Sendo assim, destaca-se a necessidade e conhecimentos, habilidades e treinamento do enfermeiro e equipe para o manejo seguro dos dispositivos intravasculares a fim de evitar as infecções por corrente sanguínea (OGSTON-Tuck S, 2012).

\section{MÉTODO}

A estratégia metodológica adotada para o alcance do objetivo proposto caracteriza-se por uma revisão Integrativa, de cunho descritivo e qualitativo, desenvolvida em seis etapas: elaboração da pergunta norteadora, busca na literatura, extração dos dados, avaliação dos estudos encontrados, análise e síntese dos resultados e, por fim, a apresentação do trabalho final. Para condução do estudo, será formulada a seguinte questão de pesquisa: Qual o papel do enfermeiro na prevenção da infecção por corrente sanguínea.

As buscas foram realizadas entre os meses de setembro a outubro de 2020 nas bases de dados SciELO (Scientific Electronic Library Online) e BVS (Biblioteca Virtual de Saúde), utilizou-se as palavras chaves: Infecções; circulação sanguínea; prevenção e enfermeiro

Consideraram-se como critérios de inclusão os artigos originais, que abordem o risco de infecção da corrente sanguínea, cujo ano de publicação posicionam-se entre 2015 e 2020 e textos em português. Foram utilizados textos em português. Inicialmente foram lidos título e resumo dos artigos resgatados por meio dos cruzamentos, e selecionados e lidos na íntegra àqueles que atendiam ao objetivo desta revisão focando na importância do enfermeiro na prevenção e no tratamento dos pacientes com infecção por corrente sanguínea. Os critérios de exclusão foram textos que não estão disponíveis na integra e os repetidos e textos referentes às teses e dissertações.

Foram identificados 52 textos científicos nas bases de dados ao utilizar as palavras-chave estabelecidas, dentre as quais, ao final da estratégia metodológica, 7 foram incluídos, viabilizando a execução deste estudo. No que diz respeito à seleção da literatura, foi realizada leitura dos títulos e seus respectivos resumos, com a finalidade de constatar a pertinência do estudo com a questão norteadora levantada para 
investigação. Nos casos em que os títulos e os resumos não se mostraram suficientes para definir a seleção inicial, procedeu-se à leitura na íntegra da publicação. Sendo realizada a leitura na íntegra dos artigos incluídos.

Figura 1 - Fluxograma da estratégia utilizada para seleção dos artigos.

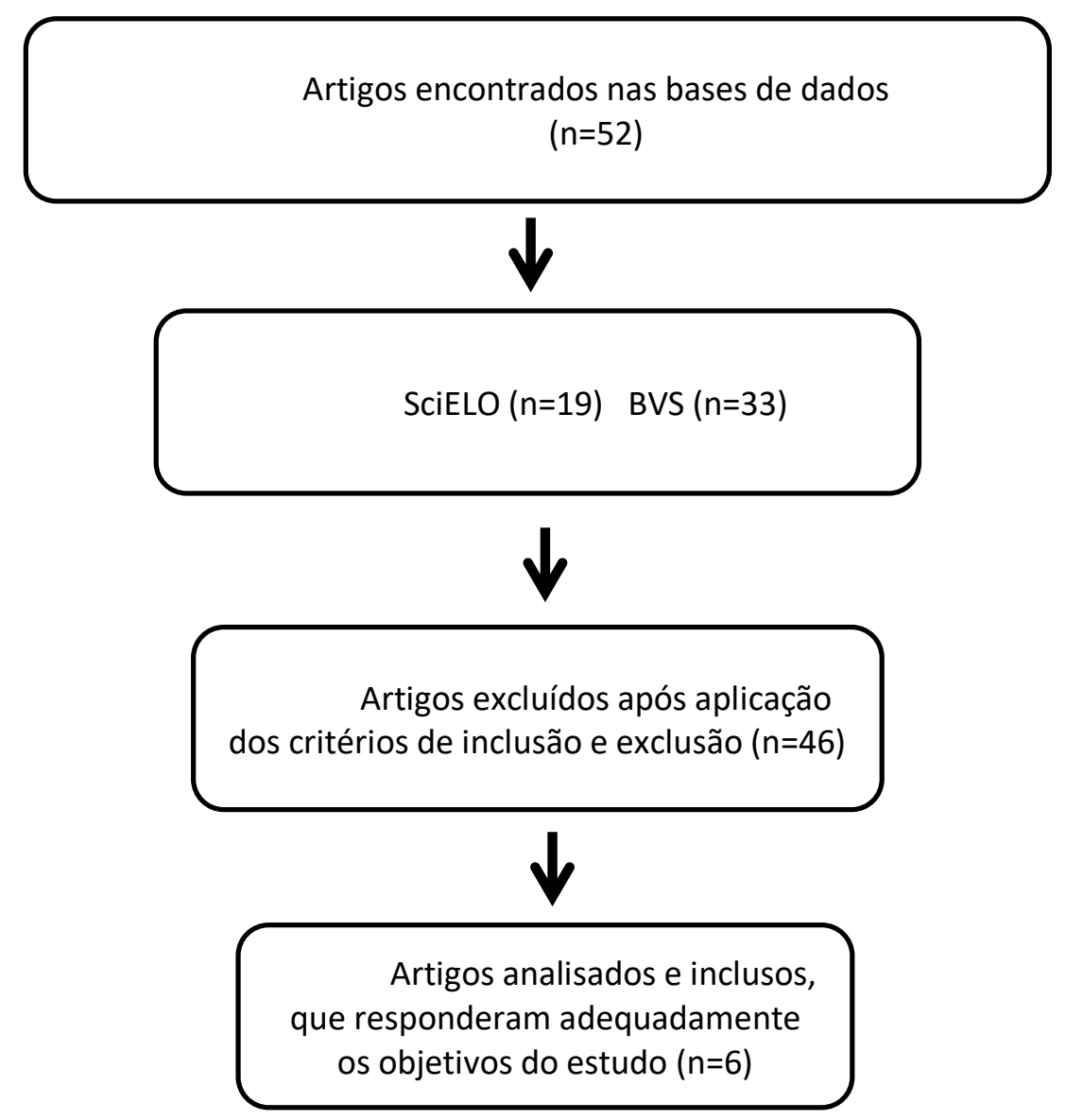

Fonte: Autoria própria (2020)

\section{RESULTADOS}

Foram incluídos 8 artigos publicados, em português, entre os anos de 2015 e 2020, relacionados à prevenção da infecção de corrente sanguínea, bem como o papel do enfermeiro diante dessa prevenção. Destacam-se, no Quadro 1, as características de cada estudo quanto ao ano de publicação, título e principais achados. 
Quadro 1 - Características dos estudos em ordem crescente de ano de publicação.

\begin{tabular}{|c|c|c|c|}
\hline Autor/ano & Título & Objetivos & Resumo dos principais achados \\
\hline $\begin{array}{l}\text { 1-Oliveira et } \\
\text { al., } 2015\end{array}$ & $\begin{array}{l}\text { O uso de indicadores } \\
\text { clínicos na avaliação } \\
\text { das práticas de } \\
\text { prevenção e controle } \\
\text { de infecção de } \\
\text { corrente sanguínea. }\end{array}$ & $\begin{array}{l}\text { Avaliar a conformidade } \\
\text { da realização das } \\
\text { práticas de prevenção e } \\
\text { controle de infecção de } \\
\text { corrente } \\
\text { sanguínea relacionada } \\
\text { ao cateter venoso } \\
\text { central, através de } \\
\text { indicadores clínicos }\end{array}$ & $\begin{array}{l}\text { Necessário a elaboração de estratégias que } \\
\text { assegurem a adesão às práticas de controle } \\
\text { e prevenção de infecção de corrente } \\
\text { sanguínea relacionada ao cateter venoso } \\
\text { central, bem como instituir avaliações } \\
\text { periódicas das condições de trabalho, no } \\
\text { sentido de elevar os índices de } \\
\text { conformidade. }\end{array}$ \\
\hline $\begin{array}{l}\text { 2-Perin et al., } \\
2016\end{array}$ & $\begin{array}{l}\text { Evidências de } \\
\text { cuidado para } \\
\text { prevenção de } \\
\text { infecção de corrente } \\
\text { sanguínea } \\
\text { relacionada a cateter } \\
\text { venoso central: } \\
\text { revisão sistemática }\end{array}$ & $\begin{array}{l}\text { Identificar evidências de } \\
\text { cuidados para prevenção } \\
\text { de infecção de corrente } \\
\text { sanguínea } \\
\text { relacionada a cateter } \\
\text { venoso central em } \\
\text { pacientes adultos em } \\
\text { Unidades de Terapia } \\
\text { Intensiva }\end{array}$ & $\begin{array}{l}\text { Cuidados no formato de bundles, bem } \\
\text { como a educação e engajamento da equipe } \\
\text { e da instituição, são estratégias que } \\
\text { contribuem com a redução das taxas de } \\
\text { infecção de corrente sanguínea }\end{array}$ \\
\hline $\begin{array}{l}\text { 3-Dantas et } \\
\text { al., } 2017\end{array}$ & $\begin{array}{l}\text { Adesão da equipe de } \\
\text { enfermagem às } \\
\text { medidas de } \\
\text { prevenção de } \\
\text { infecções de corrente } \\
\text { sanguínea }\end{array}$ & $\begin{array}{l}\text { Avaliar o conhecimento } \\
\text { e adesão da equipe de } \\
\text { enfermagem às medidas } \\
\text { de prevenção de } \\
\text { infecções de corrente } \\
\text { sanguínea relacionadas } \\
\text { ao cateter venoso } \\
\text { central (ICSR-CVC) em } \\
\text { Unidade de Terapia } \\
\text { Intensiva. }\end{array}$ & $\begin{array}{l}\text { Importante a maior a adesão das medidas } \\
\text { de prevenção de infecções de corrente } \\
\text { sanguínea relacionadas ao cateter venoso } \\
\text { central. Por meio de incentivada de } \\
\text { educação continuada para os profissionais. }\end{array}$ \\
\hline $\begin{array}{c}\text { 4-Oliveira et } \\
\text { al., } 2017\end{array}$ & $\begin{array}{l}\text { Positive Deviance } \\
\text { como estratégia na } \\
\text { prevenção e controle } \\
\text { das infecções de } \\
\text { corrente sanguínea } \\
\text { na terapia intensiva }\end{array}$ & $\begin{array}{l}\text { descrever a aplicação do } \\
\text { Positive Deviance como } \\
\text { estratégia na prevenção } \\
\text { e no controle da infecção } \\
\text { de corrente sanguínea. }\end{array}$ & $\begin{array}{l}\text { O Positive Deviance auxiliou na } \\
\text { implementação de propostas de melhorias } \\
\text { de processo de trabalho e no } \\
\text { desenvolvimento da equipe para os } \\
\text { problemas identificados no cuidado com o } \\
\text { cateter venoso central, de modo a evitar } \\
\text { infecção de corrente sanguínea. }\end{array}$ \\
\hline $\begin{array}{c}\text { 5-Silva \& } \\
\text { Oliveira, } 2017\end{array}$ & $\begin{array}{l}\text { Adesão às medidas } \\
\text { para prevenção da } \\
\text { infecção da corrente } \\
\text { sanguínea } \\
\text { relacionada ao } \\
\text { cateter venoso } \\
\text { central } \\
\end{array}$ & $\begin{array}{l}\text { Verificar a adesão da } \\
\text { equipe multiprofissional } \\
\text { para as medidas de } \\
\text { prevenção da infecção } \\
\text { da corrente sanguínea } \\
\text { relacionada ao cateter } \\
\text { venoso central } \\
\end{array}$ & $\begin{array}{l}\text { É necessária maior adesão da equipe de } \\
\text { enfermagem com a atenção a protocolos de } \\
\text { inserção dos cateteres nos períodos pré e } \\
\text { pós-intervenção. }\end{array}$ \\
\hline $\begin{array}{c}\text { 6-Crivelaro et } \\
\text { al., } 2019\end{array}$ & $\begin{array}{l}\text { Adesão da } \\
\text { enfermagem ao } \\
\text { protocolo de } \\
\text { infecção de corrente } \\
\text { sanguínea }\end{array}$ & $\begin{array}{l}\text { verificar a adesão da } \\
\text { equipe de Enfermagem } \\
\text { ao protocolo de infecção } \\
\text { de corrente sanguínea } \\
\text { em pacientes em uso de } \\
\text { cateteres } \\
\text { intravasculares. } \\
\end{array}$ & $\begin{array}{l}\text { Alta adesão da equipe de Enfermagem ao } \\
\text { protocolo e baixo índice de infecção de } \\
\text { corrente sanguínea relacionada ao cateter } \\
\text { venoso central }\end{array}$ \\
\hline
\end{tabular}

Fonte: Autoria Própria (2020) 


\section{DISCUSSค̃O}

Entre os dispositivos intravasculares, o Cateter Venoso Central constitui o principal fator de risco para a infecção da corrente sanguínea, responsável por cerca de 90\% dos casos. Existem Alguns outros fatores de risco para infecção de corrente sanguínea, como hipertensão, diabetes mellitus e hipoalbuminemia (DANSKI, et al., 2017; Silva \& Oliveira 2018b).

Entre os micro-organismos responsáveis pela infecção de corrente sanguínea, o Staphylococcus aureus se destaca. A troca do cateter e o usode antibiótico sistêmico são as principais medidas de combate às infecções (OLIVEIRA et al.,2017).

Constata-se que as infecções da corrente sanguínea causada por dispositivos intravasculares é uma complicação evitável e pode ser prevenida por meio de intervenções, durante a inserção, duração da intervenção e a manipulação dos dispositivos, avaliação do perfil do paciente atendido, dos recursos humanos e materiais, da disponibilidade de um trabalho de educação, treinamento e da vigilância com a equipe responsável pela inserção, da manutenção e dos cuidados com os dispositivos intravenosos (SOUZA et al., 2020).

O enfermeiro é responsável pelo cuidado direto ao paciente e deve conhecer todas as evidências relacionadas à prevenção da infecção de corrente sanguínea. Suas ações devem estar pautadas em conhecimento atualizado, visando sempre a assistência segura ao paciente (PERIN et al., 2016).

Entre as medidas para a prevenção de infecção de corrente sanguínea, especialmente causadas pelo uso do cateter venoso central, destacam-se: as medidas já preconizadas pelo Centers for Disease Control and Prevention (CDC), que aponta a importância do uso de barreira máxima de prevenção (gorro, máscara, avental estéril, luvas estéreis e amplos campos estéreis); utilização de bundles, avaliação do tempo de permanência dos dispositivos, avaliação do estado de conservação e higiene dos dispositivos (FERANANDES et al., 2019).

\section{COISIDERAÇÔES FInRIS}

Observa-se que a importância de conhecer e reconhecer o que já foi pesquisado, as possíveis adaptações para tornar a adesão de algumas medidas simples no controle 
e prevenção de infecções hospitalares. As ocorrências das infecções estão associadas na adesão dos profissionais nas condutas para prevenção e controle, mediante disto é possível afirmar que a Enfermagem tem papel de destaque no controle e prevenção de infecções, promovendo segurança e melhor qualidade dos serviços prestados aos clientes.

O enfermeiro é o responsável pelo cuidado integral ao paciente, devendo encontrar medidas para reduzir os agravos relacionados à infecção de corrente sanguínea. Esse profissional é fundamental na prevenção e no tratamento do paciente, proporcionando bem estar e tratamento adequado, utilizando sempre o conhecimento científico e técnicas assépticas para prevenir o risco de infecção.

\section{REFERÊกCIAS}

AGUIAR, D. F.; LIMA, A. B.; SANTOS, R. B. Uso das precauções-padrão na assistência de enfermagem: um estudo retrospectivo. Esc. Anna Nery, Rio de Janeiro; 12(3):571-75, 2008. Doi: 10.1590/S1414-81452008000300027.

ALVIM, A. L. S.; COUTO, B. R. G. M.; GAZZINELLI, A. Perfil epidemiológico das infecções relacionadas à assistência à saúde causadas por Enterobactérias produtoras de Carbapenemase. Rev Esc Enferm da USP, São Paulo, v. 53: e03474, 2019. Doi: 10.1590/s1980-220x2018001903474.

ARAÚJO, F.L.; MANZO, B.F.; COSTA A.C.L.; CORRÊA, A.R.; MARCATTO, J.O.; SIMÃO, D.A.S. Adesão ao bundle de inserção de cateter venoso central em unidades neonatais e pediátricas. Rev Esc Enferm da USP, São Paulo, v.51: e03269, 2017. Doi: 10.1590/s1980-220x2017009603269.

BARROS, M. M.; PEREIRA, E. D.; CARDOSO, F. N.; SILVA, R. A. O enfermeiro na prevenção e controle de infecções relacionadas à assistência à saúde. Universitas: Ciências da Saúde, v. 14, n. 1, p. 15-21, 2016. Doi: 10.5102/ucs.v14i1.3411.

BARROS, L.M.; BENTO, J.N.C.; CAETANO, J.A.C.; MOREIRA, R.A.N.; PEREIRA, F.G.F.; FROTA, N. M.; ARAÚJO, T.M.; SOARES, E. Prevalência de microorganismo e sensibilidade antimicrobiana de infecções hospitalares em unidade de terapia intensiva de hospital público no Brasil. Rev Ciênc Farm Básica, 33(3):429-35, 2012.

CRIVELARO, N; CONTRIN, L.M.; BECCARIA, L.M.; FRUTUOSO, I.S.; SILVEIRA, A.M.; WERNECK, A.L. Adesão da enfermagem ao protocolo de infecção de corrente sanguínea. Rev Enferm UFPE OnLine, Recife, v. 12, n. 9, p. 2361-7, 2018. Doi: 10.5205/1981-8963-v12i9a234886p2361-2367-2018. 
CURAN, G. R. F.; ROSSETTO, E. G. Medidas para redução de infecção associada a cateter central em recém-nascidos: revisão integrativa. Texto Contexto Enferm, Florianópolis, v. 26, n. 1: e5130015, 2017. Doi: 10.1590/010407072017005130015.

DANSKI, M. T. R.; PONTES, L.A; SCHWANKE, A. A.; LIND, J. Infecção da corrente sanguínea relacionada a cateter venoso central para hemodiálise: revisão integrativa. Revista baiana enfermagem, v. 31, n. 1: e16342, 2017. Doi: 10.18471/rbe.v31i1.16342.

DANTAS, G.D.; FIGUEIREDO, D.S.T.O.; NOBRE, A.M.D.; PIMENTEL, E.R.S. Adesão da equipe de enfermagem às medidas de prevenção de infecções de corrente sanguínea. Rev enferm UFPE OnLine, Recife, v. 11, n. 10: 3698-706, 2017. Doi: 10.5205/reuol.12834-30982-1-SM.1110201701.

DIAS, I.C.B.; LIMA, E.F.A; FIORESI, M.; CARRARA, D.; OLIVEIRA, I.S.; PRIMO, C.C. Construção de hipermídia para prevenção de infecção da corrente sanguínea. Rev Bras Enferm, Brasília, v. 73, n. 6, p. 1-6, 2020. Doi: 10.1590/0034-7167-20190593.

FERNANDES, M.S.; FERNANDES, M.S.; NOGUEIRA, H.K.L.; PONTES, F.S.; GOES, A.C.F.; DE OLIVEIRA, D.F. Bundle para a prevenção de infecção de corrente sanguínea. Rev enferm UFPE OnLine, Recife, v. 13, n. 1, p. 1-8, 2019. Doi: 10.5205/1981-8963v13i01a237743p1-8-2019.

FORTUNATTI, C.F.P. Impacto de dois bundles na infeção relacionada a cateter central em pacientes críticos. Rev Latino-Am de Enfermagem, Ribeirão Preto, v. 25: e2951, 2017. Doi: 10.1590/1518-8345.2190.2951.

LLAPA-RODRÍGUEZ, E.O.; OLIVEIRA, J.K.A.; MELO, F.C.; SILVA, G.G.; MATTOS, M.C.T; MACIEIRA JR, V.P. Inserção de cateter vascular central: adesão a bundle de prevenção de infecção. Rev Bras Enferm, Brasília, v.72, n. 3, p. 810-6, 2019. Doi: 10.1590/0034-7167-2018-0124.

LAMY, B.; DARGÈRE, S.; ARENDRUP, M. C.; PARIENTI, J-J.; TATTEVIN, P. How to optimize the use of blood cultures for the diagnosis of blood stream infections? A stateof-the art. Front Microbiol, 12;7:697, 2016. Doi: 10.3389/fmicb.2016.00697.

LUCAS, T.C.; SA, P.L.C.; SANTOS, L.P.; LEITE, C.A.; CALDEIRA, A.L.P.; OLIVEIRA, A. C. Desafio da higienização das mãos para a implementação dos bundles de cateter venoso central. Rev Epidemiol Control Infec, Santa Cruz do Sul, v. 8, n. 3, p. 216223, 2018. Doi: 10.17058/reci.v8i3.11283.

MARTINEZ, M. R.; CAMPOS, A. F.L.A.; NOGUEIRA, K. P. C. Adesão à técnica de lavagem de mãos em unidade de terapla intensiva neonatal. Rev Paul Pediatri, São Paulo, 27(2):179-85, 2009. Doi: 10.1590/S0103-05822009000200010. 
MEDEIROS, A.E.S. Efeito de um programa educacional na redução de infecção da corrente sanguínea relacionada ao cateter venoso central. Rev Paul Pediatr, São Paulo, 28(4):290-1, 2010. Doi: 10.1590/S0103-05822010000400001.

MENDONÇA, K. M.; NEVES, H.C.C.; BARBOSA, D.F.S.; SOUZA, A. C.S.; TIPPLE, A.F.V.; DO PRADO, M.A. Atuação da enfermagem na prevenção e controle de infecção de corrente sanguínea relacionada a cateter. Rev Enferm UERI, Rio de Janeiro, 19(2):330-3, 2011.

OGTON-TUCK, S. Intravenoustherapy: guidanceondevices, management andcare. Br J Community Nurs, v.17, n.10, 474-484, 2012. Doi: 10.12968/bjcn.2012.17.10.474.

OLIVERIA, F.T.; FERREIRA, M.M.F.; ARAUJO, S.T.C.; BESSA, A.T.T.; MORAES, A.C.B.; STIPP, M.A.C. Positive Deviance como estratégia na prevenção e controle das infecções de corrente sanguínea na terapia intensiva. Rev Esc Enferm USP, São Paulo, v. 51: e03212, 2017. Doi: 10.1590/s1980-220x2016182303212.

OLIVEIRA, F.J.G.; CAETANO, J.A.; SILVA, V.M.; ALMEIDA, P.C.; RODRIGUES, A.B.; SIQUEIRA, J.F. O uso de indicadores clínicos na avaliação das práticas de prevenção e controle de infecção de corrente sanguínea. Texto Contexto Enferm, Florianópolis, v. 24, n. 4, p. 1018-26, 2015. Doi: 10.1590/01040707201500004040014.

PERIN, D. C.; ERDMANN, A. L.; HIGASHI, G. D. C.; SASSO, G. T. M. Evidências de cuidado para prevenção de infecção de corrente sanguínea relacionada a cateter venoso central: revisão sistemática. Rev Latino-Am Enferm, Ribeirão Preto, 24:e2787, 2016. Doi: 10.1590/1518-8345.1233.2787.

SANTOS, S. F.; VIANA, R.S.; ALCOFORADO, C.L.G.C.; CAMPOS, C.C.; MATOS, S.S.; ERCOLE, F.F. Ações de enfermagem na prevenção de infecções relacionadas ao cateter venoso central: uma revisão integrativa. Revista SOBECC, 19(4): 219-225, 2014. Doi: 10.5327/Z1414-4425201400040008.

SILVA, A. G.; OLIVEIRA, A. C. Adesão às medidas para prevenção da infecção da corrente sanguínea relacionada ao cateter venoso central. Enfermagem em Foco, Brasília, v. 8, n. 2, p. 36-41, 2017. Doi: 10.21675/2357-707X.2017.v8.n2.977.

SILVA, A. G.; OLIVEIRA, A. C. Conhecimento autorreferido das equipes médica e de enfermagem quanto às medidas de prevenção de infecção da corrente sanguínea. Texto Contexto Enferm, Florianópolis, v. 27, n. 3: e3480017, 2018. Doi: 10.1590/0104-070720180003480017.

SILVA, A. G.; OLIVEIRA, A. C. Impacto da implementação dos bundles na redução das infecções da corrente sanguínea: uma revisão integrativa. Texto Contexto Enferm, Florianópolis, v. 27, n. 1: e3540016, 2018 (b). Doi: 10.1590/010407072018003540016.

SILVA, M.P.C.; BRAGATO, A.G.C.; FERREIRA, D.O.; ZAGO, L.B.; TOFFANO, S.E.M.; NICOLUSSI, A.C.; CONTIM, D. Bundle para manuseio do cateter central de 
inserção periférica em neonatos. Acta Paul Enferm, São Paulo, v. 32, n. 3, p. 2616, 2019. Doi: 10.1590/1982-0194201900036.

SOUZA, R.S.; OLIVEIRA, P.P.; DIAS, A.A.L.; SIMÃO, D.A.S.; PELIZARI, A.E.B.; FIGUEIREDO, R.M. Prevenção de infecções associadas a cateteres periféricos: construção e validação de cenário clínico. Rev Bras Enferm, Brasília, v. 73, n. 5, p. 1-8, 2020. Doi: 10.1590/0034-7167-2019-0390.

STOCCO, J.G.D.; HOERS, H.; POTT, F.S.; CROZETA, K.; BARBOSA, D.A.; MEIER, M.J. Cateteres venosos centrais de segunda geração na prevenção de infecção de corrente sanguínea: revisão sistemática. Rev Latino-Am Enfermagem, Ribeirão Preto, v. 24: e2722, 2016. Doi: 10.1590/1518-8345.0756.2722. 


\section{ATENGŌ̃O PRIMÁRIA À SAÚDE NO BRASIL}

\section{DESAFICSE POSSIBIILDADES ND GENÁRIO CONTEMPORÂAEEO}

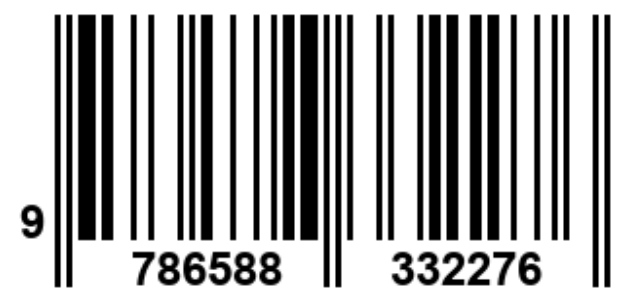

